Universitat Politècnica de València

Instituto de TeCnOlogía QuímicA

\title{
Desarrollo de catalizadores de cobalto polinucleares y multifuncionales para la activación de moléculas pequeñas.
}

\author{
Tesis doctoral \\ Presentada por \\ Silvia GutiérRez Tarriño \\ Dirigida por \\ Prof. Avelino Corma Canós \\ Dr. Pascual Oña Burgos
}

Valencia, Junio de 2021. 

Prof. AVELINO CORMA CANÓS, profesor de investigación del Instituto Universitario Mixto de Tecnología Química (UPV-CSIC), y Dr. PASCUAL OÑA BURGOS, investigador distinguido del del Instituto Universitario Mixto de Tecnología Química (UPV-CSIC).

CERTIFICAN: Que la presente tesis doctoral, titulada: "DESARROLLO DE CATALIZADORES DE COBALTO POLINUCLEARES Y MULTIFUNCIONALES PARA LA ACTIVACIÓN DE MOLÉCULAS PEQUEÑAS", ha sido desarrollada por SILVIA GUTIÉRREZ TARRIÑO, bajo su dirección, en el Instituto Universitario Mixto de Tecnología Química (UPVCSIC) de la Universitat Politècnica de València. 



\section{Índice}

Capítulo 1. Introducción......................................................................................... 1

1.1. Química Sostenible...................................................................................5

1.1.1. Principios de la Química Verde..........................................................................6

1.2 Aspectos fundamentales de la catálisis: actividad, selectividad y Sostenibilidad. .................................................................................................9

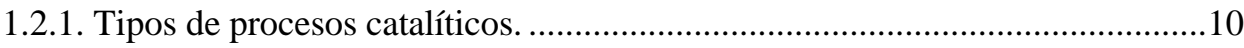

1.2.2. De catalizadores basados en metales nobles a catalizadores basados en metales

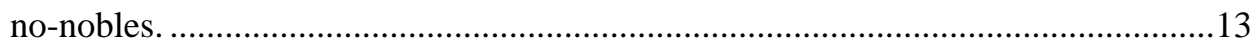

1.3. Propiedades del Cobalto y su aplicación en catálisis. ........................ 15

1.4. Técnicas de heterogeneización de catalizadores homogéneos......... 19

1.4.1. Inmobilización en soportes inorgánicos. .........................................................22

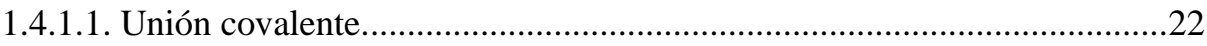

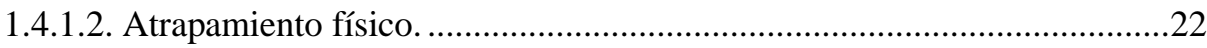

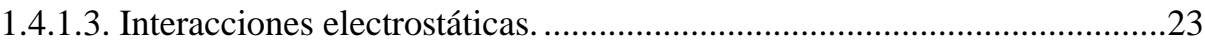

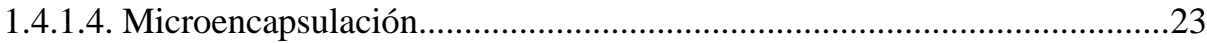

1.4.2. Inmovilización en soportes poliméricos.........................................................23

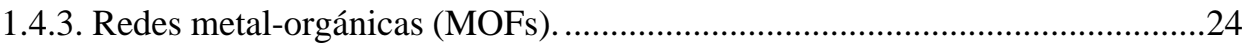

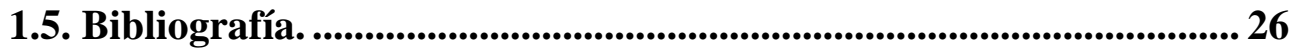

Capítulo 2. Objetivos.........................................................................35

Capítulo 3. Materiales y métodos...........................................39

3.1. Consideraciones generales......................................................................... 43

3.2. Técnicas instrumentales. ............................................................................ 43 
3.3. Bibliografía.

\section{Capítulo 4. Complejos de Cobalto para la hidrosililación de alquenos en condiciones aeróbicas

\subsection{Introducción ...........................................................................................5}

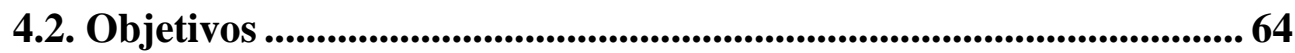

4.3. Resultados y discusión .................................................................64

4.3.1. Estudio de la influencia del ligando y el estado de oxidación del metal en la actividad catalítica....................................................................................64

4.3.2. Síntesis y elucidación estructural de los catalizadores ...............................65

4.3.3. Evaluación de los precatalizadores de cobalto. ...........................................71

4.3.4. Generalidad de la reacción ...................................................................74

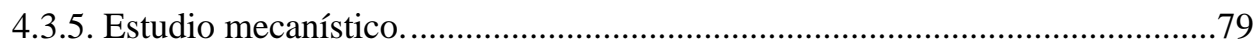

4.4. Conclusiones ................................................................................................ 82

4.5. Sección experimental ....................................................................83

4.5.1. Procedimiento detallado para la síntesis de los catalizadores........................83

4.5.2. Caracterización de los catalizadores......................................................84

4.5.3. Procedimiento de las reacciones catalíticas..............................................94

4.5.3.1. Optimización de las condiciones de reacción........................................94

4.5.3.2. Procedimiento general para las reacciones de hidrosililación ..................94

4.5.3.3. Estudio cinético para la hidrosililación de 4-vinilciclohexeno con $\mathrm{PhSiH}_{3}$.

4.5.3.4. Procedimiento para la reacción de hidrosililación del 1-octeno con

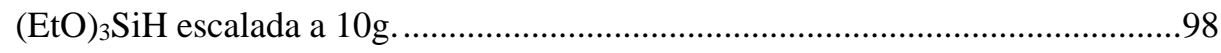

4.5.3.5. Síntesis de los polímeros de entrecruzamiento de siliconas. ....................98

4.5.3.6. Caracterización de los productos de reacción..........................................98

4.6. Bibliografía .............................................................................................. 104 


\section{Capítulo 5. Nanoclústeres de Cobalto como catalizadores para la hidrogenación quimioselectiva de nitroarenos y reacciones tándem ............................................................................109}

5.1. Introducción. .................................................................................. 113

5.2. Objetivos .................................................................................. 117

5.3. Resultados y discusión .................................................................. 117

5.3.1. Síntesis de los catalizadores Co@NC-T ........................................................118

5.3.2. Optimización de las condiciones de reacción .............................................. 118

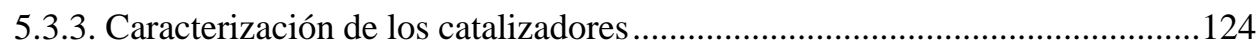

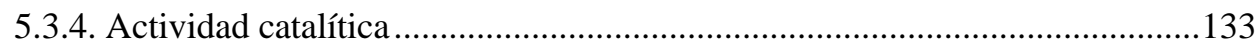

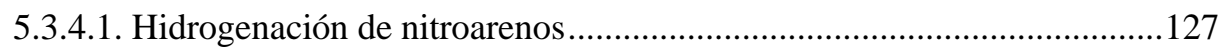

5.3.4.2. Reacciones tándem que implican la reducción de nitroarenos ................131

5.4. Conclusiones ....................................................................................................... 141

5.5. Sección experimental ..................................................................... 142

5.5.1. Síntesis y caracterización de los catalizadores ..........................................142

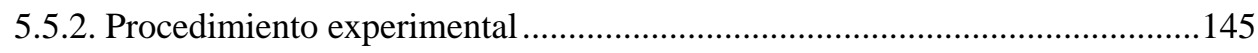

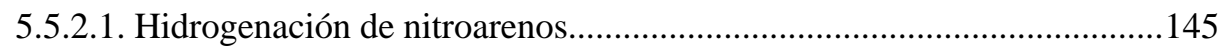

5.5.2.2. Síntesis de aminas secundarias por aminación reductiva....................... 145

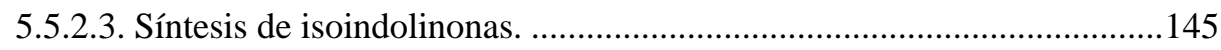

5.5.2.4. Estudio quimioselectividad por ATR-FTIR. ................................... 146

5.5.3. Caracterización de los productos de reacción sintetizados.......................... 147

5.5. Bibliografía .................................................................................................... 154 


\section{Capítulo 6. Complejos tetranucleares de cobalto para la oxidación selectiva de ciclohexano .............................................167}

6.1. Introducción .............................................................................. 171

6.2. Objetivos ................................................................................................ 174

6.3. Resultados y discusión ............................................................... 174

6.3.1. Síntesis y caracterización de los catalizadores ...............................................174

6.3.2. Evaluación de los clústeres de cobalto en la oxidación de ciclohexano.........179

6.3.3. Estudio mecanístico de la reacción de oxidación de ciclohexano ...................184

6.3.3.1. Estudio EPR de la descomposición de CHHP por los clústeres de cobalto 1-6 mediante atrapamiento de spin.......................................................................186

6.3.3.2. Transferencia de oxígeno desde el CHHP al ciclohexano mediada por los

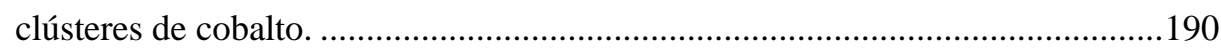

6.3.3.3. Espectroscopía Raman in-situ empleando oxígeno molecular................192

6.3.3.3. Influencia de la naturaleza del clúster de cobalto en el mecanismo de

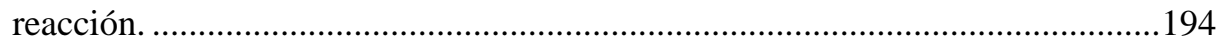

6.4. Conclusiones .............................................................................. 196

6.5. Sección experimental ................................................................. 197

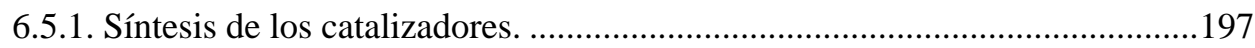

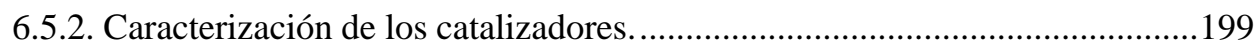

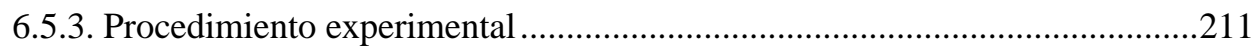

6.5.4. Resultados catalíticos para la oxidación de ciclohexano ................................212

6.5.5. Estudio del mecanismo de reacción...............................................................214

6.5.5.1. Resonancia paramagnética electrónica...................................................214

6.5.5.2. Cálculo de la eficiencia para la reacción de transferencia de oxígeno desde

el CHHP al ciclohexano. ...............................................................................218

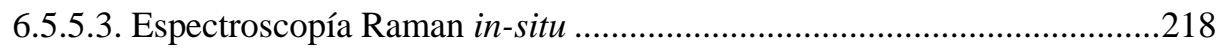




\section{Capítulo 7. MOFs de Cobalto como Catalizadores para la Oxidación Electrocatalítica del Agua en Medio Neutro. 229}

7.1. Introducción 233

7.2. Objetivos 239

7.3. Resultados y discusión. 239

7.3.1. Síntesis y caracterización de los MOFs de Cobalto..... 239

7.3.1.1. Síntesis y caracterización del $\mathbf{C o}_{2}-\mathbf{M O F}$. .239

7.3.1.2. Síntesis y caracterización del 2D-Co-MOF apilado por interacciones $\pi-\pi$. .249

7.3.2. Estudio electroquímico de los MOFs de cobalto. .261

7.3.2.1. Estudio electroquímico del Co2-MOF y comparación con Co-MOF. ..261 7.3.2.2. Estudio electroquímico del 2D-Co-MOF. Relación entre la electroquímica redox y la química de coordinación del composite 2D-Co-MOF@ Nafion........266 7.3.3. Actividad electrocatalítica de los MOFs de cobalto en la reacción de evolución de oxígeno (OER) en medio neutro. .272

7.3.3.1. Actividad electrocatalítica del $\mathbf{C o}_{2}$-MOF en la reacción de evolución de oxígeno (OER).

7.3.3.2. Actividad electrocatalítica del 2D-Co-MOF en la reacción de evolución de oxígeno (OER). 280

7.3.4. Análisis comparativo del rendimiento electrocatalítico del Co2-MOF@Nafion y el 2D-Co-MOF @ Nafion para la reacción de oxidación del agua.........................292

7.4. Conclusiones ................................................................................ 295

7.5. Sección experimental ....................................................................296

7.5.1. Síntesis y caracterización de los MOFs de Cobalto..........................................296

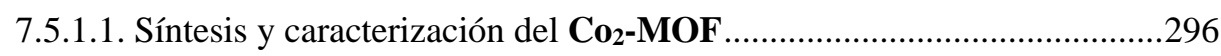


7.5.1.2. Síntesis y caracterización del 2D-Co-MOF ............................................298

7.5.2. Procedimiento experimental para las medidas de adsorción. ............................306

7.5.3. Procedimiento experimental para las medidas electroquímicas y la reacción de evolución de oxígeno. .308

7.6. Bibliografía ......................................................................................... 311

Capítulo 8. Conclusiones generales...........................................331

Publicaciones.........................................................................337

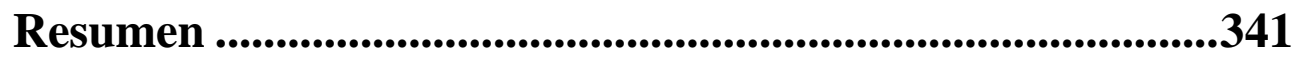

Índice de Figuras ..............................................................................349

Índice de Esquemas .................................................................365

Índice de Tablas .................................................................................369

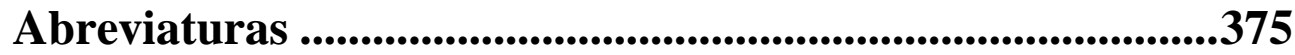




\section{Capítulo 1}

\section{Introducción}





\section{Índice}

1.1. Química Sostenible.......................................................................................5

1.1.1. Principios de la Química Verde..........................................................................6

1.2 Aspectos fundamentales de la catálisis: actividad, selectividad y sostenibilidad. ...................................................................................

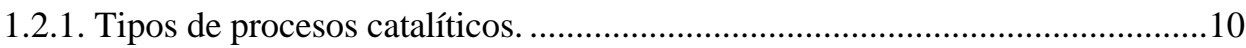

1.2.2. De catalizadores basados en metales nobles a catalizadores basados en metales

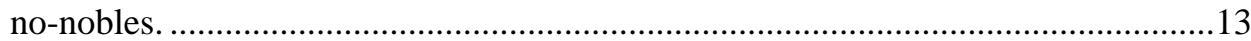

1.3. Propiedades del Cobalto y su aplicación en catálisis. ....................... 15

1.4. Técnicas de heterogeneización de catalizadores homogéneos......... 19

1.4.1. Inmobilización en soportes inorgánicos. ........................................................22

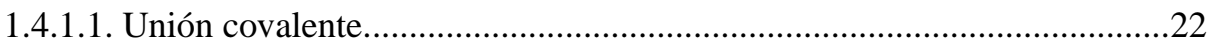

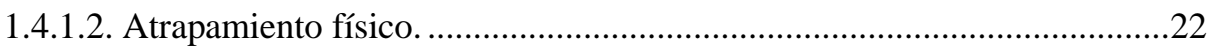

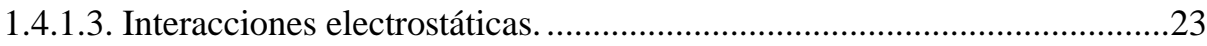

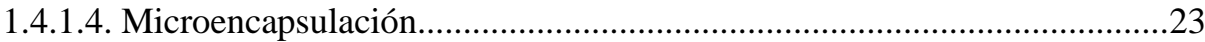

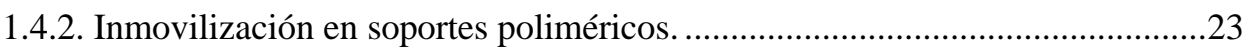

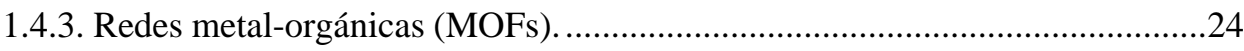

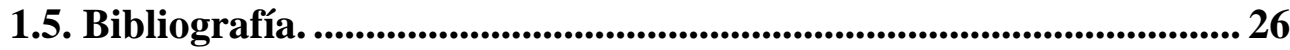





\subsection{Química Sostenible.}

Uno de los principales objetivos de la química actual es el desarrollo de procesos menos contaminantes para el medio ambiente, tratando de combinar adecuadamente seguridad, tiempo y eficacia en términos económicos y de sostenibilidad. Esto es lo que se define como química sostenible o química verde. ${ }^{1}$

Este cambio de paradigma surgió a finales de los años 90, impulsado por la EPA (del inglés, Environmental Protection Agency), la cual demandaba un cambio drástico en los procedimientos que se utilizaban hasta ese momento en los procesos químicos. Dos de los principales motivos que promovieron este cambio fueron el aumento de la contaminación y el agotamiento de las materias primas, los cuales obligaron a encontrar alternativas para la producción. ${ }^{1}$

El procedimiento tradicional a la hora de obtener un compuesto consistía generalmente en: ${ }^{2,3}$

1. Partir de una materia prima derivada del petróleo.

2. Disolverla en un disolvente adecuado.

3. Añadir un reactivo.

4. Hacerlos reaccionar hasta formar un intermedio adecuado.

5. Repetir varias veces el proceso anterior hasta la formación del producto final, descartar el residuo y el reactivo no consumido, y reciclar el disolvente si era económicamente viable.

6. Transportar el producto a todas las partes del mundo, donde se almacenaría el tiempo oportuno.

7. Liberar el producto al ecosistema sin realizar una evaluación previa de sus efectos a largo plazo.

En esta metodología, denominada tradicional, la mayor parte del coste del proceso, en torno al $40 \%$, se debía al desecho de los residuos que no podían ser recuperados. En este sentido, las industrias son cada vez más conscientes de que además de los costes directos tradicionales derivados de la fabricación (el coste de las materias primas o la mano de obra), existen otros costes directos (los derivados de la ineficiencia en la fabricación, el mal uso de la energía y la generación de subproductos) e indirectos (los generados por los residuos), sobre los que pesan cada vez más la mayor concienciación social y el control legislativo por parte de los Gobiernos. Por estos motivos, se han replanteado las 
metodologías empleadas y los procedimientos se han modificado de forma sustancial para transformarlos en procesos más sostenibles, teniendo en cuenta los siguientes aspectos: $:^{2,3}$

1. Diseñar una molécula que tenga un impacto mínimo sobre el medio ambiente, es decir, que sea biodegradable (bajo tiempo de residencia en el medio ambiente).

2. Fabricarla a partir de materias primas renovables.

3. Uso de catalizadores en su síntesis que sean fácilmente recuperables.

4. Realizar la reacción preferiblemente en ausencia de disolvente, y si fuese necesario utilizarlo, que el disolvente sea totalmente reutilizable y/o sostenible.

5. Sintetizar la molécula en el menor número de pasos posibles.

6. Disminuir los costes de transporte y almacenamiento realizando la producción cerca del centro de uso o del centro de extracción de las materias primas.

El gran impulso de la química verde se debe, en parte, al progresivo conocimiento de la toxicidad de las sustancias y de sus efectos sobre el medio ambiente y, por supuesto, a la creciente capacidad de los químicos para manipular los sistemas moleculares. ${ }^{2,3}$

Aunque el empleo por primera vez del término "Química Verde" ha sido asignado a Paul Anastas, ${ }^{4}$ parece que el término ya había sido empleado con anterioridad por Trevor Kletz, quien lo uso en 1978 en un artículo en el que se instaba al uso responsable de procesos químicos y búsqueda de procesos sostenibles. ${ }^{5}$ En 1998, Paul Anastas y John C. Warner publicaron un conjunto de principios para guiar la práctica de la Química verde. ${ }^{4}$ Estos doce principios establecen la forma de reducir el impacto ambiental y sanitario de la producción química, y las prioridades de la investigación para el desarrollo de las tecnologías de esta química.

\subsubsection{Principios de la Química Verde}

Los doce principios de la Química Verde publicados por Anastas y Warner recogen los ideales impulsados por la EPA, y son los siguientes:

1. Prevención: Es mejor prevenir la formación de residuos que tratar de eliminarlos tras su formación. Un parámetro frecuentemente usado en el tratamiento de los residuos es el factor E, ${ }^{6}$ descrito por Roger Sheldon, el cual indica la proporción entre los residuos generados y productos obtenidos. 


$$
\text { Factor } \mathrm{E}=\frac{\text { Masa total de residuos }}{\text { Masa de productos }}
$$

Ecuación 1.1

En la Tabla 1.1 se muestran los valores de producción y generación de residuos, así como el Factor E en determinados campos industriales:

Tabla 1.1. Datos de producción y generación de residuos en diversos campos industriales. ${ }^{6,7}$

\begin{tabular}{|c|c|c|c|}
\hline Sector industrial & $\begin{array}{c}\text { Producción } \\
\text { Anual (t) }\end{array}$ & Factor E & Residuos generados (t) \\
\hline Refinería & $10^{6}-10^{8}$ & 0.1 & $10^{5}-10^{7}$ \\
\hline Productos básicos & $10^{4}-10^{6}$ & $<1-5$ & $10^{4}-5 \cdot 10^{6}$ \\
\hline Química Fina & $10^{2}-10^{4}$ & $5-50$ & $5 \cdot 10^{2}-5 \cdot 10^{5}$ \\
\hline Farmacéuticas & $10-10^{3}$ & $25-100$ & $2.5 \cdot 10^{2}-10^{5}$ \\
\hline
\end{tabular}

A pesar de los datos mostrados en la Tabla 1.1, el campo que presenta mayor valor del factor E, (e imposible de calcular de forma fiable) son los propios laboratorios de investigación, pues es donde se obtienen menores cantidades de productos, y los valores de residuos son proporcionalmente más elevados.

De la expresión matemática del factor E se puede deducir que cuanto más elevado sea el valor, mayor será la cantidad de desechos que se producen. Sin embargo, no sólo es importante considerar el volumen de residuos generados, sino también, su naturaleza y su grado de toxicidad, así como de los reactivos empleados. Debido a las exigencias en la legislación de los países desarrollados en cuanto a los residuos sólidos, vertido, almacenamiento, transporte y uso de reactivos peligrosos y/o nocivos tanto para el ser humano como para el medio ambiente, se define otro concepto más adecuado, conocido como Factor Medioambiental $\mathrm{EQ},{ }^{8}$ que resulta del producto obtenido de la multiplicación del Factor E por un valor arbitrario Q, el cual gradúa la agresividad hacia el medio ambiente del reactivo o el producto.

$$
E Q=\text { Factor } E x Q
$$

Ecuación 1.2

El factor Q se determina a partir de las frases R de cada uno de los compuestos empleados en un proceso químico, así como del impacto medioambiental que supone su producción. Por lo tanto, un aspecto importante del desarrollo sostenible es que los precios de los productos finales deben reflejar todos los costes, no sólo económicos, sino también medioambientales y sociales. ${ }^{9}$ 
Otro factor importante que hay que considerar en un proceso químico es lo que se conoce como Factor Climático o Factor C, introducido por Christensen en 2008. ${ }^{10}$ Dicho factor relaciona la cantidad de $\mathrm{CO}_{2}$ producido por cantidad de producto formado, obteniendo así, un número que revela su renovabilidad.

$$
\text { Factor } C=\frac{\mathrm{CO}_{2}(\mathrm{~kg})}{\text { Producto }(\mathrm{kg})}
$$

Ecuación 1.3

2. Eficiencia atómica: Los métodos sintéticos deben ser diseñados para conseguir la máxima incorporación en el producto final de todas las materias usadas en el proceso. El concepto de "economía atómica" de una reacción fue desarrollado por Trost en 1991, ${ }^{11}$ y ampliado por Sheldon en el año 2000. ${ }^{12}$ Tradicionalmente, la eficiencia de una reacción se medía mediante el cálculo del rendimiento. Sin embargo, una reacción con un rendimiento del $100 \%$ puede tener a la vez solo la mitad de la masa de los reactivos incorporados en el producto deseado, mientras que la otra mitad se desperdicia en subproductos no deseados. Por tanto, la economía atómica se define como:

$$
\% \text { Economía atómica }=\frac{\text { Masa de átomos utilizados }}{\text { Masa de átomos reactivos }} \cdot 100 \quad \text { Ecuación } 1.4
$$

3. Síntesis segura: Siempre que sea posible, se deben diseñar metodologías sintéticas para el uso y la generación de sustancias con escasa toxicidad humana y ambiental.

4. Productos seguros: Se deben diseñar productos químicos que, preservando la eficacia de su función, presenten una mínima toxicidad. Es decir, debe reducirse al mínimo la toxicidad, manteniendo simultáneamente la función y la eficacia.

5. Disolventes seguros: Las sustancias auxiliares (disolventes, agentes de separación, etc.) deben reducirse o eliminarse en lo posible y, si se usan, deben ser inocuas.

6. Eficiencia energética: Las necesidades energéticas deben ser consideradas en relación a sus impactos ambientales y económicos. Cuando sea posible, los métodos sintéticos deben ser llevados a temperatura y presión ambientales.

7. Fuentes renovables: Las materias primas de partida deben ser renovables y no extinguibles, en la medida que esto resulte posible técnica y económicamente.

8. Evitar derivados: La formación innecesaria de derivados (bloqueo de grupos, protección/desprotección, modificación temporal de procesos físicos/químicos) debe ser evitada siempre que sea posible. 
9. Catalizadores: Los métodos catalíticos (tan selectivos como sea posible) son superiores a los estequiométricos. Un catalizador se define como "una sustancia que cambia la velocidad de una reacción sin que ella misma cambie durante el proceso". Se reduce la energía de activación de la reacción sin consumirse el catalizador. Esto significa que, al menos en principio, se pueden utilizar pequeñas cantidades y ser reciclados de forma indefinida, es decir, sin generación de residuos.

10. Biodegradabilidad: Los productos químicos han de ser diseñados de manera que, al final de su función, no persistan en el medioambiente, sino que se fragmenten en productos de degradación inertes.

11. Analizar en tiempo real para evitar la contaminación: Se deben desarrollar metodologías analíticas que permitan la monitorización a tiempo real durante el proceso y el control previo a la formación de sustancias peligrosas.

12. Prevención de accidentes: Las sustancias y las formas de su uso en un proceso químico, deben ser elegidas de manera que resulte mínima la posibilidad de accidentes.

Una vez establecidos los 12 principios que implica una "Química Verde”, su implementación y seguimiento, en la medida de lo posible, por la industria química y por la sociedad en general, tendrá un gran impacto medioambiental. Por ello se han creado innumerables organismos, instituciones y programas educativos relacionados con la misma.

\subsection{Aspectos fundamentales de la catálisis: actividad, selectividad y sostenibilidad.}

Entre los principios de la Química Verde se identifica la catálisis como una de las herramientas más importantes para su aplicación. Como se ha mencionado anteriormente, la catálisis consiste en el incremento de la velocidad de una reacción química a través de la interacción de los reactivos con una sustancia (catalizador) que proporciona un camino de reacción alternativo con menor energía de activación (Figura 1.1), facilitando así la formación de los productos. ${ }^{13}$ 


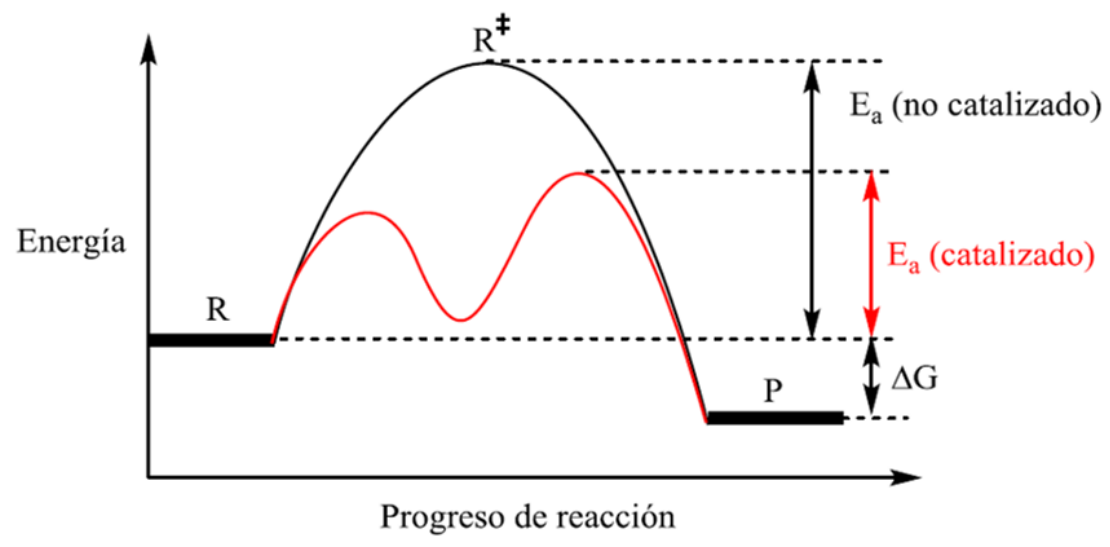

Figura 1.1. Progreso de la reacción química catalizada (rojo) y sin catalizar (negro).

Desde que se descubrió la catálisis hace más de 150 años, se ha empleado como herramienta para conseguir avances significativos, principalmente: 1) descubrimiento de nuevas reacciones químicas que sólo se consiguen mediante la catálisis; 2) incremento de la velocidad de reacción (menor energía de activación), lo cual permite llevar a cabo una reacción a menor temperatura y en menos tiempo; 3) mayor selectividad de las reacciones, obteniendo el producto deseado sin formar otros subproductos; 4) sostenibilidad del proceso químico, generando menos subproductos o residuos, disminuyendo la toxicidad y mejorando la eficiencia atómica. Hoy en día, alrededor del $80 \%$ de los procesos químicos que se llevan a cabo dependen de una u otra manera de la catálisis, ${ }^{14}$ es por ello por lo que se está realizando un gran esfuerzo en el desarrollo de nuevos procesos catalíticos.

\subsubsection{Tipos de procesos catalíticos.}

Los procesos catalíticos se pueden clasificar, en primer lugar, en función de la energía que se requiere para llevar a cabo una transformación química. Entre las formas de energía que se utilizan para llevar a cabo una transformación química destacan la energía térmica (catálisis térmica o convencional), las ondas electromagnéticas (catálisis por microondas), las ondas mecánicas (sonocatálisis), la luz (fotocatálisis) o la electricidad (electrocatálisis).

La catálisis térmica consiste en aplicar energía en forma de calor a la reacción química, de forma que esta energía aumenta la cinética de las partículas, incrementando la velocidad de la reacción, tal y como explica la teoría de colisiones. Por otro lado, existen 
algunos casos en los que los catalizadores necesitan ser activados a una temperatura determinada para generar las especies activas que van a catalizar la reacción.

Una variante de la catálisis térmica es la catálisis activada por microondas. La catálisis por microondas representa una técnica alternativa para proporcionar energía térmica a una reacción. Esta forma de calentamiento utiliza la propiedad de algunas moléculas de transformar la energía electromagnética en calor. La radiación provoca la rotación de los dipolos dentro del disolvente, lo cual causa que las moléculas polares se alineen y luego se relajen en el campo oscilante de la radiación electromagnética. Cuando la energía de la rotación de esos dipolos se disipa, se produce el calentamiento del líquido. ${ }^{15} \mathrm{Al}$ aumentar la temperatura del medio, como se ha mencionado anteriormente, aumentaría la velocidad de la reacción.

Por otro lado, la sonocatálisis utiliza ondas mecánicas para acelerar la velocidad de la reacción. En este caso, los ultrasonidos afectan a la reactividad del catalizador durante la catálisis aumentando la transferencia de masa y la energía de entrada. Por ejemplo, en catálisis heterogénea, donde el catalizador está en una fase diferente a los reactivos, la dispersión por ultrasonidos aumenta el área superficial disponible para los reactivos. ${ }^{16}$

Por otro lado, la fotocatálisis es un proceso que implica la combinación de la fotoquímica con la catálisis. En este caso, tanto la luz como el catalizador son necesarios para llevar a cabo una reacción fotocatalítica. En este proceso, la luz con la que se irradia el sistema se convierte en energía química en la superficie del catalizador, que consiste en un material semiconductor, el cual acelera la velocidad de la reacción. La etapa inicial de este proceso consiste en la generación de un par electrón-hueco en el catalizador. Cuando un fotón con una energía igual o superior a la energía del salto de banda del material semiconductor, $\mathrm{E}_{\mathrm{g}}$, incide sobre éste, se promueve un electrón de la banda de valencia a la banda de conducción, generándose un hueco en la banda de valencia. Durante el proceso fotocatalítico pueden tener lugar reacciones tanto de oxidación como de reducción. ${ }^{17}$

En el caso de la electrocatálisis, se aplica energía en forma de electricidad. La electrocatálisis es un proceso catalítico que implica el uso de un catalizador (electrocatalizador) en una reacción redox no espontánea, la cual se produce a través de la aplicación de una diferencia de potencial. La celda unidad básica para llevar a cabo una reacción electrocatalítica consiste en un ánodo, un cátodo, un separador o diafragma, una fuente de alimentación y un electrolito. En dicha celda, la energía eléctrica se suministra aplicando una diferencia de potencial entre los dos electrodos, los cuales están inmersos en el electrolito. La conversión de la energía eléctrica en energía química tiene 
lugar en la interfase electrodo-electrolito a través de reacciones de transferencia de carga. ${ }^{18}$

Por otro lado, en función de las fases que estén presentes en el proceso de reacción, se definen dos tipos de catálisis. Si todos los componentes se encuentran disueltos en el medio de reacción, se trata de un proceso de catálisis homogénea. Por el contrario, la catálisis heterogénea implica la presencia de dos fases, donde el catalizador no se encuentra disuelto con los reactivos. ${ }^{19}$

Los catalizadores más utilizados en catálisis homogénea están basados principalmente en compuestos de coordinación, los cuales son capaces de alcanzar velocidades de reacción y selectividades muy elevadas, gracias a importantes avances en el diseño de ligandos y el uso de distintos aditivos. La caracterización mediante distintas técnicas como resonancia magnética nuclear, difracción de rayos X y espectroscopía infrarroja, entre otras, de los complejos organometálicos permite saber su estructura de manera bien definida y comprender el proceso a nivel molecular. Como resultado, es posible llevar a cabo el diseño racional de complejos para reacciones muy específicas. Sin embargo, los catalizadores homogéneos presentan importantes limitaciones en su aplicabilidad en reacciones a gran escala debido a su alto coste, su inestabilidad a temperaturas de reacción relativamente altas, la dificultad en la separación del catalizador del medio de reacción, el reciclado y su elevada toxicidad. ${ }^{13}$ Por estos motivos, los catalizadores heterogéneos son preferidos en la industria química, especialmente por la facilidad en su separación y reutilización (con o sin paso de regeneración) y a su mayor estabilidad a elevadas temperaturas. ${ }^{20} \mathrm{El}$ conocimiento de la estructura molecular de los catalizadores sólidos es más complicado, y su actividad y selectividad suelen ser inferiores debido a la mayor dificultad en controlar el proceso de síntesis para tener centros activos bien definidos. En la Tabla 1.2 se muestran las principales características de los catalizadores homogéneos y heterogéneos. ${ }^{19}$ 
Tabla 1.2. Comparativa catalizadores homogéneos y heterogéneos.

\begin{tabular}{|c|c|c|}
\hline \multicolumn{1}{|c|}{ Centros activos } & Todos los átomos & Catisis hólisis heterogénea \\
\hline Selectividad & Alta & Variable \\
\hline Problemas de difusión & Nulos & Presentes \\
\hline Condiciones de reacción & Media & Severas \\
\hline Aplicabilidad & Limitada & Extensa \\
\hline Pérdida de actividad & Irreversible & Reversible \\
\hline Estructura & Definida & Indefinida \\
\hline Estabilidad térmica & Baja & Alta \\
\hline Separación & Laboriosa & Fácil \\
\hline Vida del catalizador & Variable & Larga \\
\hline Coste por pérdida & Alta & Baja \\
\hline Mecanismo & Asequible & Menos asequible \\
\hline
\end{tabular}

\subsubsection{De catalizadores basados en metales nobles a catalizadores basados en metales} no-nobles.

Desde sus inicios en la década de 1960, la investigación en el campo de la catálisis homogénea ha dado lugar a una amplia variedad de catalizadores organometálicos para llevar a cabo reacciones de gran interés industrial y, no menos importante, a una profunda comprensión fundamental de la reactividad de los complejos de metales de transición. El Premio Nobel ha sido concedido 3 veces al campo de la catálisis homogénea a principios del siglo XXI, lo cual pone de manifiesto el impacto que este campo ha tenido en el campo de la síntesis y de la química general. ${ }^{21-23}$ Cabe destacar que las reacciones por las que se han concedido estos premios nobeles utilizan predominantemente metales nobles del grupo del platino. Esto ilustra la importancia histórica y el predominio del uso de metales nobles en el campo de la catálisis homogénea en particular, y en el de la catálisis en general, desde la síntesis orgánica a pequeña escala en los laboratorios farmacéuticos hasta los procesos industriales a gran escala. 
En muchos casos, los metales nobles realizan el trabajo pesado, rompiendo o activando enlaces $\mathrm{H}-\mathrm{H}$, formando enlaces $\mathrm{C}-\mathrm{H}$ o C-C. Estos metales se han hecho tan familiares en estas funciones que en algunos casos el metal noble y su reactividad catalítica parece que van prácticamente unidos. El catalizador de Wilkinson, un complejo de rodio, desempeñó un papel fundamental en la comprensión de las hidrogenaciones. ${ }^{24}$ Más recientemente, Noyori y sus colaboradores desarrollaron complejos de rutenio altamente reactivos para hidrogenaciones catalíticas asimétricas de enlaces $\mathrm{C}=\mathrm{O},{ }^{25}$ y Grubbs y colaboradores desarrollaron varias generaciones de catalizadores de rutenio que facilitaron el desarrollo del método de metátesis en síntesis orgánica. ${ }^{26,27}$ Han pasado más de 150 años desde el descubrimiento de una pila de combustible que oxida el hidrógeno, sin embargo, las pilas de combustible de baja temperatura modernas siguen necesitando platino. ${ }^{28}$ Muchas reacciones de acoplamiento carbono-carbono utilizadas ampliamente en síntesis orgánica funcionan eficazmente con cargas extremadamente bajas de catalizadores de paladio. ${ }^{29}$

La investigación de alternativas a los catalizadores basados en metales nobles ha aumentado rápidamente en los últimos años, y se espera que experimente un mayor crecimiento en un futuro cercano. ${ }^{30,31}$ La razón más obvia para sustituir los metales nobles es que son muy caros, a menudo cuestan más de 100 o 1000 veces el coste de los metales de la primera serie de transición. El elevado coste está obviamente relacionado con la escasa abundancia de estos metales. Es importante destacar que algunos usos a gran escala, como el almacenamiento y la conversión de energía que se están considerando actualmente, requerirían de grandes cantidades de metales nobles. Por ejemplo, en el transporte automotriz, el cambio a una "economía del hidrógeno" basada completamente en pilas de combustible que requieren platino, no sería factible, no sólo por su alto coste, sino porque no hay suficiente platino disponible para implantarlo en una escala de uso tan grande. ${ }^{32}$

Por estos motivos, la comunidad científica se ha interesado por el estudio y el desarrollo de catalizadores basados en metales no nobles. El uso de metales como el manganeso, el hierro y el cobalto promete aliviar, al menos en parte, algunos de estos problemas. De hecho, en los últimos años, se han publicado numerosos trabajos que muestran como catalizadores que no requieren metales preciosos pueden acabar suplantando el uso de éstos en algunos tipos de reacciones. ${ }^{30,31}$ Para desarrollar nuevos tipos de catalizadores, en primer lugar, hay que estudiar el mecanismo de reacción y conocer que características debe tener el nuevo catalizador para que cumpla el objetivo deseado y, seguidamente, buscar la forma de utilizar metales abundantes para la síntesis de catalizadores de forma que cumplan con la función propuesta. En muchos casos, esos mecanismos son 
diferentes de los que siguen las reacciones catalizadas por metales nobles. ${ }^{30,31}$ En este sentido, los metales de la primera serie de transición suelen presentar múltiples estados de oxidación, a menudo espaciados por diferencias de un electrón, y presentan una fuerte tendencia a adoptar configuraciones de electrones de alto espín, lo cual conduce a una química marcadamente diferente para los metales no nobles con respecto a los metales nobles, por ejemplo, en términos de labilidad cinética y tiempos de vida de los intermedios. ${ }^{30,31}$ Por lo tanto, se espera que la investigación en el desarrollo de catalizadores basados en metales no nobles desvele patrones de reactividad fundamentalmente nuevos, que conduzcan a nuevos catalizadores y, no menos importante, a nuevas aplicaciones. Además, a diferencia de lo que ocurría en los primeros tiempos de la catálisis, la disponibilidad actual de herramientas espectroscópicas y analíticas avanzadas, incluidos los métodos computacionales, permite ahora una caracterización y comprensión detalladas de los catalizadores heterogéneos basados en metales no nobles y de los intermedios de reacción.

\subsection{Propiedades del Cobalto y su aplicación en catálisis.}

El cobalto es un metal de la primera serie de transición, ubicado en el grupo 9 de la Tabla Periódica. Su número atómico es 27 y su estructura electrónica $[\mathrm{Ar}] 3 \mathrm{~d}^{7} 4 \mathrm{~s}^{2}$. Algunas propiedades físicas de este metal se resumen en la Tabla 1.3.

Tabla 1.3. Propiedades del cobalto.

\begin{tabular}{|c|c|}
\hline Propiedad & Valor \\
\hline Número atómico & 27 \\
\hline Peso atómico & $58.933200(9)$ \\
\hline Configuración electrónica & {$[\mathrm{Ar}] 3 \mathrm{~d}^{7} 4 \mathrm{~s}^{2}$} \\
\hline Estados de oxidación & $0,+1,+2,+3,+4,+5$ \\
\hline Electronegatividad & 1.8 \\
\hline Radio metálico & 125 \\
\hline Temperatura de fusión $\left({ }^{\circ} \mathbf{C}\right)$ & 1495 \\
\hline Temperatura de ebullición $\left({ }^{\circ} \mathbf{C}\right)$ & 3100 \\
\hline Densidad & 8.90 \\
\hline
\end{tabular}


La abundancia del cobalto en la corteza terrestre se estima en torno a 29 partes por millón (ppm), es decir, $0.0029 \%$ y está ampliamente distribuido. ${ }^{33}$ Se conocen más de 200 minerales que contienen cobalto, aunque no todos presentan valor comercial. Los más importantes son los arseniuros y los sulfuros como la esmaltita $\left(\mathrm{CoAs}_{2}\right)$, la cobaltita (CoAsS) y la linnaeíta $\left(\mathrm{Co}_{3} \mathrm{~S}_{4}\right) .{ }^{33} \mathrm{El}$ principal productor mundial de cobalto es la República Democrática del Congo (Kinshasa), responsable algo más de la mitad de toda la producción de este elemento. A este país, le siguen en orden de producción, pero en una magnitud mucho menor, Rusia, Australia y Canadá. Durante 2017 la producción mundial alcanzó un volumen de 123.000 toneladas. ${ }^{34}$

El uso de cobalto en aplicaciones industriales comenzó en el siglo XX. En la década de 1920, se descubrió el uso del cobalto como matriz para la producción de carburo de tungsteno cementado, que también se denomina "metal duro". Este carburo cementado presenta importantes propiedades físicas como resistencia al calor, dureza y fuerza, y se usa en la industria en la fabricación de taladros y herramientas de corte de alta velocidad. ${ }^{35}$ Además, el cobalto fue uno de los componentes de la primera aleación magnética permanente, llamada alnico, que se desarrolló en la década de 1930. A partir de la Segunda Guerra Mundial, el uso del cobalto aumentó rápidamente, alcanzando su máxima producción a mediados de la década de 1980. Cabe destacar que el desarrollo de imanes compuestos de cobalto y tierras raras, caracterizados por sus importantes ventajas de potencia y tamaño contribuyó a la miniaturización de los equipos eléctricos y electrónicos en la década de $1980 .{ }^{35}$

Por otro lado, el cobalto es un elemento esencial en el ser humano, necesario para la formación de vitamina B12 (hidroxocobalamina). La coenzima B12 es uno de los compuestos de coordinación naturales más complejos, siendo especialmente destacable la presencia de un enlace metal-carbono, que hace que sea el primer, y hasta ahora único ejemplo, de un compuesto organometálico natural..$^{36,37}$ Este complejo cataliza reacciones como la síntesis de metionina, el metabolismo de las purinas y los folatos, y la formación del ácido metilmalónico o el ácido succínico.

Tanto el cobalto metálico como muchos de sus compuestos son claves en importantes y variadas aplicaciones en diversos campos, entre las que destaca la producción de productos químicos para las industrias de la cerámica y la pintura. En la actualidad muchos de los pigmentos industriales basados en cobalto están protegidos por patentes, ${ }^{38}$ pero en general se puede decir que existen dos grandes grupos de pigmentos de este tipo, los llamados "azules de cobalto" y los llamados "verdes de cobalto". En ambos casos se trata de materiales que presentan estructura de espinela. ${ }^{38}$ Otros usos incluyen la 
fabricación de aleaciones magnéticas, como el alnico, mencionado anteriormente. ${ }^{35}$ Por otro lado, los compuestos de cobalto también se emplean como catalizadores en una serie de reacciones orgánicas.

La facilidad con la que el cobalto produce reacciones de oxidación-reducción ha impulsado su amplia aplicación en el campo de la catálisis..$^{39}$ En la Tabla 1.4 se reúnen algunos de los procesos industriales más importantes que emplean catalizadores basados en compuestos de cobalto.

Tabla 1.4. Ejemplos de procesos catalíticos industriales importantes basados en catalizadores de cobalto.

\begin{tabular}{|c|c|}
\hline Oxidación de p-xileno & \begin{tabular}{c} 
Producto(s) \\
\hline Hidrodesulfuración
\end{tabular} \\
\hline Síntesis de Fischer-Tropsch & Petróleos libres de derivadico con $\mathrm{S}$ \\
\hline Síntesis OXO & Hidrocarburos a partir de $\mathrm{CO} / \mathrm{H}_{2}$ \\
\hline Reacción de Pauson-Khand & Aldehídos por adición de $\mathrm{CO} / \mathrm{H}_{2}$ a olefinas \\
\hline Fluoración & Ciclopentenonas \\
\hline Oxidación de tolueno & Compuestos perfluorocarbonados \\
\hline Oxidación de ciclohexano & Ácido benzoico \\
\hline
\end{tabular}

Un proceso de elevada importancia industrial es la oxidación de p-xileno a ácido tereftálico (Esquema 1.1), ya que este producto es la materia prima para la obtención del conocido poliéster PET (del inglés, polyethylene terephtalate) utilizado en la fabricación de botellas y otros envases plásticos. El sistema catalítico que se utiliza en este proceso es una mezcla de sales de cobalto y manganeso, generalmente sus respectivos acetatos. ${ }^{40}$

Por otro lado, el proceso de hidrodesulfurización se utiliza para eliminar compuestos sulfurados (sulfuros de dialquilo/diarilo, mercaptanos, tiofenos o benzotiofenos, etc.) de petróleos o derivados. Para ello se utilizan catalizadores metálicos del tipo $\mathrm{Mo} / \mathrm{Co}$, soportados en alúmina. ${ }^{41,42}$ 
Otro proceso industrial importante que se lleva a cabo con un catalizador de cobalto es la reacción de Fischer-Tropsch (Esquema 1.1). Este proceso permite obtener hidrocarburos y compuestos oxigenados por reacción entre $\mathrm{CO}$ e $\mathrm{H}_{2}$, trabajando en presencia de catalizadores adecuados y a presiones relativamente elevadas. Los hidrocarburos que constituyen la mayor parte del producto son, en general, parafinas de cadenas lineales y olefinas lineales. Prácticamente todos los metales de los grupos 8,9 y 10 de la tabla periódica presentan una actividad catalítica interesante para esas reacciones. ${ }^{43}$ En este proceso, el rutenio, junto con el hierro, cobalto y níquel son los metales más activos. Sin embargo, en las condiciones habituales de trabajo, el níquel produce demasiado metano y el rutenio resulta demasiado caro. Por estos motivos, tanto el hierro como el cobalto son los dos elementos que se han utilizado más como catalizadores en este proceso. De entre los dos últimos, el cobalto resulta más resistente a la desactivación y, en ciertas condiciones de reacción, resulta más eficiente que el hierro. Los catalizadores basados en cobalto habitualmente se preparan soportando el metal en algún tipo de soporte (sílice, alúmina, zeolitas) para aumentar su superficie específica. ${ }^{43}$

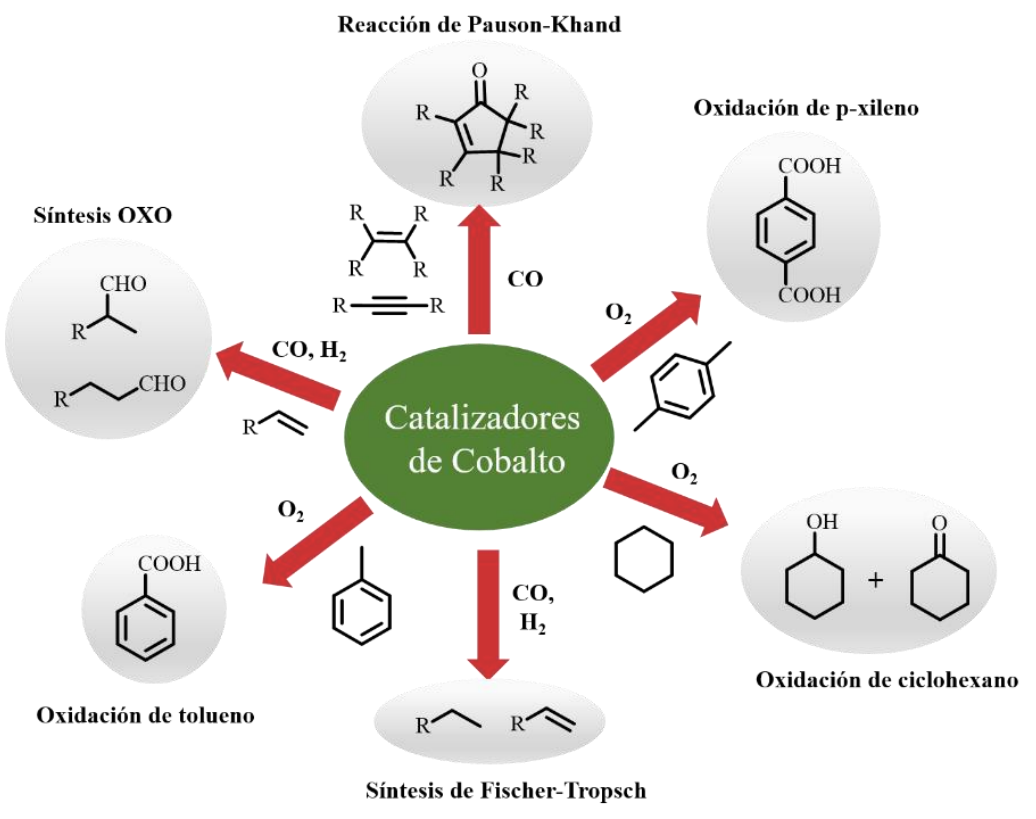

Esquema 1.1. Ejemplos de procesos catalíticos industriales importantes con catalizadores de cobalto. 
Por otro lado, el ácido benzoico, uno de los ácidos orgánicos simples más importantes en la industria química moderna, es un intermedio fundamental para la síntesis de pinturas, perfumes, productos farmacéuticos o productos agroquímicos. Habitualmente se produce con excelente rendimiento por oxidación parcial del tolueno con oxígeno en presencia de naftenato de cobalto como catalizador (Esquema 1.1). ${ }^{44}$

El mismo catalizador, naftenato de cobalto, se utiliza a nivel industrial en la oxidación de ciclohexano para producir ciclohexanol y ciclohexanona (Esquema 1.1). ${ }^{45}$ Ambos compuestos son intermedios importantes en la síntesis del nylon.

Además, el cobalto, junto al litio, ha adquirido una gran importancia en el diseño de las nuevas baterías destinadas a su empleo en vehículos eléctricos o en el almacenamiento de energía. Entre las tecnologías energéticas emergentes de conversión y almacenamiento de energía, además de las baterías, la división del agua para generar hidrógeno se considera de gran importancia debido a su alta eficiencia, seguridad energética y compatibilidad medioambiental. ${ }^{46,47}$ En este campo, la ruptura del agua (WS, del inglés water splitting) para producir hidrógeno y oxígeno, juega un papel fundamental. En este sentido, el cobalto se ha convertido en un metal interesante por su poder catalítico en esta reacción. ${ }^{48}$ Esto ha hecho que el cobalto se considere actualmente como un elemento estratégico para las nuevas tecnologías energéticas.

En base a todo lo comentado anteriormente, resulta evidente que el cobalto juega y jugará un papel muy importante en un futuro próximo, fundamentalmente en el campo en continuo desarrollo de la "economía energética verde". Finalmente, hay que recordar sus variadas aplicaciones como catalizador en diversos procesos industriales importantes, que han seguido aumentando en los últimos años.

\subsection{Técnicas de heterogeneización de catalizadores homogéneos.}

Si se observan con atención los procesos industriales descritos en el apartado anterior, la mayoría hacen uso de catalizadores basados en compuestos de coordinación, es decir, de catalizadores homogéneos. Hoy en día, los catalizadores heterogéneos son preferidos en la industria química, especialmente por la facilidad en su separación y reutilización. Sin embargo, el desarrollo de un sistema heterogéneo con centros metálicos bien definidos que presente una gran eficiencia catalítica y que sea totalmente reproducible es un verdadero reto. Aunque el reto presente cierta dificultad, el desarrollo de sistemas catalíticos heterogéneos es muy importante, y llevar a cabo estudios en este campo es la única forma de allanar el camino con el fin de conseguir un proceso químico ideal, que presente todos los principios de la química sostenible. ${ }^{49}$ 
Normalmente, el principal motivo para inmovilizar los compuestos en soportes sólidos es facilitar su manipulación y separación, un problema especialmente difícil cuando se trata de catalizadores homogéneos. Tras la heterogeneización, los compuestos inmovilizados pueden separarse fácilmente del medio de reacción mediante técnicas sencillas como la filtración, la decantación y la centrifugación, permitiendo así su reutilización y el reciclaje múltiple de los compuestos inmovilizados, lo que resulta especialmente beneficioso cuando se trabaja con materiales caros. ${ }^{50-52}$ Además, varios estudios han demostrado que la heterogeneización de los catalizadores homogéneos puede mejorar la estabilidad de los compuestos inmovilizados y, en algunos casos, potenciar la reactividad y la selectividad en las reacciones catalíticas. ${ }^{53}$

Tanto la naturaleza del soporte del catalizador como el proceso de heterogeneización influyen en la actividad de los catalizadores heterogéneos. Hasta la fecha, se han utilizado numerosos soportes catalíticos, tanto orgánicos como inorgánicos, y se han empleado diferentes metodologías para la inmovilización de los catalizadores homogéneos. ${ }^{54}$ Las propiedades resultantes y la aplicación potencial de un catalizador inmovilizado dependen en gran medida de la naturaleza fisicoquímica, la porosidad y las dimensiones del soporte, pero también de la naturaleza y longitud del espaciador entre los centros catalíticos y la superficie del soporte y de la densidad de los centros catalíticos en la superficie del mismo.

La inmovilización de los catalizadores homogéneos se basa normalmente en interacciones intermoleculares entre el soporte y la especie catalíticamente activa. Estas interacciones se clasifican en tres tipos: enlace covalente, interacciones no covalentes y encapsulación. En la unión covalente los catalizadores están unidos covalentemente al soporte, mientras que, en las interacciones no covalentes, que también se denominan fisisorción, los catalizadores se adsorben en la superficie del soporte a través de interacciones intermoleculares débiles, como enlaces por puente de hidrógeno o interacciones electrostáticas o de van der Waals. Por último, la encapsulación implica el atrapamiento físico del catalizador dentro de los poros o cavidades del soporte. Más recientemente, han surgido los polímeros de coordinación metal-orgánicos que se sintetizan a partir de la coordinación de ligandos multifuncionales e iones metálicos, sin necesidad de utilizar ningún tipo de soporte. ${ }^{49}$ Todo esto se resume en la Figura 1.2. 


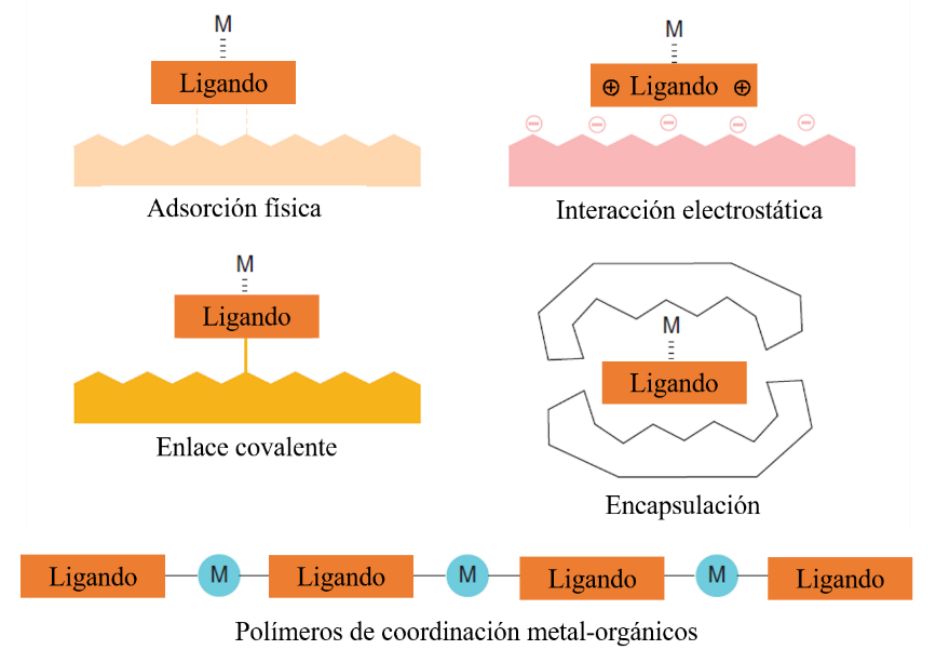

Figura 1.2. Métodos de inmovilización de catalizadores en soportes sólidos.

Para que un catalizador heterogéneo se considere de utilidad, debe cumplir los siguientes requisitos generales ${ }^{50}$ :

- La preparación del catalizador debe ser sencilla, eficaz, reproducible y lo más generalizada posible.

- La actividad del catalizador inmovilizado debe ser comparable, o mejor, que la del catalizador homogéneo.

- La separación del catalizador heterogéneo de la mezcla de reacción después de la reacción debe ser posible mediante un proceso simple en el que se debe recuperar más del $95 \%$ del catalizador.

- La lixiviación de las especies activas del catalizador debe ser mínima.

- El catalizador heterogéneo debe poder reutilizarse sin que presente una apreciable pérdida de la actividad.

- Los soportes en los que se va a inmovilizar el catalizador deben ser mecánica, térmica y químicamente estables. 


\subsubsection{Inmobilización en soportes inorgánicos.}

Los soportes inorgánicos utilizados para inmovilizar precursores homogéneos suelen ser estructuras porosas inertes con una superficie específica alta. Los más utilizados son los óxidos amorfos, en particular la sílice (zeolitas), y en menor medida la alúmina, la zirconia, el óxido de cinc. Existe una gran variedad de estos materiales, en la que varía el tamaño de poro, la distribución del tamaño de los poros o el tamaño de partícula, los cuales son comerciales o se pueden sintetizar fácilmente. ${ }^{51}$

\subsubsection{Unión covalente.}

La unión covalente del ligando a un soporte sólido a través de un conector bifuncional adecuado es una de las formas más populares y versátiles de heterogeneizar un precursor. Tanto los polímeros orgánicos como los sólidos inorgánicos son soportes útiles en esta estrategia de síntesis, pero estos últimos presentan la ventaja de ser materiales más robustos. La unión puede realizarse a través de métodos post-sintéticos, adhiriendo el compuesto deseado a la superficie del soporte previamente funcionalizada. ${ }^{52-56} \mathrm{El}$ mayor inconveniente de estos sistemas es que los ligandos tienen que estar funcionalizados, lo cual requiere de un gran esfuerzo de preparación, ya que tanto la síntesis como la posterior purificación pueden ser tediosas. Una ventaja importante es que los compuestos de coordinación unidos mediante enlaces covalentes no experimentan lixiviación del soporte y forman un catalizador estable. ${ }^{50}$

\subsubsection{Atrapamiento físico.}

El atrapamiento físico es uno de los métodos más sencillos de inmovilización en sílice. Para ello, los compuestos se adsorben al soporte de sílice a través de interacciones débiles, ${ }^{57-59}$ por lo que no se producen cambios importantes en la estructura ni en las propiedades intrínsecas de los compuestos inmovilizados. Sin embargo, estos sistemas son propensos a la lixiviación de las especies activas debido a que las interacciones entre el compuesto atrapado y el soporte son débiles. Esta estrategia de inmovilización puede llevarse a cabo de dos formas diferentes. La primera consiste en introducir el compuesto objetivo en la mezcla de reacción durante la preparación del soporte, que suele basarse en métodos sol-gel o técnicas de co-precipitación. ${ }^{60,61}$ La segunda consiste en incorporar los compuestos dentro de sistemas presintetizados mediante métodos de precipitación o impregnación. ${ }^{62-64}$ 


\subsubsection{Interacciones electrostáticas.}

Este método es adecuado para compuestos iónicos que son capaces de interactuar con soportes cargados. Algunos ejemplos son los líquidos iónicos, enzimas o catalizadores organometálicos. ${ }^{65}$ Como resultado, es posible unir compuestos iónicos con la carga opuesta a la superficie del soporte mediante interacciones electrostáticas. Otros enfoques se basan en la modificación de la superficie del soporte con grupos funcionales cargados para lograr este tipo de unión. ${ }^{66}$ Estas interacciones electrostáticas entre el compuesto inmovilizado y el soporte son bastante fuertes y, por tanto, son poco frecuentes los procesos de lixiviación.

\subsubsection{Microencapsulación.}

La microencapsulación es un proceso en el que partículas de tamaño micrométrico sólidas, gotas de líquido o gases se encierran en un recubrimiento inerte. ${ }^{67}$ El objetivo es proteger los compuestos de reacciones no deseadas como la hidrólisis o la oxidación separándolos del entorno exterior o facilitar la manipulación de ciertos materiales. A diferencia de otras técnicas de inmovilización, la microencapsulación no requiere de ningún tipo de interacción entre el material inmovilizado y el soporte, por lo tanto, prácticamente cualquier compuesto puede ser microencapsulado. Sin embargo, el material del recubrimiento debe ser inerte hacia los compuestos confinados y, además, proporcionar estabilidad. ${ }^{68,69}$

\subsubsection{Inmovilización en soportes poliméricos.}

Se han estudiado varios polímeros orgánicos, solubles e insolubles como soportes de catalizadores. Su síntesis es relativamente fácil y son fácilmente aislables del medio de reacción. ${ }^{70-72}$

Los polímeros insolubles, también conocidos como polímeros de entrecruzamiento o resinas, son fáciles de sintetizar, son químicamente inertes, baratos y se separan fácilmente del medio de reacción por filtración. La síntesis de estos polímeros se puede llevar a cabo por polimerización de una suspensión. ${ }^{73,74}$ En este proceso, la mezcla de síntesis compuesta por el monómero, el iniciador radical y agentes estabilizadores (surfactantes) y de entrecruzamiento se dispersan en un disolvente. Utilizando diferentes tipos y concentraciones de estos parámetros se obtienen resinas de diferentes tamaños y grados de entrecruzamiento.

Otro grupo de polímeros utilizados como soportes de catalizadores son las resinas de intercambio iónico (catiónico y aniónico). ${ }^{75-77}$ Las resinas de intercambio iónico se 
emplean para soportar nanopartículas (NPs) metálicas dentro de los poros de la estructura mediante interacciones no covalentes. Las NPs metálicas se estabilizan electrostática y estéricamente a través de los grupos funcionales cargados y la porosidad de la matriz. ${ }^{78}$

A pesar de las ventajas de los catalizadores soportados en polímeros insolubles, tales como fácil separación y recuperación del catalizador o mayor estabilidad catalítica, existen varios inconvenientes como la baja capacidad de carga y la fragilidad del soporte. Además, se obtiene una menor actividad del catalizador en comparación con el catalizador homogéneo como consecuencia de la dificultad de difusión de los reactivos hasta los centros catalíticos debido al alto grado de entrecruzamiento. ${ }^{72}$

Por otro lado, a principios de la década de 1970, se propusieron soportes alternativos viables basados en polímeros solubles para superar las limitaciones asociadas a los polímeros insolubles. ${ }^{79,80}$ Los polímeros solubles proporcionan un entorno homogéneo, imitando la actividad de los catalizadores no soportados, y pueden recuperarse por filtración con membranas, precipitación o extracción líquido-líquido. ${ }^{72,81-84}$

\subsubsection{Redes metal-orgánicas (MOFs).}

Los sistemas catalíticos heterogéneos mencionados anteriormente pueden recuperarse fácilmente del medio de reacción utilizando técnicas sencillas de separación física como la filtración, la extracción, la decantación y la centrifugación. Sin embargo, su actividad catalítica, en general, no es tan buena como la de sus homólogos homogéneos debido la baja relación entre el área superficial de los centros activos y el volumen total del material, lo que hace que el contacto entre el sustrato y los centros catalíticos activos sea reducido. ${ }^{49}$

Las redes metal-orgánicas (del inglés metal-organic frameworks, MOFs) y sus derivados están formados principalmente por iones o clústeres metálicos coordinados con ligandos orgánicos puente. ${ }^{82}$ Estos compuestos han resultado ser materiales muy prometedores para su aplicación en catálisis heterogénea debido a propiedades como su alta porosidad y cristalinidad y la posibilidad de ajustar fácilmente el tamaño, la forma y el entorno químico de sus poros. ${ }^{86,87}$

Existen diferentes posibilidades para usar los MOFs como catalizadores. La primera se basa en usar los MOFs como tal en transformaciones catalíticas, ya que estos materiales presentan posiciones de coordinación libres que pueden facilitar la coordinación de los sustratos a los centros metálicos. ${ }^{88}$ Otra opción es anclar especies activas a los iones metálicos en los MOFs que contienen vacantes de coordinación ${ }^{89-92}$ o usar conectores 
orgánicos con grupos funcionales que pueden servir como posiciones de anclaje de complejos organometálicos u organocatalizadores. ${ }^{93}$ Los MOFs podrían actuar como soportes eficientes de catalizadores homogéneos, sin embargo estos materiales generalmente presentan una baja estabilidad térmica y su estructura puede degradarse en determinados medios de reacción, lo cual puede limitar su aplicación práctica. 


\subsection{Bibliografía.}

(1) Clark, J.; Macquarrie, D., Handbook of green chemistry and technology. Oxford [England]: Blackwell Science, 2002.

(2) Chen, T.-L.; Kimc, H.; Pan, S.-H.; Tseng, P.-C.; Lina, Y.-P.; Chianga, P.-C., Implementation of green chemistry principles in circular economy system towards sustainable development goals: Challenges and perspectives, Science of the Total Environment 2020, 716, 136998.

(3) Anastas, P.; Eghbali, N., Green Chemistry: Principles and Practice, Chem. Soc. Rev. 2010, 39, 301-312.

(4) Anastas, P. T.; Warner, J. C., Green Chemistry: Theory and Practice, Oxford University Press, New York, 1998.

(5) Kletz, T. A., Chemistry and Industry 1978, 287-292.

(6) Sheldon, R. A., The E Factor: fifteen years on, Green Chemistry 2007, 9, 12, 1273-1283.

(7) Sheldon, R. A.; Dakka, J., Heterogeneous catalytic oxidations in the manufacture of fine chemicals, Catalysis Today 1994, 19, 2, 215-245.

(8) Wilson, K.; Sheldon, R. A.; Arends I.; Hanefeld, U., Green chemistry and catalysis, Wiley-VCH, 2007.

(9) Sheldon, R. A., The E factor 25 years on: the rise of green chemistry and sustainability, Green Chemistry 2017, 19, 1, 18-43.

(10) Christensen, C. H.; Rass-Hansen, J.; Marsden, C. C.; Taarning, E.; Egeblad, K., The Renewable Chemicals Industry, ChemSusChem 2008, 1, 4, 283-289.

(11) Trost, B. M., The atom economy-a search for synthetic efficiency, Science 1991, 254, 1471-1477.

(12) Sheldon, R. A., Atom efficiency and catalysis in organic synthesis, Pure Appl. Chem. 2000, 72, 7, 1233-1246.

(13) Van Leeuwen, P. W., Homogeneous catalysis: understanding the art. Springer Science \& Business Media, 2006. 
(14) Delidovich, I.; Palkovits, R., Catalytic versus stoichiometric reagents as a key concept for Green Chemistry, Green Chemistry, 2016, 18, 3, 590-593.

(15) Bond, G.; Moyes, R. B.; Whan, D. A., Recent applications of microwave heating in catalysis, Catal. Today 1993, 17, 427-437.

(16) Chatel, G., How sonochemistry contributes to green chemistry?, Ultrasonics Sonochemistry 2018, 40, 117-122.

(17) Ameta, R.; Solanki, M. S.; Benjamin, S.; Ameta, S. C., Advanced Oxidation Processes for Waste Water Treatment, Emerging Green Chemical Technology, Chapter 6, 2018, 135-175.

(18) Koper, M. T. M., Introductory Lecture Electrocatalysis: theory and experiment at the interface, Faraday Discuss. 2009, 140, 11-24.

(19) Kakaei, K.; Esrafili, M. D.; Ehsani, A., Introduction to Catalysis, Interface Science and Technology 2019, 27, 1-21

(20) Delmon, B.; Ertl, G.; Knözinger, H.; Weitkamp, J., Handbook of Heterogeneous Catalysis 1997, 264.

(21) El Premio Nobel de Química en 2001 fue concedido a William S. Knowles, Ryoji Noyori y K. Barry Sharpless por su trabajo "chirally catalyzed hydrogenation reactions". www.nobelprize.org/nobel_prizes/chemistry/laureates/2001/.

(22) El Premio Nobel de Química en $\mathbf{2 0 0 5}$ fue concedido a Yves Chauvin, Robert H. Grubbs y Richard R. Schrock por el desarrollo del método de metátesis en síntesis orgánica. www.nobelprize.org/nobel_prizes/chemistry/laureates/2005/.

(23) El Premio Nobel de Química en 2010 fue concedido a Richard F. Heck, Ei-ichi Negishi y Akira Suzuki por su trabajo "palladium-catalyzed cross couplings in organic synthesis". www.nobelprize.org/nobel_prizes/chemistry/laureates/2010/.

(24) Osborn, J. A.; Jardine, F. H.; Young J. F.; Wilkinson, G., The preparation and properties of tris(triphenylphosphine)halogenorhodium(I) and some reactions thereof including catalytic homogeneous hydrogenation of olefins and acetylenes and their derivatives, J. Chem. Soc. A 1966, 1711-1732.

(25) Noyori, R.; Hashiguchi, S., Asymmetric Transfer Hydrogenation Catalyzed by Chiral Ruthenium Complexes, Acc. Chem. Res. 1997, 30, 2, 97-102. 
(26) Schwab, P.; France, M. B.; Ziller, J. W.; Grubbs, R. H., A Series of WellDefined Metathesis Catalysts-Synthesis of $\left[\mathrm{RuCl}_{2}\left(\mathrm{CHR}^{\prime}\right)\left(\mathrm{PR}_{3}\right)_{2}\right]$ and Its Reactions, Angew. Chem. Int. Ed. Engl. 1995, 34, 2039-2041.

(27) Schwab, P.; Grubbs, R. H.; Ziller, J. W., Synthesis and Applications of $\mathrm{RuCl}_{2}\left(\mathrm{CHR}^{\prime}\right)\left(\mathrm{PR}_{3}\right)_{2}$ : The Influence of the Alkylidene Moiety on Metathesis Activity, $J$. Am. Chem. Soc. 1996, 118, 100-110.

(28) Holton, O. T.; Stevenson, J. W., The Role of Platinum in Proton Exchange Membrane Fuel Cells, Platinum Metals Rev. 2013, 57, 4, 259-271.

(29) Yin, L.; Liebscher, J., Carbon-Carbon Coupling Reactions Catalyzed by Heterogeneous Palladium Catalysts, Chem. Rev. 2007, 107, 1, 133-173.

(30) Bullock, R. M., Catalysis Without Precious Metals, Wiley-VCH, 2011.

(31) Gebbink, R. J. M. K.; Moret, M.-E., Non-Noble Metal Catalysis: Molecular Approaches and Reactions, Wiley-VCH, 2019.

(32) Tollefson, J., Worth its weight in platinum, Nature 2007, 450, 334-335.

(33) Greenwood, N. N.; Earnshaw, A., Chemistry of the Elements, 1997.

(34) U.S. Department of Interior, U.S. Geological Survey. Mineral Commodity Summaries 2018.

(35) Barceloux, B. G., Cobalt, Clinical Toxicology 1999, 37, 2, 201-216.

(36) Baran, E. J., Química Bioinorgánica, McGraw-Hill Interamericana de España S.A., Madrid, 1995.

(37) Lippard S. A.; Berg, J. A., Principles of Bioinorganic Chemistry, University Science Books, Mill Valley, CA, 1994.

(38) Buxbaum, G., Industrial Inorganic Pigments, 2nd. Edit., Wiley-VCH, Weinheim, 1998.

(39) Hawkins, M., Why we need cobalt, Appl. Earth Sci. 2001, 110, 66-70.

(40) Xiao, Y.; Luo, W. P.; Zhang, X. Y.; Guo, C. C.; Liu, Q.; Jiang G. F.; Li, Q. H., Aerobic Oxidation of p-Toluic Acid to Terephthalic Acid over T(p$\mathrm{Cl}) \mathrm{PPMnCl} / \mathrm{Co}(\mathrm{OAc})_{2}$ Under Moderate Conditions, Catal Lett. 2010, 134, 155-161. 
(41) Angelici, R. J., Acc. Chem. Res. 1988, 21, 387-394.

(42) Vasudevan P. T.; Fierro, J. L. G., A Review of Deep Hydrodesulfurization Catalysis, Catal. Rev. Sci. Eng. 1996, 38, 161-188.

(43) Cu, W.; Chernavskii, P. A.; Gengembre, L.; Pankina, G. A.; Fongarland, P.; Khodakov, A. Y., Cobalt species in promoted cobalt alumina-supported Fischer-Tropsch catalysts, J. of Catal. 2007, 252, 2, 215-230.

(44) Wade, L. G., Organic Chemistry, Harlow Pearson, London, 2014.

(45) Schuchardt, U.; Carvalho W.A.; Spinacé E.V., Why is it Interesting to Study Cyclohexane Oxidation?, Synlett 1993, 10, 713-718.

(46) Wang, J.; Zhang, H.; Wang, X., Recent Methods for the Synthesis of NobleMetal-Free Hydrogen-Evolution Electrocatalysts: From Nanoscale to Sub-nanoscale, Small Methods 2017, 1, 1700118.

(47) Shrivastav, V.; Sundriyal, S.; Goel, P.; Kaur, H.; Tuteja, S.K.; Vikrant, K.; Kim, K. H.; Tiwari, U. K.; Deep, A.; Metal-organic frameworks (MOFs) and their composites as electrodes for lithium battery applications: Novel means for alternative energy storage, Coord. Chem. Rev. 2019, 393, 48-78.

(48) Wang, J.; Cui, W.; Liu, Q.; Xing, Z.; Asiri, A. M.; Sun, X., Recent Progress in Cobalt-Based Heterogeneous Catalysts for Electrochemical Water Splitting, Adv. Mater. 2016, 28, 215-230.

(49) Piermatti, O.; Abu-Reziq, R.; Vaccaro, L., Catalyst Immobilization: Methods and Applications, Wiley-VCH, 2020.

(50) De Vos, D. E.; Vankelecom, I. F. J.; Jacobs, P. A., Chiral Catalyst Immobilization and Recycling, Wiley-VCH, 2000.

(51) Regalbuto, J., Catalyst Preparation: Science and Engineering. CRC Press, Taylor \& Francis Group, 2007.

(52) Bruhwiler, D., Postsynthetic functionalization of mesoporous silica, Nanoscale 2010, 2, 887-892.

(53) González-Arellano, C.; Corma, A.; Iglesias, M.; Sánchez, F., Improved Palladium and Nickel Catalysts Heterogenised on Oxidic Supports (Silica, MCM-41, ITQ-2, ITQ-6), Adv. Synth. Catal. 2004, 346, 1316-1328. 
(54) Karimi, B.; Khorasani, M., Selectivity Adjustment of SBA-15 Based Tungstate Catalyst in Oxidation of Sulfides by Incorporating a Hydrophobic Organic Group inside the Mesochannels, ACS Catal. 2013, 3, 7, 1657-1664.

(55) Kume, Y.; Qiao, K.; Tomida, D.; Yokoyama, C., Selective hydrogenation of cinnamaldehyde catalyzed by palladium nanoparticles immobilized on ionic liquids modified-silica gel, Catal. Commun. 2008, 9, 369-375.

(56) Walcarius, A.; Etienne, M.; Bessière, J., Rate of Access to the Binding Sites in Organically Modified Silicates. 1. Amorphous Silica Gels Grafted with Amine or Thiol Groups, Chem. Mater. 2002, 14, 6, 2757-2766.

(57) Avnir, D.; Braun, S.; Lev, O.; Ottolenghi, M., Enzymes and other proteins entrapped in sol-gel materials, Chem. Mater. 1994, 6, 1605-1614.

(58) Rosenfeld, A.; Avnir, D.; Blum, J., Sol-gel encapsulated transition metal quaternary ammonium ion pairs as highly efficient recyclable catalysts, J. Chem. Soc. Chem. Commun. 1993, 583-584.

(59) Rosenfeld, A.; Blum, J.; Avnir, D., Disproportionation of dihydroarenes by solgel entrapped $\mathrm{RhCl}_{3}$-quaternary ammonium ion pair catalysts, J. Catal. 1996, 164, 363368 .

(60) Blum, J.; Gelman, F.; Abu-Reziq, R.; Miloslavski, I.; Schumann, H.; Avnira. D., Sol-gel entrapped heteronuclear transition metal catalysts, Polyhedron 2000, 19, 509-512.

(61) Wu, Q.; Eriksen, W. L.; Duchstein, L. D. L.; Christensen, J. M.; Damsgaard, C. D.; Wagner, J. B.; Temel, B.; Grunwaldt, J.-D.; Jensen, A. D., Influence of preparation method on supported $\mathrm{Cu}-\mathrm{Ni}$ alloys and their catalytic properties in high pressure $\mathrm{CO}$ hydrogenation, Catal. Sci. Technol. 2014, 4, 378-386.

(62) Bezemer, G. L.; Radstake, P. B.; Koot, V.; van Dillen, A. J.; Geus, J. W.; de Jong, K. P, Preparation of Fischer-Tropsch cobalt catalysts supported on carbon nanofibers and silica using homogeneous deposition-precipitation, J. Catal. 2006, 237, 291-302.

(63) Imperor-Clerc, M.; Bazin, D.; Appay, M.-D.; Beaunier, P.; Davidson, A., Crystallization of $\beta-\mathrm{MnO}_{2}$ Nanowires in the Pores of SBA-15 Silicas: In Situ Investigation Using Synchrotron Radiation, Chem. Mater. 2004, 16, 1813-1821. 
(64) Moreno, M. S.; Weyland, M.; Midgley, P. A.; Bengoa, J. F.; Cagnoli, M. V.; Gallegos, N. G.; Alvarez, A. M.; Marchetti, S. G., Highly anisotropic distribution of iron nanoparticles within MCM-41 Mesoporous Silica, Micron, 2006, 37, 52-56.

(65) McMorn, P.; Hutchings, G. J., Heterogeneous enantioselective catalysts: strategies for the immobilisation of homogeneous catalysts, Chem. Soc. Rev. 2004, 33, $108-122$.

(66) Lei, C.; Shin, Y.; Liu, J.; Ackerman, E. J., Entrapping enzyme in a functionalized nanoporous support, J. Am. Chem. Soc. 2002, 124, 11242-11243.

(67) Akiyama, R; Kobayashi, S., "Microencapsulated" and related catalysts for organic chemistry and organic synthesis, Chem. Rev. 2009, 109, 594-642.

(68) Fujiwara, M.; Shiokawa, K.; Hayashi, K.; Morigaki, K.; Nakahara, Y., Direct encapsulation of BSA and DNA into silica microcapsules (hollow spheres), J. Biomed. Mater. Res. Part A 2007, 81A, 103-112.

(69) Galgali, G.; Schlangen, E.; van der Zwaag, S., Synthesis and characterization of silica microcapsules using a sustainable solvent system template, Mater. Res. Bull. 2001, $46,2445-2449$.

(70) Altava, B.; Burguete, M.I.; García-Verdugo, E.; Luis, S.V., Chiral catalysts immobilized on achiral polymers: effect of the polymer support on the performance of the catalyst, Chem. Soc. Rev. 2018, 47, 2722-2771.

(71) Buchmeiser, M. R., Polymeric Materials in Organic Synthesis and Catalysis, Wiley-VCH, Weinheim, 2006.

(72) Lu, J.; Toy, P. H., Organic polymer supports for synthesis and for reagent and catalyst immobilization, Chem. Rev. 2009, 109, 815-838.

(73) Sherrington, D. C., Preparation, structure and morphology of polymer supports, Chem. Commun. 1998, 2275-2286.

(74) Arshady, R.; Ledwith, A., Suspension polymerisation and its application to the preparation of polymer supports, React. Polym. Ion Exch. Sorb. 1983, 1, 159-174.

(75) Gelbard, G., Organic synthesis by catalysis with ion-exchange resins, Ind. Eng. Chem. Res. 2005, 44, 8468-8498. 
(76) Harmer, M. A.; Sun, Q., Solid acid catalysis using ion-exchange resins, Appl. Catal. A: Gen. 2001, 221, 45-62.

(77) Barbaro, P., Recycling Asymmetric Hydrogenation Catalysts by Their Immobilization onto Ion-Exchange Resins, Chem. Eur. J. 2006, 12, 5666-5675.

(78) Liguori, F.; Moreno-Marrodan, C.; Barbaro, P., Metal nanoparticles immobilized on ion-exchange resins: A versatile and effective catalyst platform for sustainable chemistry, Chin. J. Catal. 2015, 36, 1157-1169.

(79) Bayer, E.; Mutter, M., Liquid phase synthesis of peptides, Nature 1972, 237, 512-513.

(80) Mutter, M.; Hagenmaier, H.; Bayer, E., New method of polypeptide synthesis, Angew. Chem. Int. Ed. 1971, 10, 811-812.

(81) Bergbreiter, D. E.; Sung, S. D., Liquid/liquid biphasic recovery/reuse of soluble polymer-supported catalysts, Adv. Synth. Catal. 2006, 348, 1352-1366.

(82) Toy, P. H.; Janda, K. D., Soluble polymer-supported organic synthesis, Acc. Chem. Res. 2000, 33, 546-554.

(83) Chen, J.; Yang, G.; Zhang, H.; Chen, Z., A review: Non-cross-linked polystyrene bound reagents, catalysts and syntheses, React. Funct. Polym. 2006, 66, 1434-1451.

(84) Bergbreiter, D. E., Soluble polymers as tools in catalysis, ACS Macro Lett. 2014, 3, 260-265.

(85) Kaskel, S., The Chemistry of Metal-Organic Frameworks: Synthesis, Characterization, and Applications. Wiley-VCH, 2016.

(86) MacGillivray, L. R., Metal-Organic Frameworks: Design and Application. Wiley-VCH, 2010.

(87) García, H.; Navalón, S., Metal-Organic Frameworks: Applications in Separations and Catalysis. Wiley-VCH, 2018.

(88) Llabrés i Xamena, F. X.; Gascon, J., Metal-Organic Frameworks as Heterogeneous Catalysts. Cambridge, UK: The Royal Society of Chemistry, 2013. 
(89) Chughtai, A. H.; Ahmad, N.; Younus, H. A.; Laypkov, A.; Verpoort, F., Metalorganic frameworks: versatile heterogeneous catalysts for efficient catalytic organic transformations, Chem. Soc. Rev. 2015, 44, 6804-6949.

(90) Fang, X.; Shang, Q.; Wang, Y.; Jiao, L.; Yao, T.; Li, Y.; Zhang, Q.; Luo, Y.; Jiang, H.-L., Single Pt atoms confined into a metal-organic framework for efficient photocatalysis, Adv. Mater. 2018, 30, 1705112.

(91) Wu, C.-D.; Zhao, M., Incorporation of molecular catalysts in metal-organic frameworks for highly efficient heterogeneous catalysis, Adv. Mater. 2017, 29, 1605446.

(92) Zhu, L.; Liu, X.-Q.; Jiang, H.-L.; Sun, L.-B., Metal-organic frameworks for heterogeneous basic catalysis, Chem. Rev. 2017, 117, 8129-8176.

(93) Li, G.; Feng, Y. Q.; Li, X. G.; Gao, P.; Wang, J.; Xie, J. Y., Preparation and characterization of polyurea microcapsules containing colored electrophoretic responsive fluid, J. Mater. Sci. 2007, 42, 4838-4844. 
Capítulo 2

Objetivos 

El objetivo general de la presente Tesis Doctoral es el desarrollo de catalizadores de cobalto para llevar a cabo reacciones de interés industrial o relacionadas con las tecnologías energéticas sostenibles emergentes, a través de la activación de moléculas pequeñas, siguiendo las directrices de la Química Verde.

A partir de este objetivo general, se plantean los siguientes objetivos específicos:

1. Diseño de compuestos de coordinación de cobalto estables al aire y a la humedad, que sean activos y selectivos para la reacción de hidrosililación de alquenos, buscando la sinergia metal-ligando. Se evitará el uso de co-catalizadores o aditivos, llevando a cabo las reacciones en condiciones suaves de reacción y eliminando el uso de disolventes anhidros, con el fin de reducir las limitaciones existentes para aplicación industrial de catalizadores de cobalto en este proceso.

2. Heterogeneización de los catalizadores homogéneos obtenidos para el proceso anterior con el fin de obtener materiales heterogéneos activos, con centros catalíticos bien definidos y distribuidos en la estructura final, estudiando las limitaciones de los catalizadores reportados en bibliografía. Estos catalizadores se utilizarán en la reacción de reducción de nitroarenos y reacciones tándem para obtener compuestos de interés. Para llevar a cabo esta reacción, se estudiará el uso de disolventes benignos y de condiciones de reacción más suaves que las que se han usado hasta el momento.

3. Desarrollo de una familia de clústeres tetranucleares de cobalto para la reacción de oxidación de ciclohexano a ciclohexanol y ciclohexanona, en la que se puedan modular las propiedades electrónicas a través del uso del ligando adecuado, con el fin de correlacionar cómo afectan estas propiedades a la actividad del catalizador. Para ello se llevarán a cabo una serie de estudios in-situ y experimentales que permitan correlacionar la estructura con la actividad del catalizador.

4. Uso de precursores de cobalto polinucleares con centros bien definidos para la síntesis de nuevos MOFs que presenten nodos metálicos con topologías de interés, haciendo uso de ligandos mono y bifuncionales ampliamente utilizados en la síntesis de estos materiales. Se estudiará la actividad catalítica de estos MOFs de cobalto en la reacción de oxidación del agua a $\mathrm{pH}$ neutro, lo cual es una de las mayores limitaciones que se presentan en la actualidad en el uso de estos materiales, que necesitan de $\mathrm{pH}$ muy básicos para ser activos en este proceso. 
5. Todos los materiales obtenidos se caracterizarán de manera exhaustiva con el fin de determinar su estructura y sus propiedades estructurales, así como de identificar los centros activos y su accesibilidad, y de esta forma poder correlacionar su estructura con la actividad catalítica. En todos los casos se optimizará el catalizador y las condiciones de reacción, se estudiará la generalidad del proceso y se llevará a cabo un estudio estructura-actividad del catalizador, con el fin de profundizar en el mecanismo de reacción y poder continuar con el estudio diseñando un catalizador a medida para cada proceso. 


\section{Capítulo 3}

Materiales y métodos 



\section{Índice}

3.1. Consideraciones generales............................................................................ 43

3.2. Técnicas instrumentales. ....................................................................43

3.3. Bibliografía. .......................................................................................... 51 



\subsection{Consideraciones generales.}

Los reactivos químicos que se han empleado en el desarrollo de esta tesis doctoral han sido obtenidos generalmente de casas comerciales y se han utilizado sin purificación adicional a menos que se indique lo contrario. Los compuestos que se han sintetizado aparecen caracterizados junto con el procedimiento experimental que se ha seguido para obtenerlos.

\subsection{Técnicas instrumentales.}

A continuación, se detallan las técnicas empleadas para caracterizar los catalizadores sintetizados, llevar a cabo el seguimiento de las reacciones, caracterizar los compuestos obtenidos y analizar las especies activas.

Cromatografía de gases (GC): Esta técnica se ha empleado principalmente para cuantificar el rendimiento de las reacciones que se llevan a cabo con catalizadores heterogéneos y para los análisis cinéticos. El cálculo de los rendimientos se ha realizado mediante el método del patrón interno, añadiendo un compuesto patrón en cantidad conocida a la mezcla de reacción. Al analizar las alícuotas se obtienen las áreas cromatográficas del patrón y del analito, y a partir del factor de respuesta de este (calculado mediante una recta de calibrado), se obtiene la concentración de analito presente en la muestra. Generalmente, el compuesto empleado como patrón interno ha sido el n-dodecano o el n-hexadecano. Las medidas se han llevado a cabo con un cromatógrafo de gases Agilent equipado con una columna capilar HP5 (30m x $250 \mu \mathrm{m})$. El volumen de inyección se fijó en $1 \mu \mathrm{L}$, con un ratio de división a la entrada de 50:1. Las temperaturas de entrada y del detector se fijaron a $250^{\circ}$ y $300^{\circ} \mathrm{C}$, respectivamente. Como gas portador se usa Helio, con un flujo constante de $2 \mathrm{~mL} / \mathrm{min}$. El programa de temperatura usado para los análisis fue: $80^{\circ} \mathrm{C}, 2 \mathrm{~min}, 10^{\circ} \mathrm{C} / \mathrm{min}$ hasta $160^{\circ}, 14^{\circ} \mathrm{C} / \mathrm{min}$ hasta $300^{\circ} \mathrm{C}, 5 \mathrm{~min}$.

Cromatografía de gases acoplada a espectrometría de masas (GC-MS): Esta técnica se ha empleado para elucidar los productos que se forman en la reacción en base a la fragmentación de sus masas (huella dactilar de la molécula) por comparación con una base de datos. Estas medidas se han llevado a cabo con un instrumento Agilent 6890 Network acoplado a un detector selectivo de masas Agilent 5973 Network equipado con una columna capilar HP-5MS $(30 \mathrm{~m}$ x $250 \mu \mathrm{m})$. El volumen de inyección se fijó en $1 \mu \mathrm{L}$, con un ratio de división a la entrada de 60:1. Las temperaturas de entrada y del detector se fijaron a $250^{\circ}$ y $280^{\circ} \mathrm{C}$, respectivamente. Como gas portador se usa Helio, con un flujo 
constante de $1.2 \mathrm{~mL} / \mathrm{min}$. El programa de temperatura usado para los análisis fue: $50^{\circ} \mathrm{C}$, $2 \mathrm{~min}, 30^{\circ} \mathrm{C} / \mathrm{min}$ hasta $280^{\circ}, 15 \mathrm{~min}$.

Espectrometría de masas de alta resolución (HRMS): Esta técnica se ha empleado para obtener la masa exacta de los compuestos químicos y complejos de cobalto. Para ello se ha utilizado un espectrómetro Waters ACQUITYTM XevoQToF conectado a un sistema UPLC a través de la interfaz de ionización por electrospray (ESI). La fuente ESI se usó en modo de ionización positivo con el voltaje del capilar a $3.0 \mathrm{kV}$. La temperatura de la fuente y desolvatación se fijó a $120^{\circ} \mathrm{C}$ y $400^{\circ} \mathrm{C}$, respectivamente. Los flujos de gas del cono y desolvatación fueron $10 \mathrm{~L} / \mathrm{h}$ y $800 \mathrm{~L} / \mathrm{h}$, respectivamente. Se usó leucinaencefalina como estándar, que genera un ión $[\mathrm{M}+\mathrm{H}]^{+}(\mathrm{m} / \mathrm{z} 556.2771)$ a una concentración de $500 \mathrm{pg} / \mathrm{mL}$ y una velocidad de flujo de $20 \mu \mathrm{L} / \mathrm{min}$ para garantizar la precisión durante el análisis de MS.

Estudios de intercambio isotópico: Los experimentos de intercambio de hidrógeno/deuterio (H/D) se llevaron a cabo en un reactor en flujo con el fin de estudiar la capacidad de activación del $\mathrm{H}_{2}$ de los catalizadores basados en nanopartículas de cobalto. Para ello, se pasó un flujo del gas de alimentación, compuesto por una mezcla de $\mathrm{H}_{2}\left(4 \mathrm{ml} \mathrm{min}^{-1}\right), \mathrm{D}_{2}\left(4 \mathrm{ml} \mathrm{min}^{-1}\right)$ y $\mathrm{Ar}\left(17 \mathrm{ml} \mathrm{min}^{-1}\right)$. La salida del reactor está acoplada a un espectrómetro de masas (Balzer, Tecnovac), el cual trabaja en el modo de detección de iones múltiples (MID) y registra las señales de masa (m/z) $2\left(\mathrm{H}_{2}\right), 3(\mathrm{HD})$ y $4\left(\mathrm{D}_{2}\right)$. Para llevar a cabo el experimento, en primer lugar, se pasa un flujo de $\operatorname{Ar}\left(25 \mathrm{ml} \mathrm{min}^{-1}\right)$ a $25^{\circ} \mathrm{C}$ hasta que se estabiliza la señal de masa. A continuación, se cambia el flujo de $\mathrm{Ar}$ a la mezcla de reacción $\mathrm{H}_{2} / \mathrm{D}_{2} / \mathrm{Ar}$ y, tras 30 minutos de estabilización a $25^{\circ} \mathrm{C}$, se incrementa la temperatura secuencialmente a 60,100 y $120^{\circ} \mathrm{C}$, manteniéndose en cada temperatura durante al menos 30 minutos.

Espectroscopía atómica de emisión por plasma de inducción acoplada (ICP-AES): Esta técnica se empleó para determinar el contenido metálico de catalizadores sólidos tras disgregarlos en disolución acuosa con una mezcla de ácido sulfúrico y $\mathrm{H}_{2} \mathrm{O}_{2}$ a $100^{\circ} \mathrm{C}$. Se trabajó con un espectrómetro de emisión con fuente de plasma de inducción Varian 715ES.

Análisis elemental (EA): Esta técnica se empleó para determinar la cantidad de C, H, N y $\mathrm{S}$ de los catalizadores basados en redes metal orgánicas (MOFs) y complejos organometálicos mediante un analizador elemental Fisons CHNS. 
Análisis termogravimétrico (TGA): Esta técnica se ha empleado para estudiar la descomposición y la desorción de moléculas de los catalizadores sólidos con la temperatura. Los análisis se han llevado a cabo bajo atmósfera de $\mathrm{N}_{2}$ seco o aire con una termobalanza Mettler Toledo TGA/STDA 851 operando con una rampa de calentamiento de $10{ }^{\circ} \mathrm{C} / \mathrm{min}$ hasta una temperatura de $800^{\circ} \mathrm{C}$.

Resonancia magnética nuclear (RMN): Esta técnica se ha empleado, por un lado, para caracterizar los productos orgánicos y los compuestos organometálicos de cobalto formados y, por otro lado, para cuantificar el rendimiento de las reacciones que se llevan a cabo con catalizadores homogéneos. En este último caso, los rendimientos se calcularon añadiendo una cantidad conocida de un patrón interno, a partir del cálculo de las áreas correspondientes al patrón y a una señal conocida del compuesto a analizar, teniendo en cuenta los protones correspondientes. Los espectros RMN de ${ }^{1} \mathrm{H},{ }^{13} \mathrm{C}$, DEPT, etc. se han adquirido con un espectrómetro Bruker Avance de $300 \mathrm{MHz}$ usando como disolvente $\mathrm{CDCl}_{3}, \mathrm{CD}_{2} \mathrm{Cl}_{2}, \mathrm{CD}_{3} \mathrm{CN}, \mathrm{D}_{2} \mathrm{O}$ o DMSO según se indique. Los datos para los espectros de ${ }^{1} \mathrm{H}$ RMN se presentan de la siguiente forma: desplazamiento químico $(\delta$, $\mathrm{ppm})$, multiplicidad $(\mathrm{s}=$ singlete, $\mathrm{d}=$ doblete, $\mathrm{t}=$ triplete, $\mathrm{q}=$ cuadruplete, $\mathrm{m}=$ multiplete, $\mathrm{dd}=$ doble doblete, $\mathrm{bs}=$ señal ancha), las constantes de acoplamiento y la integración. Los datos para los espectros de ${ }^{13} \mathrm{C}$ RMN se presentan en desplazamiento químico $(\delta, \mathrm{ppm})$.

Resonancia paramagnética electrónica (EPR): Esta técnica se ha empleado para estudiar los intermedios radicalarios formados en las reacciones de oxidación. Los espectros se han medido a $100 \mathrm{~K}$ con un instrumento Bruker EMX-12 operando en banda X a 9.5 $\mathrm{GHz}$, amplitud de modulación de $1 \mathrm{G}$ y frecuencia de modulación de 100KHz.

Voltametría cíclica (CV): Esta técnica se ha empleado para estudiar las propiedades redox de los distintos catalizadores con el fin de poder correlacionar el potencial de oxidación con la actividad catalítica. Para ello se utilizó una celda con tres electrodos que consistía en un disco de platino como electrodo de trabajo, un hilo de platino como electrodo auxiliar y $\mathrm{Ag} / \mathrm{AgCl}$ como electrodo de referencia. Todos los estudios electroquímicos se llevaron a cabo a temperatura ambiente. Para realizar el calibrado antes de las mediciones se utilizó ferroceno. Las disoluciones de las muestras se prepararon en acetonitrilo con una concentración $1 \mathrm{mM}$ de catalizador y $0.01 \mathrm{M}$ de perclorato de tetrabutilamonio, que se utilizó como electrolito. Todas las disoluciones se purgaron argón y se mantuvieron en atmósfera inerte durante la medida. 
Medidas electroquímicas: La voltamperometría de barrido lineal, la cronoamperometría y la espectroscopía de impedancia electroquímica se llevaron a cabo usando un AUTOLAB PGSTAT 30, de Eco Chemie B.V, en una celda de vidrio de tres electrodos equipada con una entrada de gas y termostatizada con una camisa externa de agua. El electrodo de referencia es de platino y el electrodo medidor es un electrodo saturado de $\mathrm{Ag}|\mathrm{AgCl}| \mathrm{NaCl}$. El electrodo de referencia está conectado a la disolución de la celda a través de un puente salino y la celda se mantuvo a temperatura ambiente $\left(25 \pm 1^{\circ} \mathrm{C}\right)$ usando una configuración isotérmica. Como electrodo de trabajo se utilizó un electrodo de grafito pirolítico de fabricación propia, construido acoplando una varilla de grafito pirolítico altamente orientado de Mineral Technologies en una carcasa de PEEK, de modo que se expone el borde de los planos de grafito, con un área geométrica circular de $0.07 \mathrm{~cm}^{2}$. Previamente al recubrimiento con los distintos electrocatalizadores, los electrodos de grafito se pulen con papel de lija abrasivo P2400 y luego se lavan con agua Millipore y se secan antes de soportar los distintos catalizadores.

Producción de oxígeno: La producción de oxígeno durante la electrólisis, $\Delta m_{\mathrm{O}_{2}}$ se ha medido con un sensor de oxígeno polarográfico (OXI 45P de Crison Instruments).

Espectroscopía Raman: Esta técnica se ha empleado para estudiar los intermedios de reacción y las especies activas en las reacciones de hidrosililación y de oxidación y para la caracterización de los catalizadores MOFs antes y después de reacción. Los espectros se han medido con una excitación láser de 514 o $785 \mathrm{~nm}$ en un espectrómetro Raman Renishaw ("Refelx") equipado con un detector CCD. La potencia del láser sobre la muestra se fijó entre 5-50\% y se adquirieron un total de 30 adquisiciones para cada espectro.

Para llevar a cabo los experimentos in-situ en las reacciones de oxidación se utilizó una celda Linkam 600. En primer lugar, un flujo de Ar se pasó por la muestra durante 24h para eliminar cualquier especie adsorbida sobre el catalizador. Después de esas 24 horas, se caracterizaron las muestras manteniendo el flujo de Ar, tras lo cual un flujo de oxígeno se pasó por las muestras para observar si aparecían nuevas bandas, pudiendo ser asignadas a especies Co-O.

Espectroscopía ultravioleta-visible de absorción (UV-vis): Esta técnica se ha empleado para caracterizar los complejos mononucleares de cobalto. Para ello se ha usado un espectrofotómetro Varían modelo UV0811M209. 
Espectroscopía de Infrarrojos por Transformada de Fourier- Reflectancia Total Atenuada (ATR-FTIR): Esta técnica se ha empleado para confirmar la selectividad de los catalizadores hacía un grupo funcional frente a otro. Para llevar a cabo estos experimentos, el reactivo se adsorbe en la superficie del catalizador por impregnación húmeda mediante una disolución en etanol. Para ello, se disuelven $50 \mathrm{mg}$ del reactivo en $3 \mathrm{~mL}$ de etanol y se agitan con 100mg del catalizador durante $30 \mathrm{~min}$ en atmósfera de nitrógeno. A continuación, se elimina el disolvente a vacío en atmósfera inerte y el material con la molécula sonda pre-adsorbida se mezcla con $\mathrm{KBr}$ y se compacta en una placa plana para el análisis. Para realizar la medida de FTIR se utilizó un accesorio de PIKE technologies Horizontal ATR (HATR). El prisma ATR es de Seleniuro de Zinc y tiene $4 \mathrm{~mm}$ de espesor y $80 \mathrm{~mm}$ de longitud, siendo el ángulo de incidencia de $45^{\circ}$. El número total de reflexiones con estos valores es de 10. Los espectros se registraron con un espectrómetro Bruker 70V utilizando un detector DTGS y adquiriendo con una resolución de $4 \mathrm{~cm}^{-1}$.

Espectroscopía de Absorción de Rayos X (XAS): Esta técnica se ha empleado para la caracterización de catalizadores, en concreto para analizar en profundidad el estado de oxidación y número de coordinación de los centros metálicos en catalizadores heterogéneos. Los experimentos de XAS en el borde Co K $(7709 \mathrm{eV})$ se realizaron en la línea de haz CLAESS del sincrotrón español ALBA (Cerdanyola del Vallès, España). ${ }^{1}$ El haz blanco es monocromatizado utilizando un doble cristal de $\mathrm{Si}$ (111) enfriado con nitrógeno líquido; el rechazo armónico se realizó utilizando dos espejos de silicio recubiertos de Rh. Las muestras se presionaron en pellets de $13 \mathrm{~nm}$ y se colocaron en una celda que permitió realizar experimentos in-situ. Los espectros se recogieron en modo de transmisión utilizando cámaras de ionización llenas de una cantidad apropiada de gases como detectores. Como referencia para la alineación de los datos se utilizó una lámina metálica de cobalto, que se situó entre las cámaras de ionización I1 e I2. Se recogieron varios espectros para cada muestra a fin de garantizar la reproducibilidad de los espectros y una buena relación señal-ruido. La resolución de los datos y la extracción de $\chi(\mathrm{k})$ se realizaron utilizando el paquete IFEFFIT. ${ }^{2}$

Espectroscopía de fotoelectrones emitidos por rayos X (XPS): Esta técnica se ha empleado para ver el estado de oxidación del metal y los tipos de enlace en superficie en los catalizadores heterogéneos. Para ello se utilizó un espectrómetro SPECS equipado con un analizador multicanal Phoibos 150MCD-9 utilizando una irradiación no monocromática $\mathrm{Mg} \mathrm{Ka}(1253.6 \mathrm{eV})$. Los espectros se registraron utilizando una energía de paso del analizador de $30 \mathrm{eV}$ y una potencia de rayos $\mathrm{X}$ de $100 \mathrm{~W}$ y bajo una presión operativa de $10^{-9}$ mbar. Las intensidades máximas se calcularon después de una 
sustracción de fondo no lineal de tipo Shirley y se corrigieron mediante la función de transmisión del espectrómetro y se utilizaron las curvas gausiano-lorenzanas para el ajuste de los picos. Durante el procesamiento de los datos de los espectros XPS, los valores de energía de enlace (BE) se referenciaron al pico C1s $(284,5 \mathrm{eV})$. Para el tratamiento de los espectros se utilizó el software Casa XPS. ${ }^{3}$

Difracción de Rayos X de polvo (PXRD): Esta técnica se ha empleado para la caracterización de los catalizadores heterogéneos, tanto nanopartículas como MOFs. Las medidas de difracción de rayos $\mathrm{X}$ fueron adquiridas en geometría Bragg-Bretano utilizando un difractómetro CUBIX de PANalytical equipado con un detector PANalytical X'Celerator. Se utilizó una radiación de rayos X de $\mathrm{Cu} \mathrm{K} \alpha$ y el rango de medida fue de $5.0^{\circ}$ a $80^{\circ}(2 \theta)$ con un paso de $0.020^{\circ}(2 \theta)$

Difracción de Rayos X de monocristal: Esta técnica se ha empleado para la resolución de la estructura de los complejos mono y tetranucleares de cobalto y de los MOFs. Los monocristales de los MOFs de cobalto (Co2-MOF y 2D-Co-MOF) se montaron en un crioloop usando un aceite de poliisobutileno viscoso para recubrir el cristal. Los datos de rayos $\mathrm{X}$ se recogieron a $120 \mathrm{~K}$ en un difractómetro Supernova equipado con una fuente de rayos $X$ de grafito monocromático mejorado (Mo) $(\lambda=0.71073 \AA$ ). El programa CrysAlisPro, Oxford Diffraction Ltd. se utilizó para la determinación de la celda unidad y la reducción de datos. La corrección de absorción empírica se realizó usando armónicos esféricos, implementados en el algoritmo de escalado SCALE3 ABSPACK. Las estructuras cristalinas fueron resueltas y refinadas contra todos los valores de F2 utilizando el conjunto de programas SHELXTL y Olex2. ${ }^{4,5}$ Los átomos diferentes al hidrógeno fueron refinados anisotrópicamente y los átomos de hidrógeno fueron colocados en posiciones calculadas refinadas utilizando geometrías idealizadas y se les asignaron parámetros fijos de desplazamiento isotrópicos.

Para los compuestos de coordinación mono y tetranucleares, se recogieron los monocristales de la misma forma con un aceite de poliisobutileno. En este caso fueron medidos con un difractómetro de geometría $\kappa$, el CCD Bruker X8 APEXII, equipado con una fuente de rayos $X$ de grafito monocromático mejorado (Mo) $(\lambda=0.71073 \AA)$ a $100 \mathrm{~K}$. Los datos preliminares revelaron el sistema de cristal. Las estructuras se integraron con el paquete de software Bruker SAINT utilizando un algoritmo de encuadre limitado. Se identificó el grupo espacial y se corrigieron los datos por efectos de absorción utilizando el método Multi-Scan (SADABS). Las estructuras se resolvieron utilizando métodos directos (SHELXT2014), se completaron posteriormente con una síntesis de Fourier y 
se refinaron mediante procedimientos de mínimos cuadrados de matriz completa utilizando SHELXL2016/6.

Estos datos se pueden obtener gratuitamente en la página de Cambridge Crystalographic Data Centre vía www.ccdc.cam.ac.uk/data_request/cif (o del Cambridge Crystallographic Data Centre, 12 Union Road, Cambridge CB21EZ, UK; fax: (+44)1223-336-033; o deposit@ccdc.cam.ac.uk). Los números CCDC para los datos cristalográficos suplementarios para estos compuestos son: CCDC 1817714, CCDC 1817709, CCDC 1874019 , CCDC 1874000 , CCDC 1873998 , CCDC 1898281 у CCDC 1994492.

Reducción a temperatura programada (TPR): Esta técnica se utilizó para estudiar las propiedades redox y la reducibilidad del metal en los catalizadores heterogéneos. Para ello se utilizó el sistema Micromeritics Auto-Chem 2910 con un detector de conductividad térmica (TCD). Antes de cada experimento, se trataron previamente unos $40 \mathrm{mg}$ de muestra a temperatura ambiente en un flujo de Helio $(10 \mathrm{~mL} / \mathrm{min})$ durante 20 min. La muestra calentó de $25^{\circ} \mathrm{C}$ a $600^{\circ} \mathrm{C}$ a una velocidad de $5^{\circ} \mathrm{C} / \mathrm{min}$ en un flujo de 10 vol $\% \mathrm{H}_{2}$ en Ar. El flujo total de gas fue de $50 \mathrm{~mL} / \mathrm{min}$.

Medidas de adsorción: Esta técnica se utilizó para estudiar la capacidad de adsorción de los MOFs y la selectividad hacia distintos gases. Para ello se midieron las isotermas de adsorción de alta resolución de hasta 1 bar en una Micromerítica ASAP 2010. $150 \mathrm{mg}$ de los MOFs fueron sumergidos en un baño termostático de circulación líquida dentro de un portamuestras de vidrio. Antes de cada isoterma, las muestras se desgasifican durante la noche a $333 \mathrm{~K}$ en alto vacío. A continuación, se adquirieron las isotermas de adsorción de $\mathrm{CO}_{2}$ a 273, 283, 298, 313 y $333 \mathrm{~K}$.

Las isotermas de adsorción de alta presión se evaluaron en un analizador gravimétrico IGA-3 (HidenIsochema). Para ello, se cargaron unos $50 \mathrm{mg}$ de muestra y se desgasificaron a $333 \mathrm{~K}$ en alto vacío durante 4 horas. No se registró ninguna pérdida de peso al final del proceso de desgasificación. A continuación, la muestra se enfrió hasta la temperatura de adsorción a vacío previamente a la adquisición de las isotermas. Se midieron isotermas de $\mathrm{CO}_{2}$ y $\mathrm{CH}_{4}$ hasta $1 \mathrm{MPa}(10$ bar) a 283, 298, 313 y $333 \mathrm{~K}$.

Las propiedades de adsorción del 2D-Co-MOF fueron estudiadas empleando un paso de activación a $100^{\circ} \mathrm{C}$ bajo vacío. El 2D-Co-MOF resultante absorbe muy poco $\mathrm{N}_{2}$ a $176^{\circ} \mathrm{C}$, lo que sugiere que se producen severas limitaciones difusionales durante la adsorción de $\mathrm{N}_{2}$ a temperaturas criogénicas. Siguiendo las recomendaciones de la IUPAC, se midió la isoterma de adsorción de $\mathrm{CO}_{2}$ a $0^{\circ} \mathrm{C}{ }^{6}$ 
Microscopía electrónica de barrido de emisión de campo (FESEM): Esta técnica se utilizó para estudiar la morfología de los catalizadores. Las imágenes FESEM se adquirieron con un Ultra 55 (Zeiss) a $2,0 \mathrm{kV}$, utilizando muestras de polvo preparadas en un portamuestras con una cinta adhesiva de doble cara para la dispersión de la muestra. Las muestras se recubrieron con platino para evitar el efecto de carga.

Microscopía electrónica de barrido con rayo de iones focalizado (FIB): Esta técnica se utilizó para estudiar las secciones transversales de los catalizadores. Las imágenes FIB fueron adquiridas usando AURIGA Compact (Zeiss). Las muestras se prepararon en un portamuestras con cinta adhesiva de doble cara utilizando muestras de polvo y se recubrieron con platino para evitar el efecto de carga.

Microscopía electrónica de transmisión de alta resolución (HRTEM): Esta técnica se emplea para analizar el tamaño de las partículas soportadas en catalizadores heterogéneos, así como su dispersión y homogeneidad. El equipo empleado ha sido un JEOL $200 \mathrm{KeV}$ del servicio de microscopía de la Universitat Politècnica de València.

Para la purificación de los compuestos orgánicos sintetizados se han utilizado técnicas de separación habituales: cromatografía en columna o en TLC preparativa o por recristalización. Para la cromatografía en columna se ha usado generalmente sílice con un área externa de $230 \mathrm{~m}^{2} / \mathrm{g}$ y para la cromatografía preparativa en capa fina (TLC) se han usado placas de sílice de $20 \mathrm{~cm}$ x $20 \mathrm{~cm}$ en una cubeta, empleando la mezcla de disolventes correspondiente (generalmente hexano, acetato de etilo y diclorometano). Todos los compuestos obtenidos se han analizado por GC-MS y RMN $\left({ }^{1} \mathrm{H},{ }^{13} \mathrm{C}\right.$, DEPT...) y, además, se han comparado con los resultados descritos en la bibliografía siempre que ha sido posible. 


\subsection{Bibliografía.}

(1) Simonelli, L.; Marini, C.; Olszewski, W.; Avila-Perez, M.; Ramanan, N.; Guilera, G.; Cuartero V.; Klementiev, K., CLÆSS: The hard X-ray absorption beamline of the ALBA CELLS synchrotron, Cogent Phys. 2016, 3, 1231987.

(2) Ravel B.; Newville, M., ATHENA, ARTEMIS, HEPHAESTUS: data analysis for X-ray absorption spectroscopy using IFEFFIT, J. Synchrotron Radiat. 2005, 12, 537541.

(3) Fairley, N.; CasaXPS Version 2.3.14, Casa Software Ltd. 2008.

(4) Sheldrick, G. M.; A short history of SHELX. ActaCrystallogr.Sect. A 2008, 64, 112-122.

(5) Dolomanov, O. V.; Bourhis, L. J.; Gildea, R. J.; Howard, J. A. K.; Puschmann, H.; OLEX2: a complete structure solution, refinement, and analysis program. J. Appl. Crystallogr. 2009, 42, 339-341.

(6) Thommes M.; Kaneko K.; Neimark A. V.; Olivier J. P.; Rodriguez-Reinoso F.; Rouquerol J.; Sing K. S. W.; Physisorption of Gases, with Special Reference to the Evaluation of Surface Area and Pore Size Distribution (IUPAC Technical Report), Pure and Applied Chemistry 2015, 87, 1051-1069. 



\section{Capítulo 4.}

\section{Complejos de Cobalto para}

hidrosililación de alquenos en condiciones aeróbicas. 



\section{Índice}

4.1. Introducción .............................................................................................5 57

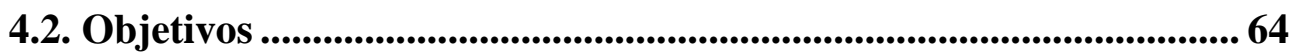

4.3. Resultados y discusión ..........................................................................64

4.3.1. Estudio de la influencia del ligando y el estado de oxidación del metal en la actividad catalítica. ...................................................................................64

4.3.2. Síntesis y elucidación estructural de los catalizadores .................................65

4.3.3. Evaluación de los precatalizadores de cobalto. ..........................................71

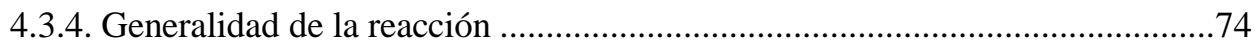

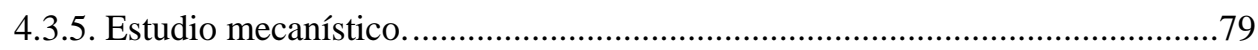

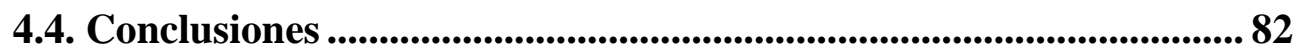

4.5. Sección experimental ......................................................................83 83

4.5.1. Procedimiento detallado para la síntesis de los catalizadores........................83

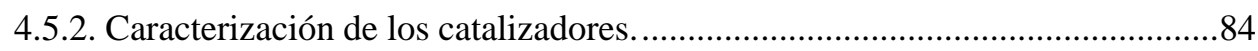

4.5.3. Procedimiento de las reacciones catalíticas............................................94

4.5.3.1. Optimización de las condiciones de reacción.........................................94

4.5.3.2. Procedimiento general para las reacciones de hidrosililación catalizadas.

4.5.3.3. Estudio cinético para la hidrosililación de 4-vinilciclohexeno con $\mathrm{PhSiH}_{3}$.

4.5.3.4. Procedimiento para la reacción de hidrosililación del 1-octeno con

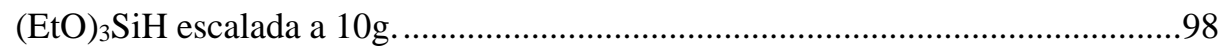

4.5.3.5. Síntesis de los polímeros de entrecruzamiento de siliconas. ....................98

4.5.3.6. Caracterización de los productos de reacción.........................................98

4.6. Bibliografía ....................................................................................................... 104 



\subsection{Introducción}

Las reacciones en la que las que un hidruro de silicio se adiciona a un enlace múltiple se denominan hidrosililaciones (Esquema 4.1).

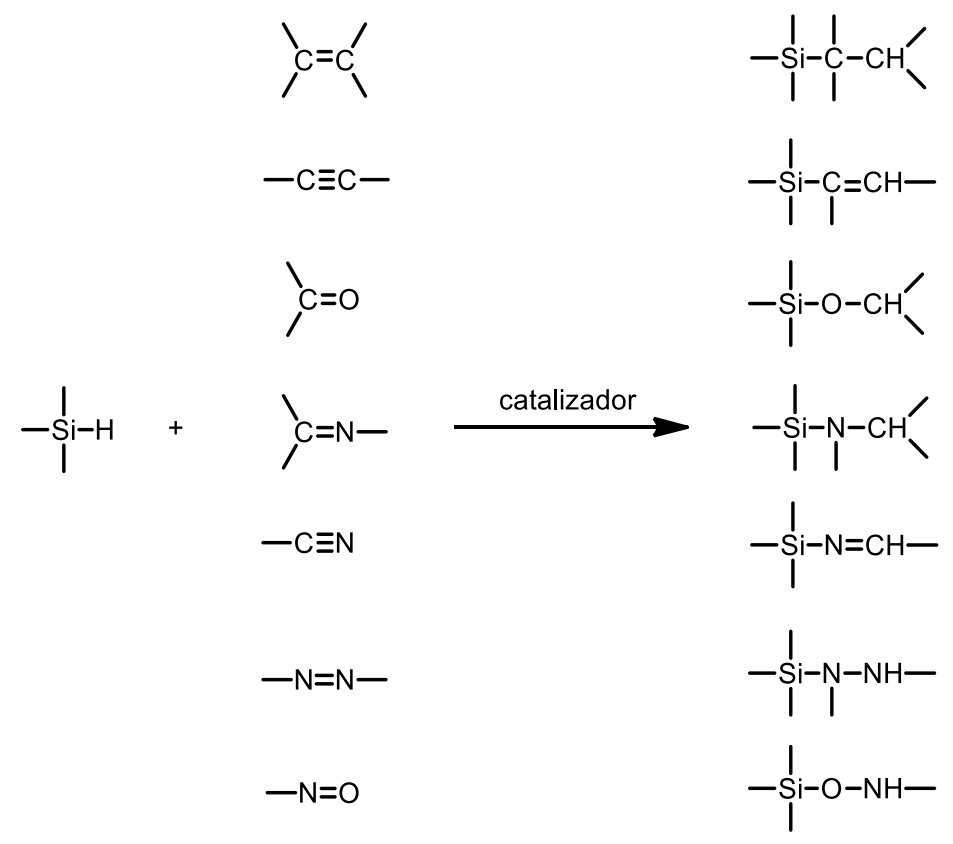

Esquema 4.1. Hidrosililación de enlaces múltiples.

El primer ejemplo fue la hidrosililación del 1-octeno con triclorosilano, reportada en 1947 por Leo Sommer (Esquema 4.2). Sin embargo, el descubrimiento del ácido hexacloroplatínico en 1957 por John L. Speier como catalizador eficiente para la hidrosililación de alquenos se convirtió en un punto estratégico para una aplicación general de este proceso, que se sigue estudiando exhaustivamente desde entonces. ${ }^{1}$

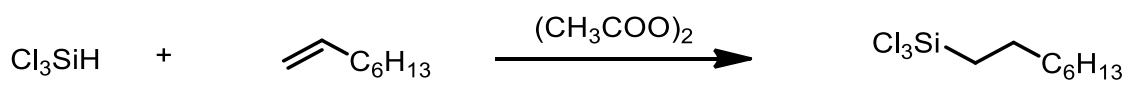

Esquema 4.2. Hidrosililación de 1-octeno con triclorosilano.

A nivel económico, la reacción de hidrosililación de alquenos catalizada por metales es una de las aplicaciones que se llevan a cabo a mayor escala en catálisis homogénea. ${ }^{2-4}$ Esta reacción da lugar a productos organosililados que se utilizan como precursores de 
alcoholes o como moléculas plataforma para la producción de polímeros basados en silicio. ${ }^{1,3,5,6-8}$ Por ejemplo, el (n-octil)Si(OEt) 3 , que se utiliza para mejorar el rendimiento de productos de mampostería y vidrio, se fábrica a escala de más de 6000 toneladas al año. ${ }^{9}$ También se utiliza como emulsión selladora para mejorar la resistencia al clima de carreteras, puentes y pistas.

En la mayoría de los procesos de hidrosililación, los complejos basados en $\mathrm{Pt}^{10-13}$ han sido ampliamente estudiados. Dos complejos de Pt, el catalizador de Speier ${ }^{12}\left(\mathrm{H}_{2} \mathrm{PtCl}_{6}\right.$. $6 \mathrm{H}_{2} \mathrm{O} / \mathrm{iPrOH}$ ) y el catalizador de Karstedt ${ }^{13}$ (Figura 4.1) continúan siendo los sistemas catalíticos más usados para la síntesis comercial de siliconas.

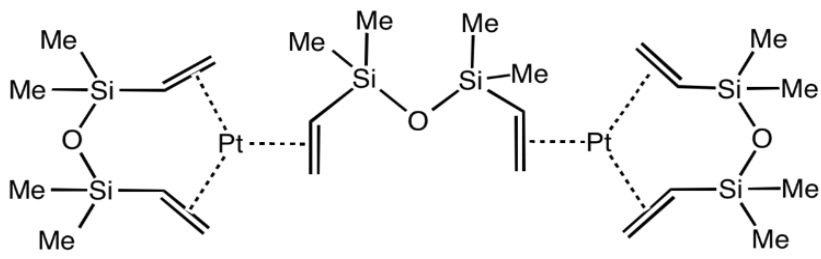

Figura 4.1. Catalizador de Karstedt.

De hecho, durante los últimos años, se han seguido desarrollando catalizadores basados en platino para la hidrosililación de alquenos debido a su alta eficacia y selectividad. Sin embargo, los catalizadores basados en este metal presentan una serie de desventajas, como su precio, correlacionado con su escasez en la corteza terrestre (en torno a 0.005 ppm). ${ }^{14}$ Además, la demanda del Pt en el proceso de hidrosililación de alquenos es muy elevada. De hecho, se consumen aproximadamente 5.6 toneladas de Pt anualmente en la industria de las siliconas, y la mayor parte del metal utilizado no se puede recuperar. ${ }^{15}$ Otras aplicaciones importantes, como el control de emisiones de vehículos y el refino de petróleo, también consumen una gran cantidad de Pt (más de 100 toneladas al año).

Todos estos puntos han inspirado al desarrollo de nuevas generaciones de catalizadores basados en metales de transición abundantes en la corteza terrestre, como el hierro, el cobalto y el níquel. El cobalto, debido a su abundancia en la Tierra y a sus propiedades químicas, parece un candidato ideal. En concreto, desde que Chalk y Harrod descubrieron en la década de 1960 que el $\mathrm{Co}_{2}(\mathrm{CO})_{8}$ catalizaba la hidrosililación de alquenos terminales, ${ }^{16}$ ha aumentado el interés por el descubrimiento de nuevos catalizadores de cobalto para reacciones de hidrosililación. El catalizador octacarbonilo de dicobalto $\mathrm{Co}_{2}(\mathrm{CO})_{8}$ es el catalizador basado en cobalto más estudiado en esta reacción. En 1965, Chalk y Harrod publicaron que, en atmósfera de nitrógeno, el $\mathrm{Co}_{2}(\mathrm{CO})_{8}$ podía catalizar 
la hidrosililación de alquenos terminales alquil sustituidos (1-octeno, 1-hexeno y 1-penteno) con silanos terciarios $\left(\mathrm{Et}_{3} \mathrm{SiH},(\mathrm{OMe})_{3} \mathrm{SiH}\right.$, and $\left.\mathrm{PhCl}_{2} \mathrm{SiH}\right)$ para producir selectivamente los productos de adición anti-Markovnikov (Esquema 4.3). ${ }^{16,17}$ La reacción se llevaba a cabo sin disolvente, a bajas temperaturas $\left(0-60^{\circ} \mathrm{C}\right)$ y con baja carga de catalizador (0.6-0.06\% mol). Una desventaja de esta reacción es el uso de un exceso de alqueno (3 equivalentes en relación con el silano) debido a la coexistencia de reacciones de isomerización de los alquenos terminales a alquenos internos. El estudio refleja que esta reacción secundaria es más rápida que la hidrosililación y más marcada que en el caso de reacciones catalizadas con platino o rodio. ${ }^{16}$

Estudio de Chalk y Harrod:

$$
\mathrm{R} \curvearrowright+\mathrm{HSiR}_{3} \frac{0.001 \mathrm{M} \mathrm{Co}_{2}(\mathrm{CO})_{8}}{25^{\circ} \mathrm{C} \text {, neto }} \underset{\mathrm{R}}{\longrightarrow} \mathrm{SiR}_{3}
$$

3 equiv.

$$
\begin{aligned}
& \mathrm{R}=\mathrm{n}-\mathrm{C}_{3} \mathrm{H}_{7}, \mathrm{n}-\mathrm{C}_{4} \mathrm{H}_{9}, \mathrm{n}-\mathrm{C}_{6} \mathrm{H}_{13} ; \\
& \mathrm{HSiR}_{3}=\mathrm{HSiEt}{ }_{3}, \mathrm{HSi}(\mathrm{OMe})_{3}, \mathrm{HSiPhCl}_{2}
\end{aligned}
$$

\section{Estudio de Kalinin:}

$$
\begin{aligned}
& \mathrm{R} \curvearrowright+\underset{1-3.4 \text { equiv. }}{\mathrm{HSi}(\mathrm{OEt})_{3}} \frac{0.02 \mathrm{M} \mathrm{Co}_{2}(\mathrm{CO})_{8}}{20-40^{\circ} \mathrm{C} \text {, neto }} \underset{35-95 \% \text { rendimiento aislado }}{\mathrm{R}} \overbrace{\text { Si }(\mathrm{OEt})_{3}}^{\longrightarrow} \\
& \mathrm{R}=\mathrm{C}_{6} \mathrm{H}_{5}, \mathrm{SiMe}_{3}, \mathrm{o}-\mathrm{C}_{2} \mathrm{~B}_{10} \mathrm{H}_{11}, \mathrm{CH}_{2} \mathrm{~N}\left(\mathrm{Si}(\mathrm{OEt})_{3}\right)_{2}
\end{aligned}
$$

Esquema 4.3. Hidrosililación de alquenos catalizada por $\mathrm{Co}_{2}(\mathrm{CO})_{8}$.

Además de la hidrosililación de alquenos alquil sustituidos, Kalinin y colaboradores investigaron la hidrosililación catalítica del estireno, el viniltrimetilsilano, el 1-vinil-ocarborano y la alil di(trietoxisilil)amina con $(\mathrm{EtO})_{3} \mathrm{SiH}_{\mathrm{H}} \mathrm{Co}_{2}(\mathrm{CO})_{8}$ como catalizador (Esquema 4.3). ${ }^{18}$ Estas reacciones se llevaban a cabo con cantidades equimolares del sustrato y proporcionaban selectivamente los productos de adición anti-Markovnikov, pero se encontró que el rendimiento de la reacción dependía de la naturaleza del alqueno.

Otra aplicación interesante de la hidrosililación de alquenos catalizada por $\mathrm{Co}_{2}(\mathrm{CO})_{8}$ es la preparación de grupos protectores organosililados como soporte para polímeros. ${ }^{19}$ Darling y colaboradores encontraron que, en presencia de 2-4\% de $\mathrm{Co}_{2}(\mathrm{CO})_{8}$, los grupos vinilo residuales del (vinil)poliestireno podían reaccionar lentamente con 
hidroclorosilanos, $\left(\mathrm{Me}_{2} \mathrm{ClSiH}, \quad \operatorname{Pr}_{2}{ }_{2} \mathrm{ClSiH}\right.$ y $\left.\mathrm{MeCl}_{2} \mathrm{SiH}\right)$ para dar polímeros funcionalizados con grupos clorosilano. ${ }^{19}$ La conversión de los grupos vinilo alcanzaba un $50 \%$ a los 5 días de reacción.

Aunque estos estudios preliminares no resultaron en el descubrimiento de un catalizador de cobalto altamente eficiente para las reacciones de hidrosililación por su falta de reactividad, fue a partir de estos estudios pioneros de los que se propusieron los dos mecanismos más importantes para la hidrosililación de alquenos catalizada por metales de transición, el mecanismo de Chalk-Harrod ${ }^{17}$ y el mecanismo modificado de ChalkHarrod. ${ }^{20}$

En el mecanismo de Chalk-Harrod (Esquema 4.4) ${ }^{17}$ el precatalizador $\mathrm{Co}_{2}(\mathrm{CO})_{8}(\mathbf{A})$ inicialmente reacciona con $\mathrm{R}_{3} \mathrm{SiH}$ para dar la especie cobalto-silil $\left(\mathrm{R}_{3} \mathrm{SiCo}(\mathrm{CO})_{4}\right)(\mathbf{B})$ y el hidruro de cobalto, $\mathrm{HCo}(\mathrm{CO})_{\mathrm{n}}(\mathbf{C})$. La especie hidruro interacciona con la molécula de alqueno para producir un carbonil alquilcobalto intermedio (Ea, Eb). Una segunda interacción de la especie carbonil alquilcobalto (Ea) con la especie $\mathrm{R}_{3} \mathrm{SiH}$ podría producir el producto de adición oxidativa $\left(\mathrm{R}_{3} \mathrm{Si}\right)(\mathrm{H})-\left(\mathrm{R}^{\prime} \mathrm{CH}_{2} \mathrm{CH}_{2}\right) \mathrm{Co}(\mathrm{CO})_{n}(\mathbf{F})$ que experimenta una reacción de eliminación reductiva para formar el producto de hidrosililación y el hidruro de cobalto $\left(\mathrm{HCo}(\mathrm{CO})_{\mathrm{n}}\right)(\mathbf{C})$. Por otro lado, se puede formar el producto de isomerización (vía $\mathbf{E b ) . ~}{ }^{17}$

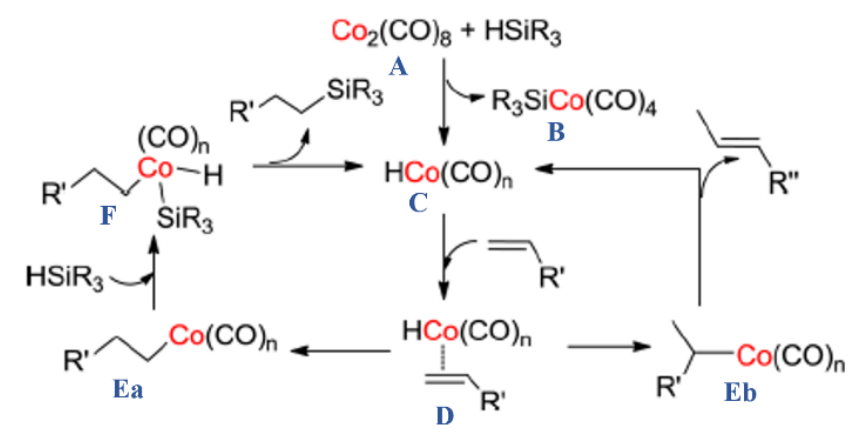

Esquema 4.4. Mecanismo de Chalk-Harrod para la hidrosililación de alquenos catalizada por $\mathrm{Co}_{2}(\mathrm{CO})_{8}$.

El mecanismo de Chalk-Harrod explica la reacción lateral de la isomerización de alquenos (Esquema 4.4), pero no explica la formación de alquenilsilanos. ${ }^{21}$ Sin embargo, esta última reacción se considera en el mecanismo modificado de Chalk-Harrod (Esquema 4.5), en el que se presenta una especie cobalto-silil (B) como intermedio. En el mecanismo modificado de Chalk-Harrod, la inserción migratoria del alqueno en el 
enlace Co-Si para formar la especie cobalto $\beta$-alquilsilil (D) y la adición oxidativa del complejo alquilo con la molécula de hidrosilano (Ea), seguido de la eliminación reductiva por la formación del enlace $\mathrm{C}-\mathrm{H}(\mathbf{F})$, constituyen los pasos clave. ${ }^{20} \mathrm{La}$ formación de los alquenilsilanos se explica por la reacción de eliminación del $\beta$-hidruro (Eb) de la especie de cobalto $\beta$-alquilsilil (D) (Esquema 4.5).

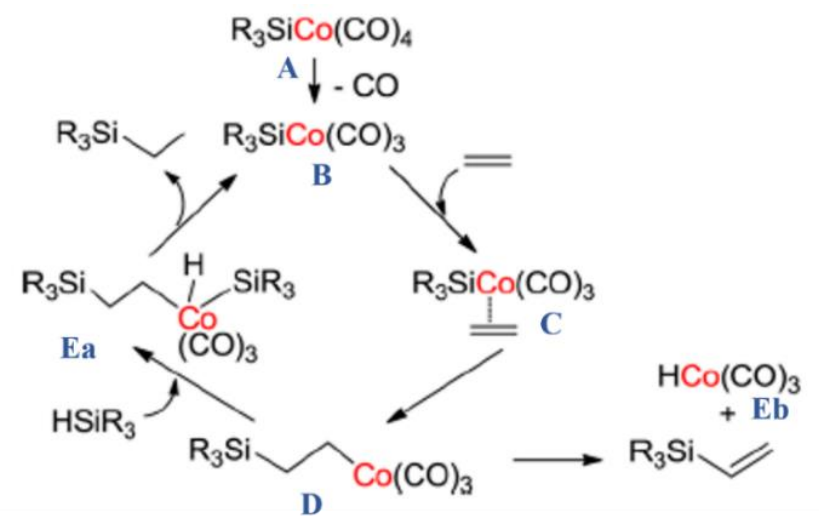

Esquema 4.5. Mecanismo de Chalk-Harrod modificado para la hidrosililación de alquenos catalizada por $\mathrm{Co}_{2}(\mathrm{CO})_{8}$.

Con el fin de desarrollar catalizadores basados en cobalto más activos en la reacción de hidrosililación de alquenos que los basados en carbonilos de cobalto, se han reportado en la literatura catalizadores basados en cobalto con ligandos fosfina, ciclopentadienilo, carbenos N-heterocíclicos (NHC) y 2,6-diiminopiridina entre otros.

Un gran descubrimiento en el desarrollo de catalizadores basados en metales no nobles para hidrosililaciones fue el complejo de hierro con un ligando derivado de la 2,6iminopiridina desarrollado por Chirik y colaboradores en 2012, el cual presenta una actividad en la reacción de hidrosililación de alquenos que es comparable a la de los catalizadores de platino. ${ }^{22}$ El estudio posterior de los complejos de cobalto con el ligando 2,6-iminopiridina (A en la Figura 4.2) por el mismo grupo ha llevado al descubrimiento de nuevos catalizadores de cobalto para la sililación deshidrogenativa de alquenos. 


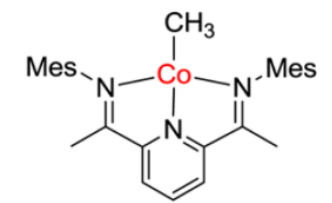

A

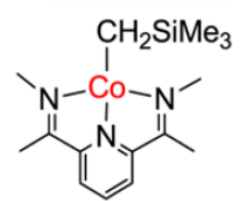

B

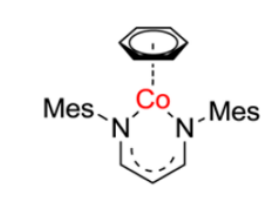

C

Figura 4.2. Ejemplos de catalizadores de cobalto usados en hidrosililación de alquenos.

Además, en una patente reciente, el mismo grupo describe la actividad catalítica de una serie de complejos de cobalto con ligandos $N$-alquil 2,6-diiminopiridina en la reacción de hidrosililación de alquenos con hidrosilanos. ${ }^{23} \mathrm{Al}$ contrario que los complejos mencionados en el párrafo anterior que catalizaban la sililación deshidrogenativa de alquenos, este nuevo compuesto de coordinación, ( $\left.\mathrm{PDI}{ }^{\mathrm{Me}}\right) \mathrm{Co}\left(\mathrm{CH}_{2} \mathrm{SiMe}_{3}\right)$ (B en la Figura 4.2), es un catalizador eficiente para la hidrosililación de alquenos con (EtO) $3 \mathrm{SiH}$. En esta patente también se destaca que el tipo de silano usado afecta a la selectividad de la reacción. Así, en las reacción del 1-octeno con $\mathrm{Me}\left(\mathrm{OSiMe}_{3}\right)_{2} \mathrm{SiH}$, $\mathrm{HSiMe}_{2} \mathrm{OSiMe}_{2} \mathrm{CH}_{2} \mathrm{CH}_{2} \mathrm{SiMe}_{3}$ y $\mathrm{HSiMe}_{2} \mathrm{CH}_{2} \mathrm{CH}_{2} \mathrm{SiMe}_{3}$ con $\left(\mathrm{PDI}^{\mathrm{Me}}\right) \mathrm{Co}\left(\mathrm{CH}_{2} \mathrm{SiMe}_{3}\right)$ se forma una mezcla de productos de hidrosililación, sililación deshidrogenativa e hidrogenación.

En 2015, el grupo de Holland desarrolló complejos de cobalto (I) con ligandos $\beta$ diketiminato para la hidrosililación de alquenos. ${ }^{24}$ Tras examinar una serie de complejos de cobalto (I) que contenían diferentes ligandos $\beta$-diketiminato, se determinó que el complejo Co(I)-benceno con el ligando N-mesitil-3-(mesitilimino)prop-1-en-1-amina (C en la Figura 4.2) era el más efectivo para reacciones de hidrosililación de un amplio rango de alquenos terminales con $\mathrm{PhSiH}_{3}$ o $(\mathrm{EtO})_{3} \mathrm{SiH}$. Estas reacciones se llevaron a cabo sin disolvente, obteniéndose los productos de hidrosililación con altos rendimientos y selectividad.

A pesar de que varios grupos, entre los que destacan los de Thomas, ${ }^{25}$ Chirik $^{9}$ y Nagashima, ${ }^{26,27}$ han desarrollado varias estrategias de activación de precatalizadores de cobalto, las especies catalíticamente activas presentan problemas de estabilidad, debido fundamentalmente a la presencia de ligandos alquilo en su estructura. Esto hace que estas especies sean sensibles al aire y a la humedad y por ello deban ser manipuladas en atmósfera inerte usando reactivos y disolventes anhidros. Esta alta sensibilidad al aire y a la humedad de los precatalizadores es un gran desafío para su implementación a nivel 
industrial. Para superar esta limitación, varios grupos han reportado el uso de catalizadores de cobalto estables, pero que necesitan ser activados en el medio de reacción mediante co-catalizadores organometálicos como EtMgBr, BuLi, $\mathrm{NaEt}_{3} \mathrm{BH}$, or $\mathrm{NaO} t \mathrm{Bu} .{ }^{28,29}$

Esta estrategia presenta 3 grandes desventajas: 1) Estos activadores también son sensibles a la humedad aunque en menor medida; 2) Son nucleófilos fuertes que pueden potenciar la ruptura de los enlaces Si-O en los alcoxisilanos y siloxanos; 3) El Li, Mg o B procedentes del activador pueden incorporarse en el producto final. Todos estos riesgos potenciales deben tenerse en cuenta, principalmente en la síntesis de polímeros de silicona. Además, esta metodología resulta, en la mayoría de los casos, en una disminución de la actividad y la selectividad del catalizador.

Los avances mencionados han demostrado el potencial de los complejos de cobalto como una nueva generación de catalizadores de metales de transición para las reacciones de hidrosililación de alquenos. Por ello, se sigue estudiando el diseño de nuevos catalizadores a través de la introducción de nuevos conjuntos de ligandos y el ajuste del estado de oxidación de los centros metálicos. Los complejos de coordinación activos para esta reacción reportados en bibliografía presentan, principalmente, ligandos tipo pinza, ${ }^{9,22-27}$ con dos o tres heteroátomos, normalmente $\mathrm{N}$, unidos al centro metálico.

A pesar de los grandes progresos en este campo, la investigación sobre los catalizadores basados en cobalto para reacciones de hidrosililación se encuentra todavía en la fase inicial. Desde el punto de vista de uso práctico en la industria, un catalizador ideal para esta reacción debe ser estable cuando se expone al aire y a la humedad, además de ser altamente eficiente. Sin embargo, los catalizadores de cobalto conocidos hasta el momento son generalmente sensibles a la exposición a la humedad y al aire, y la mayoría deben utilizarse usando alta carga de catalizador (más de $1 \%$ en mol). En resumen, un buen catalizador para este proceso debería ser estable al aire y a la humedad, y ser activo en condiciones aeróbicas sin necesidad de un activador externo. 


\subsection{Objetivos}

Una vez conocidos los antecedentes y los retos que se presentan en este proceso, los objetivos propuestos en este capítulo de la tesis doctoral son los siguientes:

- Desarrollo de un catalizador de cobalto que sea estable al aire y a la humedad, que sea activo y selectivo en la reacción de hidrosililación de alquenos, y permita el uso tanto de distintos silanos como de distintos alquenos, evitando el uso de activadores externos. Además, estas reacciones deberán llevarse a cabo sin necesidad de atmósfera inerte o disolventes anhidros.

- Realizar un estudio mecanístico que permita identificar la especie intermedia activa en las reacciones de hidrosililación.

\subsection{Resultados y discusión}

Aunque los grupos de Chirik ${ }^{9}$ y Nagashima ${ }^{26,27}$ han reportado el uso de catalizadores de cobalto estables al aire en este proceso, las reacciones se deben llevar a cabo en condiciones de atmósfera inerte y con disolventes secos. En este sentido, el desarrollo de catalizadores que sean estables al aire y a la humedad en condiciones de reacción y que no requieran del uso de aditivos es fundamental.

En esta tesis doctoral, la hipótesis de partida es el uso de sales de cobalto estables, comerciales y asequibles económicamente y que ofrezcan diversidad estructural acompañados de ligandos tipo pinza que sean también estables y comerciales y que puedan activar el sustrato en la reacción a través de un mecanismo de cooperación metalligando. ${ }^{30-35}$

\subsubsection{Estudio de la influencia del ligando y el estado de oxidación del metal en la actividad catalítica.}

Con el fin de elegir el ligando óptimo para la síntesis de los complejos que se van a estudiar como catalizadores en la hidrosililación de alquenos, siguiendo la línea de investigación de los ligandos tipo pinza con $\mathrm{N}$ como átomos dadores, se evaluaron dos ligandos comerciales, uno de ellos bidentado, 2,2'-bipiridina (bpy) y otro tridentado, 2,2':6,2"-terpiridina (tpy), con precursores de cobalto comerciales como son el acetato de cobalto (II) o el acetilacetonato de cobalto en estado de oxidación (II) y (III) en una reacción de hidrosililación modelo (hidrosililación del 1-octeno con el $\mathrm{PhSiH}_{3}$, Tabla 4.1). 
Tabla 4.1. Evaluación de la influencia del ligando y el estado de oxidación del metal en la actividad de los complejos de cobalto para la hidrosililación del 1-octeno con $\mathrm{PhSiH}_{3}{ }^{[a]}$

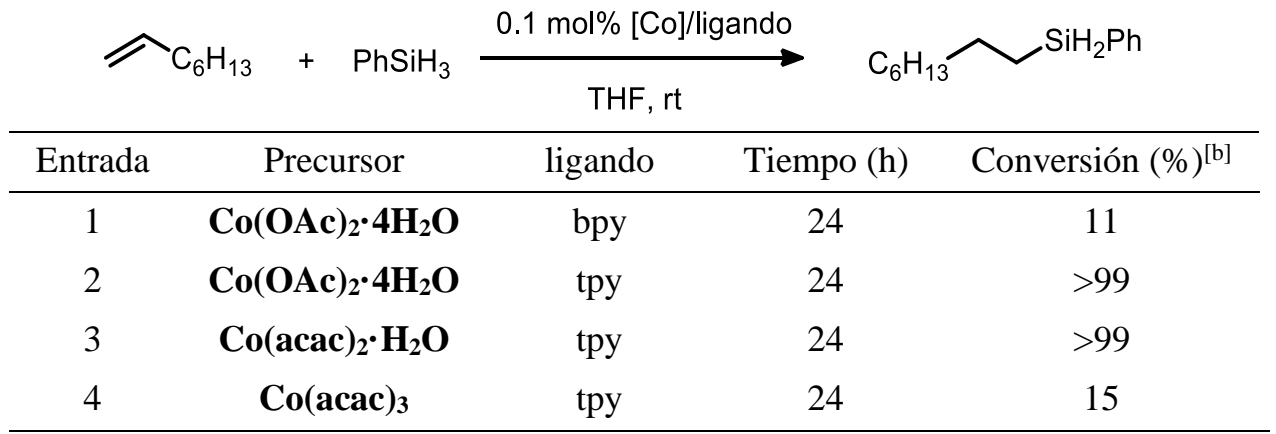

${ }^{[a]}$ Todas las reacciones se llevaron a cabo usando $0.89 \mathrm{mmol}$ de silano y olefina en condiciones aeróbicas. La mezcla de los precursores de cobalto con el ligando (relación 1:1) correspondiente se preparó previamente. ${ }^{[b]}$ Determinada por análisis de ${ }^{1} \mathrm{H}$ NMR del crudo de reacción.

Estos resultados experimentales ponen de manifiesto que el ligando bidentado no es capaz de activar al cobalto para llevar a cabo la reacción de hidrosililación propuesta y que la especie de cobalto activa es el cobalto en estado de oxidación II.

\subsubsection{Síntesis y elucidación estructural de los catalizadores}

A partir del estudio anterior, se sintetizaron varios catalizadores de cobalto partiendo de distintos precursores de Co (II) y el ligando terpiridina. El Esquema 4.6 muestra de manera esquemática la síntesis de dichos complejos de cobalto con el ligando terpiridina (tpy) y diferentes carboxilatos de cobalto (II), con el fin de evaluar cómo afecta el sustituyente a la estabilidad y la actividad del catalizador, en concreto acetato de cobalto (II) tetrahidratado (1a), acetilacetonato de cobalto (II) hidratado (2a), naftenato de cobalto (II) (10\% Co) (3a) y octanato de cobalto (II) (8\% Co) (4a). A partir de estas reacciones se espera la formación de los complejos $\mathbf{1 b}-\mathbf{4 b}$ en base a la estequiometría metal-ligando empleada.

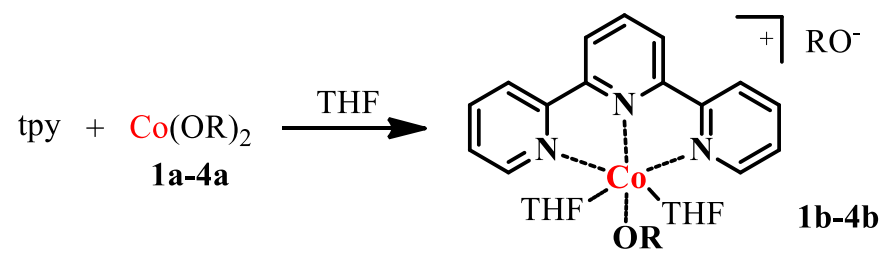

Esquema 4.6. Ilustración general de la síntesis de los complejos de cobalto(II) $\mathbf{1 b}-\mathbf{4 b}$. 
Los complejos de cobalto (II) obtenidos a partir de esta reacción se recristalizaron en una mezcla acetonitrilo:cloroformo (1:1) con unas gotas de metanol. La difracción de rayos $\mathrm{X}$ de monocristal del complejo $\mathbf{1 b}$ reveló su estructura, consistente con la fórmula molecular $\left[\mathrm{Co}(\mathrm{OAc})\left(\mathrm{H}_{2} \mathrm{O}\right)_{2}\right.$ (tpy)]OAc en la que las moléculas de THF habían sido reemplazadas por agua (Figura 4.3a).

Por otro lado, la recristalización del complejo formado entre el precursor $\mathrm{Co}(\mathrm{acac})_{2} \cdot \mathrm{H}_{2} \mathrm{O}$ y la tpy dio como resultado el complejo homoléptico (2c), que se confirmó por difracción de rayos $\mathrm{X}$ de monocristal. En este caso, los aniones acetilacetonato del precursor fueron remplazados por aniones cloruro (procedentes del $\mathrm{CHCl}_{3}$ ) (Figura $4.3 \mathrm{~b}$ ).
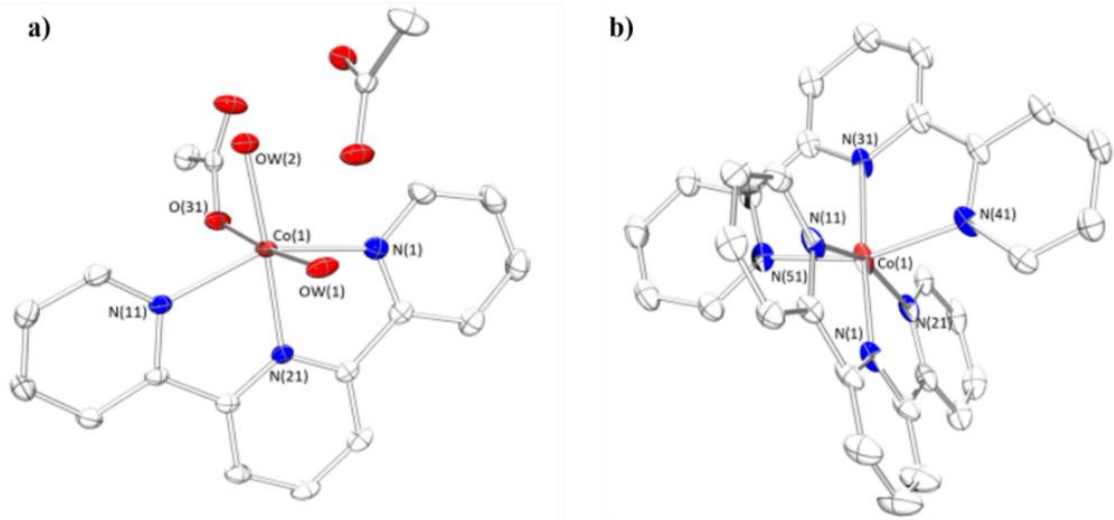

Figura 4.3. Estructuras moleculares de los complejos a) $\left[\mathrm{Co}(\mathrm{OAc})\left(\mathrm{H}_{2} \mathrm{O}\right)_{2}(\mathrm{tpy})\right] \mathrm{OAc}$, 1b y b) $\left[\mathrm{Co}(\text { tpy })_{2}\right] \mathrm{Cl}_{2} \cdot 6 \mathrm{H}_{2} \mathrm{O}$, 2c. Los elipsoides se muestran a un $30 \%$ de probabilidad. Los átomos de hidrógeno, las moléculas de disolvente y los aniones cloruro del complejo $2 \mathbf{c}$ se omiten por claridad. Gris $=\mathrm{C}$, azul $=\mathrm{N}$, rojo $=\mathrm{O}$, marrón $=$ Co.

El estudio de rayos $\mathrm{X}$ de monocristal (Tabla 4.7) reveló que ambos compuestos de coordinación $\mathbf{1 b}$ y $\mathbf{2 c}$ se basan en átomos de cobalto hexacoordinados. El primero de ellos, $\left[\mathrm{Co}(\mathrm{OAc})\left(\mathrm{H}_{2} \mathrm{O}\right)_{2}(\right.$ tpy $\left.)\right] \mathrm{OAc}$, muestra que el ligando carboxilato adopta un modo de enlace $\kappa^{1}$ con dos moléculas de agua coordinadas al centro metálico. Por otro lado, en el segundo complejo, $\left[\mathrm{Co}(\text { tpy })_{2}\right] \mathrm{Cl}_{2} \cdot 6 \mathrm{H}_{2} \mathrm{O}$, los dos ligandos tridentados están coordinados al centro metálico para dar un complejo de coordinación de tipo $\mathrm{CoN}_{6}$ con una configuración meridional. Las distancias y los ángulos de enlace más importantes para los complejos $\mathbf{1 b}$ y $\mathbf{2 c}$ se muestran en las Tablas 4.8 y 4.9 de la sección experimental, respectivamente. Además, se observa que el nitrógeno central del ligando tpy en ambos complejos está más cercano al Co(II) en comparación con los otros dos nitrógenos del mismo ligando. 
A continuación, se procedió a estudiar la estructura de los complejos en disolución por RMN. A partir de la reacción entre el precursor 1a y el ligando tpy se formó principalmente, como se ha visto por rayos $\mathrm{X}$, el complejo $\mathbf{1 b}$, con una pequeña cantidad del complejo homoléptico (Figura 4.4). ${ }^{36}$ Por otro lado, de la reacción con el precursor 2a se obtuvo exclusivamente el complejo homoléptico 2c (no se observó el complejo 2b). El espectro de RMN obtenido a partir de la reacción de la tpy con los precursores 3a y $4 \mathbf{a}$ muestran la formación de los complejos $\mathbf{3 b}$ y $\mathbf{4 b}$. Estos datos sugieren que el acetilacetonato es un ligando más lábil que el resto de carboxilatos en esas condiciones.

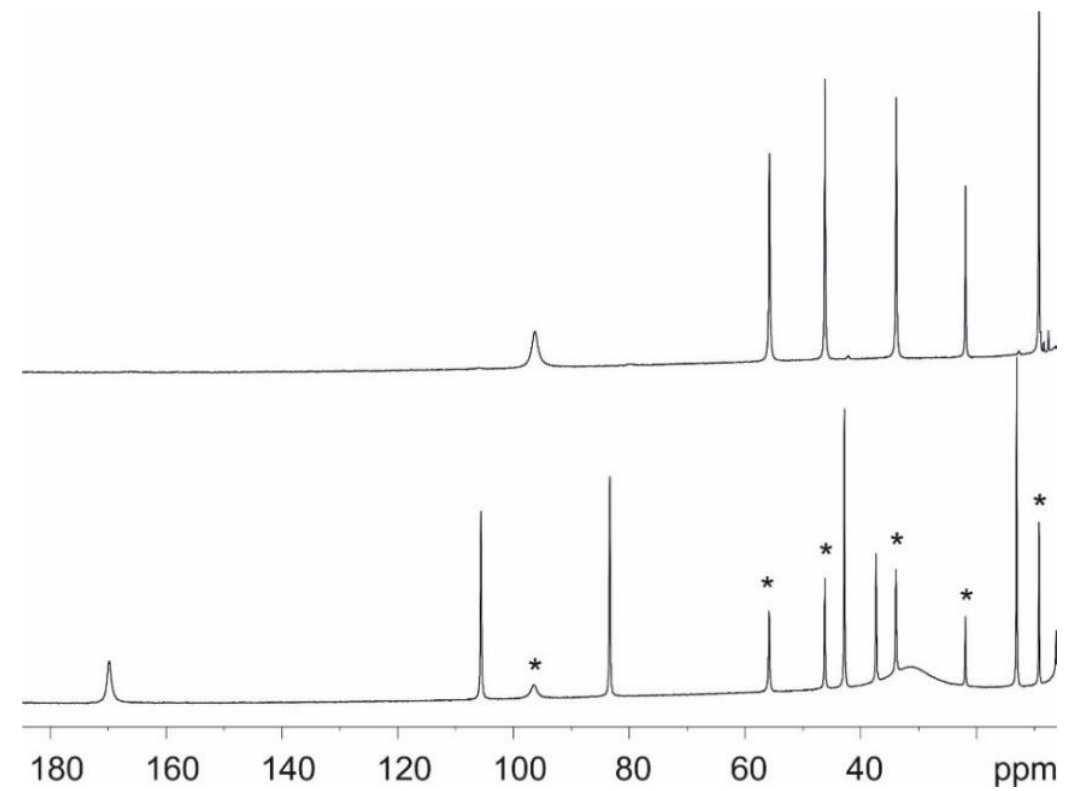

Figura 4.4. ${ }^{1} \mathrm{H}-\mathrm{RMN}$ de la mezcla de reacción del ligando tpy y el precursor de cobalto $\mathbf{1 a}$ (abajo), donde (*) son las señales del complejo homoléptico, y del ligando tpy con el precursor de cobalto 2a (arriba), respectivamente.

Los datos obtenidos por RMN concuerdan con los datos obtenidos del estudio por UVVis (Figura 4.5), en el que la banda a $350 \mathrm{~cm}^{-1}$ corrobora la coordinación del ligando tpy al centro metálico (más información en las Figuras 4.16-4.19 de la sección experimental). ${ }^{37}$ En este sentido, las diferencias entre las estructuras propuestas y el complejo homoléptico están asociadas a la absorbancia molar, que es superior para el complejo homoléptico. 


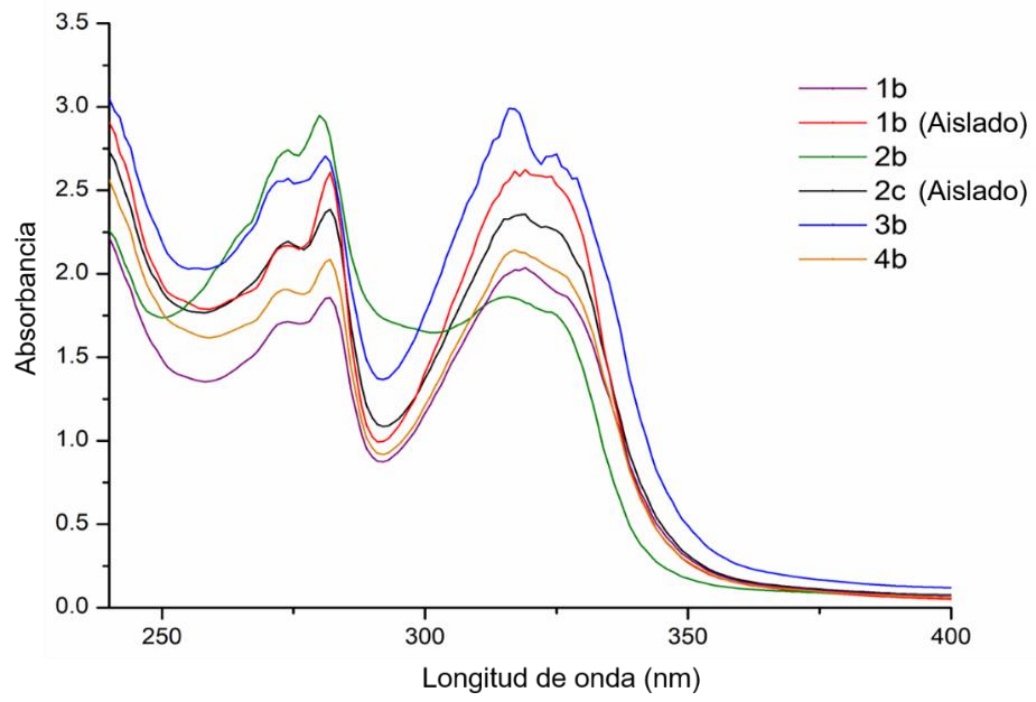

Figura 4.5. Comparación de los espectros de absorción UV-Vis para los precatalizadores de Co(II) $\mathbf{1 b}(0.0535 \mathrm{mg} / \mathrm{mL}), \mathbf{1 b}$ aislado $(0.0690 \mathrm{mg} / \mathrm{mL}), \mathbf{2 b}(0.0273 \mathrm{mg} / \mathrm{mL}), \mathbf{2 c}$ aislado $(0.0219 \mathrm{mg} / \mathrm{mL}), \mathbf{3 b}(0.0915 \mathrm{mg} / \mathrm{mL})$ and $\mathbf{4 b}(0.1025 \mathrm{mg} / \mathrm{mL})$ en metanol.

Los complejos formados fueron estudiados además usando ESI-MS con el fin de corroborar su estructura en disolución (Figuras 4.12-4.15). En este sentido, el análisis por ESI-MS para los complejos formados a partir de los precursores $1 \mathbf{1 a}$ y $\mathbf{2 a}$ concuerdan con las estructuras propuestas a partir de los datos de RMN y difracción de rayos X. Por otro lado, los complejos formados usando los precursores 3a y 4a no pueden ser estudiados usando esta técnica, ya que los precursores naftenato y octanato son una mezcla de varios isómeros. Además, estos precursores se encuentran en una solución en aceites minerales, aunque ambos representan las principales especies de cobalto usadas en la industria, por ejemplo, en la oxidación de alcanos. ${ }^{38}$

Además, la espectroscopía EPR a $r t$ y $77 \mathrm{~K}$ se empleó también para caracterizar los productos de reacción usando los precursores 1a y 2a (Figura 4.6). En ambos casos, se observó únicamente la señal con $\mathrm{S}=1 / 2$. El valor g observado $(\mathrm{g}=2.09$ ) se corresponde con el complejo homoléptico de bajo spin $\left[\mathrm{Co}(\mathrm{tpy})_{2}\right]^{2+}{ }^{39}$ No se observaron señales correspondientes a los complejos heterolépticos $\mathbf{1 b}$ o $\mathbf{2} \mathbf{b}$, que se espera que presenten especies con $S=3 / 2$. Sin embargo, las especies de $C o(I I)$ con $S=3 / 2$ pueden ser silenciosas en EPR. ${ }^{40}$ Por esta razón, se llevaron a cabo experimentos de EPR cuantitativos $^{41}$ para poder conocer el porcentaje de formación del complejo homoléptico con ambos precursores. La reacción del precursor 1a con el ligando tpy condujo a una 
señal con una intensidad correspondiente solo al $1.3 \%$ del cobalto, implicando que la especie homoléptica es minoritaria (el compuesto de coordinación $\mathbf{1 b}$ contiene un 13.5 $\%$ de Co), es decir, estaría presente en un 10\%. Por otro lado, el experimento con el precursor 2 a mostró una señal $\mathrm{S}=1 / 2$ con una intensidad correspondiente al $9 \%$ del cobalto, lo que corresponde con la formación exclusiva del complejo homoléptico (el compuesto de coordinación $\mathbf{2 c}$ contiene un $8.9 \%$ de Co).

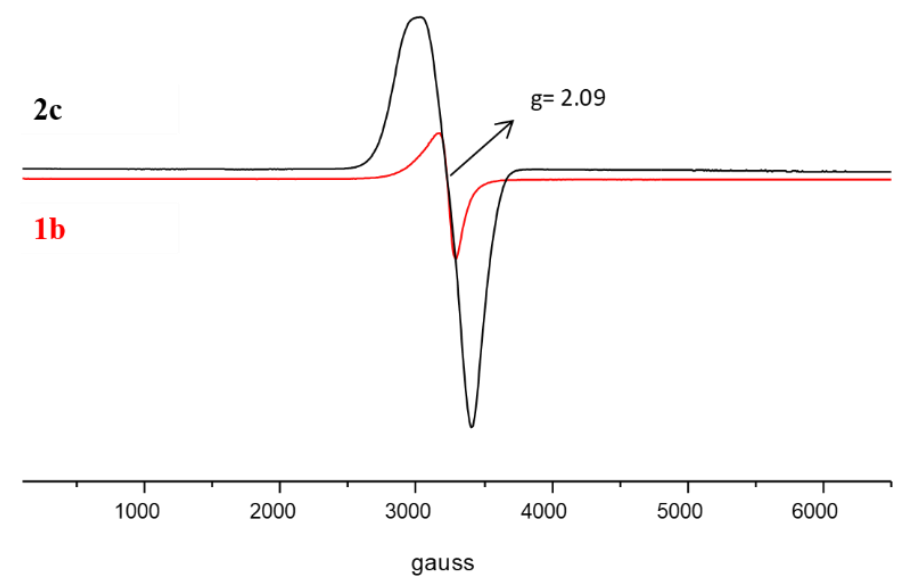

Figura 4.6. Espectros EPR de los compuestos de coordinación de cobalto (II) $\mathbf{1 b}$ (rojo) y $\mathbf{2 c}$ (negro).

Con el objetivo de estudiar el número de spin desapareado en los complejos se utilizó el método de Evans. ${ }^{42,43}$ Las medidas en disolución del momento magnético en MeOD- $\mathrm{d}_{4}$ a $23^{\circ} \mathrm{C}$ para los complejos $\mathbf{1 b}$ y $\mathbf{2 c}$ dieron como resultado una susceptibilidad magnética efectiva ( $\left.\mu_{\mathrm{eff}}\right)$ de 3.7 y 1.7 , respectivamente, lo que corresponde a 3 y 1 electrones desapareados (Figuras 4.7 y 4.8 ). 


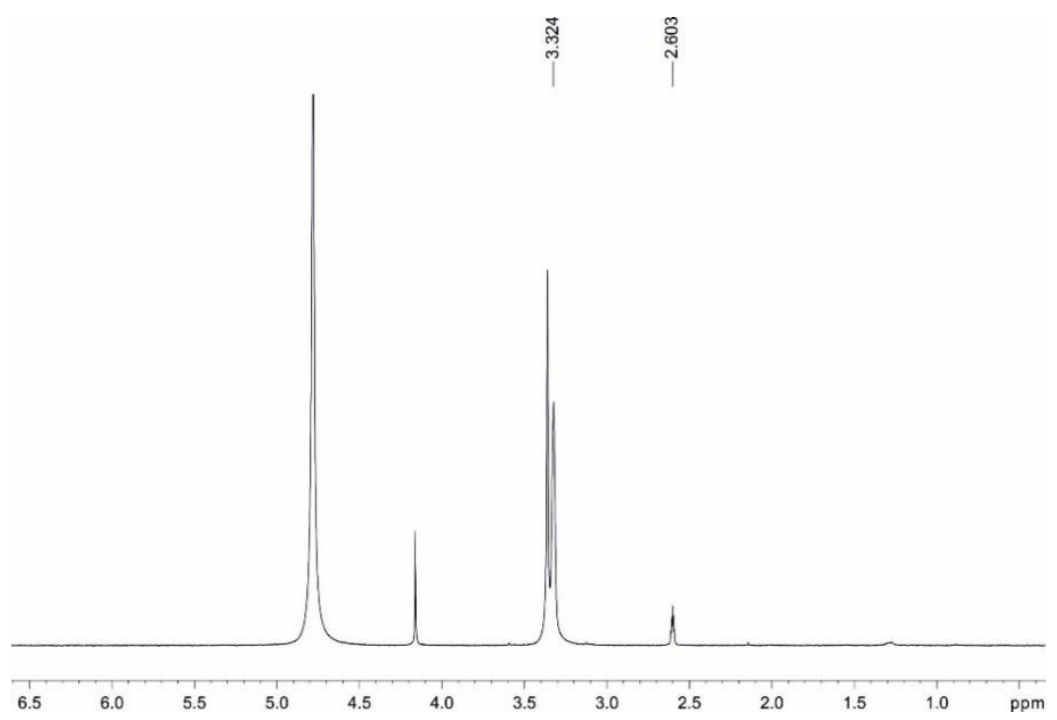

Figura 4.7. Extensión de ${ }^{1} \mathrm{H}$ RMN del complejo $\mathbf{1 b}$ en MeOD en relación con el MeOD.

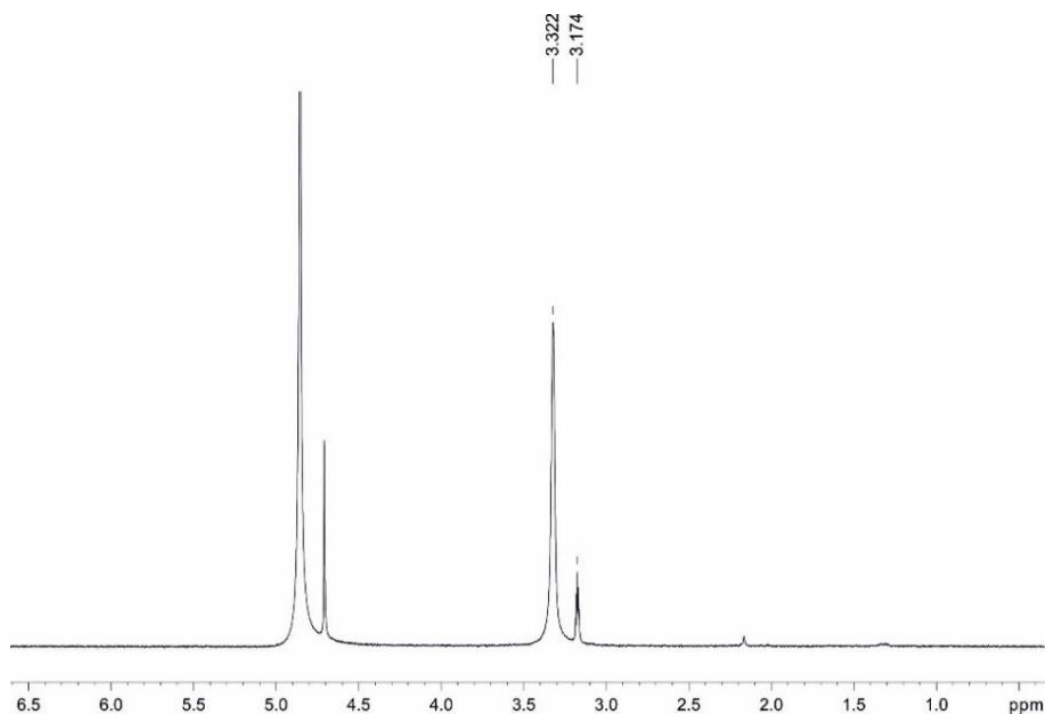

Figura 4.8. Extensión de ${ }^{1} \mathrm{H}$ RMN del complejo 2c en MeOD en relación con el MeOD. 
Por lo tanto, en base a todo lo anterior, se puede concluir que a partir de la reacción del precursor acetato de cobalto (II) (1a) con el ligando tpy se forma un complejo de Co(II) con una configuración electrónica de alto spin de fórmula molecular $\left[\mathrm{Co}(\mathrm{OAc})\left(\mathrm{H}_{2} \mathrm{O}\right)_{2}(\right.$ tpy $\left.)\right] \mathrm{OAc}(\mathbf{1 b})$, mientras que de la reacción del precursor $\mathbf{2 a}$ con el ligando tpy se forma un complejo de $\mathrm{Co}(\mathrm{II})$ con una configuración electrónica de bajo spin con fórmula molecular $\left[\mathrm{Co}(\text { tpy })_{2}\right] \mathrm{Cl}_{2} \cdot 6 \mathrm{H}_{2} \mathrm{O}$ (2c), lo cual está íntimamente relacionado con la labilidad de los ligandos, siendo el ligando acetilacetonato más lábil que el acetato. Por extrapolación de los resultados obtenidos por RMN para las reacciones con los precursores 3a y $\mathbf{4 a}$, se puede concluir que en estos casos también se forman los complejos heterolépticos con un único ligando terpiridina (3b y $\mathbf{4 b}$ ).

\subsubsection{Evaluación de los precatalizadores de cobalto.}

Para la evaluación de los precatalizadores de cobalto en la reacción de hidrosililación de alquenos, en primer lugar, se eligió un silano primario, como el fenilsilano $\left(\mathrm{PhSiH}_{3}\right)$ y una olefina alifática como el 1-octeno. Para optimizar las condiciones de reacción, se evaluaron diferentes disolventes (THF, $\mathrm{CHCl}_{3}, \mathrm{CH}_{2} \mathrm{Cl}_{2} \ldots$ ), diferentes cargas de catalizador (0.1-1\% mol de Co), temperaturas y tiempos de reacción (Tabla 4.10). La conversión de las reacciones se analizó por resonancia magnética nuclear a partir del crudo de reacción.

Una vez optimizadas las condiciones de reacción ( $0.1 \%$ del precursor de Co(II), $0.1 \%$ tpy en THF como disolvente a temperatura ambiente) se procedió a la evaluación de los precatalizadores en la reacción del 4-vinilciclohexeno con $\mathrm{PhSiH}_{3}$. En todos los casos se observó únicamente el producto anti-Markovnikov (Tabla 4.2). 
Tabla 4.2. Evaluación de los precatalizadores de cobalto para la hidrosililación del 4vinilciclohexeno con $\mathrm{PhSiH}_{3}{ }^{\text {[a] }}$

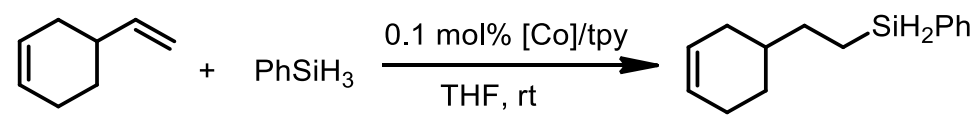

\begin{tabular}{ccccc}
\hline Entrada & Precursor Co(II) & Tiempo (min) & Conversión $(\%)^{[\mathrm{b}]}$ & TOF $\left(\mathrm{min}^{-1}\right)$ \\
\hline 1 & $\mathbf{1 a}$ & 240 & 72 & $7.00^{[\mathrm{c}]}$ \\
2 & $\mathbf{2 a}$ & 240 & 99 & $21.66^{[\mathrm{d}]}$ \\
3 & $\mathbf{3 a}$ & 180 & 99 & $22.33^{[\mathrm{d}]}$ \\
4 & $\mathbf{4 a}$ & 240 & 99 & $12.10^{[\mathrm{d}]}$ \\
5 & $\mathbf{1 a}^{[\mathrm{e}]}$ & 240 & 92 & $8.33^{[\mathrm{c}]}$ \\
6 & $\mathbf{2 a}^{[\mathrm{e}]}$ & 240 & 90 & $7.88^{[\mathrm{c}]}$ \\
\hline
\end{tabular}

[a]Todas las reacciones se llevaron a cabo usando $0.89 \mathrm{mmol}$ de silano y olefina en condiciones aeróbicas. La mezcla de los precursores de cobalto con la tpy se preparó previamente. ${ }^{[b]}$ Determinada por análisis de ${ }^{1} \mathrm{H}$ NMR del crudo de reacción. ${ }^{[c]}$ Calculado a los 60 min desde el inicio de la reacción. ${ }^{[\mathrm{d}]}$ Calculado a los 30 min desde el inicio de la reacción. ${ }^{[\mathrm{e}} \mathrm{Se}$ emplean los catalizadores aislados. La reacción en ausencia del ligando tpy no tiene lugar.

Para la evaluación de los precursores de cobalto, la reacción catalítica se siguió usando resonancia magnética nuclear, ya que es la técnica más adecuada teniendo en cuenta la estabilidad térmica de los productos de reacción. Para ello se utilizó una carga de catalizador del $0.1 \%$ en mol en THF-d y la reacción se monitorizó a varios tiempos durante 4 horas (Figura 4.9). Esto permitió calcular el TOF a los 30 minutos de reacción. 


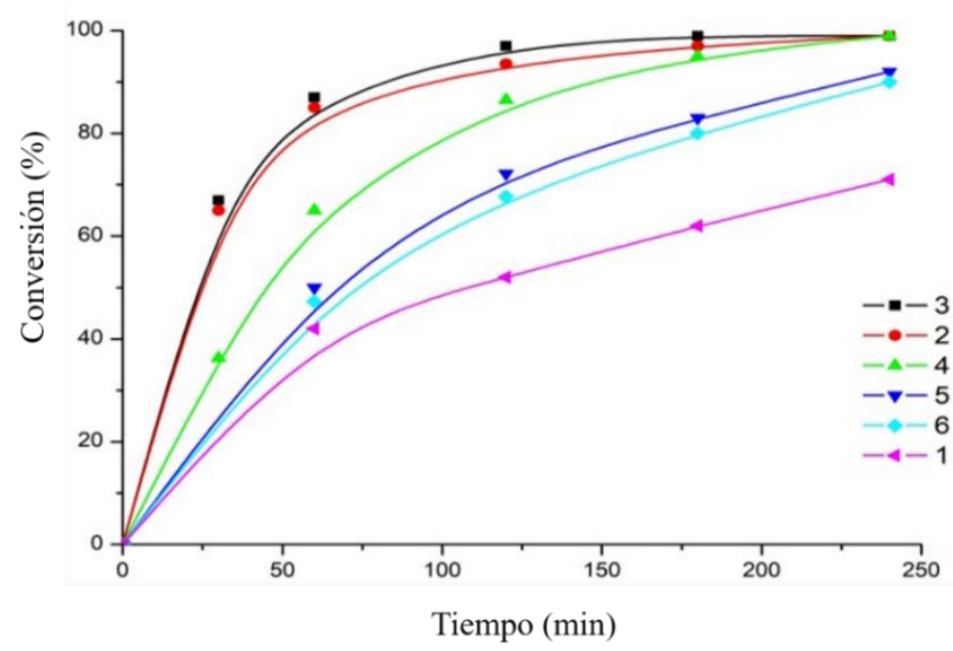

Figura 4.9. Estudio cinético de la reacción de hidrosililación del 4-vinilciclohexeno con $\mathrm{PhSiH}_{3}$ para la evaluación de los precatalizadores de cobalto. Los números en la figura se corresponden con las entradas en la Tabla 4.2.

Además, esta reacción se estudió por RMN in-situ, pudiéndose comprobar que los resultados obtenidos por ambas metodologías coinciden (Tabla 4.11, Figura 4.21 de la sección experimental). En general, todos los precursores utilizados muestran valores de TOF elevados (entradas 1-4, Tabla 4.2), aunque el precursor 3a (entrada 3) es el más activo para esta reacción $\left(\mathrm{TOF}=22.33 \mathrm{~min}^{-1}\right.$ ). El catalizador homoléptico $2 \mathrm{c}$ (entrada 6) muestra actividad para esta reacción, aunque su valor de TOF es más bajo que el preparado in-situ (entrada 2). Este hecho soporta que un ligando terpiridina es suficiente para activar los precursores de cobalto y que la formación de la especie homoléptica tiene una influencia negativa en el proceso y en la velocidad de reacción, ya que debería perder un ligando para que el reactivo se coordine al metal y la reacción tenga lugar. Finalmente, con respecto al precatalizador $\mathbf{1 b}$, preparado in-situ y aislado, se puede observar que es poco soluble en el disolvente utilizado en la reacción (THF), lo que es una limitación técnica en catálisis homogénea. En estos dos casos (entrada 1 y 5), los valores de TOF están en el mismo orden de magnitud, pero la eficiencia es mayor en el caso del complejo aislado.

El descubrimiento de precatalizadores de cobalto altamente activos, selectivos y estables en condiciones de reacción aeróbicas sin necesidad de uso de disolventes anhidros ni activadores externos, llevó a estudiar la generalidad de la reacción usando para ello un amplio rango de sustratos, tanto alquenos como silanos, en la reacción de hidrosililación. 


\subsubsection{Generalidad de la reacción}

En primer lugar, se estudió la actividad de los precatalizadores más activos, los que se obtienen utilizando los precursores de cobalto 2a, 3a y 4a, en la reacción de hidrosililación de distintos alquenos con el mismo silano primario usado para la evaluación de todos los precatalizadores (Tabla 4.3).

Tabla 4.3. Productos de hidrosililación funcionalizados con $\mathrm{PhSiH}_{3}$ usando los precursores de cobalto $\mathbf{2 a}, \mathbf{3 a}$ and $\mathbf{4 a}$ con tpy. ${ }^{[a, b]}$

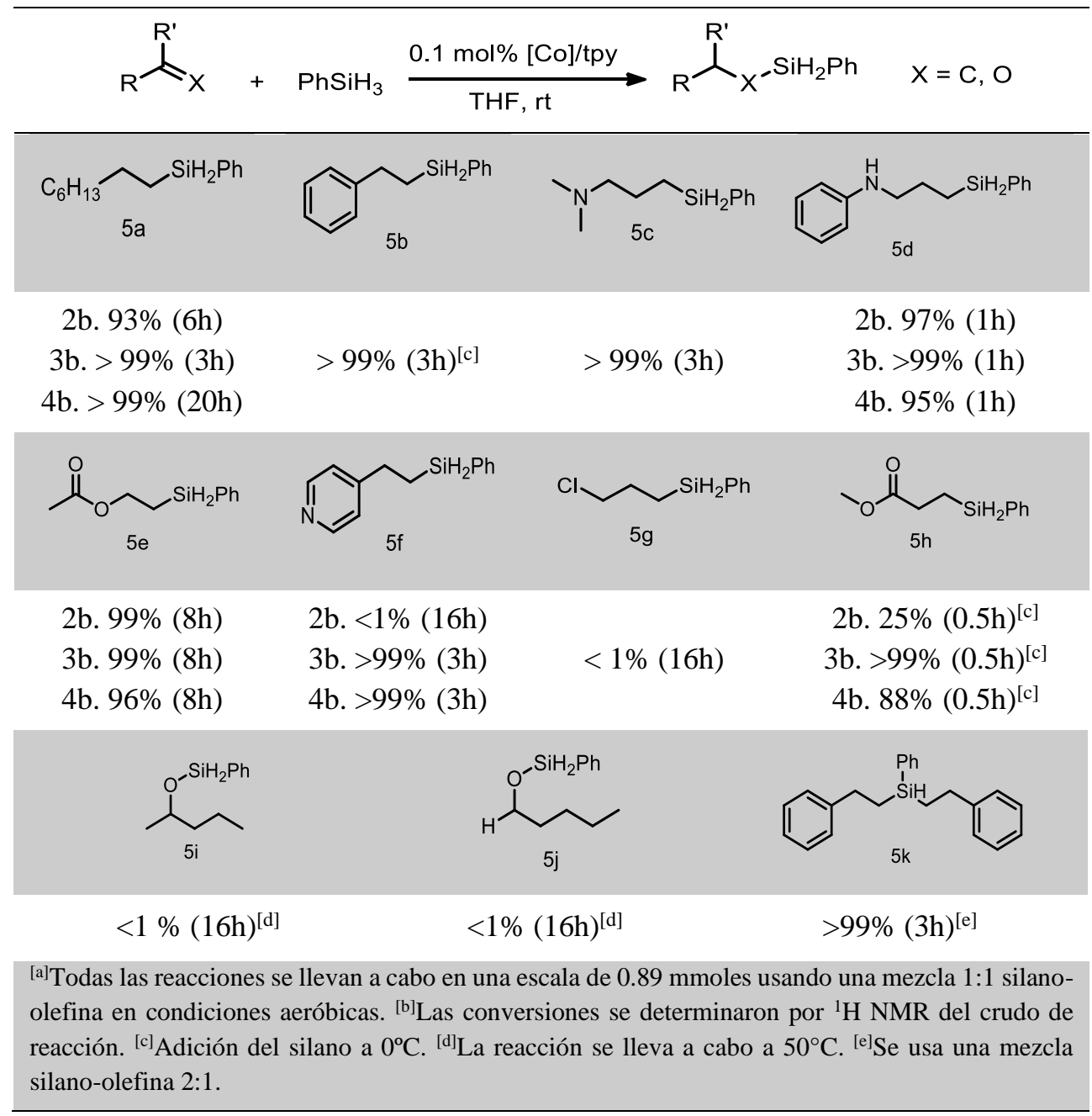


Como se observa en la Tabla 4.3, los precursores de cobalto $\mathbf{2 a}$, 3a y 4a con tpy son activos y selectivos para la hidrosililación de un amplio rango de alquenos terminales con distintos grupos funcionales con $\mathrm{PhSiH}_{3}$, mostrando excelentes conversiones a $23^{\circ} \mathrm{C}$ usando $0.1 \%$ mol de los precatalizadores de cobalto. Cabe destacar que los catalizadores de cobalto estudiados son activos en presencia de aminas secundarias y terciarias (5c, 5d).

Además, el estireno, que es un sustrato que se presenta como un reto para la hidrosililación regioselectiva, ${ }^{44}$ dio como producto exclusivamente el producto antiMarkovnikov (5b). Por otro lado, estos catalizadores de cobalto también son activos en presencia de grupos funcionales oxigenados como esteres $(\mathbf{5 e}, \mathbf{5 h})$. Otro punto que destacar es que estos precatalizadores son quimioselectivos a dobles enlaces frente a grupos carbonilos como aldehídos $(\mathbf{5 k})$ o cetonas $(\mathbf{5 j})$ y también frente a alquenos internos. Finalmente, un control de la estequiometría de la reacción da como resultado productos mono- o bi-funcionalizados, $\mathbf{5 b}$ o $\mathbf{5 l}$, cuando se añaden 1 o 2 equivalentes de estireno, respectivamente.

Seguidamente se estudió la actividad de estos precatalizadores en la hidrosililación de olefinas con un silano secundario, $\mathrm{Ph}_{2} \mathrm{SiH}_{2}$. En este caso se observó que los precatalizadores de cobalto son activos, aunque la velocidad de reacción es menor que en el caso de silanos primarios. Así, como se puede observar en la Tabla 4.4, los precursores de cobalto 2a, 3a y 4a con tpy mostraron rendimientos altos o moderados con excelente selectividad a temperatura ambiente. 
Tabla 4.4. Productos de hidrosililación funcionalizados con $\mathrm{Ph}_{2} \mathrm{SiH}_{2}$ usando los precursores de cobalto $\mathbf{2 a}, \mathbf{3 a}$ y $\mathbf{4 a}$ con tpy. ${ }^{[a, b]}$

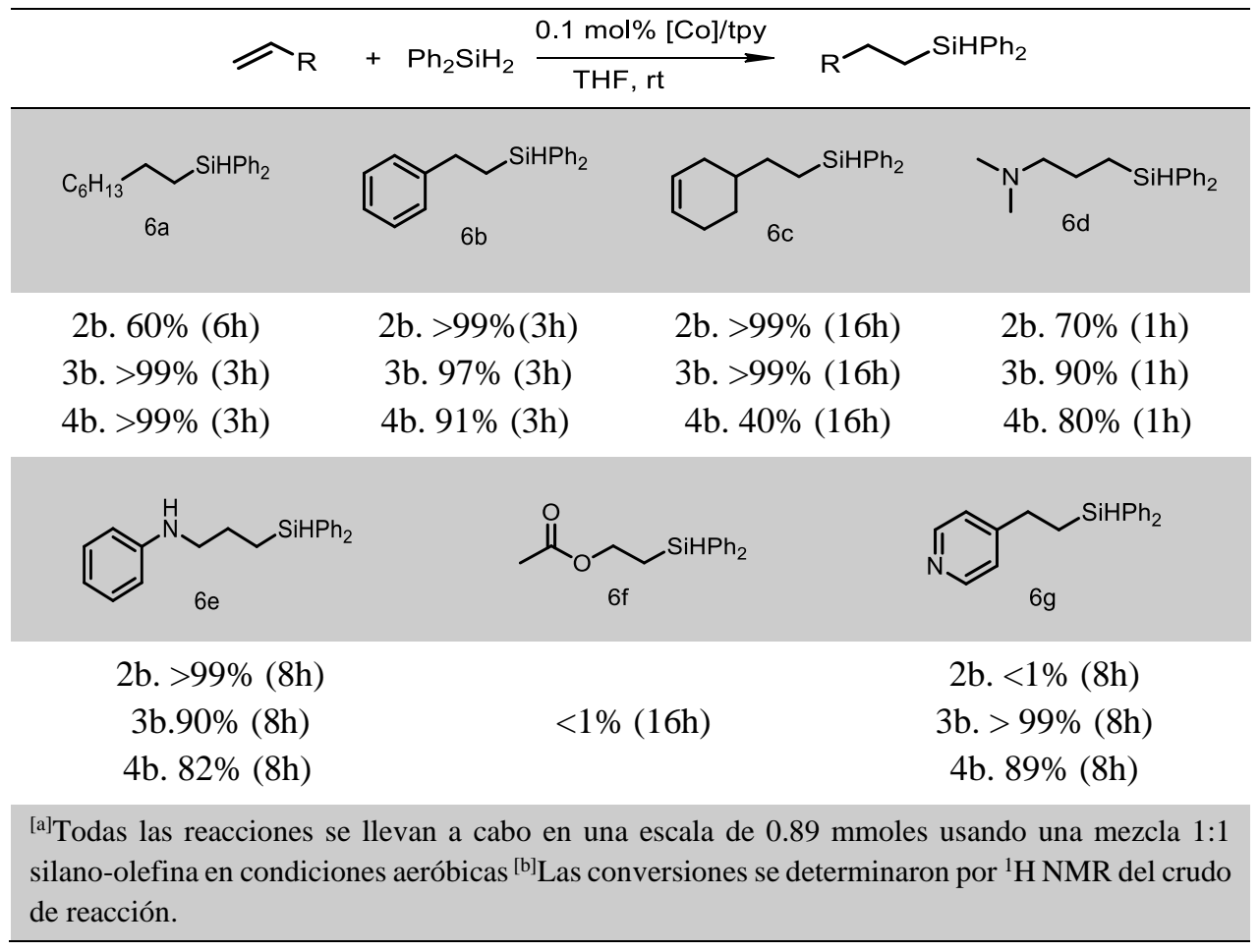

En la literatura se recoge que, normalmente, los catalizadores que son activos para hidrosililaciones con $\mathrm{PhSiH}_{3}$ o $\mathrm{Ph}_{2} \mathrm{SiH}_{2}$ suelen ser inactivos o menos eficientes para las hidrosililaciones usando hidroalcoxisilanos o hidrosiloxanos. ${ }^{27}$ Partiendo de esta base, los precursores $\mathbf{2 a}$, 3a y $\mathbf{4 a}$ con tpy se evaluaron en la activación de este tipo de silanos. En este sentido, se ha usado $(\mathrm{EtO})_{3} \mathrm{SiH}$ para evaluar la actividad de estos precatalizadores (Tabla 4.5). Las reacciones se llevaron a cabo a $50^{\circ} \mathrm{C}$ para activar el (EtO) ${ }_{3} \mathrm{SiH}$. En este caso, el naftenato de cobalto con tpy mostró los mejores resultados para los productos esperados a partir de los alquenos seleccionados. Sin embargo, se ha observado que esta reacción en presencia de este catalizador es más sensible a la presencia de algunos grupos funcionales en alquenos tales como esteres o alcoholes. Como se ha mencionado anteriormente, el producto de hidrosililación del 1-octeno con trietoxisilano se produce anualmente en una escala de más de 6000 toneladas, ya que tiene diversas aplicaciones comerciales. ${ }^{9}$ Por ello, esta reacción se ha llevado a cabo a mayor escala $(10 \mathrm{~g})$, obteniendo una conversión $>99 \%$ en 3 horas. 
Tabla 4.5. Productos de hidrosililación funcionalizados con (EtO) $)_{3} \mathrm{SiH}$ usando los precursores de cobalto $\mathbf{2 a}, 3 \mathbf{a}$ y $\mathbf{4 a}$ con tpy. ${ }^{[\mathrm{a}, \mathrm{b}]}$

$$
\gamma_{\mathrm{R}}+(\mathrm{EtO})_{3} \mathrm{SiH} \underset{\mathrm{THF}, 50^{\circ} \mathrm{C}}{\stackrel{0.1 \mathrm{~mol} \%[\mathrm{Co}] / \mathrm{tpy}}{\longrightarrow}} \mathrm{Ri}(\mathrm{OEt})_{3}
$$

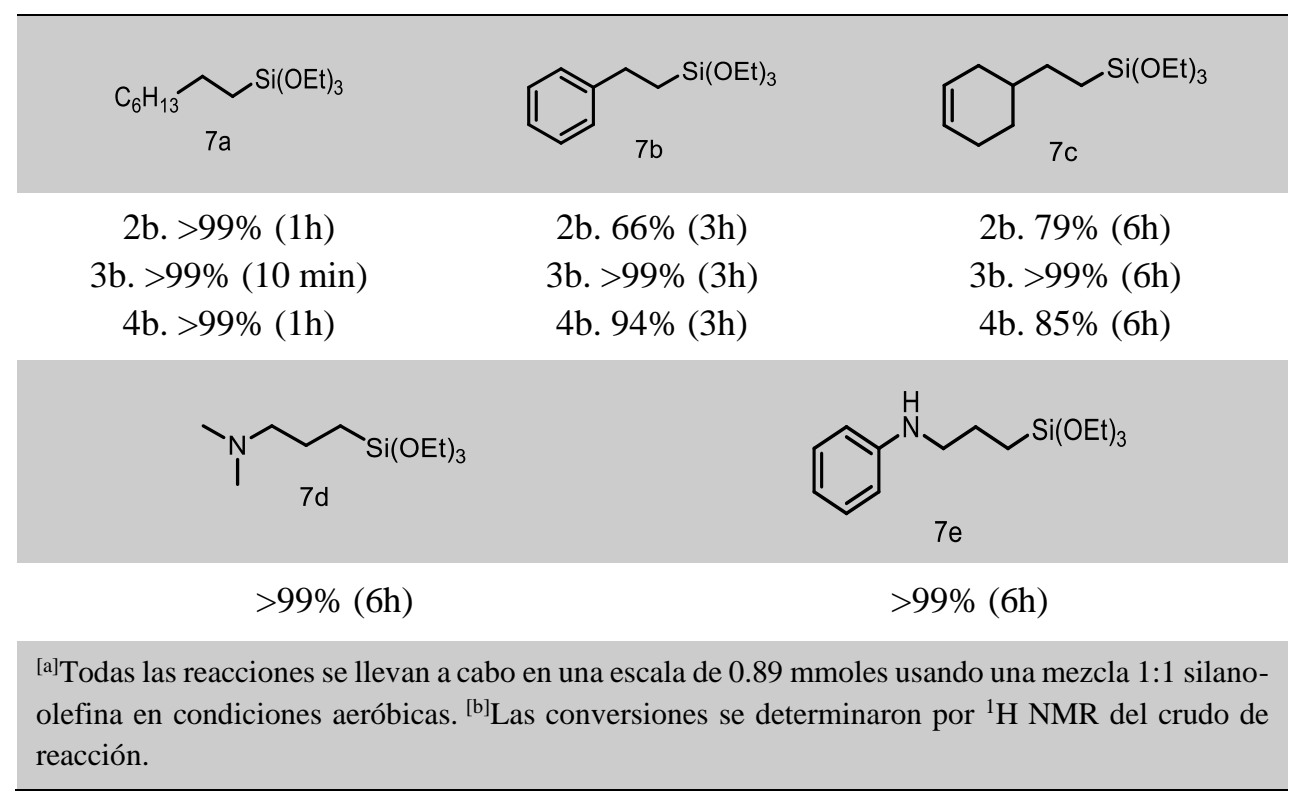

A continuación se usó el pentametildisiloxano, $\left(\mathrm{CH}_{3}\right)_{3} \mathrm{SiOSiH}\left(\mathrm{CH}_{3}\right)_{2}$, para evaluar los precatalizadores mencionados con un disiloxano (Tabla 4.6). En este caso la temperatura necesaria para activar este hidrosiloxano fue $80^{\circ} \mathrm{C}$, dando una conversión completa al producto 8a en 8 horas. Esta reacción se evaluó como primer caso en la formación de polímeros de silicona. 
Tabla 4.6. Productos de hidrosililación funcionalizados con $\left(\mathrm{CH}_{3}\right)_{3} \mathrm{SiOSiH}\left(\mathrm{CH}_{3}\right)_{2}$ usando los precursores de cobalto $\mathbf{2 a}, \mathbf{3 a}$ y $\mathbf{4 a}$ con tpy. ${ }^{[\mathrm{a}, \mathrm{b}]}$

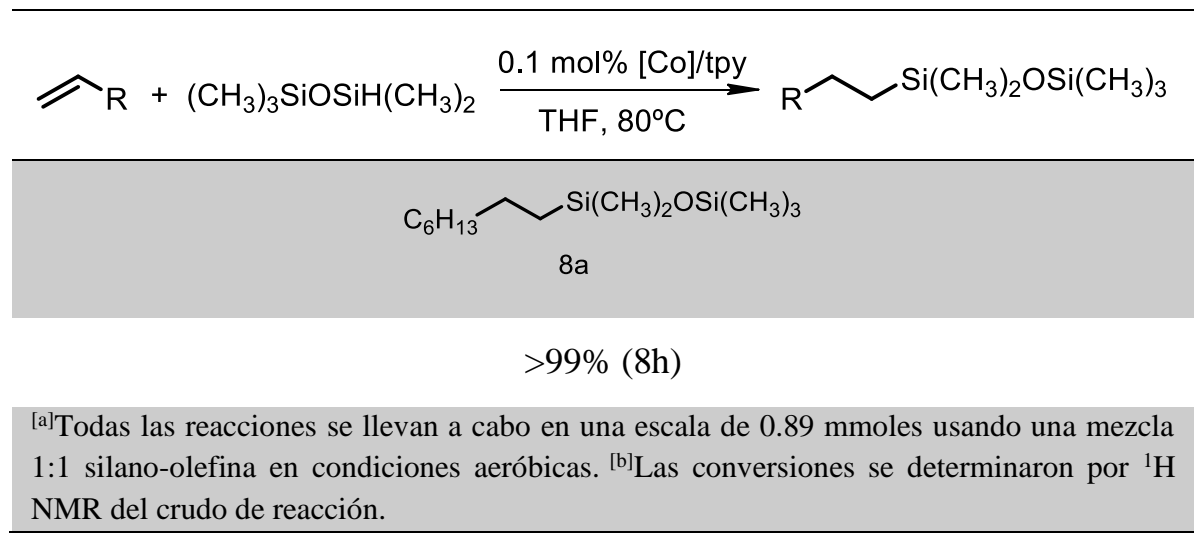

El entrecruzamiento de las siliconas catalizado por platino produce polímeros de silicona con aplicación en recubrimientos. Debido a la elevada viscosidad del producto, el platino queda atrapado en la silicona final, no pudiendo ser recuperado y siendo la consecuencia del $30 \%$ del coste final de la silicona. ${ }^{9}$ Además, los criterios comerciales exigen que este proceso de curado se lleve a cabo rápidamente con bajas cargas de catalizador y sin que se aprecie ningún tipo de color en el producto final. ${ }^{37}$ La actividad de entrecruzamiento de los precursores $\mathbf{2 a}$, 3a y $\mathbf{4 a}$ con tpy se examinó con diferentes cargas de catalizador (Esquema 4.7).
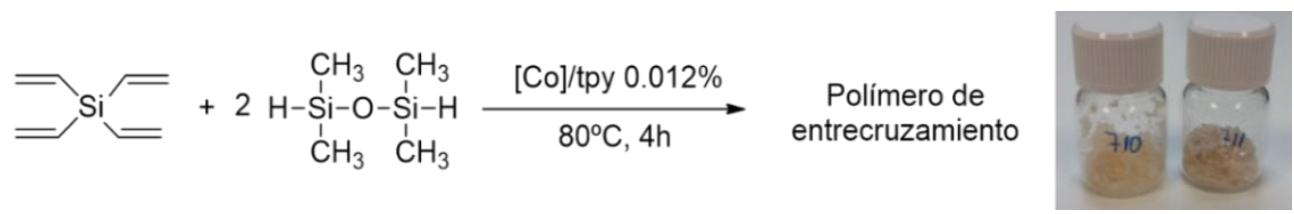

Esquema 4.7. Fluidos de entrecruzamiento de siliconas.

Como se puede observar en el Esquema 4.7, se obtiene un gel como producto de reacción y un entrecruzamiento efectivo de la silicona. La carga de catalizador relativa al silano usada fue $0.0125 \%$ mol. En un trabajo reportado por el grupo de Chirik, la carga de catalizador utilizada para el proceso fue $0.0625 \%$ mol en relación con el silano. ${ }^{9}$ Por lo tanto, este resultado está en el rango del sistema catalítico reportado por Chirik. 


\subsubsection{Estudio mecanístico.}

Con el fin de dilucidar el mecanismo que rige la reacción con esta familia de complejos, en primer lugar, se estudió la cinética de la reacción. Para ello, se siguió una metodología similar a la descrita por Bleith y Gade, ${ }^{45}$ que consiste en variar la concentración de cada componente de la reacción a la vez que se monitoriza la velocidad de reacción. En este estudio se va a monitorizar la velocidad de reacción por RMN. Para la reacción de hidrosililación del 4-vinilciclohexeno con $\mathrm{PhSiH}_{3}$ con el precatalizador $\mathbf{3 b}$ con tpy, en primer lugar, se varió la concentración de alqueno y encontramos que la velocidad inicial de la reacción no se veía afectada apreciablemente al variar la concentración de este componente, lo que indica una dependencia de orden 0 con la concentración de alqueno (Figura 4.10 a). A continuación, se estudió la dependencia de la velocidad de reacción con la concentración de silano. En este caso, se observó que la velocidad de reacción variaba al variar la concentración de $\mathrm{PhSiH}_{3}$, lo que indica una dependencia de orden uno de la concentración de silano (Figura 4.10 b). Finalmente, se encontró que la velocidad inicial depende linealmente de la carga de catalizador cuando esta se varía en el rango de 0.5 a $0.05 \%$ mol (Figura 4.10 c). Esta dependencia de primer orden de la concentración del catalizador implica que no existe tiempo de inducción y que los centros de cobalto no se agregan en este rango de concentración.

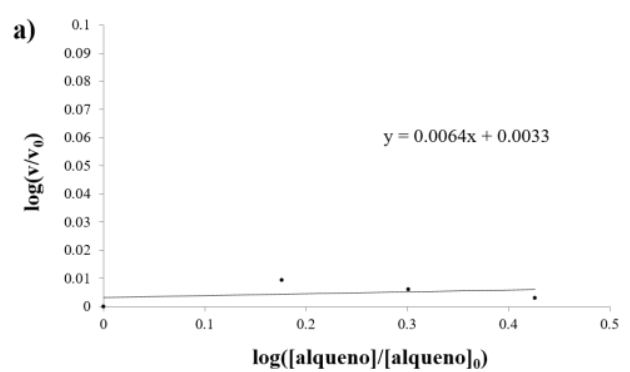

$\log \left([\text { alqueno]/[alqueno }]_{0}\right)$
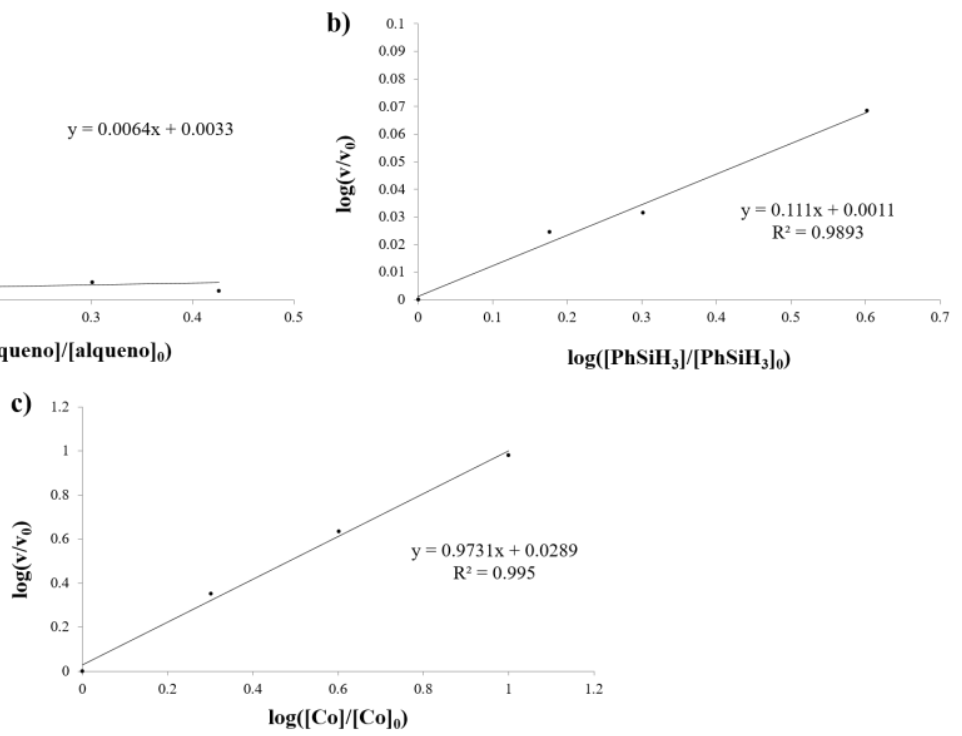

Figura 4.10. Dependencia de la velocidad inicial de la reacción con a) concentración de alqueno, b) concentración de silano y c) concentración de catalizador. 
El estudio de las especies intermedias que se forman durante la reacción entre el catalizador y los dos reactivos se hizo con ayuda de la espectroscopía Raman in-situ. Para ello, en primer lugar, se estudiaron los 3 componentes aislados, el catalizador, el $\mathrm{PhSiH}_{3}$ y 4-vinilciclohexeno. A continuación, se estudió la mezcla del catalizador y el silano, en la que se observan burbujas que pueden deberse a la formación de hidrógeno. De hecho, la reacción catalítica es muy rápida con el silano primario $\mathrm{PhSiH}_{3}$ (Tabla 4.3), por lo que cuando la relación catalizador:silano es de 1:2, el proceso es más exotérmico, a lo que hay que sumar el calentamiento debido a la irradiación del láser Raman. La elevada temperatura puede promover otros procesos, por lo que se concluyó que este no era el mejor silano para dilucidar el mecanismo. Con el fin de hacer el proceso más lento y menos exotérmico, se sustituyó el $\mathrm{PhSiH}_{3}$ por $(\mathrm{EtO})_{3} \mathrm{SiH}$ y se siguió el mismo procedimiento (Tabla 4.6). En estas condiciones, al estudiar la mezcla del (EtO $)_{3} \mathrm{SiH}$ con el catalizador, se detectó una banda fuerte a $2251 \mathrm{~cm}^{-1}$ (Figura 4.11, línea roja), y esta banda se desplazó claramente con respecto a la banda correspondiente al enlace $\mathrm{Si}-\mathrm{H}$ del silano (Figura 4.11, línea negra), que se observó durante un largo período de tiempo y desapareció al añadir el alqueno a la mezcla (Figura 4.11, línea verde). En base a este comportamiento, esta señal se asignó a un enlace Co-H. ${ }^{46}$ Además, se identificó otra nueva banda adicional correspondiente al enlace $\mathrm{Si}-\mathrm{O}$ a $465 \mathrm{~cm}^{-1} .{ }^{47}$

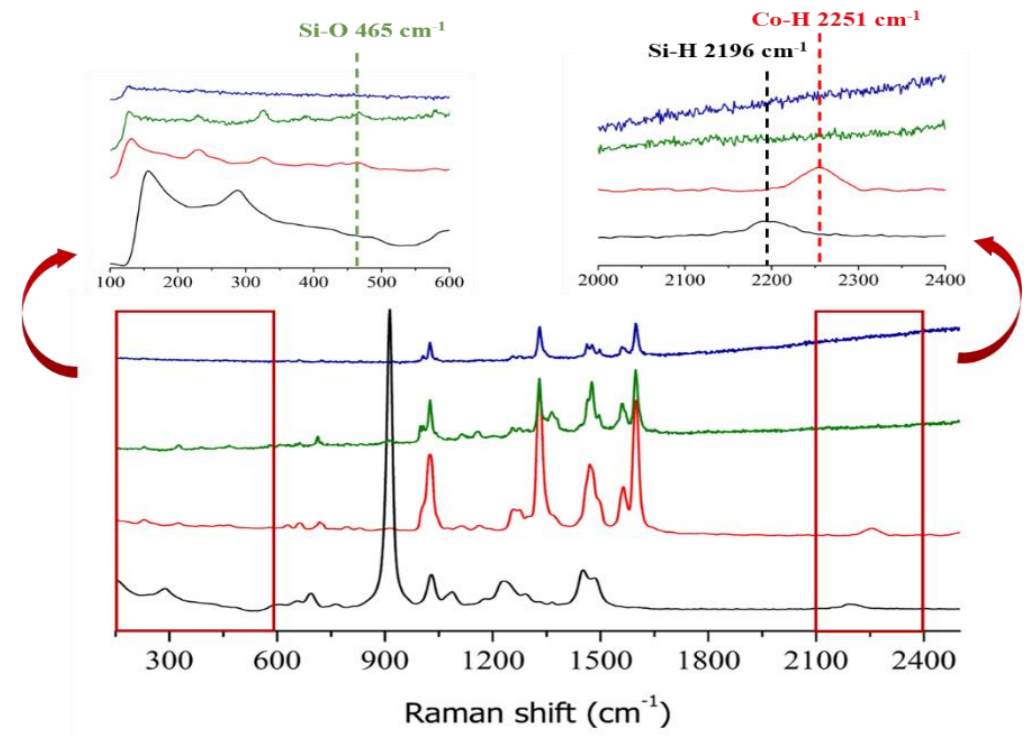

Figura 4.11. Experimento de espectroscopía Raman in-situ. Código de colores: Azul: catalizador 3b, Negro: (EtO) 3 SiH, Rojo: mezcla de reacción entre el catalizador 3b y el (EtO) 3 SiH, y Verde: mezcla de reacción tras la adición del alqueno. 
Por último, a partir de los datos cinéticos y de los intermedios observados en los experimentos de Raman in-situ, se ha propuesto un camino de reacción plausible en el Esquema 4.8. Primero tiene lugar la coordinación del silano al centro metálico del catalizador, que da como resultado el intermedio I, Co-H, y la especie Si-OR*. Éste es el paso determinante de la velocidad ya que la velocidad de reacción respecto al silano es de primer orden, como se ha observado en el estudio cinético y se basa en la metátesis del enlace $\sigma$. El intermedio I se encuentra en equilibro con la especie II, que reacciona con el alqueno para formar el complejo alquílico III que se convierte posteriormente en el complejo hidruro I al reaccionar con el silano, acompañado de la formación del alquilsilano lineal final.

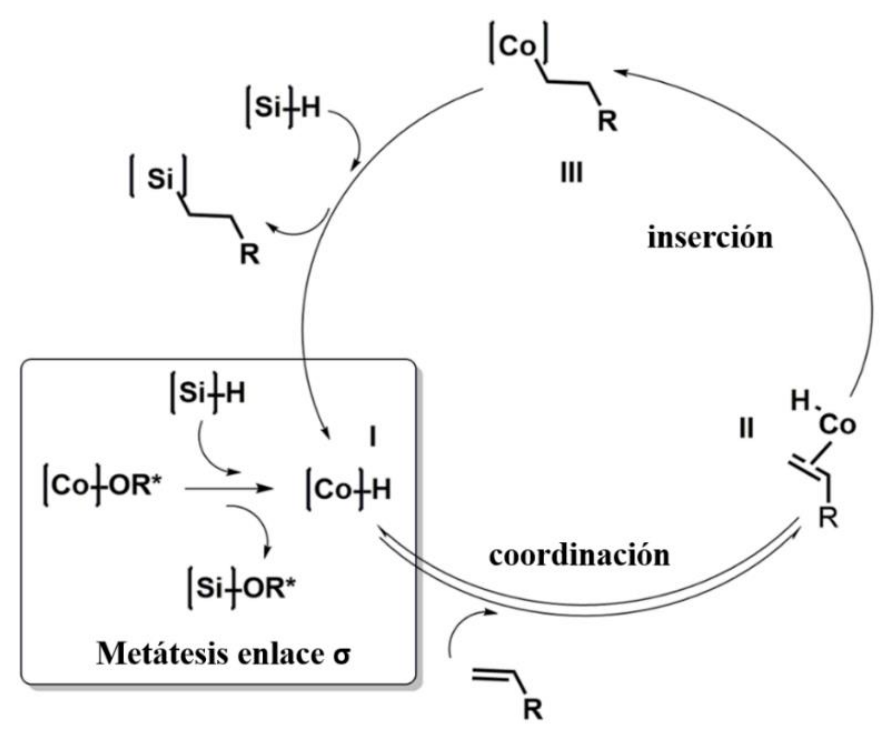

Esquema 4.8. Propuesta mecanística para la hidrosililación de alquenos catalizada por cobalto. 


\subsection{Conclusiones}

- Se ha obtenido una nueva familia de compuestos de coordinación de cobalto (II) que son estables al aire y a la humedad, los cuales se han caracterizado usando diferentes técnicas.

- Estos compuestos de coordinación son activos como catalizadores en la hidrosililación de alquenos tanto usando hidrosilanos primarios y secundarios, como alcoxisilanos e hidrosiloxanos evitando el uso de activadores externos.

- Además, estos complejos también son activos en la síntesis de polímeros de entrecruzamiento de tipo silicona, generando productos sin color.

- Este es el primer caso en el que estas reacciones se llevan a cabo en condiciones aeróbicas y con disolvente no anhidro con complejos metálicos de la primera serie de transición.

- Se ha realizado un estudio mecanístico en el que la reacción entre el silano y el catalizador genera una especie intermedia $\mathrm{Co}-\mathrm{H}$ que se ha observado por espectroscopía Raman in-situ.

- El descubrimiento de esta nueva familia de catalizadores activos y estables cuando se exponen al aire y a la humedad, abre una nueva puerta al estudio de nuevos catalizadores que puedan tener aplicación en la industria para este proceso, sustituyendo a los catalizadores basados en platino. 


\subsection{Sección experimental}

\subsubsection{Procedimiento detallado para la síntesis de los catalizadores.}

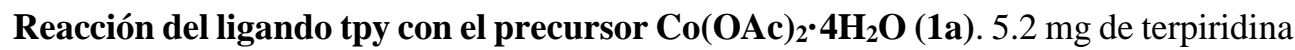
$(0.022 \mathrm{mmol})$ y $5.5 \mathrm{mg}$ de acetato de cobalto (II) tetrahidratado $(0.022 \mathrm{mmol})$ se disuelven en $5 \mathrm{~mL}$ de THF y la disolución resultante se agita durante 1 hora. Además, las mismas cantidades se disuelven en una mezcla de $\mathrm{CD}_{3} \mathrm{CN}: \mathrm{CDCl}_{3}$ con unas gotas de $\mathrm{CD}_{3} \mathrm{OD}$ en un tubo de RMN. El espectro resultante es el que se muestra en la Figura 4.4, en el que se puede observar que se forma principalmente el complejo 1:1 paramagnético (1b). ${ }^{1} \mathrm{H}$ RMN (300 MHz): $\delta=169.42$ (bs), 105.75 (bs), 83.27 (bs), 42.50 (bs), 36.92(bs) and 12.72 (bs). ${ }^{37}$ Además, en este caso se forma una pequeña cantidad del complejo homoléptico 1c. (300 MHz): $\delta=97.05$ (bs), 55.75 (bs), 45.80 (bs), 33.91 (bs), 21.98 (bs), and $9.22(\mathrm{bs}) .{ }^{37}$

Reacción del ligando tpy con el precursor $\mathrm{Co}(\mathbf{a c a c})_{2} \cdot \mathbf{H}_{2} \mathbf{O}(\mathbf{2 a}) .5 .2 \mathrm{mg}$ de terpiridina $(0.022 \mathrm{mmol})$ y $5.7 \mathrm{mg}$ de acetilacetonato de cobalto (II) hidratado $(0.022 \mathrm{mmol})$ se disuelven en $5 \mathrm{~mL}$ de THF y la disolución resultante se agita durante 5 minutos. Además, las mismas cantidades se disuelven en una mezcla de $\mathrm{CD}_{3} \mathrm{CN}: \mathrm{CDCl}_{3}$ con unas gotas de $\mathrm{CD}_{3} \mathrm{OD}$ en un tubo de RMN. El espectro resultante es el que se muestra en la Figura 4.4, en el que se puede observar que solo se forma el complejo homoléptico $2 \mathrm{c}$. ${ }^{1} \mathrm{H}$ RMN (300 $\mathrm{MHz}$ ): $\delta=96.07$ (bs), 55.57 (bs), 45.73 (bs), $33.78(\mathrm{bs}), 21.87(\mathrm{bs})$, and $9.48(\mathrm{bs}){ }^{37}$

Reacción del ligando tpy con el precursor Co(napht) $\mathbf{2}$ (3a). $5.2 \mathrm{mg}$ de terpiridina $(0.022 \mathrm{mmol})$ y $13.11 \mathrm{mg}$ de naftenato de cobalto (II) (10\% Co, $0.022 \mathrm{mmol})$ se disuelven en $5 \mathrm{~mL}$ de THF y la disolución resultante se agita durante 5 minutos.

Reacción del ligando tpy con el precursor $\mathbf{C o ( o c t )})_{2}$ (4a). $5.2 \mathrm{mg}$ de terpiridina $(0.022 \mathrm{mmol})$ y $16.4 \mathrm{mg}$ de octanato de cobalto (II) $(8 \% \mathrm{Co}, 0.022 \mathrm{mmol})$ se disuelven en $5 \mathrm{~mL}$ de THF y la disolución resultante se agita durante 5 minutos.

Preparación de $\left[\mathrm{Co}(\mathbf{O A c})\left(\mathrm{H}_{2} \mathrm{O}\right)_{2}\right.$ (tpy)]OAc (1b). $100 \mathrm{mg}$ de terpiridina $(0.428 \mathrm{mmol})$ y $106.6 \mathrm{mg}$ de acetato de cobalto(II) tetrahidratado $(0.428 \mathrm{mmol})$ se disuelven en $50 \mathrm{~mL}$ de una mezcla de acetonitrilo:cloroformo (1:1) con varias gotas de metanol. Se observa un cambio de color inmediato a naranja. Por evaporación lenta del disolvente se obtuvieron monocristales válidos para llevar a cabo la difracción de rayos $\mathrm{X}$ de monocristal. Análisis elemental para $\mathrm{C}_{19} \mathrm{H}_{21} \mathrm{CoN}_{3} \mathrm{O}_{6}$ : teórico $=\mathrm{C}, 51.131 ; \mathrm{H}, 4.743 ; \mathrm{N}, 9.415 ; \mathrm{Co}$, 13.2. Experimental = C, 51.048; H, 4.667; N, 9.543; Co, 13.5 . 
Preparación de $\left[\mathrm{Co}\left(\mathrm{tpyy}_{2} \mathbf{2}_{\mathbf{2}} \mathrm{Cl}_{\mathbf{2}} \cdot \mathbf{6} \mathbf{H}_{\mathbf{2}} \mathrm{O}(\mathbf{2 c}) .100 \mathrm{mg}\right.\right.$ de terpiridina $(0.428 \mathrm{mmol})$ y 110 $\mathrm{mg}$ de acetilacetonato de cobalto(II) hidratado $(0.428 \mathrm{mmol})$ se disuelven en $50 \mathrm{~mL}$ de una mezcla de acetonitrilo:cloroformo (1:1) con varias gotas de metanol. Se observa un cambio de color inmediato a naranja. Por evaporación lenta del disolvente se obtuvieron monocristales válidos para llevar a cabo la difracción de rayos $\mathrm{X}$ de monocristal. Análisis elemental para $\mathrm{C}_{30} \mathrm{H}_{34} \mathrm{Cl}_{2} \mathrm{CoN}_{6} \mathrm{O}_{6}$ : teórico $=\mathrm{C}, 51.745 ; \mathrm{H}, 3.764 ; \mathrm{N}, 12.069 ; \mathrm{Co}, 8.8$. Experimental $=\mathrm{C}, 51.899 ; \mathrm{H}, 3.876 ; \mathrm{N}, 11.698 ; \mathrm{Co}: 9.1$.

\subsubsection{Caracterización de los catalizadores.}

\section{Parámetros y descripción cristalográfica para los complejos 1b y 2c.}

Los monocristales de los complejos $\mathbf{1 b}$ y $\mathbf{2 c}$ se midieron por difracción de rayos $\mathrm{X}$ de monocristal. Ambos complejos presentan un sistema triclínico, y contienen dos cationes cristalográficamente independientes.

Tabla 4.7. Datos cristalográficos y detalles del refinamiento de las estructuras para los complejos $\mathbf{1 b}$ y 2c. Las coordenadas atómicas, los parámetros equivalentes de desplazamientos isotrópicos, las distancias y ángulos de enlace se pueden consultar en la base de datos (CCDC 1817714 and CCDC 1817709, respectivamente).

\begin{tabular}{|c|c|c|}
\hline Código & $1 \mathbf{b}$ & $2 c$ \\
\hline Fórmula empírica & $\mathrm{C}_{17} \mathrm{H}_{18} \mathrm{CoN}_{3} \mathrm{O}_{4} \cdot \mathrm{C}_{2} \mathrm{H}_{3} \mathrm{O}_{2}$ & $\mathrm{C}_{30} \mathrm{H}_{22} \mathrm{CoN}_{6} \cdot 2(\mathrm{Cl}) \cdot 2\left(\mathrm{H}_{2} \mathrm{O}\right)$ \\
\hline Peso molecular & 446.32 & 696.40 \\
\hline Temperatura (K) & 100 & 100 \\
\hline Longitud de onda (̊̊) & 0.71073 & 0.71073 \\
\hline Sistema cristalográfico & Triclínico & Triclínico \\
\hline Grupo espacial & $-\mathrm{P} 1$ & $-\mathrm{P} 1$ \\
\hline \multicolumn{3}{|l|}{$\begin{array}{c}\text { Dimensiones celda } \\
\text { unidad }\end{array}$} \\
\hline $\mathbf{a}(\AA)$ & $8.2931(4)$ & $8.4557(2)$ \\
\hline b $(\AA)$ & $9.4865(4)$ & $9.43955(3)$ \\
\hline c $(\AA)$ & $14.5255(6)$ & $19.0964(6)$ \\
\hline$\alpha\left({ }^{\circ}\right)$ & $73.744(3)$ & $94.6652(17)$ \\
\hline
\end{tabular}


Capítulo 4. Complejos de Cobalto para la hidrosililación de alquenos en condiciones aeróbicas.

\begin{tabular}{|c|c|c|}
\hline$\beta\left(\left(^{\circ}\right)\right.$ & $85.034(3)$ & $93.9726(16)$ \\
\hline$\gamma\left({ }^{\circ}\right)$ & $66.775(2)$ & $95.9626(16)$ \\
\hline Volumen $(\AA ̊)$ & $1007.65(8)$ & $1506.31(8)$ \\
\hline $\mathbf{Z}$ & 2 & 2 \\
\hline Densidad (calculada) & 1.471 & 1.535 \\
\hline $\begin{array}{c}\text { Coeficiente de } \\
\text { absorción }\end{array}$ & 0.892 & 0.802 \\
\hline F (000) & 462 & 714 \\
\hline Tamaño de cristal & $0.377 \times 0.352 \times 0.090$ & $0.330 \times 0.160 \times 0.020$ \\
\hline $\begin{array}{l}\text { Rango theta para la } \\
\text { recopilación de datos }\end{array}$ & $2.426-27.518^{\circ}$ & $2.147-26.420^{\circ}$ \\
\hline Rango index & $\begin{array}{c}-10 \leq \mathrm{h} \leq 10,-12 \leq \mathrm{k} \leq 12 \\
-17 \leq 1 \leq 18\end{array}$ & $\begin{array}{c}-10 \leq \mathrm{h} \leq 10,-11 \leq \mathrm{k} \leq 11, \\
-23 \leq 1 \leq 23\end{array}$ \\
\hline Reflexiones recogidas & 16436 & 39813 \\
\hline $\begin{array}{c}\text { Reflexiones } \\
\text { independientes }\end{array}$ & 4627 & 6171 \\
\hline Goodness-of-fit on F2 & 1.043 & 1.044 \\
\hline $\begin{array}{c}\text { Indices R finales } \\
{[\quad[\mathbf{I}>2 \sigma(I)]}\end{array}$ & $\mathrm{R}_{1}=0.035 w \mathrm{R}_{2}=0.075$ & $\mathrm{R}_{1}=0.048 w \mathrm{R}_{2}=0.131$ \\
\hline Índices $\mathbf{R}$ & $\mathrm{R}_{1}=0.049 \mathrm{wR}_{2}=0.069$ & $\mathrm{R}_{1}=0.073 w \mathrm{R}_{2}=0.116$ \\
\hline
\end{tabular}


Tabla 4.8. Distancias y ángulos de enlace más importantes para el complejo $\mathbf{1 b .}$

\begin{tabular}{llll}
\hline \multicolumn{4}{c}{ Distancias de enlace (A $\left.{ }^{\circ}\right)$} \\
\hline $\mathrm{Co}(1)-\mathrm{N}(1)$ & $2.1596(15)$ & $\mathrm{Co}(1)-\mathrm{N}(11)$ & $2.1700(16)$ \\
$\mathrm{Co}(1)-\mathrm{N}(21)$ & $2.0686(15)$ & $\mathrm{Co}(1)-\mathrm{OW}(1)$ & $2.0695(14)$ \\
$\mathrm{Co}(1)-\mathrm{OW}(2)$ & $2.0493(13)$ & $\mathrm{Co}(1)-\mathrm{O}(31)$ & $2.1032(13)$ \\
\hline \multicolumn{4}{c}{ Ángulos de enlace $\left(^{\mathbf{0}}\right)$} \\
\hline $\mathrm{N}(1)-\mathrm{Co}(1)-\mathrm{N}(11)$ & $151.65(6)$ & $\mathrm{N}(1)-\mathrm{Co}(1)-\mathrm{N}(21)$ & $75.73(6)$ \\
$\mathrm{N}(1)-\mathrm{Co}(1)-\mathrm{OW}(1)$ & $93.66(6)$ & $\mathrm{N}(1)-\mathrm{Co}(1)-\mathrm{OW}(2)$ & $100.64(6)$ \\
$\mathrm{N}(1)-\mathrm{Co}(1)-\mathrm{O}(31)$ & $90.17(5)$ & $\mathrm{N}(11)-\mathrm{Co}(1)-\mathrm{N}(21)$ & $75.93(6)$ \\
$\mathrm{N}(11)-\mathrm{Co}(1)-\mathrm{OW}(1)$ & $88.13(6)$ & $\mathrm{N}(11)-\mathrm{Co}(1)-\mathrm{OW}(2)$ & $107.70(6)$ \\
$\mathrm{N}(11)-\mathrm{Co}(1)-\mathrm{O}(31)$ & $90.55(6)$ & $\mathrm{N}(21)-\mathrm{Co}(1)-\mathrm{OW}(1)$ & $92.13(6)$ \\
$\mathrm{N}(21)-\mathrm{Co}(1)-\mathrm{OW}(2)$ & $175.51(6)$ & $\mathrm{N}(21)-\mathrm{Co}(1)-\mathrm{O}(31)$ & $93.00(5)$ \\
$\mathrm{OW}(1)-\mathrm{Co}(1)-\mathrm{OW}(2)$ & $85.42(6)$ & $\mathrm{OW}(1)-\mathrm{Co}(1)-\mathrm{O}(31)$ & $174.22(5)$ \\
$\mathrm{OW}(2)-\mathrm{Co}(1)-\mathrm{O}(31)$ & $89.63(5)$ & & \\
\hline
\end{tabular}


Tabla 4.9. Distancias y ángulos de enlace más importantes para el complejo 2c.

\begin{tabular}{llll}
\hline \multicolumn{4}{c}{ Distancias de enlace $(\AA)$} \\
\hline $\mathrm{Co}(1)-\mathrm{N}(1)$ & $1.896(3)$ & $\mathrm{Co}(1)-\mathrm{N}(11)$ & $2.090(2)$ \\
$\mathrm{Co}(1)-\mathrm{N}(21)$ & $2.095(2)$ & $\mathrm{Co}(1)-\mathrm{N}(51)$ & $2.054(3)$ \\
$\mathrm{Co}(1)-\mathrm{N}(41)$ & $2.053(3)$ & $\mathrm{Co}(1)-\mathrm{N}(51)$ & $2.054(3)$ \\
\hline \multicolumn{4}{c}{ Ángulos de enlace () } \\
\hline $\mathrm{N}(1)-\mathrm{Co}(1)-\mathrm{N}(11)$ & $79.73(10)$ & $\mathrm{N}(1)-\mathrm{Co}(1)-\mathrm{N}(21)$ & $79.77(10)$ \\
$\mathrm{N}(1)-\mathrm{Co}(1)-\mathrm{N}(31)$ & $176.14(11)$ & $\mathrm{N}(1)-\mathrm{Co}(1)-\mathrm{N}(41)$ & $100.94(11)$ \\
$\mathrm{N}(1)-\mathrm{Co}(1)-\mathrm{N}(51)$ & $98.28(11)$ & $\mathrm{N}(11)-\mathrm{Co}(1)-\mathrm{N}(21)$ & $159.49(11)$ \\
$\mathrm{N}(11)-\mathrm{Co}(1)-\mathrm{N}(31)$ & $96.58(11)$ & $\mathrm{N}(11)-\mathrm{Co}(1)-\mathrm{N}(41)$ & $94.98(9)$ \\
$\mathrm{N}(11)-\mathrm{Co}(1)-\mathrm{N}(51)$ & $89.41(10)$ & $\mathrm{N}(21)-\mathrm{Co}(1)-\mathrm{N}(31)$ & $103.93(11)$ \\
$\mathrm{N}(21)-\mathrm{Co}(1)-\mathrm{N}(41)$ & $88.45(9)$ & $\mathrm{N}(21)-\mathrm{Co}(1)-\mathrm{N}(51)$ & $93.98(9)$ \\
$\mathrm{N}(31)-\mathrm{Co}(1)-\mathrm{N}(41)$ & $80.43(11)$ & $\mathrm{N}(31)-\mathrm{Co}(1)-\mathrm{N}(51)$ & $80.46(11)$ \\
$\mathrm{N}(41)-\mathrm{Co}(1)-\mathrm{N}(51)$ & $160.75(11)$ & & \\
\hline
\end{tabular}




\section{Espectrometría de masas por ionización de electrospray}

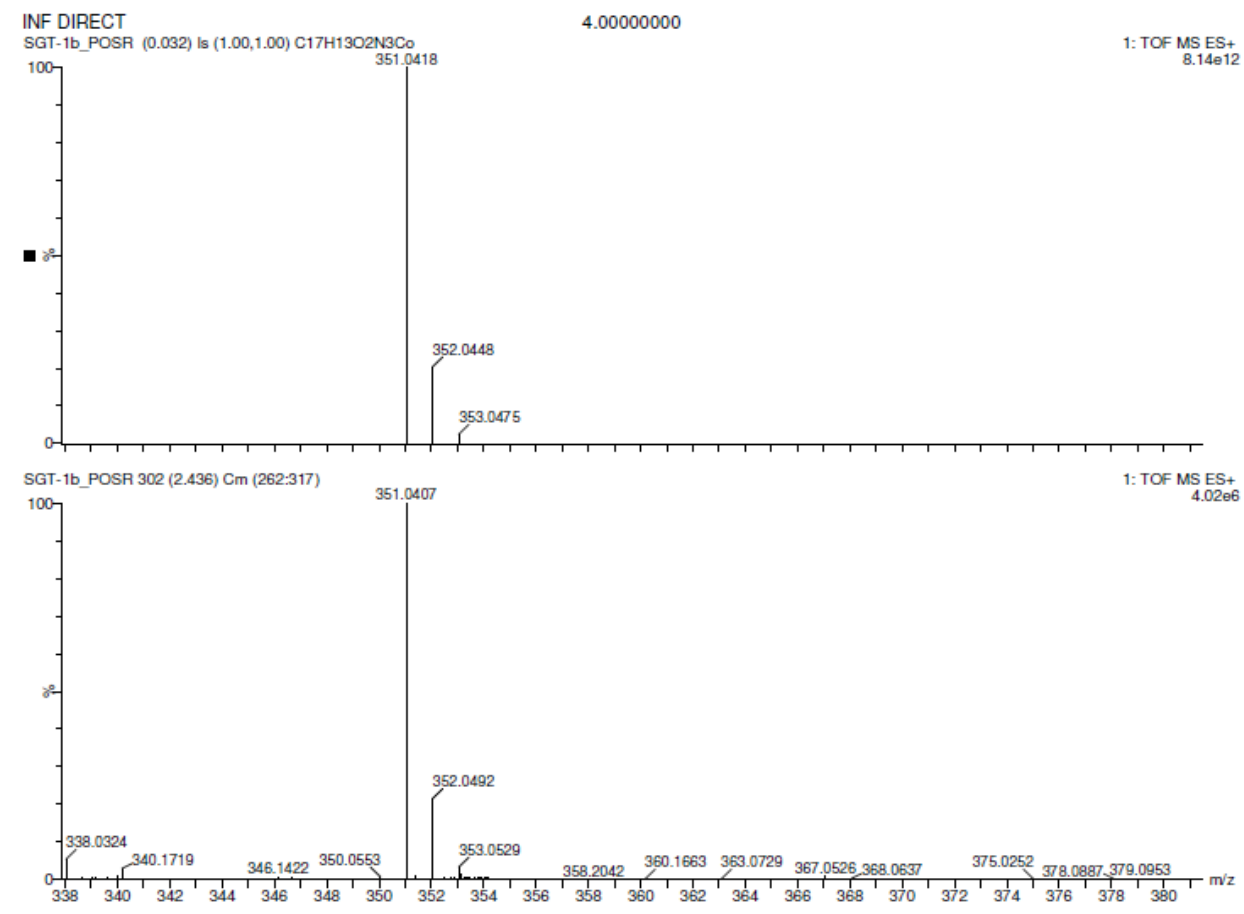

Figura 4.12. Espectro ESI del complejo 1b que corresponde a la fórmula $\mathrm{C}_{17} \mathrm{H}_{13} \mathrm{~N}_{3} \mathrm{O}_{2} \mathrm{Co}$. Espectro simulado (arriba), espectro experimental (abajo). 


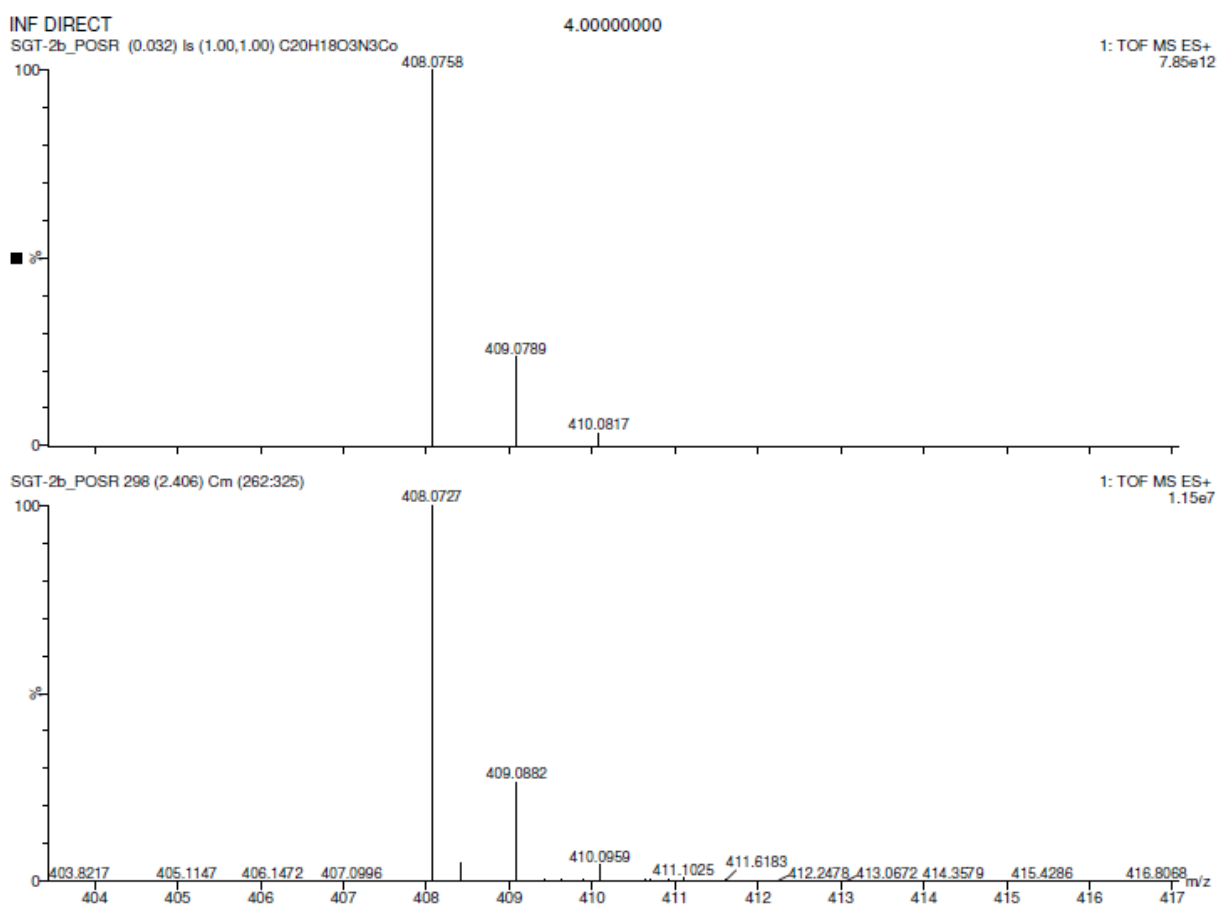

Figura 4.13. Espectro ESI del complejo 2b que corresponde a la fórmula $\mathrm{C}_{20} \mathrm{H}_{18} \mathrm{~N}_{3} \mathrm{O}_{3} \mathrm{Co}$. Espectro simulado (arriba), espectro experimental (abajo). 


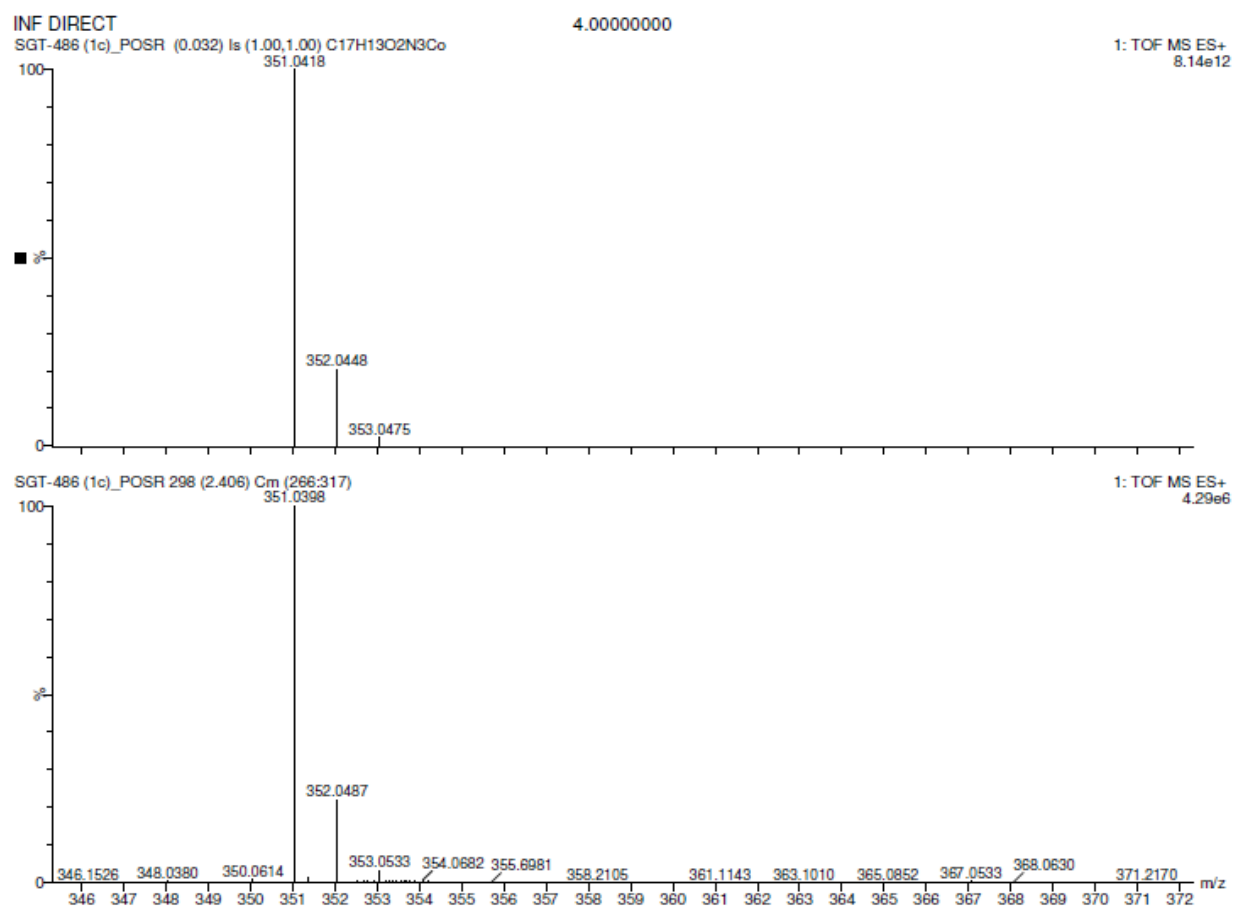

Figura 4.14. Espectro ESI del complejo 1b aislado que corresponde a la fórmula $\mathrm{C}_{17} \mathrm{H}_{13} \mathrm{~N}_{3} \mathrm{O}_{2}$ Co. Espectro simulado (arriba), espectro experimental (abajo). 


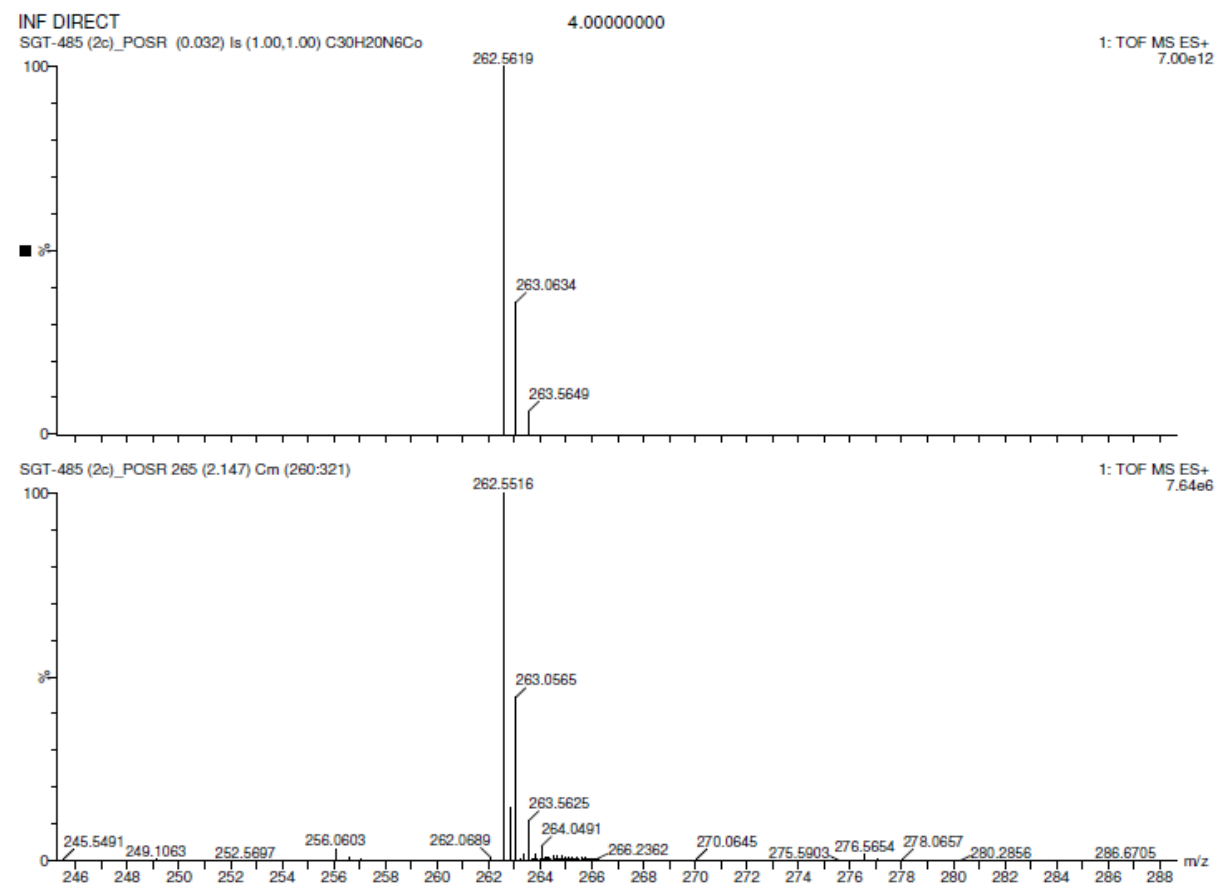

Figura 4.15. Espectro ESI del complejo 2c aislado que corresponde a la fórmula $\mathrm{C}_{30} \mathrm{H}_{20} \mathrm{~N}_{6} \mathrm{Co}$. Espectro simulado (arriba), espectro experimental (abajo). 


\section{Espectroscopía de absorción UV/Vis}

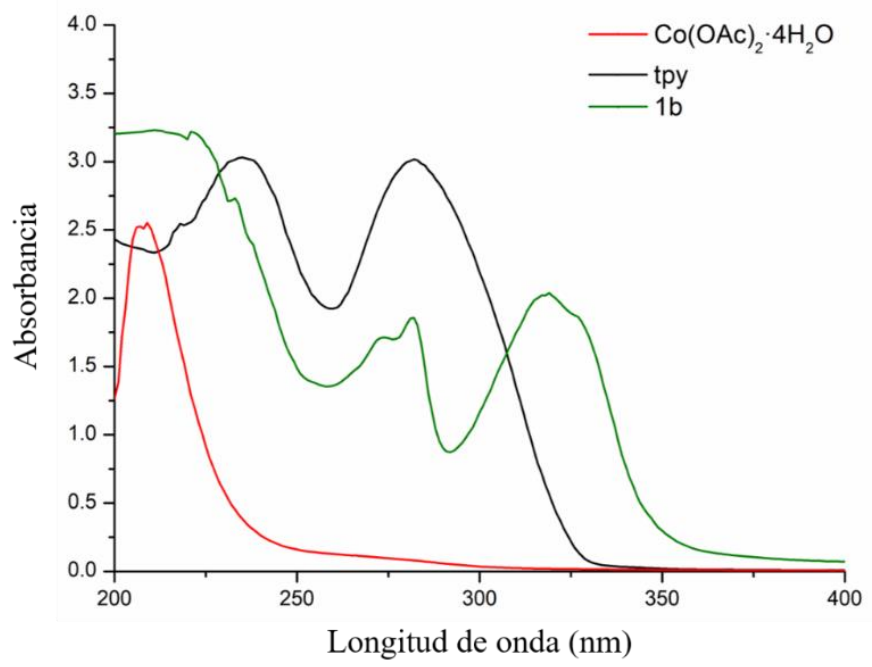

Figura 4.16. Espectro de absorción UV/Vis del $\mathrm{Co}(\mathrm{OAc})_{2} \cdot 4 \mathrm{H}_{2} \mathrm{O}(0.825 \mathrm{mg} / \mathrm{mL})$, terpiridina $(0.026 \mathrm{mg} / \mathrm{mL})$ y el complejo $\mathbf{1 b}(0.054 \mathrm{mg} / \mathrm{mL})$ en metanol.

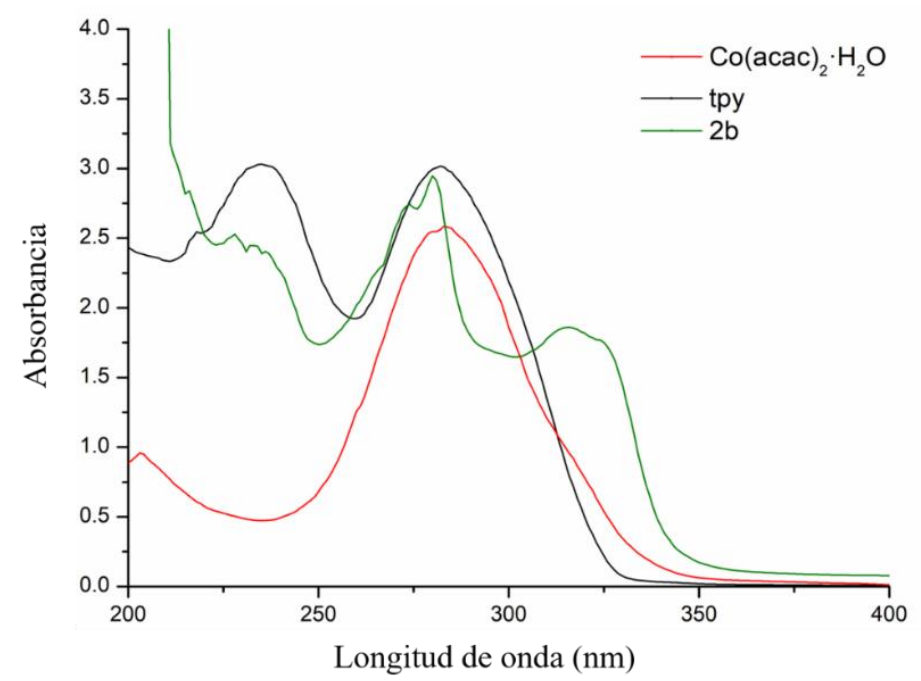

Figura 4.17. Espectro de absorción UV/Vis del $\mathrm{Co}(\mathrm{acac})_{2} \cdot \mathrm{H}_{2} \mathrm{O}(0.029 \mathrm{mg} / \mathrm{mL})$, terpiridina $(0.026 \mathrm{mg} / \mathrm{mL})$ y el complejo $\mathbf{2 b}(0.027 \mathrm{mg} / \mathrm{mL})$ en metanol. 


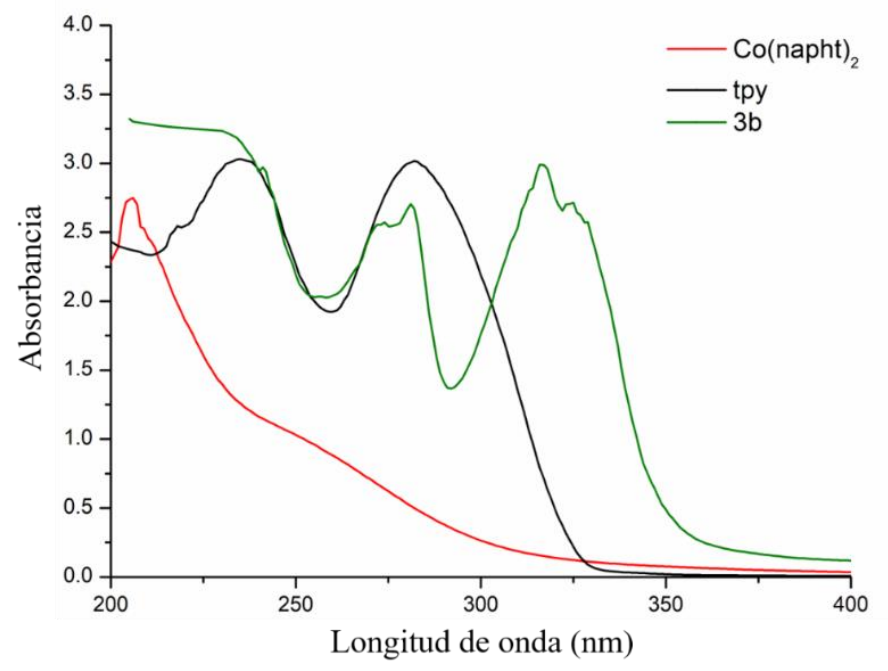

Figura 4.18. Espectro de absorción UV/Vis del Co(napht $)_{2}(1.310 \mathrm{mg} / \mathrm{mL})$, terpiridina $(0.026$ $\mathrm{mg} / \mathrm{mL})$ y el complejo $3 \mathbf{b}(0.092 \mathrm{mg} / \mathrm{mL})$ en metanol.

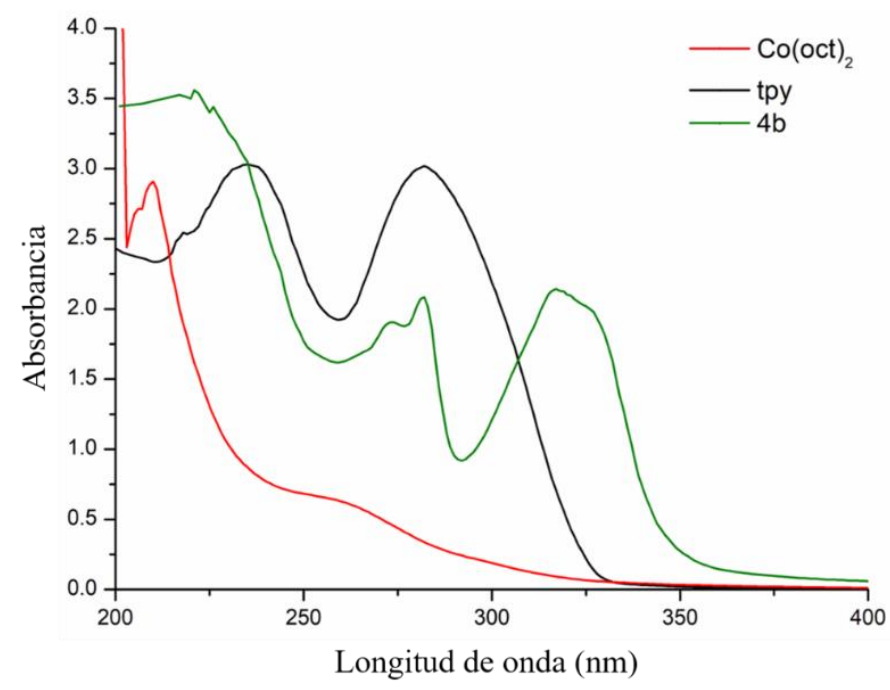

Figura 4.19. Espectro de absorción UV/Vis del $\operatorname{Co}(\mathrm{oct})_{2}(0.612 \mathrm{mg} / \mathrm{mL})$, terpiridina $(0.026$ $\mathrm{mg} / \mathrm{mL})$ y el complejo $\mathbf{4 b}(0.103 \mathrm{mg} / \mathrm{mL})$ en metanol. 


\subsubsection{Procedimiento de las reacciones catalíticas.}

\subsubsection{Optimización de las condiciones de reacción.}

Tabla 4.10. Optimización de las condiciones de reacción con el precatalizador de cobalto 3a y el ligando tpy en la reacción de hidrosililación del 4-vinilciclohexeno con $\mathrm{PhSiH}_{3}$.

\begin{tabular}{|c|c|c|c|c|}
\hline Entrada & $\mathrm{Co}(\%)$ & Tiempo (h) & Disolvente & $\begin{array}{c}\text { Conversión } \\
(\%)^{[\mathrm{b}]}\end{array}$ \\
\hline 1 & 1 & 24 & THF & $>99$ \\
\hline 2 & 0.1 & 16 & THF & $>99$ \\
\hline 3 & 0.1 & 8 & THF & $>99$ \\
\hline 4 & 0.1 & 3 & THF & $>99$ \\
\hline 5 & 0.01 & 3 & THF & 21 \\
\hline 6 & 0.1 & 16 & $\mathrm{CHCl}_{3}$ & 50 \\
\hline 7 & 0.2 & 16 & $\mathrm{CH}_{2} \mathrm{Cl}_{2}$ & $<1$ \\
\hline \multicolumn{5}{|c|}{$\begin{array}{l}{ }^{[a]} \text { Todas las reacciones se llevaron a cabo usando } 0.89 \mathrm{mmol} \text { de silano y olefina en condiciones } \\
\text { aeróbicas. La mezcla del precursor de cobalto con el ligando correspondiente se preparc } \\
\text { previamente. }{ }^{[b]} \text { Determinada por análisis de de }{ }^{1} \mathrm{H}-\mathrm{RMN} \text { del crudo de reacción. }\end{array}$} \\
\hline
\end{tabular}

\subsubsection{Procedimiento general para las reacciones de hidrosililación catalizadas.}

Método A: A un vial de reacción equipado con un agitador magnético se le añaden 0.2 $\mathrm{mL}$ de la disolución del catalizador correspondiente (0.001 equivalentes), seguido de la olefina (1 equivalente) y el silano (1 equivalente), lo que resulta en la formación de una mezcla de reacción que cambia de naranja a negro inmediatamente. El vial se sella con una tapa y se agita a la temperatura indicada en cada caso. Al terminar la reacción, se añade n-hexano al crudo de reacción y se filtra el catalizador. A continuación, se elimina el n-hexano en el rotavapor y se analiza una alícuota por ${ }^{1} \mathrm{H}-\mathrm{RMN}$ en $\mathrm{CDCl}_{3}$. 
Método B: A un vial de reacción equipado con un agitador magnético se le añaden 0.2 $\mathrm{mL}$ de la disolución del catalizador correspondiente (0.001 equivalentes), seguido de la olefina ( 2 equivalentes) y el silano (1 equivalente), lo que resulta en la formación de una mezcla de reacción que cambia de naranja a negro inmediatamente. El vial se sella con una tapa y se agita a la temperatura indicada en cada caso. Al terminar la reacción, se añade n-hexano al crudo de reacción y se filtra el catalizador. A continuación, se elimina el n-hexano en el rotavapor y se analiza una alícuota por ${ }^{1} \mathrm{H}-\mathrm{RMN}$ en $\mathrm{CDCl}_{3}$.

\subsubsection{Estudio cinético para la hidrosililación de 4-vinilciclohexeno con $\mathrm{PhSiH}_{3}$.}

Método C: El catalizador aislado (0.001 equivalentes) se disuelve en $0.2 \mathrm{~mL}$ de THF y se añade a un vial equipado con un agitador magnético. A continuación, se añade el 4vinilciclohexeno ( $96.4 \mathrm{mg}, 0.89 \mathrm{mmol}$ ), el fenilsilano ( $96.3 \mathrm{mg}, 0.89 \mathrm{mmol}$ ) y mesetileno como patrón interno $(107 \mathrm{mg}, 0.89 \mathrm{mmol})$. Se sella el vial con una tapa y se agita la reacción a temperatura ambiente. Cada 30 minutos se extrae una alícuota del crudo de reacción que se analiza por ${ }^{1} \mathrm{H}-\mathrm{RMN}$ en $\mathrm{CDCl}_{3}$.

Método D: $0.2 \mathrm{~mL}$ de disolución del catalizador fresco (0.001 equivalentes) se añaden a un vial equipado con un agitador magnético. A continuación, se añade el 4vinilciclohexeno ( $96.4 \mathrm{mg}, 0.89 \mathrm{mmol}$ ), el fenilsilano ( $96.3 \mathrm{mg}, 0.89 \mathrm{mmol}$ ) y mesetileno como patrón interno (107 mg, $0.89 \mathrm{mmol})$. Se sella el vial con una tapa y se agita la reacción a temperatura ambiente. Cada 30 minutos se extrae una alícuota del crudo de reacción que se analiza por ${ }^{1} \mathrm{H}-\mathrm{RMN}$ en $\mathrm{CDCl}_{3}$ (Figura 4.20).

Método E: En un tubo de RMN se añaden $0.2 \mathrm{~mL}$ de la disolución del catalizador en THF-d ${ }^{8}$ seguido de 4-vinilciclohexeno ( $96.3 \mathrm{mg}, 0.89 \mathrm{mmol}$ ), fenilsilano (96.3 mg, 0.89 mmol) y mesetileno $(107 \mathrm{mg}, 0.89 \mathrm{mmol})$. La reacción se lleva a cabo dentro del espectrómetro de RMN (Tabla 4.11, Figura 4.20). 

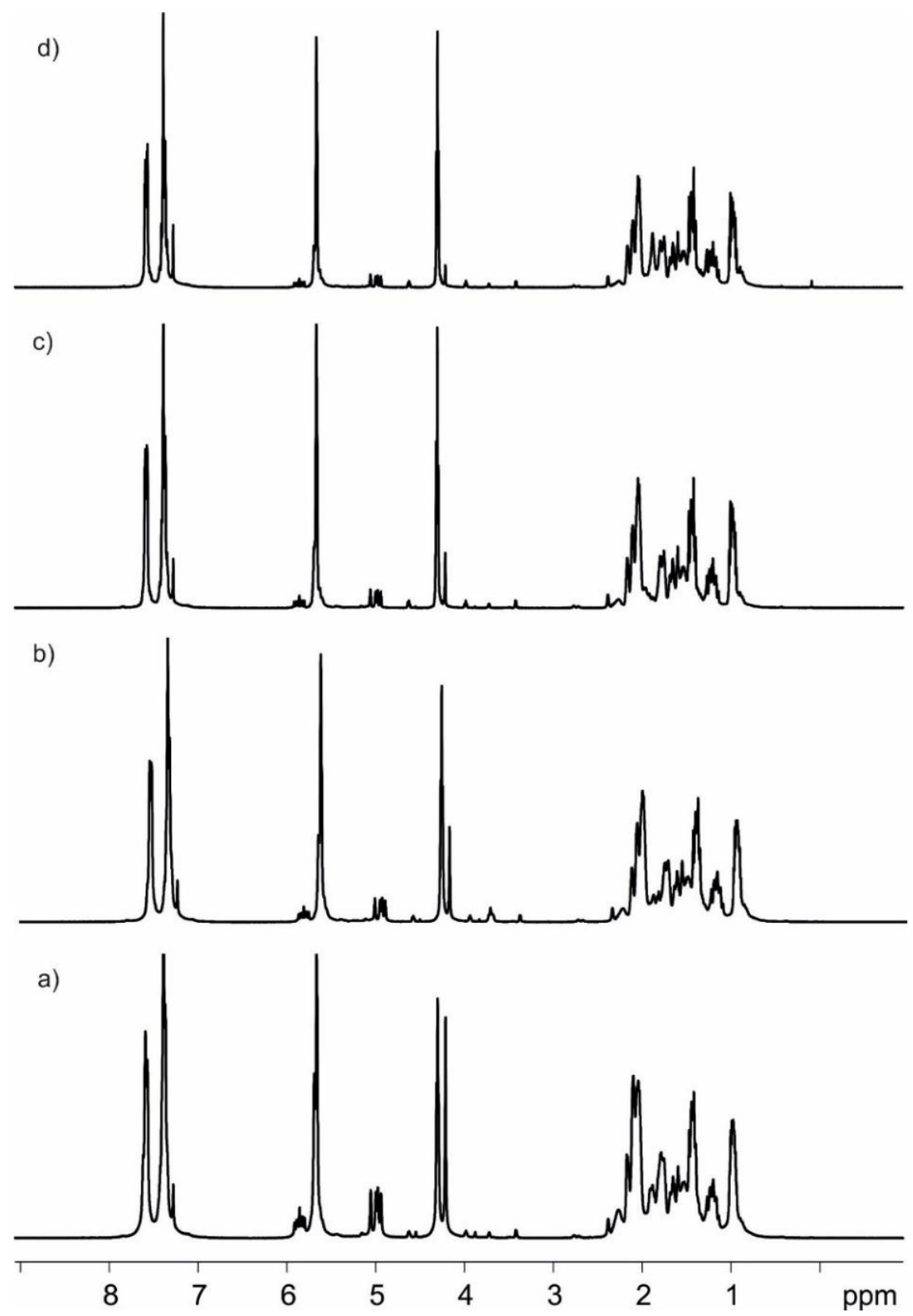

Figura 4.20. ${ }^{1} \mathrm{H}-\mathrm{RMN}$ del crudo de reacción de 4-vinilciclohexeno y $\mathrm{PhSiH}_{3}$ catalizada por el precatalizador $\mathbf{3 b}$ cada 30 minutos, a) $30 \mathrm{~min}$; b) $60 \mathrm{~min}$; c) $90 \mathrm{~min}$; d) $120 \mathrm{~min}$. 
Tabla 4.11. Evaluación de los precatalizadores de cobalto en la reacción de hidrosililación del 4-vinilciclohexeno con $\mathrm{PhSiH}_{3}$ por ${ }^{1} \mathrm{H}$-RMN in-situ.

\begin{tabular}{|c|c|c|c|c|}
\hline Entrada & $\begin{array}{c}\text { Precatalizador de } \\
\text { Co(II) }\end{array}$ & $\begin{array}{c}\text { Tiempo } \\
(\mathrm{min})\end{array}$ & $\begin{array}{c}\text { Conversión } \\
(\%)\end{array}$ & $\mathrm{TOF}\left(\mathrm{min}^{-1}\right)$ \\
\hline 1 & $2 b$ & 240 & 96 & $13.3^{[\mathrm{a}]}$ \\
\hline 2 & $3 b$ & 240 & 98 & $16^{[\mathrm{a}]}$ \\
\hline 3 & $4 b$ & 240 & 91 & $9^{[a]}$ \\
\hline
\end{tabular}

[a]TOF calculado a los 30 minutos desde el comienzo de la reacción.

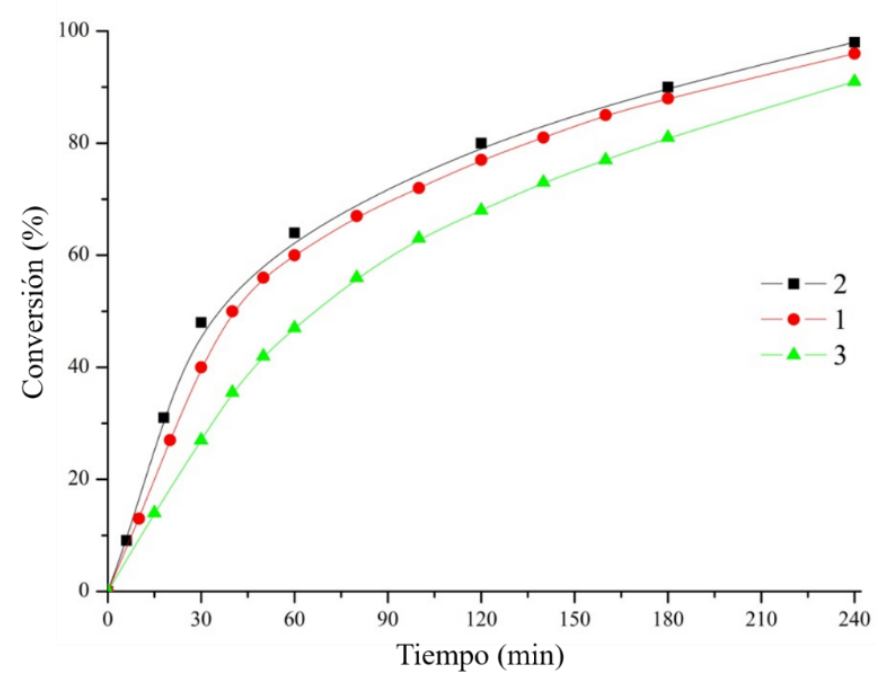

Figura 4.21. Estudio cinético de la reacción de hidrosililación de 4-vinilciclohexeno con $\mathrm{PhSiH}_{3}$ para la evaluación de los precatalizadores de cobalto por ${ }^{1} \mathrm{H}-\mathrm{RMN}$ in-situ. Los números de la figura se corresponden con las entradas de la Tabla 4.11. 
4.5.3.4. Procedimiento para la reacción de hidrosililación del 1-octeno con (EtO) ${ }_{3} \mathrm{SiH}$ escalada a $10 \mathrm{~g}$.

A un matraz equipado con un agitador magnético se añaden $20 \mathrm{~mL}$ de la disolución del catalizador fresco (0.001 equivalentes), seguido del 1-octeno (10g, $89 \mathrm{mmol}$ ) y trietoxisilano (14.62 g, $89 \mathrm{mmol})$. El matraz se sella con una tapa y se agita durante 3 horas a $50^{\circ} \mathrm{C}$, que resulta en la formación de una disolución oscura tras la adicción del silano. Con el fin de calcular el rendimiento aislado, en primer lugar, se evapora el THF. A continuación, se añade n-hexano a la mezcla de reacción y se filtra el catalizador. Finalmente, se elimina el disolvente y se pesa el producto de reacción. (Rendimiento $97 \%)$.

\subsubsection{Síntesis de los polímeros de entrecruzamiento de siliconas.}

Para la síntesis de los polímeros de silicona, $0.1 \mathrm{~mL}$ de la disolución del catalizador fresco (0.00025 equivalentes) se añaden a un vial equipado con un agitador magnético. A continuación, se añade tetravinilsilano (1 equivalente, $250.1 \mathrm{mg}, 1.78 \mathrm{mmoles}$ ) y 1,1,3,3-tetrametildisiloxano (2 equivalentes, $478.2 \mathrm{mg}, 3.56$ mmoles). El vial se sella con una tapa y se agita a $80^{\circ} \mathrm{C}$. A las 4 horas, se observa la formación de un gel claro y sin color. El vial se abre y el polímero resultante se rompe con una espátula para comprobar el color y la consistencia del producto obtenido.

4.5.3.6. Caracterización de los productos de reacción.

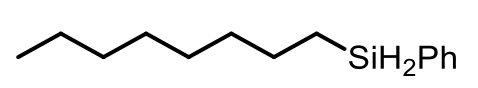

Fenil(octil)silano (5a). Se prepara siguiendo el método

A usando $0.1 \%$ del catalizador, 1-octeno $(100 \mathrm{mg}, 0.89$ mmol) y fenilsilano $(96.3 \mathrm{mg}, 0.89 \mathrm{mmol}) .{ }^{1} \mathrm{H} \mathrm{RMN}\left(300 \mathrm{MHz}, \mathrm{CDCl}_{3}\right) \delta=7.60(\mathrm{~m}$, 2H), 7.41-7.39 (t, $J=3.7 \mathrm{~Hz}, 3 \mathrm{H}), 4.33(\mathrm{t}, J=3.6 \mathrm{~Hz}, 2 \mathrm{H}), 1.50(\mathrm{~m}, 2 \mathrm{H}), 1.39-1.30(\mathrm{~m}$, $10 \mathrm{H}), 1.11(\mathrm{~m}, 2 \mathrm{H}), 0.92(\mathrm{t}, J=7.0 \mathrm{~Hz}, 3 \mathrm{H}) .{ }^{13} \mathrm{C} \mathrm{RMN}(75 \mathrm{MHz}, \mathrm{CDCl} 3): \delta=135.21$, $132.85,129.45,127.94,127.88,32.83,31.89,29.23,29.20,25.09,22.67,14.08,10.02$. Los espectros están en consonancia con la literatura. ${ }^{48}$

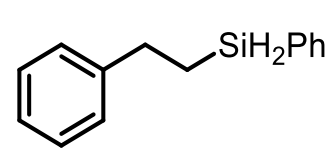

Fenil(feniletil)silano (5b). Se prepara siguiendo el método A usando $0.1 \%$ mol del catalizador, estireno (92.7 $\mathrm{mg}, 0.89 \mathrm{mmol}$ ) y fenilsilano (96.3 mg, $0.89 \mathrm{mmol})$. ¡Precaución! La adicción del silano produce una reacción exhotérmica y tiene que ser añadido a $0^{\circ} \boldsymbol{C} .{ }^{1} \mathrm{H} \mathrm{RMN}\left(300 \mathrm{MHz}, \mathrm{CDCl}_{3}\right): \delta=7.49-7.46(\mathrm{~m}, 2 \mathrm{H}), 7.29-7.26(\mathrm{~m}, 3 \mathrm{H})$, 7.18-7.16 (m, 2H), 7.11-7.08 (m, 3H), 4.26 (t, $J=3.6 \mathrm{~Hz}, 2 \mathrm{H}), 2.71-2.65$ (m, 2H), 1.19$1.18(\mathrm{~m}, 2 \mathrm{H}) .{ }^{13} \mathrm{C} \mathrm{RMN}(75 \mathrm{MHz}, \mathrm{CDCl} 3): \delta=144.00,135.29,132.20,129.68,128.41$, 
$128.08,127.94,125.85,31.16,12.14$. Los espectros están en consonancia con la literatura. ${ }^{49}$

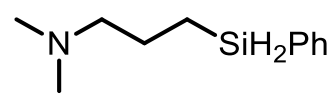

N,N-dimetil-(fenilsilil)propan-1-amina (5c). Se prepara siguiendo el método A, usando $0.1 \%$ mol del catalizador, $\mathrm{N}, \mathrm{N}$ dimetilalilamina $(75.8 \mathrm{mg}, 0.89 \mathrm{mmol})$ y fenilsilano $(96.3 \mathrm{mg}$, $0.89 \mathrm{mmol}) .{ }^{1} \mathrm{H} \mathrm{RMN}\left(300 \mathrm{MHz}, \mathrm{CDCl}_{3}\right): \delta=7.60-7.57(\mathrm{~m}, 2 \mathrm{H}), 7.39-7.36(\mathrm{~m}, 3 \mathrm{H})$, $4.33(\mathrm{t}, J=3.6 \mathrm{~Hz}, 2 \mathrm{H}), 2.31(\mathrm{t}, J=7.3 \mathrm{~Hz}, 2 \mathrm{H}), 2.21(\mathrm{~s}, 6 \mathrm{H}), 1.64-1.61(\mathrm{~m}, 2 \mathrm{H}), 0.99-$ 0.93 (m, 2H). ${ }^{13} \mathrm{C}$ RMN (75 MHz, CDCl3): $\delta=135.13,133.00,129.45,127.94,62.24$, $45.39,23.17,7.86$. Los espectros están en consonancia con la literatura. ${ }^{24}$

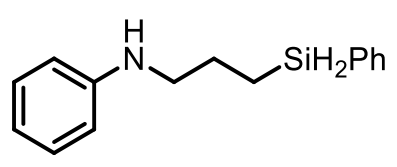

$\mathbf{N}$-(3-(fenilsilil)propil)anilina (5d). Se prepara siguiendo el método A, usando $0.1 \%$ mol del catalizador, N,N-alilanilina (124.8 mg, $0.89 \mathrm{mmol})$ y fenilsilano $(96.3 \mathrm{mg}, 0.89$ mmol). ${ }^{1} \mathrm{H}$ RMN $\left(300 \mathrm{MHz}, \mathrm{CDCl}_{3}\right): \delta=7.67-7.64(\mathrm{~m}$, 2H), 7.47-7.44 (m, 3H), 7.24-7.22 (m, 2H), $6.77(\mathrm{t}, J=7.5 \mathrm{~Hz}, 1 \mathrm{H}), 6.64(\mathrm{~d}, J=7.5 \mathrm{~Hz}$, $2 \mathrm{H}), 4.43(\mathrm{t}, J=3.6 \mathrm{~Hz}, 2 \mathrm{H}), 3.62(\mathrm{bs}, 1 \mathrm{H}), 3.21(\mathrm{t}, J=7 \mathrm{~Hz}, 2 \mathrm{H}), 1.86-1.81(\mathrm{~m}, 2 \mathrm{H})$, 1.13-1.09 (m, 2H). ${ }^{13} \mathrm{C}$ RMN (75 MHz, CDCl3): $\delta=148.33,135.26,132.23,129.76$, 129.30, 128.14, 117.27, 112.81, 46.45, 25.18, 7.66. GC-MS: calculado para $\mathrm{C}_{15} \mathrm{H}_{19} \mathrm{NSi}$ 241.4. Experimental: 241.1.<smiles>CC(=O)OCC[SiH2]c1ccccc1</smiles>

Acetato de 2-(phenilsilil)etilo (5e). Se prepara siguiendo el método A, usando $0.1 \%$ mol del catalizador, acetato de vinilo (76.6 $\mathrm{mg}, 0.89 \mathrm{mmol})$ y fenilsilano $(96.3 \mathrm{mg}, 0.89 \mathrm{mmol}) .{ }^{1} \mathrm{H} \mathrm{RMN}$ $\left(300 \mathrm{MHz}, \mathrm{CDCl}_{3}\right): \delta=7.51-7.48(\mathrm{~m}, 2 \mathrm{H}), 7.32-7.28(\mathrm{~m}, 3 \mathrm{H}), 4.26(\mathrm{t}, J=3.6 \mathrm{~Hz}, 2 \mathrm{H})$, 4.19-4.14 (m, 2H), 1.90 (s, 3H), 1.36-1.30 (m, 2H). ${ }^{13} \mathrm{C} \mathrm{RMN} \mathrm{(75} \mathrm{MHz,} \mathrm{CDCl3):} \delta=$ 170.97, 135.18, 131.05, 129.90, 128.14, 62.13, 20.87, 11.24. GC-MS: calculado para $\mathrm{C}_{10} \mathrm{H}_{15} \mathrm{O}_{2} \mathrm{Si}$ 194.3. Experimental: 194.1.

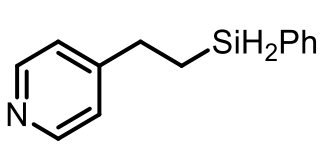

1-(4'-piridil)-2-(fenilsilil)etano (5f). Se prepara siguiendo el método $\mathrm{A}$, usando $0.1 \%$ mol del catalizador, 4-vinilpiridina (98.5 mg, $0.89 \mathrm{mmol})$ y fenilsilano $(96.3 \mathrm{mg}, 0.89 \mathrm{mmol}) .{ }^{1} \mathrm{H}$ RMN (300 MHz, $\left.\mathrm{CDCl}_{3}\right): \delta=8.49-8.48(\mathrm{~m}, 2 \mathrm{H}), 7.59-7.56(\mathrm{~m}$, 2H), 7.42-7.39 (m, 3H), 7.12-7.11 (m, 2H), 4.36 (t, $J=3.6 \mathrm{~Hz}, 2 \mathrm{H}), 2.79-2.73(\mathrm{~m}, 2 \mathrm{H})$, 1.28 (m, 2H). ${ }^{13} \mathrm{C}$ RMN (75 MHz, CDCl3): $\delta=152.66,149.71,135.20,131.48,129.87$, $128.15,123.31,30.44,10.92$. Los espectros están en consonancia con la literatura. ${ }^{50}$ 
<smiles>COC(=O)CC[SnH2]c1ccccc1</smiles>

2-(fenilsilil)propanoato de metilo (5h). Se prepara siguiendo el método A, usando $0.1 \%$ mol del catalizador, metil vinil cetona (62.4 mg, $0.89 \mathrm{mmol}$ ) y fenilsilano (96.3 mg, $0.89 \mathrm{mmol}$ ). añadido a $0^{\circ} \boldsymbol{C} .{ }^{1} \mathrm{H} \mathrm{RMN}\left(300 \mathrm{MHz}, \mathrm{CDCl}_{3}\right): \delta=7.61-7.57(\mathrm{~m}, 2 \mathrm{H}), 7.42-7.38(\mathrm{~m}, 3 \mathrm{H})$, $4.35(\mathrm{t}, J=3.6 \mathrm{~Hz}, 2 \mathrm{H}), 3.67(\mathrm{~s}, 3 \mathrm{H}), 2.46(\mathrm{t}, J=8.1 \mathrm{~Hz}, 2 \mathrm{H}), 1.30-1.25(\mathrm{~m}, 2 \mathrm{H}) .{ }^{13} \mathrm{C}$ $\mathrm{RMN}\left(75 \mathrm{MHz}, \mathrm{CDCl}_{3}\right): \delta=174.51,135.22,131.54,129.81,128.09,51.62,29.51,5.39$. GC-MS: calculado para $\mathrm{C}_{10} \mathrm{H}_{14} \mathrm{O}_{2} \mathrm{Si}$ 194.3. Experimental: 194.1.

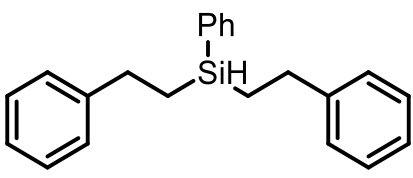

$(\mathrm{q}, J=3.4 \mathrm{~Hz}, 1 \mathrm{H}), 2.63-2.57(\mathrm{~m}, 2 \mathrm{H}), 1.17-1.13(\mathrm{~m}, 2 \mathrm{H}) .{ }^{13} \mathrm{C} \mathrm{RMN}\left(75 \mathrm{MHz}, \mathrm{CDCl}_{3}\right)$ : $\delta=144.49,134.92,134.78,129.53,128.42,128.08,127.91,125.79,30.63,14.00$. Los espectros están en consonancia con la literatura. ${ }^{50}$

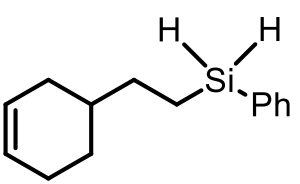

(2-(ciclohex-3-en-1-il)etill)(fenil)silano (5l). Se prepara siguiendo el método $\mathrm{A}$, usando $0.1 \%$ mol del catalizador, 4-vinilciclohexeno (96.3 mg, $0.89 \mathrm{mmol})$ y fenilsilano (96.3 $\mathrm{mg}, 0.89$ mmol). ${ }^{1} \mathrm{H}$ RMN (300 MHz, $\left.\mathrm{CDCl}_{3}\right) \delta=7.51-7.48(\mathrm{~m}, 2 \mathrm{H}), 7.31-$ $7.28(\mathrm{~m}, 3 \mathrm{H}), 5.58(\mathrm{~s}, 2 \mathrm{H}), 4.22(\mathrm{t}, J=3.6 \mathrm{~Hz}, 2 \mathrm{H}), 1.51-0.86(\mathrm{~m}, 11 \mathrm{H}) .{ }^{13} \mathrm{C} \mathrm{RMN}(75$ $\left.\mathrm{MHz}, \mathrm{CDCl}_{3}\right) \delta=135.20,134.63,129.51,127.97,127.06,126.52,36.10,31.79,31.52$, $28.43,25.25,7.17$. Los espectros están en consonancia con la literatura. ${ }^{48}$

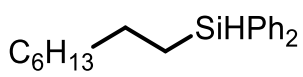

Difenil(octil)silano (6a). Se prepara siguiendo el método A, usando $0.1 \% \mathrm{~mol}$ del catalizador, 1 -octeno (100 $\mathrm{mg}, 0.89 \mathrm{mmol})$ y difenilsilano (164 mg, $0.89 \mathrm{mmol}$ ). ${ }^{1} \mathrm{H} \mathrm{RMN}(400 \mathrm{MHz}$, $\left.\mathrm{CDCl}_{3}\right): \delta=7.64-7.60(\mathrm{~m}, 4 \mathrm{H}), 7.4157 .41(\mathrm{~m}, 6 \mathrm{H}), 4.92(\mathrm{t}, J=3.7 \mathrm{~Hz}, 1 \mathrm{H}),, 1.53-1.19$ $(\mathrm{m}, 14 \mathrm{H}), 0.93(\mathrm{t}, J=6.8 \mathrm{~Hz}, 3 \mathrm{H}) .{ }^{13} \mathrm{C} \mathrm{RMN}\left(75 \mathrm{MHz}, \mathrm{CDCl}_{3}\right): \delta=135.16,134.78$, 129.47, 127.96, 33.19, 31.91, 31.63, 29.21, 24.43, 22.68, 14.11, 12.19. Los espectros están en consonancia con la literatura. ${ }^{51}$

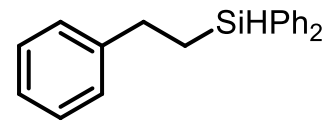

1-fenil-2-(difenilsilil)etano (6b). Se prepara siguiendo el método A, usando $0.1 \%$ mol del catalizador, estireno (92.7 mg, 0.89 mmol) y difenilsilano (164 mg, $0.89 \mathrm{mmol}) .{ }^{1} \mathrm{H}$ RMN (300 
$\left.\mathrm{MHz}, \mathrm{CDCl}_{3}\right): \delta=7.66-7.63(\mathrm{~m}, 4 \mathrm{H}), 7.46-7.43(\mathrm{~m}, 6 \mathrm{H}), 7.33-7.31(\mathrm{~m}, 2 \mathrm{H}), 7.27-7.23$ $(\mathrm{m}, 3 \mathrm{H}), 4.97(\mathrm{t}, J=3.6 \mathrm{~Hz}, 1 \mathrm{H}), 2.87-2.81(\mathrm{~m}, 2 \mathrm{H}), 1.62-1.55(\mathrm{~m}, 2 \mathrm{H}) .{ }^{13} \mathrm{C}$ RMN $(75$ $\left.\mathrm{MHz}, \mathrm{CDCl}_{3}\right): \delta=144.39,135.20,134.16,129.68,128.38,128.09,127.89,125,76$, $30.49,14.32$. Los espectros están en consonancia con la literatura. ${ }^{52}$

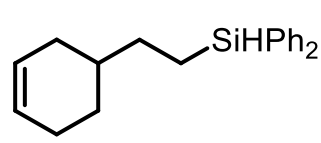

4-[2-(difenilsilil)etil]ciclohexeno (6c). Se prepara siguiendo el método A, usando $0.1 \%$ mol del catalizador, 4-vinilciclohexeno (96.3 mg, $0.89 \mathrm{mmol}) \mathrm{y}$ difenilsilano (164 mg, $0.89 \mathrm{mmol}) .{ }^{1} \mathrm{H}$ RMN (300 MHz, $\left.\mathrm{CDCl}_{3}\right): \delta=7.64-7.61(\mathrm{~m}, 4 \mathrm{H}), 7.45-7.41(\mathrm{~m}$, $6 \mathrm{H}), 5.74-5.67(\mathrm{~m}, 2 \mathrm{H}), 4.92(\mathrm{t}, J=3.7 \mathrm{~Hz}, 1 \mathrm{H}), 2.25-2.15(\mathrm{~m}, 1 \mathrm{H}), 2.09-2.06(\mathrm{~m}, 2 \mathrm{H})$, 1.86-1.79 (m, 1H), 1.73-1.69 (m, 1H), 1.64-1.57 (m, 1H), 1.53-1.48 (m, 2H), 1.27-1.21 $(\mathrm{m}, 3 \mathrm{H}) .{ }^{13} \mathrm{C} \mathrm{RMN}\left(75 \mathrm{MHz}, \mathrm{CDCl}_{3}\right): \delta=135.16,134.64,129.53,128.00,127.09$, 126.59, 36.68, 31.60, 31.13, 28.47, 25.34, 9.29. Los espectros están en consonancia con la literatura. ${ }^{53}$

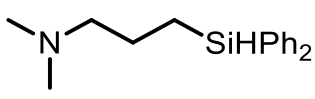

N,N-dimetil-(difenilsilil)propanamina (6d). Se prepara siguiendo el método A, usando $0.1 \%$ mol del catalizador, N,N-dimetilallilamina $(75.8 \mathrm{mg}, 0.89 \mathrm{mmol}) \mathrm{y}$ difenilsilano $(164 \mathrm{mg}$, $0.89 \mathrm{mmol}) .{ }^{1} \mathrm{H} \mathrm{RMN}\left(300 \mathrm{MHz}, \mathrm{CDl}_{3}\right): \delta=7.62-7.59(\mathrm{~m}, 4 \mathrm{H}), 7.43-7.39(\mathrm{~m}, 6 \mathrm{H}), 4.93$ $(\mathrm{t}, J=3.7 \mathrm{~Hz}, 1 \mathrm{H}), 2.33(\mathrm{t}, J=7.3 \mathrm{~Hz}, 2 \mathrm{H}), 2.20(\mathrm{~s}, 6 \mathrm{H}), 1.68(\mathrm{q}, J=7.6 \mathrm{~Hz}, 2 \mathrm{H}), 1.22-$ $1.16(\mathrm{~m}, 2 \mathrm{H}) .{ }^{13} \mathrm{C} \mathrm{RMN}\left(75 \mathrm{MHz}, \mathrm{CDCl}_{3}\right): \delta=135.14,134.34,129.55,127.99,62.61$, $45.36,22.50,9.83$. Los espectros están en consonancia con la literatura. ${ }^{54}$

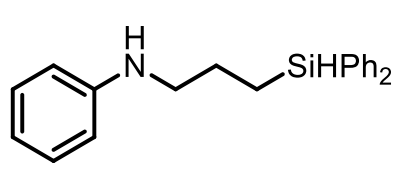

$\mathbf{N}$-(3-(difenilsilil)propil)anilina (6e). Se prepara siguiendo el método A, usando $0.1 \%$ mol del catalizador, $\mathrm{N}$-alilanilina (124.8 $\mathrm{mg}, 0.89 \mathrm{mmol})$ y difenilsilano (164 $\mathrm{mg}, 0.89$ mmol). ${ }^{1} \mathrm{H}$ RMN (300 MHz, $\left.\mathrm{CDCl}_{3}\right): \delta=7.62-7.58(\mathrm{~m}, 4 \mathrm{H})$, 7.45-7.39 (m, 6H), 7.21-7.16 (m, 2H), $6.72(\mathrm{t}, J=7.5 \mathrm{~Hz}, 1 \mathrm{H}), 6.57(\mathrm{~d}, J=7.5 \mathrm{~Hz}, 2 \mathrm{H})$, $4.94(\mathrm{t}, J=3.7 \mathrm{~Hz}, 1 \mathrm{H}), 3.62(\mathrm{~s}, 1 \mathrm{H}), 3.18(\mathrm{t}, J=7 \mathrm{~Hz}, 2 \mathrm{H}), 1.83-1.78(\mathrm{~m}, 2 \mathrm{H}), 1.31-$ 1.24 (m, 2H). ${ }^{13} \mathrm{C} \mathrm{RMN} \mathrm{(75} \mathrm{MHz,} \mathrm{CDCl3):} \delta=148.29,135.12,134.11,129.70,129.123$, 128.08, 117.17, 112.74, 46.65, 24.48, 9.69. GC-MS: Calculado para $\mathrm{C}_{21} \mathrm{H}_{23} \mathrm{NSi} 317.5$. Experimental: 317.2 .

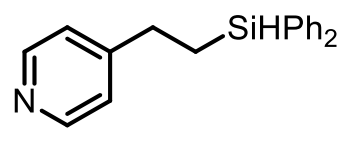

1-(4'-piridil)-2-(difenilsilil)etano (6g). Se prepara siguiendo el método $\mathrm{A}$, usando $0.1 \%$ mol del catalizador, 4-vinilpiridina (98.5 mg, $0.89 \mathrm{mmol})$ y difenilsilano (164 mg, $0.89 \mathrm{mmol}) .{ }^{1} \mathrm{H}$ RMN (300 MHz, $\left.\mathrm{CDCl}_{3}\right): \delta=8.50(\mathrm{~d}, J=5.8 \mathrm{~Hz}, 2 \mathrm{H}), 7.63-7.60(\mathrm{~m}, 4 \mathrm{H}), 7.46-7.40(\mathrm{~m}$, 
$6 \mathrm{H}), 7.14(\mathrm{~d}, J=5.8 \mathrm{~Hz}, 2 \mathrm{H}), 4.96(\mathrm{t}, J=3.7 \mathrm{~Hz}, 1 \mathrm{H}), 2.80-2.75(\mathrm{~m}, 2 \mathrm{H}), 1.56-1.49(\mathrm{~m}$, $2 \mathrm{H}) .{ }^{13} \mathrm{C} \mathrm{RMN}\left(75 \mathrm{MHz}, \mathrm{CDCl}_{3}\right): \delta=153.03,149.68,135.12,133.53,129.89,128.19$, $123.40,29.88,13.11$. Los espectros están en consonancia con la literatura. ${ }^{55}$

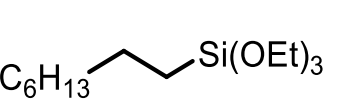

Octil(trietoxi)silano (7a). Se prepara siguiendo el método A, usando $0.1 \%$ mol del catalizador, 1-octeno $(100 \mathrm{mg}, 0.89$ mmol) y trietoxisilano (146.2 mg, $0.89 \mathrm{mmol}) .{ }^{1} \mathrm{H}$ RMN (300 $\left.\mathrm{MHz}, \mathrm{CDCl}_{3}\right): \delta=3.84(\mathrm{q}, J=7.0 \mathrm{~Hz}, 6 \mathrm{H}), 1.29-1.21(\mathrm{~m}, 21 \mathrm{H}), 0.89(\mathrm{t}, J=7.1 \mathrm{~Hz}, 3 \mathrm{H})$, $0.67-0.61(\mathrm{~m}, 2 \mathrm{H}) .{ }^{13} \mathrm{C} \mathrm{RMN}\left(75 \mathrm{MHz}, \mathrm{CDCl}_{3}\right): \delta=58.26,33.17,31.89,29.35,29.20$, $22.64,18.27,14.05,10.38$. Los espectros están en consonancia con la literature. ${ }^{22}$

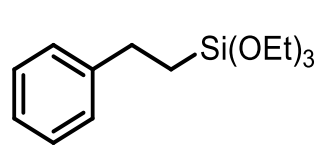

Trietoxi(feniletil)silano (7b). Se prepara siguiendo el método A, usando $0.1 \%$ mol del catalizador, estireno ( $92.7 \mathrm{mg}, 0.89 \mathrm{mmol})$ y trietoxisilano $(146.2 \mathrm{mg}, 0.89 \mathrm{mmol}) .{ }^{1} \mathrm{H}$ RMN $(300 \mathrm{MHz}$, $\mathrm{CDCl} 3): \delta=7.25(\mathrm{~m}, 5 \mathrm{H}), 3.89(\mathrm{q}, J=7.0 \mathrm{~Hz}, 6 \mathrm{H}), 2.80-2.74(\mathrm{~m}$, $2 \mathrm{H}), 1.27(\mathrm{t}, J=7.0 \mathrm{~Hz}, 9 \mathrm{H}), 1.06-1.00(\mathrm{~m}, 2 \mathrm{H}) .{ }^{13} \mathrm{C} \mathrm{RMN}\left(75 \mathrm{MHz}, \mathrm{CDCl}_{3}\right): \delta=144.64$, $128.29,127.79,125.61,58.40,28.29,18.30,12.53$. Los espectros están en consonancia con la literatura. ${ }^{9}$

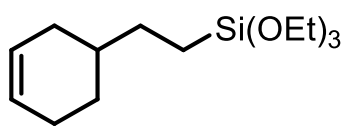

(2-(Ciclohex-3-en-1-il)etil)trietoxisilane (7c). Se prepara siguiendo el método $\mathrm{A}$, usando $0.1 \%$ mol del catalizador, 4-vinilciclohexeno ( $96.3 \mathrm{mg}, 0.89 \mathrm{mmol})$ y trietoxisilano $(146.2$ $\mathrm{mg}, 0.89 \mathrm{mmol}) .{ }^{1} \mathrm{H} \mathrm{RMN}\left(300 \mathrm{MHz}, \mathrm{CDCl}_{3}\right): \delta=5.67-5.61(\mathrm{~m}, 2 \mathrm{H}), 3.82(\mathrm{q}, J=7.0$ $\mathrm{Hz}, 6 \mathrm{H}), 2.15-2.07(\mathrm{~m}, 1 \mathrm{H}), 2.06-1.98(\mathrm{~m}, 2 \mathrm{H}), 1.79-1.71(\mathrm{~m}, 1 \mathrm{H}), 1.66-1.56(\mathrm{~m}, 1 \mathrm{H})$, $1.50-1.41(\mathrm{~m}, 1 \mathrm{H}), 1.40-1.33(\mathrm{~m}, 2 \mathrm{H}), 1.23(\mathrm{t}, J=7.0 \mathrm{~Hz}, 9 \mathrm{H}), 1.20-1.13(\mathrm{~m}, 1 \mathrm{H}), 0.68-$ $0.62(\mathrm{~m}, 2 \mathrm{H}) .{ }^{13} \mathrm{C} \mathrm{RMN}\left(75 \mathrm{MHz}, \mathrm{CDCl}_{3}\right): \delta=127.2,126.8,58.3,36.3,31.6,29.5,28.6$, 25.5, 18.5, 7.6. Los espectros están en consonancia con la literatura. ${ }^{9}$

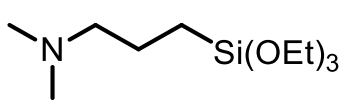

$N, N$-dimetil-3-(trietoxisilil)propanamina (7d). Se prepara siguiendo el método A, usando $0.1 \%$ mol del catalizador, $\mathrm{N}, \mathrm{N}$ dimetilalilamina (75.8 $\mathrm{mg}, 0.89 \mathrm{mmol})$ y trietoxisilano $(146.2$ $\mathrm{mg}, 0.89 \mathrm{mmol}) .{ }^{1} \mathrm{H} \mathrm{RMN}\left(300 \mathrm{MHz}, \mathrm{CDCl}_{3}\right): \delta=3.81$ (q, $\left.J=7.0 \mathrm{~Hz}, 6 \mathrm{H}\right), 2.26(\mathrm{t}, J=$ $7.5 \mathrm{~Hz}, 2 \mathrm{H}), 2.21(\mathrm{~s}, 6 \mathrm{H}), 1.62-1.53(\mathrm{~m}, 2 \mathrm{H}), 1.21(\mathrm{t}, J=7.0 \mathrm{~Hz}, 9 \mathrm{H}), 0.64-0.57(\mathrm{~m}, 2 \mathrm{H})$. ${ }^{13} \mathrm{C} \mathrm{RMN}\left(75 \mathrm{MHz}, \mathrm{CDCl}_{3}\right): \delta=62.9,58.5,45.6,21.1,18.4,8.1$. Los espectros están en consonancia con la literatura. ${ }^{22}$ 


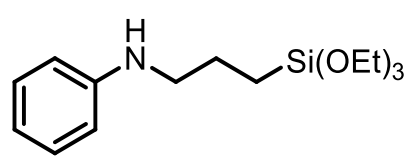

$N$-(3-(trietoxisilil)propil)anilina (7e). Se prepara siguiendo el método $\mathrm{A}$, usando $0.1 \%$ mol del catalizador, $\mathrm{N}$ alilanilina (124.8 $\mathrm{mg}, 0.89 \mathrm{mmol})$ y trietoxisilano $(146.2$ $\mathrm{mg}, 0.89 \mathrm{mmol}) .{ }^{1} \mathrm{H}$ RMN (300 MHz, $\left.\mathrm{CDCl}_{3}\right): \delta=7.17$ (dd, $J=8.5,7.4 \mathrm{~Hz}, 2 \mathrm{H}), 6.68(\mathrm{t}, J=7.3 \mathrm{~Hz}, 1 \mathrm{H}), 6.61(\mathrm{~d}, J=7.7 \mathrm{~Hz}, 2 \mathrm{H}), 3.92(\mathrm{br} \mathrm{s}$, $1 \mathrm{H}$ ), 3.83 (q, $J=7.0 \mathrm{~Hz}, 6 \mathrm{H}$ ), 3.13 (t, $J=7.1 \mathrm{~Hz}, 2 \mathrm{H}$ ), 1.75 (app. pent., $J=7.2 \mathrm{~Hz}, 2 \mathrm{H}$ ), 1.23 (t, $\left.J=7.0 \mathrm{~Hz}, 9 \mathrm{H}), 0.74-0.69(\mathrm{~m}, 2 \mathrm{H}) .{ }^{13} \mathrm{C} \mathrm{RMN} \mathrm{(75} \mathrm{MHz,} \mathrm{CDCl}_{3}\right): \delta=148.4$, 123.3, 117.2, 112.9, 58.6, 46.6, 22.9, 18.5, 8.0. Los espectros están en consonancia con la literatura. ${ }^{56}$

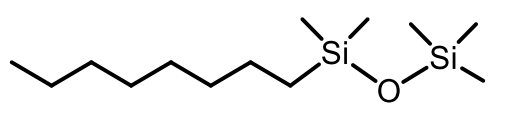

1,1,1,3,3-pentamethyl-3-octyl-disiloxane (8a). Se prepara siguiendo el método A, usando $0.1 \%$ mol del catalizador, 1-octeno $(100 \mathrm{mg}, 0.89 \mathrm{mmol})$ y pentametildisiloxano (139 mg, $0.89 \mathrm{mmol}) .{ }^{1} \mathrm{H}$ RMN $\left(300 \mathrm{MHz}, \mathrm{CDCl}_{3}\right): \delta=1.38-1.21(\mathrm{~m}$, $12 \mathrm{H}), 0.96-0.82(\mathrm{~m}, 3 \mathrm{H}), 0.51(\mathrm{dd}, J=9.2,6.0 \mathrm{~Hz}, 2 \mathrm{H}), 0.06(\mathrm{~s}, 9 \mathrm{H}), 0.04(\mathrm{~s}, 6 \mathrm{H}) .{ }^{13} \mathrm{C}$ RMN (75 MHz, $\left.\mathrm{CDCl}_{3}\right): \delta=33.6,32.1,29.5,29.4,23.4,22.9,18.6,14.3,2.1,0.5$. Los espectros están en consonancia con la literatura. ${ }^{56}$ 


\subsection{Bibliografía}

(1) Marciniec, B., Maciejewski, H.; Pietraszuk, C.; Pawluc, P. in Hydrosilylation: A Comprehensive Review on Recent Advances, Ed: B. Merciniec, Springer: Berlin 2009, 3-51.

(2) Marciniec, B., Catalysis by Transition Metal Complexes of Alkene Silylation Recent Progress and Mechanistic Implications, Coord. Chem. Rev. 2005, 249 (21-22), 2374-2390.

(3) Nakajima, Y.; Shimada, S., Hydrosilylation Reaction of Olefins: Recent Advances and Perspectives, RSC Adv. 2015, 5 (26), 20603-20616.

(4) Marciniec, B., Maciejewski, H., Pietraszok, C. \& Pawluc, P. Advances in Silicone Science Vol. 1, Springer, 2009.

(5) Sun, J.; Deng, L., Cobalt Complex-Catalyzed Hydrosilylation of Alkenes and Alkynes, ACS Catal. 2016, 6 (1), 290-300.

(6) Wang, C.; Teo, W. J.; Ge, S., Cobalt-Catalyzed Regiodivergent Hydrosilylation of Vinylarenes and Aliphatic Alkenes: Ligand- and Silane-Dependent Regioselectivities, ACS Catal. 2017, 7 (1), 855-863.

(7) Marciniec, B.; Gulinski, J.; Urbaniac, W.; Kornetka, Z. W. in Comprehensive Handbook on Hydrosilylation, Pergamon, Oxford, U. K. 1992.

(8) Marciniec, B.; Applied Homogeneous Catalysis with Organometallic Compounds; Wiley-VCH: Weinheim, Germany, 1996.

(9) Schuster, C. H.; Diao, T.; Pappas, I.; Chirik, P. J., Bench-Stable, SubstrateActivated Cobalt Carboxylate Pre-Catalysts for Alkene Hydrosilylation with Tertiary Silanes, ACS Catal. 2016, 6 (4), 2632-2636.

(10) Troegel, D.; Stohrer, J., Recent Advances and Actual Challenges in Late Transition Metal Catalyzed Hydrosilylation of Olefins from an Industrial Point of View, Coord. Chem. Rev. 2011, 255 (13-14), 1440-1459.

(11) Carver, J. C.; Schweitzer, G. K.; Carlson, T. A., Use of X-Ray Photoelectron Spectroscopy to Study Bonding in Cr, Mn, Fe, and Co Compounds, J. Chem. Phys. 1972, 57 (2), 973-982.

(12) Speier, J. L.; Webster, J. A.; Barnes, G. H., The Addition of Silicon Hydrides to 
Olefinic Double Bonds. Part II. The Use of Group VIII Metal Catalysts, J. Am. Chem. Soc. 1957, 79 (4), 974-979.

(13) Karstedt, B. D. General Electric Company. U.S. Patent US3775452A 1973.

(14) American Society for Testing Materials (ASTM). Symposium on Spectrocemical Analysis for Trace Elements; ASTM International: Washington, DC, 1958, 71.

(15) Holwell, A. J., Global Release Liner Industry Conference 2008, Platin. Met. Rev. 2008, 52 (4), 243-246.

(16) Harrod, J. F.; Chalk, A. J., Dicobalt Octacarbonyl as a Catalyst for Hydrosilation of Olefins, J. Am. Chem. Soc. 1965, 87, 1133.

(17) Chalk, A. J.; Harrod, J. F., Homogeneous Catalysis. IV. Some Reactions of Silicon Hydrides in the Presence of Cobalt Carbonyls, J. Am. Chem. Soc. 1967, 89, 1640-1647.

(18) Magomedov, G. K. I.; Andrianov, K. A.; Shkolnik, O. V.; Izmailov, B. A.; Kalinin, V. N., Hydrosilylation of olefins in the presence of metal carbonyls, J. Organomet. Chem. 1978, 149, 29-36.

(19) Stranix, B. R.; Liu, H. Q.; Darling, G. D., Functional polymers from (vinyl) polystyrene. Recyclable polymer-supported organosilicon protecting groups for solidphase synthesis, J. Org. Chem. 1997, 62, 6183-6186.

(20) Seitz, F.; Wrighton, M. S., Photochemical Reaction of $\left[(\mathrm{CO})_{4} \mathrm{Co}\left(\mathrm{SiEt}_{3}\right)\right]$ with Ethylene: Implications for Cobaltcarbonyl-Catalyzed Hydrosilation of Alkenes, Angew. Chem., Int. Ed. Engl. 1988, 27, 289-291.

(21) Takeshita, K.; Seki, Y.; Kawamoto, K.; Murai, S.; Sonoda, N., The catalyzed reaction of. alpha., beta-unsaturated esters with various hydrosilanes, J. Org. Chem. 1987, 52, 4864-4868.

(22) Tondreau, A. M.; Atienza, C. C. H.; Weller, K. J.; Nye, S. A.; Lewis, K. M.; Delis, J. G. P.; Chirik, P. J., Iron catalysts for selective anti-Markovnikov alkene hydrosilylation using tertiary silanes, Science 2012, 335, 567-570.

(23) Diao, T.; Chirik, P. J.; Roy, A. K.; Lewis, K.; Nye, S.; Weller, K. J.; Delis, J. G. P.; Yu, R., U.S. Patent US20150080536 A1, 2015. 
(24) Chen, C.; Hecht, M. B.; Kavara, A.; Brennessel, W. W.; Mercado, B. Q.; Weix, D. J.; Holland, P. L., Rapid, regioconvergent, solvent-free alkene hydrosilylation with a cobalt catalyst, J. Am. Chem. Soc. 2015, 137, 13244-13247.

(25) Challinor, A. J.; Calin, M.; Nichol, G. S.; Carter, N. B.; Thomas, S. P., AmineActivated Iron Catalysis: Air-and Moisture-Stable Alkene and Alkyne Hydrofunctionalization, Adv. Synth. Catal. 2016, 358, 2404-2409.

(26) Sunada, Y.; Noda, D.; Soejima, H.; Tsutsumi, H.; Nagashima, H., Combinatorial approach to the catalytic hydrosilylation of styrene derivatives: catalyst systems composed of organo iron (0) or (II) precursors and isocyanides, Organometallics 2015, 34, 2896-2906.

(27) Noda, D.; Tahara, A.; Sunada, Y.; Nagashima, H., Non-precious-metal catalytic systems involving iron or cobalt carboxylates and alkyl isocyanides for hydrosilylation of alkenes with hydrosiloxanes, J. Am. Chem. Soc. 2016, 138, 2480-2483.

(28) Docherty, J. H.; Peng, J.; Dominey, A. P.; Thomas, S. P. Activation and Discovery of Earth-Abundant Metal Catalysts Using Sodium Tert-Butoxide, Nat. Chem. 2017, 9 (6), 595-600.

(29) Greenhalgh, M. D.; Frank, D. J.; Thomas, S. P. Iron-Catalysed Chemo-, Regio, and Stereoselective Hydrosilylation of Alkenes and Alkynes Using a Bench-Stable Iron(II) Pre-Catalyst, Adv. Synth. Catal. 2014, 356 (2-3), 584-590.

(30) Casey, C. P.; Guan, H., An efficient and chemoselective iron catalyst for the hydrogenation of ketones, J. Am. Chem. Soc. 2007, 129, 5816-5817.

(31) Zuo, W.; Lough, A. J.; Li, Y. F.; Morris, R. H., Amine (imine) diphosphine iron catalysts for asymmetric transfer hydrogenation of ketones and imines, Science 2013, 342, 1080-1083.

(32) Langer, R.; Leitus, G.; Ben-David, Y.; Milstein, D., Efficient hydrogenation of ketones catalyzed by an iron pincer complex, Angew. Chem., Int. Ed. 2011, 50, 2120-2124.

(33) Chirik, P. J., Iron-and cobalt-catalyzed alkene hydrogenation: catalysis with both redox-active and strong field ligands, Acc. Chem. Res. 2015, 48, 1687-1695.

(34) Harman, W. H.; Peters, J. C., Reversible $\mathrm{H}_{2}$ Addition across a Nickel-Borane Unit as a Promising Strategy for Catalysis, J. Am. Chem. Soc. 2012, 134, 5080-5082. 
(35) Zhao, B.; Han, Z.; Ding, K., The N-H Functional Group in Organometallic Catalysis, Angew. Chem., Int. Ed. 2013, 52, 4744-4788.

(36) Constable, E. C.; Housecroft, C. E.; Jullien, V.; Neuburger, M.; Schaffner, S., Structural characterisation of a 1:1 cobalt(II) - 2,2':6, $2^{\prime \prime}$-Terpyridine complex, Inorg. Chem. Commun. 2006, 9, 504-506.

(37) Indumathy, R.; Radhika, S.; Kanthimathi, M.; Weyhermuller, T.; Nair, B.U., Cobalt complexes of terpyridine ligand: Crystal structure and photocleavage of DNA, $J$. Inorg. Biochem. 2007, 101, 434-443.

(38) Schuchardt, U.; Carvalho W.A.; Spinacé E.V., Why is it Interesting to Study Cyclohexane Oxidation?, Synlett 1993, 10, 713-718.

(39) Mizuno, K.; Imamura, S.; Lunsford, J. H., Cobalt complexes of terpyridine ligand: crystal structure and photocleavage of DNA, Inorg. Chem. 1984, 23, 3510-3514.

(40) Cibian, M.; Hana, G. S., Geometry and spin change at the heart of a cobalt (II) complex: a special case of solvatomorphism, Chem. Eur. J. 2015, 21, 9474-9481.

(41) Eaton, G. R.; Eaton, S. S.; Barr, D. P.; Weber, R. T.; in Quantitative EPR Springer-Verlag Wien, Austria, 2010.

(42) Evans, D. F., The Determination of the Pararnagnetic Susceptibility of Substances in Solution by Nuclear Magnetic Resonance, J. Chem. Soc. 1959, $2003-$ 2005.

(43) Garland, C. W.; Nibler, J. W.; Shoemaker, D. P.; Experiments in Physical Chemistry, 8th Ed.; McGraw-Hill; New York: 2003, 371-379.

(44) Sprengers, J. W.; de Greef, M.; Duin, M. A.; Elsevier, C. J., Stable Platinum(0) Catalysts for Catalytic Hydrosilylation of Styrene and Synthesis of [Pt(Ar-bian) $\left(\eta^{2}-\right.$ alkene)] Complexes, Eur. J. Inorg. Chem. 2003, 2003, 3811-3819.

(45) Bleith, T.; Gade, L. H., Mechanism of the iron (II)-catalyzed hydrosilylation of ketones: activation of iron carboxylate precatalysts and reaction pathways of the active catalyst, J. Am. Chem. Soc. 2016, 138, 4972-4983.

(46) Socrates, G., Infrared and Raman Characteristic Group Frequencies, John Wiley \& Sons Ltd, Chichester, UK, 2001.

(47) Park, E. S.; Ro, H. W.; Nguyen, C. V.; Jaffe, R. L.; Yoon, D. Y., Infrared 
Spectroscopy Study of Microstructures of Poly(silsesquioxanes), Chem. Mater. 2008, $20,1548-1554$.

(48) Du, X.; Zhang, Y.; Peng, D.; Haung, Z., Base-Metal-Catalyzed Regiodivergent Alkene Hydrosilylations, Angew. Chem. Int. Ed. 2016, 55, 6671-6675.

(49) Ge, S.; Meetsma, A.; Hessen, B., Highly efficient hydrosilylation of alkenes by organoyttrium catalysts with sterically demanding amidinate and guanidinate ligands, Organometallics 2008, 27, 3131-3135.

(50) Mark, D. G.; Dominik, J. F.; Stephen, P. T., Iron-Catalysed Chemo-, Regio-, and Stereoselective Hydrosilylation of Alkenes and Alkynes using a Bench-Stable Iron (II) Pre-Catalyst, Adv. Synth. Catal. 2014, 356, $584-590$.

(51) Peng, D.; Zhang, Y.; Du, X.; Zhang, L.; Leng, X.; Walter, M. D.; Huang, Z., Phosphinite-iminopyridine iron catalysts for chemoselective alkene hydrosilylation, $J$. Am. Chem. Soc. 2013, 135, 19154.

(52) Nielsen, L.; Skrydstrup, T., Sequential C- Si bond formations from diphenylsilane: application to silanediol peptide isostere precursors, J. Am. Chem. Soc. 2008, 130, 13145-13151.

(53) Buslov, I.; Becouse, J.; Mazza, S.; Montandon-Clerc, M.; Hu, X., Chemoselective alkene hydrosilylation catalyzed by nickel pincer complexes, Angew. Chem. Int. Ed. 2015, 54, 14523 -14526.

(54) Srinivas, V.; Nakajima, Y.; Ando, W.; Sato, K.; Shimada, S., (Salicylaldiminato) Ni (II)-catalysts for hydrosilylation of olefins, Catal. Sci. Technol. 2015, 5, 2081-2084.

(55) Kuznetsov, A.; Onishi, Y.; Inamoto, Y.; Gevorgyan, V., Fused heteroaromatic dihydrosiloles: synthesis and double-fold modification, Org. Lett. 2013, 15, 2498-2501.

(56) Cui, X.; Junge, K.; Dai, X.; Kreyenschulte, C.; Pohl, M. M.; Wohlrab, S.; Shi, F.; Brückner, A.; Beller, M., Synthesis of single atom based heterogeneous platinum catalysts: high selectivity and activity for hydrosilylation reactions, ACS Cent. Sci. 2017, $3,580-585$. 


\section{Capítulo 5.}

\section{Nanoclústeres de Cobalto}

como catalizadores para la hidrogenación quimioselectiva de nitroarenos y reacciones tándem. 

Capítulo 5. Nanoclústeres de Cobalto como catalizadores para la hidrogenación quimioselectiva de nitroarenos y reacciones tándem.

\section{Índice}

5.1. Introducción.

5.2. Objetivos

5.3. Resultados y discusión

5.3.1. Síntesis de los catalizadores Co@NC-T ......................................................118

5.3.2. Optimización de las condiciones de reacción ................................................118

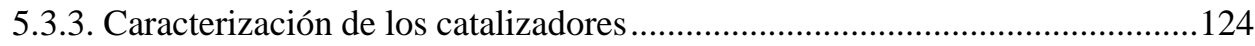

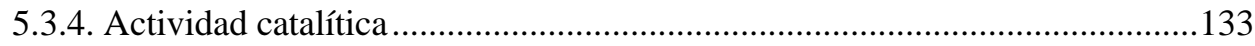

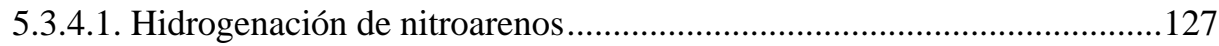

5.3.4.2. Reacciones tándem que implican la reducción de nitroarenos ................131

5.4. Conclusiones ................................................................................... 141

5.5. Sección experimental ...................................................................... 142

5.5.1. Síntesis y caracterización de los catalizadores ................................................ 142

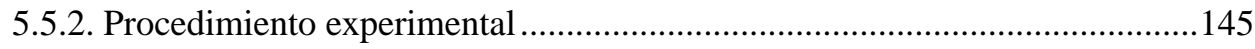

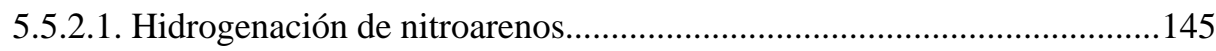

5.5.2.2. Síntesis de aminas secundarias por aminación reductiva.........................145

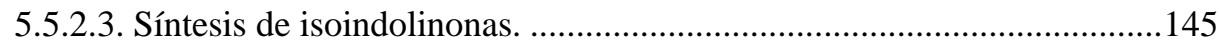

5.5.2.4. Estudio quimioselectividad por ATR-FTIR......................................... 146

5.5.3. Caracterización de los productos de reacción sintetizados..............................147

5.5. Bibliografía ...................................................................................................... 154 



\subsection{Introducción.}

En 2018, la producción mundial de anilina alcanzó un volumen de 7,8 millones de toneladas, y se estima que en 2024 alcanzará los 10,6 millones de toneladas. Este enorme aumento en la producción de anilina se debe al uso de este compuesto como reactivo para la producción de metilendianilina, precursor clave en la generación de diisocianato de metileno (MDI), que desempeña un papel fundamental en la síntesis de espumas rígidas de poliuretano. ${ }^{1}$ Por otro lado, la reducción selectiva del grupo nitro en presencia de grupos reactivos como alquenos, alquinos, halógenos, cetonas, aldehídos, ácidos, ésteres y amidas representa una transformación imprescindible en síntesis orgánica, ${ }^{2,3}$ ya que las anilinas funcionalizadas son intermediarios claves para la producción de productos químicos, farmacéuticos y agroquímicos. ${ }^{4-6}$

La reducción convencional de Béchamp con $\mathrm{Fe}$ y $\mathrm{HCl}$ o la reducción con agentes reductores como $\mathrm{H}_{2} \mathrm{~S}$ o $\mathrm{NaSH}$ han sido ampliamente aplicados en la industria para la producción de anilinas funcionalizadas a partir de sus correspondientes nitroarenos. ${ }^{7} \mathrm{Sin}$ embargo, estos procesos no catalíticos generan grandes cantidades de subproductos indeseados, lo cual lleva asociados una serie de problemas medioambientales. Otros métodos desarrollados incluyen la hidrogenación por transferencia utilizando agentes donantes de hidrógeno como la hidracina, $\mathrm{NaBH}_{4} \mathrm{o}$ el ácido fórmico. ${ }^{8-12} \mathrm{Sin}$ embargo, la hidrogenación catalítica usando catalizadores metálicos e hidrógeno como agente reductor es el método más eficaz en términos de eficiencia atómica, consumo de energía y sostenibilidad. ${ }^{13-15}$

En la última década, la preparación de catalizadores basados en nanopartículas metálicas soportadas activas y estables ha sido objeto de estudio por diferentes grupos de investigación. ${ }^{16} \mathrm{La}$ principal ventaja de estos catalizadores es la separación y recuperación de estos, lo cual es una característica esencial en procesos de fabricación a escala industrial. En 2006, nuestro grupo publicó un artículo sobre un catalizador heterogéneo de Au que era activo en la reducción selectiva de grupos nitro en presencia de otros grupos reducibles. ${ }^{17-20}$ Posteriormente, se han publicado trabajos en los que se demuestra que otros metales preciosos como Pd, Pt, Ir, Ru y Re son activos y selectivos como catalizadores para la reducción selectiva de nitroarenos. ${ }^{21-25}$ Por desgracia, la escasez, toxicidad y el alto coste de estos metales nobles impulsan al desarrollo de catalizadores basados en metales no nobles abundantes en la corteza terrestre para esta reacción, como los metales de la primera serie de transición. 
Las desventajas de los catalizadores basados en metales de la primera serie de transición para su aplicación en reacciones de hidrogenación, especialmente en reducción de nitroarenos, están relacionadas con la necesidad de condiciones de reacción muy severas para la obtención de un rendimiento razonable, como altas temperaturas $\left(>100^{\circ} \mathrm{C}\right) \mathrm{y} / \mathrm{o}$ presiones (30-50 bar de $\mathrm{H}_{2}$ ). Por lo tanto, la hidrogenación de nitroarenos en condiciones de reacción más suaves utilizando estos metales sigue siendo un reto hoy en día. Entre ellos, los catalizadores basados en níquel, han sido los más utilizados en reacciones de hidrogenación de varios grupos funcionales. ${ }^{7,26,27}$ Sin embargo, los catalizadores de este metal suelen presentar diversos inconvenientes, entre los que cabe destacar su sensibilidad al aire y a la humedad y la dificultad para controlar su selectividad y reciclabilidad, ya que requieren de condiciones de reacción muy severas. ${ }^{7}$ A pesar de estos inconvenientes, en 2008, nuestro grupo desarrolló un catalizador de Ni soportado en $\mathrm{TiO}_{2}$ capaz de llevar a cabo la hidrogenación selectiva de nitroarenos en condiciones suaves de reacción. ${ }^{28}$ Los catalizadores basados en hierro presentan inconvenientes similares a los de $\mathrm{Ni}^{29}$

Por otro lado, los catalizadores de cobalto son muy activos en esta reacción. ${ }^{7}$ En este sentido, varios trabajos han reportado que la actividad de los catalizadores de cobalto depende tanto del tamaño de las nanopartículas metálicas y su estado de oxidación como de la naturaleza del soporte. ${ }^{30}$ En relación al tamaño, la bibliografía recoge que las partículas de cobalto de mayor tamaño (>10 nm) son las más activas, ya que las más pequeñas son fácilmente oxidables en presencia de aire. ${ }^{30}$ En este sentido, en nuestro grupo de investigación se han desarrollado metodologías sencillas para recubrir las nanopartículas de cobalto de tamaño medio con carbono, lo que estabiliza su naturaleza y su tamaño. ${ }^{31,32}$ Por otro lado, como se ha mencionado anteriormente, la naturaleza y la superficie del soporte también desempeñan un papel importante en la dispersión metálica y en el tamaño de las partículas. ${ }^{30,33}$ Por ello, se han utilizado ampliamente soportes heterogéneos dopados con nitrógeno para estabilizar las partículas metálicas con el fin de obtener una mejor dispersión del metal en el soporte inorgánico. ${ }^{33-38}$ Además, según la bibliografía, los soportes ricos en nitrógeno facilitan la ruptura heterolítica del hidrógeno en condiciones más suaves, ${ }^{33}$ lo que sería un punto a favor para llevar a cabo reacciones de hidrogenación. En este contexto, varios grupos independientes han desarrollado numerosos catalizadores basados en cobalto soportados en carbono dopado con nitrógeno para la hidrogenación selectiva de nitroarenos funcionalizados.

El grupo de Beller ha utilizado diferentes ligandos basados en nitrógeno para formar complejos de cobalto que deposita en una matriz de carbono (Vulcan XC72R), al que aplican un proceso de carbonización. ${ }^{39}$ Sin embargo, este método conlleva una falta de 
control del tamaño de las partículas metálicas y de la dispersión de las especies de cobalto en el soporte, y, por tanto, la hidrogenación de nitroarenos solo es posible a alta presión (50 bar) y altas temperaturas $\left(110^{\circ} \mathrm{C}\right)$. En este trabajo, los autores reportan que la sinergia que existe entre las nanopartículas de cobalto y el soporte carbonoso dopado con nitrógeno es crucial en este proceso catalítico. ${ }^{40}$

A raíz de este estudio, se han publicado diferentes metodologías para la síntesis de catalizadores de cobalto. Sin embargo, normalmente se obtienen especies de cobalto poco definidas en la matriz sólida y, como consecuencia, estos catalizadores siguen requiriendo de condiciones severas para llevar a cabo la reacción catalítica. ${ }^{33,39-47}$ Recientemente, el grupo de Kempe ha reportado la deposición de nanopartículas de cobalto sobre una matriz de carbonitruro de silicio. ${ }^{48}$ En este caso, se obtuvieron nanopartículas de cobalto muy pequeñas en este soporte, aunque no se obtuvieron mejoras considerables en la hidrogenación de nitroarenos respecto a otros catalizadores reportados. ${ }^{48}$ Sin embargo, aunque se afirma que las nanopartículas de cobalto desempeñan un papel fundamental en este proceso de hidrogenación, la razón detrás de su actividad catalítica sigue sin ser concluyente. En este sentido, el grupo de Cheng depositó nanopartículas de Co sobre nanotubos de carbono, utilizando fenantrolina como ligando para lograr el dopado con $\mathrm{N}$ de la matriz carbonosa, obteniendo nanopartículas de Co con un tamaño de $100 \mathrm{~nm} .{ }^{49}$ Este sólido se lavó con ácido concentrado $(\mathrm{HCl})$ para eliminar las especies metálicas. Sin embargo, después de este proceso de lixiviado, el sólido obtenido seguía teniendo actividad catalítica. En este estudio se concluyó que las nanopartículas no desempeñan un papel principal en el proceso, y se sugirió que las especies activas reales son sitios de Co- $\mathrm{N}_{\mathrm{x}}$ altamente dispersos a escala atómica y subnanométrica situados en la matriz de carbono que no se modifican tras el lavado. ${ }^{49}$ Por el contrario, en trabajos desarrollados por nuestro grupo de investigación, se ha reportado que la hidrogenación de nitroarenos no tenía lugar tras la lixiviación ácida de un catalizador Co@C, lo que sugiere que las nanopartículas de cobalto accesibles son las responsables de la actividad catalítica. ${ }^{32}$ En el mismo sentido, el grupo de Wang obtuvo resultados similares usando un catalizador Co@ $\mathrm{NC}$ obtenido a partir de la pirólisis del MOF ZIF-67.50

Otra cuestión relacionada con el uso de este tipo de catalizadores es la desactivación. Los catalizadores basados en metales no nobles sufren aún más la desactivación debido a las duras condiciones de reacción necesarias normalmente para llevar a cabo la catálisis. Estos problemas están relacionados frecuentemente con la sinterización de las partículas metálicas y la lixiviación del metal. Por ello, la mayoría de los catalizadores basados en cobalto para hidrogenaciones en fase líquida se desactivan tras pocos 
ciclos. ${ }^{51-54}$ Por ejemplo, el grupo de Gascón reportó que el catalizador Co@ NC, derivado de la pirólisis del ZIF-67, se desactivaba después de 3 ciclos, atribuyendo esta desactivación al bloqueo parcial de los sitios activos por especies de reacción fuertemente adsorbidas. ${ }^{43}$ Otros autores atribuyeron la desactivación de diferentes catalizadores de cobalto a la lixiviación del metal y al cambio del estado de oxidación de las nanopartículas de cobalto (formación del $\mathrm{Co}_{3} \mathrm{O}_{4}$ ). ${ }^{40,55}$

A pesar de los grandes logros alcanzados en este campo, en la mayoría de los casos, se requieren de disolventes contaminantes o de condiciones de reacción severas para obtener conversiones y selectividades elevadas. Por ello, es necesario desarrollar métodos altamente eficientes y benignos con el medioambiente para la transformación de nitrocompuestos en aminas (Esquema 5.1).

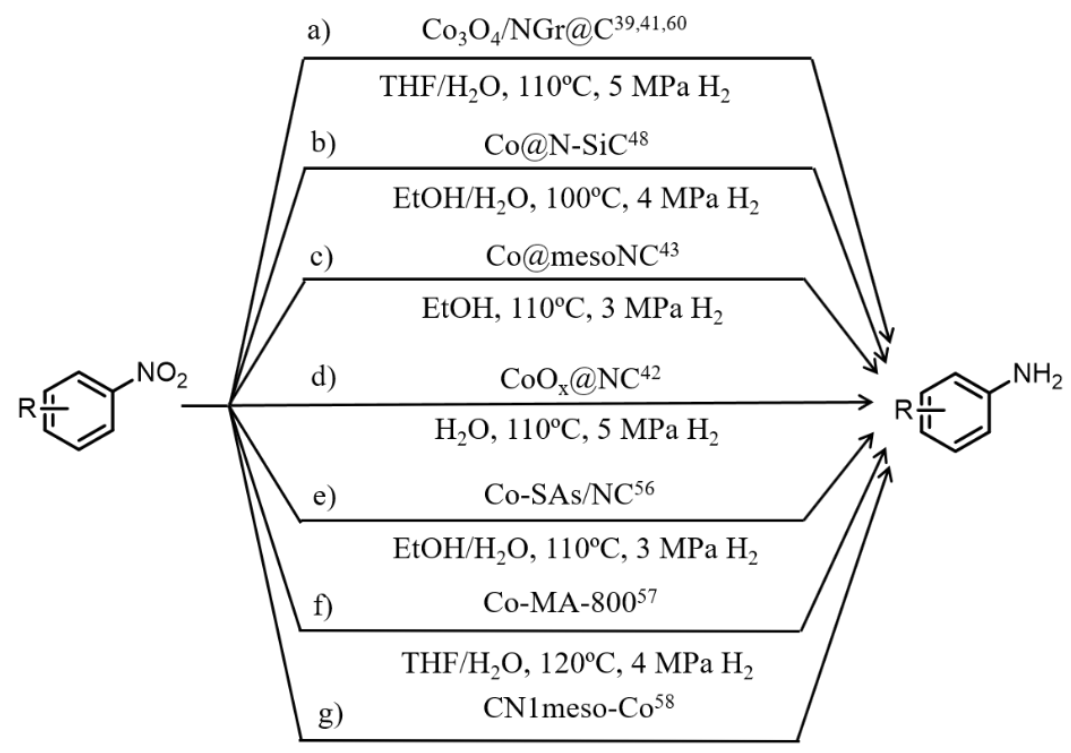

Propanol, base, $100^{\circ} \mathrm{C}, 1.5 \mathrm{MPa} \mathrm{H}_{2}$

Esquema 5.1. Hidrogenación de nitroarenos catalizada por Co.

Por otro lado, también es importante el desarrollo de sistemas catalíticos que sean multifuncionales, y que sean activos también en reacciones en cascada, evitando así el aislamiento y la purificación de los intermedios de reacción. Por ejemplo, la aminación reductiva de grupos carbonilo con una amina primaria ofrece una vía directa y selectiva para la síntesis de aminas secundarias. Un catalizador activo y selectivo ampliamente reportado para este proceso es el Pd/C. ${ }^{59-62}$ Recientemente, se ha estudiado activamente 
el desarrollo de catalizadores eficientes y selectivos basados en metales de transición para esta reacción. ${ }^{48,63-67}$ En concreto, ha habido mucho interés en encontrar un catalizador eficiente que pueda catalizar tanto la hidrogenación de nitroarenos como la aminación reductiva de las anilinas resultantes en presencia de un aldehído sin que esta venga acompañada de la generación de productos secundarios no deseados. ${ }^{68-74}$ Algunos de los retos en este caso particular son obtener la amina de forma selectiva en lugar de la imina y llevar a cabo la reacción en condiciones suaves y favoreciendo el uso de disolventes no contaminantes, como el agua, como medio de reacción.

\subsection{Objetivos}

Una vez conocido el estado del arte y los retos que se presentan en estos procesos, los objetivos propuestos en este capítulo de la tesis doctoral son los siguientes:

- Síntesis y caracterización de catalizadores basados en cobalto, que sean activos y selectivos en la reacción de hidrogenación de nitroarenos a anilinas en condiciones de reacción suaves, usando agua como medio de reacción y sin necesidad de ser activados previamente. Además, estos catalizadores heterogéneos deben ser activos en varios ciclos de reacción sin desactivarse.

- Este material, además, debe ser multifuncional y eficiente en reacciones multietapa como la aminación reductiva o la síntesis de isoindolinonas.

- Estudiar en profundidad la estructura de este catalizador para poder establecer una relación estructura-actividad.

\subsection{Resultados y discusión}

En esta tesis doctoral, se ha propuesto el uso del compuesto de coordinación homoléptico $\mathrm{Co}($ tpy)2, estudiado como catalizador para la hidrosililación de alquenos en el capítulo anterior, como fuente de cobalto. Este precursor se ha inmovilizado mediante un proceso de impregnación húmeda en una matriz de carbono. El hecho de que el complejo precursor tenga una relación 1:2 entre el cobalto y el ligando hace que dicho metal esté rodeado de seis átomos de nitrógeno, lo que le confiere una mayor estabilidad en la matriz carbonosa que en el caso del uso de complejos con cuatro átomos de nitrógeno rodeando al metal. Para este objetivo, es necesario formar exclusivamente el complejo homoléptico. En este sentido, se espera que el nitrógeno procedente del ligando dope la matriz de carbono, sirva como sitios de anclaje para el metal e intervenga en las reacciones de hidrogenación, favoreciendo la ruptura heterolítica del hidrógeno. Este 
Capítulo 5. Nanoclústeres de Cobalto como catalizadores para la hidrogenación quimioselectiva de nitroarenos y reacciones tándem.

material se va a utilizar como catalizador en reacciones de hidrogenación de nitroarenos y en reacciones tándem, como la aminación reductiva y la síntesis de isoindolinonas.

\subsubsection{Síntesis de los catalizadores Co@NC-T}

Para llevar a cabo la síntesis de los catalizadores heterogéneos, se utilizó como fuente de cobalto el complejo homoléptico con 2 equivalentes del ligando terpiridina, $\mathrm{Co}(\text { tpy })_{2}\left(\mathrm{NO}_{3}\right)_{2}$. Para ello, se disolvieron el nitrato de cobalto (II) y el ligando 2,2':6',2'”terpiridina (Co:terpiridina 1:2) en etanol (Esquema 5.2). Este complejo se soportó en una matriz carbonosa (Vulcan XC72R) mediante un proceso de impregnación húmeda. Finalmente, se pirolizó el material obtenido en un horno vertical a distintas temperaturas (400, 500, 600, 700 y 800 $\left.{ }^{\circ} \mathrm{C}\right)$. Los catalizadores obtenidos se nombran Co@NC-T, donde NC representa la matriz de carbono dopada con nitrógeno y $\mathrm{T}$ representa la temperatura de pirólisis (más detalles en la sección experimental). Con fines comparativos, este catalizador se sintetizó también en ausencia del ligando terpiridina (Co-P1@NC-800 and Co-P $@$ @NC-800), y cambiando el ligando nitrogenado por 1,10fenantrolina (Co-L $\left.\mathbf{L}_{2} @ \mathbf{N C - 8 0 0}\right)$ y ácido etilendiaminotetraacético $\left(\mathbf{C o}-\mathbf{L}_{3} @ \mathbf{N C - 8 0 0}\right)$.

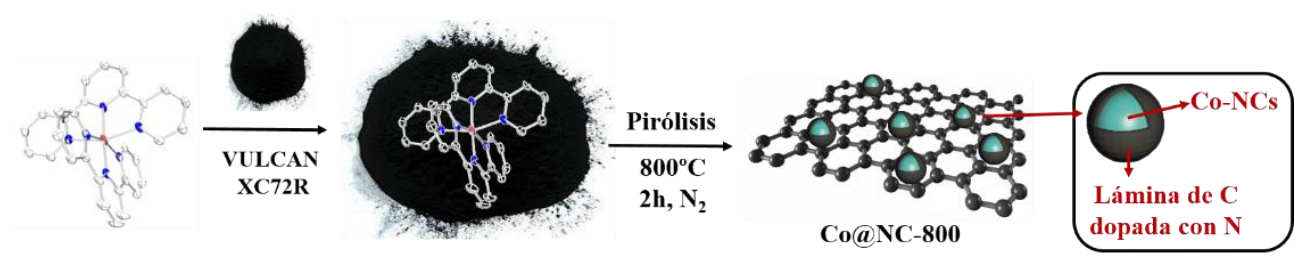

Esquema 5.2. Síntesis de los catalizadores Co@NC-800 por pirólisis del complejo $\left[\mathrm{Co}(\text { tpy })_{2}\right]\left(\mathrm{NO}_{3}\right)_{2}$ soportado en carbón. Reproducido de la ref 75 con permiso de la Royal Society of Chemistry.

\subsubsection{Optimización de las condiciones de reacción}

Para optimizar las condiciones de reacción, en primer lugar, los catalizadores sintetizados se probaron, sin ningún tipo de pretratamiento, en la reacción de hidrogenación catalítica de nitrobenceno como reacción modelo. Esta reacción se llevó a cabo inicialmente usando las condiciones de reacción reportadas más comunes ${ }^{39}$ a elevada presión y temperatura $\left(110^{\circ} \mathrm{C}\right.$ y $5 \mathrm{MPa}$ de $\left.\mathrm{H}_{2}\right)$ con el catalizador Co@ $@ \mathbf{N C - 8 0 0}$ en diferentes disolventes, con el fin de estudiar el efecto de la polaridad del medio de reacción en la actividad catalítica (entradas 1-4 de la Tabla 5.1). Como cabría esperar, el disolvente tiene una fuerte influencia en la eficiencia de reacción, pero, al contrario de lo encontrado comúnmente en bibliografía para otros catalizadores donde la reacción se 
llevaba a cabo con alta eficiencia en medios como THF o tolueno, en este caso la conversión a anilina aumenta al aumentar la polaridad del medio de reacción, siendo el agua el disolvente en el que el catalizador muestra la mejor actividad catalítica con una conversión completa y total selectividad hacia el producto deseado.

A continuación, se llevó a cabo una segunda serie de experimentos usando los catalizadores obtenidos a distintas temperaturas de pirólisis $\left(400,500,600,700,800^{\circ} \mathrm{C}\right)$ en las mismas condiciones de reacción usando agua como disolvente (entradas 5-8 de la Tabla 5.1), siendo el catalizador pirolizado a $800^{\circ} \mathrm{C}$ el que mostró los mejores resultados catalíticos. Esto indica que la temperatura de pirólisis presenta una influencia considerable en la actividad catalítica, lo que podría estar correlacionado con la naturaleza o con el tamaño de las especies metálicas que se forman a cada temperatura.

Por otro lado, se estudiaron factores como la carga de catalizador, el volumen de disolvente la presión de hidrógeno y la temperatura de reacción con el catalizador más activo, Co@NC-800, en agua como medio de reacción para la hidrogenación de nitrobenceno (entradas 9-18 de la Tabla 5.1). Como se puede observar, se obtiene una conversión completa de nitrobenceno a anilina incluso en condiciones de reacción suaves. Al disminuir la presión de hidrógeno manteniendo la temperatura y la carga de metal $(0.34 \%$ w/w) se obtiene una menor conversión de nitrobenceno (entrada 9$)$. De la misma forma, se observa que la actividad catalítica depende de la temperatura de reacción (entradas 11-15), aunque se obtiene una conversión completa de nitrobenceno a anilina aumentando la carga de cobalto a un $1.8 \%$ (50 mg de catalizador) a $70^{\circ} \mathrm{C}$ (entrada 13), siendo estas condiciones las más suaves reportadas para esta reacción usando un catalizador de cobalto en medio acuoso con una conversión y una selectividad total hacia anilina. Basándonos en los resultados anteriores, las condiciones de reacción óptimas elegidas para esta reacción, llegando a un compromiso entre disminución de la presión, disminución de la temperatura y disminución de la carga de catalizador fueron $1 \mathrm{MPa}$ de $\mathrm{H}_{2}, 100^{\circ} \mathrm{C}$ y $1 \%$ de cobalto ( $30 \mathrm{mg}$ del catalizador con $1 \%$ de carga de metal). Cabe destacar que el perfil cinético de la reacción (Figura 5.1) indica que el nitrobenceno se convierte lentamente a anilina, no detectándose ningún intermedio de reacción por cromatografía de gases durante el proceso de reacción. 
Capítulo 5. Nanoclústeres de Cobalto como catalizadores para la hidrogenación quimioselectiva de nitroarenos y reacciones tándem.

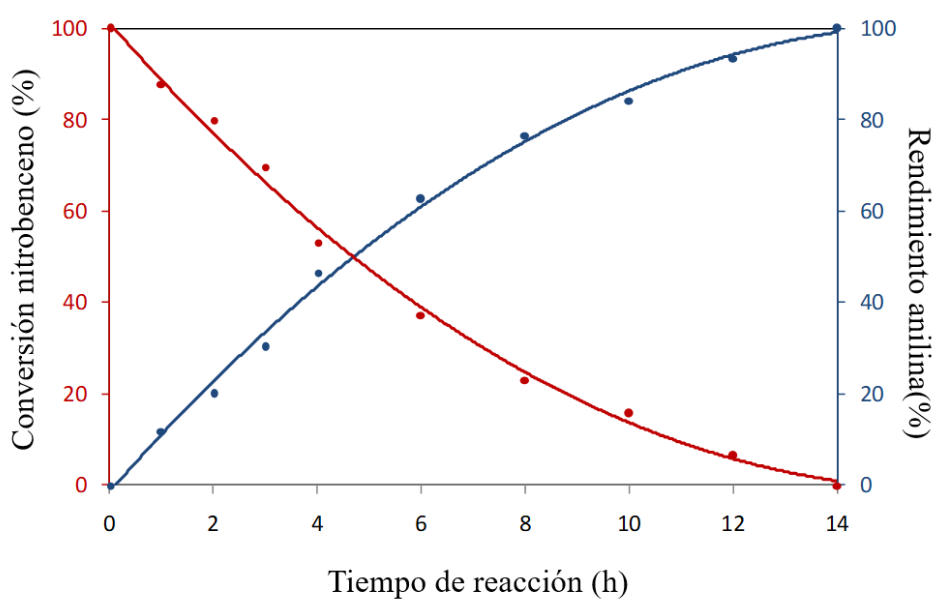

Figura 5.1. Perfil cinético para la hidrogenación de nitrobenceno a anilina catalizada por Co@NC-800 en las condiciones optimizadas de reacción (entrada 18, tabla 5.1).

Reproducida de la ref 75 con permiso de la Royal Society of Chemistry.

Con fines comparativos, se han probado otros complejos de cobalto con ligandos nitrogenados como la 1,10-fenantrolina $\left(\mathrm{L}_{2}\right)$ y el ácido etilendiaminotetraacético $\left(\mathrm{L}_{3}\right)$ como precursores (entradas 19 y 20). Aunque Co- $\mathbf{L}_{2} @ \mathbf{N C - 8 0 0}$ es activo en la reducción de nitrobenceno, este no presenta la misma actividad que el Co@NC-800 en condiciones suaves de reacción $\left(1 \mathrm{MPa}, 100^{\circ} \mathrm{C}, 1 \% \mathrm{Co}\right)$. Además, los catalizadores heterogéneos Co$\mathbf{P}_{1} @ \mathbf{C - 8 0 0}$ y Co-P $\mathbf{P}_{\mathbf{2}} @ \mathbf{C - 8 0 0}$, sintetizados en ausencia de ligandos nitrogenados (entradas 21 y 22) se probaron también como catalizadores en las condiciones mencionadas anteriormente de presión y temperatura. En ambos casos, no se detectó la presencia de anilina por cromatografía de gases después de 14 horas, lo que indica que el nitrógeno que dopa la matriz carbonosa y que actúa como soporte del cobalto juega un papel importante tanto en la estructura del material como en la activación de la molécula de hidrógeno, además de favorecer la formación de partículas más pequeñas, lo que también puede influir en la actividad del catalizador. 
Tabla 5.1. Optimización de las condiciones de reacción. ${ }^{[a]}$

\begin{tabular}{|c|c|c|c|c|c|c|}
\hline Entrada & Catalizador & Disolvente & $\begin{array}{c}\mathrm{P}(\mathrm{MPa}) \\
\mathrm{H}_{2}\end{array}$ & $\begin{array}{c}\mathrm{T} \\
\left({ }^{\circ} \mathrm{C}\right)\end{array}$ & $\begin{array}{c}\text { Co } \\
(\%)^{[\mathrm{b}]}\end{array}$ & $\begin{array}{c}\text { Conversión } \\
(\%)^{[\mathrm{c}]}\end{array}$ \\
\hline 1 & Co@NC-800 & THF & 5 & 110 & 0.34 & 15 \\
\hline 2 & Co@NC-800 & Tolueno & 5 & 110 & 0.34 & 25.8 \\
\hline 3 & Co@NC-800 & $\mathrm{EtOH}$ & 5 & 110 & 0.34 & 97 \\
\hline 4 & Co@NC-800 & $\mathrm{H}_{2} \mathrm{O}$ & 5 & 110 & 0.34 & $>99$ \\
\hline 5 & Co@NC-400 & $\mathrm{H}_{2} \mathrm{O}$ & 5 & 110 & 0.34 & 1.4 \\
\hline 6 & Co@NC-500 & $\mathrm{H}_{2} \mathrm{O}$ & 5 & 110 & 0.34 & 4.2 \\
\hline 7 & Co@NC-600 & $\mathrm{H}_{2} \mathrm{O}$ & 5 & 110 & 0.34 & 12.1 \\
\hline 8 & Co@NC-700 & $\mathrm{H}_{2} \mathrm{O}$ & 5 & 110 & 0.34 & 14 \\
\hline 9 & Co@NC-800 & $\mathrm{H}_{2} \mathrm{O}$ & 3 & 110 & 0.34 & 62.5 \\
\hline 10 & Co@NC-800 & $\mathrm{H}_{2} \mathrm{O}$ & 1 & 110 & 1 & $>99$ \\
\hline 11 & Co@NC-800 & $\mathrm{H}_{2} \mathrm{O}$ & 1 & 90 & 1 & 76.5 \\
\hline 12 & Co@NC-800 & $\mathrm{H}_{2} \mathrm{O}$ & 1 & 90 & 1.8 & $>99$ \\
\hline 13 & Co@NC-800 & $\mathrm{H}_{2} \mathrm{O}$ & 1 & 70 & 1.8 & $>99$ \\
\hline 14 & Co@NC-800 & $\mathrm{H}_{2} \mathrm{O}$ & 1 & 50 & 1.8 & 34 \\
\hline 15 & Co@NC-800 & $\mathrm{H}_{2} \mathrm{O}$ & 1 & $\mathrm{rt}$ & 1.8 & 12.5 \\
\hline 16 & Co@NC-800 $0^{[\mathrm{d}]}$ & $\mathrm{H}_{2} \mathrm{O}$ & 1 & 100 & 0.67 & $>99$ \\
\hline 17 & Co@NC-800 $[\mathrm{e}][\mathrm{f}]$ & $\mathrm{H}_{2} \mathrm{O}$ & 1 & 100 & 0.34 & $>99$ \\
\hline 18 & Co@NC-800 & $\mathrm{H}_{2} \mathrm{O}$ & 1 & 100 & 1 & $>99$ \\
\hline 19 & Co-L ${ }_{2} @ N C-800^{[\mathrm{g}]}$ & $\mathrm{H}_{2} \mathrm{O}$ & 1 & 100 & 1 & 65.4 \\
\hline 20 & Co-L 3 @NC-800 ${ }^{[\mathrm{h}]}$ & $\mathrm{H}_{2} \mathrm{O}$ & 1 & 100 & 1 & 1.2 \\
\hline 21 & Co-P $1 @ \mathrm{C}-800^{[\mathrm{i}]}$ & $\mathrm{H}_{2} \mathrm{O}$ & 1 & 100 & 1 & 0 \\
\hline
\end{tabular}


Capítulo 5. Nanoclústeres de Cobalto como catalizadores para la hidrogenación quimioselectiva de nitroarenos y reacciones tándem.

\begin{tabular}{|c|c|c|c|c|c|c|}
\hline 22 & Co-P ${ }_{2} @ \mathrm{C}-800^{[j]}$ & $\mathrm{H}_{2} \mathrm{O}$ & 1 & 100 & 1 & 0 \\
\hline 23 & $\mathrm{Co}_{3} \mathrm{O}_{4}$ & $\mathrm{H}_{2} \mathrm{O}$ & 1 & 100 & 12.5 & 0 \\
\hline 24 & $\mathrm{Co}(\mathrm{tpy})_{2}\left(\mathrm{NO}_{3}\right)_{2}$ & $\mathrm{H}_{2} \mathrm{O}$ & 1 & 100 & 10 & 0 \\
\hline 25 & Soporte $C^{[\mathrm{k}]}$ & $\mathrm{H}_{2} \mathrm{O}$ & 1 & 100 & - & 0 \\
\hline 26 & Blanco & $\mathrm{H}_{2} \mathrm{O}$ & 1 & 100 & - & 0 \\
\hline \multicolumn{7}{|c|}{ 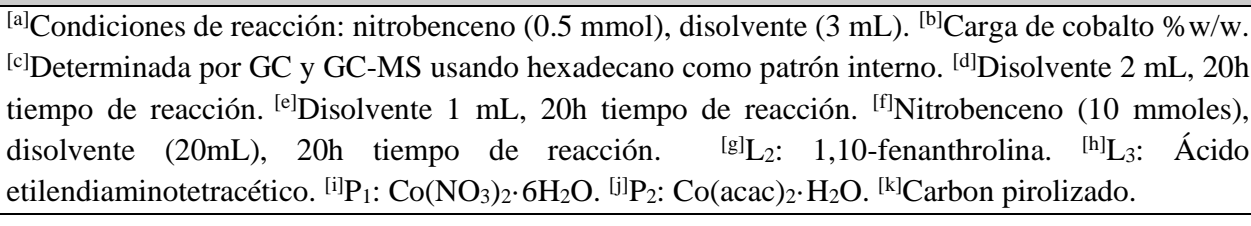 } \\
\hline
\end{tabular}

Para arrojar algo de luz sobre el papel del nitrógeno en la actividad del catalizador se comparó la actividad de los catalizadores Co@NC-800, Co- $\mathbf{L}_{2} @ \mathbf{N C - 8 0 0}$ y Co-P 1 @C800 en ensayos de intercambio H/D. Los experimentos de intercambio isotópico mostraron que Co@NC-800 disocia el $\mathrm{H}_{2}$ más rápidamente que el $\mathbf{C o L}_{2} @ \mathbf{N C - 8 0 0 , y}$ que $\mathbf{C o P}_{1} @ \mathbf{C - 8 0 0}$ no disocia nada de $\mathrm{H}_{2}$ en las mismas condiciones. La relación de la señal de masa $\mathrm{HD} / \mathrm{H}_{2}$ durante los experimentos de intercambio $\mathrm{H} / \mathrm{D}$ a tiempo real a la temperatura de reacción $\left(100^{\circ} \mathrm{C}\right)$ utilizando Co@ NC-800 y $\mathbf{C o L}_{2} @ \mathbf{N C - 8 0 0}$ dio un valor de 0.09 y 0.062 , respectivamente. Una mayor relación de la señal de masa $\mathrm{HD} / \mathrm{H}_{2}$ está relacionada con una mayor ruptura heterolítica del $\mathrm{H}_{2}$ en las condiciones de reacción, $\mathrm{y}$, por lo tanto, con una mayor actividad del catalizador. Además, se llevó a cabo un estudio de quimisorción de $\mathrm{H}_{2}$ para los catalizadores Co@NC-800, Co- $\mathbf{L}_{2} @ \mathbf{N C}-800$ y Co$\mathbf{P}_{1} @ \mathbf{C - 8 0 0}$ con el fin de dilucidar el número de centros metálicos activos. ${ }^{76} \mathrm{Sin}$ embargo, no se detectó quimisorción de $\mathrm{H}_{2}$, lo que significa que está metodología sintética promueve centros metálicos que no son directamente accesibles, ya que están recubiertos por carbón dopado con nitrógeno.

Como cabría esperar, la presencia de nanopartículas de cobalto en el catalizador es esencial para llevar a cabo la reacción de hidrogenación, ya que no se ha observado actividad en ausencia del cobalto en la matriz carbonosa o en presencia del complejo precursor de cobalto $\left[\mathrm{Co}(\text { tpy })_{2}\right]\left(\mathrm{NO}_{3}\right)_{2}$ o del nano- $\mathrm{Co}_{3} \mathrm{O}_{4}$ puro como catalizadores (entradas 23-26 de la Tabla 5.1).

Finalmente, esta reacción se ha escalado 20 veces a 10 mmoles de nitrobenceno (1.196 g) con un excelente resultado (> 99\% de conversión y selectividad a anilina, entrada 17f, Tabla 1). 
Teniendo en cuenta estos resultados, la elevada actividad de este catalizador $(\mathrm{TOF}=11.8$ $\mathrm{h}^{-1}$ ) se ha comparado con otros catalizadores de cobalto descritos (Tabla 5.2). Para obtener resultados similares a los obtenidos en esta tesis doctoral, otros catalizadores necesitan disolventes orgánicos, altas cargas de metal o altas presiones.

Tabla 5.2. Comparación de la actividad catalítica de Co@NC-800 en la reducción de nitrobenceno con otros catalizadores de Co reportados en bibliografía.

\begin{tabular}{|c|c|c|c|c|c|c|c|c|}
\hline Catalizador & $\begin{array}{c}\text { Sustrato/ } \\
\text { Metal }\end{array}$ & $\begin{array}{c}\mathbf{T} \\
\left({ }^{\circ} \mathrm{C}\right)\end{array}$ & Disolvente & $\begin{array}{c}\mathbf{t} \\
(\mathbf{h})\end{array}$ & $\begin{array}{c}\mathbf{H}_{2} \\
\text { (bar) }\end{array}$ & $\begin{array}{c}\text { Conv. } \\
(\%) \\
\end{array}$ & $\begin{array}{c}\text { TOF } \\
\left(\mathbf{h}^{-1}\right)^{[\mathbf{a}]}\end{array}$ & Ref \\
\hline Co-L/C & 100 & 110 & THF- $\mathrm{H}_{2} \mathrm{O}$ & 6 & 50 & 91 & $20^{[b]}$ & 39 \\
\hline $\mathrm{Co}_{3} \mathrm{O}_{4} / \mathrm{NGr} @ \mathrm{C}$ & 100 & 110 & THF- $\mathrm{H}_{2} \mathrm{O}$ & 12 & 50 & $>99$ & - & 63 \\
\hline Co@C/CNT & 12.5 & 110 & EtOH & 12 & 30 & 98 & $10^{[\mathrm{b}]}$ & 40 \\
\hline $\mathrm{Co} @ \mathrm{C} / \mathrm{SiO}_{2}$ & 20 & 110 & $\mathrm{EtOH}-\mathrm{H}_{2} \mathrm{O}$ & 15 & 50 & $>99$ & - & 48 \\
\hline Co@C & 20 & 100 & Tolueno & 10 & $7-11$ & 95 & $\begin{array}{l}8.2^{[\mathrm{c}]} \\
3.3^{[\mathrm{b}]}\end{array}$ & 32 \\
\hline Co/CoO@C & 10 & 120 & THF- $\mathrm{H}_{2} \mathrm{O}$ & 4 & 30 & 95 & - & 77 \\
\hline Co-Mo-S & 30 & 150 & Tolueno & 7 & 11 & $>99$ & - & 78 \\
\hline Co@NC & 24 & 110 & EtOH & 3 & 30 & 99 & - & 43 \\
\hline CoC@C & 20 & 120 & Tolueno & 3 & $7-11$ & 95 & - & 31 \\
\hline Co-L7/C & - & 110 & EtOH- $\mathrm{H}_{2} \mathrm{O}$ & 8 & 50 & $>99$ & - & 41 \\
\hline $\begin{array}{c}\mathrm{Co} / \mathrm{N}-\mathrm{C}-800- \\
\mathrm{BT}\end{array}$ & - & 110 & $\mathrm{H}_{2} \mathrm{O}$ & 1.5 & 3.5 & $>99$ & - & 35 \\
\hline Co@mesoNC & 150 & 110 & EtOH & 2 & 30 & 73 & $45.9^{[b]}$ & 79 \\
\hline Co@N-SiC & 50 & 100 & EtOH- $\mathrm{H}_{2} \mathrm{O}$ & 20 & 40 & $>99$ & - & 80 \\
\hline CoOx@NC & 10 & 110 & $\mathrm{H}_{2} \mathrm{O}$ & 5 & 50 & 100 & - & 74 \\
\hline Co@CN-800 & 4.1 & 70 & $\mathrm{H}_{2} \mathrm{O}$ & 2 & 20 & $>99$ & - & 81 \\
\hline $\begin{array}{c}\text { CMK-3-CoPc- } \\
\text { WII }\end{array}$ & 15.8 & 40 & $\begin{array}{l}\text { MeTHF- } \\
\mathrm{H}_{2} \mathrm{O}\end{array}$ & 24 & 20 & $>99$ & - & 82 \\
\hline
\end{tabular}


Capítulo 5. Nanoclústeres de Cobalto como catalizadores para la hidrogenación quimioselectiva de nitroarenos y reacciones tándem.

\begin{tabular}{|c|c|c|c|c|c|c|c|c|}
\hline CoSAs/NC & 260 & 110 & $\mathrm{EtOH}-\mathrm{H}_{2} \mathrm{O}$ & 8 & 30 & 99.7 & - & 42 \\
\hline Co-MA-800 & 14.7 & 120 & THF- $\mathrm{H}_{2} \mathrm{O}$ & 18 & 40 & $>99$ & - & 57 \\
\hline CN1meso-Co & 71.8 & 100 & $\begin{array}{l}\text { Propanol- } \\
\mathrm{Et}_{3} \mathrm{~N}\end{array}$ & 14 & 15 & $>99$ & - & 58 \\
\hline Co@NC-800 & 100 & 100 & $\mathrm{H}_{2} \mathrm{O}$ & 14 & 10 & $>99$ & 11.8 & $\begin{array}{l}\text { Esta } \\
\text { tesis }\end{array}$ \\
\hline Co@NC-800 & 69 & 70 & $\mathrm{H}_{2} \mathrm{O}$ & 14 & 10 & $>99$ & 8.3 & $\begin{array}{l}\text { Esta } \\
\text { tesis }\end{array}$ \\
\hline
\end{tabular}

[a]El valor del TOF se ha calculado a partir de la fórmula TOF $=$ mmol producto convertido/(mmol metal - tiempo). ${ }^{[b]}$ El valor ha sido calculado a partir de los datos cinéticos reportados en el trabajo, a un $20 \%$ de conversión, teniendo en cuenta el \%Co total presente en el material. ${ }^{[c]}$ Valor de TOF indicado en el trabajo, teniendo en cuenta los átomos de cobalto superficiales.

\subsubsection{Caracterización de los catalizadores}

Todos los catalizadores sintetizados se caracterizaron extensamente mediante el uso de diferentes técnicas con el fin de conocer la naturaleza de las especies de cobalto.

Teniendo en cuenta que la actividad catalítica está correlacionada con la temperatura de pirólisis, las propiedades redox de los catalizadores Co@NC-T se estudiaron mediante un proceso de reducción a temperatura programada (TPR). Como se muestra en la Figura 5.2, el consumo de hidrógeno decrece a medida que la temperatura de pirólisis del catalizador aumenta. Además, el catalizador pirolizado a $800^{\circ} \mathrm{C}$ muestra un consumo de $\mathrm{H}_{2}$ considerablemente menor que el resto, lo que sugiere que presenta una mayor cantidad de especies de cobalto reducidas. 


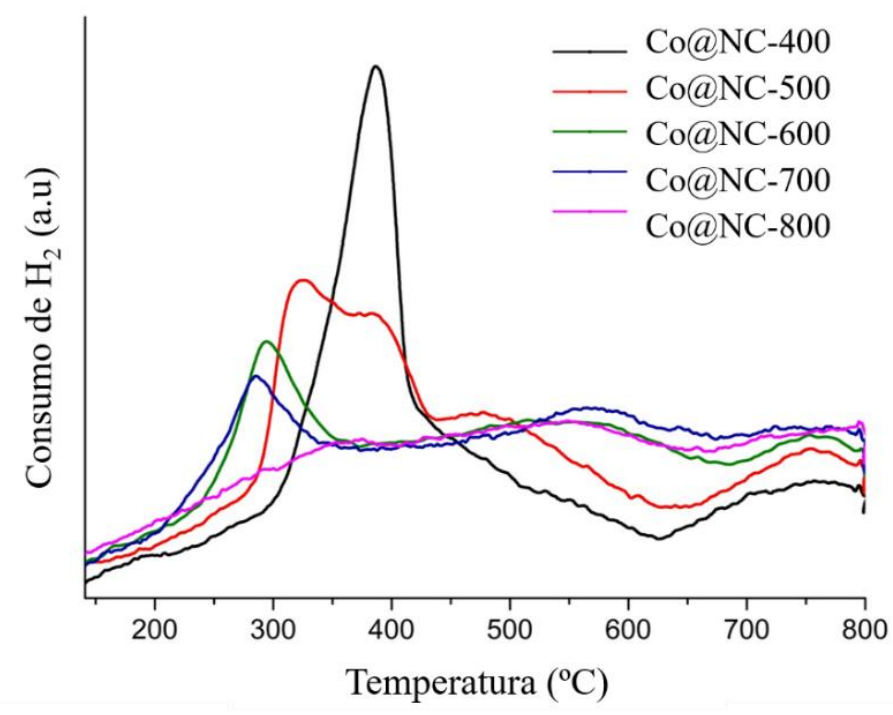

Figura 5.2. Análisis por reducción a temperatura programada de los catalizadores Co@NC-T. Reproducida de la ref 75 con permiso de la Royal Society of Chemistry.

Por otro lado, se llevaron a cabo estudios de microscopía electrónica de transmisión de barrido en campo oscuro anular a ángulos grandes (HAADF-STEM) y de espectroscopía de rayos $\mathrm{X}$ de energía dispersiva (EDX) con el objetivo de conocer en más detalle el motivo de la gran diferencia de actividad entre el Co@NC-800 y el resto de los catalizadores sintetizados. 
Capítulo 5. Nanoclústeres de Cobalto como catalizadores para la hidrogenación quimioselectiva de nitroarenos y reacciones tándem.
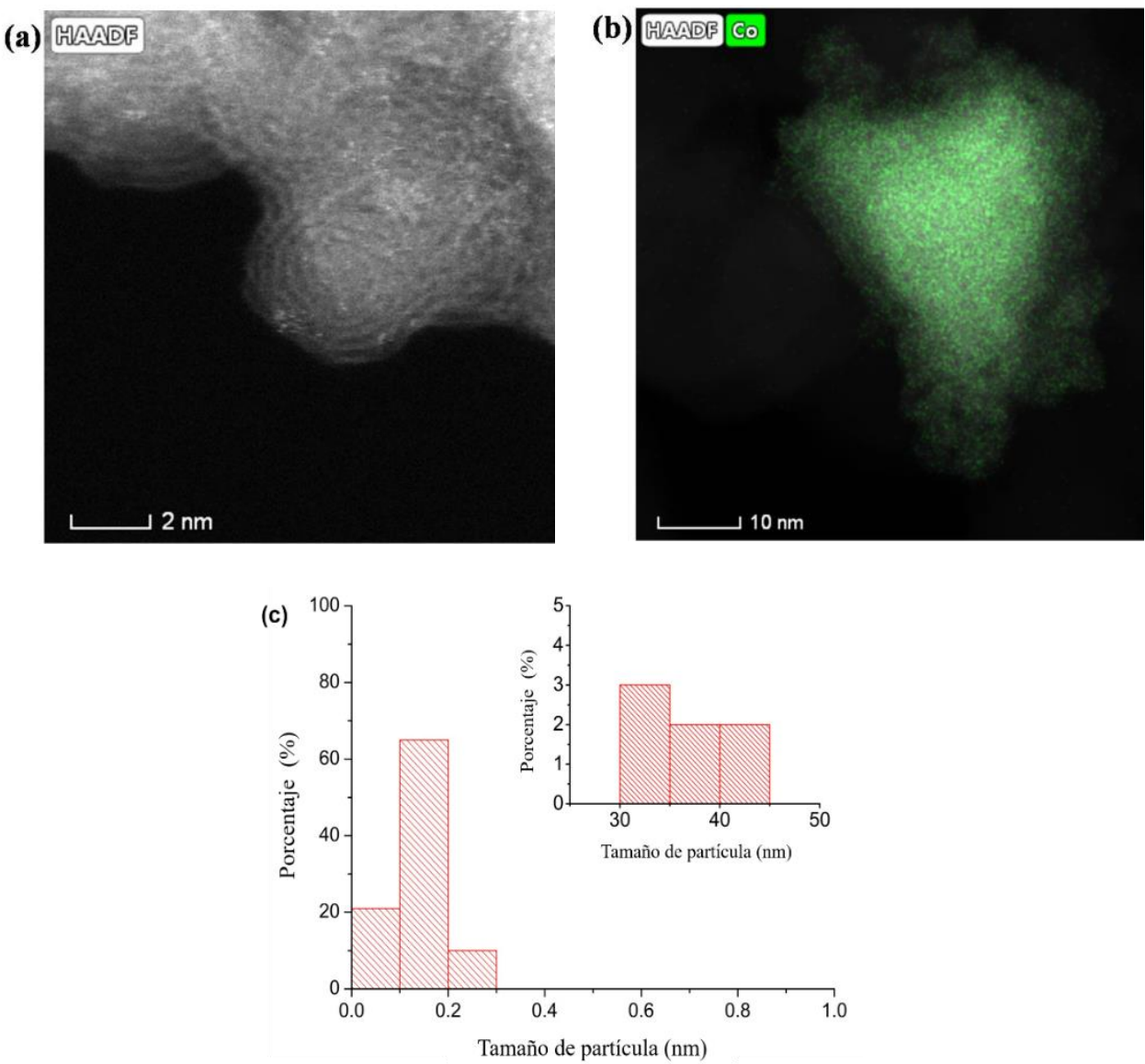

Figura 5.3. a) imagen del Co@NC-800 tomada con HAADF-STEM. Los puntos brillantes de alta intensidad corresponden a nanoclústeres de Co, b) mapa STEM-EDX de alta resolución de Co@NC-800. El mapa de cobalto se ha superpuesto en la imagen de STEMHAADF. c) Distribución del tamaño de partícula del catalizador Co@NC-800 (se han contado 200 partículas). El diagrama insertado muestra el porcentaje de partículas entre 30 y $50 \mathrm{~nm}$. Reproducida de la ref 75 con permiso de la Royal Society of Chemistry.

El tamaño de partícula varía significativamente al variar la temperatura de pirólisis del material, como se puede observar en la Figura 5.9 de la sección experimental. El sistema catalítico más activo, Co@NC-800, presenta una distribución del tamaño de partícula bastante amplia, con una importante fracción de nanoclústeres por debajo de $1 \mathrm{~nm}$ y una pequeña contribución, alrededor de un 7\%, de agregados en el rango de 30-50 nm (Figura 5.3 c). Sin embargo, cuando se analizó el catalizador menos activo en esta reacción, 
Co@NC-400, el tamaño de las nanopartículas era mayor de 200 nm (Figura 5.9). A partir de estos resultados se podría concluir que a medida que la temperatura de pirólisis de los materiales aumenta, la cantidad de agregados de metal disminuye, siendo los clústeres subnanométricos la especie mayoritaria cuando se piroliza el material a $800^{\circ} \mathrm{C}$.

Por otro lado, al estudiar el tamaño de partícula en los materiales sintetizados sin usar ligandos nitrogenados $\left(\mathbf{C o} @ \mathbf{P}_{\mathbf{1}}-\mathbf{C - 8 0 0}\right.$ y $\left.\mathbf{C o} @ \mathbf{P}_{\mathbf{2}} @ \mathbf{C - 8 0 0}\right)$ se vio que estaba en el rango de 10-20 nm, siendo estas especies también mayores que las encontradas en Co@NC$\mathbf{8 0 0}$ (Figura 5.9). Finalmente, la alta dispersión y la distribución homogénea del cobalto en la matriz de carbono del Co@NC-800 se confirmó mediante análisis de alta resolución STEM-EDX (Figura 5.3 b). Por lo tanto, a partir de estos resultados se puede concluir que, como en muchas reacciones catalíticas, el catalizador más activo es el que presenta la mayor dispersión metálica y un mayor carácter metálico.

Los patrones de difracción de rayos X (PXRD) para los diferentes materiales sintetizados se muestran en la Figura 5.4. En el caso del catalizador Co@NC-800 las señales observadas corresponden al $7 \%$ del cobalto que se presenta como agregados en el material, ya que las especies subnanométricas están por debajo del límite de detección de la técnica. Esta técnica revela que la especie principal en el material Co@NC-800 es el cobalto metálico. De hecho, los picos a 44.0, 51.3 y 75.4 grados corresponden a los planos cristalinos de una estructura de cobalto cúbica (100), (200) y $(220)^{83}\left(\right.$ JCPDS n $^{\circ}$ 15-0806). Cabe destacar que el pico a $2 \theta$ por debajo de $44^{\circ}$ es característico de la especie Co- $\mathrm{N}_{\mathrm{x}}\left(\mathrm{JCPDS} \mathrm{n}^{\mathrm{o}}\right.$ 41.0943). ${ }^{84,85}$
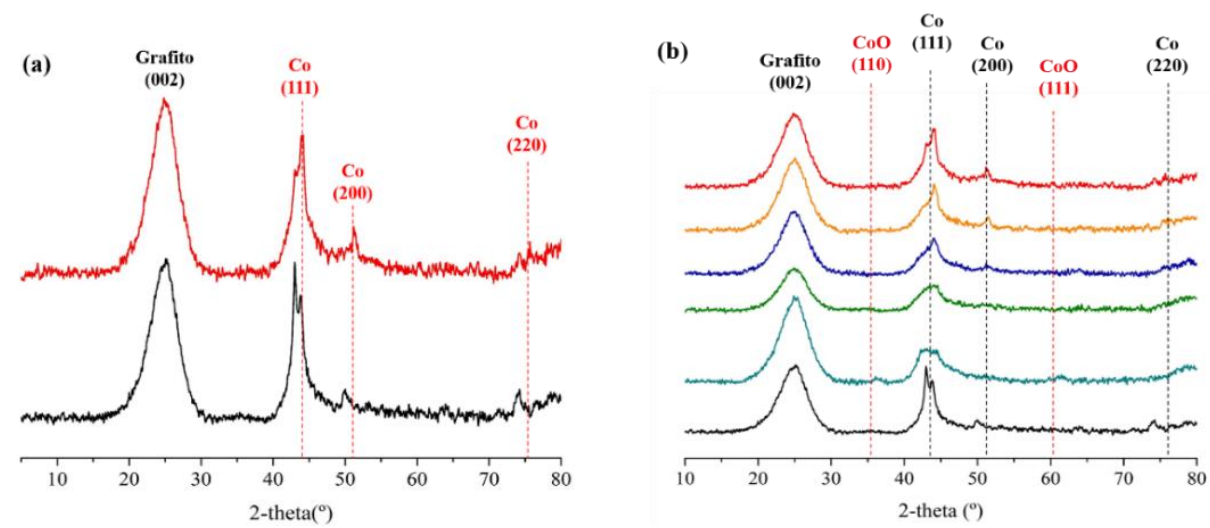

Figura 5.4. Patrones de difracción de rayos $X$ de a) soporte de carbón (negro) y Co@NC800 (rojo), b) soporte de carbón (negro), Co@NC-400 (azul claro), Co@NC-500 (verde), Co@NC-600 (azul oscuro), Co@NC-700 (naranja) y Co@NC-800 (rojo). Reproducida de la ref 75 con permiso de la Royal Society of Chemistry. 
Además, el pico ancho que aparece alrededor de $25^{\circ}$ se atribuye al soporte de carbón amorfo. Estos datos se usan principalmente para comparar las especies presentes en los catalizadores pirolizados a distintas temperaturas con las presentes en el catalizador pirolizado a $800^{\circ} \mathrm{C}$. En este sentido, los patrones de difracción de rayos X para los materiales Co@NC-400 y Co@NC-500 revelan que la principal especie presente es $\mathrm{CoO}$, con picos anchos a 36.6 y $61.8^{\circ}$, correspondientes a los planos cristalinos del $\mathrm{CoO}$ cúbico (110) y (111), (JCPDS nº 001-1227). ${ }^{86}$ Para los otros dos materiales, Co@NC600 y Co@NC-700, una mezcla señales de ambas especies, Co y CoO, se observan en los difractogramas (Figura 5.4 b).

La espectroscopía Raman (Figura 5.10) muestra que la estructura del carbono grafítico del soporte se mantiene en el material final. En el espectro se pueden observar tanto la banda $\mathrm{G}$ a $1590 \mathrm{~cm}^{-1}$, relacionada con las vibraciones en el plano de los átomos de carbono $\mathrm{sp}^{2}$, como la banda $\mathrm{D}$ a $1350 \mathrm{~cm}^{-1}$, relacionada con los defectos inducidos en la estructura del material, que no es perfectamente cristalina. ${ }^{87}$

Con el fin de profundizar más en la estructura del catalizador, y especialmente en el papel del nitrógeno procedente del ligando orgánico, se llevaron a cabo estudios de espectroscopía fotoelectrónica de rayos X (XPS). Estos estudios permiten estudiar la composición superficial y el estado de oxidación del metal y del nitrógeno en el catalizador Co@NC-800. La Figura 5.5 a prueba que el nitrógeno se incorpora en la matriz de carbono, indicando que el ligando empleado participa en la generación de estos materiales.
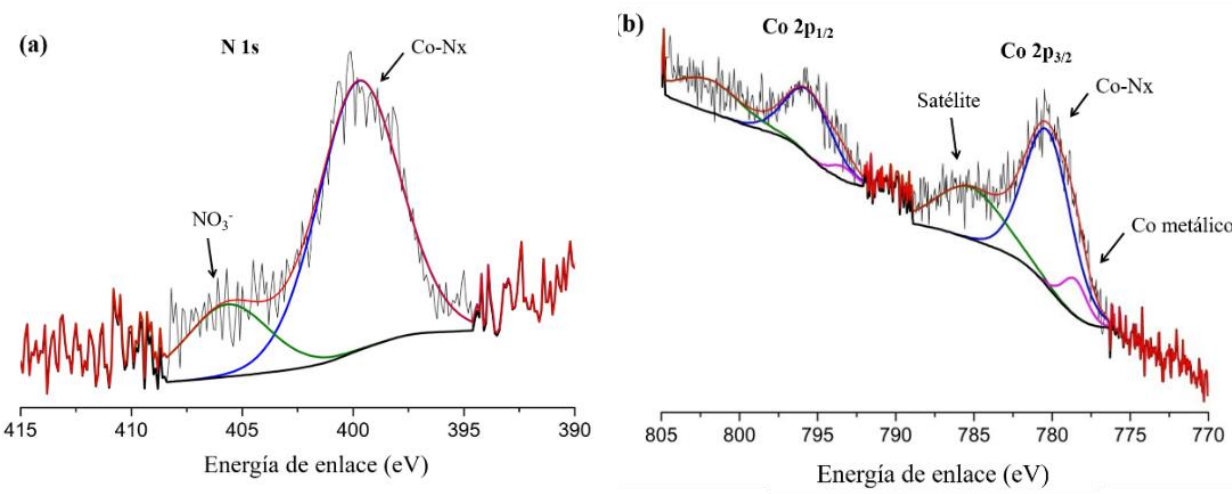

Figura 5.5. Espectros XPS del Co@NC-800 de las líneas a) N 1s y b) Co 2p. Reproducida de la ref 75 con permiso de la Royal Society of Chemistry. 
La deconvolución del espectro de N 1s (Figura 5.5 a) da lugar a dos picos, lo que significa que hay dos tipos de nitrógeno presentes en la estructura. Las energías de enlace (binding energy, BE) observadas en la deconvolución del espectro se corresponden con el $\mathrm{N}$ del fragmento $\mathrm{NO}_{3}{ }^{-}(405.6 \mathrm{eV})$ y con un nitrógeno pirrólico o coordinado a Co (centros Co$\left.\mathrm{N}_{\mathrm{x}}\right)(399.8 \mathrm{eV}){ }^{88}$ Claramente, el pico asignado a nitrógeno pirrólico o $\mathrm{N}$ coordinado a Co indica que este tipo de nitrógeno es el mayoritario, el cual puede servir como anclaje para los átomos de cobalto. La deconvolución de este espectro reveló que alrededor del $74.9 \%$ de los átomos de nitrógeno están unidos al metal. ${ }^{88}$

Por otro lado, el espectro XPS del Co $2 \mathrm{p}_{3 / 2}$ se deconvolucionó en tres picos individuales a $778.7,780.5$ y $785.6 \mathrm{eV}$ (Figura $5.5 \mathrm{~b}$ ). El pico a $778.7 \mathrm{eV}$ corresponde a cobalto metálico ${ }^{89}$ mientras que el pico a $780.5 \mathrm{eV}$ ese asocia a especies Co- $\mathrm{N}_{\mathrm{x}} \cdot{ }^{89-91}$ Finalmente, el pico a $785.6 \mathrm{eV}$ corresponde al pico satélite del $\mathrm{Co}^{2+} .{ }^{29}$ Esto indica que la mayoría de los átomos de cobalto de la superficie se encuentran en la forma Co- $\mathrm{N}_{\mathrm{x}}$.

El espectro normalizado XANES en el borde $\mathrm{K}$ del Co para el precursor de cobalto $\left[\mathrm{Co}(\text { tpy })_{2}\right]\left(\mathrm{NO}_{3}\right)_{2}$, y para el catalizador Co@NC-800 se muestran en la Figura 5.6. Como cabría esperar, el precursor de cobalto (Figura 5.6 a) muestra una posición de borde $(\sim 7720 \mathrm{eV})$ similar a la del estándar $\mathrm{Co}(\mathrm{OAc})_{2}$, típica del $\mathrm{Co}^{2+}$. Además, la geometría octaédrica no centrosimétrica para el Co en el complejo se deduce de la presencia de un pico de pre-borde a $7710 \mathrm{eV}$, como resultado de la hibridación p-d de los orbitales del átomo de cobalto con los de los ligandos de su entorno. ${ }^{92} \mathrm{El}$ complejo presenta diferentes distancias Co-N (Tabla 5.2) que refuerzan su carácter no centrosimétrico. 

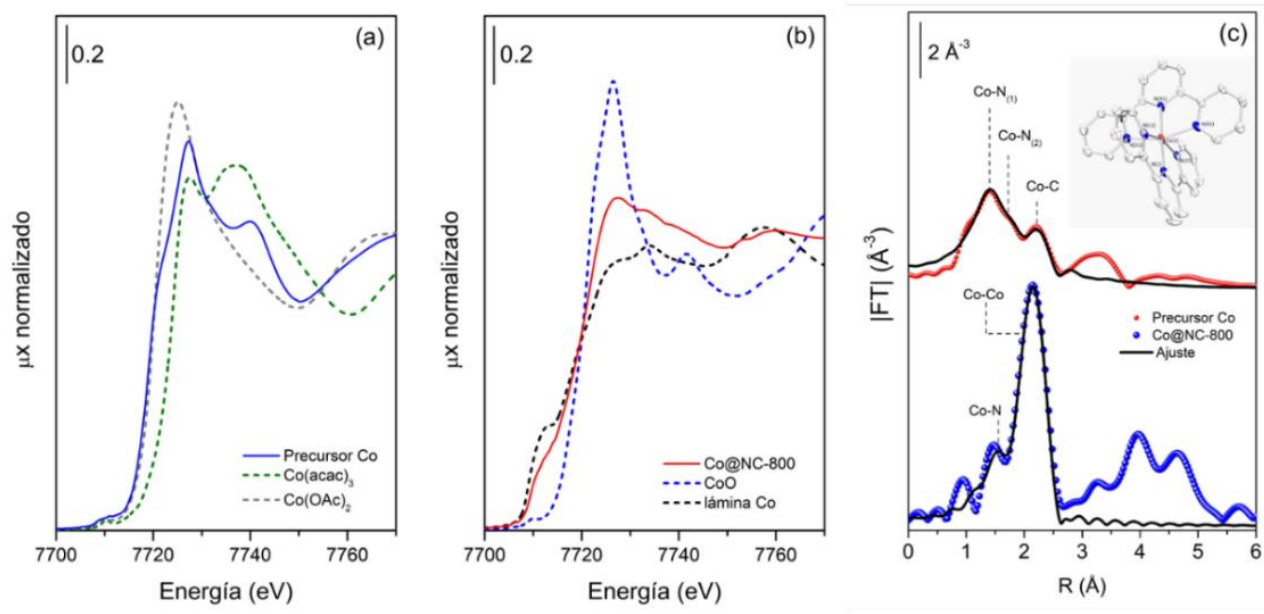

Figura 5.6. Espectros XANES normalizados $(\mathrm{a}, \mathrm{b})$ en el borde $\mathrm{K}$ del Co para el precursor de Co, Co@NC-800 y los respectivos estándares de cobalto con posible similitud a las muestras estudiadas. c) Modulo de la transformada de Fourier y ajustes de la curva para el precursor de Co y Co@NC-800. Reproducida de la ref 75 con permiso de la Royal Society of Chemistry.

El espectro XANES del Co@NC-800 (Figura 5.6 b) cambia drásticamente con respecto al del precursor de cobalto. La posición del borde se desplaza a 7709 eV (similar a la lámina de cobalto metálico que se usa como estándar), lo que demuestra la reducción de las especies de $\mathrm{Co}^{2+}$ a $\mathrm{Co}^{0}$, confirmando la formación de nanoclústeres de cobalto. Sin embargo, a pesar de la similitud en la posición de los bordes, las características XANES no se asemejan completamente a las del Co metálico. En concreto, la mayor intensidad de la línea blanca en el espectro de Co@NC-800 en comparación con la lámina de cobalto sugiere cierto grado de oxidación del cobalto, lo que concuerda con el análisis XPS. Sin embargo, en el espectro no se aprecian directamente rasgos relacionados con los óxidos de cobalto, lo que podría indicar que los átomos de cobalto oxidados están implicados en un tipo de vecindad diferente, muy probablemente rodeados de átomos de nitrógeno y carbono, y con una geometría diferente. En la Figura 5.6 c se muestra la transformada de Fourier de los espectros EXAFS ponderados por $\mathrm{k}^{2} \mathrm{y}$ los ajustes de las curvas para el precursor de cobalto y para el material Co@NC-800. El precursor de cobalto muestra una señal bastante fuerte alrededor de $4 \AA$ dividida en tres contribuciones diferentes, lo que demuestra el alto grado de orden y cristalinidad. 
El espectro del precursor de Co se ajustó utilizando la información cristalográfica obtenida por difracción de rayos $\mathrm{X}$ de monocristal en el estudio de estos complejos en el capítulo anterior, lo cual demuestra ser un modelo excelente y conduce a resultados bastante similares cuando se comparan ambas técnicas. Dado el gran número de átomos implicados y el enorme número de trayectorias diferentes que habría que considerar para describir el precursor, como primer paso se sumaron todas las trayectorias generadas por FEFF a partir de este modelo, dando lugar a $|\mathrm{FT}|$ iguales (Figura 5.11). A continuación, se realizó también dicho ajuste, dejando sólo cuatro parámetros libres, considerando todas las trayectorias sumadas como modelo, dando lugar a un buen ajuste de la curva hasta $4 \AA$ (Figura 5.11). Ambos resultados demuestran el excelente modelo que representa la estructura obtenida por difracción de rayos $\mathrm{X}$ de monocristal y la calidad del compuesto precursor. Con el fin de realizar una evaluación cuantitativa se llevó a cabo un ajuste más sencillo considerando únicamente las dos primeras capas de coordinación. Como se ha mencionado anteriormente, se obtuvieron dos contribuciones diferentes de Co-N a 1.4 y $1.7 \AA$ ( $\sin$ corrección de fase) con un total de $\mathrm{N}_{\mathrm{Co}-\mathrm{N}}=6$ y una tercera (y menos precisa) contribución de Co-C a $2.2 \AA$ con $\mathrm{N}_{\mathrm{Co}-\mathrm{C}}=5.5$. En el caso del catalizador objeto de estudio, Co@NC-800, se observa una intensa contribución de CoCo a $2.1 \AA ̊$ con $\mathrm{N}_{\mathrm{Co-Co}}=5.9$, que representaría nanoclústeres de Co con un diámetro de alrededor de $0.8 \mathrm{~nm}$, considerando una geometría cubo-octaédrica y una distribución de tamaño de partícula limitada. ${ }^{93,94}$ Además, es posible observar un pequeño hombro a $\sim 1.4 \AA$ que se ajusta como una contribución de $\mathrm{Co}-\mathrm{N}(\mathrm{O})$ con $\mathrm{N}_{\mathrm{Co}-\mathrm{N}}=2$, lo que apoya los resultados XANES sobre la presencia de especies de cobalto oxidadas después de la pirólisis. Este hombro se ha observado en la literatura para un sistema similar. ${ }^{43} \mathrm{La}$ información cuantitativa obtenida para los ajustes EXAFS se recoge en la Tabla 5.3. 
Capítulo 5. Nanoclústeres de Cobalto como catalizadores para la hidrogenación quimioselectiva de nitroarenos y reacciones tándem.

Tabla 5.3. Resumen de los parámetros optimizados mediante el ajuste de los datos EXAFS en el borde $\mathrm{K}$ del Co. ${ }^{[\mathrm{a}]}$

\begin{tabular}{|c|c|c|c|c|c|c|}
\hline Muestra & $\mathbf{N}$ & Enlace & $\mathbf{R}(\AA)$ & $\sigma^{2}\left(\AA^{2}\right)$ & $\begin{array}{l}\Delta \mathbf{E}_{0} \\
(\mathrm{eV})\end{array}$ & $\begin{array}{c}\text { factor-r } \\
(\%)\end{array}$ \\
\hline $\begin{array}{c}\text { Lámina } \\
\text { Co }\end{array}$ & 12 & Co-Co & $\begin{array}{c}2.495 \pm \\
0.001\end{array}$ & $\begin{array}{c}0.0063 \pm \\
0.0001\end{array}$ & $\begin{array}{c}7.6 \pm \\
0.2\end{array}$ & 0.0004 \\
\hline \multirow{3}{*}{$\begin{array}{c}\text { Precursor } \\
\text { Co }\end{array}$} & $3^{[\mathrm{b}]}$ & $\mathrm{Co}-\mathrm{N}$ & $\begin{array}{c}1.950 \pm \\
0.009\end{array}$ & $\begin{array}{c}0.0081 \pm \\
0.0013\end{array}$ & \multirow{3}{*}{$\begin{array}{c}0.7 \pm \\
0.7\end{array}$} & \multirow{3}{*}{0.0049} \\
\hline & $3^{[\mathrm{b}]}$ & Co-N & $\begin{array}{c}2.127 \pm \\
0.012\end{array}$ & $\begin{array}{c}0.0080 \pm \\
0.0022\end{array}$ & & \\
\hline & $5.4 \pm 0.6$ & Co-C & $\begin{array}{c}2.874 \pm \\
0.014\end{array}$ & $\begin{array}{c}0.0084 \pm \\
0.0047\end{array}$ & & \\
\hline \multirow{2}{*}{$\begin{array}{c}\text { Co@NC- } \\
800\end{array}$} & $2.1 \pm 1.2$ & $\mathrm{Co}-\mathrm{N}$ & $\begin{array}{c}1.928 \pm \\
0.025\end{array}$ & $\begin{array}{c}0.0090 \pm \\
0.0088\end{array}$ & \multirow{2}{*}{$\begin{array}{c}0.5 \pm \\
1.5\end{array}$} & \multirow{2}{*}{0.0083} \\
\hline & $5.9 \pm 0.6$ & Co-Co & $\begin{array}{c}2.499 \pm \\
0.008\end{array}$ & $\begin{array}{c}0.0063 \pm \\
0.0011\end{array}$ & & \\
\hline
\end{tabular}

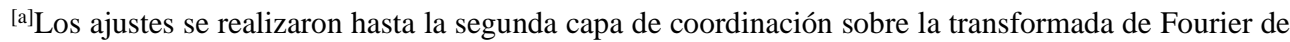
las funciones $\chi(\mathrm{k})$ ponderadas por $\mathrm{k}^{2}$ realizadas en los intervalos $\Delta \mathrm{k}=2.2-12.2 \AA^{-1} \mathrm{y} \Delta \mathrm{R}=1.2-2.8 \AA$. Los parámetros no optimizados (o fijos ${ }^{[b]}$ ) se reconocen por la ausencia de la barra de error correspondiente. $\mathrm{S}_{0}{ }^{2}=0.76 . \mathrm{N}_{\mathrm{Co} \text {-Co }}$ igual a $5.9 \pm 0.6$ corresponde a nanoclústeres de cobalto de $0.8-0.9$ $\mathrm{nm} .{ }^{94}$

Teniendo en cuenta todos los resultados obtenidos tras una extensa caracterización del catalizador Co@NC-800, se propone un confinamiento geométrico de los nanoclústeres de Co dentro de una capa de carbono grafítico dopado con nitrógeno. Los nanoclústeres de Co están cubiertos por capas de Co- $\mathrm{N}_{\mathrm{x}}$, lo que protege al metal de la sobreoxidación por el aire. Además, el nitrógeno en el soporte de carbono sirve como sitios activos para interactuar con los sustratos funcionalizados y activar la molécula de $\mathrm{H}_{2}$, lo cual se refleja en la diferencia de rendimiento catalítico con los catalizadores en los que el soporte carbonoso no está dopado con N, Co-P $@$ @C-800 y Co-P $\mathbf{2} @ \mathbf{C - 8 0 0}$ (Tabla 5.1, entradas 21 y 22). 


\subsubsection{Actividad catalítica}

\subsubsection{Hidrogenación de nitroarenos}

Una vez caracterizado por completo el catalizador con el que se va a llevar a cabo el estudio catalítico, se procedió a explorar el rendimiento catalítico general de dicho catalizador, Co@NC-800, en la síntesis de anilinas. Para ello se usaron una amplia gama de nitroarenos sustituidos que contenían grupos dadores y atractores de electrones en diferentes posiciones del anillo, utilizando las condiciones de reacción optimizadas en la Tabla 5.4.

En dicha tabla se muestran los resultados obtenidos en la síntesis de diferentes anilinas. Como se puede observar, este sistema catalítico tolera perfectamente un amplio rango de funcionalidades. En primer lugar, se probaron sustratos que contienen halógenos en su estructura. En este caso, ni la presencia ni la posición del F, $\mathrm{Cl}$ o Br en el anillo aromático afectaron a la actividad catalítica y a la selectividad del proceso. Incluso con 1-iodo-2nitrobenceno, un sustrato con un grupo funcional muy sensible como el iodo, no se observó ningún tipo de deshalogenación. Por otro lado, se probaron nitroarenos con diferentes grupos funcionales reducibles como amidas, ésteres, cetona, nitrilo, alqueno y alquino. En todos los casos, las anilinas correspondientes se obtuvieron con excelentes rendimientos y sin que se observaran productos secundarios, con una selectividad total $>99 \%$, permaneciendo los demás grupos reducibles intactos, lo que pone de manifiesto la excelente quimioselectividad del catalizador Co@NC-800. Además, la presencia de grupos de gran volumen en posición orto al grupo nitro en el anillo aromático, que podrían causar impedimento estérico en el proceso catalítico, no afectan a la actividad ni a la selectividad de la reacción. Finalmente, debido a que las anilinas con heteroátomos en su estructura son importantes productos intermedios en las industrias agroquímica y farmacéutica, estos compuestos se estudiaron en esta tesis doctoral, pudiéndose obtener a través de la correspondiente reducción del grupo nitro con rendimientos cuantitativos. La reducción de sustratos importantes en el ámbito farmacéutico como el nitroresorcinol o la flutamida se han llevado a cabo debido al gran interés que presentan los correspondientes productos reducidos como intermedios clave en la preparación de compuestos con actividad biológica.

Para comprobar la quimioselectividad del catalizador en la reducción del 3-nitroestireno, se llevaron a cabo por separado la hidrogenación del estireno y del nitrobenceno en idénticas condiciones de reacción. Como se muestra en la Tabla 5.4, la anilina se obtuvo con una conversión completa después de 14 horas, mientras que, para el mismo tiempo 
Capítulo 5. Nanoclústeres de Cobalto como catalizadores para la hidrogenación quimioselectiva de nitroarenos y reacciones tándem.

de reacción, el etilbenceno no se detectó en el análisis GC, indicando la reducción preferente del grupo nitro frente al grupo vinilo. Esta metodología ha sido ampliamente estudiada por nuestro grupo con catalizadores como el $\mathrm{Au} / \mathrm{TiO}_{2}{ }^{28}$

Tabla 5.4. Hidrogenación de nitroarenos sustituidos catalizada por Co@ NC-800. ${ }^{[a, b]}$<smiles>C#Cc1cccc(N)c1</smiles>

\footnotetext{
${ }^{[\mathrm{a}]}$ Todas las reacciones se llevaron a cabo con 0.5 mmoles de reactivo. ${ }^{[\mathrm{b}]}$ Las conversiones se determinaron por análisis GC-MS del crudo de reacción. ${ }^{[c]}$ Se ha usado etanol como disolvente. ${ }^{[\mathrm{d}]} 20$ horas de tiempo de reacción.
}

Con el fin de demostrar la adsorción y activación del grupo nitro frente al doble enlace en el catalizador Co@NC-800, se llevó a cabo un estudio con la técnica ATR-FTIR usando nitrobenceno y 3-nitroestireno como moléculas sonda. Este es un estudio 
comúnmente desarrollado en bibliografía con materiales que contienen metales de transición. ${ }^{20,32}$ Este estudio se basa en que los diferentes modos de adsorción de los grupos nitro y vinilo del 3-nitroestireno podrían estar correlacionados con la selectividad del proceso. En todos estos casos, las bandas $v_{\text {as }}$ asimétricas y $v_{\mathrm{s}}$ simétricas del grupo nitro se detectaron preferentemente en los espectros de FTIR en lugar de las bandas $v$ $(\mathrm{C}=\mathrm{C})$ y $\delta(=\mathrm{C}-\mathrm{H})$, lo cual indica una adsorción preferente del grupo nitro sobre el catalizador, lo que favorece su reducción frente al doble enlace. En nuestro caso particular, cuando se adsorbió la molécula de nitrobenceno sobre el catalizador y se midió por espectroscopía FTIR se detectaron las bandas $v_{\text {as }}$ y $v_{\mathrm{s}}$ del $-\mathrm{NO}_{2}$ a 1523 y 1346 $\mathrm{cm}^{-1}$ (Figura 5.7), las cuales aparecen desplazadas respecto a las que se observan cuando se absorbe nitrobenceno puro sobre $\mathrm{KBr}$ (Figura 5.12). Este hecho prueba la fuerte interacción del grupo nitro con el catalizador Co@NC-800. Además, cuando se adsorbió la molécula 3-nitroestireno en la superficie del catalizador, sólo se observaron las bandas asociadas a la función nitro ( $v_{\mathrm{as}} \mathrm{y} v_{\mathrm{s}}$ en 1527 y $1348 \mathrm{~cm}^{-1}$ respectivamente), lo que confirma la adsorción preferente del grupo nitro frente al doble enlace (las bandas $v(\mathrm{C}=\mathrm{C})$ y $\delta(=\mathrm{C}-\mathrm{H})$ aparecerían a 1636 y $1416 \mathrm{~cm}^{-1}$ respectivamente $) .{ }^{95}$ Como consecuencia de esta adsorción preferente del grupo nitro, la hidrogenación del 3nitroestireno ocurre de forma quimioselectiva, obteniéndose como resultado la correspondiente anilina derivada utilizando Co@NC-800 como catalizador.

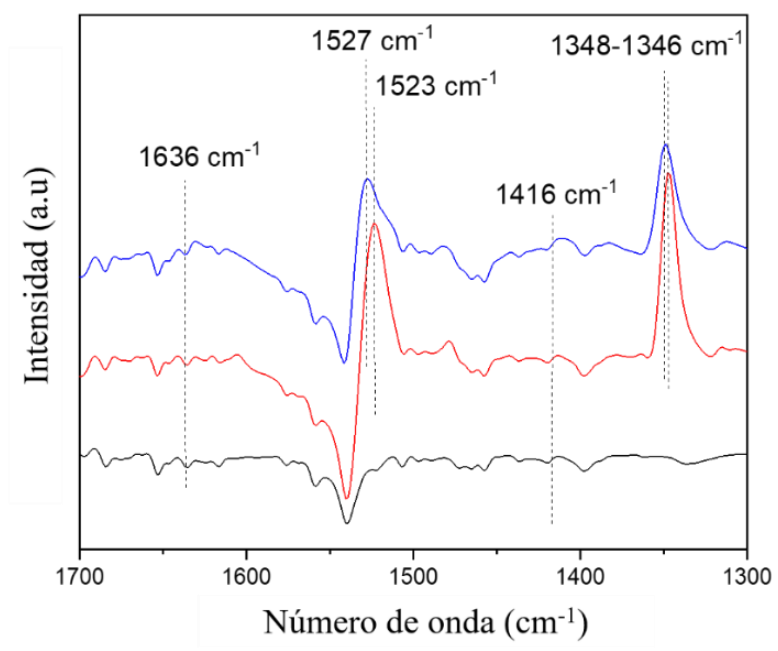

Figura 5.7. Espectro ATR-IR del catalizador Co@NC-800 sin pretratamiento (línea negra) y con las especies pre-adsorbidas, nitrobenceno (línea roja) y 3-nitroestireno (línea azul). Reproducida de la ref 75 con permiso de la Royal Society of Chemistry. 
A continuación, se estudió la estabilidad y heterogeneidad del catalizador $\mathbf{C o @ N C - 8 0 0 . ~}$ Para ello, una vez completada la reducción del nitrobenceno, el catalizador se separó del medio de reacción, se lavó con acetona y se secó al vacío a $60^{\circ} \mathrm{C}$ durante toda la noche previamente al siguiente uso. Como se puede observar en la Figura 5.8 a, el catalizador mantiene su actividad y puede reutilizarse al menos 3 veces, con solo una pequeña disminución de la actividad en cada reuso y manteniendo en todos los casos $>99 \%$ de selectividad hacia la anilina. Durante estos experimentos, se detectó un ligero aumento de la masa del catalizador incluso después de un secado al vacío, lo que puede indicar algún depósito residual en la superficie del catalizador que no puede eliminarse fácilmente. Esta podría ser la razón de la pequeña disminución de la actividad después de cada reuso. Para comprobar esta teoría, tras el tercer reuso, el catalizador se sometió a un proceso de pirólisis a $800^{\circ} \mathrm{C}$ y se volvió a probar en reacción. Tras este proceso de regeneración, el catalizador volvió a recuperar por completo su actividad inicial.
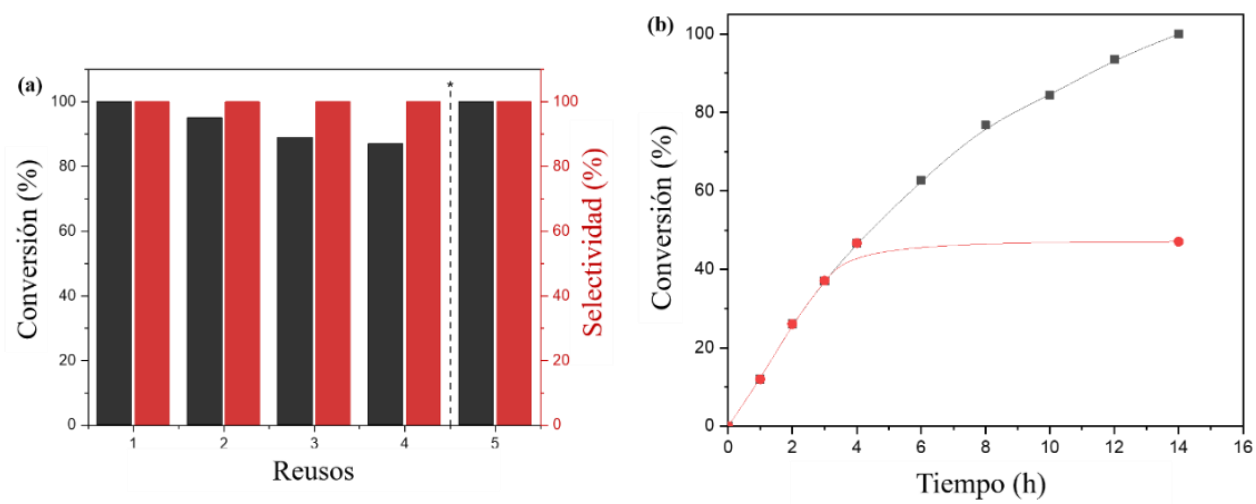

Figura 5.8. a) Experimentos de reusos del catalizador Co@NC-800, se hace un tratamiento de pirólisis (línea discontinua) después del cuarto uso y b) test de filtración en caliente para la hidrogenación catalítica de nitrobenceno a anilina en las condiciones optimizadas. Reproducida de la ref 75 con permiso de la Royal Society of Chemistry.

Además, se llevó a cabo un experimento de filtración en caliente para confirmar la heterogeneidad del catalizador (Figura 5.8 b). Para ello, la reacción se llevó a cabo durante 4 horas, tras lo cual se eliminó el catalizador y el filtrado resultante se puso de nuevo en condiciones de reacción durante 10 horas más. Tras analizar los resultados de este experimento, no se detectó ningún incremento adicional de la conversión de nitrobenceno a anilina, lo que indica que no se lixiviaron las especies activas de cobalto 
del catalizador al medio de reacción y que el catalizador Co@ NC-800 actúa como un verdadero catalizador heterogéneo.

\subsubsection{Reacciones tándem que implican la reducción de nitroarenos.}

Una vez estudiada la aplicabilidad general de este catalizador en la reducción de una amplia variedad de nitroarenos, se procedió a estudiar reacciones tándem que incluyesen un paso de hidrogenación de nitroarenos, como por ejemplo la síntesis directa de aminas secundarias a partir de un nitroareno y un aldehído.

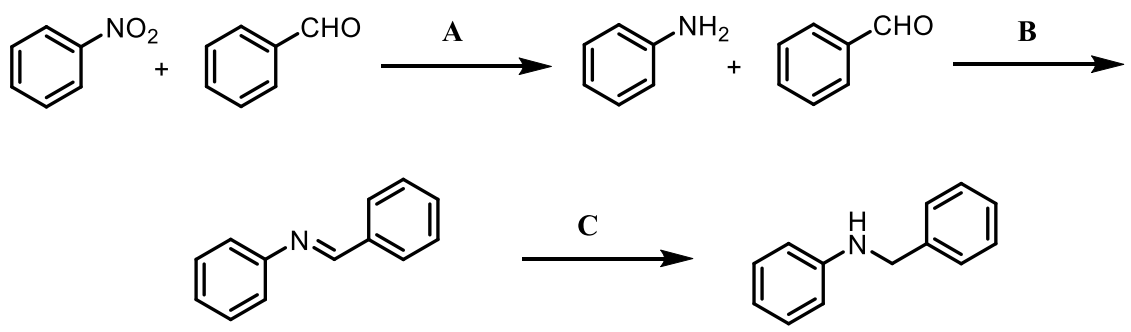

Esquema 5.3. Camino de reacción para la reacción de aminación reductiva. Reproducido de la ref 75 con permiso de la Royal Society of Chemistry.

Esta reacción se denomina aminación reductiva (Esquema 5.3). En primer lugar, se reduce el nitrocompuesto a anilina (A). A continuación, debe suceder la formación rápida de una imina (B), que luego se transformará en la amina secundaria deseada mediante hidrogenación catalítica (C). Además, cuando se emplea un aldehído aromático como el benzaldehído, el producto final de la reacción de aminación reductiva debe permanecer intacto, sin que se rompa el enlace $\mathrm{C}-\mathrm{N}$ por hidrogenolisis. 
Capítulo 5. Nanoclústeres de Cobalto como catalizadores para la hidrogenación quimioselectiva de nitroarenos y reacciones tándem.

Tabla 5.5. Reacción tándem para aminación reductiva de nitroarenos sustituidos con benzaldehído catalizada por Co@NC-800. ${ }^{[a, b]}$
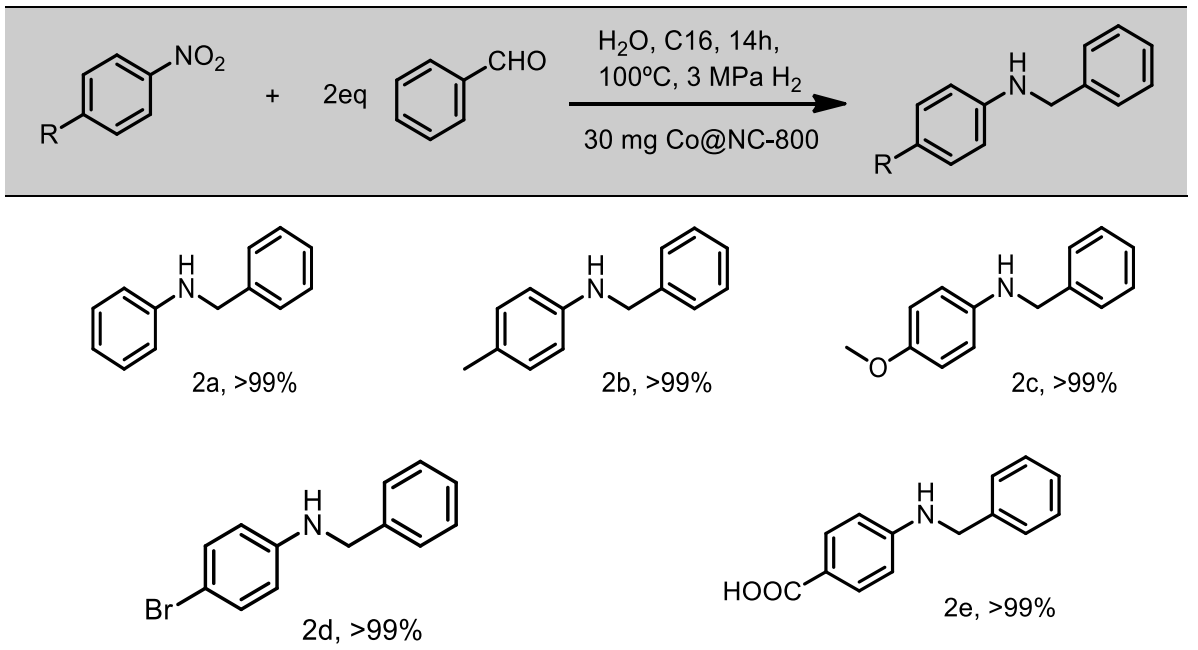

\footnotetext{
${ }^{[a]}$ Todas las reacciones se llevaron a cabo con 0.5 mmoles de nitroareno. ${ }^{[b]}$ Las conversiones se determinaron por análisis GC-MS del crudo de reacción.
}

Cabe destacar que, utilizando Co@NC-800 como catalizador, no se produjo la reducción del benzaldehído en las condiciones de reacción optimizadas. Además, se estudió el acoplamiento con varios nitroarenos aromáticos con grupos dadores y atractores de electrones para demostrar la aplicabilidad general del método (Tabla 5.5). Además, la selectividad del proceso se puede controlar variando la presión de $\mathrm{H}_{2}$ de la reacción. Si la presión se fija a $1 \mathrm{MPa}$ de $\mathrm{H}_{2}$, el producto obtenido es la imina, mientras que, si se aumenta la presión de $\mathrm{H}_{2}$ a $3 \mathrm{MPa}$, el producto obtenido es mayoritariamente la amina. En conclusión, la selectividad del proceso puede controlarse hacia la amina o la imina variando las condiciones de presión en las que se lleva a cabo la reacción.

Finalmente, estos resultados se han comparado con los obtenidos para otros catalizadores heterogéneos reportados basados en cobalto, ${ }^{63,64,73}$ resultando que el Co@NC-800 es activo en condiciones de reacción más suaves (Esquema 5.4). Además, en esta tesis doctoral, la aminación reductiva se ha llevado a cabo en agua como disolvente, lo que hace de esta reacción un proceso más sostenible. 


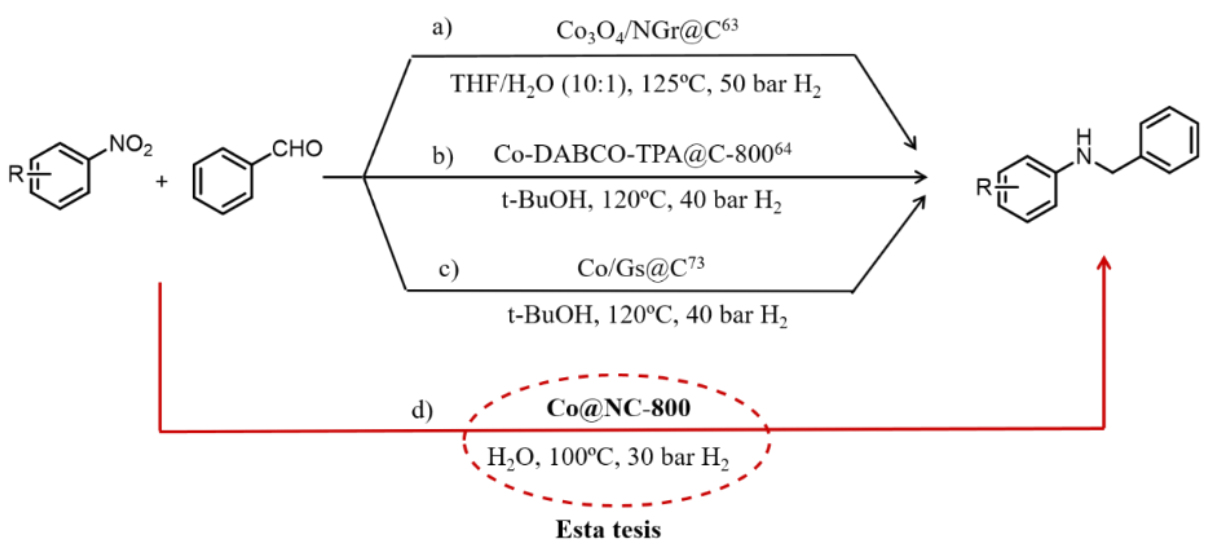

Esquema 5.4. Aminación reductiva de nitroarenos con catalizadores heterogéneos basados en cobalto. Reproducido de la ref 75 con permiso de la Royal Society of Chemistry.

Por otro lado, se llevó a cabo otro tipo de reacción tándem que implica como primer paso la hidrogenación de un nitroareno, concretamente la reacción de obtención de isoindolinonas a partir del ácido 1-formilbenzóico y el nitroareno correspondiente. También en este caso se obtuvieron los productos deseados con un buen rendimiento y selectividad partiendo de varios nitroarenos con distintas funcionalidades, tanto dadores como aceptores de electrones, para demostrar la aplicabilidad general del método (Tabla 5.6). Al igual que en la reacción de aminación reductiva, no se produjo la reducción del ácido 2-formilbenzoico en las condiciones de reacción optimizadas. 
Capítulo 5. Nanoclústeres de Cobalto como catalizadores para la hidrogenación quimioselectiva de nitroarenos y reacciones tándem.

Tabla 5.6. Reacción tándem para la síntesis de isoindolinonas a partir de nitroarenos sustituidos y 2-carboxibenzaldehído catalizada por Co@NC-800. ${ }^{[a, b]}$

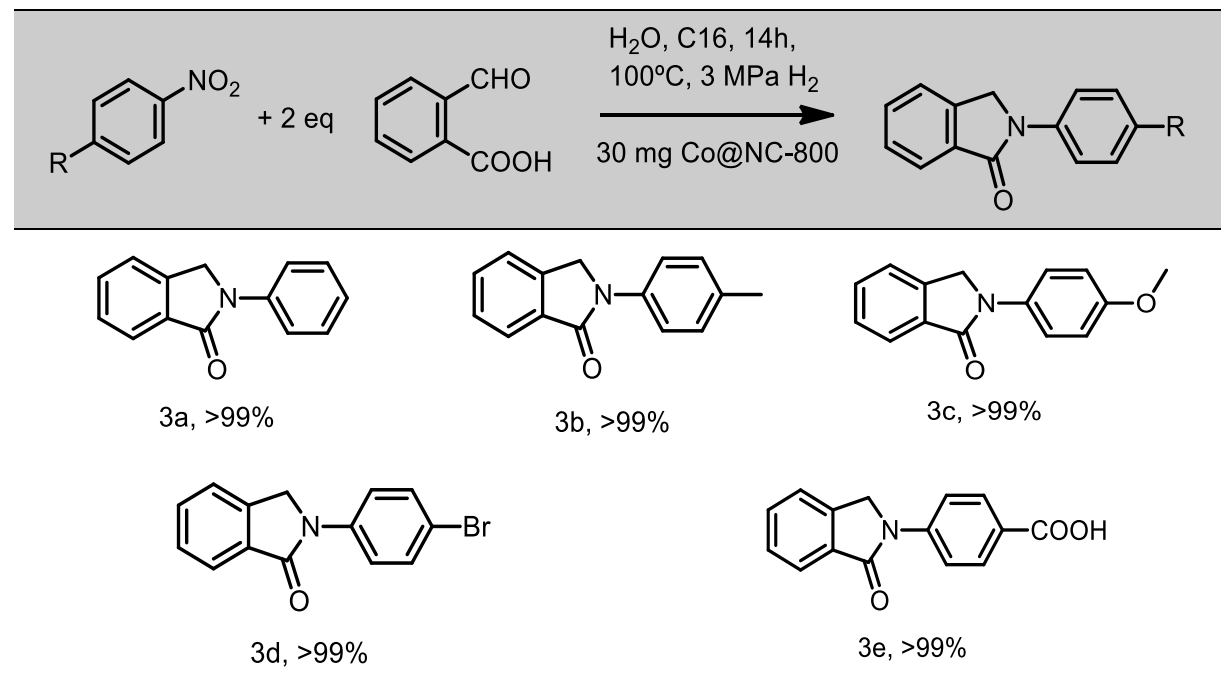

${ }^{[\mathrm{a}]}$ Todas las reacciones se llevaron a cabo con 0.5 mmoles de nitroareno. ${ }^{[\mathrm{b}}$ Las conversiones se determinaron por análisis GC-MS del crudo de reacción.

Las isoindolinonas son compuestos orgánicos que se encuentran en diversos productos naturales bioactivos. ${ }^{96,97}$ Además, se conocen una gran variedad de compuestos sintéticos, que contienen el fragmento isoindolinona en su estructura, que también han demostrado tener actividades farmacológicas. Algunos de ellos ya se han desarrollado como fármacos para el tratamiento de diferentes enfermedades. ${ }^{98-103}$ Por ello, es importante desarrollar catalizadores para llevar a cabo la síntesis de estos compuestos en condiciones menos severas de reacción y con disolventes verdes, como el agua. 


\subsection{Conclusiones}

- Se ha desarrollado una estrategia de síntesis para el catalizador Co@NC-800 en el que los nanoclústeres metálicos de Co están estabilizados por la especie Co- $\mathrm{N}_{\mathrm{x}} \mathrm{y}$ recubiertos por capas de carbón dopado con nitrógeno. Estas capas protegen al cobalto metálico de la sinterización y de la sobreoxidación en condiciones aeróbicas, evitando el crecimiento y la oxidación de estos centros de cobalto. Esto es posible debido al uso del complejo molecular adecuado que presenta seis enlaces Co-N junto con una alta temperatura de pirólisis.

- Este catalizador muestra una elevada dispersión de los nanoclústeres metálicos en el soporte carbonoso, lo cual se ha confirmado por PXRD, HAADF-STEM y EXAFS. La presencia de una mayor cantidad de nitrógeno en el soporte de carbón facilita la ruptura heterolítica del hidrógeno en condiciones suaves, lo cual se ha demostrado con experimentos de intercambio isotópico.

- Como consecuencia, este catalizador ha demostrado ser altamente activo y selectivo en la hidrogenación de un amplio rango de nitroarenos en condiciones suaves de reacción ( $\left.1 \mathrm{MPa}_{2}, 100^{\circ} \mathrm{C}\right)$ usando agua como medio de reacción. Además, este catalizador puede ser reutilizado en varios ciclos de reacción con una mínima pérdida de actividad a lo largo de los ciclos, la cual puede ser recuperada por completo tras un proceso de pirólisis del catalizador.

- Por otro lado, este catalizador es activo en reacciones tándem como la síntesis de aminas secundarias e isoindolinonas usando también agua como medio de reacción y condiciones de reacción más suaves que las reportadas en bibliografía.

- Finalmente, los estudios de adsorción usando IR se han llevado a cabo para explicar la quimioselectividad del Co@NC-800 por el grupo nitro frente a la función alqueno en el 3-nitroestireno. 

nitroarenos y reacciones tándem.

\subsection{Sección experimental}

\subsubsection{Síntesis y caracterización de los catalizadores}

El nitrato de cobalto(II) hexahidratado (Sigma-Aldrich $\geq 98 \%, 35,3 \mathrm{mg}, 0,119 \mathrm{mmol}$ ) y la 2,2':6',2"-terpiridina (abcr, 97\%, 57,2 mg, 0,238 mmol) (relación molar Co:terpiridina $=1: 2)$ se disolvieron en etanol $(40 \mathrm{~mL})$ y se agitaron durante 10 minutos a temperatura ambiente. A continuación, se añadió a la disolución el carbón que va a hacer la función de soporte $(696 \mathrm{mg}$ ) (VULCAN® XC72R, Cabot Corporation Prod. Code XVC72R; CAS No. 1333-86-4) y la mezcla resultante se dejó agitar a temperatura ambiente durante toda la noche. A continuación, se eliminó el etanol al vacío. El sólido final obtenido se secó a $60{ }^{\circ} \mathrm{C}$ durante 12 horas, tras lo cual se molió hasta obtener un polvo fino. Seguidamente, el polvo molido se transfirió a un reactor de cuarzo y se colocó en un horno vertical. El horno se purgó haciendo 3 ciclos de vacío/ $\mathrm{N}_{2}$. A continuación, la muestra se pirolizó a la temperatura correspondiente, con una rampa de calentamiento de $25^{\circ} \mathrm{C} / \mathrm{min}$, y se mantuvo a $400,500,600,700$ u $800^{\circ} \mathrm{C}$ durante 2 horas bajo flujo de nitrógeno. Por último, la muestra se enfrió hasta la temperatura ambiente. Durante todo el proceso se hizo pasar constantemente nitrógeno a través del horno. A los catalizadores obtenidos se les denominó Co@NC-T, donde T representa la temperatura de pirólisis. Con fines comparativos, también se sintetizaron catalizadores análogos en ausencia del ligando tpy utilizando $\mathrm{Co}\left(\mathrm{NO}_{3}\right)_{2} \cdot 6 \mathrm{H}_{2} \mathrm{O}$ y $\mathrm{Co}(\mathrm{acac})_{2} \cdot \mathrm{H}_{2} \mathrm{O}$ como fuentes de cobalto (Co$\mathbf{P}_{1} @ \mathbf{C - 8 0 0}$ y Co-P $\mathbf{C} @ \mathbf{C - 8 0 0}$, respectivamente) y cambiando el ligando nitrogenado por 1,10-fenantrolina o ácido etilendiaminotetraacético (Co-L $\mathbf{L}_{2} @ \mathbf{N C}-800$ y Co-L $\mathbf{L}_{3} @ \mathbf{N C}-$ $\mathbf{8 0 0}$, respectivamente). 

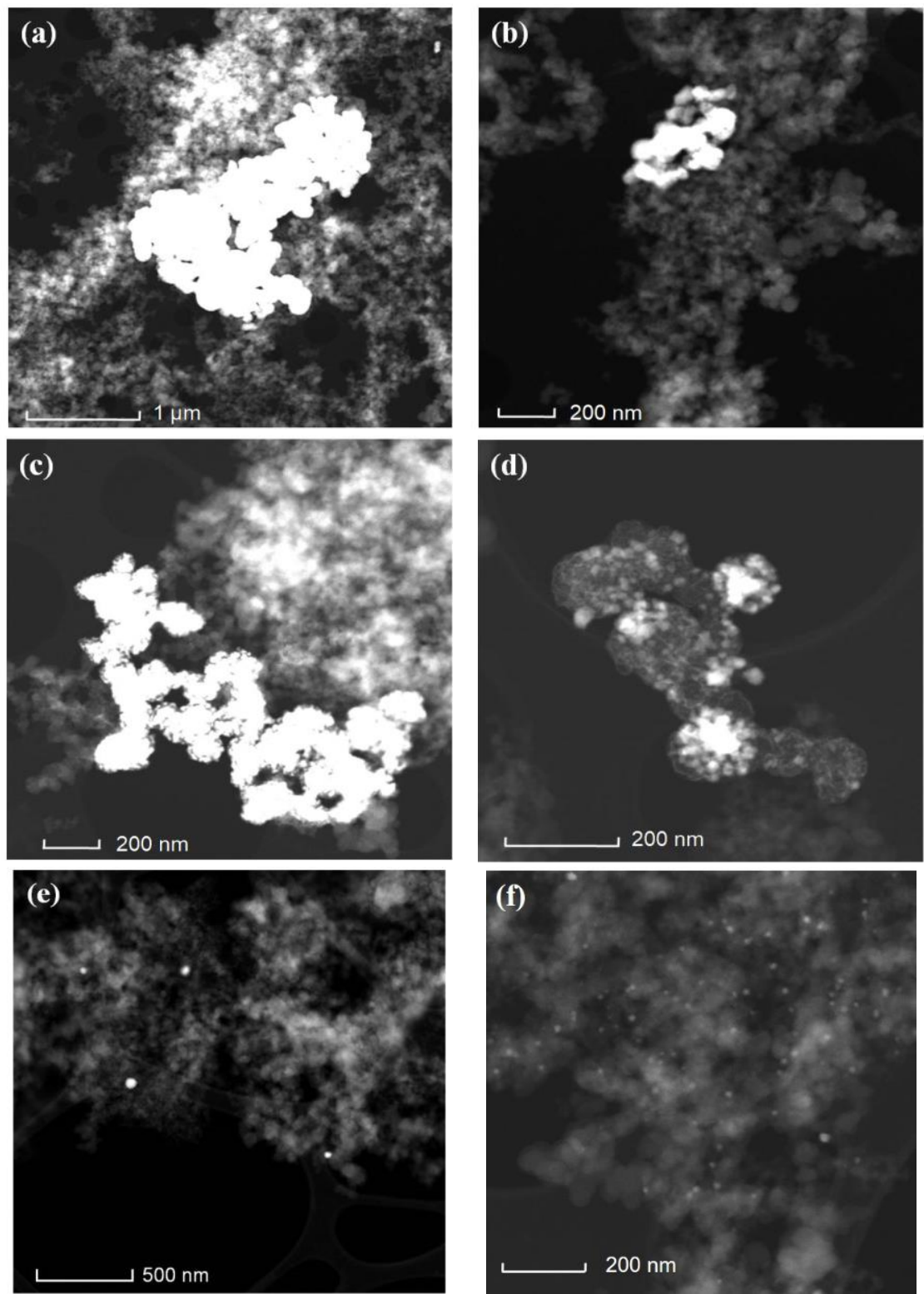

Figura 5.9. Imágenes STEM de a) Co@NC-400, b) Co@NC-500, c) Co@NC-600, d) Co@NC-700, e) Co@NC-800 y f) Co@C-800. Reproducida de la ref 75 con permiso de la Royal Society of Chemistry. 

nitroarenos y reacciones tándem.

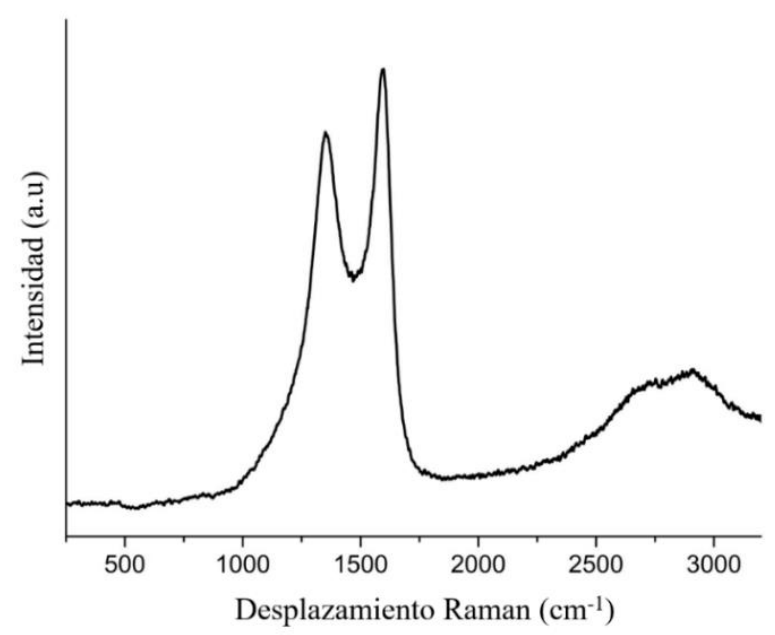

Figura 5.10. Espectro Raman para Co@NC-800. Reproducida de la ref 75 con permiso de la Royal Society of Chemistry.

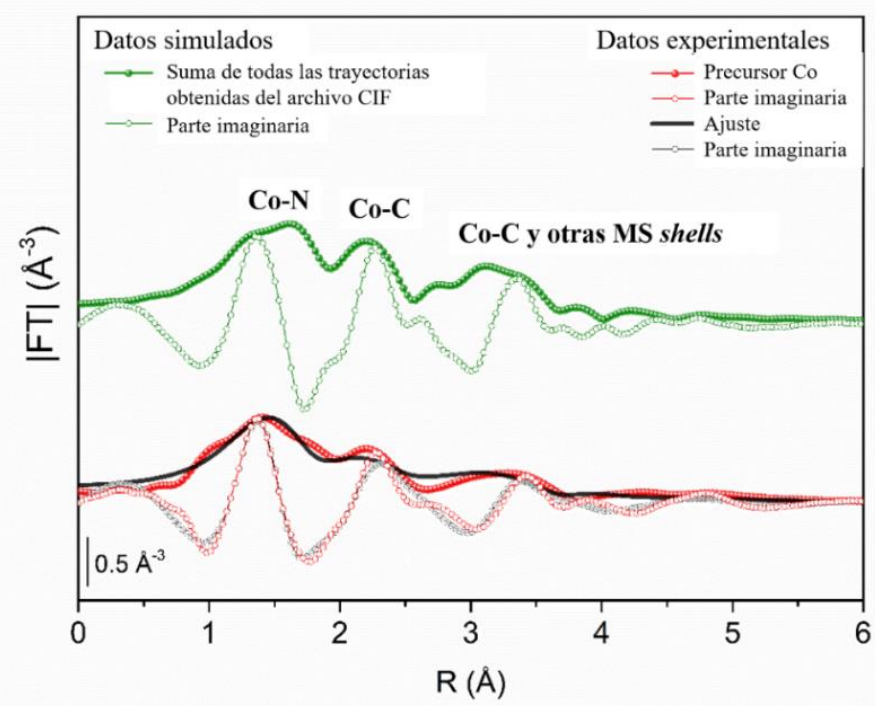

Figura 5.11. $|\mathrm{FT}|$ ponderada en $\mathrm{k}^{2}$ (puntos rojos) y ajuste de la curva alternativo (línea negra) usando como referencia el archivo CIF de la estructura de monocristal para el precursor de Co. La línea verde representa la suma de todas las trayectorias generadas por FEFF al utilizar el CIF del complejo como modelo. Las partes imaginarias se han representado también con fines comparativos. Reproducida de la ref 75 con permiso de la Royal Society of Chemistry. 


\subsubsection{Procedimiento experimental.}

\subsubsection{Hidrogenación de nitroarenos.}

La hidrogenación quimioselectiva de nitroarenos se llevó a cabo en un vial de vidrio de reacción de $7 \mathrm{~mL}$ con un tapón tipo septum. En este reactor se añadieron $0.5 \mathrm{mmol}$ del reactivo, $100 \mu \mathrm{L}$ de patrón interno (hexadecano), $3 \mathrm{~mL}$ de agua y $30 \mathrm{mg}$ del catalizador de Co@NC-T (1\% pp de Co). A continuación, se introdujo el vial de reacción en un autoclave de $300 \mathrm{~mL}$ (con capacidad para 7 viales), se purgó con hidrógeno tres veces y finalmente se presurizó a 10 bares. La mezcla de reacción se dejó agitar durante 14 h a $100{ }^{\circ} \mathrm{C}$. Tras enfriar la mezcla de reacción a temperatura ambiente, se despresurizó el autoclave lentamente. A continuación, se filtró el catalizador y se extrajo el producto con acetato de etilo. Las alícuotas extraídas de la mezcla de reacción se analizaron por cromatografía de gases y por GC-MS. Finalmente, el acetato de etilo se eliminó a vacío y los productos se caracterizaron también por RMN (Tabla 5.4).

\subsubsection{Síntesis de aminas secundarias por aminación reductiva.}

Para llevar a cabo el proceso de acoplamiento mediante la reacción de aminación reductiva se utilizó el mismo sistema que para la reducción de nitroarenos. A este reactor se añadieron 0.5 mmoles del nitroareno correspondiente, 2 equivalentes de benzaldehído ( $1 \mathrm{mmol}$ ), $100 \mu \mathrm{L}$ de patrón interno (hexadecano), $3 \mathrm{~mL}$ de agua y $30 \mathrm{mg}$ del catalizador Co@NC-800 ( $1 \%$ Co). A continuación, el vial se introdujo en el autoclave de $300 \mathrm{~mL}$, se purgó 3 veces con hidrógeno y finalmente se presurizó a 30 bares. Tras enfriar el autoclave hasta temperatura ambiente en un baño de agua-hielo, se despresurizó lentamente. Seguidamente, se filtró el catalizador y se extrajeron los productos de reacción con acetato de etilo, los cuales se analizaron posteriormente por por cromatografía de gases y por GC-MS. Finalmente, los productos obtenidos se aislaron del benzaldehído en exceso por cromatografía en columna utilizando sílice como fase estacionaria en n-hexano/acetato de etilo 9:1. Los productos puros se caracterizaron por RMN (Tabla 5.5, productos $2 \mathrm{a}-2 \mathrm{e}$ )

\subsubsection{Sintesis de isoindolinonas.}

La síntesis de isoindolinonas por acoplamiento entre un nitroareno y el 2carboxibenzaldehído se llevó a cabo en el mismo sistema descrito anteriormente. Para ello, el un vial de vidrio se añadieron 2 equivalentes de 2 -carboxibenzaldehído (1 mmol) a la mezcla descrita en el proceso anterior $(0.5 \mathrm{mmol}$ del nitroareno correspondiente, $100 \mu \mathrm{L}$ de patrón interno (hexadecano), $3 \mathrm{~mL}$ de agua y $30 \mathrm{mg}$ del catalizador Co@NC- 
800 (1\% de Co)). El vial de reacción se introdujo en el autoclave de $300 \mathrm{~mL}$, se purgó con hidrógeno 3 veces y finalmente se presurizó a 30 bares. La mezcla de reacción se dejó agitar durante 14 horas a $100^{\circ} \mathrm{C}$. Tras enfriar el autoclave en una mezcla de aguahielo hasta temperatura ambiente, este se despresurizó lentamente. A continuación, se filtró el catalizador, se extrajeron los productos con acetato de etilo y se analizaron por cromatografía de gases y por GC-MS. Finalmente, los productos obtenidos se aislaron del benzaldehído en exceso por cromatografía en columna utilizando sílice como fase estacionaria en n-hexano/acetato de etilo 3:1. Los productos puros se caracterizaron por RMN (Tabla 5.6, productos 3a-3e).

\subsubsection{Estudio quimioselectividad por ATR-FTIR.}

Con el fin de estudiar la quimioselectividad del catalizador Co@NC-800 en la hidrogenación del 3-nitroestireno se llevaron a cabo una serie de experimentos usando ATR-FTIR. Para llevarlos a cabo, el reactivo (nitrobenceno o 3-nitroestireno) se adsorbe en la superficie del catalizador por impregnación húmeda en etanol. Para ello, se disuelven $50 \mathrm{mg}$ del reactivo en $3 \mathrm{~mL}$ de etanol y se agitan con $100 \mathrm{mg}$ del catalizador durante 30 minutos en atmósfera inerte. A continuación, se elimina el disolvente a vacío en atmósfera inerte y el material con la molécula sonda pre-adsorbida se mezcla con $\mathrm{KBr}$ y se compacta en una placa plana para el análisis. Para tomarlos como referencia, tanto el nitrobenceno como el 3-nitroestireno se adsorben en $\mathrm{KBr}$ sin catalizador.

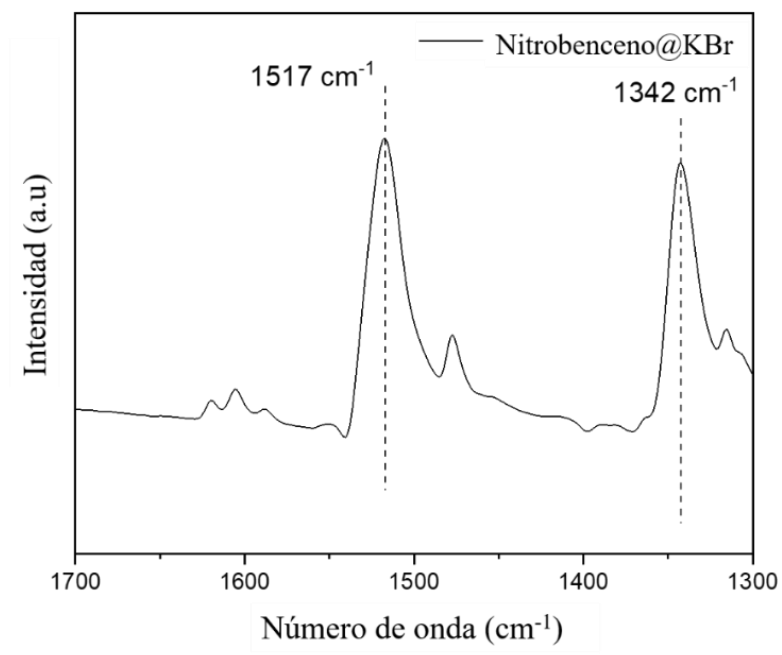

Figura 5.12. Espectro FTIR del nitrobenceno en $\mathrm{KBr}$. Reproducida de la ref 75 con permiso de la Royal Society of Chemistry. 


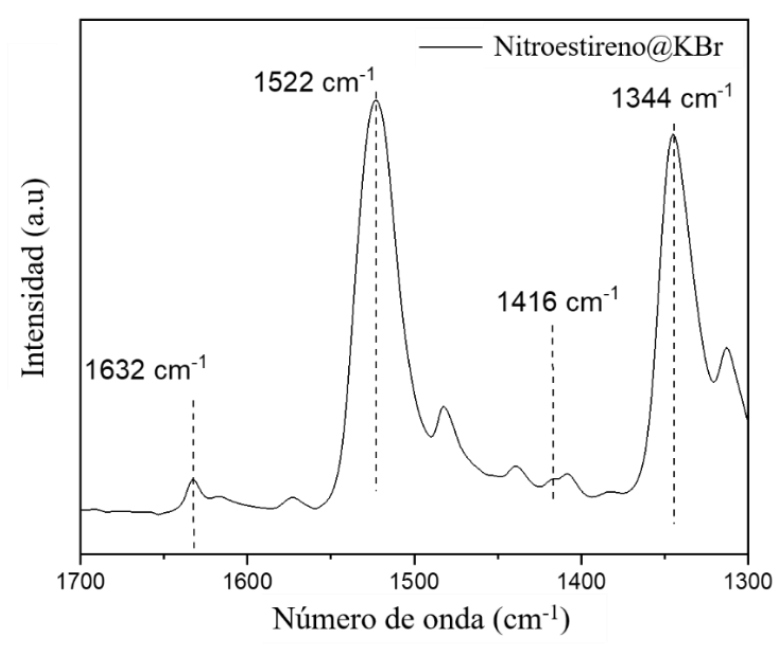

Figura 5.13. Espectro FTIR del 3-nitroestireno en KBr. Reproducida de la ref 75 con permiso de la Royal Society of Chemistry.

\subsubsection{Caracterización de los productos de reacción sintetizados.}<smiles>Nc1ccccc1</smiles>

Anilina (1a). ${ }^{1} \mathrm{H}$ NMR $\left(300 \mathrm{MHz}, \mathrm{CDCl}_{3}\right) \delta=7.25(\mathrm{t}, J=7.8 \mathrm{~Hz}$, $2 \mathrm{H}), 6.86(\mathrm{t}, J=7.8 \mathrm{~Hz}, 1 \mathrm{H}), 6.75(\mathrm{~d}, J=7.5 \mathrm{~Hz}, 2 \mathrm{H}), 3.69$ (br s, $2 \mathrm{H})$. ${ }^{13} \mathrm{C}$ NMR (75 MHz, CDCl3): $\delta=146.58,129.39,118.59,115.21$. Los espectros están en consonancia con la literatura. ${ }^{78}$ GC-MS: calculado para $\mathrm{C}_{6} \mathrm{H}_{7} \mathrm{~N}$ 93.2. Experimental: 93.2.<smiles>Nc1ccccc1F</smiles>

2-fluoroanilina (1b). ${ }^{1} \mathrm{H}$ NMR $\left(300 \mathrm{MHz}, \mathrm{CDCl}_{3}\right) \delta=7.04-6.95$ (m, $2 \mathrm{H}), 6.84-6.73$ (m, 2H), 3.72 (br s, 2H). ${ }^{13} \mathrm{C} \mathrm{NMR}(75 \mathrm{MHz}, \mathrm{CDCl} 3)$ : $\delta=153.37,134.49,124.52,118.71,116.98,115.14$. Los espectros están en consonancia con la literatura. ${ }^{78}$ GC-MS: calculado para $\mathrm{C}_{6} \mathrm{H}_{6} \mathrm{NF}$ 111.2. Experimental: 111.3. 
<smiles>Nc1cccc(Cl)c1</smiles>

3-cloroanilina (1c). ${ }^{1} \mathrm{H}$ NMR $\left(300 \mathrm{MHz}, \mathrm{CDCl}_{3}\right) \delta=7.01-6.95(\mathrm{~m}$, $1 \mathrm{H}), 6.66-6.58(\mathrm{~m}, 2 \mathrm{H}), 6.48-6.45(\mathrm{~m}, 1 \mathrm{H}), 3.63(\mathrm{br} \mathrm{s}, 2 \mathrm{H}) .{ }^{13} \mathrm{C} \mathrm{NMR}$ $(75 \mathrm{MHz}, \mathrm{CDCl} 3): \delta=147.64,134.88,130.33,118.49,114.95$, 113.20. Los espectros están en consonancia con la literatura. ${ }^{78} \mathrm{GC}$ MS: calculado para $\mathrm{C}_{6} \mathrm{H}_{6} \mathrm{NCl}$ 127.5. Experimental: 127.4.<smiles>Nc1ccc(Br)cc1</smiles>

4-bromoanilina (1d). ${ }^{1} \mathrm{H} \mathrm{NMR}\left(300 \mathrm{MHz}, \mathrm{CDCl}_{3}\right) \delta=7.15$ (d, $J=8.8 \mathrm{~Hz}, 2 \mathrm{H}), 6.47(\mathrm{~d}, J=8.8 \mathrm{~Hz}, 2 \mathrm{H}), 3.57(\mathrm{br} \mathrm{s}, 2 \mathrm{H}) .{ }^{13} \mathrm{C}$ $\operatorname{NMR}\left(75 \mathrm{MHz}, \mathrm{CDCl}_{3}\right): \delta=145.46,132.03,116.73,110.20$. Los espectros están en consonancia con la literatura. ${ }^{51}$ GC-MS: calculado para $\mathrm{C}_{6} \mathrm{H}_{6} \mathrm{NBr}$ 172.0. Experimental: 172.0.<smiles>Nc1ccccc1I</smiles>

2-iodoanilina (1e). ${ }^{1} \mathrm{H} \mathrm{NMR}\left(300 \mathrm{MHz}, \mathrm{CDCl}_{3}\right) \delta=7.65(\mathrm{~d}, J=8.0$ $\mathrm{Hz}, 1 \mathrm{H}), 7.15(\mathrm{t}, J=8.0 \mathrm{~Hz}, 1 \mathrm{H}), 6.77(\mathrm{~d}, J=8.0 \mathrm{~Hz}, 1 \mathrm{H}), 6.49$ (t, $J=8.0 \mathrm{~Hz}, 1 \mathrm{H}), 4.01$ (br s, $2 \mathrm{H}) .{ }^{13} \mathrm{C} \mathrm{NMR}\left(75 \mathrm{MHz}, \mathrm{CDCl}_{3}\right) \delta=$ 146.8, 139.0, 129.3, 120.0, 114.7, 84.2. Los espectros están en consonancia con la literatura. ${ }^{104}$ GC-MS: calculado para $\mathrm{C}_{6} \mathrm{H}_{6} \mathrm{NI}$ 219.0. Experimental: 219.0.

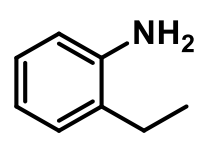

2-etilanilina (1f). ${ }^{1} \mathrm{H}$ NMR $\left(300 \mathrm{MHz}, \mathrm{CDCl}_{3}\right) \delta=7.10-7.04(\mathrm{~m}, 2 \mathrm{H})$, $6.78(\mathrm{t}, J=8.1 \mathrm{~Hz}, 1 \mathrm{H}), 6.71(\mathrm{~d}, J=8.1 \mathrm{~Hz}, 1 \mathrm{H}) 3.56(\mathrm{br} \mathrm{s}, 2 \mathrm{H}), 2.55$ $(\mathrm{q}, J=7.0 \mathrm{~Hz}, 2 \mathrm{H}), 0.91(\mathrm{t}, J=7.0 \mathrm{~Hz}, 3 \mathrm{H}) .{ }^{13} \mathrm{C}$ NMR $(75 \mathrm{MHz}$, $\left.\mathrm{CDCl}_{3}\right): \delta=143.9,128.4,128.2,126.8,118.9,115.5,23.7,13.0$. Los espectros están en consonancia con la literatura. ${ }^{105}$ GC-MS: calculado para $\mathrm{C}_{7} \mathrm{H}_{9} \mathrm{~N}$ 121.2. Experimental: 121.2.<smiles>Cc1ccc(N)cc1</smiles>

4-metilanilina (1g). ${ }^{1} \mathrm{H} \mathrm{NMR}\left(300 \mathrm{MHz}, \mathrm{CDCl}_{3}\right) \delta=6.90(\mathrm{~d}, J=$ $8.1 \mathrm{~Hz}, 2 \mathrm{H}), 6.53$ (d, $J=8.1 \mathrm{~Hz}, 2 \mathrm{H}), 3.51$ (br s, 2H), 2.30 (s, 3H). ${ }^{13} \mathrm{C}$ NMR $\left(75 \mathrm{MHz}, \mathrm{CDCl}_{3}\right): \delta=143.81,129.75,127.81,115.27$, 20.42. Los espectros están en consonancia con la literatura. ${ }^{96} \mathrm{GC}-\mathrm{MS}$ : calculado para $\mathrm{C}_{7} \mathrm{H}_{9} \mathrm{~N}$ 107.2. Experimental: 107.3.

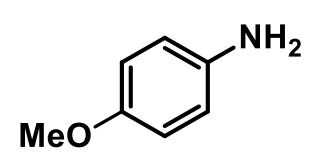

4-metoxianilina (1h). ${ }^{1} \mathrm{H} \mathrm{NMR}\left(300 \mathrm{MHz}, \mathrm{CDCl}_{3}\right) \delta=7.77$ (d, $J=8.6 \mathrm{~Hz}, 2 \mathrm{H}), 6.55(\mathrm{~d}, J=8.6 \mathrm{~Hz}, 2 \mathrm{H}), 4.03(\mathrm{br} \mathrm{s}, 2 \mathrm{H}), 3.78$ (s, 3H). ${ }^{13} \mathrm{C}$ NMR $\left(75 \mathrm{MHz}, \mathrm{CDCl}_{3}\right): \delta=150.87,131.61,119.74$, 113.80, 51.58. Los espectros están en consonancia con la literatura. ${ }^{78}$ GC-MS: calculado para $\mathrm{C}_{8} \mathrm{H}_{11} \mathrm{NO}_{2}$ 153.2. Experimental: 153.2. 
<smiles>N#Cc1ccc(N)cc1</smiles>

4-aminobenzonitrilo (1i). ${ }^{1} \mathrm{H} \mathrm{NMR}\left(300 \mathrm{MHz}, \mathrm{CDCl}_{3}\right) \delta=7.33$ $(\mathrm{d}, J=8.7 \mathrm{~Hz}, 2 \mathrm{H}), 6.57(\mathrm{~d}, J=8.7 \mathrm{~Hz}, 2 \mathrm{H}), 4.13(\mathrm{br} \mathrm{s}, 2 \mathrm{H}) .{ }^{13} \mathrm{C}$ $\operatorname{NMR}\left(75 \mathrm{MHz}, \mathrm{CDCl}_{3}\right): \delta=150.51,133.81,120.19,114.46$, 100.10. Los espectros están en consonancia con la literatura. ${ }^{78}$ GC-MS: calculado para $\mathrm{C}_{7} \mathrm{H}_{6} \mathrm{~N}_{2}$ 118.1. Experimental: 118.2.<smiles>CC(=O)c1ccccc1N</smiles>

2'-aminoacetofenona (1j). ${ }^{1} \mathrm{H}$ NMR $\left(300 \mathrm{MHz}, \mathrm{CDCl}_{3}\right) \delta=7.73$ $7.70(\mathrm{~m}, 1 \mathrm{H}), 7.30-7.24(\mathrm{~m}, 1 \mathrm{H}), 6.68-6.62(\mathrm{~m}, 2 \mathrm{H}) 6.31(\mathrm{br} \mathrm{s}, 2 \mathrm{H})$, $2.58(\mathrm{~s}, 3 \mathrm{H}) .{ }^{13} \mathrm{C} \mathrm{NMR}\left(75 \mathrm{MHz}, \mathrm{CDCl}_{3}\right): \delta=200.75,150.33,134.38$, $132.05,118.28,117.23,115.74,27.84$. Los espectros están en consonancia con la literatura. ${ }^{78} \mathrm{GC}-\mathrm{MS}$ : calculado para $\mathrm{C}_{8} \mathrm{H}_{9} \mathrm{NO}$ 135.2. Experimental: 135.3 .<smiles>Nc1ccc(O)cc1</smiles>

4-Aminofenol (1k). ${ }^{1} \mathrm{H}$ NMR $\left(300 \mathrm{MHz}, \mathrm{CDCl}_{3}\right) \delta=8.33$ (s, $1 \mathrm{H}), 6.47$ (d, 2H, $J=8.6 \mathrm{~Hz}), 6.41$ (d, 2H, $J=8.6 \mathrm{~Hz}), 4.37$ (br s, $2 \mathrm{H}) .{ }^{13} \mathrm{C} \mathrm{NMR}\left(75 \mathrm{MHz}, \mathrm{CDCl}_{3}\right): \delta=148.19,140.63,115.50$, 115.20. Los espectros están en consonancia con la literatura. ${ }^{51}$ GC-MS: calculado para $\mathrm{C}_{6} \mathrm{H}_{7} \mathrm{NO}$ 109.1. Experimental: 109.1.<smiles>CSc1ccc(N)cc1</smiles>

4-(tio-1-metil)anilina (11). ${ }^{1} \mathrm{H} \mathrm{NMR}\left(300 \mathrm{MHz}, \mathrm{CDCl}_{3}\right) \delta=$ $7.10(\mathrm{~d}, J=8.6 \mathrm{~Hz}, 2 \mathrm{H}), 6.55(\mathrm{~d}, J=8.6 \mathrm{~Hz}, 2 \mathrm{H}), 3.50$ (br s, $2 \mathrm{H}), 2.34$ (s, $3 \mathrm{H}) .{ }^{13} \mathrm{C}$ NMR $\left(75 \mathrm{MHz}, \mathrm{CDCl}_{3}\right): \delta=145.11$, 131.11, 125.88, 115.77, 18.81. Los espectros están en consonancia con la literatura. ${ }^{78}$ GC-MS: calculado para $\mathrm{C}_{7} \mathrm{H}_{9} \mathrm{NS}$ 139.2. Experimental: 139.2 .<smiles>NC(=O)c1ccc(N)cc1</smiles>

4-Aminobenzamida (1m). ${ }^{1} \mathrm{H} \mathrm{NMR}\left(300 \mathrm{MHz}, \mathrm{CDCl}_{3}\right) \delta$ $=7.57(\mathrm{~d}, 2 \mathrm{H}, J=8.7 \mathrm{~Hz}), 7.50(\mathrm{br} \mathrm{s}, 2 \mathrm{H}), 6.52(\mathrm{~d}, 2 \mathrm{H}, J=$ $8.7 \mathrm{~Hz}), 5.58$ (br s, $2 \mathrm{H}) .{ }^{13} \mathrm{C} \mathrm{NMR}\left(75 \mathrm{MHz}, \mathrm{CDCl}_{3}\right): \delta=$ 168.00, 151.61, 129.07, 120.95, 112.42. Los espectros están en consonancia con la literatura. ${ }^{78}$ GC-MS: calculado para $\mathrm{C}_{7} \mathrm{H}_{8} \mathrm{~N}_{2} \mathrm{O}$ 136.2. Experimental: 136.2 .<smiles>Nc1cccnc1</smiles>

3-aminopiridina (1n). ${ }^{1} \mathrm{H}$ NMR $\left(300 \mathrm{MHz}, \mathrm{CDCl}_{3}\right) \delta=8.01-7.94$ (m, 2H), 7.00-6.96 (m, 1H), 6.90-6.86 (m, 1H), 3.69 (br s, 2H). ${ }^{13} \mathrm{C}$ $\operatorname{NMR}\left(75 \mathrm{MHz}, \mathrm{CDCl}_{3}\right): \delta=142.66,139.88,137.47,123.72,121.41$. 
Capítulo 5. Nanoclústeres de Cobalto como catalizadores para la hidrogenación quimioselectiva de nitroarenos y reacciones tándem.

Los espectros están en consonancia con la literatura. ${ }^{106}$ GC-MS: calculado para $\mathrm{C}_{5} \mathrm{H}_{6} \mathrm{~N}_{2}$ 94.1. Experimental: 94.2.

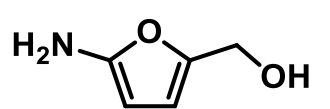

5-amino-furfuril alcohol (1o). ${ }^{1} \mathrm{H} \mathrm{NMR}\left(300 \mathrm{MHz}, \mathrm{CDCl}_{3}\right)$ $\delta=7.32-7.29(\mathrm{~m}, 1 \mathrm{H}), 6.53-6.50(\mathrm{~m}, 1 \mathrm{H}), 5.54(\mathrm{br} \mathrm{s}, 1 \mathrm{H})$, $4.52(\mathrm{~s}, 2 \mathrm{H}), 3.22(\mathrm{br} \mathrm{s}, 2 \mathrm{H}) .{ }^{13} \mathrm{C} \mathrm{NMR}\left(75 \mathrm{MHz}, \mathrm{CDCl}_{3}\right): \delta$ $=164.5,156.3,117.9,115.1,61.3$. Los espectros están en consonancia con la literatura. GC-MS: calculado para $\mathrm{C}_{5} \mathrm{H}_{7} \mathrm{NO}_{2}$ 113.1. Experimental: 113.1.

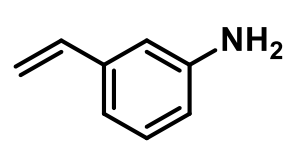

3-vinilanilina (1p). ${ }^{1} \mathrm{H}$ NMR $\left(300 \mathrm{MHz}, \mathrm{CDCl}_{3}\right) \delta=7.14$ (t, $J$ $=7.8 \mathrm{~Hz}, 1 \mathrm{H}), 6.85(\mathrm{~d}, J=7.8 \mathrm{~Hz}, 1 \mathrm{H}), 6.77(\mathrm{~s}, 1 \mathrm{H}), 6.71-6.61$ (m, 2H), $5.73(\mathrm{~d}, J=17.6,1 \mathrm{H}), 5.23(\mathrm{~d}, J=10.9,1 \mathrm{H}) .3 .51(\mathrm{br}$ s, 2H). ${ }^{13} \mathrm{C}$ NMR $\left(75 \mathrm{MHz}, \mathrm{CDCl}_{3}\right): \delta=146.5,138.7,137.0$, 129.4, 117.0, 114.8, 113.6, 112.8. Los espectros están en consonancia con la literatura. ${ }^{78}$ GC-MS: calculado para $\mathrm{C}_{8} \mathrm{H}_{9} \mathrm{~N}$ 119.2. Experimental: 119.2.

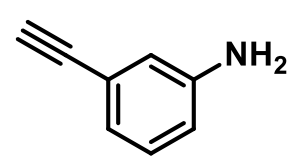

3-Etinilanilina (1q). ${ }^{1} \mathrm{H}$ NMR $\left(300 \mathrm{MHz}, \mathrm{CDCl}_{3}\right) \delta=7.15$ $7.10(\mathrm{~m}, 1 \mathrm{H}), 6.93(\mathrm{~d}, 1 \mathrm{H}, J=7.8 \mathrm{~Hz}), 6.83(\mathrm{~s}, 1 \mathrm{H}), 6.67(\mathrm{~d}$, $1 \mathrm{H}, J=7.8 \mathrm{~Hz}) 3.70(\mathrm{br} \mathrm{s}, 2 \mathrm{H}), 3.06(\mathrm{~s}, 1 \mathrm{H}) .{ }^{13} \mathrm{C}$ NMR $(75$ $\left.\mathrm{MHz}, \mathrm{CDCl}_{3}\right): \delta=146.34,129.33,122.78,122.49,118.33$, 115.86, 84.00, 76.63. Los espectros están en consonancia con la literatura. ${ }^{78}$ GC-MS: calculado para $\mathrm{C}_{8} \mathrm{H}_{7} \mathrm{~N}$ 117.1. Experimental: 117.1.<smiles>Nc1c(O)cccc1O</smiles>

2-amino-1,3-bencenodiol (1r). ${ }^{1} \mathrm{H}$ NMR (300 MHz, DMSO) $\delta=$ 8.84 (br s, 2H), 6.30-6.22 (m, 3H), 3.84 (br s, 2H). ${ }^{13} \mathrm{C}$ NMR $(75$ $\left.\mathrm{MHz}, \mathrm{CDCl}_{3}\right): \delta=145.4,124.3,116.4,107.1$. Los espectros están en consonancia con la literatura. ${ }^{107}$ GC-MS: calculado para $\mathrm{C}_{6} \mathrm{H}_{7} \mathrm{NO}_{2}$ 125.1. Experimental: 125.1.

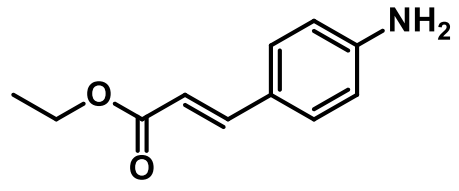

2-propenoato-(2E)-3-(4-aminofenil) de etilo (1s). ${ }^{1} \mathrm{H}$ NMR $\left(300 \mathrm{MHz}, \mathrm{CDCl}_{3}\right) \delta=7.64-7.58(\mathrm{~d}, J=$ $15.9 \mathrm{~Hz}, 1 \mathrm{H}), 7.35(\mathrm{~m}, 2 \mathrm{H}), 6.65(\mathrm{~m}, 2 \mathrm{H}), 6.27-6.22$ $(\mathrm{d}, J=15.9 \mathrm{~Hz}, 1 \mathrm{H}) 4.25(\mathrm{q}, J=7.1 \mathrm{~Hz}, 2 \mathrm{H}), 3.96$ (br s, $2 \mathrm{H}), 1.33$ (t, $J=7.1 \mathrm{~Hz}, 2 \mathrm{H}) .{ }^{13} \mathrm{C}$ NMR $\left(75 \mathrm{MHz}, \mathrm{CDCl}_{3}\right): \delta=167.70,148.66$, 144.85, 129.86, 124.79, 114.83, 113.76, 60.15, 14.38. Los espectros están en consonancia con la literatura. ${ }^{78} \mathrm{GC}-\mathrm{MS}$ : calculado para $\mathrm{C}_{11} \mathrm{H}_{13} \mathrm{NO}_{2}$ 191.2. Experimental: 191.2. 


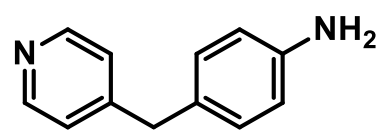

4-(4-piridilmetil)anilina (1t). ${ }^{1} \mathrm{H}$ NMR $(300 \mathrm{MHz}$, $\left.\mathrm{CDCl}_{3}\right) \delta=8.39(\mathrm{~d}, J=6.1 \mathrm{~Hz}, 2 \mathrm{H}), 7.01(\mathrm{~d}, J=6.1 \mathrm{~Hz}$, $2 \mathrm{H}), 6.88(\mathrm{~d}, J=8.5 \mathrm{~Hz}, 2 \mathrm{H}), 6.57(\mathrm{~d}, J=8.5 \mathrm{~Hz}, 2 \mathrm{H})$, 3.78 (br s, 2H), 3.55 (br s, 2H). $\left.{ }^{13} \mathrm{C} \mathrm{NMR} \mathrm{(75} \mathrm{MHz,} \mathrm{CDCl}_{3}\right): \delta=150.89,149.74$, 145.05, 129.91, 188.78, 124.09, 115.53, 40.41. Los espectros están en consonancia con la literatura. ${ }^{78}$ GC-MS: calculado para $\mathrm{C}_{12} \mathrm{H}_{12} \mathrm{~N}_{2}$ 184.2. Experimental: 184.2.<smiles>CC(C)C(=O)Nc1ccc(N)c(C(F)(F)F)c1</smiles>

N-[4-amino-3-(trifluorometil)fenil]-2-metil-propanamida (1u). ${ }^{1} \mathrm{H}$ NMR $\left(300 \mathrm{MHz}, \mathrm{CDCl}_{3}\right) \delta=9.64(\mathrm{~s}, 1 \mathrm{H})$ $7.73(\mathrm{~d}, J=2.6 \mathrm{~Hz}, 1 \mathrm{H}), 7.42(\mathrm{dd}, J=8.8,2.6 \mathrm{~Hz}, 1 \mathrm{H})$, $6.79(\mathrm{~d}, J=8.8 \mathrm{~Hz}, 1 \mathrm{H}), 5.32(\mathrm{br} \mathrm{s}, 2 \mathrm{H}), 2.51(\mathrm{dt}, J=13.3$, $6.6 \mathrm{~Hz}, 1 \mathrm{H}), 1.08(\mathrm{~d}, J=6.7 \mathrm{~Hz}, 6 \mathrm{H}) .{ }^{13} \mathrm{C} \mathrm{NMR}(75 \mathrm{MHz}$, $\left.\mathrm{CDCl}_{3}\right): 175.2,142.5\left({ }^{3} J_{\mathrm{FC}} 2.3 \mathrm{~Hz}\right), 128.8,125.5\left({ }^{3} J_{\mathrm{FC}} 1,4 \mathrm{~Hz}\right), 125.4\left({ }^{1} J_{\mathrm{FC}} 270 \mathrm{~Hz}\right)$, 117.6, 117.4 $\left({ }^{2} J_{\mathrm{FC}} 5.7 \mathrm{~Hz}\right), 110.8\left({ }^{2} J_{\mathrm{FC}} 29.9 \mathrm{~Hz}\right), 35.2,19.9$. Los espectros están en consonancia con la literatura. ${ }^{108}$ GC-MS: calculado $\mathrm{C}_{11} \mathrm{H}_{14} \mathrm{NOF}_{3}$ 247.1. Found: 247.1.

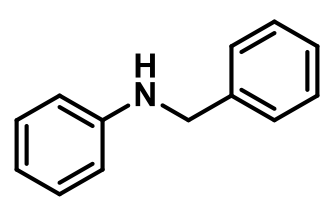

N-Bencilanilina (2a). ${ }^{1} \mathrm{H}$ NMR $\left(300 \mathrm{MHz}, \mathrm{CDCl}_{3}\right) \delta=7.45$ $7.33(\mathrm{~m}, 5 \mathrm{H}), 7.26-7.21(\mathrm{~m}, 2 \mathrm{H}), 6.77(\mathrm{t}, J=8.7 \mathrm{~Hz}, 1 \mathrm{H})$, $6.70(\mathrm{~d}, J=8.7 \mathrm{~Hz}, 2 \mathrm{H}), 4.38(\mathrm{~s}, 2 \mathrm{H}), 4.07$ (br s, $1 \mathrm{H}) .{ }^{13} \mathrm{C}-$ NMR (75 MHz, $\left.\mathrm{CDCl}_{3}\right): \delta=148.21,139.51,129.31,128.68$, 127.56, 127.27, 117.64, 112.92, 48.39. Los espectros están en consonancia con la literatura. ${ }^{109}$ GC-MS: calculado para $\mathrm{C}_{13} \mathrm{H}_{13} \mathrm{~N}$ 183.3. Experimental: 183.2.

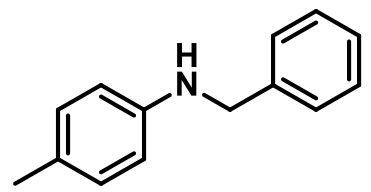

N-Bencil-4-metilanilina (2b). ${ }^{1} \mathrm{H}$ NMR $(300 \mathrm{MHz}$, $\left.\mathrm{CDCl}_{3}\right) \delta=7.38-7.25(\mathrm{~m}, 5 \mathrm{H}), 6.98(\mathrm{~d}, J=8.8 \mathrm{~Hz}, 2 \mathrm{H})$, $6.56(\mathrm{~d}, J=8.8 \mathrm{~Hz}, 2 \mathrm{H}), 4.31$ (s, 2H), 3.90 (br s, 1H), 2.23 (s, 3H). ${ }^{13} \mathrm{C}-\mathrm{NMR}\left(75 \mathrm{MHz}, \mathrm{CDCl}_{3}\right): \delta=145.9,139.7$, 129.8, 128.6, 127.5, 127.2, 126.8, 113.0, 48.7, 20.5. Los espectros están en consonancia con la literatura. ${ }^{109}$ GC-MS: calculado para $\mathrm{C}_{14} \mathrm{H}_{15} \mathrm{~N}$ 197.3. Experimental: 197.3.

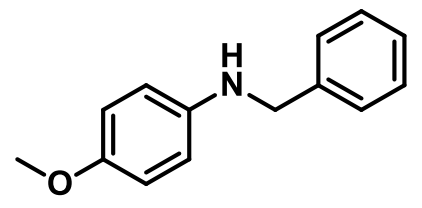

N-Bencil-4-metoxianilina (2c). ${ }^{1} \mathrm{H}$ NMR $(300 \mathrm{MHz}$, $\left.\mathrm{CDCl}_{3}\right) \delta=7.29-7.19(\mathrm{~m}, 5 \mathrm{H}), 6.70(\mathrm{~d}, J=8.8 \mathrm{~Hz}, 2 \mathrm{H})$, $6.55(\mathrm{~d}, J=8.8 \mathrm{~Hz}, 2 \mathrm{H}), 4.22(\mathrm{~s}, 2 \mathrm{H}), 3.67(\mathrm{~s}, 3 \mathrm{H}) .{ }^{13} \mathrm{C}-$ NMR (75 MHz, $\left.\mathrm{CDCl}_{3}\right): \delta=152.5,142.0,139.4,128.6$, 
Capítulo 5. Nanoclústeres de Cobalto como catalizadores para la hidrogenación quimioselectiva de nitroarenos y reacciones tándem.

127.7, 127.2, 114.9, 114.5, 55.8, 49.5. Los espectros están en consonancia con la literatura. ${ }^{109}$ GC-MS: calculado para $\mathrm{C}_{14} \mathrm{H}_{15} \mathrm{NO}$ 213.3. Experimental: 213.3.

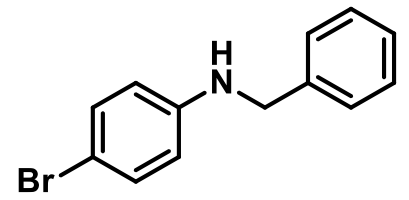

N-Bencil-4-bromoanilina (2d). ${ }^{1} \mathrm{H}$ NMR $(300 \mathrm{MHz}$, $\left.\mathrm{CDCl}_{3}\right) \delta=7.37-7.27(\mathrm{~m}, 5 \mathrm{H}), 7.12(\mathrm{~d}, J=4.4 \mathrm{~Hz}, 2 \mathrm{H})$, $6.56(\mathrm{~d}, J=4.4 \mathrm{~Hz}, 2 \mathrm{H}), 4.32$ (s, 2H), 4.07 (br s, $1 \mathrm{H}) .{ }^{13} \mathrm{C}-$ NMR $\left(75 \mathrm{MHz}, \mathrm{CDCl}_{3}\right): \delta=146.6,138.9,129.0,128.7$, 127.4, 127.3, 122.1, 113.9, 48.3. Los espectros están en consonancia con la literatura. ${ }^{110} \mathrm{GC}-\mathrm{MS}$ : calculado para $\mathrm{C}_{13} \mathrm{H}_{12} \mathrm{NBr}$ 262.2. Experimental: 262.2.

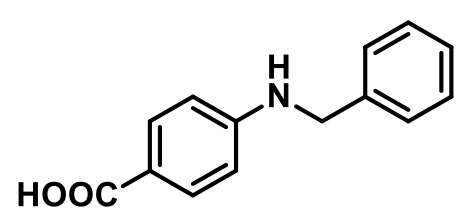

Ácido 4-(bencilamino) benzoico (2e). ${ }^{1} \mathrm{H}$ NMR (300 $\left.\mathrm{MHz}, \mathrm{CDCl}_{3}\right) \delta=7.93-7.91(\mathrm{~m}, 2 \mathrm{H}), 7.39-7.28(\mathrm{~m}$, $5 \mathrm{H}), 6.61(\mathrm{~d}, J=8.8 \mathrm{~Hz}, 2 \mathrm{H}), 4.41$ (s, 2H), 4.07 (br s, 1H). ${ }^{13} \mathrm{C}-\mathrm{NMR}\left(75 \mathrm{MHz}, \mathrm{CDCl}_{3}\right): \delta=146.6,138.9$, 129.0, 128.7, 127.4, 127.3, 122.1, 113.9, 48.3. Los espectros están en consonancia con la literatura. ${ }^{110} \mathrm{GC}-\mathrm{MS}$ : calculado para $\mathrm{C}_{14} \mathrm{H}_{13} \mathrm{NO}_{2}$ 227.3. Experimental: 227.3.

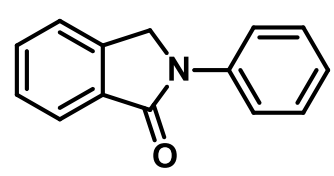

Fenilisoindolin-1-ona (3a). ${ }^{1} \mathrm{H}$ NMR $\left(300 \mathrm{MHz}, \mathrm{CDCl}_{3}\right) \delta=$ $7.95(\mathrm{~d}, J=7.6 \mathrm{~Hz}, 1 \mathrm{H}), 7.90(\mathrm{~d}, J=7.6 \mathrm{~Hz}, 2 \mathrm{H}), 7.62-7.43$ $(\mathrm{m}, 5 \mathrm{H}), 7.21(\mathrm{~m}, 1 \mathrm{H}), 4.90(\mathrm{~s}, 2 \mathrm{H}) .{ }^{13} \mathrm{C}-\mathrm{NMR}(75 \mathrm{MHz}$, $\left.\mathrm{CDCl}_{3}\right): \delta=167.5,140.1,139.5,133.3,132.1,129.2,128.4$, 124.5, 124.2, 122.6, 119.5, 50.8. Los espectros están en consonancia con la literatura. ${ }^{109}$ GC-MS: calculado para $\mathrm{C}_{14} \mathrm{H}_{11} \mathrm{NO}$ 209.2. Experimental: 209.2.

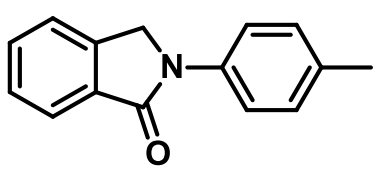

2-(4-metilfenil)isoindolin-1-ona (3b). ${ }^{1} \mathrm{H}$ NMR $(300 \mathrm{MHz}$, $\left.\mathrm{CDCl}_{3}\right) \delta=7.85(\mathrm{~d}, J=8 \mathrm{~Hz}, 1 \mathrm{H}), 7.66(\mathrm{~d}, J=8.4 \mathrm{~Hz}, 2 \mathrm{H})$, 7.53-7.50 (m, $1 \mathrm{H}), 7.45(\mathrm{~d}, J=8 \mathrm{~Hz}, 2 \mathrm{H}), 7.17(\mathrm{~d}, J=8.4$ $\mathrm{Hz}, 2 \mathrm{H}), 4.78$ (s, $2 \mathrm{H}), 2.29$ (s, $3 \mathrm{H}) .{ }^{13} \mathrm{C}-\mathrm{NMR}(75 \mathrm{MHz}$, $\left.\mathrm{CDCl}_{3}\right): \delta=167.4,140.2,136.7,134.2,133.4,131.9,129.7,128.4,124.1,122.6,119.7$, 50.9, 20.9. Los espectros están en consonancia con la literatura. ${ }^{109}$ GC-MS: calculado para $\mathrm{C}_{15} \mathrm{H}_{13} \mathrm{NO}$ 223.3. Experimental: 223.3.

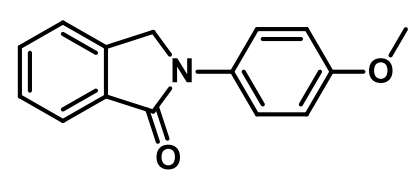

2-(4-metoxifenil)isoindolin-1-ona (3c). ${ }^{1} \mathrm{H}$ NMR (300 $\left.\mathrm{MHz}, \mathrm{CDCl}_{3}\right) \delta=7.85(\mathrm{~d}, J=7.2 \mathrm{~Hz}, 1 \mathrm{H}), 7.67(\mathrm{~d}, J=8.8$ $\mathrm{Hz}, 2 \mathrm{H}), 7.52-7.42$ (m, $3 \mathrm{H}), 6.90(\mathrm{~d}, J=7.2 \mathrm{~Hz}, 2 \mathrm{H})$, 
4.76 (s, $2 \mathrm{H}), 3.77$ (s, $3 \mathrm{H}) .{ }^{13} \mathrm{C}-\mathrm{NMR}\left(75 \mathrm{MHz}, \mathrm{CDCl}_{3}\right): \delta=167.3,156.7,140.2,133.3$, 132.7, 131.8, 128.4, 124.1, 122.6, 121.6, 114.4, 55.5, 51.2. Los espectros están en consonancia con la literatura. ${ }^{109} \mathrm{GC}-\mathrm{MS}$ : calculado para $\mathrm{C}_{15} \mathrm{H}_{13} \mathrm{NO}_{2}$ 239.3. Experimental: 239.3 .

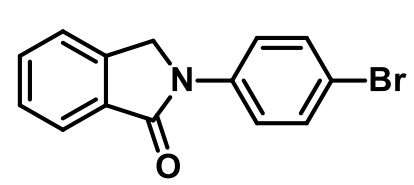

2-(4-Bromofenil)isoindolin-1-ona (3d). ${ }^{1} \mathrm{H}$ NMR (300 $\left.\mathrm{MHz}, \mathrm{CDCl}_{3}\right) \delta=7.95(\mathrm{~d}, J=8.4 \mathrm{~Hz}, 1 \mathrm{H}), 7.82(\mathrm{~d}, J=7.2$ $\mathrm{Hz}, 2 \mathrm{H}), 7.66-7.61(\mathrm{~m}, 1 \mathrm{H}), 7.57-7-54(\mathrm{~m}, 4 \mathrm{H}), 4.86(\mathrm{~s}$, $2 \mathrm{H}) .{ }^{13} \mathrm{C}-\mathrm{NMR}\left(75 \mathrm{MHz}, \mathrm{CDCl}_{3}\right): \delta=167.6,160.0,158.3$, 139.9, 138.6, 132.1, 128.6, 124.3, 122.7, 120.8, 117.3, 116.7, 50.6. Los espectros están en consonancia con la literatura. ${ }^{111}$ GC-MS: calculado para $\mathrm{C}_{14} \mathrm{H}_{10} \mathrm{NOBr} 289.1$. Experimental: 289.2 .

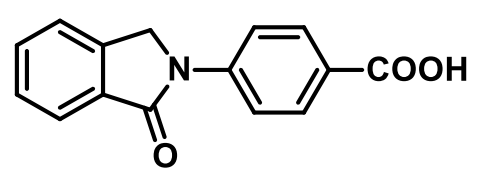

Ácido 4-(1-Oxoisoindolin-2-il) benzoico (3e). ${ }^{1} \mathrm{H}$ $\mathrm{NMR}\left(300 \mathrm{MHz}, \mathrm{CDCl}_{3}\right) \delta=12.91(\mathrm{~s}, 1 \mathrm{H}), 8.07(\mathrm{~d}, J$ $=8.8 \mathrm{~Hz}, 2 \mathrm{H}), 8.01(\mathrm{~d}, J=8.8 \mathrm{~Hz}, 2 \mathrm{H}), 7.82(\mathrm{~d}, J=$ $7.6 \mathrm{~Hz}, 1 \mathrm{H}), 7.72(\mathrm{t}, J=7.6 \mathrm{~Hz}, 1 \mathrm{H}), 7.68(\mathrm{~d}, J=7.6$ $\mathrm{Hz}, 1 \mathrm{H}), 7.57(\mathrm{t}, J=7.6 \mathrm{~Hz}, 1 \mathrm{H}), 5.09(\mathrm{~s}, 2 \mathrm{H}) .{ }^{13} \mathrm{C}-\mathrm{NMR}\left(75 \mathrm{MHz}, \mathrm{CDCl}_{3}\right): \delta=167.4$, $160.7,158.3,139.9,135.5,132.9,128.4,124.1,122.6,121.3,121.2,115.9,115.7,50.9$. Los espectros están en consonancia con la literatura. ${ }^{12}$ GC-MS: calculado para $\mathrm{C}_{15} \mathrm{H}_{11} \mathrm{NO}_{3}$ 253.3. Experimental: 253.3. 
Capítulo 5. Nanoclústeres de Cobalto como catalizadores para la hidrogenación quimioselectiva de nitroarenos y reacciones tándem.

\subsection{Bibliografía}

(1) https://www.imarcgroup.com/global-aniline-market (accessed 29-01-2021).

(2) Formenti, D.; Ferretti, F.; Scharnagl, F. K.; Beller, M., Reduction of Nitro Compounds Using 3d-Non-Noble Metal Catalysts, Chem. Rev. 2019, 119, 2611-2680.

(3) Orlandi, M.; Brenna, D.; Harms, R.; Jost, S.; Benaglia, M., Recent Developments in the Reduction of Aromatic and Aliphatic Nitro Compounds to Amines, Org. Process Res. Dev. 2018, 22, 430-445.

(4) Downing, R. S.; Kunkeler P. J.; Van Bekkum, H., Catalytic syntheses of aromatic amines, Catal. Today 1997, 37, 121-136.

(5) Ono, N., The Nitro Group in Organic Synthesis, Wiley-VCH, New York, 2001.

(6) Blaser, H.-U.; Malan, C.; Pugin, B.; Spindler, F.; Steiner H.; Studer, M., Selective hydrogenation for fine chemicals: Recent trends and new developments, $A d v$. Synth. Catal. 2003, 345, 103-151.

(7) Nishimura, S., Handbook of Heterogeneous Catalytic Hydrogenation for Organic Synthesis, Wiley, New York, 2001.

(8) Zhao, Z.; Yang, H.; Li, Y.; Guo, X., Cobalt-Modified Molybdenum Carbide as an Efficient Catalyst for Chemoselective Reduction of Aromatic Nitro Compounds, Green Chem. 2014, 16, 1274-1281.

(9) Patra, A. K.; Dutta, A.; Bhaumik, A., Cu Nanorods and Nanospheres and Their Excellent Catalytic Activity in Chemoselective Reduction of Nitrobenzenes, Catal. Commun. 2010, 11, 651-655.

(10) Shalom, M.; Molinari, V.; Esposito, D.; Clavel, G.; Ressnig, D.; Giordano, C.; Antonietti, M., Sponge-Like Nickel and Nickel Nitride Structures for Catalytic Applications, Adv. Mater. 2014, 26, 1272-1276.

(11) Long, J.; Zhou, Y.; Li, Y., Transfer Hydrogenation of Unsaturated Bonds in the Absence of Base Additives Catalyzed by a Cobalt-Based Heterogeneous Catalyst, Chem. Commun. 2015, 51, 2331-2334.

(12) Chen, X.; Zhou, S.; Chen, Y.; Dong, Z.; Gao, Y.; Qian, C.; He, C., Application of Alkoxide in Catalytic Transfer Hydrogenation of Unsaturated Nitrogen Compounds, Res. Chem. Intermediat. 2012, 38, 2255-2269. 
(13) Song, J. J.; Huang, Z. F.; Pan, L.; Li, K.; Zhang, X. W.; Wang, L.; Zou, J. J., Review on selective hydrogenation of nitroarene by catalytic, photocatalytic and electrocatalytic reactions, Appl. Catal. B 2018, 227, 386-408.

(14) Lara, P.; Philippot, K., The hydrogenation of nitroarenes mediated by platinum nanoparticles: an overview, Catal. Sci. Technol. 2014, 4, 2445-2465.

(15) Blaser, H. U.; Steiner H.; Studer, M., Selective Catalytic Hydrogenation of Functionalized Nitroarenes: An Update, ChemCatChem 2009, 1, 210-221.

(16) Liu, L.; Corma, A., Metal Catalysts for Heterogeneous Catalysis: From Single Atoms to Nanoclusters and Nanoparticles, Chem. Rev. 2018, 118, 4981-5079.

(17) Corma, A.; Serna, P., Chemoselective Hydrogenation of Nitro Compounds with Supported Gold Catalysts, Science 2006, 313, 332- 334.

(18) Blaser, H.-U., CHEMISTRY: A Golden Boost to an Old Reaction, Science 2006, 313, 312-313.

(19) Corma, A.; Concepción, P.; Serna, P., A Different Reaction Pathway for the Reduction of Aromatic Nitro Compounds on Gold Catalysts, Angew. Chem., Int. Ed. 2007, 46, 7266-7269.

(20) Boronat, M.; Concepción, P.; Corma, A.; González, S.; Illas, F.; Serna, P., A Molecular Mechanism for the Chemoselective Hydrogenation of Substituted Nitroaromatics with Nanoparticles of Gold on $\mathrm{TiO}_{2}$ Catalysts: A Cooperative Effect between Gold and the Support, J. Am. Chem. Soc. 2007, 129, 16230-16237.

(21) Sheldon, R. A.; Arends, I. W. C. E.; Hanefeld, U., Green Chemistry and Catalysis; Wiley, 2007.

(22) Hagen, J., Industrial Catalysis; Wiley, 2005.

(23) Weissermel, K.; Arpe, H., Industrial Organic Chemistry; Wiley, 2003.

(24) Deutschmann, O.; Knözinger, H.; Kochloefl, K.; Turek, T., Heterogeneous Catalysis and Solid Catalysts, 3. Industrial Applications. In Ullmann's Encyclopedia of Industrial Chemistry; Wiley-VCH: Weinheim, Germany 2011.

(25) Oliveira, R. L.; He, W.; Klein Gebbink, R. J. M.; de Jong, K. P., Palladium Nanoparticles Confined in Thiol-Functionalized Ordered Mesoporous Silica for More Stable Heck and Suzuki Catalysts, Catal. Sci. Technol. 2015, 5, 1919-1928. 
Capítulo 5. Nanoclústeres de Cobalto como catalizadores para la hidrogenación quimioselectiva de nitroarenos y reacciones tándem.

(26) Covert, L. W.; Connor R.; Adkins, H., The use of nickel as a catalyst for hydrogenation. II, J. Am. Chem. Soc. 1932, 54, 1651-1663.

(27) Chen, F.; Topf, C.; Radnik, J.; Kreyenschulte, C.; Lund, H.; Schneider, M.; Surkus, A. E.; He, L.; Junge K.; Beller, M., Stable and Inert Cobalt Catalysts for Highly Selective and Practical Hydrogenation of $\mathrm{C} \equiv \mathrm{N}$ and $\mathrm{C}=\mathrm{O}$ Bonds, J. Am. Chem. Soc. 2016, $138,8781-8788$.

(28) Corma, A.; Serna, P.; Concepción P.; Calvino, J. J., Transforming nonselective into chemoselective metal catalysts for the hydrogenation of substituted nitroaromatics, J. Am. Chem. Soc. 2008, 130, 8748-8753.

(29) Chen, B.; Li, F.; Huang Z.; Yuan, G., Recyclable and Selective Nitroarene Hydrogenation Catalysts Based on Carbon-Coated Cobalt Oxide Nanoparticles, ChemCatChem 2016, 8, 1132-1138.

(30) Melaet, G.; Ralston, W. T.; Li, C. S.; Alayoglu, S.; An, K.; Musselwhite, N.; Kalkan B.; Somorjai, G. A., Evidence of Highly Active Cobalt Oxide Catalyst for the Fischer-Tropsch Synthesis and $\mathrm{CO}_{2}$ Hydrogenation, J. Am. Chem. Soc. 2014, 136, 2260 2263.

(31) Liu, L.; Gao, F.; Concepción P.; Corma, A., A new strategy to transform mono and bimetallic non-noble metal nanoparticles into highly active and chemoselective hydrogenation catalysts, J. Catal. 2017, 350, 218-225.

(32) Liu, L.; Concepción P.; Corma, A., Non-noble metal catalysts for hydrogenation: A facile method for preparing Co nanoparticles covered with thin layered carbon, J. Catal. 2016, 340, 1-9.

(33) Formenti, D.; Topf, C.; Junge, K.; Ragaini F.; Beller, M., $\mathrm{Fe}_{2} \mathrm{O}_{3} / \mathrm{NGr} @ \mathrm{C}$ and $\mathrm{Co}-\mathrm{Co}_{3} \mathrm{O}_{4} / \mathrm{NGr} @ \mathrm{C}$-catalysed hydrogenation of nitroarenes under mild conditions, Catal. Sci. Technol. 2016, 6, 4473-4477.

(34) Liao, Y.; Cheng, Z.; Zuo, W.; Thomas A.; Faul, C. F. J., Nitrogen-rich conjugated microporous polymers: facile synthesis, efficient gas storage, and heterogeneous catalysis, ACS Appl. Mater. Interfaces 2017, 9, 38390-38400.

(35) Zhou, P.; Jiang, L.; Wang, F.; Deng, K.; Lv K.; Zhang, Z., High performance of a cobalt-nitrogen complex for the reduction and reductive coupling of nitro compounds into amines and their derivatives, $S c i$. $A d v$. 2017, 3, 1-11. 
(36) Li, M.; Xu, F.; Li H.; Wang, Y., Nitrogen-doped porous carbon materials: promising catalysts or catalyst supports for heterogeneous hydrogenation and oxidation, Catal. Sci. Technol. 2016, 6, 3670-3693.

(37) Wickramaratne, N. P.; Xu, J.; Wang, M.; Zhu, L.; Dai L.; Jaroniec, M., Nitrogen Enriched Porous Carbon Spheres: Attractive Materials for Supercapacitor Electrodes and $\mathrm{CO}_{2}$ Adsorption, Chem. Mater. 2014, 26, 2820-2828.

Li, Y.; Zhang, J.; Wang, Q.; Jin, Y.; Huang, D.; Cui Q.; Zou, G., Nitrogen-rich carbon nitride hollow vessels: synthesis, characterization, and their properties, J. Phys. Chem. B 2010, 114, 9429-9434.

(39) Westerhaus, F. A.; Jagadeesh, R. V.; Wienhöfer, G.; Pohl, M. M.; Radnik, J.; Surkus, A. E.; Rabeah, J.; Junge, K.; Junge, H.; Nielsen, M.; Brückner, A.; Beller, M., Heterogenized Cobalt Oxide Catalysts for Nitroarene Reduction by Pyrolysis of Molecularly Defined Complexes, Nat. Chem. 2013, 5 (6), 537-543.

(40) Wei, Z.; Wang, J.; Mao, S.; Su, D.; Jin, H.; Wang, Y.; Xu, F.; Li, H.; Wang, Y., In Situ-Generated $\mathrm{Co}^{0}-\mathrm{Co}_{3} \mathrm{O}_{4} / \mathrm{N}$-Doped Carbon Nanotubes Hybrids as Efficient and Chemoselective Catalysts for Hydrogenation of Nitroarenes, ACS Catal. 2015, 5 (8), 4783-4789.

(41) Formenti, D.; Ferretti, F.; Topf, C.; Surkus, A. E.; Pohl, M. M.; Radnik, J.; Schneider, M.; Junge, K.; Beller, M.; Ragaini, F., Co-Based Heterogeneous Catalysts from Well-Defined A-Diimine Complexes: Discussing the Role of Nitrogen, J. Catal. 2017, 351, 79-89.

(42) Song, T.; Ren, P.; Duan, Y.; Wang, Z.; Chen, X.; Yang, Y., Cobalt Nanocomposites on N-Doped Hierarchical Porous Carbon for Highly Selective Formation of Anilines and Imines from Nitroarenes, Green Chem. 2018, 20 (20), 4629-4637.

(43) Sun, X.; Olivos-Suarez, A. I.; Oar-Arteta, L.; Rozhko, E.; Osadchii, D.; Bavykina, A.; Kapteijn, F.; Gascon, J., Metal-Organic Framework Mediated Cobalt/Nitrogen-Doped Carbon Hybrids as Efficient and Chemoselective Catalysts for the Hydrogenation of Nitroarenes, ChemCatChem 2017, 9 (10), 1854-1862.

(44) Dai, Y.; Jiang, C.; Xu, M.; Bian, B.; Lu, D.; Yang, Y., Cobalt in N-Doped Carbon Matrix Catalyst for Chemoselective Hydrogenation of Nitroarenes, Appl. Catal. A 2019, 580, 158-166. 
Capítulo 5. Nanoclústeres de Cobalto como catalizadores para la hidrogenación quimioselectiva de nitroarenos y reacciones tándem.

(45) Cui, X.; Liang, K.; Tian, M.; Zhu, Y.; Ma, J.; Dong, Z., Cobalt Nanoparticles Supported on N-Doped Mesoporous Carbon as a Highly Efficient Catalyst for the Synthesis of Aromatic Amines, J. Colloid Interface Sci. 2017, 501, 231-240.

(46) Baramov, T.; Loos, P.; Hassfeld, J.; Alex, H.; Beller, M.; Stemmler, T.; Meier, G.; Gottfried, M.; Roggan, S., Encapsulated Cobalt Oxide on Carbon Nanotube Support as Catalyst for Selective Continuous Hydrogenation of the Showcase Substrate 1-Iodo4- Nitrobenzene, Adv. Synth. Catal. 2016, 358 (18), 2903-2911.

(47) Alex, H.; Loos, P.; Baramov, T.; Barry, J.; Godiawala, T.; Hassfeld, J.; Steinfeldt, N., Polymer Encapsulated Cobalt-Based Catalysts (Co EnCatTM) for Selective Continuous Hydrogenation of 1-Iodo-4-Nitrobenzene, ChemCatChem 2017, 9 (16), 3210-3217.

(48) Schwob, T.; Kempe, R. A Reusable Co Catalyst for the Selective Hydrogenation of Functionalized Nitroarenes and the Direct Synthesis of Imines and Benzimidazoles from Nitroarenes and Aldehydes, Angew. Chem., Int. Ed. 2016, 55 (48), 15175-15179.

(49) Cheng, T.; Yu, H.; Peng, F.; Wang, H.; Zhang, B.; Su, D., Identifying Active Sites of CoNC/CNT from Pyrolysis of Molecularly Defined Complexes for Oxidative Esterification and Hydrogenation Reactions, Catal. Sci. Technol. 2016, 6 (4), $1007-1015$.

(50) Wang, X.; Li, Y., Chemoselective Hydrogenation of Functionalized Nitroarenes Using MOF-Derived Co-Based Catalysts, J. Mol. Catal. A: Chem. 2016, 420, 56-65.

(51) Nandi, S.; Patel, P.; Khan, N. U. H.; Biradar, A. V.; Kureshy, R. I., NitrogenRich Graphitic-Carbon Stabilized Cobalt Nanoparticles for Chemoselective Hydrogenation of Nitroarenes at Milder Conditions, Inorg. Chem. Front. 2018, 5 (4), 806-813.

(52) Hu, A.; Lu, X.; Cai, D.; Pan, H.; Jing, R.; Xia, Q.; Zhou, D.; Xia, Y., Selective Hydrogenation of Nitroarenes over MOF-Derived Co@CN Catalysts at Mild Conditions, Mol. Catal. 2019, 472, 27-36.

(53) Ji, P.; Manna, K.; Lin, Z.; Feng, X.; Urban, A.; Song, Y.; Lin, W., Single-Site Cobalt Catalysts at New $\mathrm{Zr}_{12}\left(\mu_{3}-\mathrm{O}\right)_{8}\left(\mu_{3}-\mathrm{OH}\right)_{8}\left(\mu_{2}-\mathrm{OH}\right)_{6}$ Metal-Organic Framework Nodes for Highly Active Hydrogenation of Nitroarenes, Nitriles, and Isocyanides, J. Am. Chem. Soc. 2017, 139, 7004-7011. 
(54) Cao, Y.; Liu, K.; Wu, C.; Zhang, H.; Zhang, Q., In Situ-Formed Cobalt Embedded into N-Doped Carbon as Highly Efficient and Selective Catalysts for the Hydrogenation of Halogenated Nitrobenzenes under Mild Conditions, Appl. Catal. A 2020, 592, 117434.

(55) Zhang, J. J.; Ge, J. M.; Wang, H. H.; Wei, X.; Li, X. H.; Chen, J. S., Activating Oxygen Molecules over Carbonyl-Modified Graphitic Carbon Nitride: Merging Supramolecular Oxidation with Photocatalysis in a Metal-Free Catalyst for Oxidative Coupling of Amines into Imines, ChemCatChem 2016, 8 (22), 3441-3445.

(56) Wang, H.; Wang, Y.; Li, Y.; Lan, X.; Ali, B.; Wang, T., Highly Efficient Hydrogenation of Nitroarenes by N-Doped Carbon-Supported Cobalt Single-Atom Catalyst in Ethanol/Water Mixed Solvent, ACS Applied Mater. Interfaces 2020, 12, 30, 34021-34031.

(57) Goyal, V.; Sarki, N.; Singh, B.; Ray, A.; Poddar, M.; Bordoloi, A,; Narani, A.; Natte, K., Carbon-Supported Cobalt Nanoparticles as Catalysts for the Selective Hydrogenation of Nitroarenes to Arylamines and Pharmaceuticals, ACS Applied Nano Mater. 2020, 3, 11070-11079.

(58) Oliveira, R. L.; Ben Ghorbel, M. C.; Praetz, S.; Meiling, D.; Schlesiger, C.; Schomäcker, R.; Thomas, A., Confinement of Cobalt Species in Mesoporous N-Doped Carbons and the Impact on Nitroarene Hydrogenation, ACS Sustainable Chem. Eng. 2020, 8, 11171-11182.

(59) Feng, J.; Handa, S.; Gallou F.; Lipshutz, B. H., Safe and selective nitro group reductions catalyzed by sustainable and recyclable $\mathrm{Fe} / \mathrm{ppm} \mathrm{Pd}$ nanoparticles in water at room temperature, Angew. Chemie - Int. Ed. 2016, 55, 8979-8983.

(60) Yu, C.; Guo, X.; Xi, Z.; Muzzio, M.; Yin, Z.; Shen, B.; Li, J.; Seto C. T.; Sun, S., AgPd Nanoparticles Deposited on $\mathrm{WO}_{2.72}$ Nanorods as an Efficient Catalyst for OnePot Conversion of Nitrophenol/Nitroacetophenone into Benzoxazole/Quinazoline, $J$. Am. Chem. Soc. 2017, 139, 5712-5715.

(61) García-Ortiz, A.; Vidal, J. D.; Climent, M. J.; Concepción, P.; Corma A.; Iborra, S., Chemicals from Biomass: selective synthesis of N-substituted furfuryl amines by the one-pot direct reductive amination of furanic aldehydes, ACS Sustain. Chem. Eng. 2019, 7, 6243-6250. 
Capítulo 5. Nanoclústeres de Cobalto como catalizadores para la hidrogenación quimioselectiva de nitroarenos y reacciones tándem.

(62) Garcia-Ortiz, A.; Vidal, J. D.; Iborra, S.; Climent, M. J.; Cored, J.; Ruano, D.; Pérez-Dieste, V.; Concepción P.; Corma, A., Synthesis of a hybrid $\mathrm{Pd}^{0} / \mathrm{Pd}$ carbide/carbon catalyst material with high selectivity for hydrogenation reactions, $J$. Catal. 2020, 389, 706-713.

(63) Jagadeesh, R. V.; Stemmler, T.; Surkus, A. E.; Bauer, M.; Pohl, M. M.; Radnik, J.; Junge, K.; Junge, H.; Brückner A.; Beller, M., Cobalt-based nanocatalysts for green oxidation and hydrogenation processes, Nat. Protoc. 2015, 10, 916-926.

(64) Jagadeesh, R. V.; Murugesan, K.; Alshammari, A. S.; Neumann, H.; Pohl, M. M.; Radnik J.; Beller, M., MOF-derived cobalt nanoparticles catalyze a general synthesis of amines, Science 2017, 358, 326-332.

(65) Mao, F.; Sui, D.; Qi, Z.; Fan, H.; Chen R.; Huang, J., Heterogeneous cobalt catalysts for reductive amination with $\mathrm{H}_{2}$ : General synthesis of secondary and tertiary amines, $R S C A d v$. 2016, 6, 94068-94073.

(66) Pisiewicz, S.; Stemmler, T.; Surkus, A. E.; Junge K.; Beller, M., Synthesis of Amines by Reductive Amination of Aldehydes and Ketones using $\mathrm{Co}_{3} \mathrm{O}_{4} / \mathrm{NGr} @ \mathrm{C}$ Catalyst, ChemCatChem 2015, 7, 62-64.

(67) Kato, H.; Shibata, I.; Yasaka, Y.; Tsunoi, S.; Yasuda M.; Baba, A., The reductive amination of aldehydes and ketones by catalytic use of dibutylchlorotin hydride complex, Chem. Commun. 2006, 4189-4191.

(68) Zhou, P.; Yu, C.; Jiang, L.; Lv K.; Zhang, Z., One-pot reductive amination of carbonyl compounds with nitro compounds with $\mathrm{CO} / \mathrm{H}_{2} \mathrm{O}$ as the hydrogen donor over non-noble cobalt catalyst, J. Catal. 2017, 352, 264-273.

(69) Chen, Y. Z.; Zhou, Y. X.; Wang, H.; Lu, J.; Uchida, T.; Xu, Q.; Yu S. H.; Jiang, H. L., Multifunctional PdAg@MIL-101 for one-pot cascade reactions: combination of host-guest cooperation and bimetallic synergy in catalysis, ACS Catal. 2015, 5, 20622069.

(70) Zhou P.; Zhang, Z.; One-pot Reductive Amination of carbonyl Compounds with Nitro Compounds by Transfer Hydrogenation over $\mathrm{Co}-\mathrm{N}_{\mathrm{x}}$ as catalyst, ChemSusChem 2017, 10, 1892-1897.

(71) Sreedhar, B.; Surendra-Reddy P.; Keerthi-Devi, D., Direct one-pot reductive amination of aldehydes with nitroarenes in a domino fashion: catalysis by gum-acacia- 
stabilized palladium nanoparticles, J. Org. Chem. 2009, 74, 8806-8809.

(72) Cho, A.; Byun S.; Kim, B. M., AuPd- $\mathrm{Fe}_{3} \mathrm{O}_{4}$ Nanoparticle Catalysts for Highly Selective, One-Pot Cascade Nitro-Reduction and Reductive Amination, Adv. Synth. Catal. 2018, 360, 1253-1261.

(73) Murugesan, K.; Chandrashekhar, V. G.; Senthamarai, T.; Jagadeesh R. V.; Beller, M., Reductive amination using cobalt-based nanoparticles for synthesis of amines, Nat. Protoc. 2020, 15, 1313-1337.

(74) Duan, Y.; Song, T.; Dong X.; Yang, Y., Enhanced catalytic performance of cobalt nanoparticles coated with a N,P-codoped carbon shell derived from biomass for transfer hydrogenation of functionalized nitroarenes, Green Chem. 2018, 20, 2821-2828.

(75) Gutiérrez-Tarriño, S.; Rojas-Buzo, S.; Lopes, C. W.; Agostini, G.; Calvino, J. J.; Corma, A.; Oña-Burgos, P., Cobalt Nanoclusters Cover by N-Doped Carbon Layers as Core-Shell for Tandem Reactions in Aquo Media Mediated by Chemoselective Nitroarene Hydrogenation, Green Chem. 2021, doi.org/10.1039/D1GC00706H.

(76) Martínez, A.; Prieto G.; Rollán, J., Nanofibrous $\gamma-\mathrm{Al}_{2} \mathrm{O}_{3}$ as support for Co-based Fischer-Tropsch catalysts: Pondering the relevance of diffusional and dispersion effects on catalytic performance J. Catal. 2009, 263, 292-305.

(77) Chen, B.; Li, F.; Huang Z.; Yuan, G., Recyclable and Selective Nitroarene Hydrogenation Catalysts Based on Carbon-Coated Cobalt Oxide Nanoparticles, ChemCatChem 2016, 8, 1132-1138.

(78) Sorribes, I.; Liu L.; Corma, A., Nanolayered Co-Mo-S catalysts for the chemoselective hydrogenation of nitroarenes, ACS Catal. 2017, 7, 2698-2708.

(79) Sun, X.; Olivos-Suarez, A. I.; Osadchii, D.; Romero, M. J. V.; Kapteijn F.; Gascon, J., Single cobalt sites in mesoporous N-doped carbon matrix for selective catalytic hydrogenation of nitroarenes, J. Catal. 2018, 357, 20-28.

(80) Eckardt, M.; Zaheer M.; Kempe, R., Nitrogen-doped mesoporous SiC materials with catalytically active cobalt nanoparticles for the efficient and selective hydrogenation of nitroarenes, Sci. Rep. 2018, 8, 2567.

(81) Hu, A.; Lu, X.; Cai, D.; Pan, H.; Jing, R.; Xia, Q.; Zhou, D.; Xia, Y., Selective hydrogenation of nitroarenes over MOF-derived Co@CN catalysts at mild conditions, Molecular Catalysis 2019, 472, 27-36. 
Capítulo 5. Nanoclústeres de Cobalto como catalizadores para la hidrogenación quimioselectiva de nitroarenos y reacciones tándem.

(82) Li, W.; Artz, J.; Broicher, C.; Junge, K.; Hartmann, H.; Besmehn, A.; Palkovits, R.; Beller, M., Superior activity and selectivity of heterogenized cobalt catalysts for hydrogenation of nitroarenes, Catal. Sci. Technol. 2019, 9, 157-162.

(83) Barakat, N. A. M.; Kim, B.; Park, S. J.; Jo, Y.; Jung M. H.; Kim, H. Y., Cobalt nanofibers encapsulated in a graphite shell by an electrospinning process, J. Mater. Chem. 2009, 19, 7371-7378.

(84) Hou, Y.; Wen, Z.; Cui, S.; Ci, S.; Mao S.; Chen, J., An advanced nitrogen-doped graphene/cobalt-embedded porous carbon polyhedron hybrid for efficient catalysis of oxygen reduction and water splitting, Adv. Funct. Mater. 2015, 25, 872-882.

(85) Wang, Z. L.; Hao, X. F.; Jiang, Z.; Sun, X. P.; Xu, D.; Wang, J.; Zhong, H. X.; Meng F. L.; Zhang, X. B., C and N hybrid coordination derived Co-C-N complex as a highly efficient electrocatalyst for hydrogen evolution reaction, J. Am. Chem. Soc. 2015, 137, 15070-15073.

(86) Zhang, L.; Hu, P.; Zhao, X.; Tian, R.; Zou R.; Xia, D., Controllable synthesis of core-shell Co@CoO nanocomposites with a superior performance as an anode material for lithium-ion batteries, J. Mater. Chem. 2011, 21, 18279-18283.

(87) Mhamane, D.; Ramadan, W.; Fawzy, M.; Rana, A.; Dubey, M.; Rode, C.; Lefez, B.; Hannoyer B.; Ogale, S., From graphite oxide to highly water dispersible functionalized graphene by single step plant extract-induced deoxygenation, Green Chem. 2011, 13, 1990-1996.

(88) Jaouen, F.; Herranz, J.; Lefévre, M.; Dodelet, J. P.; Kramm, U. I.; Herrmann, I.; Bogdanoff, P.; Maruyama, J.; Nagaoka, T.; Garsuch, A.; Dahn, J. R.; Olson, T.; Pylypenko, S.; Atanassov P.; Ustinov, E. A., Cross-laboratory experimental study of non-noble-metal electrocatalysts for the oxygen reduction reaction, ACS Appl. Mater. Interfaces 2009, 1, 1623-1639.

(89) Yin, P.; Yao, T.; Wu, Y.; Zheng, L.; Lin, Y.; Liu, W.; Ju, H.; Zhu, J.; Hong, X.; Deng, Z.; Zhou, G.; Wei S.; Li, Y., Single cobalt atoms with precise N-coordination as superior oxygen reduction reaction catalysts, Angew. Chemie - Int. Ed. 2016, 55, 1080010805.

(90) Shang, L.; Yu, H.; Huang, X.; Bian, T.; Shi, R.; Zhao, Y.; Waterhouse, G. I. N.; Wu, L. Z.; Tung C. H.; Zhang, T., Well-dispersed ZIF-derived Co, N-co-doped carbon nanoframes through mesoporous-silica-protected calcination as efficient oxygen 
reduction electrocatalysts, Adv. Mater. 2016, 28, 1668-1674.

(91) Fei, H.; Dong, J.; Arellano-Jiménez, M. J.; Ye, G.; Dong Kim, N.; Samuel, E. L. G.; Peng, Z.; Zhu, Z.; Qin, F.; Bao, J.; Yacaman, M. J.; Ajayan, P. M.; Chen D.; Tour, J. M., Atomic cobalt on nitrogen-doped graphene for hydrogen generation, Nat. Commun. 2015, 6, 1-8.

(92) Yamamoto, T., Assignment of pre-edge peaks in K-edge x-ray absorption spectra of $3 \mathrm{~d}$ transition metal compounds: electric dipole or quadrupole?, X-Ray Spectrom. 2008, 36, 27-34.

(93) Agostini, G.; Piovano, A.; Bertinetti, L.; Pellegrini, R.; Leofanti, G.; Groppo E.; Lamberti, C., Effect of different face centered cubic nanoparticle distributions on particle size and surface area determination: a theoretical study, J. Phys. Chem. C 2014, 118, 4085-4094.

(94) Montejano-Carrizales, J. M.; Aguilera-Granja F.; Morán-López, J. L., Direct enumeration of the geometrical characteristics of clusters, Nanostructured Mater. 1997, $8,269-287$.

(95) Tan, Y.; Liu, X. Y.; Zhang, L.; Wang, A.; Li, L.; Pan, X.; Miao, S.; Haruta, M.; Wei, H.: Wang, H.; Wang, F.; Wang X.; Zhang, T., ZnAl-Hydrotalcite-Supported $\mathrm{Au}_{25}$ Nanoclusters as Precatalysts for Chemoselective Hydrogenation of 3-Nitrostyrene, Angew. Chemie 2017, 129, 2753-2757.

(96) Speck, K.; Magauer, T., The chemistry of isoindole natural products, Beilstein J. Org. Chem. 2013, 9, 2048-2078.

(97) Wang, K.; Bao, L.; Qi, Q.; Zhao, F.; Ma, K.; Pei, Y.; Liu, H., Erinacerins C-L, isoindolin-1-ones with $\alpha$-glucosidase inhibitory activity from cultures of the medicinal mushroom Hericium erinaceus, J. Nat. Prod. 2015, 78, 146-154.

(98) Sorbera, L. A.; Leeson, P. A.; Silvestre J.; Castañer, J., Pagoclone-anxiolytic GABA-A/BZD site partial agonist, Drugs Future 2001, 26, 651-657.

(99) Stuk, T. L.; Assink, B. K.; Bates Jr., R. C.; Erdman, D. T.; Fedij, V.; Jennings, S. M.; Lassig, J. A.; Smith R. J.; Smith, T. L., An efficient and cost-effective synthesis of pagoclone, Org. Process Res. Dev. 2003, 7, 851-855.

(100) Wada T.; Fukuda, N., Pharmacologic profile of a new anxiolytic, DN-2327: effect of Ro15-1788 and interaction with diazepam in rodents, Psychopharmacology 
Capítulo 5. Nanoclústeres de Cobalto como catalizadores para la hidrogenación quimioselectiva de nitroarenos y reacciones tándem.

1991, 103, 314-322.

(101) Hussein, Z.; Mulford, D. J.; Bopp B. A.; Granneman, G. R., Stereoselective pharmacokinetics of pazinaclone, a new non-benzodiazepine anxiolytic, and its active metabolite in healthy subjects., Br. J. Clin. Pharmacol. 1993, 36, 357-361.

(102) Kanamitsu, N.; Osaki, T.; Itsuji, Y.; Yoshimura, M.; Tsujimoto H.; Soga, M., Novel water-soluble sedative-hypnotic agents: isoindolin-1-one derivatives, Chem. Pharm. Bull. 2007, 55, 1682-1688.

(103) Uemura, S.; Fujita, T.; Sakaguchi Y.; Kumamoto, E., Actions of a novel watersoluble benzodiazepine-receptor agonist JM-1232 (-) on synaptic transmission in adult rat spinal substantia gelatinosa neurons, Biochem. Biophys. Res. Commun. 2012, 418, 695-700.

(104) Fu, Z.; Hao, G.; Fu, Y.; He, D.; Tuo, X.; Guo S.; Cai, H., Transition metal-free electrocatalytic halodeborylation of arylboronic acids with metal halides $\mathrm{MX}(\mathrm{X}=\mathrm{I}, \mathrm{Br})$ to synthesize aryl halides, Org. Chem. Front. 2020, 7, 590-595.

(105) Panja, S.; Kundu, D.; Ahammed S.; Ranu, B. C., Highly chemoselective reduction of azides to amines by $\mathrm{Fe}(0)$ nanoparticles in water at room temperature, Tetrahedron Lett. 2017, 58, 3457-3460.

(106) Meng, F.; Zhu, X.; Li, Y.; Xie, J.; Wang, B.; Yao J.; Wan, Y., Efficient CopperCatalyzed Direct Amination of Aryl Halides Using Aqueous Ammonia in Water, European J. Org. Chem. 2010, 6149-6152.

(107) Formenti, D.; Ferretti, F.; Topf, C.; Surkus, A. E.; Pohl, M. M.; Radnik, J.; Schneider, M.; Junge, K.; Beller M.; Ragaini, F., Co-based heterogeneous catalysts from well-defined $\alpha$-diimine complexes: Discussing the role of nitrogen, J. Catal., 2017, 351, 79-89.

(108) Xu, Y.; Zhang, Z.; Qiu, C.; Chen, S.; Ling X.; Su, C., Photocatalytic WaterSplitting Coupled with Alkanol Oxidation for Selective N-alkylation Reactions over Carbon Nitride, ChemSusChem, 2021, 14, 582-589.

(109) Cho, A.; Byun S.; Kim, B. M., AuPd- $-\mathrm{Fe}_{3} \mathrm{O}_{4}$ Nanoparticle Catalysts for Highly Selective, One-Pot Cascade Nitro-Reduction and Reductive Amination, Adv. Synth. Catal. 2018, 360, 1253-1261.

(110) Hoshimoto, Y.; Kinoshita, T.; Hazra, S.; Ohashi M.; Ogoshi, S., Main-Group- 
Catalyzed Reductive Alkylation of Multiply Substituted Amines with Aldehydes Using $\mathrm{H}_{2}$, J. Am. Chem. Soc. 2018, 140, 7292-7300.

(111) Tian, Y.; Wei, J.; Wang, M.; Li G.; Xu, F., Hantzsch ester triggered metal-free cascade approach to isoindolinones, Tetrahedron Lett. 2018, 59, 1866-1870.

(112) Zhou, Y.; Chen, P.; Lv, X.; Niu, J.; Wang, Y.; Lei M.; Hu, L., A facile and efficient method for the synthesis of $\mathrm{N}$-substituted isoindolin-1-one derivatives under $\mathrm{Pd}$ $(\mathrm{OAc})_{2} / \mathrm{HCOOH}$ system, Tetrahedron Lett. 2017, 58, 2232-2235. 



\section{Capítulo 6}

\section{Complejos tetranucleares de}

cobalto para la oxidación selectiva de ciclohexano. 



\section{Índice}

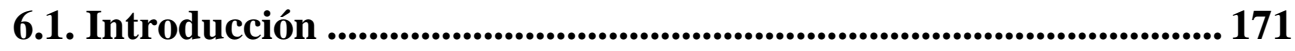

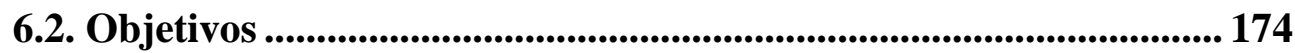

6.3. Resultados y discusión ........................................................................ 174

6.3.1. Síntesis y caracterización de los catalizadores ..............................................174

6.3.2. Evaluación de los clústeres de cobalto en la oxidación de ciclohexano.........179

6.3.3. Estudio mecanístico de la reacción de oxidación de ciclohexano ...................184

6.3.3.1. Estudio EPR de la descomposición de CHHP por los clústeres de cobalto

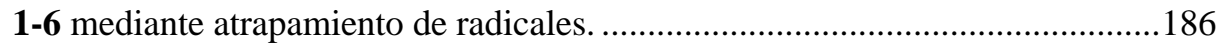

6.3.3.2. Transferencia de oxígeno desde el CHHP al ciclohexano mediada por los

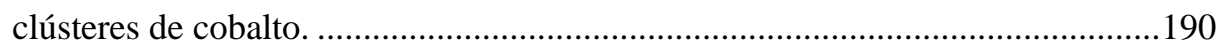

6.3.3.3. Influencia de la naturaleza del clúster de cobalto en el mecanismo de

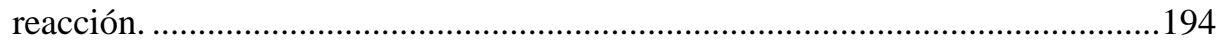

6.4. Conclusiones .......................................................................................... 196

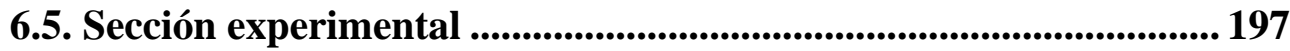

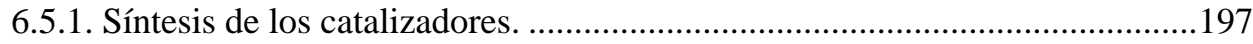

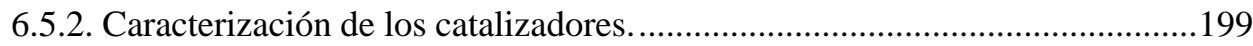

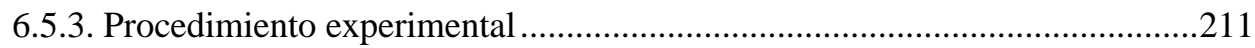

6.5.4. Resultados catalíticos para la oxidación de ciclohexano .................................212

6.5.5. Estudio del mecanismo de reacción.................................................................214

6.5.5.1. Resonancia paramagnética electrónica.....................................................214

6.5.5.2. Calculo de la eficiencia para la reacción de transferencia de oxígeno desde

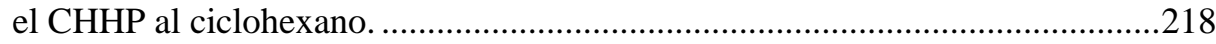

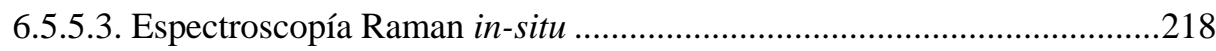

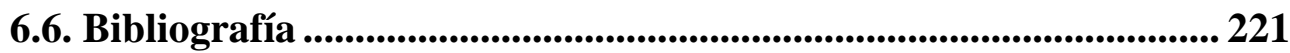





\subsection{Introducción.}

Los hidrocarburos procedentes de la destilación del petróleo y del gas natural juegan un papel muy importante hoy en día, siendo, por un lado, la fuente de energía más importante, y por otro, materias primas que se utilizan como punto de partida en la industria química. En este sentido, la oxidación selectiva de los hidrocarburos es un área de investigación destacado, tanto en la industria como a nivel académico, siendo la inserción directa del átomo de oxígeno en el enlace alifático C-H una de las cuestiones más exigentes y prometedoras tanto desde el punto de vista industrial como desde el punto de vista de síntesis, debido al alto nivel de activación requerido. ${ }^{1,2}$

Antes de la utilización de los hidrocarburos como materia prima en la química industrial, los sustratos orgánicos se oxidaban con agentes inorgánicos como óxidos de cromo o manganeso, halógenos y ácido nítrico. Con el desarrollo de la industria petroquímica, empezaron a ser necesarias una amplia gama de moléculas que contienen oxígeno en su estructura, entre ellas alcoholes, aldehídos, cetonas, epóxidos y ácidos carboxílicos, las cuales se hicieron necesarias para la producción de precursores que se transformarían posteriormente en polímeros y materiales sintéticos. ${ }^{3}$ Por ejemplo, el óxido de etileno, la acroleína, el ácido acrílico y la metacroleína se producen por la oxidación parcial de la fase de vapor de alquenos ligeros como el etileno, el propileno y butenos, ${ }^{4}$ mientras que el ácido acético, el aceite K/A (ciclohexanona y ciclohexanol), ácido benzoico, el ácido tereftálico y fenol se obtienen a partir de la oxidación catalítica de alcanos como el butano, el ciclohexano y alquilbencenos. ${ }^{5,6}$ En la actualidad, los métodos de oxidación tradicionales en los que se usaban óxidos metálicos, halógenos y ácido nítrico se consideran medioambientalmente inaceptables y, por lo tanto, se han ido reemplazando por métodos de oxidación más limpios.

De entre los procesos de oxidación mencionados, la oxidación aeróbica selectiva del ciclohexano a ciclohexanona y ciclohexanol (aceite KA) va a centrar el actual capítulo de esta tesis doctoral. Este proceso es muy importante para la industria química debido a que los productos de esta reacción son precursores de la $\varepsilon$-caprolactama y el ácido adípico, que a su vez son intermedios esenciales para la producción de nylon-6 y nylon6,6 (Esquema 6.1). ${ }^{7,8}$ De hecho, cada año se producen en todo el mundo más de 1.000 millones de toneladas de ciclohexanol y ciclohexanona. ${ }^{9,10}$ 


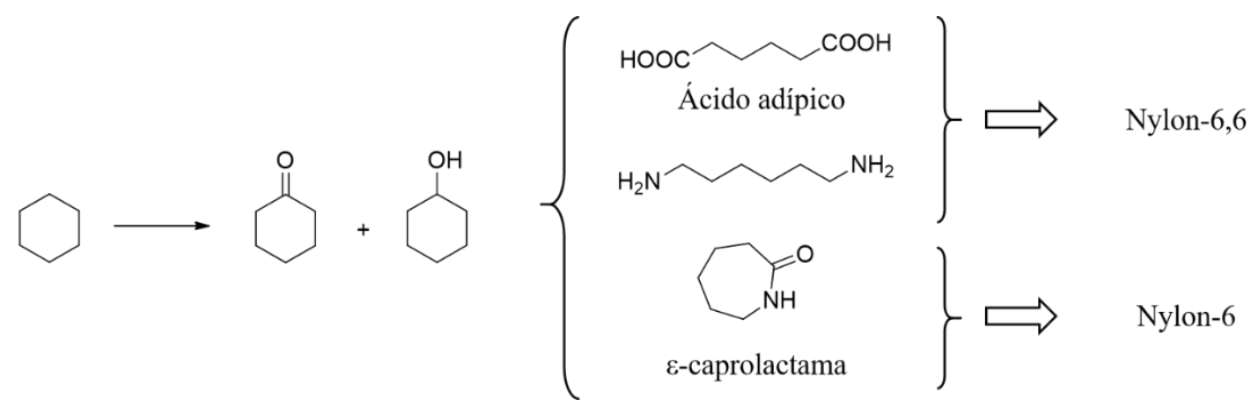

Esquema 6.1. Intermedios principales en la producción del nylon-6 y el nylon-6,6 a partir del ciclohexano.

Debido al carácter inerte intrínseco de los enlaces C-H (energía de disociación 439 $\mathrm{kJ} / \mathrm{mol}),{ }^{11}$ los productos formados, ciclohexanol y ciclohexanona, más reactivos que el ciclohexano, pueden oxidarse más fácilmente. Por este motivo, la selectividad del proceso disminuye al aumentar la conversión, lo que convierte la selectividad en la cuestión clave durante la oxidación de estas moléculas. ${ }^{12-14}$ En la actualidad, el proceso industrial se lleva a cabo termocatalíticamente con naftenatos de cobalto o manganeso como catalizadores ${ }^{15}$ en condiciones drásticas de presión y temperatura (1.5-3 MPa, 130$160^{\circ} \mathrm{C}$ ) para lograr una alta selectividad (alrededor del $80 \%$ ) del aceite KA con una conversión de ciclohexano por debajo del 9\%, lo que lleva a un alto consumo de energía y la generación de subproductos indeseados. ${ }^{16}$

En los últimos años se han reportado varios tipos de oxidantes para la oxidación de ciclohexano en fase líquida, entre los que cabe destacar el peróxido de hidrógeno, el tertbutil hidroperóxido y el oxígeno molecular. La oxidación del ciclohexano con peróxido de hidrógeno en presencia de catalizadores homogéneos o tamices moleculares con carácter redox suele mostrar una baja eficiencia y, por lo tanto, no suele ser interesante para una aplicación industrial. ${ }^{13}$ Por otro lado, el tert-butil hidroperóxido es un oxidante mucho más reactivo y suele dar eficiencias mucho más altas. Sin embargo, su precio es más elevado que el del peróxido de hidrógeno y la necesidad de utilizar el tert-butanol producido hace que este oxidante no sea atractivo para la industria. ${ }^{13}$ Por lo tanto, el oxidante ideal para esta reacción sería el oxígeno molecular (o el aire), ya que es un compuesto barato y bastante selectivo si se utilizan temperaturas no superiores a $343 \mathrm{~K}$. El desafío en este caso es encontrar catalizadores activos en estas condiciones.

Para este proceso se han reportado en los últimos años todo tipo de catalizadores; complejos organometálicos, ${ }^{17,18}$ MOFs, ${ }^{16,19}$ materiales basados en carbono, ${ }^{20,21}$ nanopartículas soportadas en sílica ${ }^{15,22}$ o zeolitas. ${ }^{23}$ Sin embargo, la mayoría de estos 
catalizadores se utilizan en presencia de aditivos o disolventes o en condiciones severas de reacción y, además, suelen requerir hidroperóxidos como agentes oxidantes. Recientemente, la preocupación por el medio ambiente se ha sumado a las razones que han impulsado el interés por el desarrollo de catalizadores que sean activos y selectivos usando aire como oxidante (en lugar de oxígeno o hidroperóxidos) en condiciones suaves y sin disolvente, evitando así el derroche de estos compuestos.

El desarrollo del clúster de cobalto $\left[\mathrm{Co}_{4} \mathrm{O}_{4}(\mathrm{OAc})_{4} \mathrm{py}_{4}\right]$ por el grupo de Beattie ${ }^{24}$ en 1998 ha dado lugar a varios trabajos de grupos de investigación independientes. En este sentido, el grupo de Dismukes describió este mismo complejo como un sistema mimético del fotosistema II de las plantas, el cuál desempeña un papel fundamental en la oxidación del agua durante la fotosíntesis, proceso en el que se forma oxígeno junto con electrones y protones. ${ }^{25}$ Además, en 2015, el grupo de Tilley estudió el mecanismo de formación del enlace O-O en este proceso, usando dicho clúster tetranuclear de cobalto. ${ }^{26}$ En este estudio se observaron varios intermedios de reacción, entre los que cabe destacar radicales hidroxilo, hidroperóxidos y peróxidos, los cuales podrían ser claves en la activación de enlaces $\mathrm{C}-\mathrm{H}$ de los alcanos menos reactivos para procesos de oxidación (Esquema 6.2 a). De hecho, el mecanismo de activación del $\mathrm{O}_{2}$ para la oxidación de enlaces C-H con hemo-catalizadores está basado también en este tipo de intermedios (Esquema 6.2 b). ${ }^{27}$ Cabe destacar también que, el grupo de Das han utilizado $\left[\mathrm{Co}_{4} \mathrm{O}_{4}(\mathrm{OAc})_{4} \mathrm{py}_{4}\right]$ para la oxidación aeróbica de enlaces $\mathrm{CH}$ activados de etilbenceno y p-xileno. $^{28}$
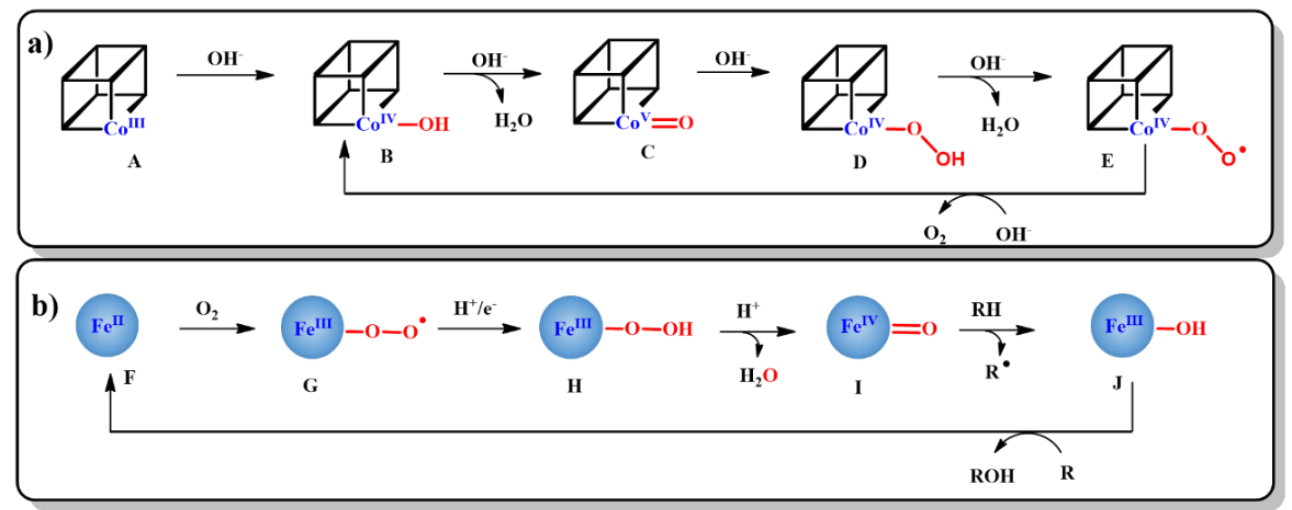

Esquema 6.2. a) Mecanismo de formación del enlace $\mathrm{O}-\mathrm{O}$ usando $\left[\mathrm{Co}_{4} \mathrm{O}_{4}(\mathrm{OAc})_{4} \mathrm{py} 4\right]$. b) Mecanismo de activación del $\mathrm{O}_{2}$ para la oxidación de enlaces $\mathrm{CH}$ usando hemocatalizadores. 


\subsection{Objetivos.}

Los grupos de Dismukes, ${ }^{25}$ Tilley $^{26}$ y Das $^{28}$ han estudiado la estructura del complejo $\left[\mathrm{Co}_{4} \mathrm{O}_{4}(\mathrm{OAc})_{4}(\mathrm{py})_{4}\right]$, su actividad como catalizador en la reacción de oxidación del agua y los intermedios de reacción generados en dicha reacción. Dichos intermedios, peróxidos e hidroperóxidos, nos llevan a pensar que este catalizador puede presentar una buena actividad catalítica en la reacción de oxidación de enlaces $\mathrm{C}-\mathrm{H}$ no activados, como la oxidación del ciclohexano. Por ello, los objetivos propuestos en este capítulo de la tesis doctoral son los siguientes:

- Síntesis de catalizadores basados en el clúster tetranuclear conocido $\left[\mathrm{Co}_{4} \mathrm{O}_{4}(\mathrm{OAc})_{4}(\mathrm{py})_{4}\right]$, modulando su densidad electrónica, que sean activos y selectivos en la reacción de oxidación de ciclohexano en condiciones suaves de reacción, sin disolvente ni aditivos y utilizando aire como oxidante.

- Una vez estudiada la actividad de los catalizadores, estudiar la correlación entre la estructura y la actividad para corroborar que las propiedades electrónicas están correlacionadas con la actividad catalítica.

- Estudiar el mecanismo de esta reacción mediante la detección de intermedios de reacción usando diferentes técnicas.

\subsection{Resultados y discusión.}

En esta tesis doctoral, se ha desarrollado una familia de clústeres tetranucleares de cobalto derivados del $\left[\mathrm{Co}_{4} \mathrm{O}_{4}(\mathrm{OAc})_{4}(\mathrm{py})_{4}\right]$, en los cuales se modula la densidad electrónica introduciendo diferentes sustituyentes en los ligandos carboxilato y piridina. Estos complejos se van a usar como catalizadores para la reacción de oxidación del ciclohexano usando aire como oxidante, lo que permitirá estudiar la relación entre la estructura y la actividad de dichos catalizadores.

\subsubsection{Síntesis y caracterización de los catalizadores.}

En esta tesis doctoral se han sintetizado una serie de complejos de cobalto tetranucleares, con la fórmula general $\left[\mathrm{Co}_{4} \mathrm{O}_{4}(\mathrm{COOR})_{4}\left(4-\mathrm{R}^{\prime}-\mathrm{py}\right)_{4}\right]$, con diferentes ligandos carboxilato y piridina siguiendo un método reportado en bibliografía (Esquema 6.3 a). ${ }^{26} \mathrm{El}$ procedimiento detallado se describe en la sección experimental. Las condiciones oxidantes que se usan en este método sintético suponen una desventaja, ya que limitan el uso de algunos ligandos bifuncionales. Para solventar este problema, se ha desarrollado un método sintético basado en un intercambio del ligando carboxilato, usando los complejos $\mathbf{1 - 3}$ como precursores y el ácido benzoico como reactivo para obtener los clústeres 4-6 con un elevado rendimiento (Esquema 6.3 b). Este intercambio 
de ligando tiene lugar debido a la diferencia en el $\mathrm{pK}_{\mathrm{b}}$ entre los dos ligandos carboxilatos (pK 9.24 y 9.81 para el acetato y el benzoato, respectivamente).
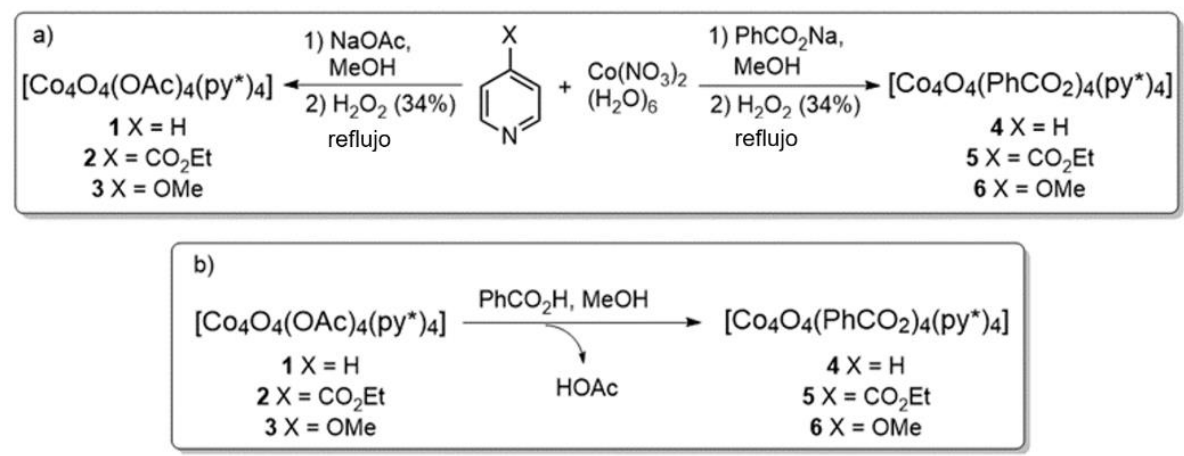

Esquema 6.3. a) Esquema sintético general de los clústeres de cobalto tetranucleares 1-6. b) Síntesis de los clústeres 4-6 usando los clústeres 1-3 como precursores.

Estos clústeres de cobalto se han caracterizado mediante el uso de varias técnicas. En primer lugar, de la síntesis de los complejos 2, 5 y 6 se obtuvieron por recristalización monocristales adecuados para su estudio mediante difracción de rayos $\mathrm{X}$ de monocristal (Figura 6.1). Los complejos $\mathbf{2}$ y $\mathbf{5}$ cristalizan en un grupo espacial triclínico con 2 y 4 unidades incluidas en la unidad asimétrica, respectivamente. Estos compuestos pueden ser formulados como $\left[\mathrm{Co}_{4} \mathrm{O}_{4}(\mathrm{RCOO})_{4}(\mathrm{p}-\mathrm{COOMe}-\mathrm{py})_{4}\right](\mathrm{R}=$ Me para el compuesto $2 \mathrm{y}$ $\mathrm{R}=\mathrm{Ph}$ para el compuesto 5). El complejo 6 cristaliza en un grupo espacial monoclínico con cuatro unidades incluidas en la unidad asimétrica, y se formula como $\left[\mathrm{Co}_{4} \mathrm{O}_{4}(\mathrm{OPh})_{4}(\mathrm{p}-\mathrm{OMe}-\mathrm{py})_{4}\right]$.

Cada oxo-cubano presenta cuatro átomos de cobalto en estado de oxidación $+3, \mathrm{y}$, como se espera para los iones $\mathrm{d}^{6}-\mathrm{Co}^{3+}$, los centros metálicos adoptan una geometría octaédrica distorsionada con coordinación 6. Los cuatro átomos de cobalto se encuentran en vértices alternativos de un cubo $\left[\mathrm{Co}_{4} \mathrm{O}_{4}\right]^{4+}$. Cada uno de ellos se encuentra coordinado a tres ligandos oxo que se encuentran en los vértices libres del cubo además de a dos ligandos $\mu_{2}$-acetato que unen los iones $\mathrm{Co}^{3+}$ a lo largo de las cuatro diagonales de las caras del cubo. Finalmente, cada cobalto está coordinado a un ligando piridina, que ocupa la posición axial, que completa la esfera de coordinación de los cuatro iones Co (III). 

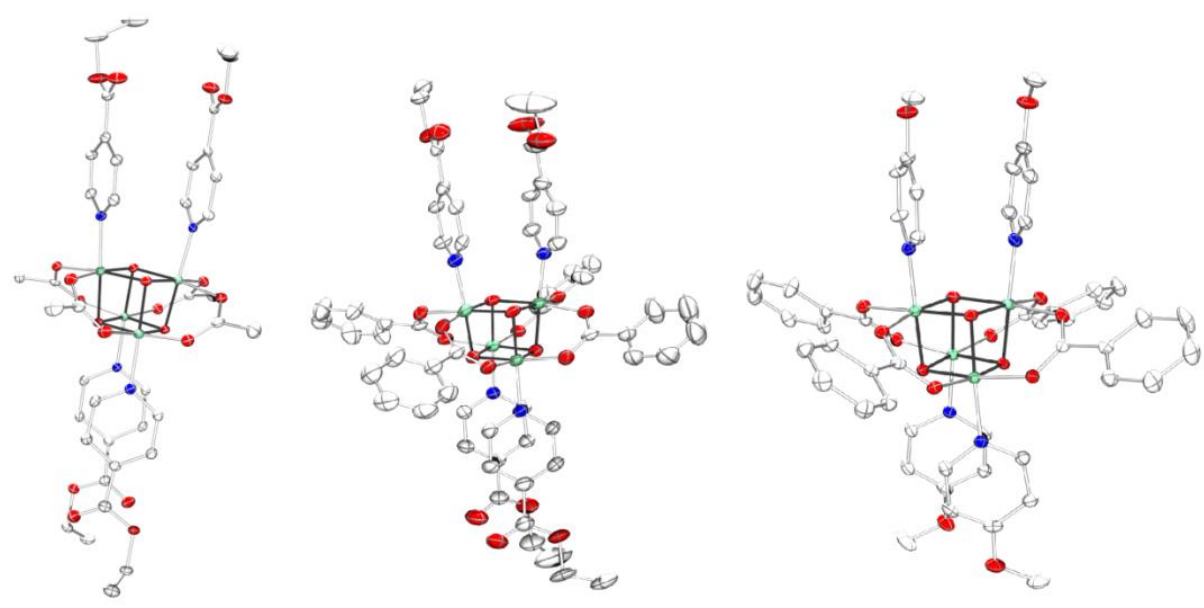

Figura 6.1. Estructura de rayos $X$ de monocristal de 2, 5 y 6, respectivamente. Los átomos de hidrógeno se han omitido por claridad de la imagen.

Para estos complejos, como se puede observar en la Tabla 6.1, las longitudes de enlace Co(III)-O(oxo) y Co (III)-O (carboxilato) se encuentran en el rango 1.848-1.884 $\AA$ y 1.928-1.979 ^, respectivamente. El ligando carboxilato que coordina a dos Co (III) refuerza además la estructura del cubano. Por otro lado, hay dos tipos de distancia CoCo: una de ellas más larga, cercana a $2.83 \AA$, en el caso en el que los cobaltos están unidos únicamente por ligandos oxo, y la segunda, un poco más corta, cercana a $2.70 \AA$, en el caso en el que los cobaltos están unidos por ligandos oxo y un ligando carboxilato bidentado. Estas distancias son comparables a las que existen para otros complejos de cobalto (III) similares que presentan una disposición $\left[\mathrm{Co}_{4}\left(\mu_{3}-\mathrm{O}\right)_{4}\right] .{ }^{28,29}$ Además, la distancia media Co-N es del orden de $1.960 \AA$ y los ángulos diedros entre dos piridinas se encuentran en el rango entre 170 y $180^{\circ}$. De esta forma, se puede concluir que los cubanos aislados $\left[\mathrm{Co}_{4} \mathrm{O}_{4}\right]$ presentan una estructura cuboidal completa estabilizadas por fuerzas intermoleculares $\pi-\pi$ entre las piridinas (más información en la Tabla 6.7 de la sección experimental). 
Tabla 6.1. Distancias interatómicas promedio ( $\AA$ ) y ángulos de enlace (deg) para los complejos 2,5 y 6 comparados con 1 y 4 .

\begin{tabular}{c|ccccc}
$\begin{array}{c}\text { Distancias }(\mathbf{A}) \mathbf{y} \text { ángulos }(\mathbf{d e g}) \\
\mathbf{d e} \text { enlace }\end{array}$ & $\mathbf{2}$ & $\mathbf{5}$ & $\mathbf{6}$ & $\mathbf{1}^{28}$ & $\mathbf{4}^{29}$ \\
\hline $\mathbf{C o}-\mathbf{N}(\mathbf{p y})(\mathbf{\AA})$ & 1.964 & 1.959 & 1.958 & 1.962 & 1.968 \\
\hline $\mathbf{C o}-\left(\boldsymbol{\mu}_{\mathbf{3}}-\mathbf{O}\right)(\mathbf{\AA})$ & 1.867 & 1.864 & 1.868 & 1.865 & 1.879 \\
\hline $\mathbf{C o}-\mathbf{O}_{\text {carbox }}(\mathbf{\AA})$ & 1.949 & 1.952 & 1.956 & 1.953 & 1.967 \\
\hline $\mathbf{C o} \cdots \mathbf{C o}^{[\mathrm{ad}]}(\stackrel{\AA}{\mathbf{A}})$ & 2.835 & 2.829 & 2.824 & 2.815 & 2.856 \\
\hline $\mathbf{C o} \cdots \mathbf{C o}^{[\mathbf{b}]}(\stackrel{\AA}{\mathbf{A}})$ & 2.701 & 2.690 & 2.701 & 2.702 & 2.725 \\
\hline $\mathbf{O}-\mathbf{C o}-\mathbf{O}^{[\mathbf{c}]}(\mathbf{d e g})$ & 84.74 & 84.88 & 85.08 & 85.21 & 84.80 \\
\hline $\mathbf{C o}-\mathbf{O}-\mathbf{C o}^{[\mathrm{cc}}(\mathbf{d e g})$ & 94.81 & 94.66 & 94.51 & 94.97 & 94.69 \\
\hline
\end{tabular}

Por otro lado, estos clústeres de cobalto, 1-6, se han caracterizado usando análisis elemental e ICP, técnicas que permiten conocer la composición porcentual de los materiales bulk (Tabla 6.2), por ESI-MS, que permitió confirmar el peso molecular exacto para cada complejo (Tabla 6.2 y Figuras 6.34-6.18 de la sección experimental) y por resonancia magnética nuclear, que aportó más datos sobre su estructura molecular (Figuras 6.19-6.30 de la sección experimental).

Tabla 6.2. Resultados de análisis elemental, ICP y ESI-MS para los clústeres de cobalto 1-6.

\begin{tabular}{|c|c|c|c|c|c|c|}
\hline \multirow{2}{*}{ Catalizador } & \multirow{2}{*}{$\begin{array}{l}\text { Fórmula } \\
\text { molecular }\end{array}$} & \multirow{2}{*}{$\begin{array}{c}\text { Peso } \\
\text { molecular } \\
(\mathrm{g} / \mathrm{mol})\end{array}$} & \multicolumn{3}{|c|}{ Análisis elemental } & \multirow{2}{*}{$\begin{array}{c}\text { ICP } \\
(\% \mathrm{Co})\end{array}$} \\
\hline & & & $\% \mathrm{C}$ & $\% \mathrm{~N}$ & $\% \mathrm{H}$ & \\
\hline 1 & $\mathrm{C}_{28} \mathrm{H}_{32} \mathrm{Co}_{4} \mathrm{~N}_{4} \mathrm{O}_{12}$ & 852.9423 & 39.720 & 6.388 & 3.978 & 26.911 \\
\hline 2 & $\mathrm{C}_{32} \mathrm{H}_{40} \mathrm{Co}_{4} \mathrm{~N}_{4} \mathrm{O}_{20}$ & 1140.0189 & 41.720 & 4.955 & 4.136 & 20.282 \\
\hline 3 & $\mathrm{C}_{32} \mathrm{H}_{48} \mathrm{Co}_{4} \mathrm{~N}_{4} \mathrm{O}_{16}$ & 971.9767 & 38.947 & 6.006 & 4.275 & 23.356 \\
\hline 4 & $\mathrm{C}_{48} \mathrm{H}_{40} \mathrm{Co}_{4} \mathrm{~N}_{4} \mathrm{O}_{12}$ & 1099.9971 & 52.618 & 4.685 & 3.869 & 22.133 \\
\hline 5 & $\mathrm{C}_{60} \mathrm{H}_{56} \mathrm{Co}_{4} \mathrm{~N}_{4} \mathrm{O}_{20}$ & 1411.0714 & 52.275 & 3.619 & 4.351 & 16.890 \\
\hline 6 & $\mathrm{C}_{52} \mathrm{H}_{48} \mathrm{Co}_{4} \mathrm{~N}_{4} \mathrm{O}_{16}$ & 1221.0471 & 50.627 & 4.552 & 3.675 & 19.912 \\
\hline
\end{tabular}


Finalmente, se estudiaron las propiedades electroquímicas de los cubanos de cobalto 16 mediante voltamperometría cíclica usando una celda con tres electrodos. Los voltamogramas cíclicos obtenidos se muestran en la Figura 6.2 (más detalles en las Figuras 6.11 y 6.12 de la sección experimental).

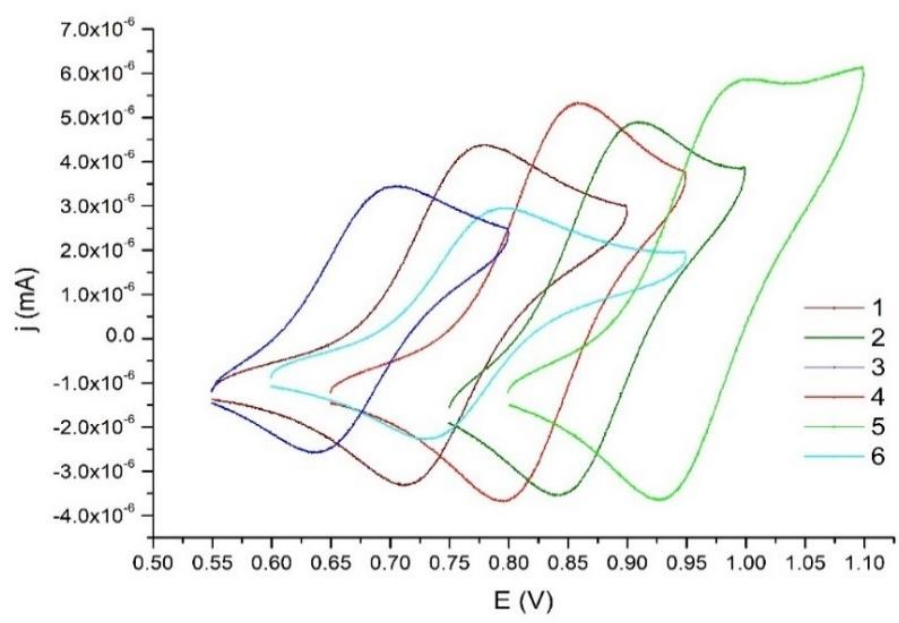

Figura 6.2. Voltamperogramas cíclicos para los clústeres de cobalto medidos a $100 \mathrm{mV} / \mathrm{s}$ en una disolución $1 \mathrm{mM}$ en acetonitrilo con $0.01 \mathrm{M}$ del electrolito TBAP. Los potenciales de oxidación calculados para cada complejo son: $1(\mathrm{E}=0.704 \mathrm{~V}), 2(\mathrm{E}=0.857 \mathrm{~V}), \mathbf{3}(\mathrm{E}=0.670$ $\mathrm{V}), \mathbf{4}(\mathrm{E}=0.783 \mathrm{~V}), \mathbf{5}(\mathrm{E}=0.956 \mathrm{~V})$ and $\mathbf{6}(\mathrm{E}=0.743 \mathrm{~V})$.

Como se puede observar en la Figura 6.2, los clústeres 3 y $\mathbf{6}$, los cuales tienen en posición para en el anillo de piridina un grupo dador de electrones (EDG) como el metoxi, presentan un semipotencial $\mathrm{E}_{1 / 2}$ de $0.670 \mathrm{~V}$ y $0.743 \mathrm{~V}$, respectivamente. Por otro lado, los clústeres $\mathbf{2}$ y $\mathbf{5}$, los cuales tienen en posición para en el anillo de piridina un grupo electrón atrayente (EWG) como el éster, tienen asociados un semipotencial $\mathrm{E}_{1 / 2}$ mayor que en el caso de los complejos anteriores ( 0.857 y $0.956 \mathrm{~V}$, respectivamente). Por último, los clústeres 1 y $\mathbf{4}$, los cuales presentan un $\mathrm{H}$ en la posición para del anillo de piridina, presentan valores intermedios ( $\mathrm{E}_{1 / 2}$ de 0.704 y $0.783 \mathrm{~V}$, respectivamente). Este hecho nos lleva a la conclusión de que un grupo dador de electrones en para promueve la oxidación de los clústeres de cobalto de $\left[\left(\mathrm{Co}^{\mathrm{III}}\right)_{4}\left(\mu_{3}-\mathrm{O}\right)_{4}\right]^{4+}$ a $\left[\left(\mathrm{Co}^{\mathrm{IIII}}\right)_{3} \mathrm{Co}^{\mathrm{IV}}\left(\mu_{3}-\mathrm{O}\right)_{4}\right]^{5+}$, mientras que un grupo electrón atrayente en para presenta el comportamiento contrario. Además, el sustituyente acetato también promueve la oxidación de estos materiales frente al sustituyente benzoato. Por lo tanto, las propiedades electrónicas del cubano de cobalto se pueden modular fácilmente introduciendo el sustituyente adecuado en el anillo de piridina o en el ligando carboxilato (Figura 6.3). 


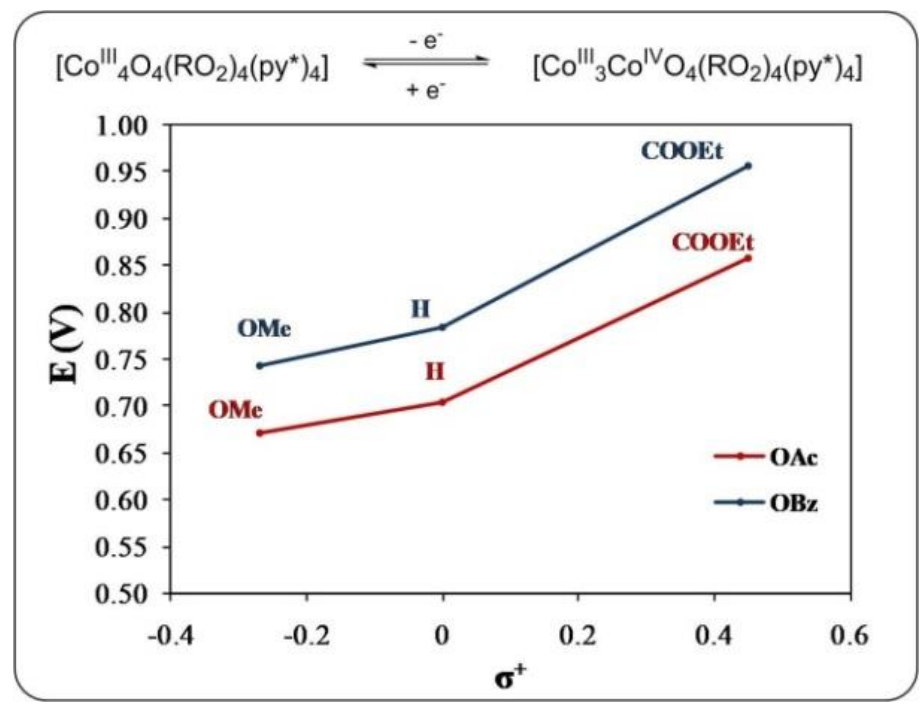

Figura 6.3. Datos de los potenciales de oxidación de los clústeres 1-6. Estos datos se correlacionan con los valores de $\sigma^{+}$de la ecuación de Hammet.

\subsubsection{Evaluación de los clústeres de cobalto en la oxidación de ciclohexano}

Como se ha mencionado en la introducción, los complejos de cobalto son catalizadores activos en la oxidación de alcanos y cicloalcanos. ${ }^{15}$ Teniendo esto en cuenta junto con las especies identificadas durante la oxidación del agua con el clúster de cobalto (Esquema 6.2 a) ${ }^{26}$ se procedió al estudio de los complejos tetranucleares de cobalto sintetizados 1-6 como catalizadores para la oxidación aeróbica del ciclohexano (el procedimiento detallado se describe en la sección experimental). En primer lugar, se llevó a cabo la reacción con condiciones de temperatura y presión similares a las reportadas en bibliografía para otros complejos, $150^{\circ} \mathrm{C}$ y 10 bares de aire (Tabla 6.3). 
Tabla 6.3. Resumen de la actividad catalítica (conversión y distribución de productos) de los catalizadores de cobalto en la oxidación de ciclohexano.

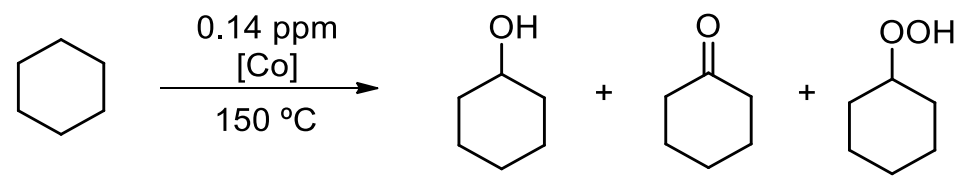

\begin{tabular}{|c|c|c|c|c|c|c|c|}
\hline \multirow{2}{*}{ Entrada } & \multirow{2}{*}{ Catalizador } & \multirow{2}{*}{$\begin{array}{c}\text { Conversión } \\
(\boldsymbol{\%})\end{array}$} & \multicolumn{6}{|c|}{ Selectividad (\%) } \\
\cline { 4 - 8 } & & $\mathbf{A}^{\mathrm{a}}$ & $\mathbf{K}^{\mathrm{b}}$ & $\mathbf{C H H P}^{\mathrm{c}}$ & $\mathbf{A A}^{\mathrm{d}}$ & Total $^{\mathrm{e}}$ \\
\hline 1 & blanco & 1.2 & 8 & 10 & 80 & 0 & 98 \\
\hline 2 & $\mathrm{Co}(\mathrm{OAc})_{2}$ & 7.1 & 50 & 35 & 8 & 1 & 94 \\
\hline 3 & $\mathbf{1}$ & 4.7 & 38 & 26 & 29 & 1 & 94 \\
\hline 4 & $\mathbf{2}$ & 6.5 & 41 & 35 & 17 & 1 & 95 \\
\hline 5 & $\mathbf{3}$ & 3.8 & 21 & 24 & 47 & 1 & 93 \\
\hline 6 & $\mathbf{4}$ & 7.1 & 43 & 39 & 14 & 1 & 97 \\
\hline 7 & $\mathbf{5}$ & 8.2 & 41 & 37 & 14 & 1 & 93 \\
\hline 8 & $\mathbf{6}$ & 5.1 & 21 & 24 & 46 & 1 & 92 \\
\hline
\end{tabular}

Condiciones de reacción: $3 \mathrm{~g}$ de ciclohexano $(36 \mathrm{mmol}) ; 0.14 \mathrm{ppm}$ de cobalto; $150{ }^{\circ} \mathrm{C} ; 10$ bar $\left(\mathrm{N}_{2}: \mathrm{O}_{2}=\right.$ 80:20); $\mathrm{Q}=10 \mathrm{ml} / \mathrm{min}$ ), tiempo de reacción 90 minutos. [a] $\mathrm{A}=$ alcohol, ciclohexanol; [b] $\mathrm{K}=$ cetona, ciclohexanona; [c] CHHP = ciclohexil hidroperóxido; [d] AA = ácido adípico; [e] Selectividad total observada $(\mathrm{A}+\mathrm{K}+\mathrm{CHHP}+\mathrm{AA})$.

Sin embargo, para estas condiciones de reacción, el proceso es muy rápido y no se observan diferencias entre los diferentes catalizadores. Por lo tanto, la temperatura de reacción se bajó hasta $130^{\circ} \mathrm{C}$ y la presión del reactor a 6 bares, usando además aire empobrecido en $\mathrm{O}_{2}$ (ratio $\mathrm{N}_{2}: \mathrm{O}_{2}$ 95:5). Esta presión se mantiene constante durante todo el tiempo de reacción (Figura 6.4, Tabla 6.8 de la sección experimental). El acetato de cobalto se utiliza inicialmente como referencia de la actividad de la especie de Co (II) (Figura $6.4 \mathrm{~g}$ ). A partir de este estudio se puede observar que la actividad catalítica de los clústeres 1-6 en condiciones de reacción menos severas es mejor que la obtenida para el $\mathrm{Co}(\mathrm{OAc})_{2}$. En lo que concierne a la selectividad del proceso, los resultados en la Figura 6.4 y en la Tabla 6.8, muestran que los clústeres de cobalto descomponen menos CHHP que el $\mathrm{Co}(\mathrm{OAc})_{2}$, lo cual está relacionado con la selectividad del proceso, y que el ratio ol/ona es mayor para los catalizadores sintetizados, mientras que el acetato de cobalto favorece la formación de más del 50\% de ciclohexanona. 

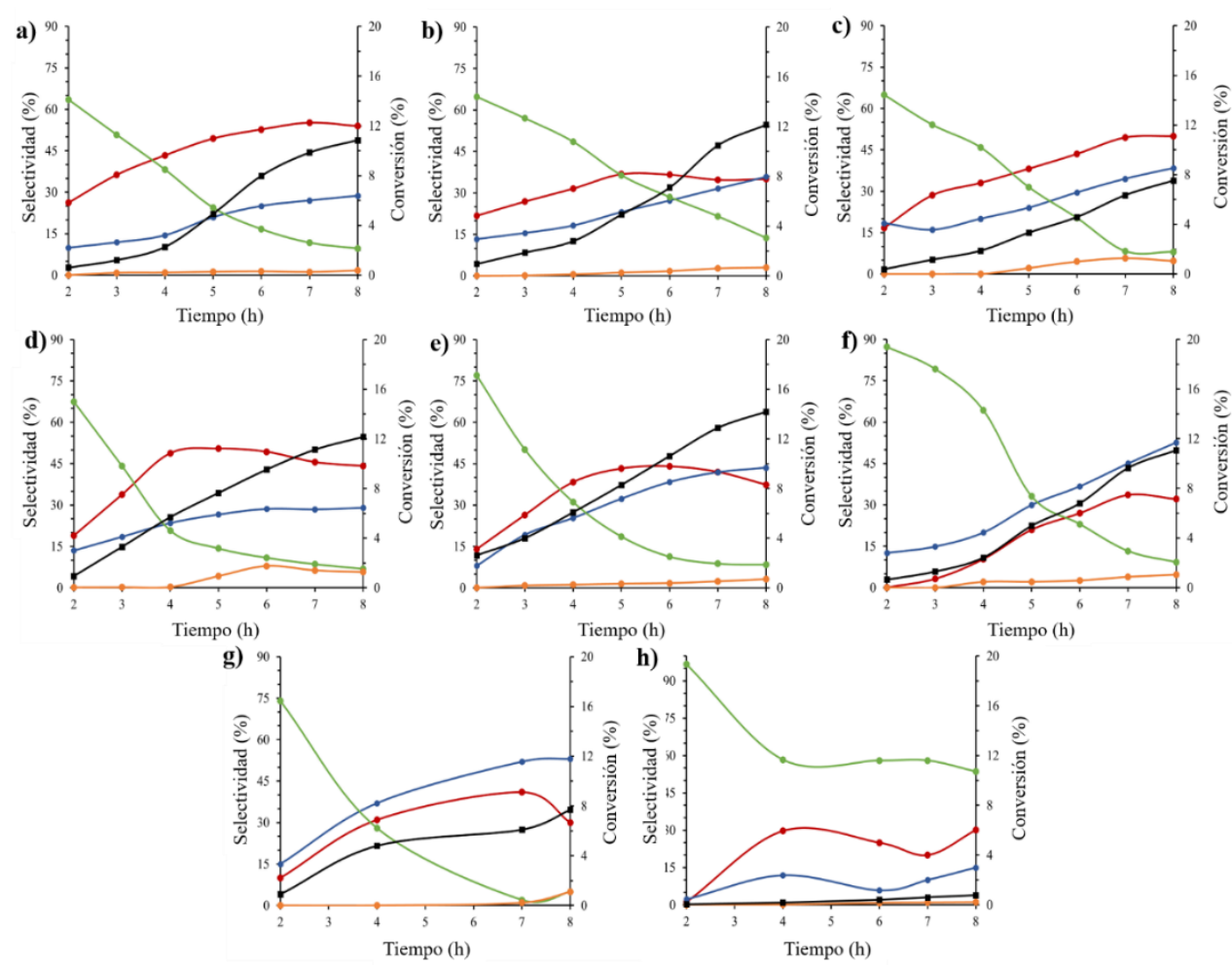

Figura 6.4. Resumen de la actividad catalítica para la oxidación de ciclohexano con los catalizadores a) 1, b) 2, c) 3, d) 4, e) 5, f) 6, g) $\mathrm{Co}(\mathrm{OAc})_{2}$ y h) blanco. Condiciones de reacción: Línea negra: conversión total (eje derecho), línea roja: ciclohexanol, línea azul: ciclohexanona, línea verde: CHHP y línea naranja: ácido adípico (eje izquierdo).

Para comparar la actividad de todos los catalizadores estudiados en este proceso se representa la cinética de la reacción, teniendo en cuenta tanto la conversión de ciclohexano como la selectividad total a los productos deseados (Figura 6.5 a).

Por otro lado, al estudiar los resultados catalíticos obtenidos con los clústeres 1-6 junto con los resultados obtenidos a partir de la voltamperometría cíclica para estos catalizadores, se observa que la actividad catalítica de cada clúster está correlacionada con sus propiedades electrónicas (Figura 6.5 b). Es decir, el catalizador con mayor potencial de oxidación es también el catalizador más activo para este proceso y viceversa. Por lo tanto, un grupo atractor de electrones en la posición para del anillo de piridina, hace que el compuesto tenga un mayor potencial de oxidación y, como consecuencia, una mayor actividad catalítica, mientras que un grupo dador de electrones 
en la posición para del anillo de piridina, hace que el compuesto tenga un menor potencial de oxidación, y como consecuencia, una menor actividad catalítica. Como resultado, el clúster 5 es el mejor catalizador de la familia de cubanos sintetizada, presentando una actividad claramente mayor que el acetato de cobalto (II). De hecho, la conversión y la selectividad obtenidas para el catalizador 5 muestra que es un catalizador prometedor para esta reacción si se comparan los resultados con otros complejos de cobalto conocidos para este proceso.
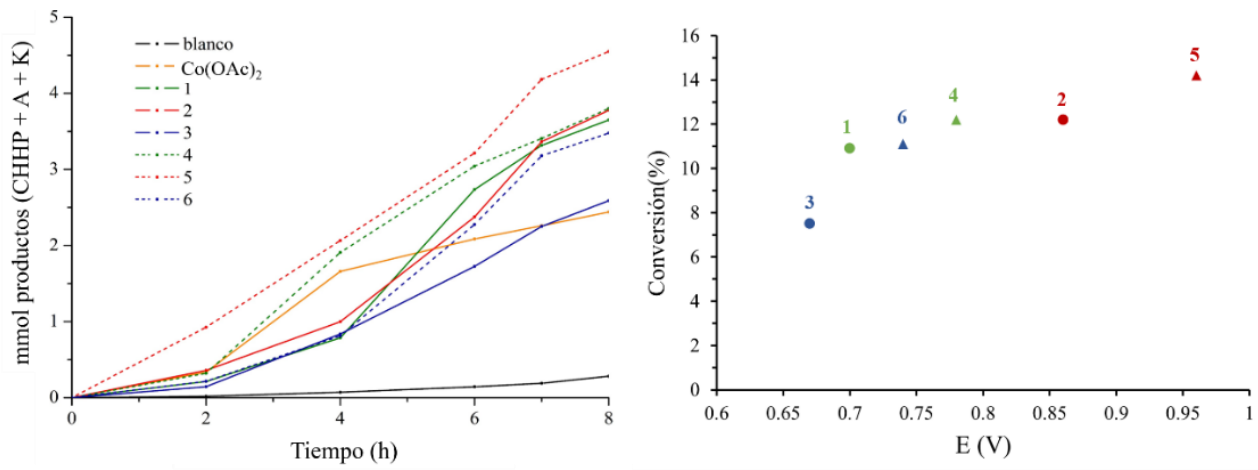

Figura 6.5. a) Estudio cinético para la oxidación del ciclohexano con los clústeres tetranucleares de cobalto 1-6 y $\mathrm{Co}(\mathrm{OAc})_{2}$. b) Correlación entre la conversión y el potencial de oxidación para cada clúster.

Los resultados de conversión y selectividad para los cubanos de cobalto 1-6 se han comparado con los mejores catalizadores reportados en bibliografía activos en condiciones de reacción similares. Como se puede observar tanto en la Figura 6.6 como en la Tabla 6.4, estos catalizadores claramente mejoran la mayoría de los materiales reportados previamente para esta reacción. 


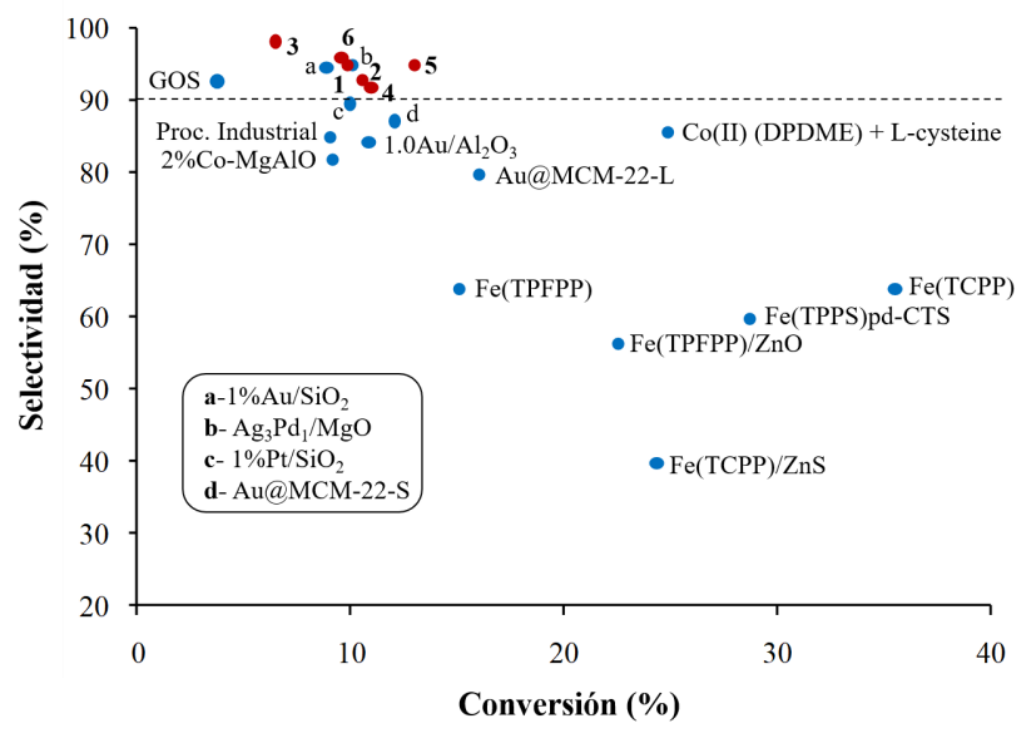

Figura 6.6. Comparación de los catalizadores de cobalto 1-6 (puntos rojos) con otros catalizadores reportados (puntos azules) para la oxidación aeróbica de ciclohexano en condiciones similares.

Tabla 6.4. Comparación entre el clúster de cobalto más activo (5) con los catalizadores reportados para la oxidación de ciclohexano en condiciones de reacción similares usando $\mathrm{O}_{2}$ o aire como oxidante.

\begin{tabular}{|c|c|c|c|c|}
\hline $\begin{array}{c}\text { Sistema } \\
\text { catalítico }\end{array}$ & Condiciones de reacción & Conv. (\%) & Select. (\%) & Ref. \\
\hline GOS & $\begin{array}{c}\mathrm{CH}=46.28 \mathrm{mmol}, \mathrm{cat}=2 \mathrm{mg}, \\
1.5 \mathrm{MPa} \mathrm{O}, 150^{\circ} \mathrm{C}, 3 \mathrm{~h}\end{array}$ & 3.8 & 92.4 & 15 \\
\hline $\mathrm{Fe}(\mathrm{TCPP})$ & $\begin{array}{c}\mathrm{CH}=1.85 \mathrm{~mol}, \mathrm{cat}=1 \mathrm{mg}, \\
0.8 \mathrm{MPa} \mathrm{O}, 160^{\circ} \mathrm{C}, 4 \mathrm{~h}\end{array}$ & 35.6 & 64 & 30 \\
\hline $\mathrm{Fe}(\mathrm{TCPP}) / \mathrm{ZnS}$ & $\begin{array}{c}\mathrm{CH}=1.85 \mathrm{~mol}, \mathrm{cat}=1 \mathrm{mg}, \\
0.8 \mathrm{MPa} \mathrm{O}, 160^{\circ} \mathrm{C}, 4 \mathrm{~h}\end{array}$ & 24.4 & 40 & 30 \\
\hline $\mathrm{Fe}(\mathrm{TPFPP})$ & $\begin{array}{c}\mathrm{CH}=1.85 \mathrm{~mol}, \mathrm{cat}=1 \cdot 10^{-3} \\
\mathrm{mmol}, 0.7 \mathrm{MPa} \mathrm{O}, 150^{\circ} \mathrm{C}, 2.5 \mathrm{~h}\end{array}$ & 15 & 64 \\
\hline $\mathrm{Fe}(\mathrm{TPFPP}) / \mathrm{ZnO}$ & $\begin{array}{c}\mathrm{CH}=1.85 \mathrm{~mol}, \mathrm{cat}=1 \cdot 10^{-3} \\
\mathrm{mmol}, 0.7 \mathrm{MPa} \mathrm{O}, 150^{\circ} \mathrm{C}, 2.5 \mathrm{~h}\end{array}$ & 22.5 & 56.5 & 31 \\
\hline $\mathrm{Fe}(\mathrm{TPPS}) \mathrm{pd}-\mathrm{CTS}$ & $\begin{array}{c}\mathrm{CH}=1.85 \mathrm{~mol}, \mathrm{cat}=1.0753 \mathrm{~g}, \\
0.8 \mathrm{MPa} \mathrm{O}, 155^{\circ} \mathrm{C}, 4 \mathrm{~h}\end{array}$ & 28.67 & 60 & 18 \\
\hline
\end{tabular}




\begin{tabular}{|c|c|c|c|c|}
\hline $1.0 \mathrm{Au} / \mathrm{Al}_{2} \mathrm{O}_{3}$ & $\begin{array}{c}\mathrm{CH}=185.1 \mathrm{mmol}, \mathrm{cat}=50 \mathrm{mg}, \\
1.5 \mathrm{MPa} \mathrm{O} \mathrm{O}_{2}, 150^{\circ} \mathrm{C}, 3 \mathrm{~h}\end{array}$ & 10.9 & 84.3 & 18 \\
\hline Au@MCM-22-S & $\begin{array}{c}\mathrm{CH}=18.51 \mathrm{mmol}, \mathrm{cat}=25 \mathrm{mg}, \\
1 \mathrm{MPa} \mathrm{O} \mathrm{O}_{2}, 150^{\circ} \mathrm{C}, 2 \mathrm{~h}\end{array}$ & 12 & 87 & 32 \\
\hline Au@MCM-22-L & $\begin{array}{c}\mathrm{CH}=18.51 \mathrm{mmol}, \mathrm{cat}=25 \mathrm{mg}, \\
1 \mathrm{MPa} \mathrm{O}, 150^{\circ} \mathrm{C}, 2 \mathrm{~h}\end{array}$ & 16 & 80 & 33 \\
\hline $2 \% \mathrm{Co}-\mathrm{MgAlO}$ & $\begin{array}{c}\mathrm{CH}=712.9 \mathrm{mmol}, \mathrm{cat}=50 \mathrm{mg}, \\
0.6 \mathrm{MPa} \mathrm{O}{ }_{2}, 150^{\circ} \mathrm{C}, 2 \mathrm{~h}\end{array}$ & 9.1 & 82 & 34 \\
\hline $1 \% \mathrm{Pt} / \mathrm{SiO}_{2}$ & $\begin{array}{c}\mathrm{CH}=185.1 \mathrm{mmol}, \mathrm{cat}=50 \mathrm{mg}, \\
1 \mathrm{MPa} \mathrm{O} \mathrm{O}_{2}, 140^{\circ} \mathrm{C}, 1 \mathrm{~h}\end{array}$ & 9.9 & 89.4 & 22 \\
\hline $1 \% \mathrm{Au} / \mathrm{SiO}_{2}$ & $\begin{array}{c}\mathrm{CH}=185.1 \mathrm{mmol}, \mathrm{cat}=50 \mathrm{mg}, \\
1 \mathrm{MPa} \mathrm{O} \mathrm{O}_{2}, 140^{\circ} \mathrm{C}, 1 \mathrm{~h}\end{array}$ & 8.9 & 94.6 & 22 \\
\hline $\begin{array}{l}\text { Co(II) (DPDME) } \\
\text { + L-cisteina }\end{array}$ & $\begin{array}{c}\mathrm{CH}=--, \mathrm{cat}=2 \cdot 10^{-5} \mathrm{~mol} / \mathrm{L}, \\
0.8 \mathrm{MPa} \mathrm{O}_{2}, 150^{\circ} \mathrm{C}, 3.5 \mathrm{~h}\end{array}$ & 24.8 & 85.8 & 35 \\
\hline $\mathrm{Ag}_{3} \mathrm{Pd}_{1} / \mathrm{MgO}$ & $\begin{array}{c}\mathrm{CH}=101 \mathrm{mmol}, \text { cat }=6 \mathrm{mg}, \\
0.3 \mathrm{MPa} \mathrm{O}_{2}, 140^{\circ} \mathrm{C}, 17 \mathrm{~h}\end{array}$ & 10 & 95 & 36 \\
\hline $\begin{array}{c}\text { Proceso } \\
\text { industrial, } \\
\text { complejos Co, } \\
\mathrm{Mn}\end{array}$ & $1.5 \mathrm{MPa} \mathrm{O}_{2}, 160^{\circ} \mathrm{C}$ & $>9$ & 85 & 37 \\
\hline $\begin{array}{l}\mathrm{Co}_{4} \mathrm{O}_{4}(\mathrm{OBz})_{4}(\mathrm{p}- \\
\mathrm{COOEt}-\mathrm{py})_{4}(5)\end{array}$ & $\begin{array}{c}\mathrm{CH}=36 \mathrm{mmol}, \mathrm{cat}=14 \mathrm{ppm} \mathrm{Co}, \\
0.6 \mathrm{MPa} \text { aire }\left(\mathrm{N}_{2}: \mathrm{O}_{2}=95: 5\right), \\
130^{\circ} \mathrm{C}, 7 \mathrm{~h}\end{array}$ & 12.9 & 95 & $\begin{array}{l}\text { Esta } \\
\text { tesis }\end{array}$ \\
\hline
\end{tabular}

\subsubsection{Estudio mecanístico de la reacción de oxidación de ciclohexano.}

Con el fin de correlacionar la estructura de los catalizadores desarrollados con su actividad catalítica y el papel de cada catalizador en este proceso, se ha llevado a cabo un amplio estudio basado en estudios experimentales y estudios in-situ. Las reacciones individuales que componen el mecanismo global de la reacción de oxidación de ciclohexano están bien establecidas en bibliografía (Esquema 6.4). La reacción A implica la formación del radical ciclohexilo mediada normalmente por moléculas orgánicas o metales. Las reacciones $\mathbf{B}$ y $\mathbf{C}$ representan el paso de propagación de este proceso, mientras que la reacción $\mathbf{D}$ es el paso de terminación del proceso radicalario, en la cual se forman una molécula de ciclohexanol, otra de ciclohexanona y una de oxígeno molecular. 


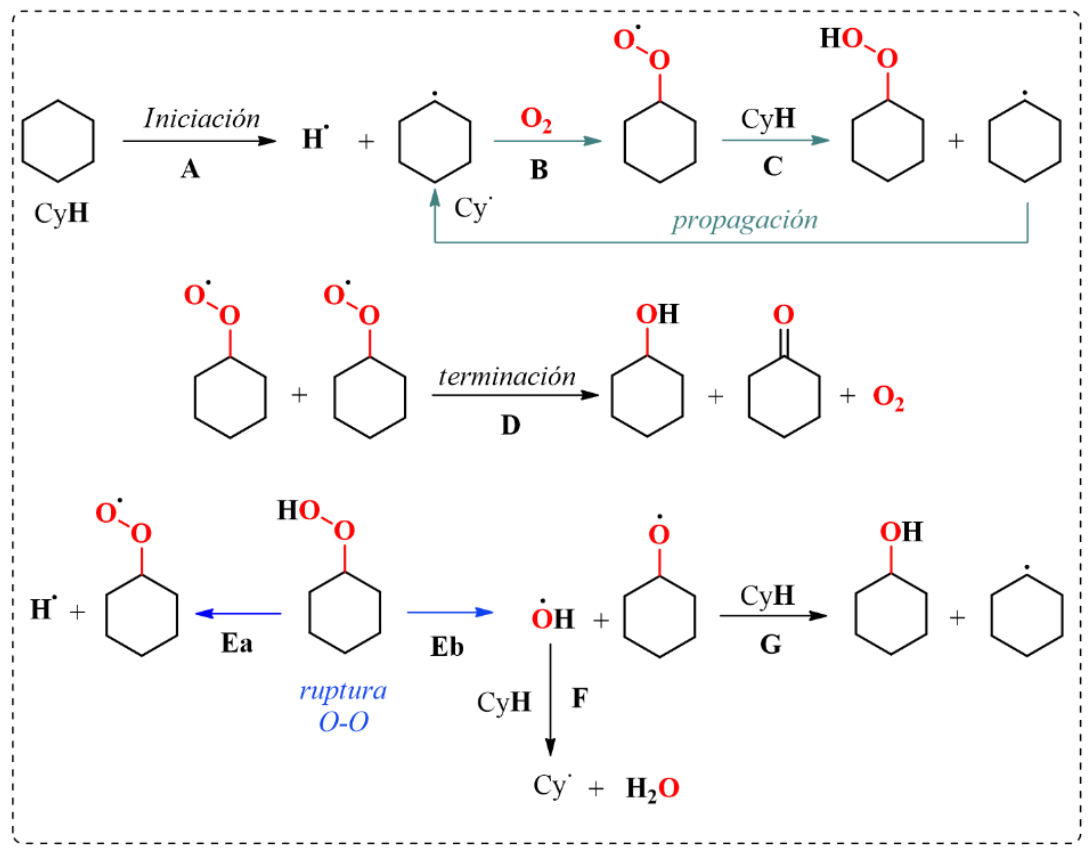

Esquema 6.4. Posibles caminos de reacción en la oxidación de ciclohexano.

Por otro lado, las reacciones Ea y Eb pueden mejorar el paso de propagación y, por tanto, mejorar la velocidad de la reacción. La reacción Ea se basa en la activación heterolítica del enlace O-O del CHHP para generar un protón radical y un radical ciclohexil peroxo, los cuales pueden reaccionar con una molécula de ciclohexano siguiendo la reacción $\mathbf{C}$ en el paso de propagación o la reacción $\mathbf{D}$ en el paso de terminación. Sin embargo, la reacción Eb supone una activación homolítica del enlace O-O del CHHP para formar radicales hidroxi y alcoxi. Ambas especies pueden reaccionar con una molécula de ciclohexano, reacciones $\mathbf{F}$ y $\mathbf{G}$, respectivamente, para formar el radical ciclohexilo junto a una molécula de agua o para formar ciclohexanol. Aunque estas especies también pueden mejorar la propagación, estas especies, sin ningún tipo de estabilización, son más reactivas que el radical peroxo y, por tanto, menos selectivas durante la abstracción de protones. Por lo tanto, el objetivo principal de este estudio es identificar el papel de los clústeres de cobalto en cada paso individual del proceso global con el fin de poder correlacionarlo con la estructura y las propiedades electrónicas de cada material. 


\subsubsection{Estudio EPR de la descomposición de CHHP por los clústeres de cobalto 1-6} mediante atrapamiento de radicales.

La descomposición del CHHP suele estar controlada por un mecanismo radicalario. Por ello, se ha estudiado el papel del CHHP en la reacción de oxidación de ciclohexano usando el método de atrapamiento de espín por EPR con el fin de establecer una relación entre la actividad catalítica de los cubanos 1-6 con los probables radicales intermedios implicados en la reacción de oxidación (como el CHHP). ${ }^{36,38}$ La metodología empleada es un método bien establecido, que se basa en el atrapamiento de radicales de corta duración por una molécula diamagnética que atrapa radicales. ${ }^{36,39}$ En este caso, el compuesto empleado para el atrapamiento de radicales es el DMPO (5,5-dimetil-1pirrolina-N-óxido), 7, que es un compuesto bastante estudiado en este proceso (Esquema 6.5). La reacción entre el DMPO y los intermedios radicalarios que intervienen en este tipo de reacciones da como resultado la formación de varios aductos de spin estables, como 8,9 y 10 (Esquema 6.5). Además, se trata de radicales libres persistentes que tienen una vida útil suficientemente larga para permitir su identificación por espectroscopía EPR. ${ }^{40,41}$ La clave para identificar y cuantificar qué especies se forman en el medio de reacción se basa en los diferentes acoplamientos hiperfinos entre el electrón desapareado en el aducto de spin y el $\mathrm{H}$ en la posición $\beta$ en el DMPO (a través de las constantes de acoplamiento $\left.\mathrm{a}_{\mathrm{N}} \mathrm{y} \mathrm{a}_{\mathrm{H}}\right){ }^{36,42,43}$
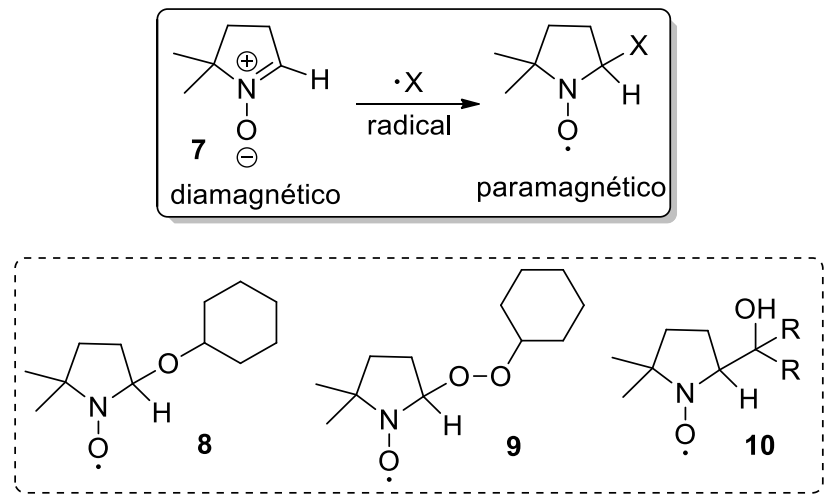

Esquema 6.5. Ilustración esquemática del principio de atracción de spin y estructura de los aductos de spin que pueden detectarse en la reacción entre el DMPO y los intermedios de reacción. 
Los espectros de EPR de onda continua $(\mathrm{CW})$ en la banda $\mathrm{X}$, obtenidos usando el DMPO para atrapar los radicales durante la descomposición del CHHP catalizada por los clústeres de cobalto 1-6 en ciclohexano se representan en la sección experimental (Figuras 6.31-6.36). En la Figura 6.7 se han representado dos de ellos (para los catalizadores 2 y 5), los más representativos, junto con la simulación combinada y la deconvolución de los distintos aductos. Con el fin de identificar las especies que se generan en esta reacción, se utilizó la simulación del espectro junto con la comparación de los valores con los reportados en bibliografía. Para el caso del clúster 2 (Figura 6.7 a), se encontraron las siguientes especies: un aducto de spin DMPO-O- $\mathrm{C}_{6} \mathrm{H}_{11}, \mathbf{8},\left(\mathrm{a}_{\mathrm{N}}=\right.$ 13.37, $\left.\mathrm{a}_{\mathrm{H}(\beta)}=5.95, \mathrm{a}_{\mathrm{H}(\gamma)}=1.91 \mathrm{G}\right),{ }^{44}$ un aducto DMPO-OO- $\mathrm{C}_{6} \mathrm{H}_{11}, 9,\left(\mathrm{a}_{\mathrm{N}}=14.46, \mathrm{a}_{\mathrm{H}}=\right.$ $10.21 \mathrm{G})^{45}$ y un aducto centrado en el carbono DMPO-C $(\mathrm{OH}) \mathrm{R}_{2}, \mathbf{1 0},\left(\mathrm{a}_{\mathrm{N}}=15.93, \mathrm{a}_{\mathrm{H}}=\right.$ $21.31 \mathrm{G})^{46}$ posiblemente originado por la apertura de un anillo, lo que podría explicar la formación de pequeñas cantidades de ácido adípico. La misma estrategia se empleó para identificar las especies en el caso del clúster 5 (Figura 6.7 b). En este caso fue posible identificar las siguientes especies: un aducto de espín DMPO-O- $\mathrm{C}_{6} \mathrm{H}_{11}, \mathbf{8},\left(\mathrm{a}_{\mathrm{N}}=13.37\right.$, $\left.\mathrm{a}_{\mathrm{H}(\beta)}=5.95, \mathrm{a}_{\mathrm{H}(\gamma)}=1.91 \mathrm{G}\right)^{45} \mathrm{y}$ un aducto centrado en el carbono DMPO-C $(\mathrm{OH}) \mathrm{R}_{2}, \mathbf{1 0}$, $\left(\mathrm{a}_{\mathrm{N}}=15.93, \mathrm{a}_{\mathrm{H}}=21.31 \mathrm{G}\right){ }^{46}$

a)

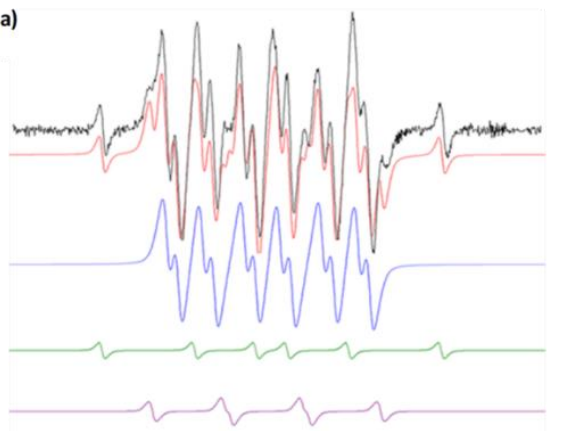

b)

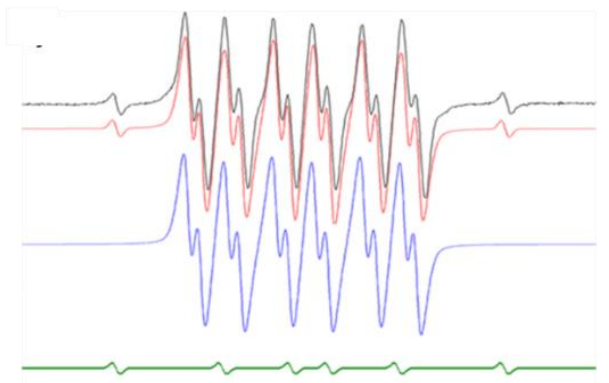

Figura 6.7. Espectro EPR experimental y deconvolución de los aductos de spin obtenidos durante la descomposición del CHHP en ciclohexano en presencia de los clústeres de cobalto 2 (a) y 5 (b). Espectro experimental (negro), espectro simulado (rojo), aducto de spin DMPO$\mathrm{O}-\mathrm{C}_{6} \mathrm{H}_{11}$ (azul), aducto centrado en el carbono, DMPO-C $(\mathrm{OH}) \mathrm{R}_{2}$ (verde) y aducto DMPOOO- $\mathrm{C}_{6} \mathrm{H}_{11}$ (morado). 
Además, la metodología de atrapamiento de spin es una técnica semicuantitativa para determinar el porcentaje de cada aducto de spin formado. Esto se debe a que la cantidad absoluta de aducto en disolución es el resultado de varios factores que compiten entre sí, como el disolvente, la temperatura, el tiempo de vida del radical y, lo que es más importante, la eficiencia de la reacción de atrapamiento. ${ }^{47}$ Para el análisis semicuantitativo de este proceso, la reacción se llevó a cabo en condiciones idénticas para los catalizadores 1-6 y, en consecuencia, cualquier variación detectada en la proporción entre los radicales generados se puede asociar a las diferentes actividades catalíticas entre los catalizadores. ${ }^{48}$

En la Tabla 6.5 se recogen los resultados de abundancia relativa de los aductos de spin formados para la descomposición del CHHP en ciclohexano catalizada por los clústeres 1-6. En todos los casos se ha detectado un exceso del aducto DMPO-OR en comparación con la cantidad de aducto DMPO-OOR. Esto es un hecho que se puede justificar teniendo en cuenta que los radicales alcoxi ( $\mathrm{RO}{ }^{\bullet}$ ) son intrínsecamente más reactivos que los radicales peroxi $(\mathrm{ROO})^{\bullet}{ }^{49}$ Este aducto primario DMPO-O- $\mathrm{C}_{6}-\mathrm{H}_{11}, \mathbf{8}$, se encuentra en un rango de 74 a $98 \%$. Esto quiere decir que hay variaciones significativas en la cantidad relativa de esta especie formada cuando se usan los distintos catalizadores de cobalto 16. Además, la gran cantidad de radicales alcóxido explica la formación de un exceso de alcohol con respecto a la cetona en este proceso. Por otro lado, el DMPO-OO- $\mathrm{C}_{6} \mathrm{H}_{11}, \mathbf{9}$, no se detecta con el catalizador 5, mientras que con el resto de los catalizadores se encuentra en un rango entre el 6 y el 20\%. Además, se puede observar que los catalizadores que presentan el ligando acetato, 1-3, promueven una mayor proporción de estas especies con respecto a los catalizadores que presentan el ligando benzoato, 4-6. Esto está correlacionado, como se ha dicho anteriormente, con el potencial de oxidación de los distintos catalizadores, que está correlacionado con los ligandos presentes en la estructura. Por consiguiente, los catalizadores con grupos electrón atrayentes en los anillos de piridina, con mayores potenciales de oxidación, también promueven una menor proporción de DMPO-OO- $\mathrm{C}_{6} \mathrm{H}_{11}, 9$, respecto a los que tienen un grupo dador de electrones en el anillo de piridina, con menor potencial de oxidación. Finalmente, cabe destacar que todos los clústeres de cobalto estudiados promueven pequeñas cantidades del aducto centrado en el carbono, $\mathbf{1 0}$, en concreto, entre un 1 y un $7 \%$. 
Tabla 6.5. Abundancia relativa (\%) de los aductos de spin con DMPO obtenidos en la reacción de descomposición del CHHP en ciclohexano.

\begin{tabular}{|c|c|c|c|c|c|}
\hline Entrada & Catalizador & Nitróxido & RO $^{\cdot}$ & ROO $^{\cdot}$ & $\mathbf{C}^{\cdot}$ \\
\hline 1 & Blanco & -- & & & \\
\hline 2 & $\mathbf{1}$ & -- & 74 & 20 & 6 \\
\hline 3 & $\mathbf{2}$ & -- & 85 & 10 & 5 \\
\hline 4 & $\mathbf{3}$ & -- & 83 & 17 & 3 \\
\hline 5 & $\mathbf{4}$ & -- & 85 & 8 & 7 \\
\hline 6 & $\mathbf{5}$ & -- & 98 & -- & 2 \\
\hline 7 & $\mathbf{6}$ & -- & 92 & 6 & 2 \\
\hline
\end{tabular}

Los tres aductos primarios detectados, los radicales $\mathrm{C}_{6} \mathrm{H}_{11}-\mathrm{O}^{\bullet}, \mathrm{C}_{6} \mathrm{H}_{11}-\mathrm{OO}^{\bullet}$ y $\mathrm{C}_{6} \mathrm{H}_{11} \bullet$ sugieren que, en las condiciones en las que se lleva a cabo la catálisis, es probable que también contribuya al mecanismo un proceso de transformación radicalario.

Tal como se describe en bibliografía, el ciclohexil hidroperóxido se puede descomponer mediante la ruptura del enlace $\mathrm{O}-\mathrm{O}$ del grupo hidroperóxido térmicamente, o mediada por un centro metálico. ${ }^{50}$ Esta reacción da como resultado la formación de un radical alcoxi y un radical hidroxi (Ecuación 6.1)

$$
\mathrm{C}_{6} \mathrm{H}_{11}-\mathrm{OOH} \rightarrow \mathrm{C}_{6} \mathrm{H}_{11}-\mathrm{O}^{\cdot}+{ }^{\cdot} \mathrm{OH}
$$

Ecuación 6.1

A su vez, el radical alcoxi puede reaccionar con una molécula de ciclohexano para dar ciclohexanol y el radical $\mathrm{C}_{6} \mathrm{H}_{11} \bullet$ (Ecuación 6.2), mientras que el radical hidroxi puede reaccionar con otra molécula de ciclohexano para dar agua y otro radical $\mathrm{C}_{6} \mathrm{H}_{11}$ • (Ecuación 6.3):

$$
\begin{aligned}
\mathrm{C}_{6} \mathrm{H}_{11}-\mathrm{O}^{\circ}+\mathrm{C}_{6} \mathrm{H}_{12} \rightarrow \mathrm{C}_{6} \mathrm{H}_{11}-\mathrm{OH}+\mathrm{C}_{6} \mathrm{H}_{11} \cdot & \text { Ecuación 6.2 } \\
{ }^{\circ} \mathrm{OH}+\mathrm{C}_{6} \mathrm{H}_{12} \rightarrow \mathrm{H}_{2} \mathrm{O}+\mathrm{C}_{6} \mathrm{H}_{11}{ }^{\circ} & \text { Ecuación 6.3 }
\end{aligned}
$$

Por otro lado, el radical $\mathrm{C}_{6} \mathrm{H}_{11} \bullet$ reacciona rápidamente con oxígeno molecular, en un paso de reacción limitado por difusión, ${ }^{50}$ formando ciclohexil peróxido, $\mathrm{CHP}\left(\mathrm{C}_{6} \mathrm{H}_{11^{-}}\right.$ $\mathrm{OO}^{\bullet}$ ) (Ecuación 6.4). Este CHP reacciona con una molécula de ciclohexano para dar ciclohexil hidroperóxido $\left(\mathrm{C}_{6} \mathrm{H}_{11}-\mathrm{OOH}\right)$ y otro radical $\mathrm{C}_{6} \mathrm{H}_{11} \bullet$ (Ecuación 6.5):

$$
\begin{array}{cc}
\mathrm{C}_{6} \mathrm{H}_{11}{ }^{*}+\mathrm{O}_{2} \rightarrow \mathrm{C}_{6} \mathrm{H}_{11} \text {-OO }^{*} & \text { Ecuación 6.4 } \\
\mathrm{C}_{6} \mathrm{H}_{11} \text {-OO }^{*}+\mathrm{C}_{6} \mathrm{H}_{12} \rightarrow \mathrm{C}_{6} \mathrm{H}_{11}-\mathrm{OOH}+\mathrm{C}_{6} \mathrm{H}_{11} \cdot & \text { Ecuación 6.5 }
\end{array}
$$


Las Ecuaciones 6.6 y 6.7 muestran una serie de reacciones, que implican la captación de $\mathrm{H}-\alpha$, en las que las moléculas de CHP/CHHP inician la formación de ciclohexanol y ciclohexanona. ${ }^{51}$ Además, en la Ecuación 6.8 se muestra la dismutación del CHP, conocida como la reacción de terminación de este proceso. ${ }^{52}$

$$
\begin{aligned}
& \mathrm{C}_{6} \mathrm{H}_{11}-\mathrm{OO}^{*}+\mathrm{C}_{6} \mathrm{H}_{11}-\mathrm{OOH} \rightarrow \mathrm{C}_{6} \mathrm{H}_{11}-\mathrm{OOH}+\mathrm{C}_{6} \mathrm{H}_{10}{ }^{(\cdot)} \mathrm{OOH} \quad \text { Ecuación } 6.6 \\
& \mathrm{C}_{6} \mathrm{H}_{10}{ }^{(\cdot)} \mathrm{OOH} \rightarrow \mathrm{C}_{6} \mathrm{H}_{10}=\mathrm{O}+{ }^{\circ} \mathrm{OH} \quad \text { Ecuación } 6.7 \\
& 2 \mathrm{C}_{6} \mathrm{H}_{11}-\mathrm{OO}^{*} \rightarrow \mathrm{C}_{6} \mathrm{H}_{11}-\mathrm{OH}+\mathrm{C}_{6} \mathrm{H}_{10}=\mathrm{O}+\mathrm{O}_{2} \quad \text { Ecuación } 6.8
\end{aligned}
$$

Varios estudios apoyan que un mecanismo de radicales libres requiere un paso de iniciación, que involucra la abstracción de un átomo de hidrógeno del ciclohexano para formar un radical ciclohexilo $\left(\mathrm{C}_{6} \mathrm{H}_{12} \rightarrow \mathrm{C}_{6} \mathrm{H}_{11} \bullet^{\bullet}\right){ }^{53}$ Si esto es así, no se necesita un radical alcoxi $\left(\mathrm{C}_{6} \mathrm{H}_{11}-\mathrm{O}^{\bullet}\right)$ para promover la reacción, y, la ciclohexanona, se va a obtener como consecuencia de una ruta de autooxidación que implica el par CHP/CHHP (ecuaciones 6-8). La conclusión de este estudio es que, si una ruta únicamente radicalaria gobierna este proceso, siempre se produciría ciclohexanona en exceso con respecto al ciclohexanol. Estudios actuales sobre la reacción de autooxidación reportan que se obtiene un ratio K/A entre 1 y 1.5 cuando no existe un control de la selectividad por parte del catalizador. ${ }^{54}$ Estos estudios concluyen que una ruptura rápida del enlace $\mathrm{O}-\mathrm{O}$ en CHHP (ecuación 1) es el camino principal para obtener un exceso de alcohol con respecto a la cetona (ecuaciones $1-8) .55,56$

\subsubsection{Transferencia de oxígeno desde el CHHP al ciclohexano mediada por los clústeres de cobalto.}

La oxidación del ciclohexano por transferencia de oxígeno es una reacción bastante conocida que puede producirse como un proceso libre de radicales mediada por sistemas de cobalto. En este proceso se cree que el CHHP es un intermediario clave, el cual desempeña un papel principal en la formación de ciclohexanol y ciclohexanona (Esquema 6.4). ${ }^{36,57,58}$ De hecho, la distribución de productos de reacción, relacionada con el ratio alcohol/cetona formado, proporciona información sobre el mecanismo. Si el proceso transcurre fundamentalmente por vía radicalaria lleva asociado una relación K/A superior a 1 , mientras que si es fundamentalmente no radicalario lleva asociado una relación K/A inferior a 1. En este sentido, se llevó a cabo un estudio para explicar el mecanismo que tiene lugar según el comportamiento observado para los cubanos de cobalto. Para ello, se ha llevado a cabo la oxidación del ciclohexano usando CHHP como oxidante primario en presencia de los clústeres sintetizados en esta tesis doctoral (Tabla 
6.6). Este estudio se lleva a cabo como punto de partida con el fin de justificar la selectividad observada cuando los cubanos de cobalto 1-6 se emplean como catalizadores en la oxidación aeróbica de ciclohexano (Figura 6.4, Tabla 6.8).

Tabla 6.6. Resumen de la actividad catalítica (conversión y distribución de productos) de los catalizadores 1-6 en la oxidación de ciclohexano empleando CHHP como oxidante primario.

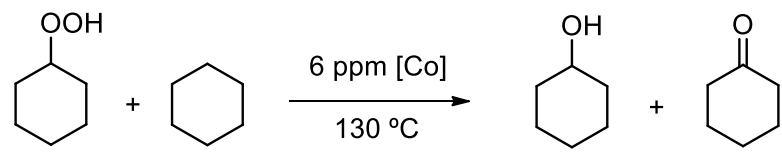

\begin{tabular}{|c|c|c|c|c|c|c|}
\hline \multirow{2}{*}{ Entrada } & \multirow{2}{*}{ Catalizador } & \multirow{2}{*}{$\begin{array}{c}\text { Conversión } \\
(\boldsymbol{\%})\end{array}$} & \multicolumn{3}{|c|}{ Selectividad (\%) } & \multirow{2}{*}{ Eficiencia $^{[\mathrm{d}]}$} \\
\cline { 4 - 6 } & & $\mathbf{A}^{[\mathrm{a}]}$ & $\mathbf{K}^{[\mathrm{b}]}$ & Total $^{[\mathrm{c}]}$ & \\
\hline 1 & Blanco & 1 & 32 & 68 & 100 & 1.05 \\
\hline 2 & $\mathbf{1}$ & 51 & 67 & 33 & 100 & 1.67 \\
\hline 3 & $\mathbf{2}$ & 54 & 72 & 28 & 100 & 1.91 \\
\hline 4 & $\mathbf{3}$ & 50 & 68 & 32 & 100 & 1.40 \\
\hline 5 & $\mathbf{4}$ & 54 & 69 & 31 & 100 & 1.68 \\
\hline 6 & $\mathbf{5}$ & 55 & 79 & 21 & 100 & 1.82 \\
\hline 7 & $\mathbf{6}$ & 54 & 69 & 31 & 100 & 1.52 \\
\hline
\end{tabular}

Condiciones de reacción: $2.874 \mathrm{~g}$ de ciclohexano $(34.17 \mathrm{mmol})$ y $0.126 \mathrm{~g}$ de CHHP (1.08 mmol); 6 ppm de cobalto (clústeres 1-6); $130{ }^{\circ} \mathrm{C}, 6$ bar $\mathrm{N}_{2}$, tiempo de reacción 1 hora. ${ }^{[a]} \mathrm{A}=$ alcohol, ciclohexanol; ${ }^{[\mathrm{b}]} \mathrm{K}=$ cetona, ciclohexanona; ${ }^{[\mathrm{c}]}$ Selectividad total observada; ${ }^{[\mathrm{d}]}$ Productos obtenidos de la transferencia de oxígeno y la descomposición del CHHP. En este sentido, el valor 1 implica solo la descomposición del CHHP, mientras que un valor mayor que 1 implica que el catalizador es capaz de descomponer el CHHP y oxidar el ciclohexano al mismo tiempo (Esquema 6.7)

Los resultados presentados en la Tabla 6.6 indican que, para esta reacción, la formación de alcohol es superior al 50\% con todos los catalizadores estudiados. Sin embargo, hay dos diferencias principales entre los diferentes catalizadores. La primera está relacionada con el ratio $\mathrm{A} / \mathrm{K}$, que siempre es mayor para los clústeres $\mathbf{2}$ y $\mathbf{5}$, que son los materiales que presentan un grupo EWG en el anillo de piridina. La segunda diferencia, de mayor importancia, es que los catalizadores con mayor potencial de oxidación promueven una mayor transferencia de oxígeno y una menor deshidrogenación oxidativa durante la descomposición del CHHP que los catalizadores con menor potencial de oxidación (Valor de eficiencia en la Tabla 6.6). Por último, estos resultados apoyan que el catalizador 5 es el más activo de esta serie, no solo para la oxidación aeróbica del 
ciclohexano, sino también para la transferencia de oxígeno usando el CHHP como oxidante primario.

\subsubsection{Espectroscopía Raman in-situ empleando oxígeno molecular.}

Con el fin de estudiar la naturaleza de las especies de oxígeno formadas cuando se lleva a cabo la reacción de oxidación aeróbica de ciclohexano con los clústeres 1-6 como catalizadores, se utilizó la espectroscopía Raman in situ. Para llevar a cabo este estudio, se pasa una corriente de oxígeno por la celda Raman en la que previamente se ha introducido la muestra pretratada con argón. Al pasar el oxígeno a través de la celda, se observa la aparición de nuevas bandas en los espectros Raman de los catalizadores. Estas nuevas bandas Raman pertenecen a las especies de oxígeno que se forman en el catalizador de cobalto, las cuales están relacionadas con las propiedades de estos clústeres, en concreto con su potencial de oxidación. Como se puede observar en la Figura 6.8, para los clústeres con los valores de potencial de oxidación más bajo, 1, 3 y 6 (por debajo de $0.74 \mathrm{~V}$ ) aparecen bandas en el rango $684-472 \mathrm{~cm}^{-1}$, las cuales se asignan a las especies Co-O ${ }^{59}$ (espectros Raman completos en las Figuras 6.37, 6.39 y 6.41 de la sección experimental), lo que implicaría una ruptura del enlace O-O.

a)

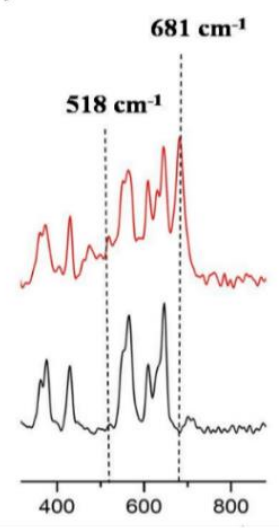

b)

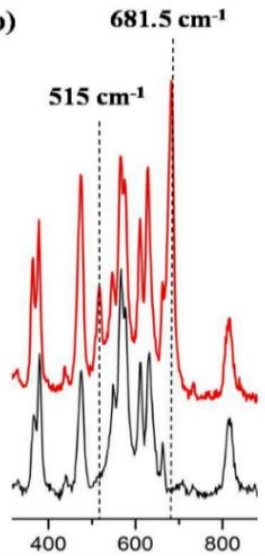

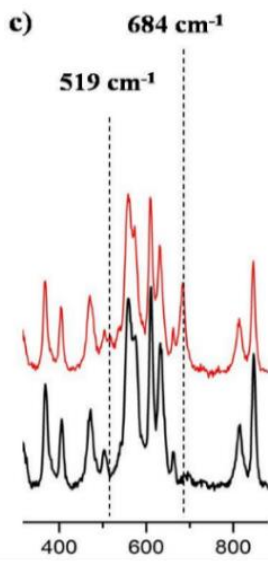

Desplazamiento Raman $\left(\mathrm{cm}^{-1}\right)$

Figura 6.8. Espectro Raman de los complejos 1 (a), 3 (b) y 6 (c) entre 850 y $350 \mathrm{~cm}^{-1}$ en argón (negro) y pasando un flujo de $\mathrm{O}_{2}$ (rojo).

Por otro lado, para los clústeres de cobalto que presentan potenciales de oxidación superiores a $0.78 \mathrm{~V}(\mathbf{2}, 4$ y 5) aparecen nuevas bandas Raman en el rango 1600-858 cm ${ }^{1}$, que pueden ser asignadas a especies de oxígeno tipo peróxido Co-O-O, lo que implica 
que en este caso no existe ruptura del enlace O-O. Sin embargo, las especies de oxígeno observadas para los catalizadores $\mathbf{2}, \mathbf{4}$ y $\mathbf{5}$ no son idénticas. En los espectros Raman de los clústeres 2 y 4, al pasar un flujo de oxígeno, aparecen bandas Raman a 1261 y 1285 $\mathrm{cm}^{-1}$, respectivamente (Figura 6.9), las cuales pueden ser asignadas a especies adsorbidas $\mathrm{O}_{2}{ }^{\delta-}(0<\delta<1)^{59-61}$ (espectros Raman completos en las Figuras 6.38 y 6.40 de la sección experimental).
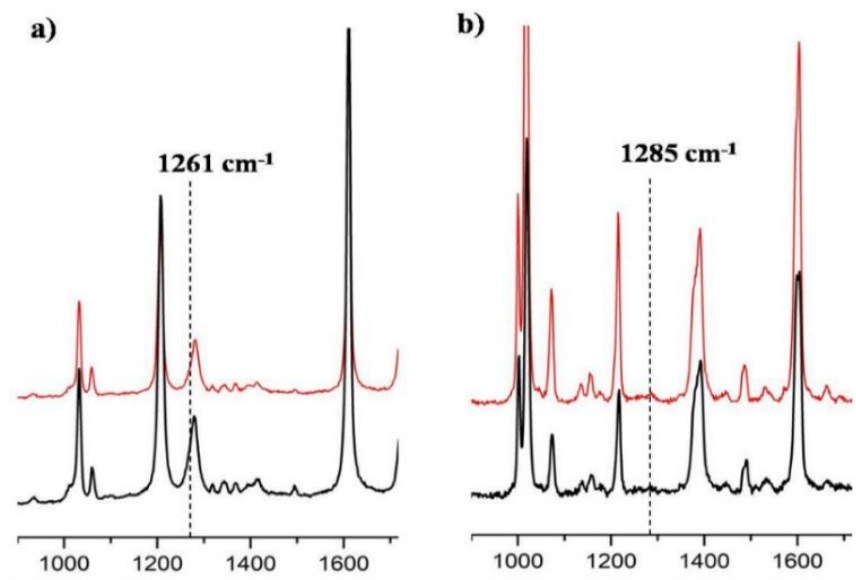

Desplazamiento Raman $\left(\mathrm{cm}^{-1}\right)$

Figura 6.9. Espectros Raman de los complejos 2 (a) y 4 (b) entre 1700 y $900 \mathrm{~cm}^{-1}$ en argón (negro) y pasando un flujo de $\mathrm{O}_{2}$ (rojo).

Finalmente, el complejo 5, el cual presenta el mayor valor para el potencial de oxidación $(0.956 \mathrm{~V})$ presenta un comportamiento totalmente diferente. En este caso se observa una banda a $1600 \mathrm{~cm}^{-1},{ }^{59}$ asociada a la absorción de oxígeno molecular y bandas a 1159 , 1138 y $1107 \mathrm{~cm}^{-1}$ que se asignan a las especies superóxido $\eta^{1}$ (Figura 6.10). ${ }^{57,60,61}$ Por otro lado, se observa la aparición de otra banda a $858 \mathrm{~cm}^{-1}$, la cual puede ser asignada a especies de peróxido no planares. ${ }^{59-63}$

A partir de estos resultados, se puede concluir que los catalizadores con mayor potencial de oxidación promueven especies de oxígeno más selectivas para este proceso que los catalizadores con valores menores de potencial de oxidación. Como resultado final, a partir de estos resultados, cabe destacar que la activación del enlace de oxígeno para formar especies peróxido y superóxido es la mejor forma de oxidar el enlace C-H de los alcanos no activados. 


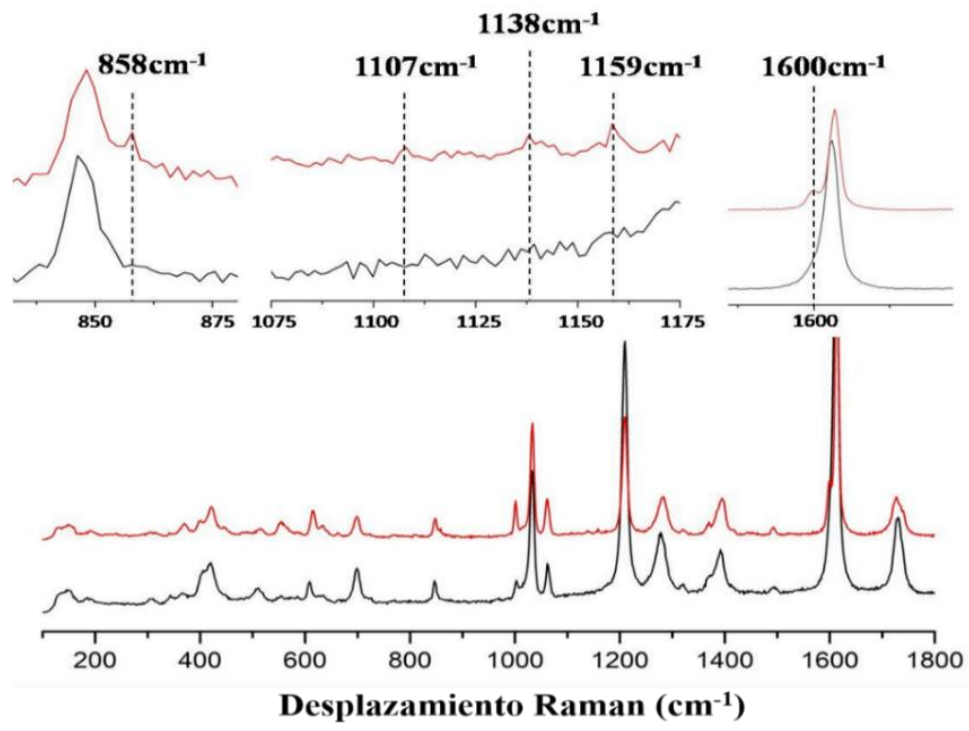

Figura 6.10. Espectro Raman del complejo 5 en argón (negro) y pasando un flujo de $\mathrm{O}_{2}$ (rojo).

6.3.3.3. Influencia de la naturaleza del clúster de cobalto en el mecanismo de reacción.

El Esquema 6.4 ilustra el mecanismo de reacción establecido en la oxidación del ciclohexano. A partir de este mecanismo y en función de los resultados anteriores, obtenidos mediante estudios experimentales combinados con estudios in-situ, se ha propuesto el siguiente mecanismo, que combina la oxidación aeróbica de ciclohexano con la transferencia de oxígeno para los clústeres de cobalto 1-6 (Esquema 6.6). Este esquema ilustra las reacciones que componen el mecanismo global ilustradas en el Esquema 6.4 con los intermedios identificados con los clústeres de cobalto durante los estudios previamente descritos, con el fin de correlacionar el papel de cada cubano en el mecanismo de reacción, el cual depende de sus propiedades electrónicas. De hecho, teniendo en cuenta las especies observadas, se puede apreciar que estos catalizadores juegan un papel principal en dos partes diferentes del proceso: por un lado, en la activación del oxígeno molecular, y, por otro lado, en la activación del CHHP. Por tanto, ambos están claramente relacionados con la activación del enlace O-O para cada molécula mencionada.

Con respecto a la activación del $\mathrm{O}_{2}$, los clústeres de cobalto juegan un papel principal en el paso de iniciación. Sin embargo, de acuerdo con las especies detectadas por 
espectroscopía Raman in-situ, estos catalizadores se pueden clasificar en dos grupos. En el primer grupo, que incluye a los catalizadores 1,3 y $\mathbf{6}$, la activación del $\mathrm{O}_{2}$ implica la ruptura del enlace $\mathrm{O}-\mathrm{O}$, mientras que, en el segundo grupo, el cual incluye a los catalizadores 2,4 y $\mathbf{5}$, la activación del $\mathrm{O}_{2}$ no implica la ruptura del enlace O-O. Este hecho indica que los clústeres 1, 3 y $\mathbf{6}$ siguen el camino de la izquierda (Esquema 6.6, reacciones Aa, B, y finalmente la propagación, D), mientras que los clústeres 2,4 y 5 siguen el camino de la derecha (Esquema 6.6, reacciones $\mathbf{A b}, \mathbf{C}$, y finalmente la propagación, D).

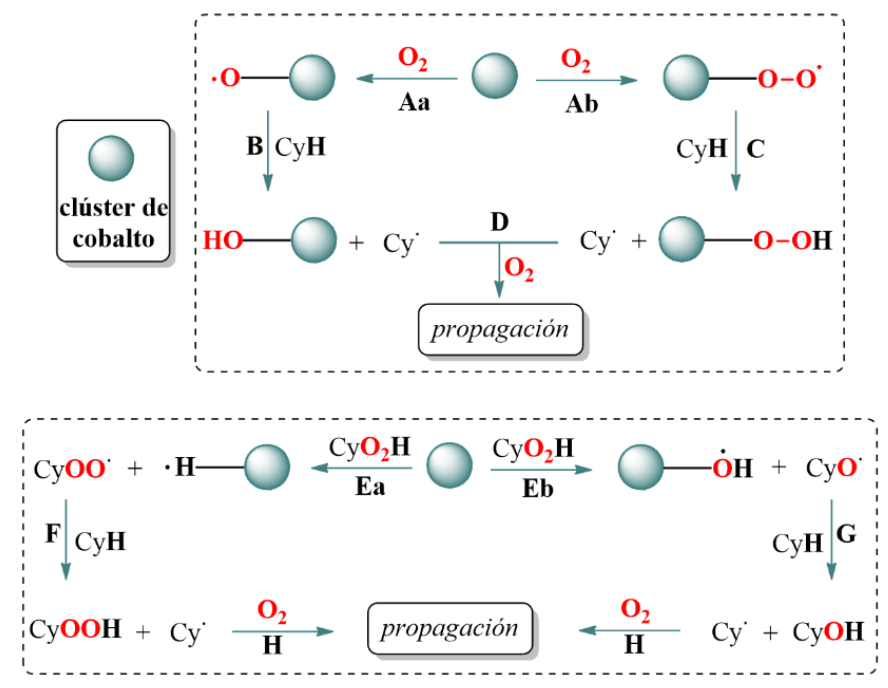

Esquema 6.6. Mecanismo propuesto para la oxidación de ciclohexano con los clústeres de cobalto 1-6. Activación de $\mathrm{O}_{2}$ (arriba) y descomposición de CHHP (abajo).

El comportamiento de estos seis catalizadores para la descomposición del CHHP es bastante similar, observando principalmente radicales alcoxi como especie principal en los experimentos de EPR. Por tanto, todos los catalizadores siguen las reacciones Ea y Eb (Esquema 6.6), excepto el clúster 5, el cual promueve exclusivamente la formación de radicales alcoxi, y, por lo tanto, sigue únicamente la reacción $\mathbf{E b}$. Además, estos catalizadores de cobalto pueden adsorber el radical hidroxilo, bloqueando su reactividad, la cual puede dañar la selectividad. Finalmente, el estudio de las reacciones de transferencia de oxígeno (oxidación de ciclohexano con CHHP) corrobora que los clústeres $\mathbf{2}$ y $\mathbf{5}$ presentan una mayor contribución en la reacción de propagación, mientras que los clústeres $\mathbf{3}$ y $\mathbf{6}$ tienen una menor influencia en este proceso. Por lo tanto, la influencia de estos catalizadores de cobalto en la reacción de transferencia durante la oxidación de ciclohexano está también correlacionada con su densidad electrónica. 


\subsection{Conclusiones}

- Se ha desarrollado una familia de clústeres de cobalto en la que se pueden modular las propiedades electrónicas del cubano $\left[\mathrm{Co}_{4} \mathrm{O}_{4}\right]$ cambiando los sustituyentes de los ligandos orgánicos. Además, se ha desarrollado una nueva estrategia sintética basada en la diferencia en el $\mathrm{pK}_{\mathrm{b}}$ de los diferentes ligandos carboxilato.

- Estos clústeres tetranucleares de cobalto han mostrado una elevada actividad y selectividad como catalizadores en la reacción de oxidación de ciclohexano en condiciones netas y usando aire empobrecido ( $5 \%$ de $\mathrm{O}_{2}$ en $\mathrm{N}_{2}$ ) como oxidante primario. En este sentido, se ha estudiado la correlación entre la estructura y la actividad de estos catalizadores pudiéndose demostrar que las propiedades electrónicas están correlacionadas con la actividad catalítica. Además, estos catalizadores también promueven la transferencia de oxígeno con CHHP durante la oxidación de ciclohexano.

- Se ha estudiado el mecanismo de reacción mediante la técnica de atrapamiento de espín por EPR, Raman in-situ y estudios experimentales. Por un lado, los experimentos de atrapamiento de espín sugieren que el mecanismo presenta una contribución radicalaria, en la que el catalizador más activo y selectivo promueve casi exclusivamente radicales alcoxi en la reacción con hidroperóxido. Por otro lado, las reacciones usando CHHP y ciclohexano en presencia de los clústeres de cobalto sugieren que la descomposición del CHHP para oxidar el ciclohexano está controlada principalmente por un proceso no radicalario. En este sentido, la densidad electrónica de los clústeres tiene una influencia clara en la distribución de los productos de reacción, la cual está correlacionada con el ratio de contribución radicalaria/no radicalaria del proceso.

- Finalmente, la espectroscopía Raman in-situ ha permitido caracterizar especies de oxígeno que actúan como intermedios de reacción. De hecho, las especies formadas en cada caso pueden ser correlacionadas con el potencial de oxidación de los clústeres de cobalto.

- En resumen, en este capítulo de la tesis se ha llevado a cabo la síntesis de seis clústeres de cobalto tetranucleares que han mostrado una elevada actividad y selectividad en la reacción de oxidación de ciclohexano sin necesidad de usar disolvente y usando aire empobrecido como oxidante y, además, se ha llevado a cabo un estudio mecanístico, a partir del cual se puede destacar la contribución de los catalizadores desarrollados en cada etapa del proceso global y relacionarla con su densidad electrónica. 


\subsection{Sección experimental.}

\subsubsection{Síntesis de los catalizadores.}

\section{Síntesis de $\left[\mathrm{Co}_{4} \mathrm{O}_{4}(\mathrm{OAc})_{4} \mathrm{py}_{4}\right](1)$}

Se disuelven en $100 \mathrm{~mL}$ de metanol $10 \mathrm{~g}$ nitrato de cobalto (II) hexahidratado (34.3 mmol) y $9.35 \mathrm{~g}$ de acetato de sodio trihidratado (68.6 mmol). A continuación, se añaden $2.8 \mathrm{~mL}$ de piridina (34 mmol). Finalmente, se añade peróxido de hidrógeno (34-37\% w/w en agua, $17.1 \mathrm{~mL}, 170 \mathrm{mmol}$ ) gota a gota a la disolución resultante y esta mezcla de reacción se deja a reflujo durante $2 \mathrm{~h}$. Una vez finalizado este tiempo, la disolución verde-marrón se seca a vacío en el rotavapor y el sólido se purifica por extracción líquido-líquido usando $100 \mathrm{~mL}$ de diclorometano y $20 \mathrm{~mL}$ de agua. Se recoge la fase orgánica y la fase acuosa se lava con otras dos porciones de $100 \mathrm{~mL}$ de diclorometano. La fase orgánica recogida se seca con $\mathrm{MgSO}_{4}$ anhidro y se concentra hasta $50 \mathrm{~mL}$ en el rotavapor. A esta fracción se le añaden $500 \mathrm{~mL}$ de hexano para inducir la cristalización. El sólido se purifica por cromatografía en columna usando como eluyente una disolución $5 \%$ de metanol en acetona. Se evapora el disolvente de las fracciones recogidas para dar un sólido verde oscuro (6.2 g, 85.6\%), el cual se observa que es puro por ${ }^{1} \mathrm{H}-\mathrm{RMN} .{ }^{26}{ }^{1} \mathrm{H}$ RMN (300 MHz, DMSO-d $\left.)_{6}\right): \delta=8.34(\mathrm{~d}, J=6.5,8 \mathrm{H}), 7.66-7.61(\mathrm{t}, J=6.6 \mathrm{~Hz}, 4 \mathrm{H})$, 7.15-7.11 (m, 8H), 1.92 (s, 12H). $\left.{ }^{13} \mathrm{C} \mathrm{RMN} \mathrm{(75} \mathrm{MHz,} \mathrm{DMSO-d} 6\right): \delta=183.97,152.11$, 136.92, 123.36, 26.08. Anal. calculado para $\mathrm{C}_{28} \mathrm{H}_{32} \mathrm{Co}_{4} \mathrm{~N}_{4} \mathrm{O}_{12}: \mathrm{C}, 39.422 ; \mathrm{H}, 3.754 ; \mathrm{N}$, 6.570; Co, 27.70. Experimental: C, 39.720; H, 3.978; N, 6.388; Co, 26.91.

\section{Síntesis de $\left[\mathrm{Co}_{4} \mathrm{O}_{4}(\mathrm{OAc})_{4}(\mathrm{p}-\mathrm{COOEt}-\mathrm{py})_{4}\right](2)$}

Para preparar el complejo $\mathrm{Co}_{4} \mathrm{O}_{4}(\mathrm{OAc})_{4}(\mathrm{p} \text {-COOEt-py) })_{4}$ se sigue el mismo método que en el caso del complejo 1, usando isonicotinato de etilo en lugar de piridina $(5.14 \mathrm{~g}, 34$ mmol). ${ }^{1} \mathrm{H}$ RMN (300 MHz, DMSO-d $): \delta=8.53(\mathrm{~d}, J=6.5 \mathrm{~Hz}, 8 \mathrm{H}), 7.55(\mathrm{~d}, J=6.6$ $\mathrm{Hz}, 8 \mathrm{H}), 4.35$ (q, $J=7.1 \mathrm{~Hz}, 8 \mathrm{H}), 1.95(\mathrm{~s}, 12 \mathrm{H}), 1.37$ (t, $J=7.2 \mathrm{~Hz}, 12 \mathrm{H}) .{ }^{13} \mathrm{C} \mathrm{RMN}(75$ MHz, DMSO-d 6 ): $\delta=184.58,163.82,153.59,137.41,122.22,61.79,26.11,13.94$. Anal. Calculado para $\mathrm{C}_{40} \mathrm{H}_{48} \mathrm{Co}_{4} \mathrm{~N}_{4} \mathrm{O}_{20}: \mathrm{C}, 42.100 ; \mathrm{H}, 4.210 ; \mathrm{N}, 4.912 ;$ Co, 20.70. Experimental: C, 41.720; H, 4.136; N, 4.955; Co, 20.28.

\section{Síntesis de [Co404(OAc)4(p-OMe-py)4] (3)}

Para preparar el complejo $\mathrm{Co}_{4} \mathrm{O}_{4}(\mathrm{OAc})_{4}(\mathrm{p}-\mathrm{OMe}-\mathrm{py})_{4}$ se sigue el mismo método que en el caso del complejo 1, usando 4-metoxipiridina (3.71 g, $34 \mathrm{mmol})$ en lugar de piridina. ${ }^{1} \mathrm{H}$ RMN (300 MHz, DMSO-d 6 ): $\delta=8.07-8.05(\mathrm{~d}, J=6.6 \mathrm{~Hz}, 8 \mathrm{H}), 6.76-6.74(\mathrm{~d}, J=6.7$ $\mathrm{Hz}, 8 \mathrm{H}), 3.83$ (s, 12H), 1.90 (s, 12H). ${ }^{13} \mathrm{C}$ RMN (75 MHz, DMSO-d 6 ): $\delta=183.75$, 
165.92, 152.80, 109.88, 64.87, 26.08. Anal. Calculado para $\mathrm{C}_{32} \mathrm{H}_{40} \mathrm{Co}_{4} \mathrm{~N}_{4} \mathrm{O}_{16}$ : C, 39.332; H, 4.097; N, 5.736; Co, 24.14. Experimental: C, 38.947; H, 4.275; N, 6.006; Co, 23.35.

\section{Síntesis de $\left[\mathrm{Co}_{4} \mathrm{O}_{4}(\mathrm{OBz})_{4} \mathrm{py}_{4}\right](4)$}

Para preparar el complejo $\mathrm{Co}_{4} \mathrm{O}_{4}(\mathrm{OBz})_{4} \mathrm{py}_{4}$ se sigue la misma metodología que en el caso del complejo 1, usando benzoato sódico $(9.89 \mathrm{~g}, 68.6 \mathrm{mmol})$ en lugar de acetato sódico. Además, el complejo $\mathrm{Co}_{4} \mathrm{O}_{4}(\mathrm{OBz})_{4} \mathrm{py}_{4}$ se puede sintetizar a través de un método de intercambio de ligando usando el complejo 1 como precursor. Para ello, se disuelven $2 \mathrm{~g}$ del complejo $\mathrm{Co}_{4} \mathrm{O}_{4}(\mathrm{OAc})_{4} \mathrm{py}_{4}(2.35 \mathrm{mmol})$ en metanol y se añaden 8 equivalentes de ácido benzoico $(2.29 \mathrm{~g}, 18.8 \mathrm{mmol})$. La mezcla se mantiene en agitación a $50^{\circ} \mathrm{C}$ durante 4 horas. El sólido resultante se recoge por filtración y se lava 3 x $50 \mathrm{~mL}$ con dietil éter. ${ }^{1} \mathrm{H}$ RMN (300 MHz, DMSO-d $\left.{ }_{6}\right): \delta=8.49-8.46(\mathrm{~d}, J=6.5 \mathrm{~Hz}, 8 \mathrm{H}), 7.81-7.77(\mathrm{~d}, J=7.4$ $\mathrm{Hz}, 8 \mathrm{H}), 7.73-7.68(\mathrm{t}, J=6.7 \mathrm{~Hz}, 4 \mathrm{H}), 7.48-7.43(\mathrm{t}, J=7.4 \mathrm{~Hz}, 4 \mathrm{H}), 7.37-7.32(\mathrm{~m}, 8 \mathrm{H})$, 7.24-7.20 (m, 8H). ${ }^{13} \mathrm{C}$ RMN (75 MHz, DMSO-d $\left.\mathrm{d}_{6}\right): \delta=179.06,152.10,137.35,135.69$, 130.97, 128.29, 127.84, 123.86. Anal. Calculado para $\mathrm{C}_{48} \mathrm{H}_{40} \mathrm{Co}_{4} \mathrm{~N}_{4} \mathrm{O}_{12}: \mathrm{C}, 52.364 ; \mathrm{H}$, 3.636; N, 5.091; Co, 21.43. Experimental: C, 52.618; H, 3.869; N, 4.685; Co, 22.13.

\section{Síntesis de $\left[\mathrm{Co}_{4} \mathrm{O}_{4}(\mathrm{OBz})_{4}(\mathrm{p}-\mathrm{COOEt}-\mathrm{py})_{4}\right](5)$}

Para preparar el complejo $\mathrm{Co}_{4} \mathrm{O}_{4}(\mathrm{OBz})_{4}(\mathrm{p}-\mathrm{COOEt}-\mathrm{py})_{4}$, se sigue el mismo procedimiento que en el caso del complejo 1, usando benzoato sódico (9.89 g, 68.6 $\mathrm{mmol})$ en lugar de acetato sódico y isonicotinato de etilo $(5.14 \mathrm{~g}, 34 \mathrm{mmol})$ en lugar de piridina. Además, el complejo $\mathrm{Co}_{4} \mathrm{O}_{4}(\mathrm{OBz})_{4}(\mathrm{p} \text {-COOEt-py })_{4}$ se puede sintetizar por un método de intercambio de ligando utilizando el complejo 2 como precursor. Para ello, se disuelve el $\mathrm{Co}_{4} \mathrm{O}_{4}(\mathrm{OAc})_{4}(\mathrm{p}-\mathrm{COOEt}-\mathrm{py})_{4}(3.26 \mathrm{~g}, 2.35 \mathrm{mmol})$ en metanol y se le añaden 8 equivalentes de ácido benzoico $(2.29 \mathrm{~g}, 18.8 \mathrm{mmol})$. La mezcla de reacción se mantiene en agitación a $50^{\circ} \mathrm{C}$ durante 4 horas. El sólido resultante re recoge por filtración y se lava 3 x $50 \mathrm{~mL}$ con dietil éter. ${ }^{1} \mathrm{H}$ RMN (300 MHz, DMSO-d 6$): \delta=8.70-8.68(\mathrm{~d}, J=6.4,8 \mathrm{H})$, 7.82-7.80 (d, $J=7.2 \mathrm{~Hz}, 8 \mathrm{H}), 7.65-7.63(\mathrm{~d}, J=6.5 \mathrm{~Hz}, 8 \mathrm{H}), 7.49-7.44(\mathrm{t}, J=7.2 \mathrm{~Hz}$, $4 \mathrm{H}), 7.37-7.32(\mathrm{~m}, 8 \mathrm{H}), 4.36(\mathrm{q}, J=7.2 \mathrm{~Hz}, 8 \mathrm{H}), 1.36(\mathrm{t}, J=7.1 \mathrm{~Hz} 12 \mathrm{H}) .{ }^{13} \mathrm{C} \mathrm{RMN}(75$ MHz, DMSO-d 6$): \delta=179.51,163.78,153.58,137.72,135.44,131.14,128.44,127.88$, 122.76, 61.81, 30.66, 13.96. Anal. Calculado para $\mathrm{C}_{60} \mathrm{H}_{56} \mathrm{Co}_{4} \mathrm{~N}_{4} \mathrm{O}_{20}: \mathrm{C}, 51.873 ; \mathrm{H}, 4.064$; N, 4.034; Co, 17.00. Experimental: C, 52.275; H, 4.351; N, 3.619; Co, 16.89.

\section{Síntesis de [Co4O4(OBz)4(p-OMe-py)4] (6)}

Para preparar el complejo $\mathrm{Co}_{4} \mathrm{O}_{4}(\mathrm{OBz})_{4}(\mathrm{p}-\mathrm{COOEt}-\mathrm{py})_{4}$ se sigue la misma metodología que en el caso del complejo 1, usando benzoato sódico (9.89 g, $68.6 \mathrm{mmol})$ en lugar de acetato sódico y 4-metoxipiridina (3.71 g, $34 \mathrm{mmol})$ en lugar de piridina. Además, el 
complejo $\mathrm{Co}_{4} \mathrm{O}_{4}(\mathrm{OBz})_{4}(\mathrm{p}-\mathrm{OMe}-\mathrm{py})_{4}$ se puede sintetizar por un método de intercambio de ligando utilizando el complejo 3 como precursor. Para ello, se disuelve el $\mathrm{Co}_{4} \mathrm{O}_{4}(\mathrm{OAc})_{4}(\mathrm{p}-\mathrm{OMe}-\mathrm{py})_{4}(2.87 \mathrm{~g}, 2.35 \mathrm{mmol})$ en metanol y se añaden 8 equivalentes de ácido benzoico $(2.29 \mathrm{~g}, 18.8 \mathrm{mmol})$. La mezcla de reacción se mantiene en agitación a $50^{\circ} \mathrm{C}$ durante 4 horas. El sólido resultante se recoge por filtración y se lava $3 \times 50 \mathrm{~mL}$ con dietil éter. ${ }^{1} \mathrm{H}$ RMN (300 MHz, DMSO-d $\left.{ }_{6}\right): \delta=8.19(\mathrm{~d}, J=6.4 \mathrm{~Hz}, 8 \mathrm{H}), 7.81-7.78$ $(\mathrm{m}, 8 \mathrm{H}), 7.46-7.43$ (t, $J=7.2 \mathrm{~Hz}, 4 \mathrm{H}), 7.37-7.32(\mathrm{~m}, 8 \mathrm{H}), 6.85(\mathrm{~d}, J=7.3 \mathrm{~Hz}, 2 \mathrm{H}), 3.85$ (s, 12H), 2.08 (s, 12H). ${ }^{13} \mathrm{C}$ RMN (75 MHz, DMSO-d $): \delta=178.8,167.5,153.0,139.9$, 128.6, 128.4, 128.1 110.7, 56.0. Anal. Calculado para $\mathrm{C}_{52} \mathrm{H}_{48} \mathrm{Co}_{4} \mathrm{~N}_{4} \mathrm{O}_{16}: \mathrm{C}, 51.146 ; \mathrm{H}$, 3.930; N, 4.590; Co, 19.32. Experimental: C, 50.627; H, 3.675; N, 4.552; Co, 19.91.

\subsubsection{Caracterización de los catalizadores.}

\section{A. Difracción de rayos $\mathrm{X}$ de monocristal.}

Tabla 6.7. Datos cristalográficos y detalles del refinamiento de las estructuras de los complejos 2, 5 y 6 . Las coordenadas atómicas, los parámetros equivalentes de desplazamiento isotrópico, las distancias y ángulos de enlace y los parámetros de desplazamiento anisotrópico se pueden encontrar en los CIFs (CCDC 1874019, CCDC 1874000 y CCDC 1873998, respectivamente).

\begin{tabular}{|c|c|c|c|}
\hline $\begin{array}{c}\text { Código de } \\
\text { identificación }\end{array}$ & $\mathbf{2}$ & $\mathbf{5}$ & $\mathbf{6}$ \\
\hline $\begin{array}{c}\text { Fórmula } \\
\text { empírica }\end{array}$ & $\mathrm{C}_{41} \mathrm{H}_{50} \mathrm{Cl}_{2} \mathrm{Co}_{4} \mathrm{~N}_{4} \mathrm{O}_{20}$ & $\mathrm{C}_{60} \mathrm{H}_{56} \mathrm{Co}_{4} \mathrm{~N}_{4} \mathrm{O}_{20}$ & $\mathrm{C}_{52} \mathrm{H}_{54} \mathrm{Cl}_{2} \mathrm{Co}_{4} \mathrm{~N}_{4} \mathrm{O}_{16}$ \\
\hline Peso molecular & 1225.47 & 1388.80 & 1330.99 \\
\hline $\begin{array}{c}\text { Temperatura } \\
(\mathbf{K})\end{array}$ & 100 & 100 & 100 \\
\hline $\begin{array}{c}\text { Longitud de } \\
\text { onda (̊) }\end{array}$ & 0.71073 & 0.71073 & 0.71073 \\
\hline $\begin{array}{c}\text { Sistema } \\
\text { cristalográfico }\end{array}$ & Triclínico & Triclínico & Monoclínico \\
\hline Grupo espacial & $-\mathrm{P} 1$ & $-\mathrm{P} 1$ & $\mathrm{P} 2{ }_{1} / \mathrm{m}$ \\
\hline $\begin{array}{c}\text { Dimensiones } \\
\text { celda unidad }\end{array}$ & $11.7374(4)$ & $17.5804(4)$ & 13.1722 \\
\hline $\begin{array}{c}\text { a (̊) } \\
\text { b (̊̊) }\end{array}$ & $13.1866(4)$ & $19.7199(4)$ & 22.6021 \\
\hline
\end{tabular}


Capítulo 6. Complejos tetranucleares de cobalto para la oxidación selectiva de ciclohexano

\begin{tabular}{|c|c|c|c|}
\hline c $(\AA)$ & $18.5347(6)$ & $21.5426(5)$ & 19.3273 \\
\hline$\alpha(\operatorname{deg})$ & $103.879(2)$ & $70.454(1)$ & 90 \\
\hline$\beta(\operatorname{deg})$ & 103.877 (2) & $80.365(2)$ & $105.554(1)$ \\
\hline$\gamma(\operatorname{deg})$ & $100.988(2)$ & 70.777 (1) & 90 \\
\hline Volumen $\left(\AA^{3}\right)$ & $2608.30(15)$ & $6631.9(3)$ & $5543.4(2)$ \\
\hline $\mathbf{Z}$ & 2 & 4 & 4 \\
\hline $\begin{array}{l}\text { Densidad } \\
\text { (calculada) }\end{array}$ & 1.560 & 1.391 & 1.595 \\
\hline $\begin{array}{c}\text { Coeficiente de } \\
\text { absorción }\end{array}$ & 1.428 & 1.055 & 1.330 \\
\hline F (000) & 1252 & 2848 & 2723 \\
\hline $\begin{array}{c}\text { Tamaño de } \\
\text { cristal }\end{array}$ & $\begin{array}{c}0.342 \times 0.203 \times \\
0.074\end{array}$ & $\begin{array}{c}0.420 \times 0.398 \times \\
0.054\end{array}$ & $\begin{array}{c}0.421 \times 0.141 \times \\
0.114\end{array}$ \\
\hline $\begin{array}{l}\text { Rango theta } \\
\text { para la } \\
\text { recopilación de } \\
\text { datos }\end{array}$ & $1.853-27.554^{\circ}$ & $1.413-25.452^{\circ}$ & $1.802-27.509$ \\
\hline Rango index & $\begin{array}{l}-15 \leq \mathrm{h} \leq 15,-16 \leq \\
\mathrm{k} \leq 17,-24 \leq 1 \leq 24\end{array}$ & $\begin{array}{c}-20 \leq \mathrm{h} \leq 21,-22 \leq \\
\mathrm{k} \leq 23,0 \leq 1 \leq 26\end{array}$ & $\begin{array}{l}-17 \leq \mathrm{h} \leq 17,-29 \leq \\
\mathrm{k} \leq 29,-25 \leq 1 \leq 25\end{array}$ \\
\hline $\begin{array}{l}\text { Reflexiones } \\
\text { recogidas }\end{array}$ & 11958 & 24369 & 12704 \\
\hline $\begin{array}{c}\text { Reflexiones } \\
\text { independientes }\end{array}$ & 8815 & 13132 & 9452 \\
\hline $\begin{array}{c}\text { Goodness of fit } \\
\text { on F2 }\end{array}$ & 1.019 & 0.999 & 1.049 \\
\hline $\begin{array}{c}\text { Índices R } \\
\text { finales } \\
{[\mathrm{I}>2 \sigma(\mathrm{I})]}\end{array}$ & $\begin{array}{c}\mathrm{R}_{1}=0.0567 \mathrm{wR} \mathrm{R}_{2}= \\
0.1422\end{array}$ & $\begin{array}{c}\mathrm{R}_{1}=0.0555 \mathrm{wR} \mathrm{R}_{2}= \\
0.1226\end{array}$ & $\begin{array}{c}\mathrm{R}_{1}=0.0436 \mathrm{wR} \mathrm{R}_{2}= \\
0.1114\end{array}$ \\
\hline Índices $\mathbf{R}$ & $\begin{array}{c}\mathrm{R}_{1}=0.0811 \mathrm{wR}_{2}= \\
0.1543\end{array}$ & $\begin{array}{c}\mathrm{R}_{1}=0.1352 w \mathrm{R}_{2}= \\
0.1519\end{array}$ & $\begin{array}{c}\mathrm{R}_{1}=0.0652 \mathrm{wR}_{2}= \\
0.1214\end{array}$ \\
\hline
\end{tabular}




\section{B. Voltamperometría cíclica.}

Para todos los sistemas de cobalto estudiados se observaron procesos de oxidación reversibles. Los voltamperogramas cíclicos muestran ondas inversas bien formadas en el rango de velocidad de medida de $25-250 \mathrm{mV} / \mathrm{s}$ estudiado.

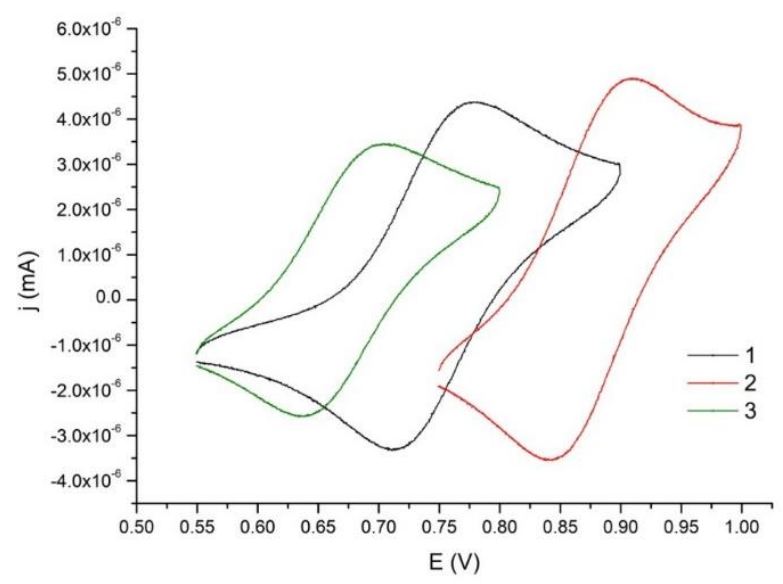

Figura 6.11. Voltamogramas cíclicos a $100 \mathrm{mV} / \mathrm{s}$ de una disolución $1 \mathrm{mM}$ de los complejos: $\mathbf{1}$ (negro), $\mathbf{2}$ (rojo) y $\mathbf{3}$ (verde) en AcN con $0.01 \mathrm{M}$ del electrolito TBAP.

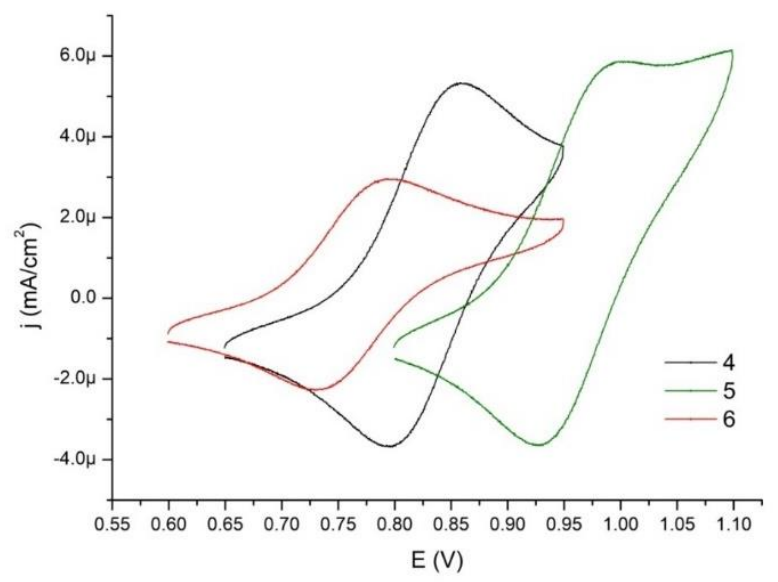

Figura 6.12. Voltamogramas cíclicos a $100 \mathrm{mV} / \mathrm{s}$ de una disolución $1 \mathrm{mM}$ de los complejos: 4 (negro), 5 (verde) y $\mathbf{6}$ (rojo) en AcN con $0.01 \mathrm{M}$ del electrolito TBAP. 


\section{Espectroscopía ESI-MS.}

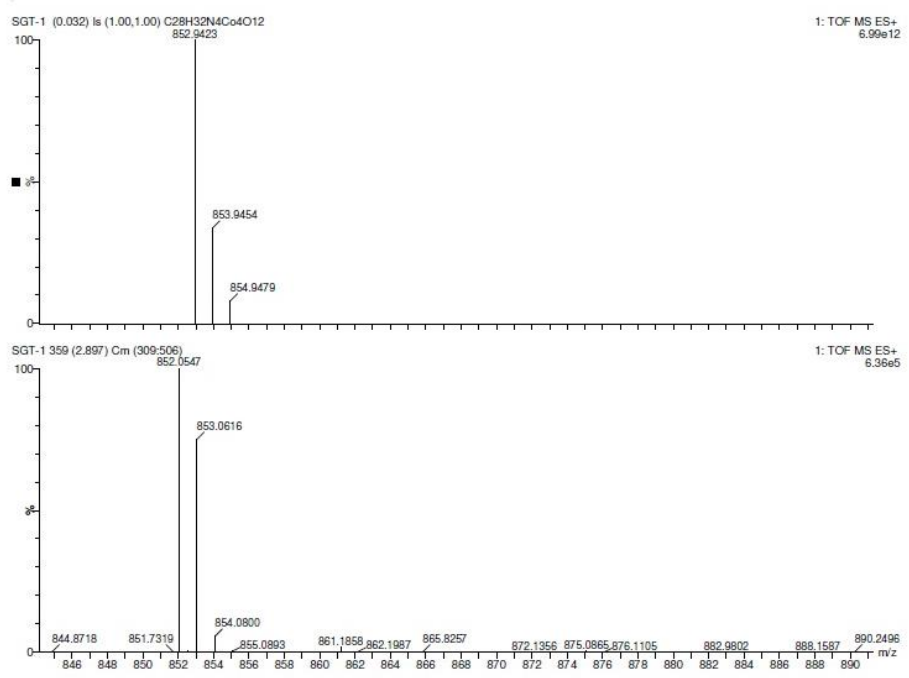

Figura 6.13. Espectro ESI del complejo 1, que corresponde con la fórmula $\mathrm{C}_{28} \mathrm{H}_{32} \mathrm{Co}_{4} \mathrm{~N}_{4} \mathrm{O}_{12}$.

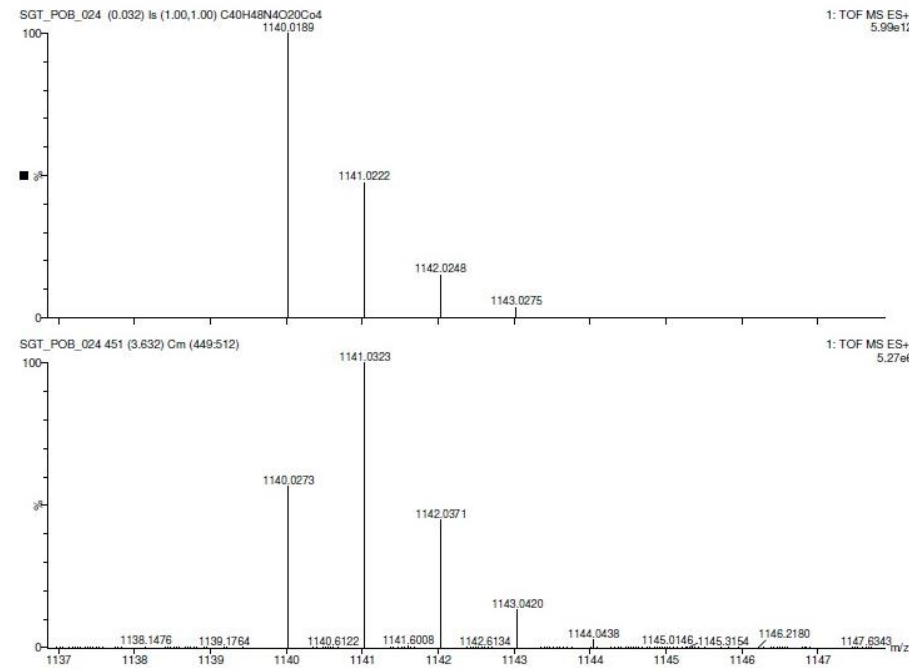

Figura 6.14. Espectro ESI del complejo 2, que corresponde con la fórmula $\mathrm{C}_{40} \mathrm{H}_{48} \mathrm{Co}_{4} \mathrm{~N}_{4} \mathrm{O}_{20}$. 


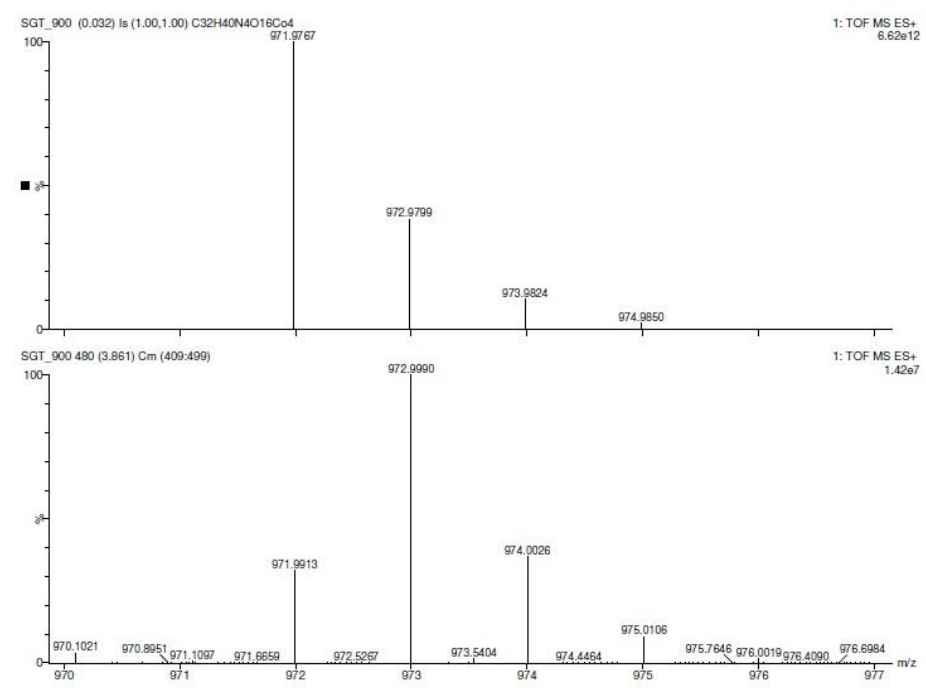

Figura 6.15. Espectro ESI del complejo 3, que corresponde con la fórmula $\mathrm{C}_{32} \mathrm{H}_{40} \mathrm{Co}_{4} \mathrm{~N}_{4} \mathrm{O}_{16}$.

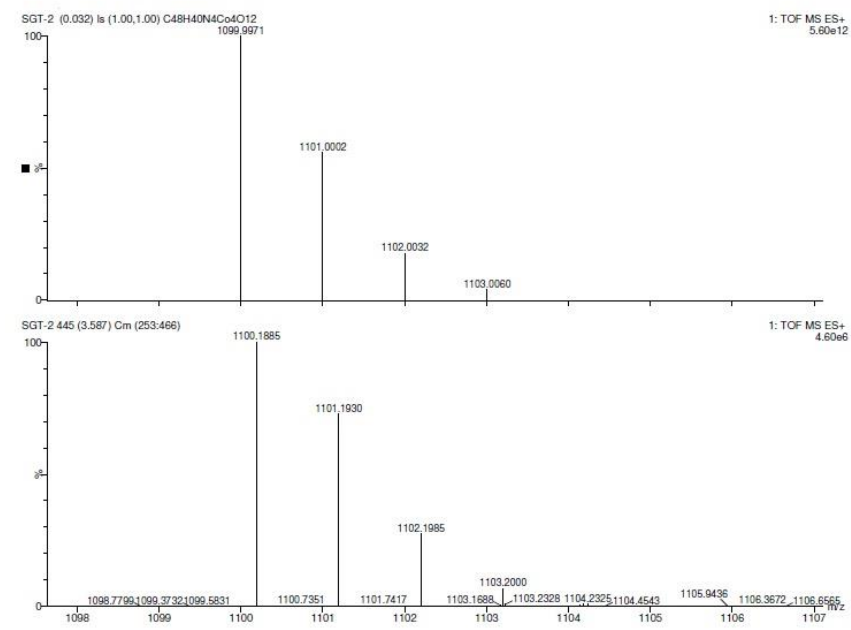

Figura 6.16. Espectro ESI del complejo 4, que corresponde con la fórmula $\mathrm{C}_{48} \mathrm{H}_{40} \mathrm{Co}_{4} \mathrm{~N}_{4} \mathrm{O}_{12}$. 


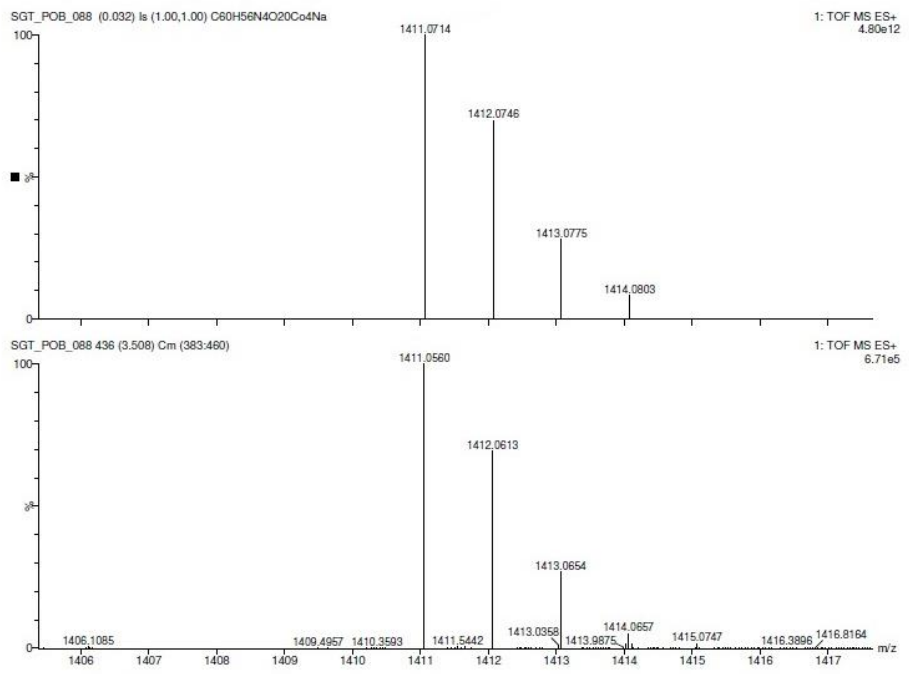

Figura 6.17. Espectro ESI del complejo 5, que corresponde con la fórmula $\mathrm{C}_{60} \mathrm{H}_{56} \mathrm{Co}_{4} \mathrm{~N}_{4} \mathrm{O}_{20}$.

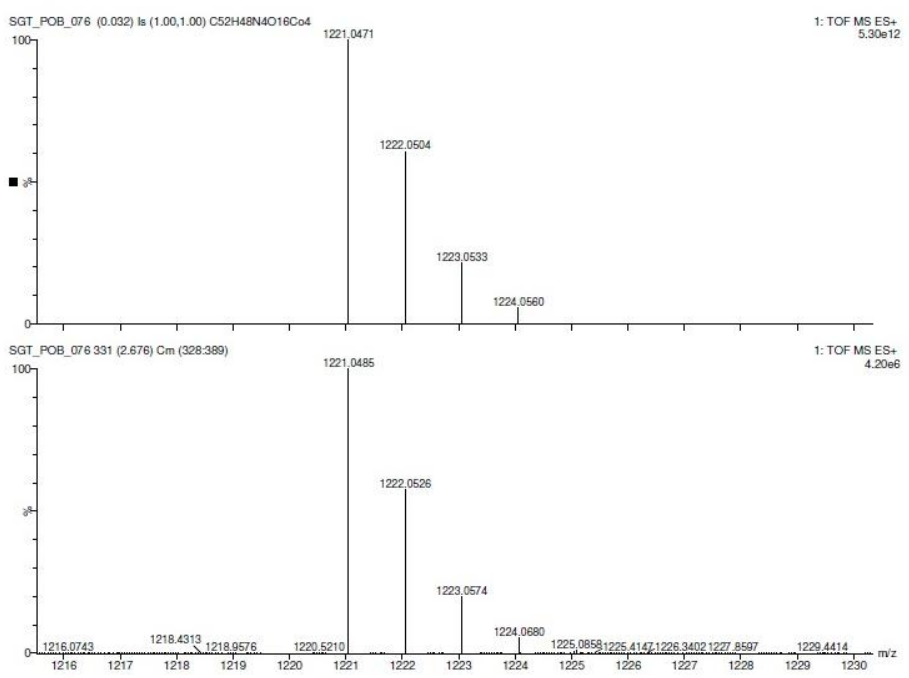

Figura 6.18. Espectro ESI del complejo 6, que corresponde con la fórmula $\mathrm{C}_{52} \mathrm{H}_{48} \mathrm{Co}_{4} \mathrm{~N}_{4} \mathrm{O}_{16}$. 


\section{Resonancia magnética nuclear (RMN)}
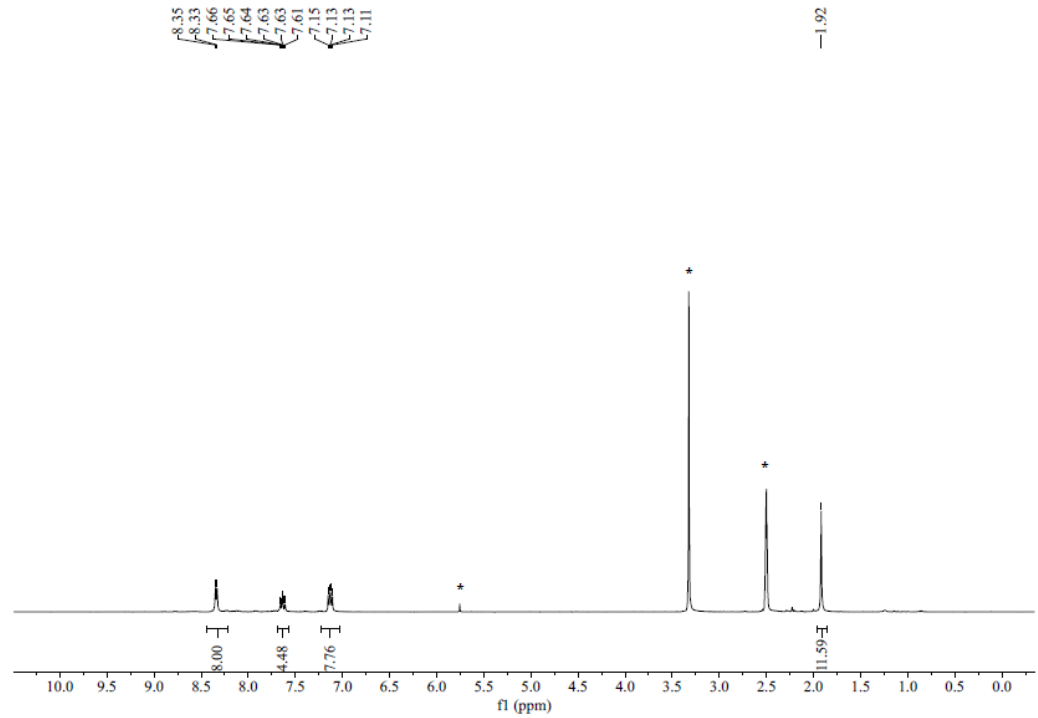

Figura 6.19. ${ }^{1} \mathrm{H}$ RMN del complejo 1. * señales del $\mathrm{CH}_{2} \mathrm{Cl}_{2}$, agua y DMSO- $\mathrm{d}_{6}$, respectivamente.

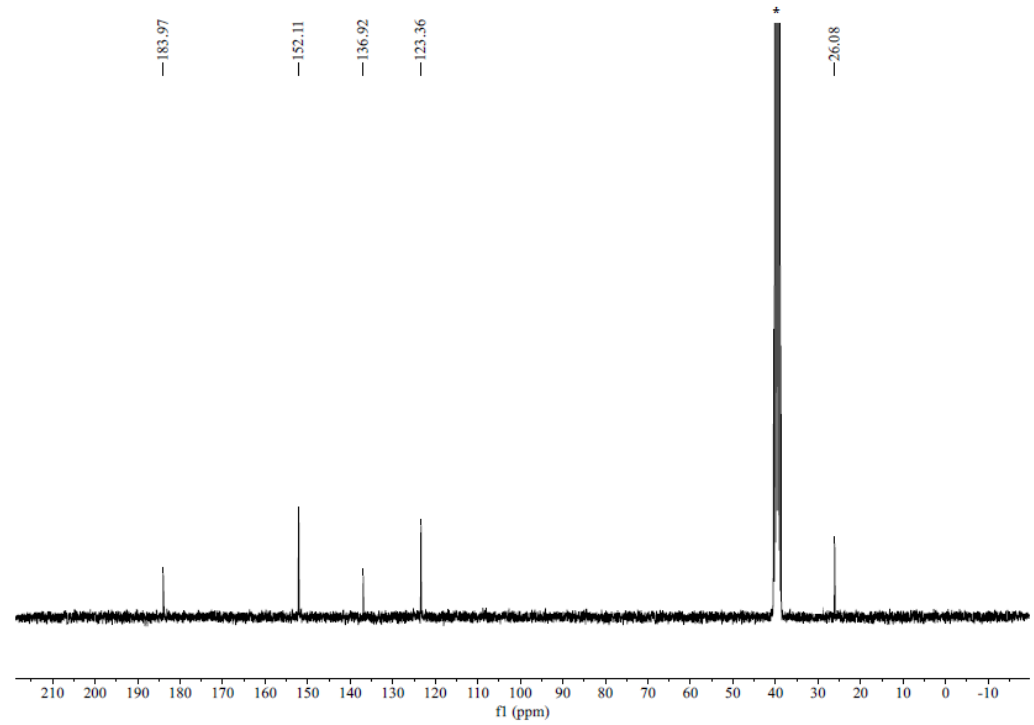

Figura 6.20. ${ }^{13} \mathrm{C}$ RMN del complejo 1. *Señal del DMSO-d 6 . 


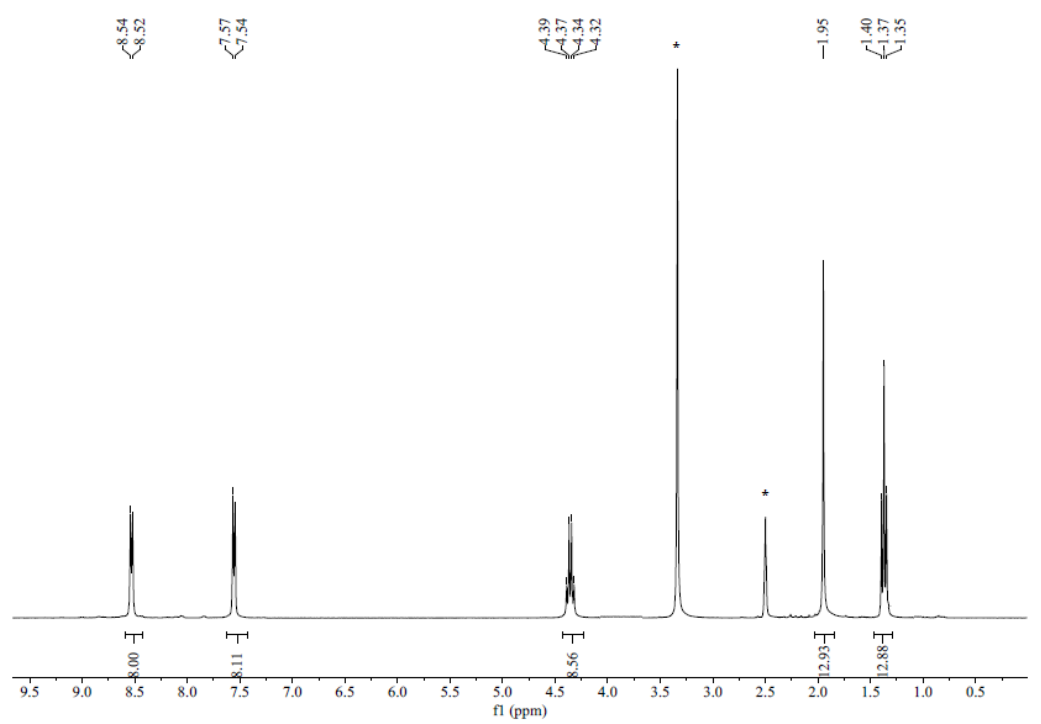

Figura 6.21. ${ }^{1} \mathrm{H}$ RMN del complejo 2. *Señales del $\mathrm{CH}_{2} \mathrm{Cl}_{2}$, agua y DMSO-d 6 , respectivamente.

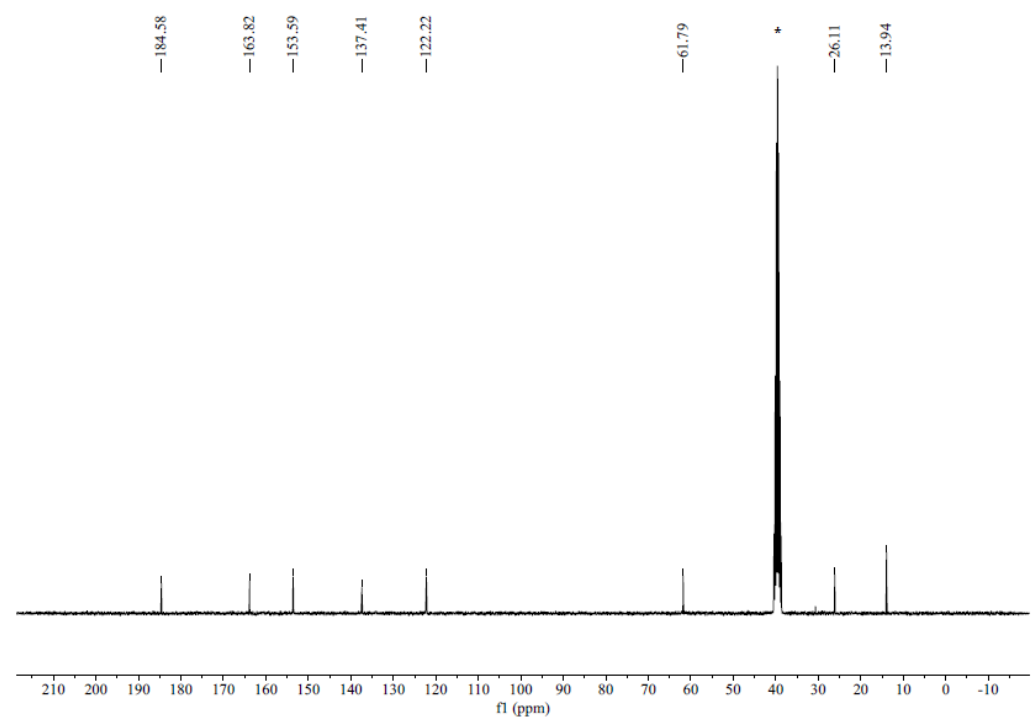

Figura 6.22. ${ }^{13} \mathrm{C}$ RMN del complejo 2. *Señal del DMSO-d 6 . 


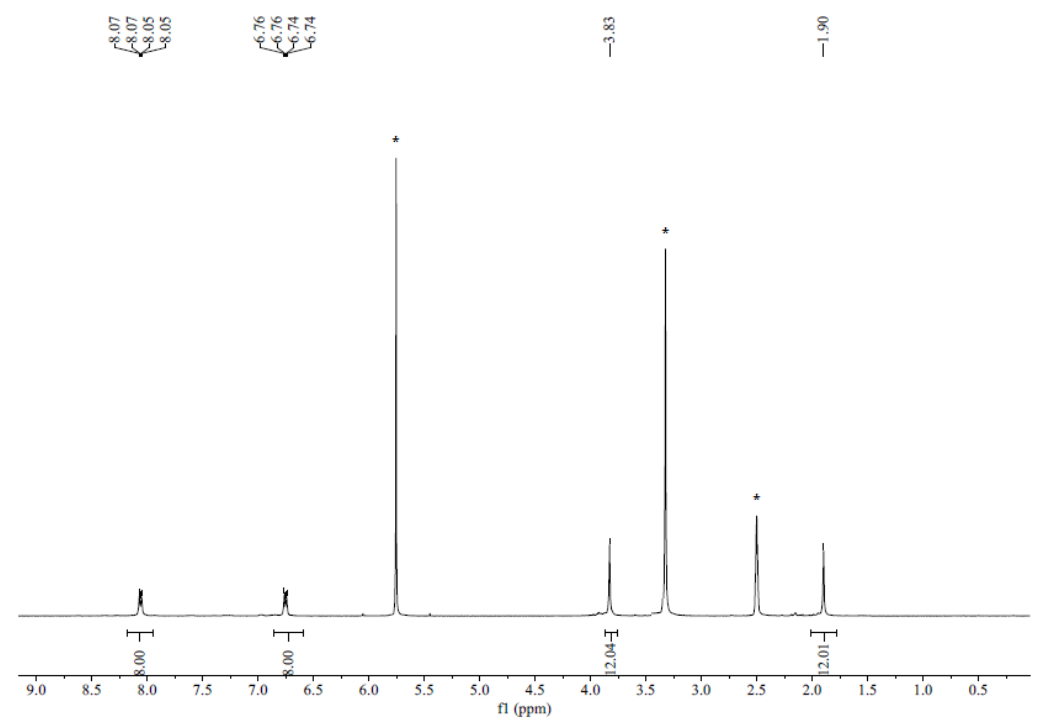

Figura 6.23. ${ }^{1} \mathrm{H}$ RMN del complejo 3. *Señales del $\mathrm{CH}_{2} \mathrm{Cl}_{2}$, agua y DMSO- $\mathrm{d}_{6}$, respectivamente.

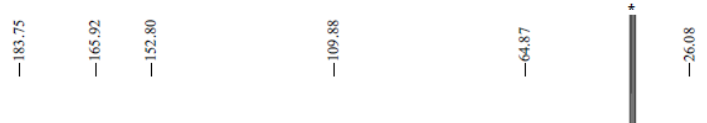
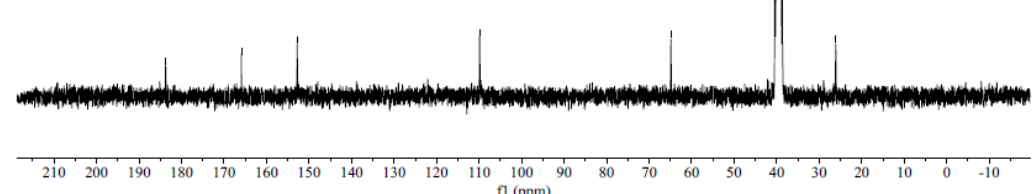

Figura 6.24. ${ }^{13} \mathrm{C}$ RMN del complejo 3. *Señal del DMSO-d 6 . 


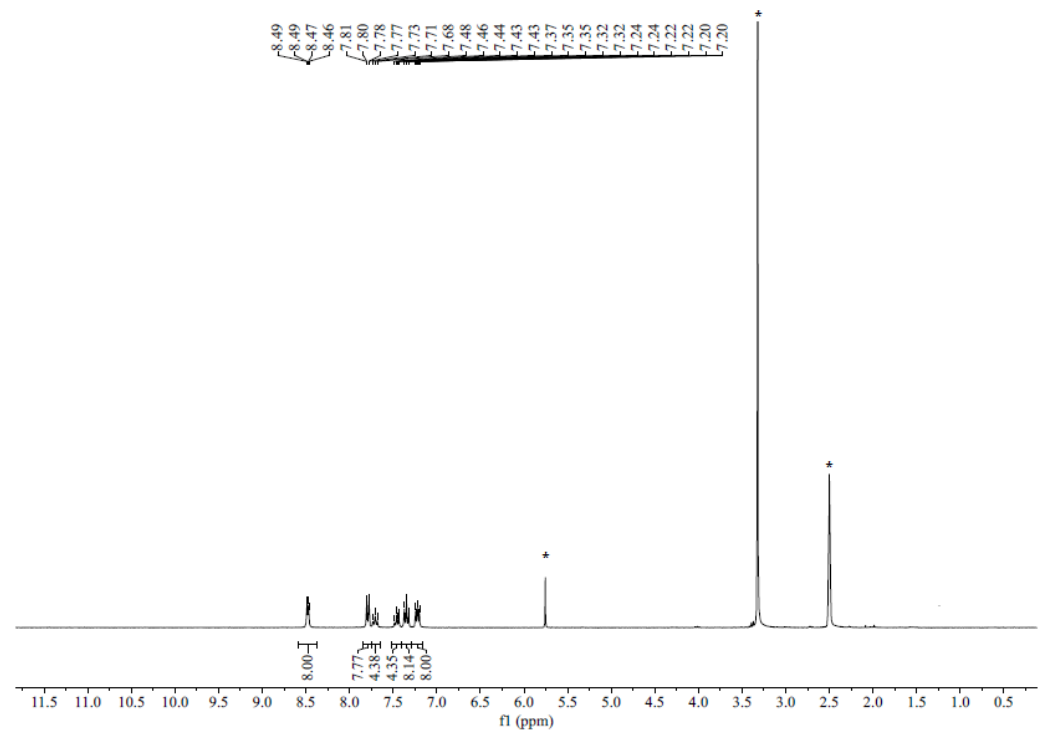

Figura 6.25. ${ }^{1} \mathrm{H}$ RMN del complejo 4. *Señales del $\mathrm{CH}_{2} \mathrm{Cl}_{2}$, agua y DMSO- $\mathrm{d}_{6}$, respectivamente.
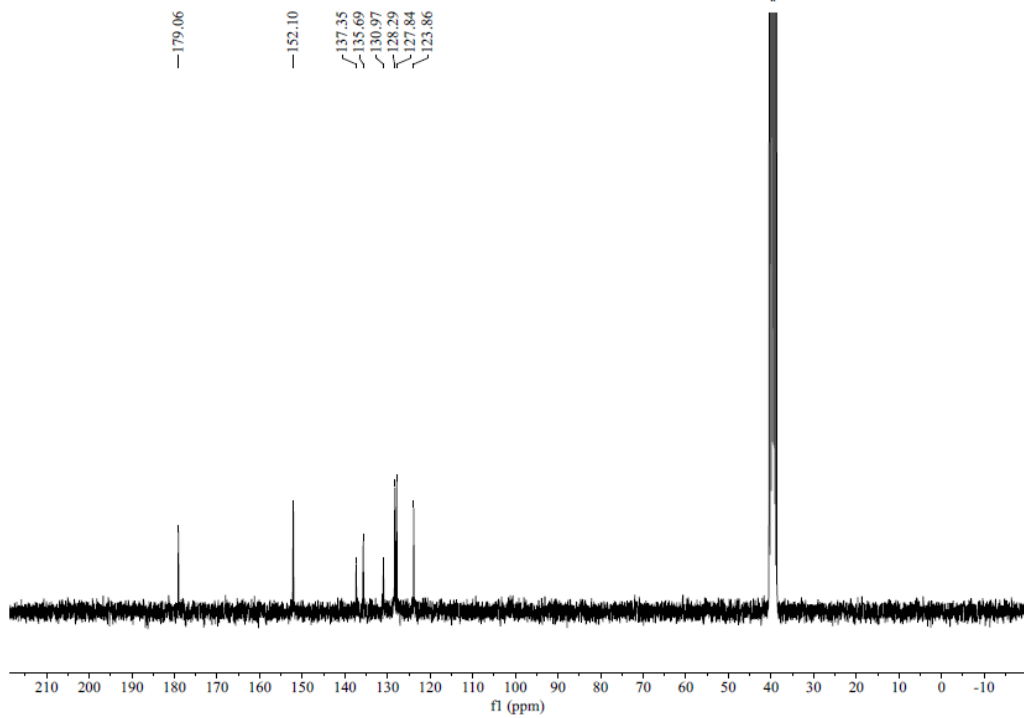

Figura 6.26. ${ }^{13} \mathrm{C}$ RMN del complejo 4. *Señal del DMSO-d 6 . 


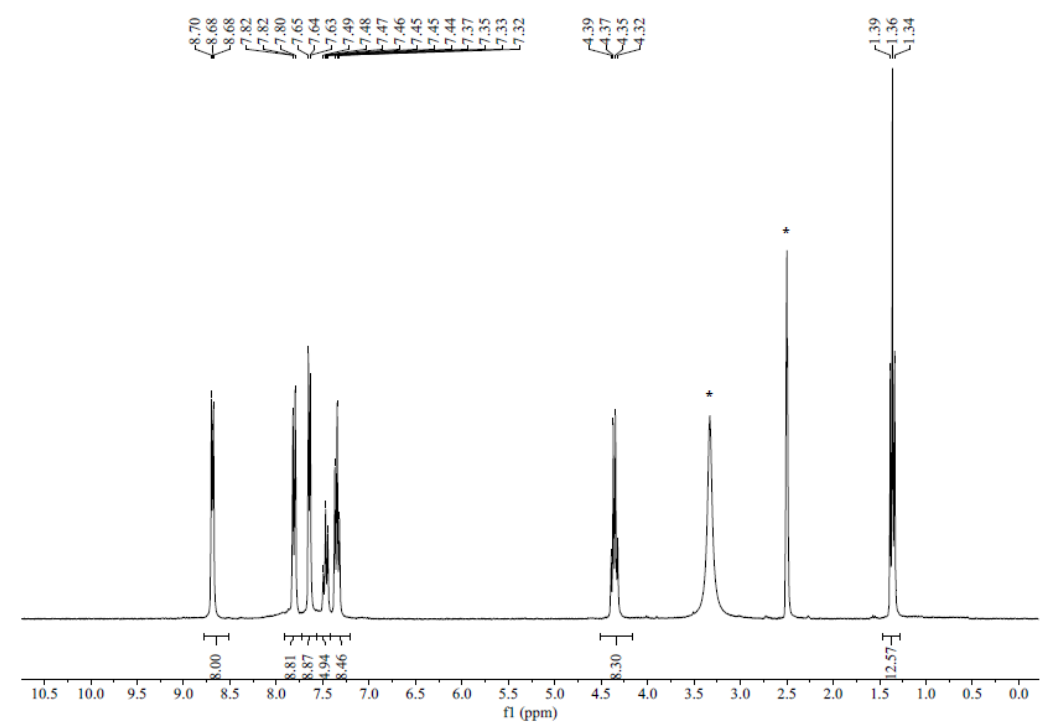

Figura 6.27. ${ }^{1} \mathrm{H}$ RMN del complejo 5. *Señales del $\mathrm{CH}_{2} \mathrm{Cl}_{2}$, agua y DMSO- $\mathrm{d}_{6}$, respectivamente.

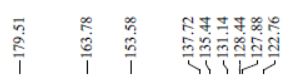
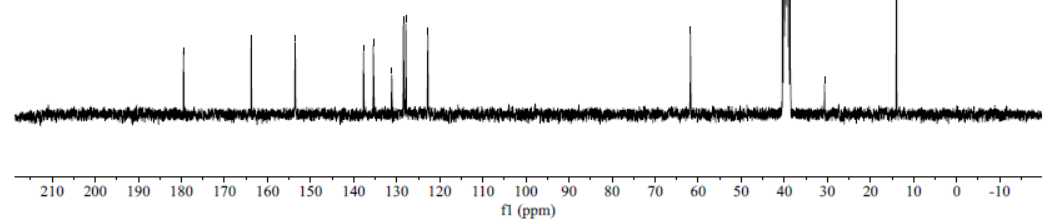

Figura 6.28. ${ }^{13} \mathrm{C}$ RMN del complejo 5. *Señal del DMSO-d 6 . 


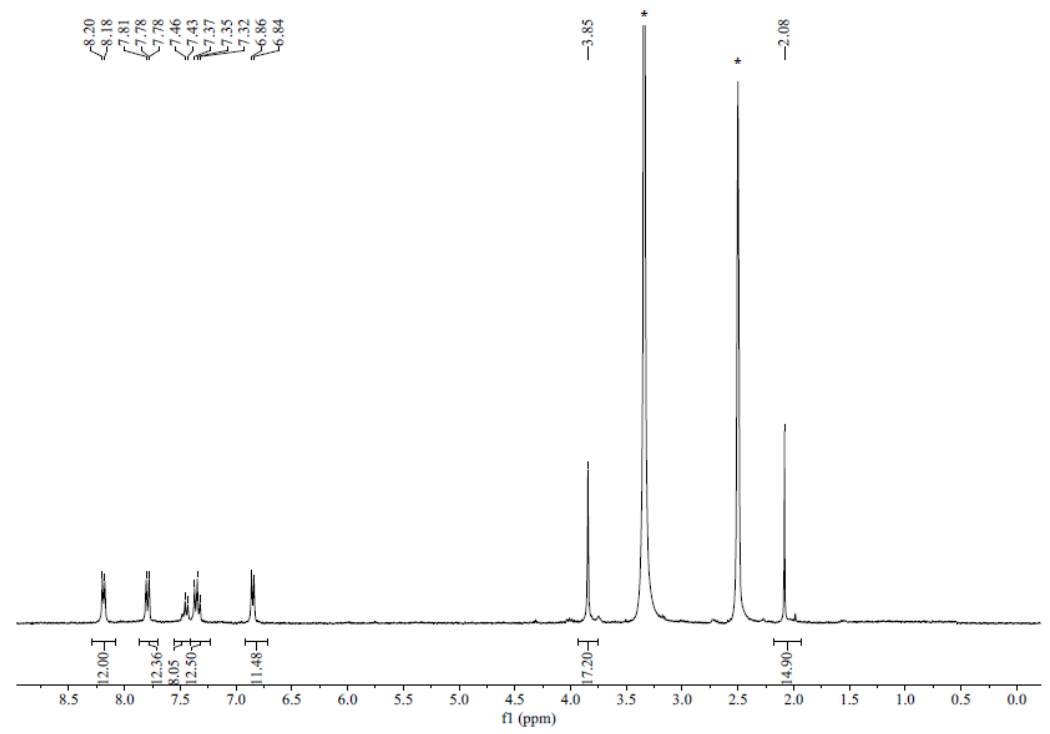

Figura 6.29. ${ }^{1} \mathrm{H}$ RMN del complejo 6. $*$ Señales del $\mathrm{CH}_{2} \mathrm{Cl}_{2}$, agua y DMSO-d $\mathrm{d}_{6}$, respectivamente

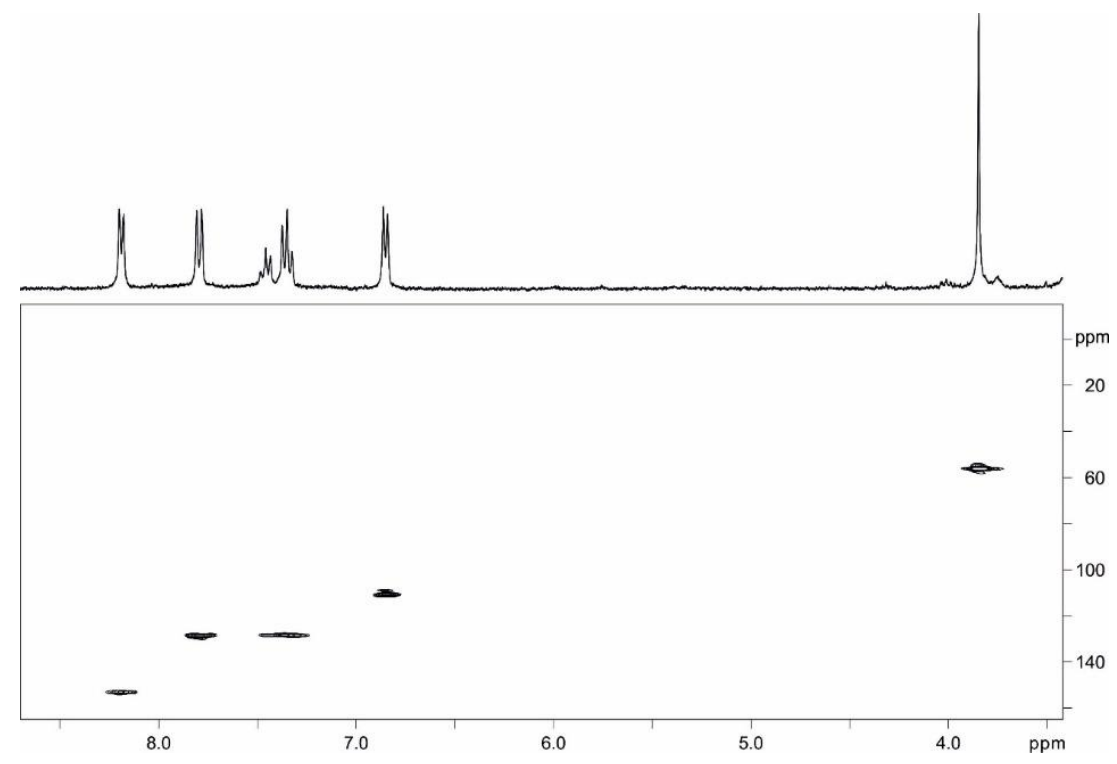

Figura 6.30. ${ }^{1} \mathrm{H},{ }^{13} \mathrm{C}$ gHMQC RMN del complejo 6. 


\subsubsection{Procedimiento experimental.}

\section{Oxidación de ciclohexano.}

Para la reacción de oxidación de ciclohexano se utilizó un reactor de $12 \mathrm{~mL}$ equipado con un agitador magnético, un manómetro, una sonda para sacar muestra y una sonda para la entrada y salida de gas. A este reactor se le añade la cantidad correspondiente de catalizador (\% mol de cobalto) seguido de $3 \mathrm{~g}$ de ciclohexano. Se purga varias veces con $\mathrm{N}_{2}$ para eliminar el oxígeno y se presuriza a 4 bar con $\mathrm{N}_{2}$. El reactor se calienta hasta $130^{\circ} \mathrm{C}$ en una placa calefactora. La presión total de la reacción a la temperatura de reacción $\left(130^{\circ} \mathrm{C}\right)$ es de 6 bares. En este momento (tiempo $\left.=0 \mathrm{~h}\right)$, se burbujea a través de la mezcla de reacción una mezcla de aire empobrecido $\left(\mathrm{N}_{2}: \mathrm{O}_{2}\right.$ 95:5), manteniendo la presión total constante a 6 bares con un controlador de presión. Para estudiar la cinética de reacción, se extraen alícuotas de muestra $(25 \mu \mathrm{l})$ a diferentes tiempos y se introducen en viales previamente preparados con $1 \mathrm{~mL}$ de acetona, $10 \mu \mathrm{l}$ de dodecano como patrón interno y $100 \mu \mathrm{L}$ de trifenilfosfina (TFF) para descomponer el CHHP formado en la reacción (TFF $10 \%$ en acetona). Una vez introducida la alícuota de muestra en el vial, se agita en un vortex para analizarla mediante cromatografía de gases. Para analizar la formación de ácido adípico y otros subproductos, se toma una muestra $(25 \mu \mathrm{l})$ y se añaden $100 \mu \mathrm{l}$ de trifluoruro de boro en metanol (10\%). Esta mezcla se calienta a $90^{\circ} \mathrm{C}$ durante 2 horas. Pasado este tiempo, se deja enfriar y se añade $1 \mathrm{~mL}$ de agua destilada y se agita vigorosamente. A continuación, se añade $1 \mathrm{~mL}$ de diclorometano y se analiza la fase orgánica por GC.

\section{Descomposición de ciclohexil hidroperóxido (CHHP).}

En el mismo reactor que la reacción de oxidación de ciclohexano, se añaden $3 \mathrm{~g}$ de una mezcla que contiene CHHP ( $3 \%$ mol) en ciclohexano y la cantidad correspondiente de catalizador. Se purga varias veces con $\mathrm{N}_{2}$ y el reactor se presuriza a 5 bares con dicho gas. Finalmente, el reactor se calienta a $100^{\circ} \mathrm{C}$ en una placa calefactora. Se toman muestras a diferentes tiempos para estudiar la cinética de la reacción, las cuales se analizan siguiendo el mismo procedimiento que para la cuantificación de CHHP en el caso anterior. 


\subsubsection{Resultados catalíticos para la oxidación de ciclohexano.}

Tabla 6.8. Resumen de la actividad catalítica (conversión y distribución de productos) de los catalizadores de cobalto para la oxidación de ciclohexano. Condiciones de reacción: $3 \mathrm{~g}$ de ciclohexano ( $36 \mathrm{mmol}), 0.14 \mathrm{ppm}$ de $\mathrm{Co}, 130^{\circ} \mathrm{C}, 6$ bar $\left(\mathrm{N}_{2}: \mathrm{O}_{2}=95: 5\right), \mathrm{Q}=10 \mathrm{ml} / \mathrm{min}$. [a] A = alcohol, ciclohexanol; $[\mathrm{b}] \mathrm{K}=$ cetona, ciclohexanona; $[\mathrm{c}] \mathrm{CHHP}=$ ciclohexil hidroperoxido; [d] AA = ácido adipico; [e] Selectividad total observada $(\mathrm{A}+\mathrm{K}+\mathrm{CHHP}+$ AA).

\section{BLANCO.}

\begin{tabular}{|c|c|c|c|c|c|c|}
\hline Tiempo de & Conversión & \multicolumn{5}{|c|}{ Selectividad (\%) } \\
\cline { 3 - 7 } reacción (h) & $(\boldsymbol{\%})$ & $\mathbf{A}^{\mathrm{a}}$ & $\mathbf{K}^{\mathrm{b}}$ & $\mathbf{C H H P}^{\mathrm{c}}$ & $\mathbf{A A}^{\mathrm{d}}$ & Total $^{\mathrm{e}}$ \\
\hline 2 & 0.1 & 1 & 2 & 97 & 0 & 100 \\
\hline 4 & 0.2 & 30 & 12 & 58 & 0 & 100 \\
\hline 6 & 0.4 & 25 & 6 & 58 & 1 & 90 \\
\hline 7 & 0.6 & 20 & 10 & 58 & 1 & 89 \\
\hline 8 & 0.8 & 30 & 15 & 54 & 1 & 100 \\
\hline
\end{tabular}

$\operatorname{Co}(\mathrm{OAc})_{2}$.

\begin{tabular}{|c|c|c|c|c|c|c|}
\hline Tiempo de & Conversión & \multicolumn{5}{|c|}{ Selectividad (\%) } \\
\cline { 3 - 7 } reacción (h) & $(\boldsymbol{\%})$ & $\mathbf{A}^{\mathrm{a}}$ & $\mathbf{K}^{\mathrm{b}}$ & $\mathbf{C H H P}^{\mathrm{c}}$ & $\mathbf{A A}^{\mathrm{d}}$ & Total $^{\mathrm{e}}$ \\
\hline 2 & 0.9 & 10 & 15 & 74 & 0 & 99 \\
\hline 4 & 4.8 & 31 & 37 & 28 & 0 & 96 \\
\hline 7 & 6.1 & 41 & 52 & 2 & 1 & 96 \\
\hline 8 & 7.7 & 30 & 53 & 5 & 5 & 93 \\
\hline
\end{tabular}

\section{Clúster 1.}

\begin{tabular}{|c|c|c|c|c|c|c|}
\hline Tiempo de & Conversión & \multicolumn{5}{|c|}{ Selectividad (\%) } \\
\cline { 3 - 7 } reacción (h) & $(\boldsymbol{\%})$ & $\mathbf{A}^{\mathrm{a}}$ & $\mathbf{K}^{\mathrm{b}}$ & $\mathbf{C H H P}^{\mathrm{c}}$ & $\mathbf{A A}^{\mathrm{d}}$ & Total $^{\mathrm{e}}$ \\
\hline 2 & 0.6 & 26 & 10 & 63 & 0 & 100 \\
\hline 4 & 2.3 & 43 & 14 & 38 & 1 & 97 \\
\hline 6 & 8.0 & 53 & 25 & 17 & 1 & 96 \\
\hline 7 & 9.9 & 55 & 27 & 12 & 1 & 95 \\
\hline 8 & 10.9 & 54 & 29 & 10 & 2 & 94 \\
\hline
\end{tabular}




\section{Clúster 2.}

\begin{tabular}{|c|c|c|c|c|c|c|}
\hline Tiempo de & Conversión & \multicolumn{5}{|c|}{ Selectividad (\%) } \\
\cline { 3 - 7 } reacción (h) & $(\boldsymbol{\%})$ & $\mathbf{A}^{\mathrm{a}}$ & $\mathbf{K}^{\mathrm{b}}$ & $\mathbf{C H H P}^{\mathbf{c}}$ & $\mathbf{A A}^{\mathrm{d}}$ & $\mathbf{T o t a l}^{\mathrm{e}}$ \\
\hline 2 & 1.0 & 22 & 13 & 65 & 0 & 100 \\
\hline 4 & 2.8 & 32 & 18 & 49 & 1 & 99 \\
\hline 6 & 7.1 & 37 & 27 & 28 & 2 & 94 \\
\hline 7 & 10.5 & 35 & 32 & 22 & 3 & 91 \\
\hline 8 & 12.2 & 35 & 36 & 14 & 3 & 88 \\
\hline
\end{tabular}

Clúster 3.

\begin{tabular}{|c|c|c|c|c|c|c|}
\hline Tiempo de & Conversión & \multicolumn{5}{|c|}{ Selectividad (\%) } \\
\cline { 3 - 7 } reacción (h) & $(\boldsymbol{\%})$ & $\mathbf{A}^{\mathbf{a}}$ & $\mathbf{K}^{\mathrm{b}}$ & $\mathbf{C H H P}^{\mathbf{c}}$ & $\mathbf{A A}^{\mathrm{d}}$ & $\mathbf{T o t a l}^{\mathrm{e}}$ \\
\hline 2 & 0.4 & 17 & 18 & 65 & 0 & 100 \\
\hline 4 & 1.9 & 33 & 20 & 46 & 1 & 99 \\
\hline 6 & 4.6 & 44 & 30 & 20 & 5 & 98 \\
\hline 7 & 6.3 & 49 & 34 & 8 & 6 & 98 \\
\hline 8 & 7.5 & 50 & 38 & 6 & 5 & 99 \\
\hline
\end{tabular}

\section{Clúster 4.}

\begin{tabular}{|c|c|c|c|c|c|c|}
\hline Tiempo de & Conversión & \multicolumn{5}{|c|}{ Selectividad (\%) } \\
\cline { 3 - 7 } reacción (h) & $(\boldsymbol{\%})$ & $\mathbf{A}^{\mathrm{a}}$ & $\mathbf{K}^{\mathrm{b}}$ & $\mathbf{C H H P}^{\mathbf{c}}$ & $\mathbf{A A}^{\mathrm{d}}$ & Total $^{\mathrm{e}}$ \\
\hline 2 & 0.9 & 19 & 14 & 67 & 0 & 100 \\
\hline 4 & 5.7 & 49 & 23 & 21 & 0 & 93 \\
\hline 6 & 9.5 & 49 & 29 & 11 & 8 & 97 \\
\hline 7 & 11.1 & 46 & 28 & 9 & 6 & 89 \\
\hline 8 & 12.2 & 44 & 29 & 7 & 6 & 86 \\
\hline
\end{tabular}




\section{Clúster 5.}

\begin{tabular}{|c|c|c|c|c|c|c|}
\hline Tiempo de & Conversión & \multicolumn{5}{|c|}{ Selectividad (\%) } \\
\cline { 4 - 7 } reacción (h) & $(\boldsymbol{\%})$ & $\mathbf{A}^{\mathrm{a}}$ & $\mathbf{K}^{\mathrm{b}}$ & $\mathbf{C H H P}^{\mathrm{c}}$ & $\mathbf{A A}^{\mathrm{d}}$ & Total $^{\mathrm{e}}$ \\
\hline 2 & 2.6 & 14 & 8 & 77 & 0 & 99 \\
\hline 4 & 6.1 & 38 & 25 & 31 & 1 & 96 \\
\hline 6 & 10.6 & 44 & 38 & 11 & 2 & 95 \\
\hline 7 & 12.9 & 42 & 42 & 9 & 2 & 95 \\
\hline 8 & 14.2 & 37 & 44 & 8 & 3 & 92 \\
\hline
\end{tabular}

\section{Clúster 6.}

\begin{tabular}{|c|c|c|c|c|c|c|}
\hline Tiempo de & Conversión & \multicolumn{5}{|c|}{ Selectividad (\%) } \\
\cline { 3 - 7 } reacción (h) & $(\boldsymbol{\%})$ & $\mathbf{A}^{\mathrm{a}}$ & $\mathbf{K}^{\mathrm{b}}$ & $\mathbf{C H H P}^{\mathrm{c}}$ & $\mathbf{A A}^{\mathrm{d}}$ & Total $^{\mathrm{e}}$ \\
\hline 2 & 0.7 & 0 & 13 & 87 & 0 & 100 \\
\hline 4 & 2.4 & 10 & 20 & 64 & 2 & 97 \\
\hline 6 & 7.8 & 27 & 37 & 23 & 3 & 89 \\
\hline 7 & 9.6 & 34 & 45 & 13 & 4 & 96 \\
\hline 8 & 11.1 & 32 & 53 & 9 & 5 & 99 \\
\hline
\end{tabular}

\subsubsection{Estudio del mecanismo de reacción.}

\subsubsection{Resonancia paramagnética electrónica.}

Para los experimentos de EPR, se preparan varias disoluciones siguiendo el siguiente procedimiento. Se mide el DMPO en ciclohexano (1\% p/p), el ciclohexil hidroperóxido en ciclohexano, y una mezcla de las dos disoluciones anteriores. Estos serán los blancos con los que se comparen los espectros de la reacción. A continuación, se prepara una disolución para cada catalizador de la siguiente forma: a $100 \mu \mathrm{L}$ de CHHP en ciclohexano se le añaden $200 \mu \mathrm{L}$ de una disolución del catalizador $(1 \mathrm{mg} / 5 \mathrm{~mL}$ de ciclohexano) y se agita durante $5 \mathrm{~min}$. A continuación, se añaden $100 \mu \mathrm{L}$ de la disolución de DMPO en ciclohexano. Todas las disoluciones se purgan con Ar antes de la medida de EPR. 


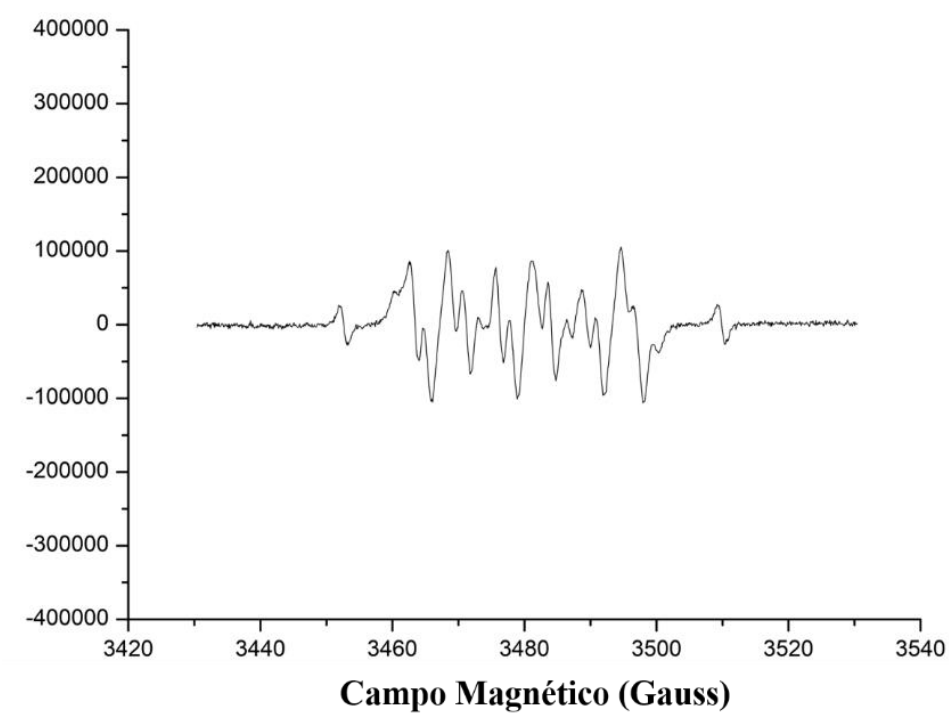

Figura 6.31. Espectro EPR del experimento de atrapamiento de spin con el catalizador 1.

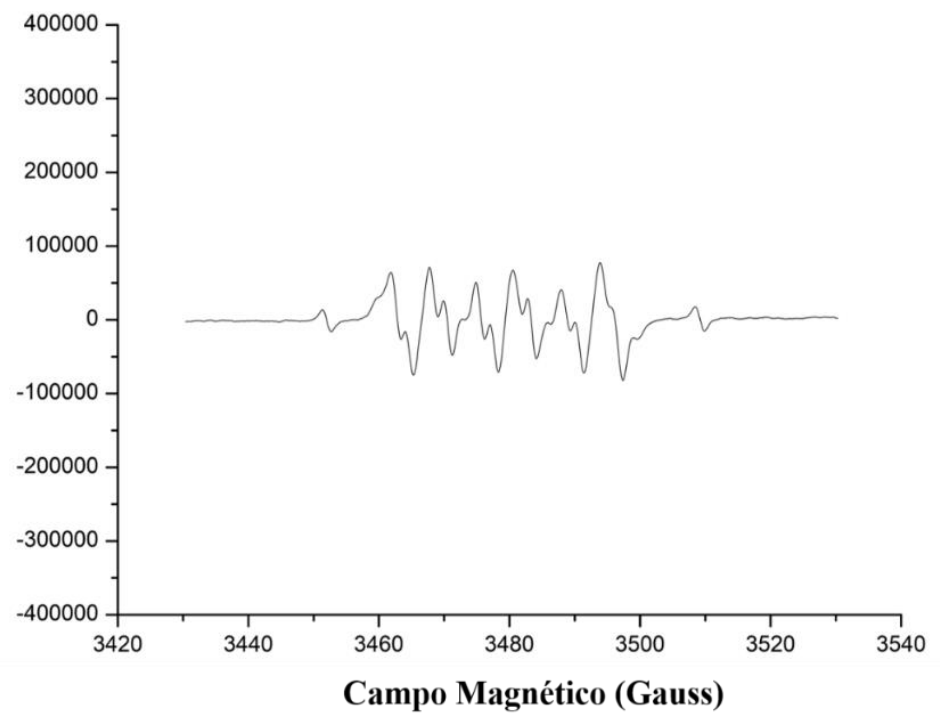

Figura 6.32. Espectro EPR del experimento de atrapamiento de spin con el catalizador 2. 


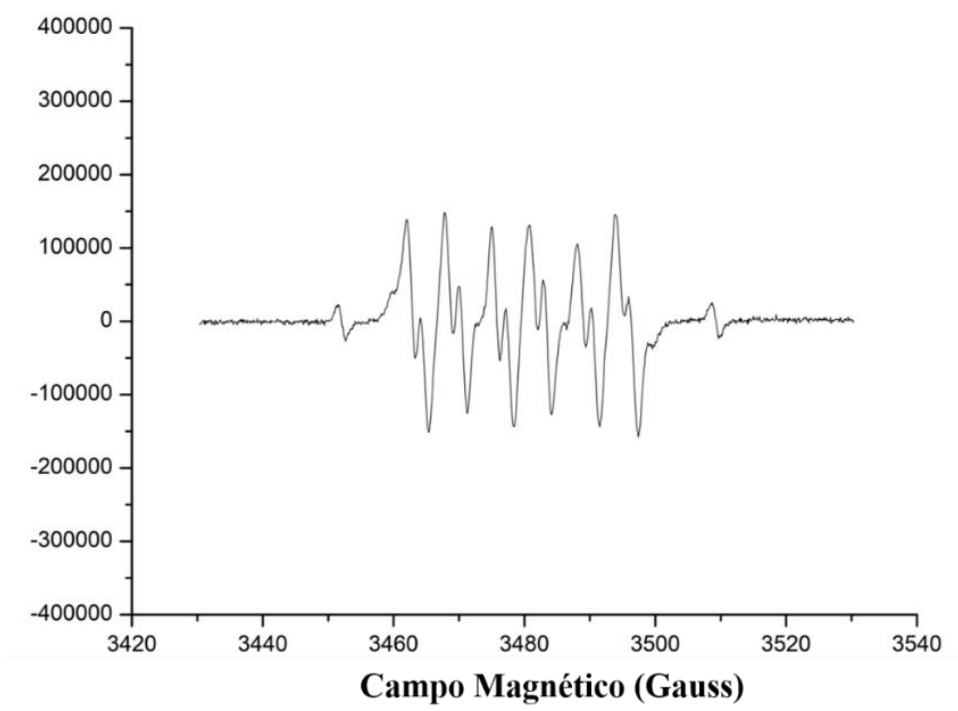

Figura 6.33. Espectro EPR del experimento de atrapamiento de spin con el catalizador 3 .

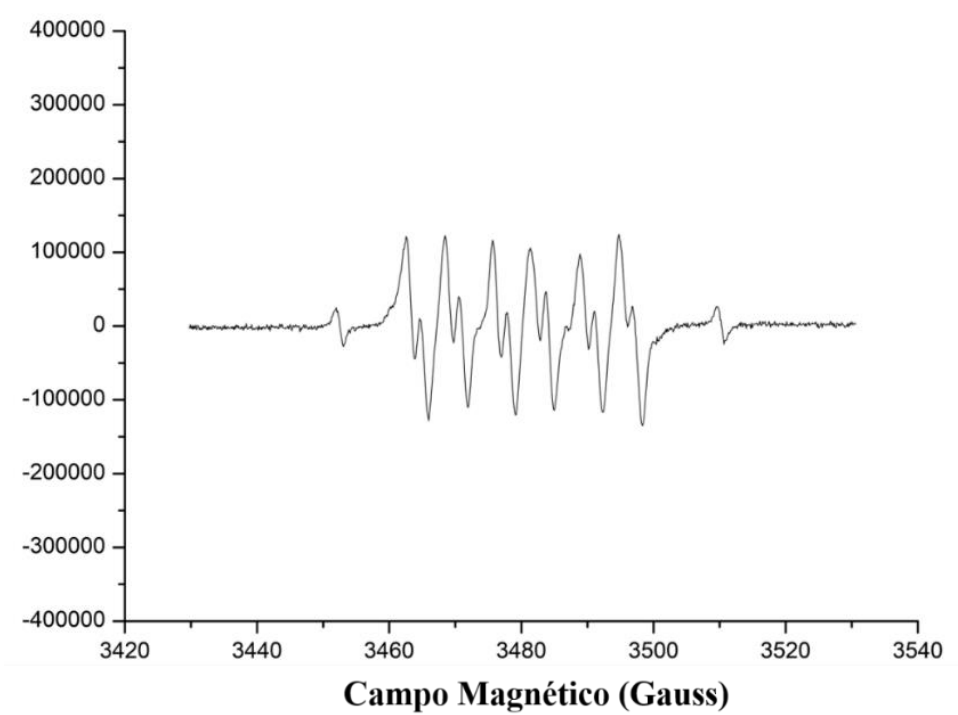

Figura 6.34. Espectro EPR del experimento de atrapamiento de spin con el catalizador 4. 


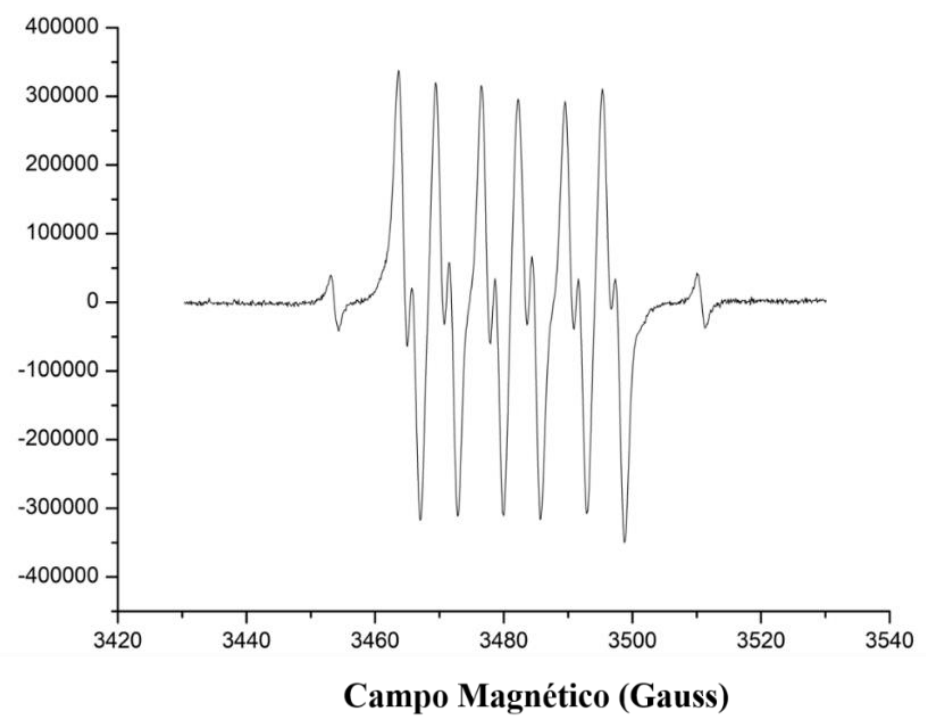

Figura 6.35. Espectro EPR del experimento de atrapamiento de spin con el catalizador 5.

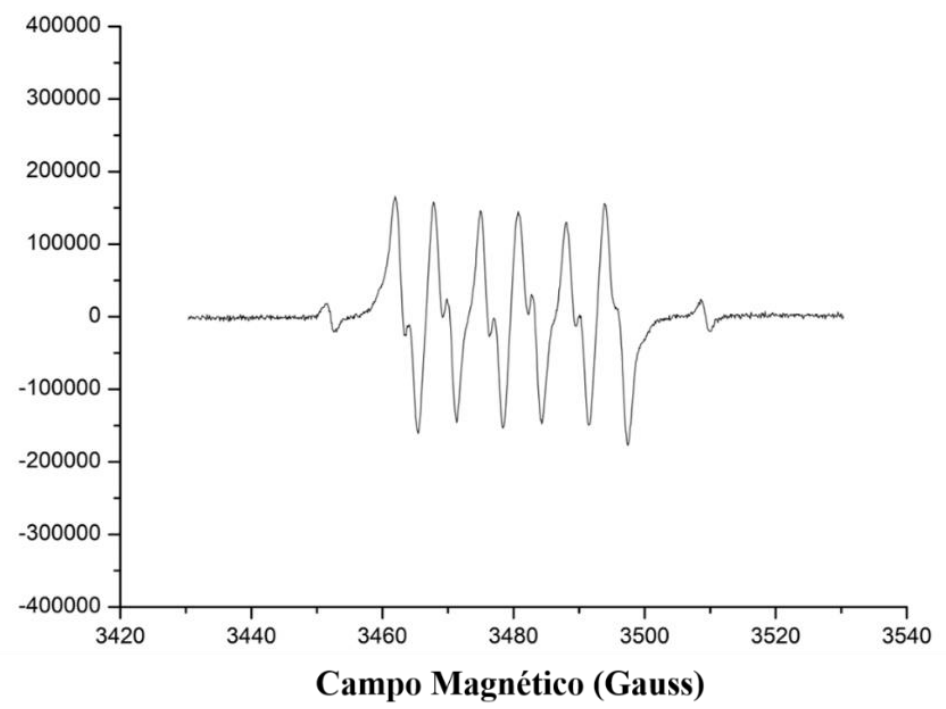

Figura 6.36. Espectro EPR del experimento de atrapamiento de spin con el catalizador 6. 
6.5.5.2. Cálculo de la eficiencia para la reacción de transferencia de oxígeno desde el CHHP al ciclohexano.

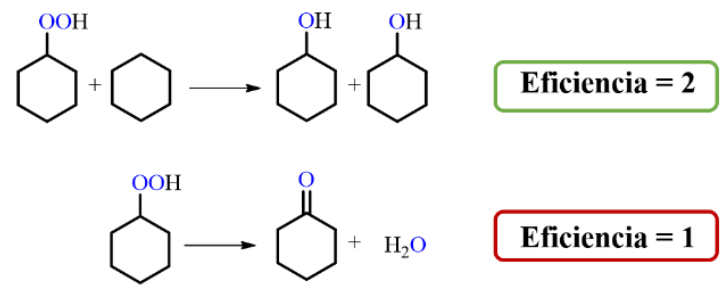

$$
\text { Eficiencia }=\frac{[\text { mol } A+\text { mol K }] \text { formados }}{[\text { mol CHHP }] \text { convertidos }}
$$

Esquema 6.7. Descomposición del CHHP y cálculo de la eficiencia de la reacción.

6.5.5.3. Espectroscopía Raman in-situ.

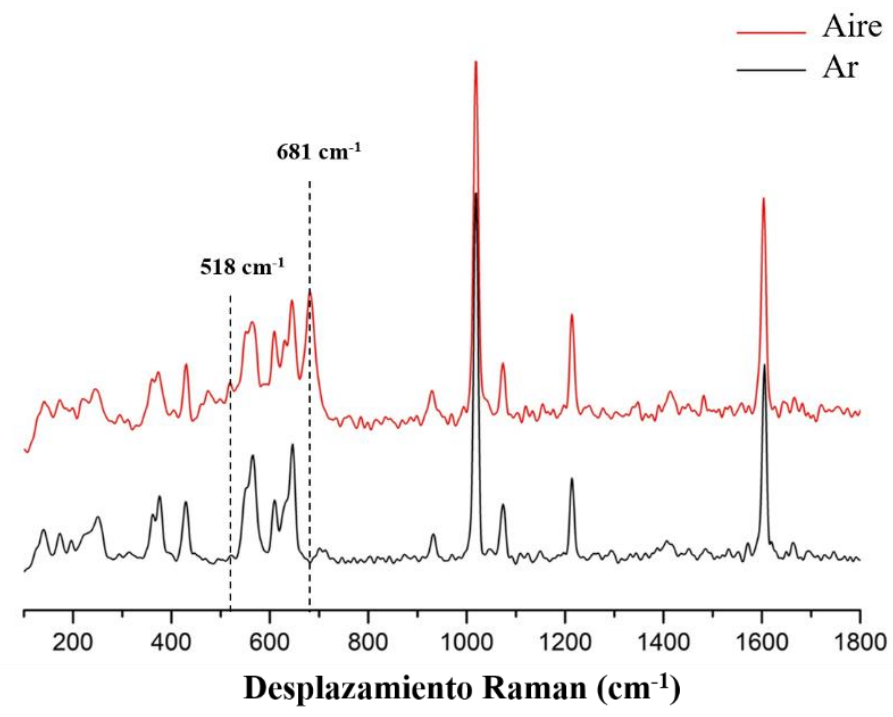

Figura 6.37. Espectro Raman del complejo $\mathbf{1}$ en argón (negro) y pasando un flujo de $\mathrm{O}_{2}$ (rojo). 


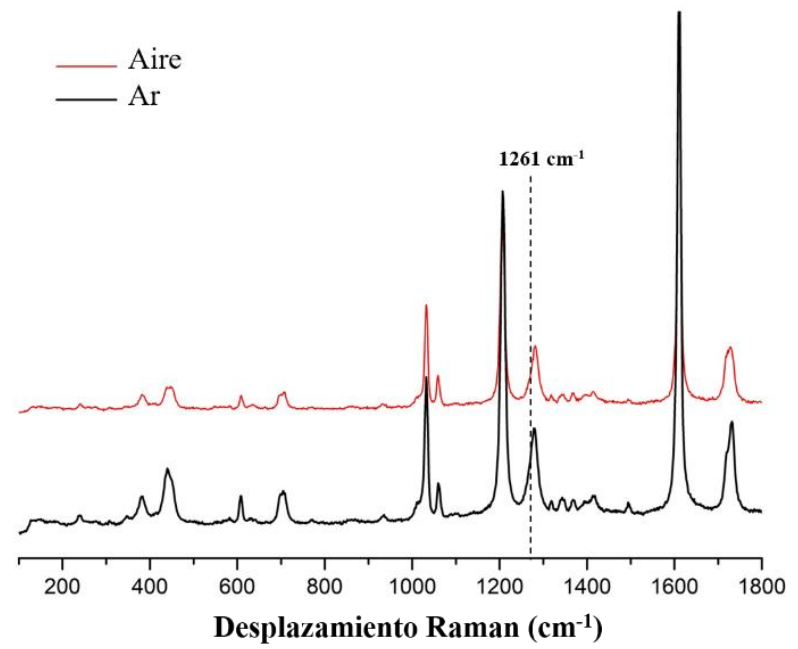

Figura 6.38. Espectro Raman del complejo 2 en argón (negro) y pasando un flujo de $\mathrm{O}_{2}$ (rojo).

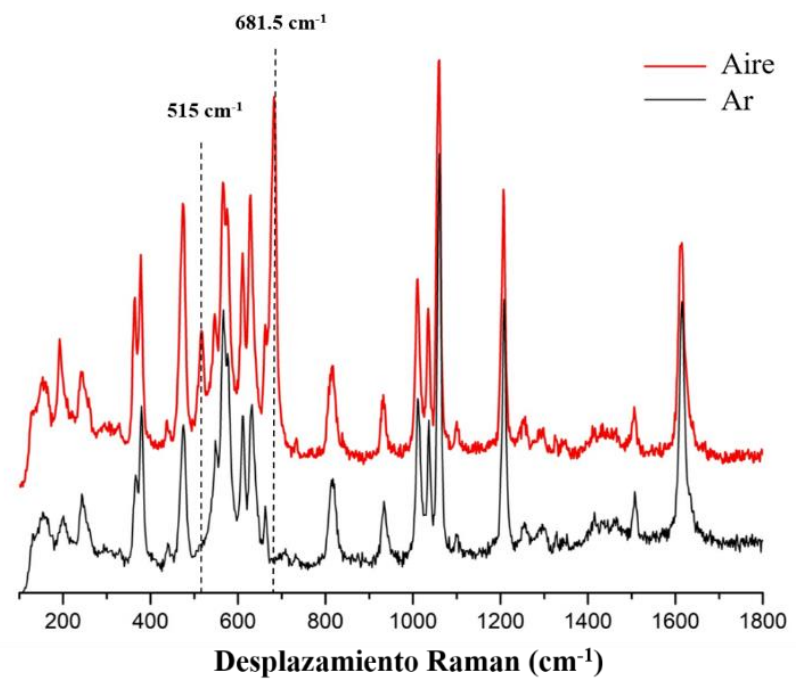

Figura 6.39. Espectro Raman del complejo 3 en argón (negro) y pasando un flujo de $\mathrm{O}_{2}$ (rojo). 


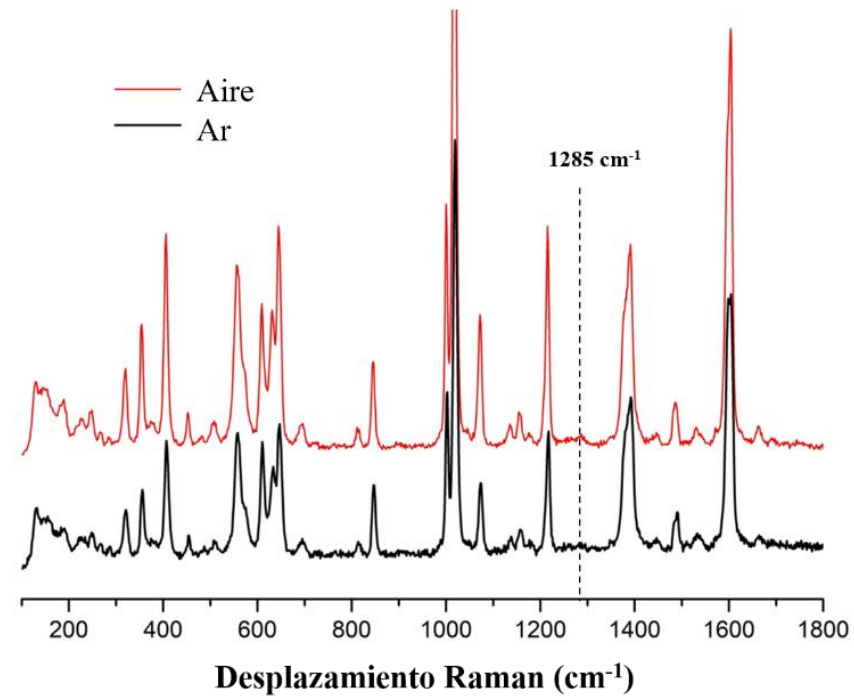

Figura 6.40. Espectro Raman del complejo 4 en argón (negro) y pasando un flujo de $\mathrm{O}_{2}$ (rojo).

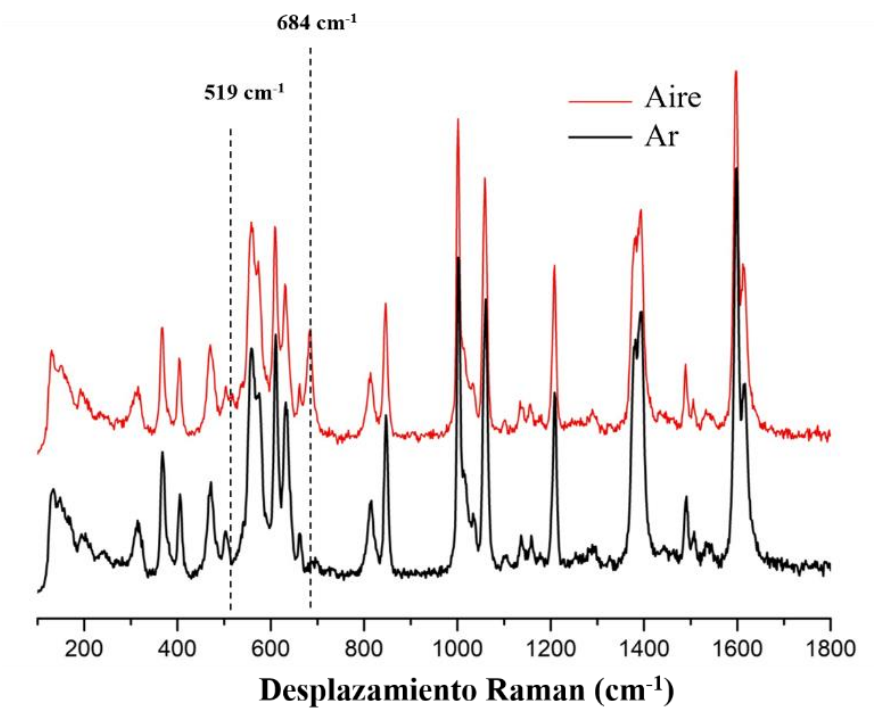

Figura 6.41. Espectro Raman del complejo 6 en argón (negro) y pasando un flujo de $\mathrm{O}_{2}$ (rojo). 


\subsection{Bibliografía}

(1) Henríquez, A.; Mansilla, H. D.; Martínez-de la Cruz, A. M.; Freer, J.; Contreras, D., Selective oxofunctionalization of cyclohexane over titanium dioxide-based and bismuth oxyhalide ( $\mathrm{BiOX}, \mathrm{X}=\mathrm{Cl}^{-}, \mathrm{Br}^{-}, \mathrm{I}^{-}$) photocatalysts by visible light irradiation, Appl. Catal. B: Environ., 2017, 206, 252-262.

(2) de Ruiter, G.; Carsch, K. M.; Gul, S.; Chatterjee, R.; Thompson, N. B.; Takase, M. K.; Yano, J.; Agapie, T., Accelerated Oxygen Atom Transfer and C-H Bond Oxygenation by Remote Redox Changes in $\mathrm{Fe}_{3} \mathrm{Mn}$-Iodosobenzene Adducts, Angew. Chem. Int. Ed. 2017, 56, 4772-4776.

(3) Du, P.; Moulijn, J. A.; Mul, G., Selective Photo(Catalytic)-Oxidation of Cyclohexane: Effect of Wavelength and $\mathrm{TiO}_{2}$ Structure on Product Yields, J. Catal. 2006, 238, 342-352.

(4) Satterfield, C. N., Heterogeneous Catalysis in Industrial Practice, McGraw-Hill, New York, 1991.

(5) Parshall, G. W.; Ittel, S. D., Homogeneous Catalysis, 2nd ed., Wiley, New York, 1992.

(6) Parshall, G. W., Industrial applications of homogeneous catalysis. A review, J. Mol. Catal. 1978, 4, 243-270.

(7) Schuchardt, U.; Carvalho, W. A.; Spinace, E. V., Why is it interesting to study cyclohexane oxidation? Synlett, 1993, 10, 713-718.

(8) Schuchardt, U.; Cardoso, D.; Sercheli, R.; Pereira, R.; de Cruz, R. S.; Guerreiro, M. C.; Mandelli, D.; Spinace, E. V.; Fires, E. L., Cyclohexane oxidation continues to be a challenge Appl. Catal. A: Gen. 2001, 211, 1-17.

(9) Eichelbaum, M.; Glaum, R.; Hävecker, M.; Wittich, K.; Heine, C.; Schwarz, H.; Dobner, C. K.; Welker-Nieuwoudt, C.; Trunschke, A.; Schlögl, R., Towards Physical Descriptors of Active and Selective Catalysts for the Oxidation of N-Butane to Maleic Anhydride. ChemCatChem, 2013, 5, 2318-2329.

(10) Retcher, B.; Costa, J. S.; Tang, J.; Hage, R.; Gamez, P.; Reedijk, J., Unexpected High Oxidation of Cyclohexane by Fe Salts and Dihydrogen Peroxide in Acetonitrile, $J$. Mol. Catal. A Chem. 2008, 286, 1-5. 
(11) Tian, Z.; Fattxiaoahi, A.; Lis, L.; Kass, S. R., Cycloalkane and Cycloalkene CH Bond Dissociation Energies. J. Am. Chem. Soc. 2006, 128, 17087-17092.

(12) Crabtree, R. H., Aspects of Methane Chemistry. Chem. Rev. 1995, 95, 9871007.

(13) Ishii, Y.; Sakaguchi, S.; Iwahama, T., Innovation of Hydrocarbon Oxidation with Molecular Oxygen and Related Reactions, Adv. Synth. Catal. 2001, 343, 393-427.

(14) Brégeault, J. M., Transition-Metal Complexes for Liquid-Phase Catalytic Oxidation: Some Aspects of Industrial Reactions and of Emerging Technologies, Dalt. Trans. 2003, 3, 3289-3302.

(15) Chen, L.; Zhou, Y.; Gui, Z.; Cheng, H.; Qi, Z., Au Nanoparticles Confined in Hybrid Shells of Silica Nanospheres for Solvent-Free Aerobic Cyclohexane Oxidation, J. Mater. Sci. 2017, 52, 7186-7198.

(16) Maksimchuk, N. V.; Kovalenko, K. A.; Fedin, V. P.; Kholdeeva, O. A., Cyclohexane Selective Oxidation over Metal-Organic Frameworks of MIL-101 Family: Superior Catalytic Activity and Selectivity, Chem. Commun. 2012, 48, 6812-6814.

(17) Silva, T. F. S.; Leod, T. C. O. M.; Martins, L. M. D. R. S.; Guedes Da Silva, M. F. C.; Schiavon, M. A.; Pombeiro, A. J. L., Pyrazole or Tris(Pyrazolyl)Ethanol OxoVanadium(IV) Complexes as Homogeneous or Supported Catalysts for Oxidation of Cyclohexane under Mild Conditions, J. Mol. Catal. A Chem. 2013, 367, 52-60.

(18) Huang, G.; Liu, Y.; Cai, J. L.; Chen, X. F.; Zhao, S. K.; Guo, Y. A.; Wei, S. J.; $\mathrm{Li}, \mathrm{X}$., Heterogeneous biomimetic catalysis using iron porphyrin for cyclohexane oxidation promoted by chitosan, Appl. Surf. Sci. 2017, 402, 436-443

(19) Kim, A. R.; Ahn, S.; Yoon, T. U.; Notestein, J. M.; Farha, O. K.; Bae, Y. S., Fast Cyclohexane Oxidation Under Mild Reaction Conditions Through a Controlled Creation of Redox-Active Fe(II/III) Sites in a Metal-Organic Framework, ChemCatChem 2019, 11, 5650-5656.

(20) De Almeida, M. P.; Martins, L. M. D. R. S.; Carabineiro, S. A. C.; Lauterbach, T.; Rominger, F.; Hashmi, A. S. K.; Pombeiro, A. J. L.; Figueiredo, J. L., Homogeneous and Heterogenised New Gold C-Scorpionate Complexes as Catalysts for Cyclohexane Oxidation, Catal. Sci. Technol. 2013, 3, 3056-3069. 
(21) Xiao, Y.; Liu, J.; Xie, K.; Wang, W.; Fang, Y., Aerobic Oxidation of Cyclohexane Catalyzed by Graphene Oxide: Effects of Surface Structure and Functionalization, Mol. Catal. 2017, 431, 1-8.

(22) Wu, P.; Cao, Y.; Wang, Y.; Xing, W.; Zhong, Z.; Bai, P.; Yan, Z., Ultrastable Bimetallic Catalyst with Tuned Surface Electronic Properties for Highly Selective Oxidation of Cyclohexane, Appl. Surf. Sci. 2018, 457, 580-590.

(23) Martins, L. M. D. R. S.; Martins, A.; Alegria, E. C. B. A.; Carvalho, A. P.; Pombeiro, A. J. L, Efficient Cyclohexane Oxidation with Hydrogen Peroxide Catalyzed by a C-Scorpionate Iron(II) Complex Immobilized on Desilicated MOR Zeolite. Appl. Catal. A Gen. 2013, 464-465, 43-50.

(24) Beattie, J. K.; Hambley, T. W.; Klepetko, J. A.; Masters, A. F.; Turner, P., The chemistry of cobalt acetate-IV. The isolation and crystal structure of the symmetric cubane, tetrakis $\left[(\mu\right.$-acetato $)\left(\mu_{3}\right.$-oxo $)$ (pyridine) $\left.\operatorname{cobalt}(\mathrm{III})\right] \cdot$ chloroform solvate, $\left[\mathrm{Co}_{4}\left(\mu_{3}-\right.\right.$ $\left.\mathrm{O})_{4}\left(\mu-\mathrm{CH}_{3} \mathrm{CO}_{2}\right)_{4}\left(\mathrm{C}_{5} \mathrm{H}_{5} \mathrm{~N}\right) \mathrm{in}_{4}\right] \cdot 5 \mathrm{CHCl}_{3}$ and of the dicationic partial cubane, trimeric, $[(\mu-$ acetato)(acetato)tris $\left(\mu\right.$-hdyroxy $\left(\mu_{3}\right.$-oxo)

hexakispyridinetricobalt(III)] hexafluorophosphate * water solvate, $\left[\mathrm{Co}_{3}\left(\mu_{3}-\mathrm{O}\right)(\mu-\right.$ $\mathrm{OH})_{3}\left(\mu-\mathrm{CH}_{3} \mathrm{CO}_{2}\left(\mathrm{CH}_{3} \mathrm{CO}_{2}\left(\mathrm{C}_{5} \mathrm{H}_{5} \mathrm{~N}\right)_{6}\left[\mathrm{PF}_{6}\right]_{2} \cdot 2 \mathrm{H}_{2} \mathrm{O}\right.\right.$, Polyhedron, 1998, 17, 1343-1354.

(25) McCool, N. S.; Robinson, D. M.; Sheats, J. E.; Dismukes, G. C., A $\mathrm{Co}_{4} \mathrm{O}_{4}$ "Cubane" Water Oxidation Catalyst Inspired by Photosynthesis, J. Am. Chem. Soc. 2011, 133, 11446-11449.

(26) Nguyen, A. I.; Ziegler, M. S.; Oña-Burgos, P.; Sturzbecher-Hohne, M.; Kim, W.; Bellone, D. E.; Don Tilley, T., Mechanistic Investigations of Water Oxidation by a Molecular Cobalt Oxide Analogue: Evidence for a Highly Oxidized Intermediate and Exclusive Terminal Oxo Participation, J. Am. Chem. Soc. 2015, 137, 40, 12865-12872.

(27) Denisov, I. G.; Makris, T. M.; Sligar, S. G.; Schlichting, I., Structure and chemistry of cytochrome P450, Chem. Rev., 2005, 105, 2253-2277.

(28) Chakrabarty, R.; Bora, S. J.; Das, B. K., Synthesis, structure, spectral and electrochemical properties, and catalytic use of cobalt (III)- oxo cubane clusters, Inorg. Chem. 2007, 46, 9450-9462.

(29) Chakrabarty, R.; Sarmah, P.; Saha, B.; Chakravorty, S.; Das, B. K., Catalytic Properties of Cobalt (III)- Oxo Cubanes in the TBHP Oxidation of Benzylic Alcohols, Inorg. Chem. 2009, 48, 6371-6379. 
(30) Jiang, Y. X.; Su, T. M.; Qin, Z. Z.; Huang, G., A Zinc Sulfide-Supported Iron Tetrakis (4-Carboxyl Phenyl) Porphyrin Catalyst for Aerobic Oxidation of Cyclohexane, RSC Adv. 2015, 5 (31), 24788-24794.

(31) Huang, G.; Mo, L. Q.; Cai, J. L.; Cao, X.; Peng, Y.; Guo, Y. A.; Wei, S. J., Environmentally Friendly and Efficient Catalysis of Cyclohexane Oxidation by Iron Meso-Tetrakis(Pentafluorophenyl)Porphyrin Immobilized on Zinc Oxide, Appl. Catal. B Environ. 2015, 162, 364-371.

(32) Xu, L. X.; He, C. H.; Zhu, M. Q.; Fang, S., A Highly Active $\mathrm{Au} / \mathrm{Al}_{2} \mathrm{O}_{3}$ Catalyst for Cyclohexane Oxidation Using Molecular Oxygen, Catal. Letters 2007, 114 (3-4), 202-205.

(33) Liu, L.; Arenal, R.; Meira, D. M.; Corma, A., Generation of Gold Nanoclusters Encapsulated in an MCM-22 Zeolite for the Aerobic Oxidation of Cyclohexane. Chem. Commun. 2019, 55 (11), 1607-1610.

(34) Liu, P.; You, K.; Deng, R.; Chen, Z.; Jian, J.; Zhao, F.; Liu, P.; Ai, Q.; Luo, H., Hydrotalcite-Derived Co-MgAlO Mixed Metal Oxides as Efficient and Stable Catalyst for the Solvent-Free Selective Oxidation of Cyclohexane with Molecular Oxygen, Mol. Catal. 2019, 466, 130-137.

(35) Zhou, W.; Hu, B.; Sun, C.; Xu, S.; Liu, Z., Efficient Selective Oxidation of Cyclohexane Catalyzed by Metallodeuteroporphyrins with Air in the Presence of LCysteine, Catal. Letters 2011, 141 (11), 1709-1712.

(36) Liu, X.; Conte, M.; He, Q.; Knight, D. W.; Murphy, D. M.; Taylor, S. H.; Whiston, K.; Kiely, C. J.; Hutchings, G. J., Catalytic Partial Oxidation of Cyclohexane by Bimetallic Ag/Pd Nanoparticles on Magnesium Oxide, Chem. - A Eur. J. 2017, 23 (49), 11834-11842.

(37) Ullmann's Encyclopedia of Industrial Chemistry, 6th ed., John Wiley and Sons, Inc. Online ISBN: 9783527306732.

(38) Jones, C. M.; Burkitt, M. J., EPR Spin-Trapping Evidence for the Direct, OneElectron Reduction of tert-Butylhydroperoxide to the tert-Butoxyl Radical by Copper(II): Paradigm for a Previously Overlooked Reaction in the Initiation of Lipid Peroxidation, J. Am. Chem. Soc. 2003, 125, 6946-6954. 
(39) Conte, M.; Wilson, K.; Chechik, V., Radical Intermediates in Chloroform Reactions over Triphenylphosphine- Protected Au Nanoparticles, Org. Biomol. Chem. 2009, 7 (7), 1361-1367.

(40) Conte, M.; Wilson, K.; Chechik, V., A Catalytic Reactor for the Trapping of Free Radicals from Gas Phase Oxidation Reactions, Rev. Sci. Instrum. 2010, 81 (10), 104102-104109.

(41) Conte, M.; Liu, X.; Murphy, D. M.; Taylor, S. H.; Whiston, K.; Hutchings, G. J., Insights into the Reaction Mechanism of Cyclohexane Oxidation Catalysed by Molybdenum Blue Nanorings, Catal. Letters 2016, 146 (1), 126-135.

(42) Finkelstein, E.; Rosen, G. M.; Rauckman, E. J., Spin Trapping. Kinetics of the Reaction of Superoxide and Hydroxyl Radicals with Nitrones, J. Am. Chem. Soc. 1980, 102 (15), 4994-4999.

(43) Duling, D. R., Simulation of Multiple Isotropic Spin-Trap EPR Spectra, Journal of Magnetic Resonance, Series B. 1994, 105-110.

(44) Baum, S. L.; Anderson, I. G. M.; Baker, R. R.; Murphy, D. M.; Rowlands, C. C., Electron Spin Resonance and Spin Trap Investigation of Free Radicals in Cigarette Smoke: Development of a Quantification Procedure, Anal. Chim. Acta 2003, 481 (1), 113.

(45) Davies, M. J.; Slater, T. F., Studies on the Photolytic Breakdown of Hydroperoxides and Peroxidized Fatty Acids by Using Electron Spin Resonance Spectroscopy. Spin Trapping of Alkoxyl and Peroxyl Radicals in Organic Solvents, Biochem. J. 1986, 240 (3), 789-795.

(46) Janzen, E. G.; Evans, C. A.; Liu, J. I. P., Factors Influencing Hyperfine Splitting in the ESR Spectra of Five-Membered Ring Nitroxides, J. Magn. Reson. 1973, 9 (3), 513-516.

(47) Ionita, P.; Conte, M.; Gilbert, B. C.; Chechik, V., Gold Nanoparticle-Initiated Free Radical Oxidations and Halogen Abstractions, Org. Biomol. Chem. 2007, 5 (21), 3504-3509.

(48) Conte, M.; Miyamura, H.; Kobayashi, S.; Chechik, V., Spin Trapping of Au-H Intermediate in the Alcohol Oxidation by Supported and Unsupported Gold Catalysts, $J$. Am. Chem. Soc. 2009, 131 (20), 7189-7196. 
(49) Griffin, B. W., Use of Spin Traps to Elucidate Radical Mechanisms of Oxidations by Hydroperoxides Catalyzed by Hemeproteins, Can. J. Chem. 1982, 60 (12), 1463-1473.

(50) Salem, I. A.; El-Maazawi, M.; Zaki, A. B., Kinetics and Mechanisms of Decomposition Reaction of Hydrogen Peroxide in Presence of Metal Complexes, Int. J. Chem. Kinet. 2000, 32 (11), 643-666.

(51) Stark, M. S., Addition of Peroxyl Radicals to Alkenes and the Reaction of Oxygen with Alkyl Radicals, J. Am. Chem. Soc. 2000, 122 (17), 4162-4170.

(52) Hermans, I.; Peeters, J.; Jacobs, P. A., Enhanced Activity and Selectivity in Cyclohexane Autoxidation by Inert H-Bond Acceptor Catalysts, ChemPhysChem, 2006, 7 (5), 1142-1148.

(53) Partenheimer, W., Methodology and Scope of Metal/Bromide Autoxidation of Hydrocarbons, Catal. Today 1995, 23 (2), 69-158.

(54) Conte, M.; Miyamura, H.; Kobayashi, S.; Chechik, V., Enhanced Acyl Radical Formation in the Au Nanoparticle-Catalysed Aldehyde Oxidation, Chem. Commun. 2010, 46 (1), 145-147.

(55) Hermans, I.; Jacobs, P. A.; Peeters, J., To the Core of Autocatalysis in Cyclohexane Autoxidation, Chem. - A Eur. J. 2006, 12 (16), 4229-4240.

(56) Chen, J. R.; Yang, H. H.; Wu, C. H., A Novel Process of Autoxidation of Cyclohexane Using Pure Oxygen, Org. Process Res. Dev. 2004, 8 (2), 252-255.

(57) Hermans, I.; Jacobs, P.; Peeters, J., The Formation of Byproducts in the Autoxidation of Cyclohexane, Chem. - A Eur. J. 2007, 13, 754-761.

(58) Hereijgers, B. P. C.; Weckhuysen, B. M., Aerobic Oxidation of Cyclohexane by Gold-Based Catalysts: New Mechanistic Insight by Thorough Product Analysis, $J$. Catal. 2010, 270 (1), 16-25.

(59) Nguyen, D.; Kang, G.; Chiang, N.; Chen, X.; Seideman, T.; Hersam, M. C.; Schatz, G. C.; Van Duyne, R. P.m Probing Molecular-Scale Catalytic Interactions between Oxygen and Cobalt Phthalocyanine Using Tip-Enhanced Raman Spectroscopy, J. Am. Chem. Soc. 2018, 140, 5948-5954. 
(60) Pozzi, E. A.; Sonntag, M. D.; Jiang, N.; Chiang, N.; Seideman, T.; Hersam, M. C.; Van Duyne, R. P., Ultrahigh Vacuum Tip-Enhanced Raman Spectroscopy with Picosecond Excitation, J. Phys. Chem. Lett. 2014, 5, 2657-2661.

(61) Jiang, N.; Foley, E. T.; Klingsporn, J. M.; Sonntag, M. D.; Valley, N. A.; Dieringer, J. A.; Seideman, T.; Schatz, G. C.; Hersam, M. C.; Van Duyne, R. P., Observation of Multiple Vibrational Modes in Ultrahigh Vacuum Tip-Enhanced Raman Spectroscopy Combined with Molecular-Resolution Scanning Tunneling Microscopy, Nano Lett. 2012, 12, 5061-5067.

(62) Zhang, R.; Zhang, Y.; Dong, Z. C.; Jiang, S.; Zhang, C.; Chen, L. G.; Zhang, L.; Liao, Y.; Aizpurua, J.; Luo, Y.; Yang J. L.; Hou J. G., Chemical Mapping of a Single Molecule by Plasmon-Enhanced Raman Scattering, Nature 2013, 498, 82-86.

(63) Steidtner, J.; Pettinger, B., Tip-Enhanced Raman Spectroscopy and Microscopy on Single Dye Molecules with 15 Nm Resolution, Phys. Rev. Lett. 2008, 100, 1-4. 



\section{Capítulo 7}

MOFs de Cobalto como Catalizadores para la Oxidación Electrocatalítica del Agua en Medio Neutro. 



\section{Índice}

7.1. Introducción ................................................................................................. 233

7.2. Objetivos .................................................................................................... 239

7.3. Resultados y discusión............................................................................ 239

7.3.1. Síntesis y caracterización de los MOFs de Cobalto..........................................239

7.3.1.1. Síntesis y caracterización del Co2-MOF ................................................239

7.3.1.2. Síntesis y caracterización del 2D-Co-MOF apilado por interacciones $\pi$ - $\pi$.

7.3.2. Estudio electroquímico de los MOFs de cobalto. .261

7.3.2.1. Estudio electroquímico del Co2-MOF y comparación con Co-MOF. ..261

7.3.2.2. Estudio electroquímico del 2D-Co-MOF. Relación entre la electroquímica redox y la química de coordinación del composite 2D-Co-MOF@ Nafion........266

7.3.3. Actividad electrocatalítica de los MOFs de cobalto en la reacción de evolución

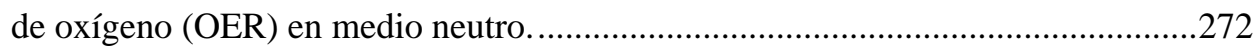

7.3.3.1. Actividad electrocatalítica del $\mathbf{C o}_{2}-\mathbf{M O F}$ en la reacción de evolución de oxígeno (OER).

272

7.3.3.2. Actividad electrocatalítica del 2D-Co-MOF en la reacción de evolución de

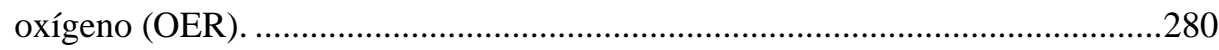

7.3.4. Análisis comparativo del rendimiento electrocatalítico del Co2-MOF @Nafion y el 2D-Co-MOF @ Nafion para la reacción de oxidación del agua.........................292

7.4. Conclusiones ........................................................................................... 295

7.5. Sección experimental ...................................................................296

7.5.1. Síntesis y caracterización de los MOFs de Cobalto.........................................296

7.5.1.1. Síntesis y caracterización del Co2-MOF .................................................296

7.5.1.2. Síntesis y caracterización del 2D-Co-MOF ..............................................298

7.5.2. Procedimiento experimental para las medidas de adsorción. ............................306 
Capítulo 7. MOFs de Cobalto como Catalizadores para la Oxidación Electrocatalítica del Agua en Medio Neutro.

7.5.3. Procedimiento experimental para las medidas electroquímicas y la reacción de

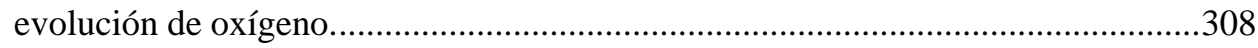

7.6. Bibliografía ............................................................................................. 311 


\subsection{Introducción.}

Desde la revolución industrial, la humanidad ha sido fuertemente dependiente de los combustibles fósiles como el petróleo, el carbón y el gas natural. Sin embargo, los problemas ambientales asociados al uso de los combustibles fósiles y una posible crisis energética mundial derivada de la escasez de dichos combustibles han motivado al desarrollo de alternativas de energía limpia, sostenible y renovable. ${ }^{1-3}$

En los últimos años, varios grupos independientes han investigado en este campo, y se han desarrollado numerosas innovaciones técnicas en el campo de las energías renovables. ${ }^{4,5}$ Entre estas tecnologías emergentes de conversión y almacenamiento de energía, las baterías metal-aire, las células de combustible y la división del agua para generar $\mathrm{H}_{2}$ han atraído la mayor atención debido a su alta eficiencia, seguridad energética y compatibilidad medioambiental. ${ }^{6,7}$ Cabe señalar que estas conversiones de energía y los dispositivos de almacenamiento implican varias reacciones electroquímicas clave para convertir la energía química en energía eléctrica o almacenar la energía en enlaces químicos. En este sentido, la ruptura del agua (WS, del inglés water splitting) juega el papel principal. En esta reacción, la energía eléctrica es almacenada en los enlaces químicos del $\mathrm{H}_{2}$, el cual es una fuente de energía limpia y de alta densidad que se ha considerado como un posible sustituto de los combustibles fósiles.

La ruptura electroquímica del agua comprende dos procesos fundamentales: reacción de oxidación del agua (WO, del inglés water oxidation) o reacción de evolución de oxígeno (OER, oxygen evolution reaction) (reacción anódica), y la reacción de evolución de hidrógeno (HER, hydrogen evolution reaction) (reacción catódica), como se muestra en la Figura 7.1.

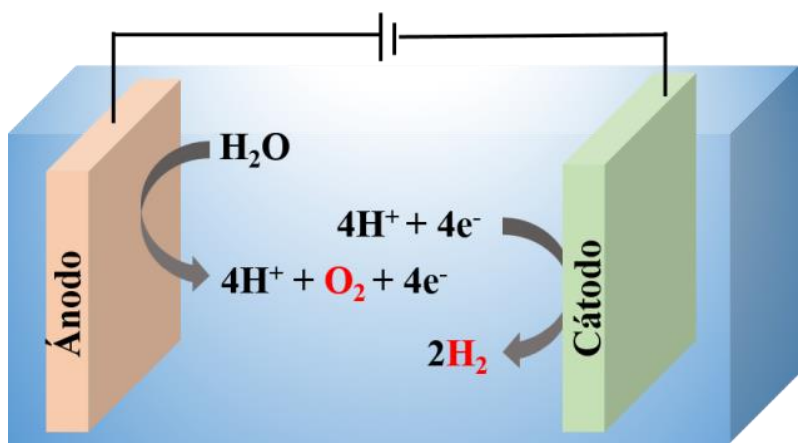

Figura 7.1. Ruptura electroquímica del agua para generar $\mathrm{O}_{2}$ e $\mathrm{H}_{2}$ mediante oxidación del agua (en el ánodo) y reducción de protones (en el cátodo), respectivamente. 
La reacción de evolución de oxígeno (OER) es termodinámicamente más exigente que la reacción de evolución de hidrógeno (HER). ${ }^{8-16}$ Mientras que en el proceso de HER se observa la transferencia de dos electrones, lo cual es cinéticamente posible, el proceso de OER implica romper los enlaces "O-H" y crear nuevos enlaces "O-O" a través de una serie de procesos multietapa, implicando la transferencia total de 4 electrones y 4 protones, lo cual es cinética y termodinámicamente desfavorable. De hecho, se necesita superar una alta barrera de energía, que requiere de un elevado sobrepotencial. ${ }^{17-29}$ Por esta razón, el desarrollo de electrocatalizadores robustos y eficientes para OER es un requisito fundamental para eliminar el cuello de botella tecnológico y satisfacer la demanda de producción a gran escala (Figura 7.2).

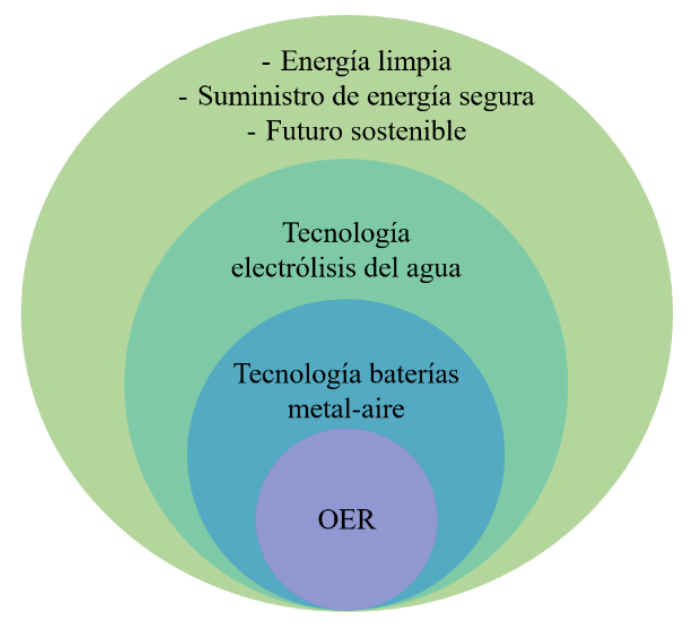

Figura 7.2. El papel del OER para un futuro sostenible y energéticamente seguro.

La eficiencia de un catalizador electroquímico, en general, se define en términos de (1) el sobrepotencial que se requiere $(\eta),(2)$ densidad de corriente obtenida (j), (3) eficiencia de Faraday (FE), (4) turnover number (TON), (5) turnover frequency (TOF) y (6) durabilidad en condiciones operacionales. Como se ha mencionado, el proceso de OER presenta un elevado sobrepotencial. Por lo tanto, se requiere del desarrollo de catalizadores que sean activos para el OER con el menor sobrepotencial posible. Además, para una aplicación real, es necesaria una densidad de corriente alta y estable, por lo que el sobrepotencial ( $\eta$ ) para obtener una densidad de corriente (j) de $10 \mathrm{~mA} / \mathrm{cm}^{2}$, es decir, Z10, es un parámetro muy importante a la hora de definir la eficiencia de un catalizador. ${ }^{8,30,31}$ La eficiencia de Faraday (FE) es una medida de la conversión de la energía eléctrica en energía química durante el OER. El TON y el TOF son dos parámetros clave en catálisis, de los cuales el TON da una estimación de la cantidad de 
producto generado (en este caso oxígeno) por sitio catalítico activo en toda la vida útil del catalizador y el TOF da la cantidad de oxígeno producido por sitio catalítico activo por unidad de tiempo. El TOF es el parámetro más adecuado a la hora de cuantificar la eficiencia de un catalizador en OER, mientras que el TON relaciona el rendimiento con su estabilidad en condiciones operacionales. La estabilidad es otro factor crucial a la hora de evaluar su aplicabilidad, ${ }^{32-36}$ la cual puede determinarse mediante una combinación de estudios experimentales y diversas técnicas de caracterización (electroquímicas y espectroscópicas). Además, también es importante la determinación de la pendiente de Tafel, que es una herramienta esencial para dilucidar el mecanismo de reacción involucrado. ${ }^{17,37}$

Teniendo en cuenta estos parámetros, varios estudios han reportado que los electrocatalizadores más eficientes para el OER son los electrodos de metales nobles y los óxidos de metales nobles. ${ }^{38}$ Entre ellos, el $\mathbf{R u O}_{2}$ es el catalizador más activo para este proceso, pero va perdiendo actividad a largo plazo debido al aumento del estado de oxidación del rutenio. ${ }^{39}$ Por el contrario, el $\mathbf{I r O}_{2}$ es estable y presenta también una actividad catalítica interesante. ${ }^{40,41}$ Estos catalizadores son los más reconocidos para este proceso. Aunque estos materiales muestran un alto rendimiento catalítico y se han descrito varios métodos sintéticos en la literatura, que han permitido relacionar el método de síntesis con la eficiencia catalítica, ${ }^{42-44}$ su comercialización a gran escala se ve dificultada por su escasez y su precio elevado. Por ello, durante los últimos años se han dedicado grandes esfuerzos al desarrollo de materiales basados en metales de la primera serie de transición que sean activos electrocatalíticamente en OER, que sean de bajo coste y posean estabilidad a largo plazo para poder reemplazar los electrocatalizadores basados en metales nobles..$^{45,46}$

En particular, el hierro, el cobalto y el níquel muestran excelentes propiedades electroquímicas, ya que poseen estructuras de electrones de valencia similares $\left(3 d^{6-8} 4 s^{2}\right)$ a las de los metales nobles mencionados. ${ }^{47}$ De hecho, en los últimos años se han estudiado ampliamente electrocatalizadores basados en $\mathrm{Fe}$, Co y Ni para este proceso ${ }^{48}$ y se ha reportado que el diseño racional de los electrocatalizadores basados en metales de transición juega un papel crítico en la transferencia electrónica y en la transferencia de masa, lo cual mejora considerablemente la electroactividad en OER.

Entre los metales de transición mencionados, el cobalto ha surgido como un interesante metal no noble por su poder catalítico hacia el WS. Se ha realizado un esfuerzo considerable por parte de numerosos grupos de investigación para desarrollar complejos basados en cobalto como catalizadores moleculares homogéneos para $\mathrm{OER}^{49-51}$ y se han 
publicado varias revisiones bibliográficas relacionadas con este tema. ${ }^{52-57} \mathrm{La}$ aplicación práctica de estos catalizadores moleculares requiere su integración en los materiales de los electrodos que operan con electrolitos acuosos, lo que sigue siendo un reto debido a las limitaciones en la síntesis de dichos complejos. ${ }^{58}$ Además, estos complejos moleculares suelen tener una baja estabilidad en condiciones de reacción y se observa frecuentemente la disociación del ligando para generar nanopartículas de $\mathrm{CoO}_{x} \cdot{ }^{59} \mathrm{En}$ consecuencia, existe un elevado interés por el desarrollo de materiales basados en cobalto que sean activos como catalizadores heterogéneos. En este sentido, se han desarrollado varios catalizadores basados en cobalto para el OER en las últimas décadas, los cuales se pueden clasificar en las siguientes categorías: $\mathrm{Co}-\mathrm{N}-\mathrm{C}$ composites, óxidos/hidróxidos de Co, calcogenuros de Co, y fosfuros y fosfatos de Co. ${ }^{60-66}$

En un campo paralelo, se han hecho enormes progresos en el área de los MOFs y materiales derivados de MOFs. ${ }^{19,32,66-73}$ Aunque la conexión entre el diseño de un catalizador para OER y un MOF surgió de forma casual en un principio, ${ }^{31,32,74-76}$ en los últimos años, se han publicado varias revisiones bibliográficas en el campo del WS con catalizadores heterogéneos, ${ }^{8,77}$ aplicaciones electroquímicas de los MOFs, ${ }^{36,68,76-81}$ y MOFs para OER electroquímico ${ }^{82,83}$ con el fin de conocer el alcance de los materiales basados en MOFs en este campo.

Las redes metal-orgánicas (MOF), una clase emergente de materiales porosos, son compuestos cristalinos que consisten en redes infinitas de unidades inorgánicas (iones o clústeres metálicos) unidas por enlaces de coordinación a ligandos orgánicos (linkers) que han despertado un considerable interés en todo el mundo. ${ }^{84,85}$ Hasta la fecha, se han reportado más de 30.000 MOFs, y su familia sigue creciendo. ${ }^{86}$ Los MOF han sido ampliamente aplicados en diferentes campos de investigación, incluyendo la catálisis heterogénea, ${ }^{69,87}$ la adsorción y separación de gases ${ }^{88-90}$ y materiales electroactivos para dispositivos, ${ }^{69,91-95}$ debido a sus propiedades estructurales y funcionales. ${ }^{96-101}$

En comparación con los materiales porosos inorgánicos tradicionales, los MOFs no sólo poseen mayores superficies y porosidades específicas, sino que también tienen una amplia diversidad de componentes y estructuras químicas ya que se pueden ajustar los componentes metálicos y los conectores orgánicos, así como las condiciones de reacción en el curso de la síntesis, lo que beneficia la construcción de MOFs con varias funcionalidades. ${ }^{102}$ A través de controles precisos, los MOF se podrían preparar en una amplia variedad de morfologías unidimensionales (1D), bidimensionales (2D), y tridimensionales (3D) (Figura 7.3). ${ }^{103,104}$ 

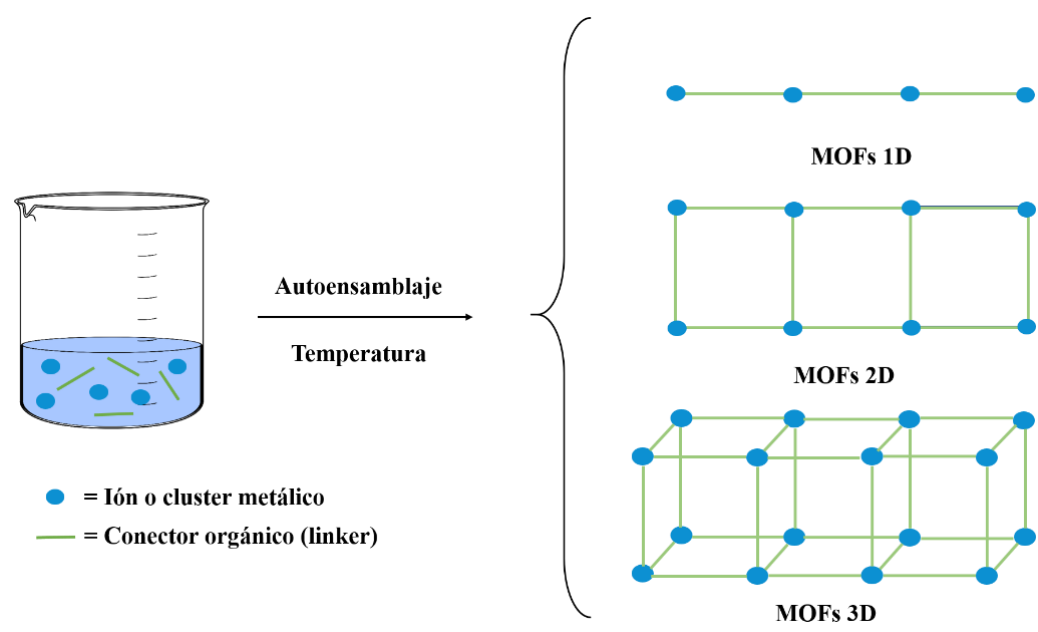

Figura 7.3. Síntesis de materiales metal-orgánicos (MOFs).

Recientemente, los materiales basados en MOFs han atraído gran atención como electrocatalizadores. ${ }^{105,106}$ Los MOFs poseen propiedades únicas, mencionadas anteriormente, y podrían proporcionar nuevas oportunidades para preparar electrocatalizadores altamente competitivos para este proceso. ${ }^{48} \mathrm{Sin}$ embargo, se han publicado pocos trabajos sobre la construcción de MOFs cobalto como electrocatalizadores para $\mathrm{OER}^{14,15,107-117}$ a pesar de sus importantes características estructurales, ya que este tipo de materiales presentan normalmente una baja conductividad. En este sentido, se han realizado numerosos esfuerzos en este campo para superar estas limitaciones. Entre las estrategias reportadas para facilitar el transporte de carga a través del MOF se encuentran:

- Un aumento de la deslocalización de la carga introduciendo interacciones de tipo dador-aceptor ${ }^{118-121}$

- Estados de valencia mixtos del nodo/conector ${ }^{122-123}$

- Apilamiento por interacciones $\pi-\pi$ o conjugación $\pi$ en la red metalorgánica. ${ }^{28}$

Además, algunas estrategias efectivas para mejorar la actividad electrocatalítica intrínseca de los MOFs se han centrado en un aumento de la accesibilidad de los sitios activos $^{113-115}$ y la modulación de su entorno electrónico. ${ }^{14,106,116,117,124}$ La optimización de vacantes de coordinación en los centros metálicos de los MOF se ha logrado mediante el ajuste del protocolo sintético ${ }^{115,124,125}$ y/o métodos de post-tratamiento a través de la 
activación de los MOFs por intercambio de ligando, ${ }^{124}$ grabado con plasma ${ }^{14,126} \mathrm{o}$ activación electroquímica. ${ }^{111,116,117}$ Además, la estructura electrónica de las unidades de construcción de los MOFs se han modulado mediante la incorporación de vacantes de ligandos y defectos de los nodos metálicos ${ }^{115,124,127-129} \mathrm{o}$ mediante la construcción de MOFs híbridos heteroestructurales que contienen dos o más metales o ligandos diferentes. ${ }^{14,112,113,116,117}$

Entre las diferentes unidades de construcción secundarias (SBUs) que componen los MOFs, la unidad dinuclear $\mathrm{M}_{2}(\mathrm{RCOO})_{4}$ paddlewheel $(\mathrm{M}=\mathrm{Cu}, \mathrm{Zn}, \mathrm{Ni}, \mathrm{Fe}, \mathrm{Co}, \mathrm{Mo}, \mathrm{Cr}$, $\mathrm{Ru})$ se considera un núcleo potencial para conseguir llevar a cabo la reacción de OER satisfactoriamente, ${ }^{112}$ probablemente debido a la cercanía de los centros de metálicos en esta unidad. De hecho, una de las hipótesis mecanísticas reportadas para la reacción de oxidación del agua con cobalto, implica un acoplamiento directo entre dos radicales oxo $\mathrm{u}$ oxilo situados en centros de cobalto distintos, que produce un intermedio peroxo puente, ${ }^{130,131} \mathrm{y}$, para ello, tiene que haber, al menos, dos centros de cobalto cercanos dentro de la estructura del MOF. Sin embargo, los MOFs de cobalto basados en esta SBU han mostrado una baja estabilidad en agua. ${ }^{132}$ Para superar esta limitación, se han utilizado diferentes estrategias para aumentar su estabilidad, pero solo se han descrito dos ejemplos de MOFs de cobalto estables en agua, empleando ligandos fijos y voluminosos ${ }^{133}$ o con una $\mathrm{SBU}$ de hierro trinuclear adicional $\left[\mathrm{Fe}_{3} \mathrm{O}(\mathrm{RCOO})_{6}\left(\mathrm{H}_{2} \mathrm{O}\right)_{3}\right]$, la cual proporcionaba estabilidad al sistema. ${ }^{112}$ Cuando esta SBU se sustituye por su isoestructural con cobalto $\left[\mathrm{Co}_{3} \mathrm{O}(\mathrm{RCOO})_{6}\left(\mathrm{H}_{2} \mathrm{O}\right)_{3}\right]$, este MOF se descompone rápidamente en agua. ${ }^{112}$

A pesar de los avances en este campo, debido a la intrínsecamente alta barrera cinética y termodinámica para OER, la mayoría de los MOFs de cobalto estudiados como electrocatalizadores operan en medios fuertemente alcalinos, lo que implica condiciones altamente corrosivas y severas para aplicaciones a gran escala. Por lo tanto, un desafío importante es el desarrollo de nuevos MOFs de cobalto para una eficiente oxidación electrocatalítica del agua a $\mathrm{pH}$ neutro. 


\subsection{Objetivos.}

Los objetivos propuestos en este capítulo de la tesis doctoral son los siguientes:

- Desarrollo de nuevos MOFs de cobalto mediante el empleo de clústeres bien definidos, empleando ligandos orgánicos ampliamente utilizados en la síntesis de MOFs, que sean eficientes en la reacción de oxidación electrocatalítica del agua a $\mathrm{pH}$ neutro.

- Caracterización de los materiales obtenidos y estudio de las propiedades redox con el fin de correlacionar la estructura con su actividad catalítica.

- Propuesta del mecanismo para la reacción de evolución de oxígeno electrocatalítica.

\subsection{Resultados y discusión.}

Teniendo en cuenta la actividad catalítica en la reacción de WS de los complejos tetranucleares de cobalto homogéneos estudiados en el apartado anterior, ${ }^{134}$ estos clústeres se han empleado en esta tesis doctoral como precursores de redes metalorgánicas, con el objetivo de desarrollar catalizadores heterogéneos activos para el proceso de OER. Para ello se han empleado ligandos mono y bifuncionales, obteniéndose dos MOFs de cobalto nuevos que se van a estudiar como electrocatalizadores en este proceso.

\subsubsection{Síntesis y caracterización de los MOFs de Cobalto.}

\subsubsection{Sintesis y caracterización del $\mathrm{Co}_{2}-\mathrm{MOF}$.}

Con el objetivo de sintetizar un MOF de cobalto con centros metálicos bien definidos en la estructura, se ha utilizado el precursor de cobalto $\left[\mathrm{Co}_{4} \mathrm{O}_{4}(\mathrm{OAc})_{4}(\mathrm{py})_{4}\right]$ estudiado en el capítulo anterior. Para ello, en primer lugar, se empleó un ligando monofuncional ampliamente estudiado para la síntesis de MOFs como el ácido benceno tricarboxílico $\left(\mathrm{H}_{3} \mathrm{BTC}\right)$. A partir de la reacción solvotermal del precursor de cobalto con este ligando en $N, N$-dimetilformamida (DMF) se obtuvieron monocristales violetas del $\mathbf{C o}_{2}$-MOF después de 72h. Esto permitió llevar a cabo la difracción de rayos $\mathrm{X}$ de monocristal para este material. Dicho estudio reveló que el Co $\mathbf{C o}_{2}$-MOF cristaliza en un grupo espacial P2 $1 / \mathrm{n}$ (Tabla 7.7 de la sección experimental) y presenta una estructura basada en dos unidades de construcción secundarias (SBU) dinucleares diferentes, denominadas SBU1 y SBU2 (Figura 7.4). 


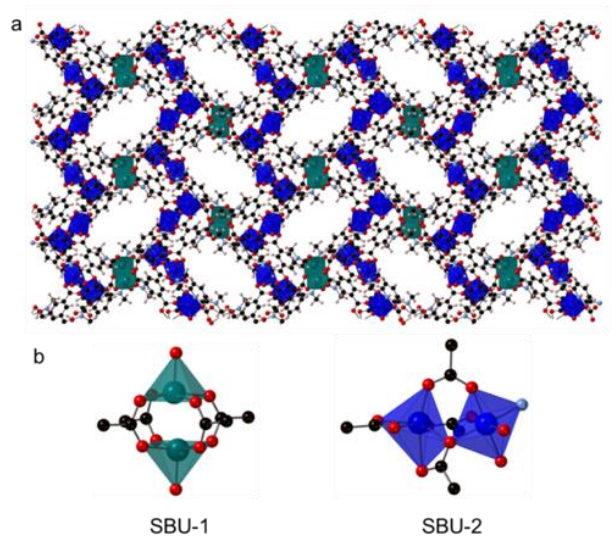

Figura 7.4. (a) Estructura cristalográfica del Co2-MOF, (b) representación de las dos unidades diméricas que forman el compuesto (SBU1 y SBU2) Los átomos de hidrógeno se han omitido para clarificar la estructura. Rojo: oxígeno, negro: carbono, azul: nitrógeno.

Reproducida con permiso de la ref 135. Copyright 2021 American Chemical Society.

La unidad SBU1 presenta una estructura conocida como paddlewheel y está formada por dos átomos de $\mathrm{Co}^{2+}$ cristalográficamente relacionados a través de un centro de inversión (Figura 7.5 a) Cada centro de cobalto se encuentra en un entorno de pirámide trigonal distorsionado y está coordinado por cuatro átomos de oxígeno de cuatro ligandos BTC ${ }^{3-}$ compartidos con el otro cobalto de la misma unidad SBU, que forman el plano de la base, y por un átomo de oxígeno de una molécula de DMF, que ocupa la posición apical. La distancia Co-Co es de $2.833 \AA$, que está en el rango de las distancias metal-metal encontradas en otros complejos $\mathrm{M}_{2}(\mathrm{RCOO})_{4} \cdot{ }^{136-141}$ La unidad SBU2 es más atípica y está formada por dos $\mathrm{Co}^{2+}$ cristalográficamente independientes, cada uno de ellos con una conectividad diferente. Uno de los centros de cobalto está coordinado a seis átomos de oxígeno de cuatro ligandos $\mathrm{BTC}^{3-}$, con distancias $\mathrm{Co}-\mathrm{O}$ en el rango de otros MOFs de cobalto reportados (Figura 7.5 b). ${ }^{136-141}$ En concreto, hay dos ligandos BTC ${ }^{3-}$ coordinados al metal en modo de quelatos, mientras que los otros dos ligandos se coordinan de forma clásica como en la estructura paddlewheel. El otro cobalto de la unidad SBU2 está coordinado por tres átomos de oxígeno de tres ligandos $\mathrm{BTC}^{3-}$ compartidos y tres moléculas de disolvente (una molécula de piridina y dos moléculas de DMF). (Figura $7.5 \mathrm{~b})$. 


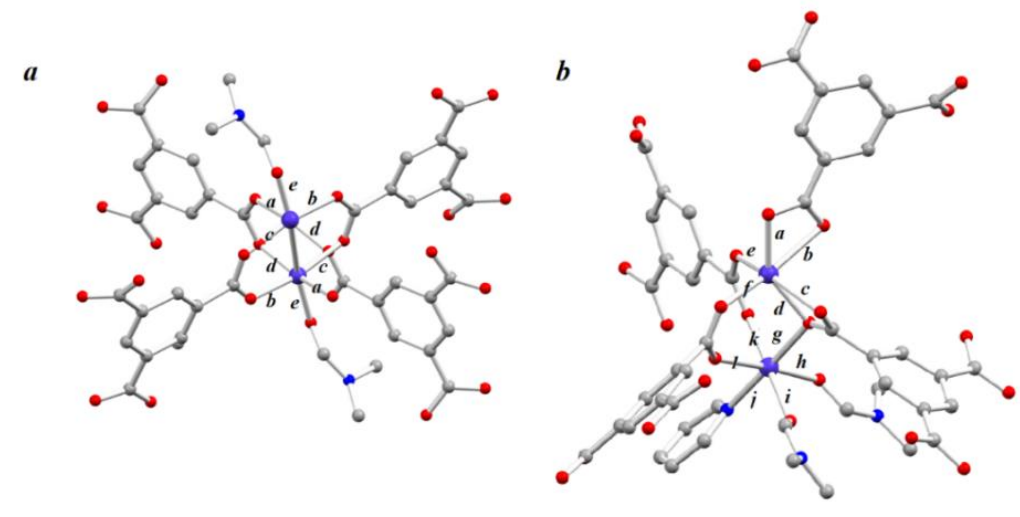

Figura 7.5. Representación de las dos SBUs diméricas encontradas en el Co2-MOF. a) Distancias de enlace en la SBU1: $\mathrm{a}=2.086 \AA$, $\mathrm{b}=2.027 \AA, \mathrm{c}=2.026 \AA$, $\mathrm{d}=2.015 \AA$, e = $1.988 \AA, \mathrm{f}=2.833 \AA$. b) Distancias de enlace en la SBU2: $\mathrm{a}=2.098 \AA, \mathrm{b}=2.241 \AA, \mathrm{c}=$ $2.402 \AA, \mathrm{d}=2.063 \AA, \mathrm{e}=2.011 \AA, \mathrm{f}=2.011 \AA, \mathrm{g}=2.132 \AA, \mathrm{h}=2.120 \AA, \mathrm{i}=2.075 \AA, \mathrm{j}=$ $2.110 \AA, k=2.055 \AA, 1=2.095 \AA$. Los átomos de hidrógeno se omiten para clarificar la estructura. Reproducida con permiso de la ref 135. Copyright 2021 American Chemical Society.

Para este compuesto, se ha comprobado que la estructura del total del material se corresponde con la estructura obtenida por difracción de rayos $\mathrm{X}$ de monocristal, simulando el difractograma de rayos $\mathrm{X}$ de polvo a partir de los datos cristalográficos obtenidos del análisis del monocristal y comparándolo con el difractograma de rayos $\mathrm{x}$ de polvo medido para el material bulk (Figura 7.6). 


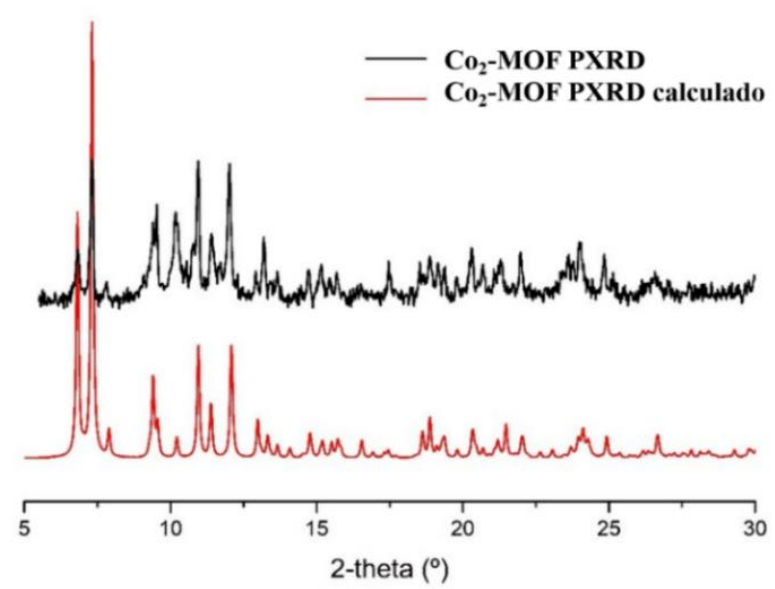

Figura 7.6. Difractograma de rayos $\mathrm{X}$ de polvo del Co2-MOF medido (negro) y calculado a partir de los datos de difracción de rayos X de monocristal (rojo). Reproducida con permiso de la ref 135. Copyright 2021 American Chemical Society.

Además, se ha observado que el uso del cubano como precursor es clave en la formación de este material, el cual no tiene precedentes en la literatura, y que no se ha conseguido obtener usando precursores de cobalto comerciales como el $\mathrm{Co}(\mathrm{OAc})_{2} \cdot 4 \mathrm{H}_{2} \mathrm{O}$ o el $\mathrm{Co}\left(\mathrm{NO}_{3}\right)_{2} \cdot 6 \mathrm{H}_{2} \mathrm{O}$ en distintas condiciones de síntesis (Figura 7.7).

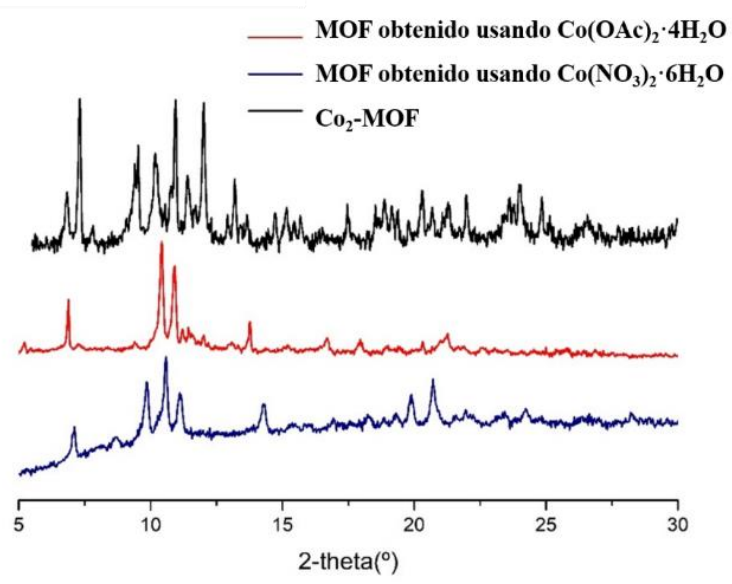

Figura 7.7. Difractograma de rayos X de polvo del Co2-MOF (negro), del MOF sintetizado usando $\mathrm{Co}(\mathrm{OAc})_{2} \cdot 4 \mathrm{H}_{2} \mathrm{O}$ como precursor (rojo) y del MOF sintetizado usando $\mathrm{Co}\left(\mathrm{NO}_{3}\right)_{2} \cdot 6 \mathrm{H}_{2} \mathrm{O}$ como precursor (azul) a $135^{\circ} \mathrm{C}$ durante 72 horas. Reproducida con permiso de la ref 135. Copyright 2021 American Chemical Society. 
Una característica de este MOF dinuclear es que la conexión entre estas dos SBUs da como resultado una red 3D con canales 1D paralelos al eje cristalográfico a (Figura 7.8).

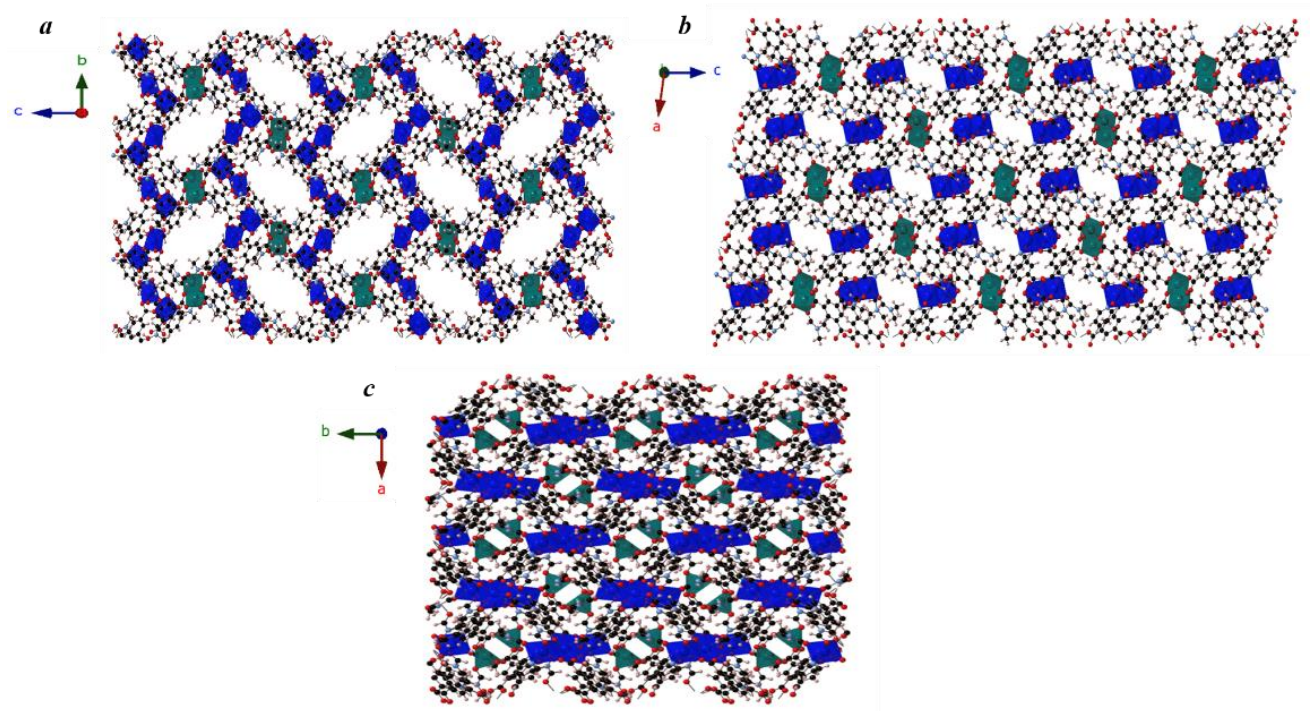

Figura 7.8. Representación del Co2-MOF: (a) a lo largo del eje a, (b) a lo largo del eje b, (c) a lo largo del eje c. Las moléculas de disolvente y los átomos de hidrógeno se omiten para clarificar la estructura. Reproducida con permiso de la ref 135. Copyright 2021 American Chemical Society.

Estos canales tienen ocluidas moléculas de DMF, lo cual se ha confirmado por análisis termogravimétrico (TGA) (Figura 7.9). Además, en esta red también se observa un sistema de canales microporosos que se entrecruzan. Las aberturas de los poros de los diferentes canales (Figura 7.8) sugieren que este nuevo Co2-MOF podría tener un interés potencial para la separación y/o almacenamiento de gases, ya que las dimensiones de los canales que dan acceso al volumen interno son lo suficientemente grandes como para permitir la difusión de moléculas relativamente pequeñas tras la eliminación del disolvente.

La activación para la adsorción de gas y la catálisis del Co2-MOF y su estabilidad térmica fueron estudiadas por termogravimetría (Figura 7.9). El gráfico de TGA muestra cuatro pérdidas de peso principales. La primera a $120^{\circ} \mathrm{C}$ se corresponde con la eliminación de las moléculas de DMF ocluidas, que se superpone con la pérdida posterior a $160^{\circ} \mathrm{C}$, asignada a la eliminación de una molécula de DMF y una molécula de piridina, que estaban coordinadas a los centros de Co. La estructura del Co2-MOF se mantiene en 
su mayor parte hasta esta temperatura, lo que indica que estas pérdidas de peso no afectan a la red del MOF. Un aumento de la temperatura hasta $\operatorname{los} 280^{\circ} \mathrm{C}$ promueve la eliminación de las dos moléculas de DMF restantes, produciéndose la pérdida de la cristalinidad. En base a estos resultados, se puede concluir que el $\mathbf{C o}_{2}$-MOF es estable hasta $160^{\circ} \mathrm{C}$ cuando parte de la DMF ocluida y la piridina se liberan y, por lo tanto, alguna apertura de poro puede ser accesible para la adsorción de gases.

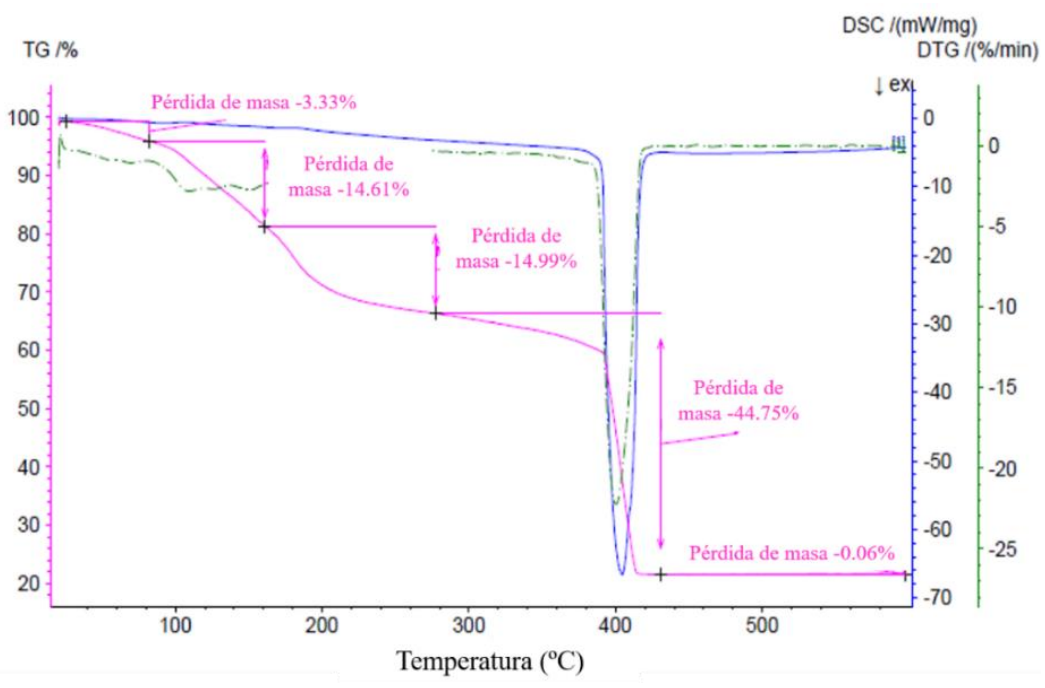

Figura 7.9. Análisis termogravimétrico del $\mathbf{C o}_{2}$-MOF. Reproducida con permiso de la ref 135. Copyright 2021 American Chemical Society.

La microporosidad del material se ha demostrado tras activar la muestra a $100^{\circ} \mathrm{C}$ a vacío, con una alta capacidad de adsorción de $\mathrm{CO}_{2}$ de $1,1 \mathrm{mmol} / \mathrm{g}$ a $0^{\circ} \mathrm{C}$ y $100 \mathrm{kPa}$ (Figura 7.10 a, b), lo que corresponde a una superficie aparente de $233 \mathrm{~m}^{2} / \mathrm{g}$. El valor del calor isostérico de adsorción de $\mathrm{CO}_{2}$ a cobertura cero $\left(\mathrm{q}_{\mathrm{st}, 0}\right)$, calculado a partir de las constantes de Henry, es de $30 \mathrm{~kJ} / \mathrm{mol}$ (Figura $7.10 \mathrm{c}$ ), siendo comparable al de una zeolita LTA (tipo A) con una relación $\mathrm{Si} / \mathrm{Al}$ de $5 .{ }^{142}$ Este valor se fijó como un buen compromiso entre la capacidad de adsorción y la regenerabilidad para un adsorbente de $\mathrm{CO}_{2}$ debido a la fuerza de las interacciones gas-sólido. Las isotermas de alta presión de $\mathrm{CO}_{2}$ y $\mathrm{CH}_{4}$ (hasta 10

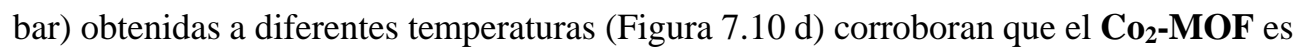
un material prometedor para la separación del $\mathrm{CO}_{2} / \mathrm{CH}_{4}$ (Figura 7.10 e) con valores muy similares a los de los tamices moleculares zeolíticos. ${ }^{143}$ Aunque la selectividad disminuye con el aumento de la presión, sigue siendo muy alta, incluso a $298 \mathrm{~K}$ y 500 $\mathrm{kPa}$. 

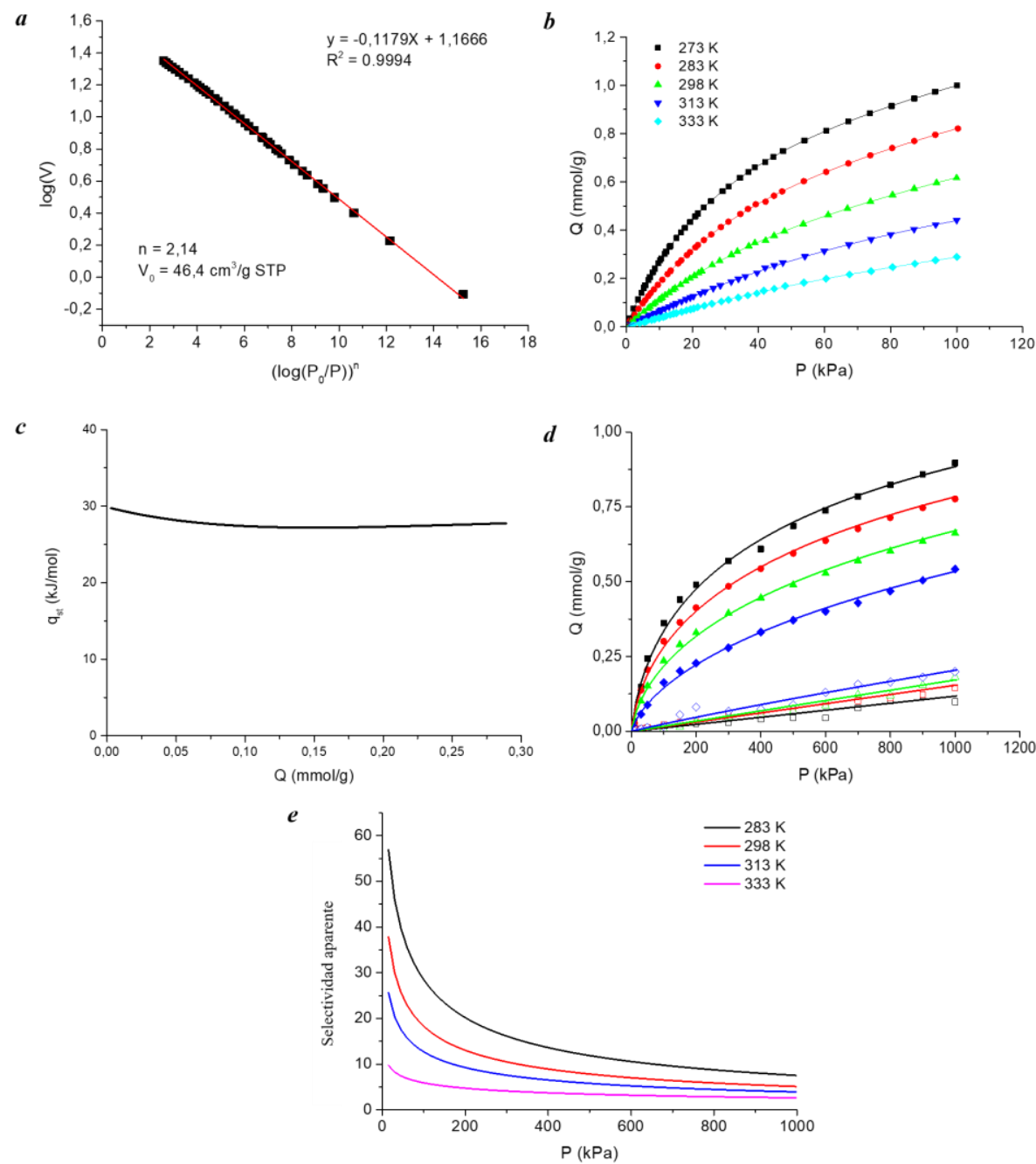

Figura 7.10. a) Aplicación de la ecuación de Dubinin-Astakhov para la adsorción de $\mathrm{CO}_{2}$ a 273K para el Co2-MOF. b) Isotermas de adsorción de $\mathrm{CO}_{2}$ para el Co2-MOF a diferentes temperaturas. Los puntos son valores experimentales y las líneas son ajustes de Virial. c) Calor isostérico de adsorción de $\mathrm{CO}_{2}$ en el Co2-MOF. d) Isotermas de adsorción de $\mathrm{CO}_{2}$ (símbolos cerrados) y $\mathrm{CH}_{4}$ (símbolos abiertos) para el Co2-MOF. Los puntos son valores experimentales y las líneas son ajustes de Virial. Negro: 283 K, Rojo: 298 K, Verde: 313 K, Azul: 333 K. e) Selectividad aparente $\mathrm{CO}_{2} / \mathrm{CH}_{4}$. Negro: $283 \mathrm{~K}$, Rojo: 298 K, Verde: $313 \mathrm{~K}$, Azul: 333 K. Reproducida con permiso de la ref 135. Copyright 2021 American Chemical Society. 
Además, se estudió la morfología del Co2-MOF mediante microscopía electrónica de barrido de emisión de campo (FESEM) y la distribución de su composición por espectroscopía de rayos X de energía dispersiva (EDX) y, como se puede observar en la Figura 7.11, el análisis EDX muestra que todos los elementos presentes en el $\mathbf{C o}_{2}$-MOF se encuentran homogéneamente distribuidos en el material.

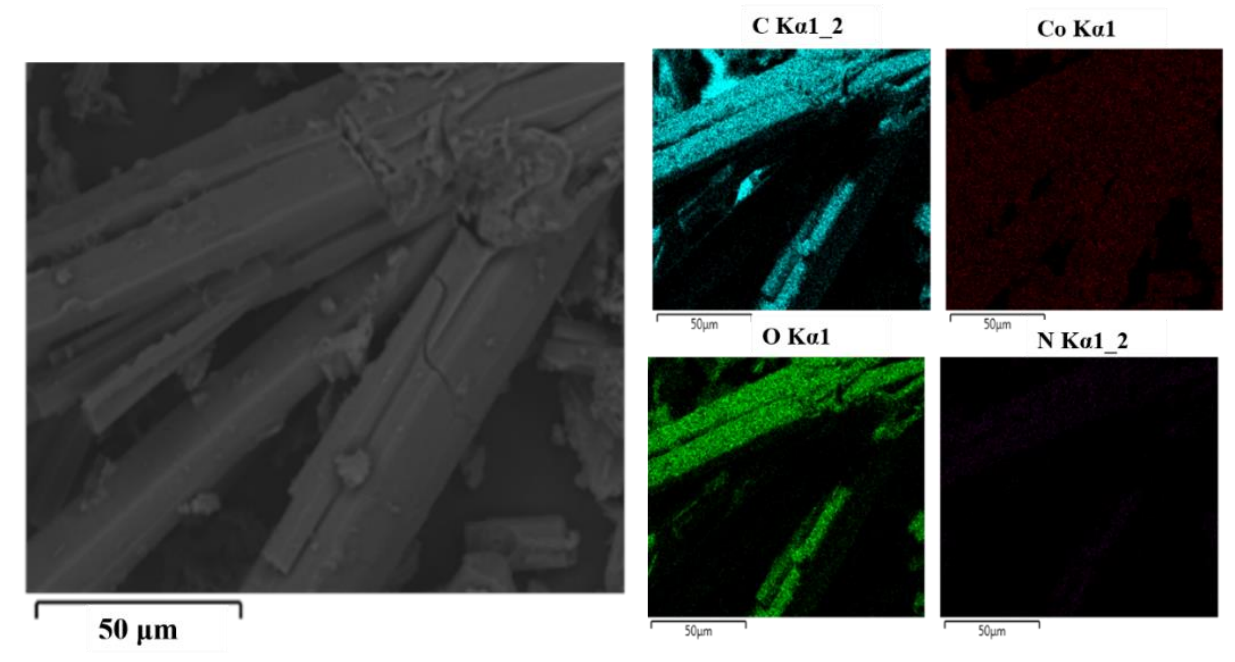

Figura 7.11. Imagen del Co2-MOF tomada con microscopía electrónica de barrido de emisión de campo (FESEM) y análisis EDX.

Por último, se estudió el Co2-MOF mediante espectroscopía de fotoelectrones emitidos por rayos X (XPS) para saber más sobre su estructura electrónica. El análisis XPS no es un proceso sencillo para los espectros de metales de transición $2 p$, ya que contienen complicaciones como el desdoblamiento de multipletes y la reorganización estructural, que dificultan la identificación de los estados químicos presentes. ${ }^{144}$ El valor de energía de enlace (Eb) se utiliza típicamente en el XPS para determinar el número de oxidación de un elemento químico. Sin embargo, para los elementos de transición $3 \mathrm{~d}$ el desdoblamiento espín-orbital es un valor más informativo. Según cálculos teóricos, ${ }^{145} \mathrm{el}$ desdoblamiento espín-orbital del Co $2 \mathrm{p}_{1 / 2}$-Co $2 \mathrm{p}_{3 / 2}$ aumenta dependiendo del número de electrones $3 \mathrm{~d}$ desapareados, estando más cerca de $16 \mathrm{eV}$ para el Co (II) de alto espín y más cerca de $15 \mathrm{eV}$ para el Co (III). En el caso del Co $\mathbf{C o}_{2}$-MOF, los valores de Eb para el Co 2 $\mathrm{p}_{3 / 2}$, Eb para el Co 2 $\mathrm{p}_{1 / 2}$ y $\Delta \mathrm{E}_{1}$ son 781.1, 796.8 y $15.7 \mathrm{eV}$, respectivamente. Además, se han observado picos satélite intensos ( $\Sigma \mathrm{sat}_{\mathrm{I}} / \mathrm{ICo}_{2 \mathrm{p}}>1.6$ ) para los espectros de Co $2 \mathrm{p}_{3 / 2}$. Tanto los valores de $\Sigma \mathrm{sat} / \mathrm{ICo}_{2 \mathrm{p}}$ como los de $\Delta \mathrm{E}_{1}$ son característicos de los compuestos de cobalto (II) de alto espín. ${ }^{146-149}$ 
El espectro XPS de la línea de Co 2p para el Co2-MOF y los resultados del ajuste se muestran en la Figura 7.12 y en la Tabla 7.1, respectivamente. A partir de este análisis, se pudo confirmar que los centros de cobalto se encuentran exclusivamente en el estado de oxidación del Co (II).

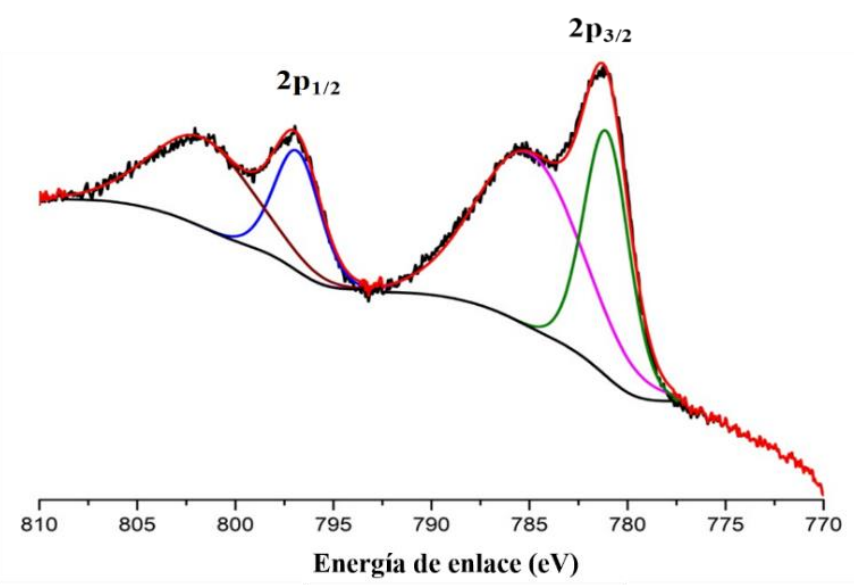

Figura 7.12. Espectro XPS de la línea del Co 2p del Co2-MOF. Reproducida con permiso de la ref 135. Copyright 2021 American Chemical Society.

Tabla 7.1. Características XPS del Co2-MOF: Energías de enlace de los diferentes picos, máxima anchura a mitad de pico (FWHM, en paréntesis), intensidades relativas (I $\Sigma$ = $\Sigma$ sat $\left./ \mathrm{I}_{\text {principal }}\right)$, interacción espín-orbital $\left(\Delta \mathrm{E}_{1}\right)$; todas las energías y FWHMs están en eV.

\begin{tabular}{|c|c|}
\hline & Co2-MOF \\
\hline $\mathrm{Co}_{2} \mathrm{p}_{3 / 2}$ & $781.1(2.7)$ \\
\hline sat1 & $785.0(6.3)$ \\
\hline $\mathbf{I}_{\Sigma}$ & 1.66 \\
\hline $\operatorname{Co2}_{1 / 2}$ & $796.8(2.8)$ \\
\hline sat1' & $801.7(6.2)$ \\
\hline$I_{\Sigma}$ & 1.66 \\
\hline$\Delta \mathrm{E} 1$ & 15.7 \\
\hline
\end{tabular}




\section{Estabilidad química del Co $_{2}-\mathbf{M O F}$.}

A pesar de la elevada estabilidad térmica del Co2-MOF, este compuesto sufre una reorganización estructural en presencia de disolventes próticos como el etanol, el agua o mezclas de ambos disolventes (Figura 7.13) y se transforma en un MOF de cobalto mononuclear, previamente descrito por el grupo de Yagui, con la fórmula $\mathrm{Co}_{3}(\mathrm{BTC})_{2}\left(\mathrm{H}_{2} \mathrm{O}\right)_{3}$, denotado como Co-MOF. ${ }^{150}$ Este material presenta una estructura tridimensional unida mediante enlaces por puentes de hidrógeno basada en cadenas en zig-zag en las que las moléculas de agua coordinadas interactúan con los grupos carboxilatos de las cadenas adyacentes.

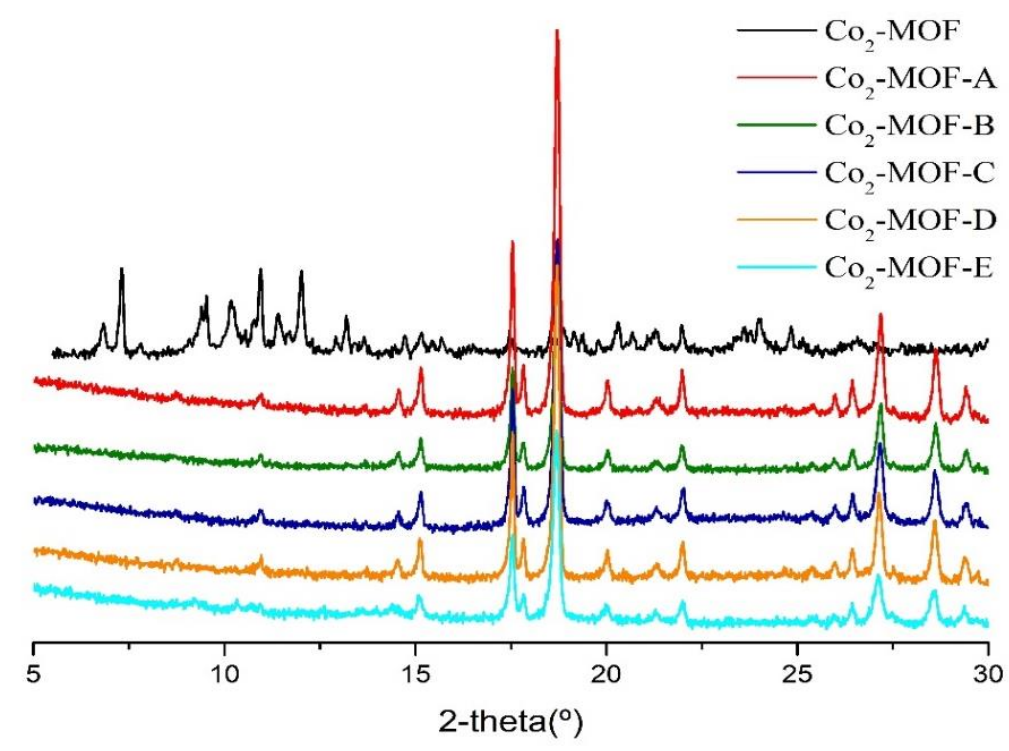

Figura 7.13. Patrones de difracción de rayos $\mathrm{X}$ de polvo del Co2-MOF antes (negro) y después de tratarlo con diferentes disolventes o mezclas de disolventes: A: agua (rojo), B: $15 \%$ etanol en agua (verde), C: $50 \%$ etanol en agua (azul), D: $15 \%$ de agua en etanol (naranja), E: etanol (azul claro). Reproducida con permiso de la ref 135. Copyright 2021 American Chemical Society.

Para evitar esta transformación, se inmovilizó el Co $\mathbf{C o}_{2}$-MOF en Nafion, dando lugar a un composite (Co2-MOF @Nafion) estable en agua. Como se puede observar en la Figura 7.14 , los difractogramas de rayos $\mathrm{X}$ de polvo para este compuesto no presentan cambios significativos antes y después de su tratamiento con agua. 
De acuerdo con estudios recientes con HKUST-1/Nafion y compuestos basados en MOF de $\mathrm{Zn}(\mathrm{II}) / \mathrm{Nafion},{ }^{151,152}$ la mejora de la estabilidad química del MOF puede atribuirse a un menor contenido de agua en el compuesto comparado con el material en ausencia de Nafion. Estos estudios explican que la disminución de la absorción de agua en el compuesto se atribuye a la reducción del número y el tamaño de poros disponibles. Además de su papel protector, el Nafion también mejora la adherencia del Co2-MOF a los electrodos de grafito, lo cual permite el estudio de su actividad electrocatalítica en la reacción de oxidación del agua.

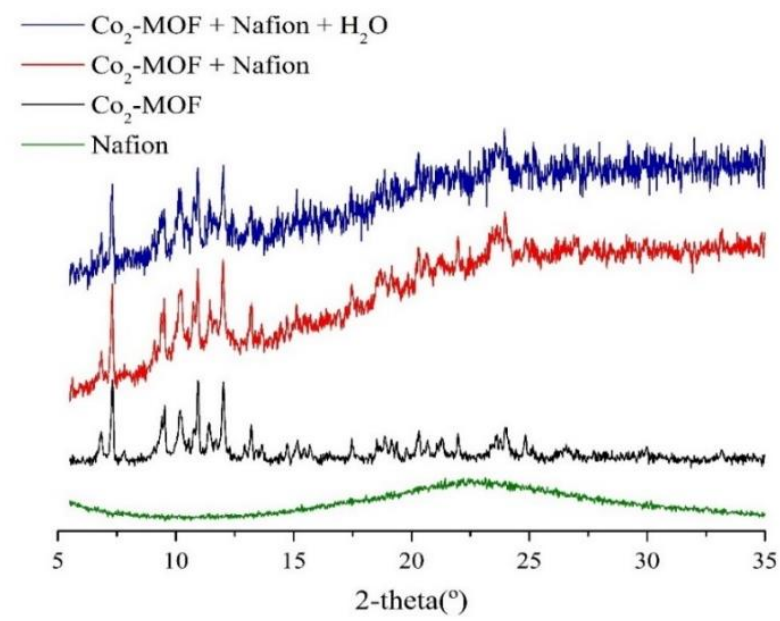

Figura 7.14. Patrones de difracción de rayos X de polvo del Co2-MOF @ Nafion (rojo), Co2MOF@Nafion tras el tratamiento con agua (azul), Co2-MOF (negro) y Nafion (verde). Reproducida con permiso de la ref 135. Copyright 2021 American Chemical Society.

\subsubsection{Sintesis y caracterización del $2 \mathrm{D}$-Co-MOF apilado por interacciones $\pi-\pi$.}

Siguiendo con el objetivo sintetizar MOFs de cobalto con centros de cobalto cercanos en su estructura, se ha utilizado el precursor de cobalto $\left[\mathrm{Co}_{4} \mathrm{O}_{4}(\mathrm{OAc})_{4}(\mathrm{py})_{4}\right]$, esta vez con un ligando bifuncional como el ácido 2,2'-bipiridil-4,4'-dicarboxílico $\left(\mathrm{H}_{2} \mathrm{bda}\right)$. A partir de la reacción solvotermal a $150^{\circ} \mathrm{C}$ del precursor de cobalto con este ligando en piridina (py) se obtuvieron monocristales rojos del 2D-Co-MOF después de 9 días, que se estudiaron por difracción de rayos X de monocristal. Este estudio reveló que el 2D-CoMOF cristaliza en un sistema monoclínico con el grupo espacial $\mathrm{P} 2{ }_{1} / \mathrm{n}$ (Tabla 7.9 de la sección experimental) donde el $\mathrm{Co}^{2+}$ se encuentra en un entorno octaédrico distorsionado (Figura 7.15). 


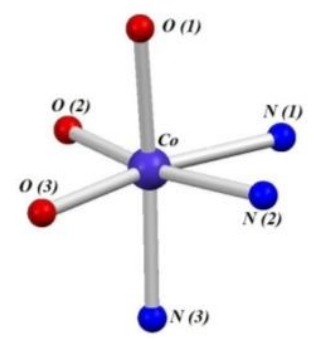

Figura 7.15. Esfera de coordinación en el 2D-Co-MOF. Distancias y ángulos más importantes: $\mathrm{Co}-\mathrm{O}(1)=2.126 \AA$, $\mathrm{Co}-\mathrm{O}(2)=2.055 \AA, \mathrm{Co}-\mathrm{O}(3)=2.088 \AA$, Co-N $(1)=2.160 \AA$, $\mathrm{Co}-\mathrm{N}(2)=2.180 \AA, \mathrm{Co}-\mathrm{N}(3)=2.146 \AA ; \mathrm{N}(1)-\mathrm{Co}-\mathrm{N}(2)=75.83^{\circ}, \mathrm{N}(1)-\mathrm{Co}-\mathrm{O}(2)=91.69^{\circ}, \mathrm{O}(2)-$ $\mathrm{Co}-\mathrm{O}(3)=91.10^{\circ}, \mathrm{O}(3)-\mathrm{Co}-\mathrm{N}(2)=101.46^{\circ}, \mathrm{O}(1)-\mathrm{Co}-\mathrm{N}(3)=172.64^{\circ}$. Reproducida con permiso de la ref 153. Copyright 2021 American Chemical Society.

Cada centro de cobalto está coordinado por tres átomos de oxígeno de tres ligandos bda ${ }^{2-}$ diferentes, uno de ellos en posición axial (oxígeno $\mathrm{sp}^{2}$ del grupo carboxilato) y los otros dos en posiciones ecuatoriales (sustituyente alcoxi del grupo carboxilato). Estos grupos carboxilatos quelatan de forma monodentada. De esta forma, cada uno de los oxígenos del grupo carboxilato está coordinado con un centro de cobalto diferente. Además, otro ligando $\mathrm{bda}^{2-}$, diferente de los 3 que se coordinan por el carboxilato al centro metálico, se coordina al $\mathrm{Co}^{2+}$ de forma bidentada por los dos átomos de nitrógeno. La sexta posición de coordinación, la segunda posición axial, la ocupa un ligando piridina, para así formar un ión metálico hexacoordinado (Figura 7.16 a).
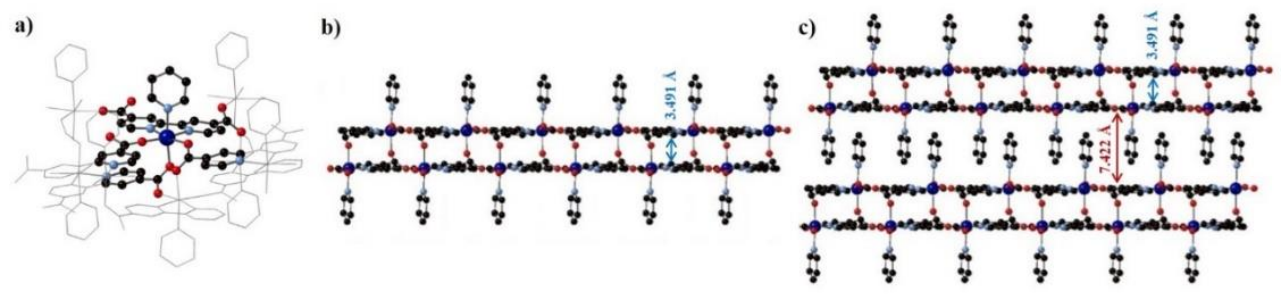

Figura 7.16. Estructura de Rayos $X$ del 2D-Co-MOF. a) unidad de construcción secundaria (SBU), b) una nanolámina que incluye dos láminas individuales, c) Estructura apilada por interacciones $\pi-\pi$ de las láminas dobles del 2D-Co-MOF. La flecha azul indica la distancia entre dos láminas individuales dentro de la nanolámina (3.491 Å) y la flecha roja indica la distancia interláminas en la estructura apilada por interacciones $\pi-\pi(7.422 \AA)$. Reproducida con permiso de la ref 153. Copyright 2021 American Chemical Society. 
Este material se extiende en dos direcciones del espacio, formando un material laminar 3D, que consiste en nanoláminas que incluyen dos láminas individuales con una distancia interplanar de $3.491 \AA$ (Figura 7.16 b). Las nanoláminas dobles consecutivas se empaquetan además en una estructura supramolecular tridimensional a través de interacciones $\pi-\pi$ entre los anillos de los ligandos piridina (Figura $7.16 \mathrm{c}$ ). La distancia entre dos centroides de los anillos de piridina es $4.238 \AA$. Por otro lado, dos átomos de cobalto de dos láminas diferentes están conectados por dos grupos carboxilato de dos ligandos $\mathrm{bda}^{2-}$ diferentes, siendo la distancia entre estos centros metálicos de $4.69 \AA$.

Para este material, se ha comprobado que la estructura del total del material se corresponde con la estructura obtenida por difracción de rayos $\mathrm{X}$ de monocristal, simulando el difractograma de rayos $\mathrm{X}$ de polvo a partir de los datos cristalográficos obtenidos del análisis del monocristal y comparándolo con el difractograma de rayos $\mathrm{X}$ de polvo medido para el material bulk (Figura 7.17).

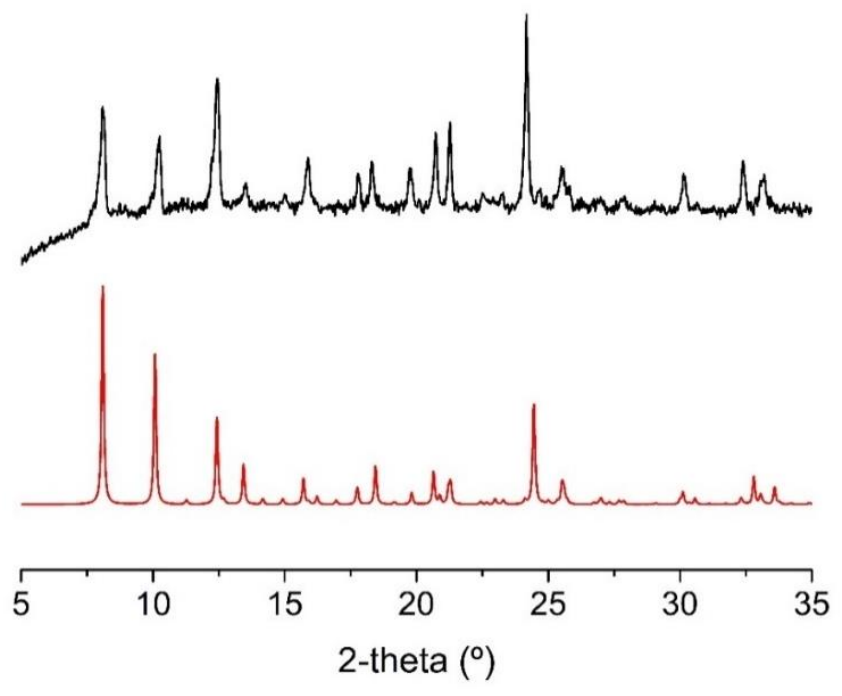

Figura 7.17. Patrones de difracción de rayos $X$ de polvo del 2D-Co-MOF medido (negro) y calculado a partir de los datos de difracción de rayos X de monocristal (rojo). Reproducida con permiso de la ref 153. Copyright 2021 American Chemical Society. 
Además, se ha observado que el uso del $\left[\mathrm{Co}_{4} \mathrm{O}_{4}(\mathrm{OAc})_{4}(\mathrm{py})_{4}\right]$ como precursor es clave en la síntesis del 2D-Co-MOF, que no se ha conseguido obtener usando precursores de cobalto comerciales como el $\mathrm{Co}(\mathrm{OAc})_{2} \cdot 4 \mathrm{H}_{2} \mathrm{O}$ o el $\mathrm{Co}\left(\mathrm{NO}_{3}\right)_{2} \cdot 6 \mathrm{H}_{2} \mathrm{O}$ en un amplio rango de condiciones diferentes de síntesis $\left(\mathrm{T}=100,135,150^{\circ} \mathrm{C}\right.$ durante $1,4,9,14$ y 25 días $)$ (más información en la Tabla 7.8 de la sección experimental).

La estabilidad térmica de este MOF de cobalto se estudió mediante su análisis termogravimétrico (Figura 7.18 a), en el cual se observan tres pérdidas de peso principales. La primera pérdida a $120^{\circ} \mathrm{C}$ corresponde a la eliminación del disolvente ocluido en el material, como se pudo comprobar al verse reducido este salto en el estudio del MOF tratado a $150^{\circ} \mathrm{C}$ durante 24 horas (Figura 7.18 b). Por otro lado, las otras dos pérdidas de peso alrededor de los $400^{\circ} \mathrm{C}$ están solapadas y se corresponden con pérdidas de peso del 73 y $72 \%$, respectivamente (tras restar la contribución del disolvente) para el material sin tratar y tratado a $150^{\circ} \mathrm{C}$, respectivamente. Esta pérdida de peso se puede asociar a la pérdida de las piridinas coordinadas y los ligandos bda (parte orgánica), cuya pérdida de masa teórica se estima en un $77 \%$. 


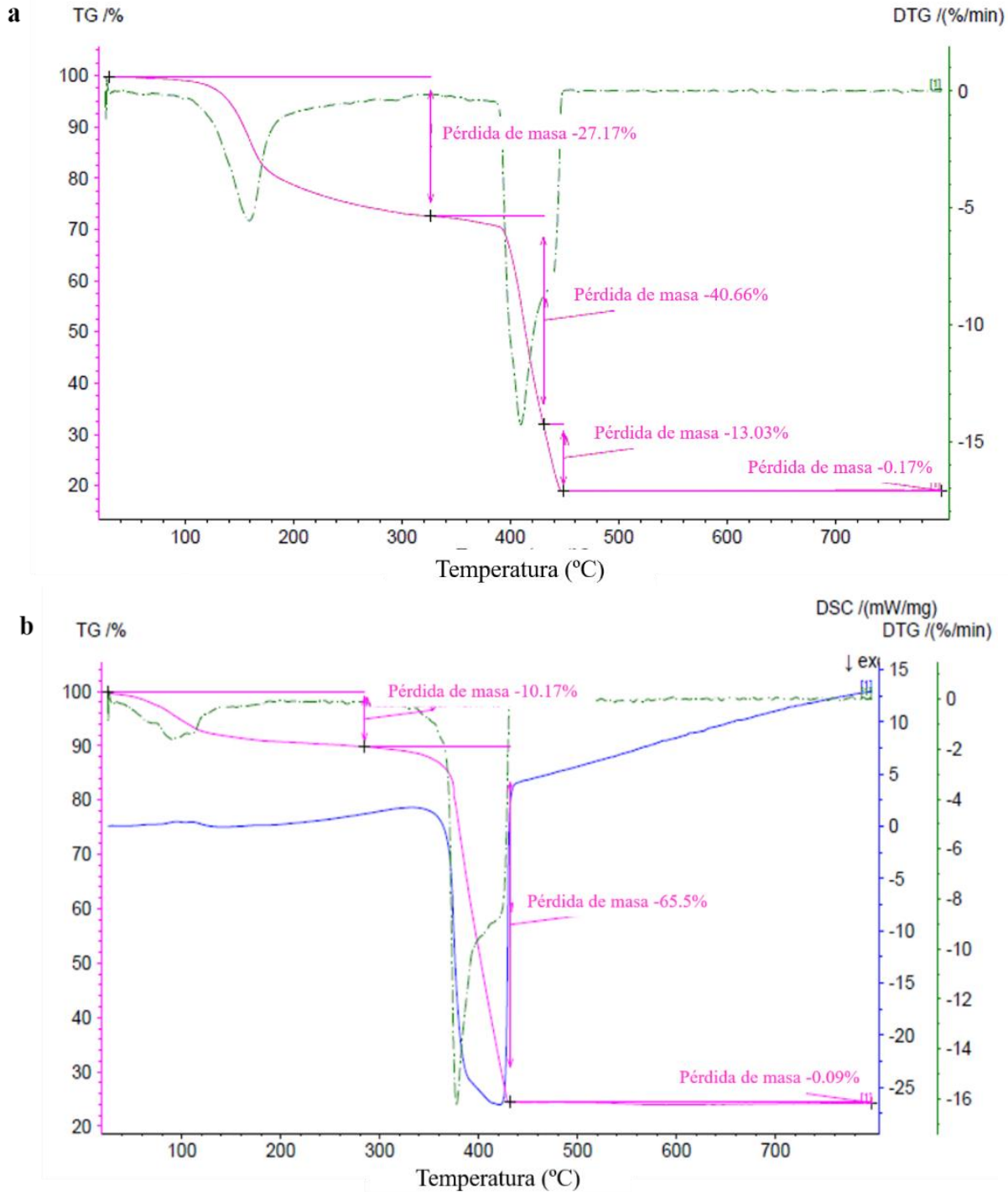

Figura 7.18. Análisis termogravimétrico de a) 2D-Co-MOF y b) 2D-Co-MOF después de tratarlo a $150^{\circ} \mathrm{C}$ durante 24 horas. Reproducida con permiso de la ref 153 . Copyright 2021 American Chemical Society. 
A través de experimentos de adsorción de $\mathrm{CO}_{2}$, se estudió la microporosidad del material, que presenta una capacidad de adsorción de este gas de $1.1 \mathrm{mmol} / \mathrm{g}$ a $0^{\circ} \mathrm{C}$ y $100 \mathrm{kPa}$ (Figura 7.19), lo que corresponde a un área superficial aparente de $61 \mathrm{~m}^{2} / \mathrm{g}$.
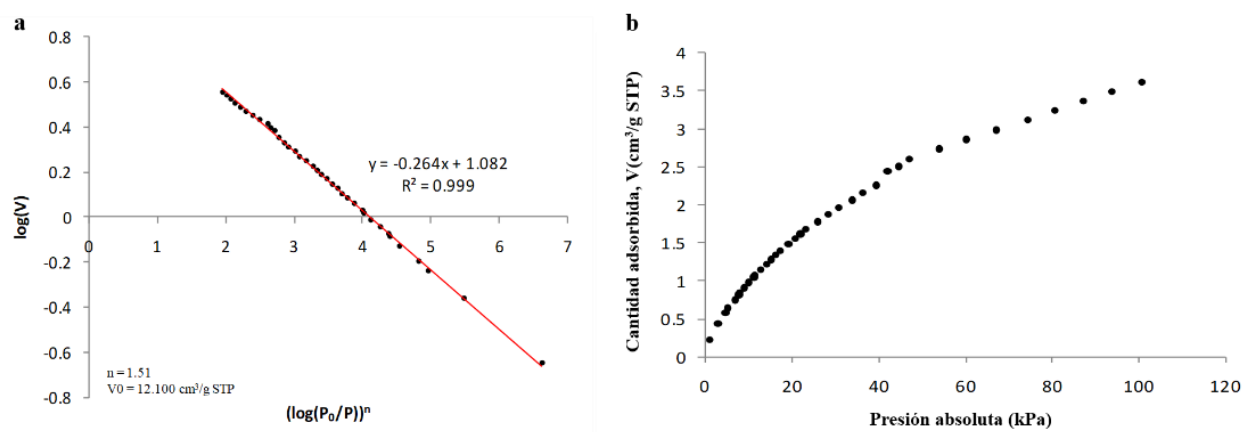

Figura 7.19. Aplicación de la ecuación de Dubinin-Astakhov de la adsorción de $\mathrm{CO}_{2}$ a 273 K al 2D-Co-MOF, b) isoterma de adsorción para el 2D-Co-MOF a 273 K. Reproducida con permiso de la ref 153. Copyright 2021 American Chemical Society.

Por otro lado, para conocer más acerca de la morfología y la composición de este material, el 2D-Co-MOF se estudió por microscopía electrónica de barrido y se analizó con EDX (Figura 7.20). Los cristales del 2D-Co-MOF presentan una morfología hexagonal, y todos los elementos constituyentes están homogéneamente distribuidos, como se puede observar en las imágenes de EDX.
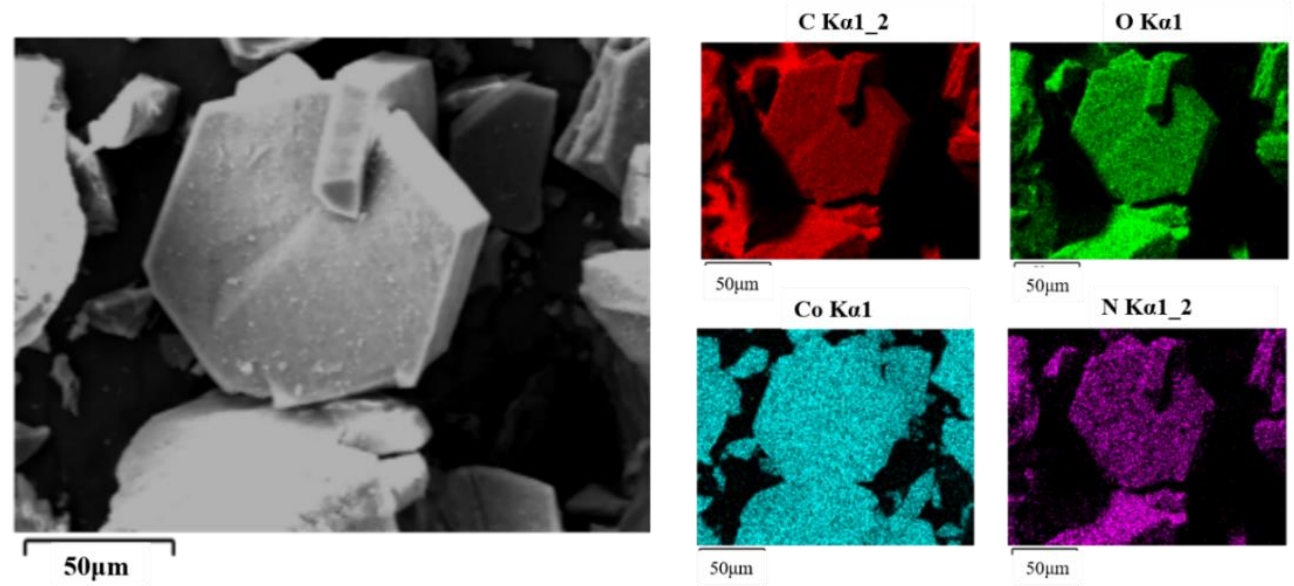

Figura 7.20. Imagen de FESEM y análisis EDX del 2D-Co-MOF. Reproducida con permiso de la ref 153. Copyright 2021 American Chemical Society. 
La estructura electrónica de este material se analizó por XPS (Figura 7.21) para dilucidar la naturaleza del entorno de coordinación del cobalto. El espectro muestra la presencia de carbono, nitrógeno, oxígeno y cobalto. Como se ha comentado para el caso del MOF dinuclear, aunque el valor de energía de enlace $(\mathrm{Eb})$ se utiliza típicamente en el XPS para determinar el número de oxidación de un elemento químico, para los elementos de transición 3d el desdoblamiento espín-orbital es un valor más informativo. En el caso del 2D-Co-MOF, los valores de Eb para el Co $2 \mathrm{p}_{3 / 2}$, Eb para el Co $2 \mathrm{p}_{1 / 2}$ y $\Delta \mathrm{E}_{1}$ son 780.7, 796.4 y $15.7 \mathrm{eV}$, respectivamente. Además, se han observado picos satélite intensos $\left(\Sigma\right.$ sat $\left./ \mathrm{ICo}_{2 \mathrm{p}}>1.6\right)$ para el espectro de Co $2 \mathrm{p}_{3 / 2}$. Tanto los valores de $\Sigma \mathrm{sat} / \mathrm{ICo}_{2 \mathrm{p}}$ como los de $\Delta \mathrm{E}_{1}$ son característicos de los compuestos de cobalto (II) de alto espín, ${ }^{146-149}$ lo cual indica que los centros de cobalto en el 2D-Co-MOF se encuentran exclusivamente en estado de oxidación Co(II). Por otro lado, el pico O 1s se deconvolucionó en dos componentes a 531.1 y $532.6 \mathrm{eV}$, correspondientes a $\mathrm{O}=\mathrm{C}-\mathrm{O}$ y $\mathrm{C}-\mathrm{O}$, respectivamente (Figura 7.21 b). Finalmente, el pico del N 1s solo presenta una contribución a 399 eV, característica de los nitrógenos piridínicos (Figura 7.21 c).
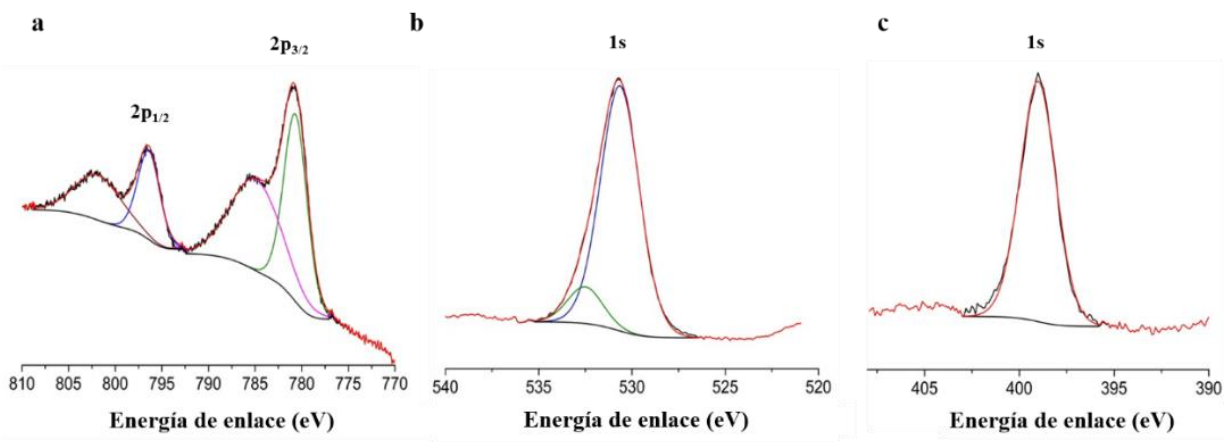

Figura 7.21. Espectro XPS de a) línea Co 2p, b) línea O 1s, c) N 1s del 2D-Co-MOF. Reproducida con permiso de la ref 153. Copyright 2021 American Chemical Society.

\section{Estabilidad química del 2D-Co-MOF.}

Finalmente, se ha estudiado la estabilidad química del nuevo 2D-Co-MOF en distintos disolventes mediante la difracción de rayos $\mathrm{X}$ de polvo. Así, se midieron los distintos difractogramas tras poner en contacto este material con disolventes próticos como el etanol o el agua, disolventes no próticos como el acetonitrilo y disolventes fuertemente alcalinos como la trietilamina $(\mathrm{pH}=12.7)$ (Figura 7.22). 


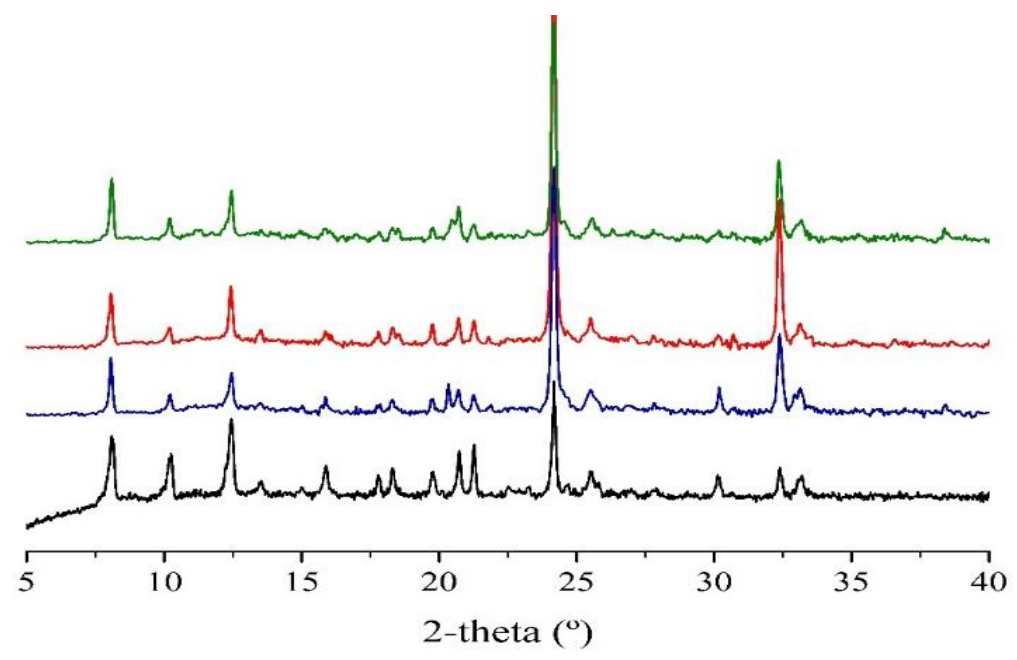

Figura 7.22. Patrones de difracción de rayos $X$ de polvo del 2D-Co-MOF (negro) y después de ser tratado con distintos disolventes como etanol (rojo), acetonitrilo (azul) y trietilamina $(\mathrm{pH}=12.7)$ (verde). Reproducida con permiso de la ref 153. Copyright 2021 American Chemical Society.

La difracción de rayos $\mathrm{X}$ de polvo revela que este material mantiene su estructura intacta en presencia de etanol, acetonitrilo y trietilamina a $25^{\circ} \mathrm{C}$, sin embargo, su tratamiento con agua produce un cambio estructural significativo.

Con el fin de evaluar la estabilidad química del 2D-Co-MOF en agua para su aplicación en la reacción de evolución de oxígeno se llevaron a cabo varios experimentos para dilucidar sus cambios estructurales. En concreto, se midieron los espectros Raman, la difracción de rayos X de polvo y el XPS del MOF de cobalto apilado por interacciones $\pi-\pi$ antes y después de su tratamiento con agua durante 5 minutos. Como se puede observar en los espectros de Raman representados en la Figura 7.23, el resultado más interesante en presencia de agua (espectro rojo) es la pérdida de las bandas Raman asociadas a los ligandos piridina coordinados axialmente $\left(768,1010\right.$ y $\left.1283 \mathrm{~cm}^{-1}\right)$. Por otro lado, tanto las bandas asociadas a la bipiridina $\left(774,1022\right.$ y $\left.1278 \mathrm{~cm}^{-1}\right)$ como las asociadas los grupos carboxilato $\left(1289,1426,1546\right.$ y $\left.1615 \mathrm{~cm}^{-1}\right)$, se mantienen en el espectro Raman, lo que indica que los centros de cobalto conservan su coordinación con los ligandos bda, tanto por los nitrógenos de la bipiridina como por los grupos carboxilato después del tratamiento con agua. 

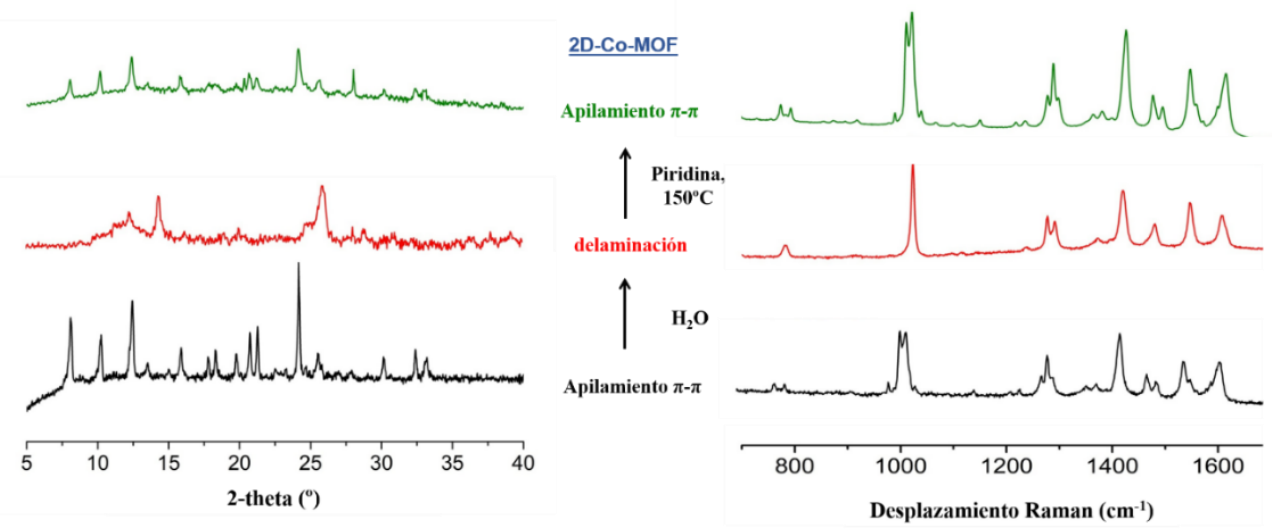

Figura 7.23. Patrón de difracción de rayos $\mathrm{X}$ de polvo (izquierda) y espectro Raman (derecha) del 2D-Co-MOF apilado por interacciones $\pi-\pi$ antes (negro) y después de tratamiento sucesivo con agua durante 5 min (rojo) y con piridina durante 2 días a $150^{\circ} \mathrm{C}$ (verde). Reproducida con permiso de la ref 153. Copyright 2021 American Chemical Society.

Por otro lado, el espectro XPS del 2D-Co-MOF después del tratamiento con agua revela que la contribución a $532.8 \mathrm{eV}$ al pico principal del $\mathrm{O} 1 \mathrm{~s}$ aumenta, lo que se atribuye a las moléculas de agua coordinadas a centros de cobalto. ${ }^{154}$ Este hecho sugiere que el ligando axial más lábil, la piridina, es sustituido por moléculas de agua (Figura 7.24). Además, el cambio general del patrón de PXRD, con la pérdida o ensanchamiento de algunas de las bandas características (espectro rojo en la Figura 7.23), es consistente con una delaminación de la estructura tridimensional apilada por interacciones $\pi-\pi$ del MOF para producir nano láminas individuales, cuya estructura de láminas dobles se conserva. 

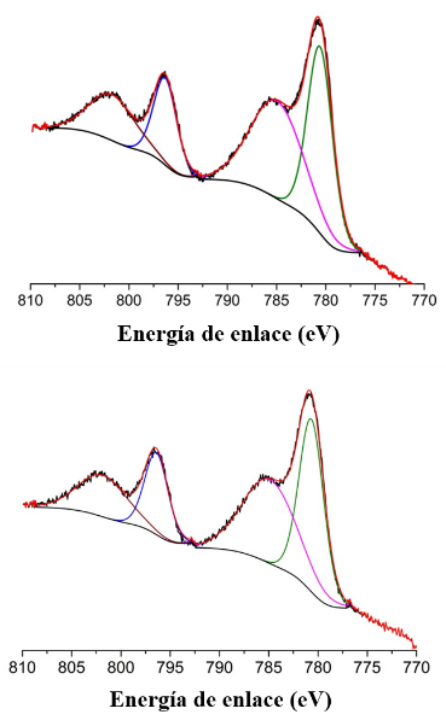
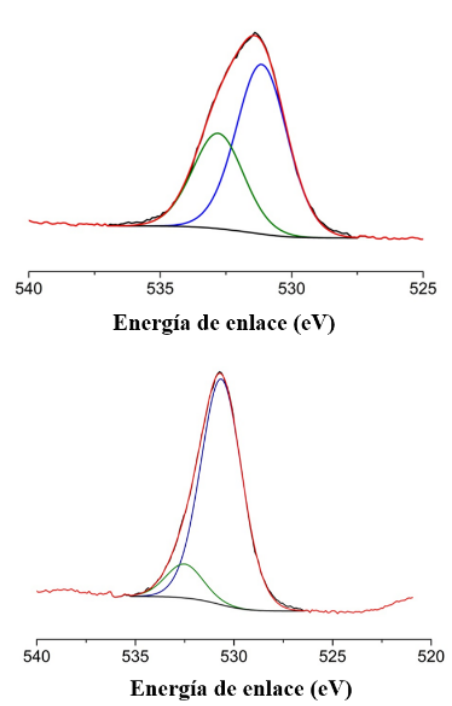

\section{D-Co-MOF}

Delaminado

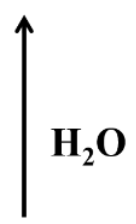

Apilamiento $\pi-\pi$

Figura 7.24. Espectro XPS de las líneas de Co 2p y O 1s del 2D-Co-MOF antes (abajo) y después (arriba) de su tratamiento con agua. Reproducida con permiso de la ref 153.

Copyright 2021 American Chemical Society.

Cabe destacar que la estructura tridimensional del 2D-Co-MOF delaminado se puede regenerar a través de un proceso solvotermal con piridina a $150{ }^{\circ} \mathrm{C}$ durante 2 días (espectro verde en la Figura 7.23). Este hecho ha sido corroborado utilizando XPS, donde la contribución a $532.8 \mathrm{eV}$ en el pico principal de $\mathrm{O} 1 \mathrm{~s}$, que se atribuye a las moléculas de agua coordinadas al cobalto, desaparece después del tratamiento con piridina (Figura 7.25), lo que indica que los ligandos piridina vuelven a coordinarse de nuevo, y, por tanto, la regeneración de la estructura $3 \mathrm{D}$ apilada por interacciones $\pi-\pi$ de los anillos de piridina. 

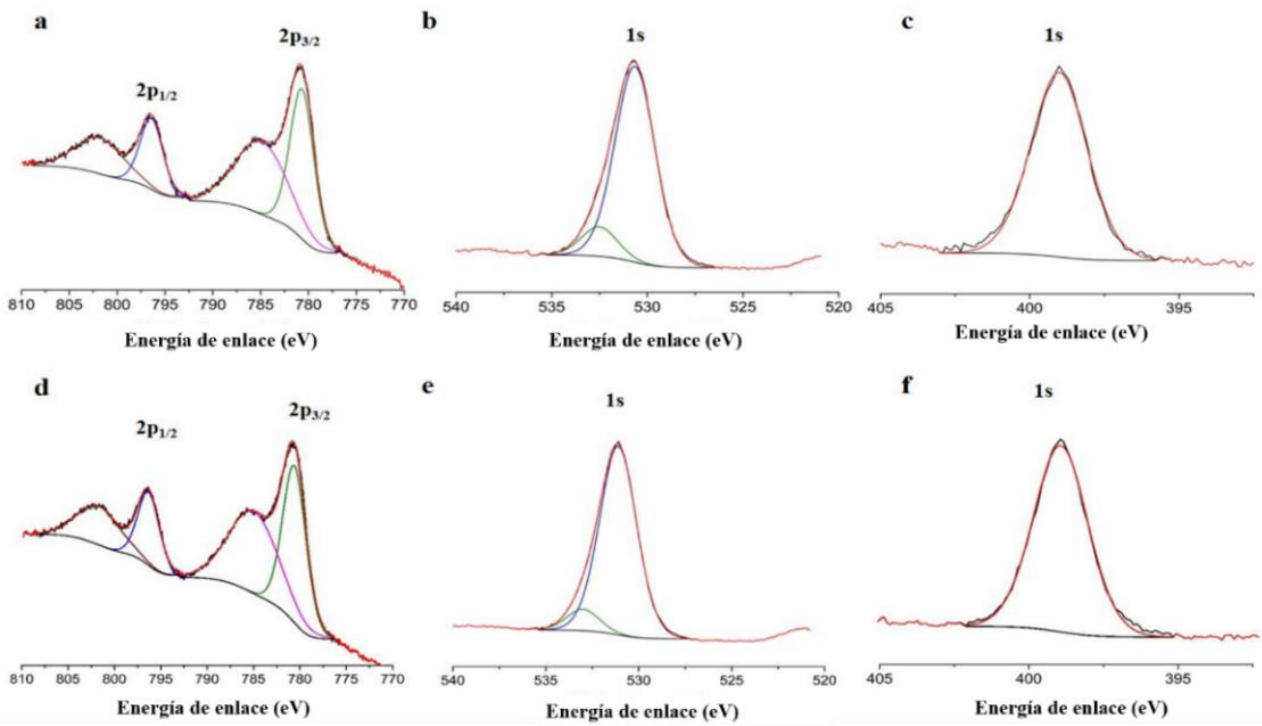

Figura 7.25. Espectro XPS para las líneas (a, d) Co 2p, (b, e) O 1s y (c, f) N 1s del 2D-CoMOF (a, b c) y el 2D-Co-MOF después de ser tratado sucesivamente con agua y con piridina a $150^{\circ} \mathrm{C}$ durante 2 días (d, e, f). Reproducida con permiso de la ref 153 . Copyright 2021 American Chemical Society.

Por último, la caracterización de la estructura regenerada del 2D-Co-MOF se ha completado con análisis elemental e ICP, que confirman la misma composición del material bulk regenerado (Tabla 7.2).

Tabla 7.2. Resultados de Análisis Elemental e ICP para el 2D-Co-MOF y el 2D-Co-MOF después de ser tratado sucesivamente con agua y con piridina a $150^{\circ} \mathrm{C}$ durante 2 días.

\begin{tabular}{|c|c|c|c|c|}
\hline Resultados AE, ICP & \% Co & \% C & \% H & \% N \\
\hline 2D-Co-MOF & 15.05 & 55.07 & 3.05 & 10.77 \\
\hline 2D-Co-MOF regenerado & 14.96 & 55.19 & 3.18 & 10.59 \\
\hline
\end{tabular}

Según los datos publicados hasta la fecha, esta es la primera vez que un MOF ha demostrado un "efecto memoria" en el proceso de delaminación-pilarización, que es típico de materiales $2 \mathrm{D}$ como las hidrotalcitas. ${ }^{155}$ 
Por otra parte, para evaluar la idoneidad del 2D-Co-MOF como electrocatalizador, se estudió la estabilidad del material obtenido al estabilizar el 2D-Co-MOF en Nafion (2DCo-MOF@Nafion). ${ }^{156}$ La influencia del Nafion en la estabilidad química de la estructura tridimensional del MOF en agua se estudió a través de la difracción de rayos $\mathrm{X}$ de polvo. A partir de la comparación de los XPRD del 2D-Co-MOF medidos antes y después de su tratamiento con agua para diferentes tiempos de contacto (Figura 7.26) se encontró que el 2D-Co-MOF apilado por interacciones $\pi$ - $\pi$ adopta una orientación preferencial [100] en el composite, donde los cristales del MOF interactúan en el plano con el Nafion. Además, en presencia de una disolución acuosa, la estructura tridimensional del MOF solo duró 40 minutos antes de sufrir el proceso de delaminación, por lo que se puede concluir que el Nafion ralentiza el intercambio de agua-piridina, pero no lo impide. Finalmente, se ha comprobado que el actual composite 2D-CoMOF@Nafion muestra una buena adherencia a los electrodos de grafito y una buena estabilidad química para su aplicación en la reacción de oxidación electrocatalítica del agua.

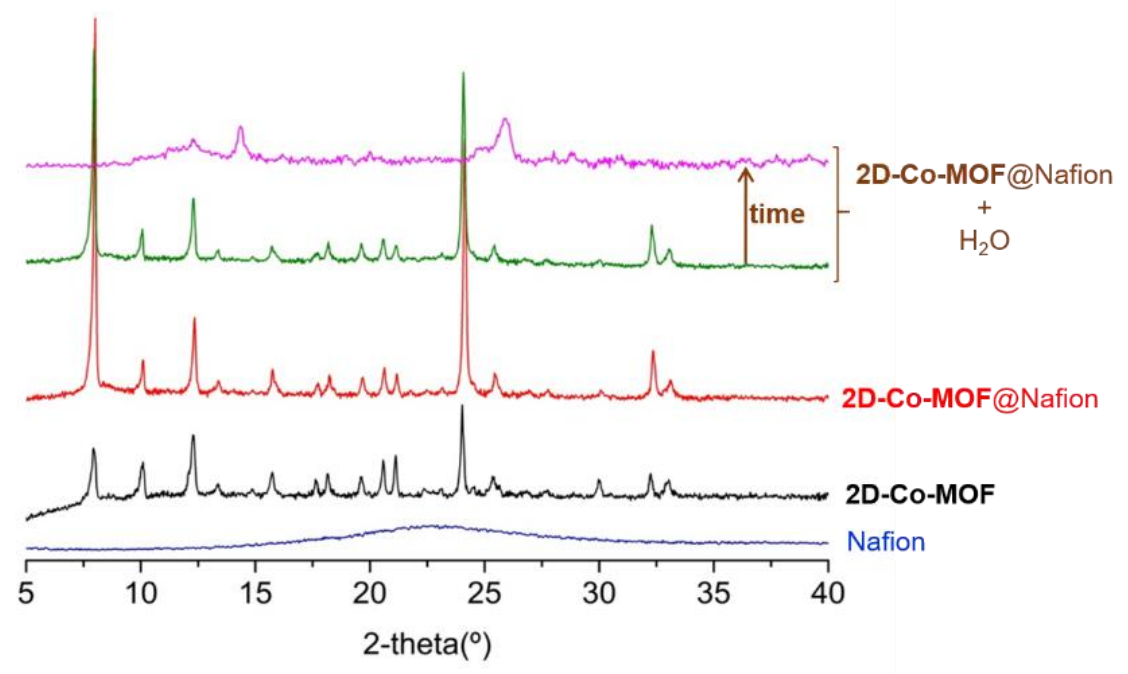

Figura 7.26. Patrones de difracción de rayos $X$ de polvo del Nafion (azul), 2D-Co-MOF apilado por interacciones $\pi$ - $\pi$ (negro), 2D-Co-MOF@Nafion (rojo), 2D-Co-MOF@ Nafion tras su tratamiento durante 5 min con agua (verde) y 2D-Co-MOF@Nafion tras su tratamiento durante 1 hora con agua (rosa). Reproducida con permiso de la ref 153 . Copyright 2021 American Chemical Society. 


\subsubsection{Estudio electroquímico de los MOFs de cobalto.}

\subsubsection{Estudio electroquímico del $\mathrm{Co}_{2}-\mathbf{M O F}$ y comparación con $\mathbf{C o}-\mathbf{M O F}$.}

Teniendo en cuenta la presencia de centros redox en el $\mathbf{C o}_{2} \mathbf{M O F}$, se estudió su comportamiento electroquímico por Voltametría cíclica (CV) empleando para ello un electrodo de grafito pirolítico recubierto con una película del $\mathbf{C o}_{2}$-MOF @ Nafion en una disolución $0.1 \mathrm{M}$ de $\left[\mathrm{Et}_{4} \mathrm{~N}\right] \mathrm{BF}_{4}$ en acetonitrilo (Figura 7.27 a). El voltamograma consiste en dos ondas cuasireversibles bien resueltas a $1.02 \mathrm{~V}$ (onda I) y $1.35 \mathrm{~V}$ (onda II), superpuestas a una corriente de fondo creciente. Para obtener información sobre la conversión redox implicada en cada onda voltamperométrica se midió también el voltamograma del Co-MOF mononuclear (Figura 7.27 a). En este caso también se observan dos ondas voltamperométricas bien resueltas situadas a $0.61 \mathrm{~V}$ y $1.35 \mathrm{~V}$, que corresponden a dos conversiones redox monoelectrónicas consecutivas $\mathrm{Co}(\mathrm{II}) / \mathrm{Co}$ (III) (onda I) y $\mathrm{Co}(\mathrm{III}) / \mathrm{Co}(\mathrm{IV}$ ) (onda II), respectivamente (esquema de la Figura 7.27 b). La similitud de la carga bajo las ondas voltamperométricas para ambos MOFs sugiere que en el caso del Co2-MOF también se están produciendo transferencias de carga monoelectrónicas. La primera se puede asignar a la conversión redox de Co(II)/Co(III). Para la segunda onda, sin embargo, hay dos escenarios viables (Figura $7.27 \mathrm{c}$ ):

- (i) la conversión redox de $\mathrm{Co}(\mathrm{II}) / \mathrm{Co}(\mathrm{III})$ del segundo centro de cobalto

- (ii) la conversión redox de $\mathrm{Co}(\mathrm{III}) / \mathrm{Co}(\mathrm{IV})$ del centro de $\mathrm{Co}(\mathrm{III})$ formado en la primera onda anódica.
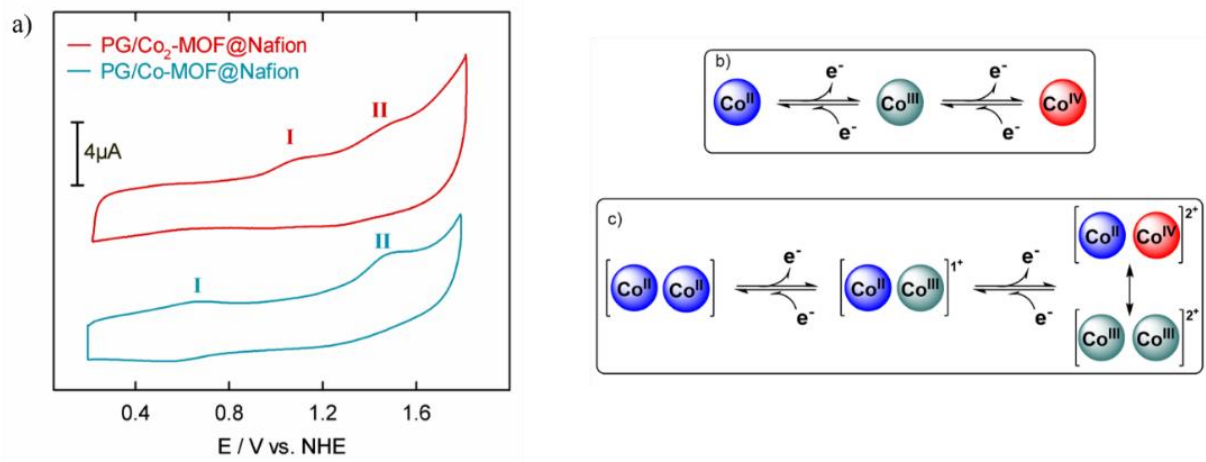

Figura 7.27. a) Voltamogramas cíclicos del electrodo de grafito pirolítico modificado con Co2-MOF@Nafion (línea roja) o con Co-MOF@Nafion (línea azul) medido a $0.05 \mathrm{~V} \mathrm{~s}^{-1}$ en una disolución que contiene $0.1 \mathrm{M}$ de $\left[\mathrm{Et}_{4} \mathrm{~N}\right] \mathrm{BF}_{4}$ en acetonitrilo a $25^{\circ} \mathrm{C}$. Conversiones redox implicadas en la respuesta voltamétrica del b) Co-MOF y c) Co2-MOF. Reproducida con permiso de la ref 135. Copyright 2021 American Chemical Society. 
Aunque no se puede discriminar entre estas dos posibilidades, la similitud de los valores de potencial para la segunda onda en el Co-MOF y el Co2-MOF sugieren que esta segunda onda del Co2-MOF también puede corresponder a la conversión redox de $\mathrm{Co}(\mathrm{III}) /(\mathrm{Co}(\mathrm{IV})$. Sin embargo, no se puede obviar que ambas especies $\mathrm{Co}(\mathrm{II})-\mathrm{Co}(\mathrm{IV})$ y $\mathrm{Co}(\mathrm{III})-\mathrm{Co}(\mathrm{III})$ podrían coexistir en equilibrio como ha propuesto recientemente el grupo de Nocera para otros catalizadores dinucleares de cobalto para OER basándose en sus características electrónicas específicas. ${ }^{131,157}$

Además, se ha observado que un aumento de la velocidad de barrido de 0.002 a $0.2 \mathrm{v} \mathrm{s}^{-1}$ resulta en una disminución de la carga de Faraday de $\sim 7.5$ a $\sim 0.6 \mu \mathrm{C}$ (Figuras 7.28 y 7.29). Este hecho se corresponde con una limitación progresiva de la conversión redox por transferencia de carga a través de un sistema multicapa. ${ }^{158,159}$ Además, la pequeña variación del potencial del pico anódico con la velocidad de barrido (Figuras 7.28 y 7.29) es un parámetro indicativo de que existen diferentes entornos para los centros de cobalto a lo largo de la lámina del MOF.
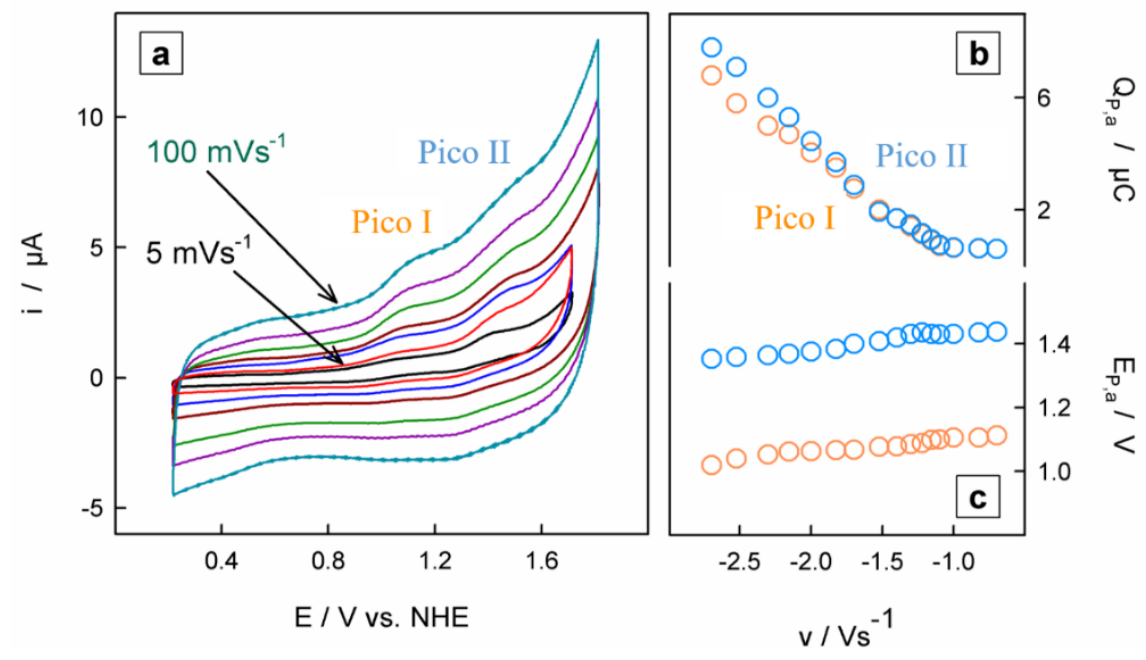

Figura 7.28. a) Voltamogramas cíclicos del electrodo de grafito pirolítico modificado con Co2-MOF@Nafion medido a diferentes velocidades de barrido de potencial en una disolución que contiene $0.1 \mathrm{M}$ de $\left[\mathrm{Et}_{4} \mathrm{~N}\right] \mathrm{BF}_{4}$ en acetonitrilo a $25^{\circ} \mathrm{C}$. b) Cargas anódicas voltamétricas de Faraday y c) picos de potencial anódicos como una función de la velocidad de barrido de potencial. Reproducida con permiso de la ref 135. Copyright 2021 American Chemical Society. 


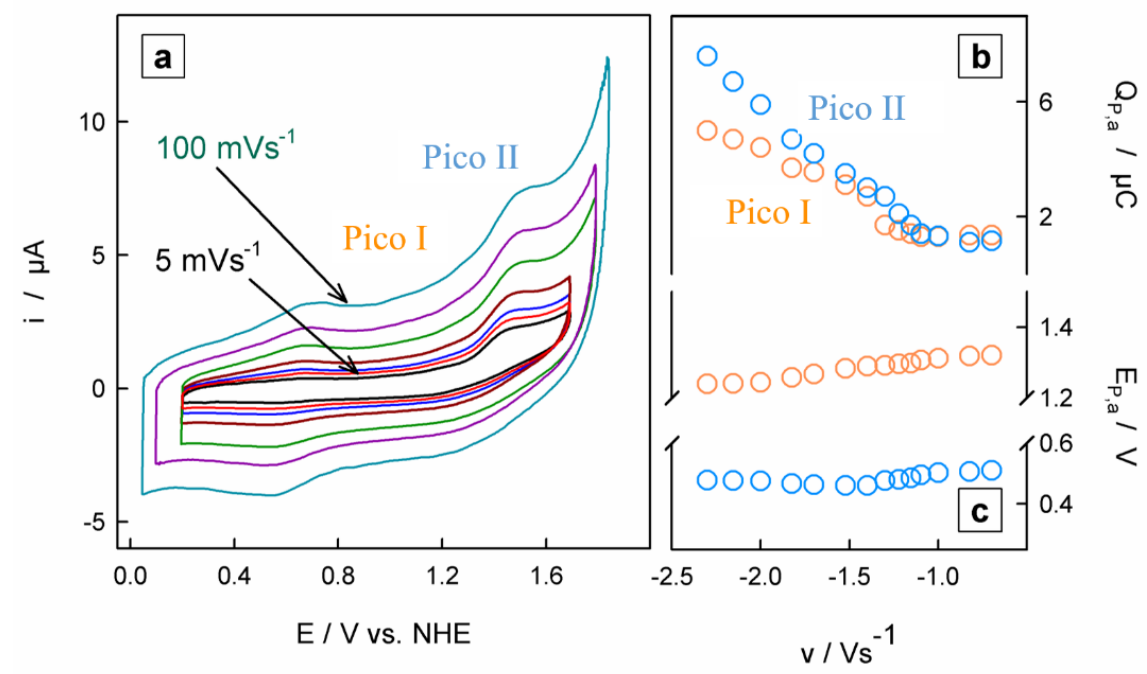

Figura 7.29. a) Voltamogramas cíclicos del electrodo de grafito pirolítico modificado con Co-MOF@ Nafion medido a diferentes velocidades de barrido de potencial en una disolución que contiene $0.1 \mathrm{M}$ de $\left[\mathrm{Et}_{4} \mathrm{~N}\right] \mathrm{BF}_{4}$ en acetonitrilo a $25^{\circ} \mathrm{C}$. b) Cargas anódicas voltamétricas de Faraday y c) picos de potencial anódicos como una función de la velocidad de barrido de potencial. Reproducida con permiso de la ref 135. Copyright 2021 American Chemical Society.

Por otro lado, cabe señalar que, al extender el barrido de potencial a valores más negativos aparecen dos ondas voltamperométricas catódicas adicionales a $-0.450 \mathrm{~V} \mathrm{y}$ $-0.870 \mathrm{~V}$ (vs NHE, Electrodo Normal de Hidrógeno), con sus correspondientes ondas anódicas a $-0.317 \mathrm{~V}$ y $-0.080 \mathrm{~V}$ (frente a NHE) (Figura 7.30). El hecho de que la onda catódica más negativa también aparezca en la medida del electrodo de grafito recubierto de Nafion sin el MOF revela que sólo la primera onda catódica a $-0.450 \mathrm{~V}$ se puede atribuir a la reducción de los centros de cobalto. La similitud de la carga con la línea base corregida con la carga total intercambiada en las dos ondas anódicas que preceden a la señal del OER sugiere que estas ondas corresponden a dos conversiones redox monoelectrónicas $\mathrm{Co}(\mathrm{II})-\mathrm{Co}(\mathrm{II}) / \mathrm{Co}(\mathrm{I})-\mathrm{Co}(\mathrm{I})$. 


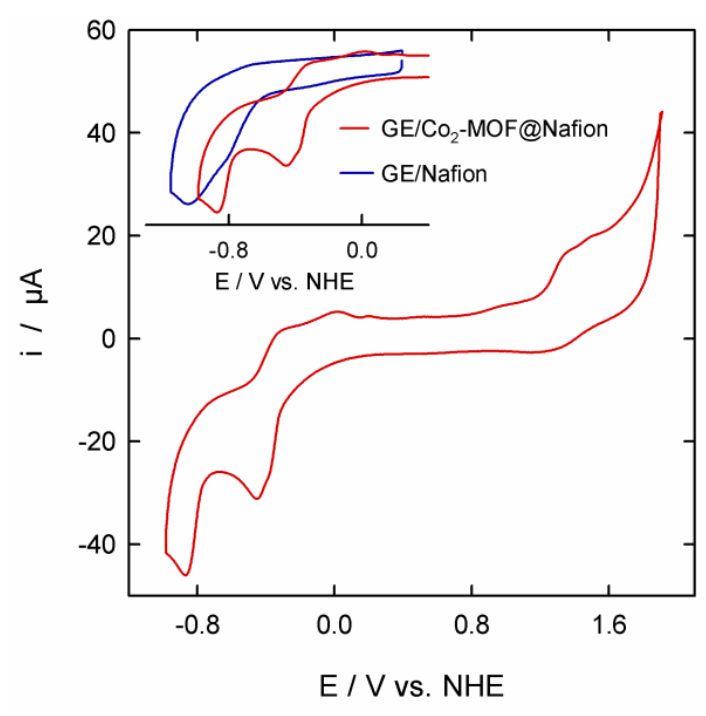

Figura 7.30. a) Voltamogramas cíclicos del electrodo de grafito pirolítico modificado con Co2-MOF@Nafion medido a $50 \mathrm{mV} \mathrm{s}^{-1}$ en una disolución que contiene $0.1 \mathrm{M}$ de $\left[\mathrm{Et}_{4} \mathrm{~N}\right] \mathrm{BF}_{4}$ en acetonitrilo a $25^{\circ} \mathrm{C}$. Diagrama integrado: respuesta voltamétrica en la ventana de potencial negativo para un electrodo de grafito pirolítico modificado con Nafion (línea azul) y con Co2MOF@Nafion (línea roja). Reproducida con permiso de la ref 135. Copyright 2021 American Chemical Society.

Por otro lado, la segunda conversión redox de los dos MOFs de cobalto (Coz-MOF y Co-MOF) va acompañada por un incremento importante de la corriente de fondo (Figura 7.27). El hecho de que esta componente de la corriente global aumente con la adición de volúmenes variables de una disolución acuosa de tampón fosfato sódico (SPB) de $\mathrm{pH} 7$ (Figura 7.31 a) indica que corresponde a una oxidación electrocatalítica del agua catalizada por el Co2-MOF, comúnmente conocido como OER. La insensibilidad de la onda voltamétrica I a la presencia de diferentes cantidades de agua pone de manifiesto que el Nafion no solo sirve para anclar el Co2-MOF a la superficie del electrodo, sino también para evitar su hidrólisis, ya que, de lo contrario, se esperaría un desplazamiento de esta onda voltamétrica hacia el valor observado para el MOF hidrolizado (Co-MOF). 

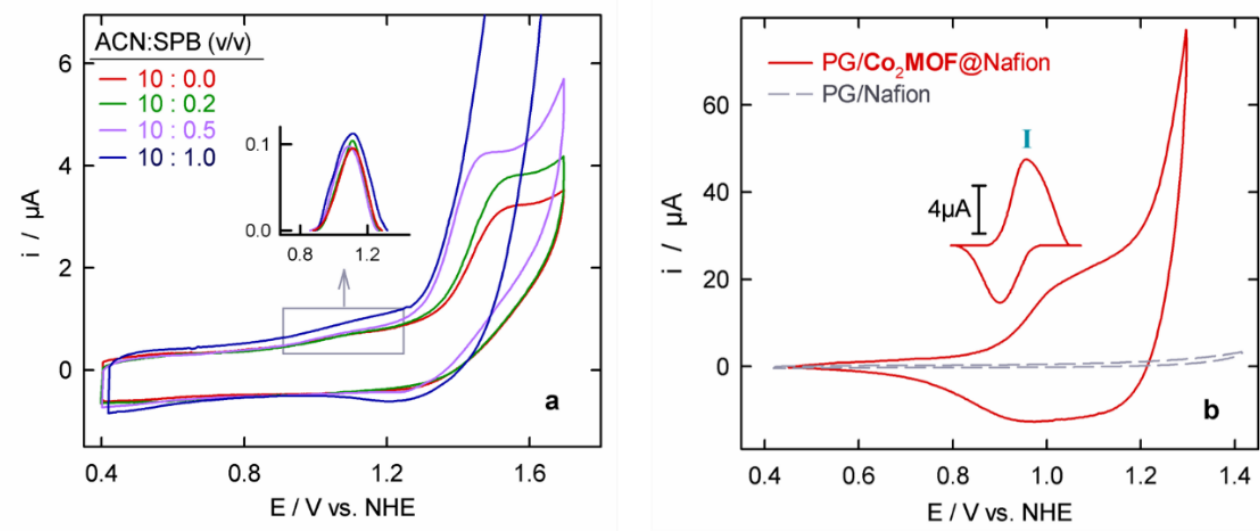

Figura 7.31. a) Voltamogramas cíclicos para el electrodo de grafito pirolítico modificado con el Co2-MOF@ Nafion medido a $10 \mathrm{mV} \mathrm{s}^{-1}$ para los ratios acetonitrilo/disolución acuosa SPB ( $\mathrm{pH}$ 7) indicados. b) Voltamogramas cíclicos para el electrodo de grafito pirolítico modificado con Nafion (línea gris discontinua) o Co2-MOF@ Nafion (línea roja) medidos a $10 \mathrm{mV} \mathrm{s}^{-1}$ en una disolución acuosa $0.1 \mathrm{M} \mathrm{SPB}(\mathrm{pH} 7)$ a $25^{\circ} \mathrm{C}$. Reproducida con permiso de la ref 135. Copyright 2021 American Chemical Society.

En la Figura 7.31 b se puede observar la respuesta voltamperométrica del Co2MOF@Nafion depositado sobre un electrodo de grafito y medido en una disolución SPB $0.1 \mathrm{M}$ de $\mathrm{pH}$ 7. En este caso, se observa solo una onda voltamperométrica (onda I) a 0.98 $\mathrm{V}$ (vs NHE) debido a la superposición del aumento exponencial de la corriente electrocatalítica del OER con la onda voltamperométrica asociada a la segunda conversión redox. En estas condiciones, la dependencia de la velocidad de barrido de los parámetros del pico voltamétrico de la onda I es similar a la observada en acetonitrilo (Figura 7.32). Por tanto, la velocidad de la conversión redox estaría limitada por un transporte de carga a lo largo del film, y se podría concluir que existen diferentes entornos locales para los centros de cobalto a lo largo del MOF. ${ }^{158,159}$ 

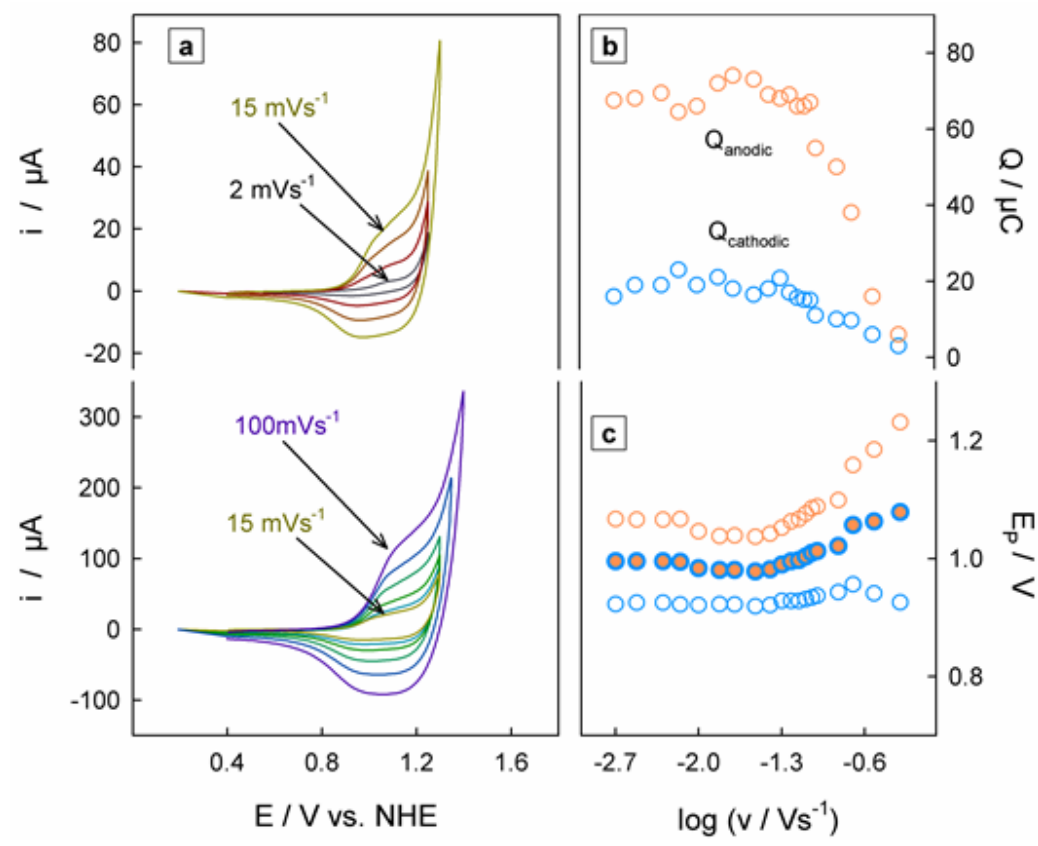

Figura 7.32. a) Voltamogramas cíclicos del electrodo de grafito pirolítico modificado con Co2-MOF@Nafion medido a diferentes velocidades de barrido de potencial en una disolución acuosa de $0.1 \mathrm{M} \mathrm{SPB}$ de $\mathrm{pH} 7$ a $25^{\circ} \mathrm{C}$. b) Cargas voltamétricas de Faraday y c) potenciales de pico y potenciales de punto medio en función de la velocidad de barrido de potencial. Reproducida con permiso de la ref 135. Copyright 2021 American Chemical Society.

7.3.2.2. Estudio electroquímico del 2D-Co-MOF. Relación entre la electroquímica redox y la química de coordinación del composite 2D-Co-MOF@Nafion.

Para el estudio de las propiedades electroquímicas del composite 2D-Co-MOF @Nafion en ausencia de agua, al igual que para el Co2-MOF, en primer lugar, se investigó la electroquímica del material midiendo la respuesta voltamperométrica de un electrodo de grafito pirolítico recubierto con el composite en una disolución de acetonitrilo que contiene 0,1 $\mathrm{M}\left[\mathrm{Et}_{4} \mathrm{~N}\right] \mathrm{PF}_{6}$. Como se puede observar en la Figura 7.33 a, su respuesta electroquímica se caracteriza por dos ondas voltamperométricas a $0.65 \mathrm{~V}$ (onda I) y 1.38 $\mathrm{V}$ (onda II) frente al NHE, que corresponden a las conversiones redox $\mathrm{Co}(\mathrm{II}) / \mathrm{Co}(\mathrm{III}) \mathrm{y}$ $\mathrm{Co}(\mathrm{III}) / \mathrm{Co}(\mathrm{IV})$, respectivamente. 


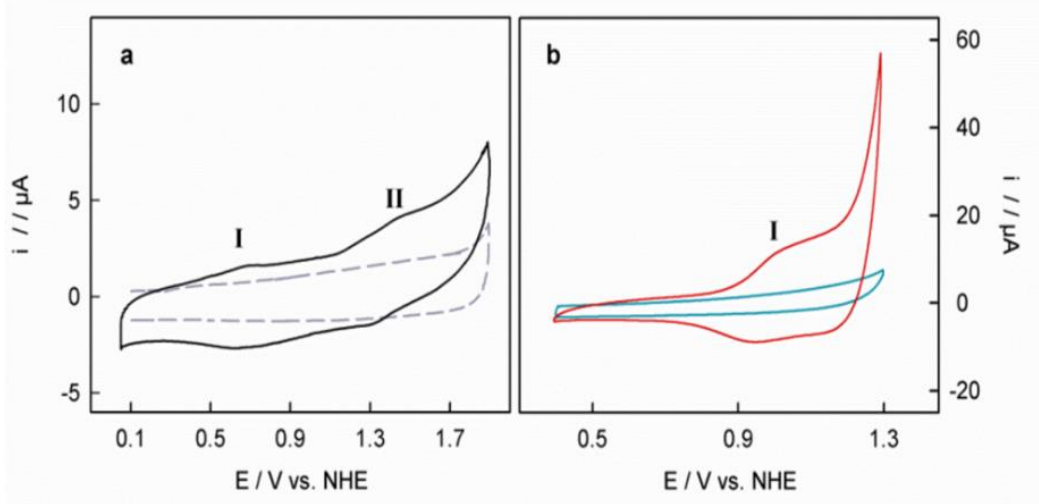

Figura 7.33. a) Voltamograma cíclico de un electrodo de grafito pirolítico modificado con Nafion (línea gris discontinua) o con 2D-Co-MOF@Nafion (línea negra) medidos a $0.05 \mathrm{~V}$ $\mathrm{s}^{-1}$ en acetonitrilo. b) Voltamograma cíclico medido a $0.05 \mathrm{~V} \mathrm{~s}^{-1}$ en una disolución acuosa de tampón fosfato de $\mathrm{pH} 7$ a $25^{\circ} \mathrm{C}$ antes (línea azul) y después (línea roja) de la activación química del 2D-Co-MOF@Nafion depositado en un electrodo de grafito pirolítico. Reproducida con permiso de la ref 153. Copyright 2021 American Chemical Society.

En una disolución tampón de fosfato sódico $0.1 \mathrm{M}(\mathrm{pH}$ 7), la detección de una conversión redox de cobalto significativa requiere la activación electroquímica del electrodo modificado mediante la aplicación de un potencial superior a $1.2 \mathrm{~V}$ (frente a NHE) durante al menos $30 \mathrm{~min}$, como se puede observar comparando los voltamogramas medidos antes (línea azul) y después (línea roja) de la activación electroquímica (Figura 7.33 b). Como se ha descrito anteriormente, la presencia de Nafion en el composite 2DCo-MOF@Nafion ralentiza el intercambio de los ligandos piridina por agua, pero no lo impide. Según este estudio, en el electrodo modificado con el 2D-Co-MOF@Nafion delaminado, los centros de cobalto se equilibran con la disolución tampón acuosa, coordinándose axialmente con las moléculas de agua.

Por lo tanto, la inactividad electroquímica inicial puede atribuirse en principio a una limitación de la migración iónica a través de la película que se requiere para compensar la carga interfacial desarrollada durante la conversión redox de los centros de cobalto. Esta limitación puede ser ocasionada por la compactación de los dominios hidrofóbicos del Nafion. Con el fin de estudiar esta posibilidad, se midieron las características voltamperométricas del 2D-Co-MOF@Nafion con distintos contenidos de Nafion (Figura 7.34), y se observó que un aumento del contenido de Nafion atenúa las incipientes características voltamperométricas asociadas a la conversión redox de cobalto y el OER. 


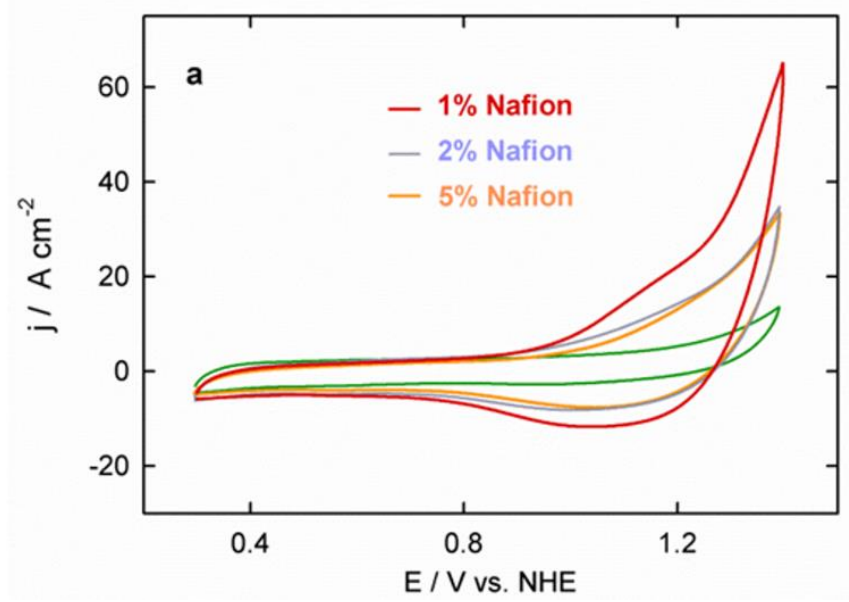

Figura 7.34. Voltamogramas cíclicos medidos a $0.05 \mathrm{~V} \mathrm{~s}^{-1}$ en una disolución acuosa $0.1 \mathrm{M}$ de tampón fosfato de $\mathrm{pH} 7$ a $25^{\circ} \mathrm{C}$ de un electrodo de grafito pirolítico modificado con 2DCo-MOF@Nafion con el contenido de Nafion indicado en el composite después de la activación electroquímica durante 2 horas. El voltamograma cíclico representado en verde corresponde al MOF no activado, independientemente del contenido de Nafion. Reproducida con permiso de la ref 153. Copyright 2021 American Chemical Society.

Este hallazgo corrobora el bloqueo inicial de las propiedades en la película de Nafion y sugiere que un aumento de la corriente electrocatalítica durante la activación electroquímica del composite podría resultar en una descompactación del film. Por otro lado, en el caso del electrodo activado electroquímicamente, solo la primera onda voltamperométrica de cobalto (a $1.04 \mathrm{~V}$ aproximadamente, frente al NHE) está bien resuelta, debido a la contribución concomitante de la corriente electrocatalítica que aumenta exponencialmente, la cual está asociada a la reacción de evolución de oxígeno.

Teniendo en cuenta que las especies electrocatalíticas activas que se han propuesto son Co(IV)-oxo o el radical Co(III)-oxilo, ${ }^{131,157,160}$ la proximidad de la corriente OER a la onda voltamperométrica indica que la formación de las especies mencionadas se favorece en disolución acuosa con respecto a la formación de Co(IV) en acetonitrilo. Para obtener más información sobre la oxidación electrocatalítica del agua catalizada por cobalto, se midió la respuesta voltamperométrica del 2D-Co-MOF@Nafion en acetonitrilo añadiendo volúmenes variables de una disolución acuosa de tampón fosfato de pH 7 a la disolución de acetonitrilo inicial en la celda electroquímica (Figura 7.35). 


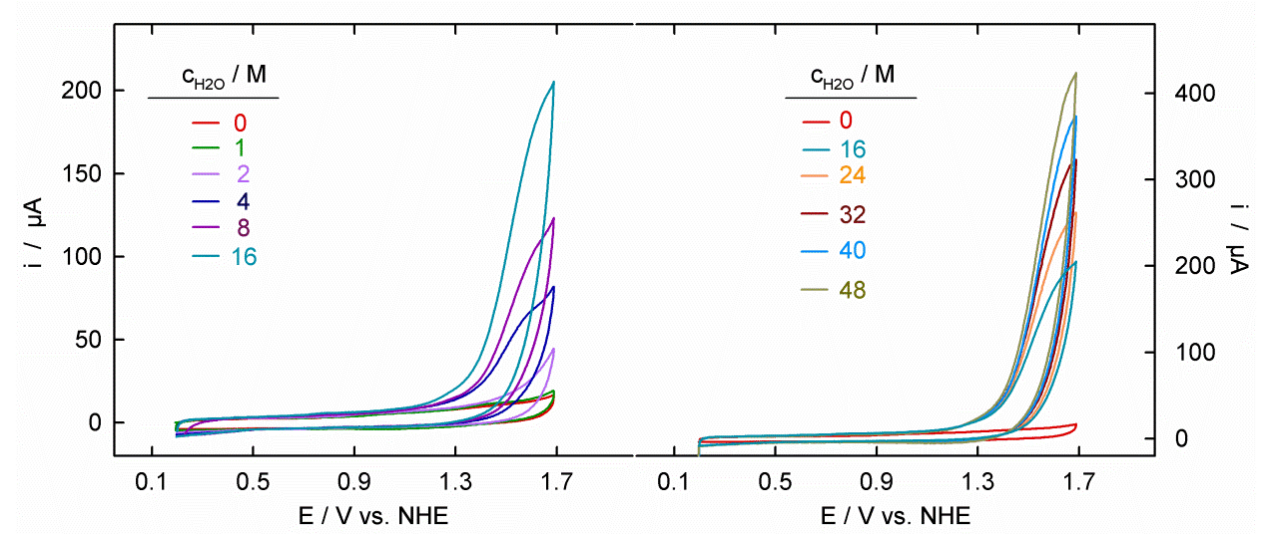

Figura 7.35. Voltamogramas cíclicos de un electrodo de grafito pirolítico modificado con 2D-Co-MOF@Nafion medidos a $0.05 \mathrm{~V} \mathrm{~s}^{-1}$ a $25^{\circ} \mathrm{C}$ en una disolución que contiene acetonitrilo y las concentraciones de agua indicadas. Reproducida con permiso de la ref 153 . Copyright 2021 American Chemical Society.

$\mathrm{El}$ aumento de la función voltamperométrica exponencial situada a $\mathrm{E}>1.3 \mathrm{~V}$ (frente a NHE) al aumentar el contenido de agua indica que este aumento es debido a la oxidación electrocatalítica del agua. Por otro lado, la pequeña histéresis entre las corrientes de avance y retroceso revela que el proceso electrocatalítico está parcialmente limitado por la difusión del agua, ya que de lo contrario se esperaría una función voltamperométrica sigmoidal (ausencia de control por transporte de masa) o en pico (controlada totalmente por el transporte de masa). ${ }^{161,162}$

Por otro lado, el análisis de la dependencia de la velocidad de barrido de la onda anódica I (Figura 7.36) revela que la conversión redox de $\mathrm{Co}(\mathrm{II}) / \mathrm{Co}(\mathrm{III})$ es rápida para velocidades de barrido bajas ( $<0.5 \mathrm{~V} \mathrm{~s}^{-1}$, comportamiento de superficie confinada) y se ve limitada por el transporte de la carga a través de la película para velocidades de barrido más altas (comportamiento de difusión). 

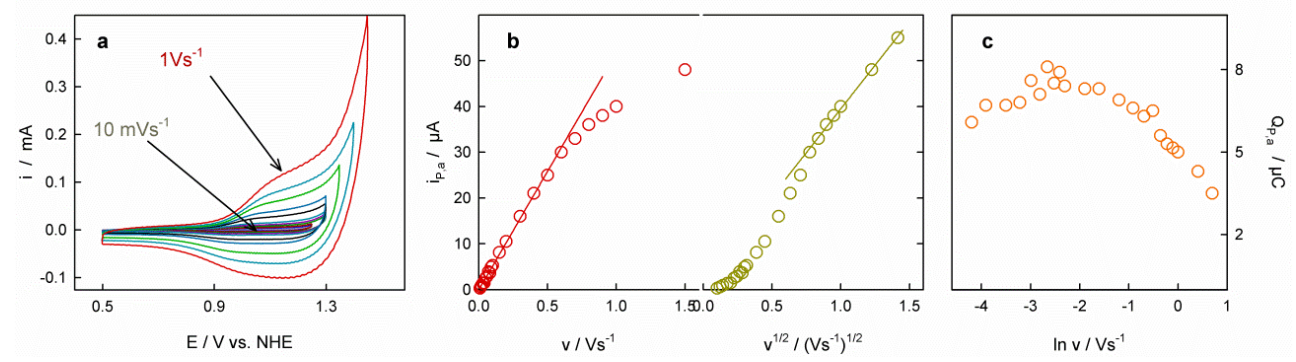

Figura 7.36. a) Voltamograma cíclico de un electrodo de grafito pirolítico modificado con 2D-Co-MOF@Nafion medido a varias velocidades de barrido de potencial en una disolución acuosa $0.1 \mathrm{M}$ de tampón fosfato de sodio $(\mathrm{pH} 7)$ a $25^{\circ} \mathrm{C}$. b) Corriente del pico anódico con la línea base corregida como una función de la velocidad de barrido de potencial (gráfica de la izquierda) o raíz cuadrada de la velocidad de barrido de potencial (gráfica de la derecha). c) Carga anódica voltamétrica faradaica en función de la velocidad de barrido de potencial. Reproducida con permiso de la ref 153. Copyright 2021 American Chemical Society.

Para obtener más información sobre el efecto de la activación electroquímica, se midieron los espectros de impedancia electroquímica (EIS) del composite inmovilizado a 1,1 V (frente a NHE) antes y después de su activación electroquímica (gráficos de Nyquist, Figura 7.37).
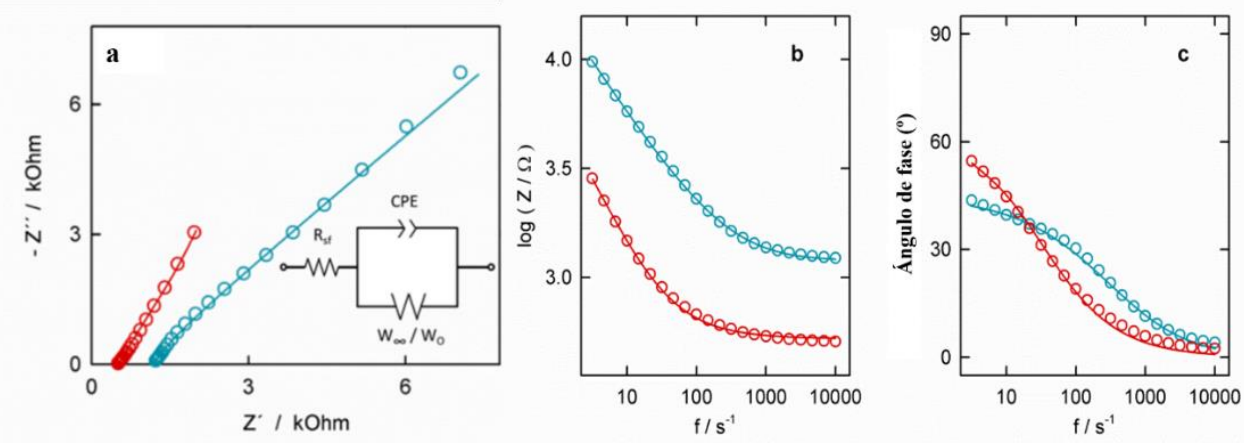

Figura 7.37. a) Representaciones de Nquist, b) y c) Representaciones de Bode para el 2DCo-MOF@Nafion depositado sobre un electrodo de grafito pirolítico, antes (símbolos azules) y después (símbolos rojos) de la activación electroquímica. Las líneas son los mejores ajustes usando el circuito equivalente insertado en a) y los valores para los parámetros que aparecen en la Tabla 7.3. Reproducida con permiso de la ref 153. Copyright 2021 American Chemical Society. 
Antes de la activación electroquímica (símbolos azules), el espectro EI muestra la forma típica esperada para un proceso redox controlado por difusión con un segmento lineal limitante de pendiente $\sim 1$ en la región de baja frecuencia (con valores altos de Z'). Este espectro se reprodujo cuantitativamente (línea azul) usando el circuito equivalente insertado en la Figura 7.37 a, donde $\mathrm{R}_{\mathrm{sf}}$ es la resistencia de la disolución y de la película, CPE es el elemento de fase constante y $\mathrm{W}_{\infty}$ el elemento Warburg de difusión semi infinita. Los valores de los parámetros para un ajuste óptimo están recogidos en la Tabla 7.3 y las correspondientes representaciones de Bode en la Figura 7.37 b,c.

Tabla 7.3. Parámetros EIS para el circuito equivalente de la Figura 7.37 (AE = Activación electroquímica).

\begin{tabular}{ccccccc}
\hline 2D-Co-MOF & $\mathbf{R}_{\text {sf }} / \mathbf{\Omega}$ & $\begin{array}{c}\mathbf{Q} / \mathbf{\Omega}^{-} \\
\mathbf{1} \cdot \mathbf{s}^{\boldsymbol{\alpha}}\end{array}$ & $\boldsymbol{\alpha}$ & $\begin{array}{c}\mathbf{W}_{\infty} / \mathbf{\Omega} \mathbf{S}^{-} \\
\mathbf{1 / 2}\end{array}$ & $\begin{array}{c}\mathbf{W}_{\text {or }} / \mathbf{\Omega} \mathbf{S}^{-} \\
\mathbf{1 / 2}\end{array}$ & $\mathbf{W}_{\text {oc }} / \mathbf{\Omega} \mathbf{S}^{\mathbf{1} / \mathbf{2}}$ \\
\hline Antes de AE & 1194 & $3.810^{-7}$ & 0.95 & 29810 & - & - \\
\hline Después de AE & 521 & $3.810^{-5}$ & 0.73 & - & 96330 & 0.41 \\
\hline
\end{tabular}

Después de la activación electroquímica, la intersección en el eje x del espectro (igual a $\mathrm{R}_{\mathrm{sf}}$ ) se desplazó hacia un valor Z' más bajo, lo que revela un aumento de la tasa de migración iónica a través del MOF, y la región de baja frecuencia muestra una curvatura ascendente, típica de una transferencia de electrones controlada por difusión limitada a través de la película. ${ }^{163-167}$ Este espectro puede ser reproducido cuantitativamente haciendo uso del circuito equivalente representado en la Figura 7.37, siempre que el elemento $\mathrm{W}_{\infty}$ de difusión semi-infinita sea sustituido por el elemento de difusión limitada con un límite totalmente definido $\mathrm{W}_{\mathrm{o}}$ (valores de los parámetros para un ajuste óptimo recogidos en la Tabla 7.3). El cambio de difusión semiinfinita a limitada es consistente con un aumento de la velocidad de transferencia de electrones a través de la película. En resumen, estos resultados revelan que la activación electroquímica facilita tanto la migración iónica como la transferencia de electrones a través del composite del 2D-CoMOF. 


\subsubsection{Actividad electrocatalítica de los MOFs de cobalto en la reacción de evolución de oxígeno (OER) en medio neutro.}

7.3.3.1. Actividad electrocatalítica del $\mathbf{C o}_{2}-\mathbf{M O F}$ en la reacción de evolución de oxígeno $(O E R)$.

Para estudiar la actividad electrocatalítica del $\mathbf{C o}_{2}$-MOF en la reacción de evolución de oxígeno en medio neutro, se empleó la voltamperometría de electrodo rotatorio para obtener las curvas de polarización de estado cuasi-estacionario. Todas las medidas se llevaron a cabo con una velocidad de barrido de $5 \mathrm{mV} \mathrm{s}^{-1}$ y una velocidad de rotación de 4000 rpm para preservar un perfil de concentración uniforme alrededor del electrodo de trabajo y para evitar la acumulación de burbujas de $\mathrm{O}_{2}$. En la Figura 7.38 a se muestra una curva de polarización típica que muestra un fuerte aumento de la corriente anódica a 1.68 V (vs RHE, Electrodo Reversible de Hidrógeno) para el Coz-MOF (línea roja) y que se asocia con el inicio de la OER electrocatalítica. Además, se observa que no hay señal de corriente apreciable en ausencia del catalizador. En las mismas condiciones experimentales, el MOF de cobalto mononuclear, Co-MOF (línea azul), produce un aumento menor de la corriente electrocatalítica, con casi el mismo potencial de inicio que su equivalente dinuclear $\mathrm{Co}_{2}$-MOF.
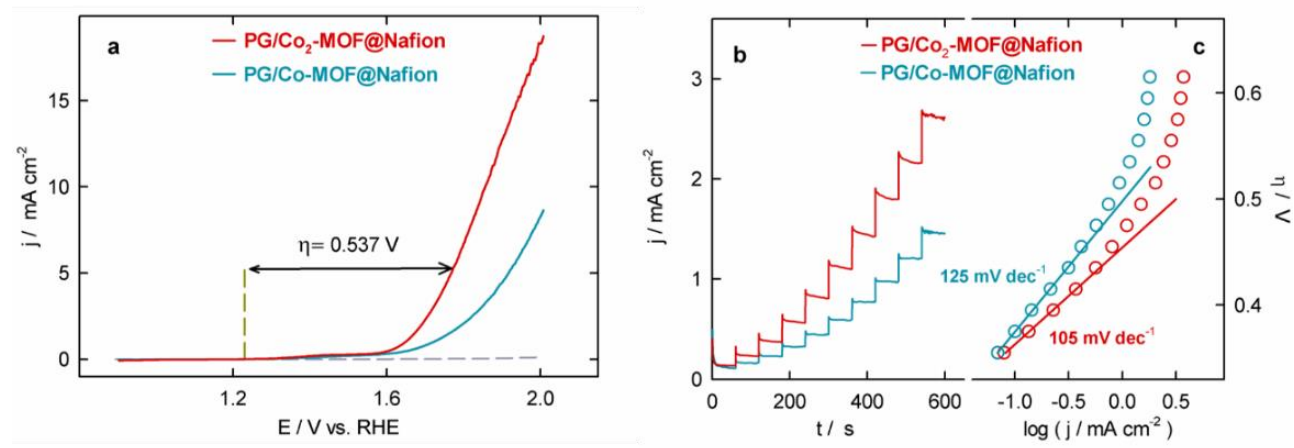

Figura 7.38. a) Voltamogramas de electrodo rotatorio del electrodo de grafito pirolítico modificado con Co2-MOF@Nafion (línea roja) o con el MOF hidrolizado CoMOF@Nafion (línea azul) medido a $5 \mathrm{mV} \mathrm{s}^{-1}$ y $4000 \mathrm{rpm}$ en una disolución acuosa $0.1 \mathrm{M}$ de SPB (pH 7) a $25^{\circ} \mathrm{C}$. La línea gris discontinua corresponde al voltamograma cíclico del electrodo de grafito pirolítico modificado con Nafion. b) Cronoamperogramas potenciostáticos del electrodo de grafito modificado con Co2-MOF@Nafion (línea roja) y Co-MOF@Nafion (línea azul) medidos a $4000 \mathrm{rpm}$ para saltos de potencial crecientes de $0.02 \mathrm{~V}$, desde $1.59 \mathrm{~V}$ a $1.85 \mathrm{~V}$, en una disolución acuosa $0.1 \mathrm{M}$ de $\mathrm{SPB}(\mathrm{pH} 7)$ a $25^{\circ} \mathrm{C}$. c) Diagrama de Tafel para los datos de densidad de corriente de estado estacionario del 
diagrama b. Reproducida con permiso de la ref 135. Copyright 2021 American Chemical Society.

La similitud entre sus potenciales para el inicio de la electrocatálisis y sus potenciales redox para la conversión $\mathrm{Co}(\mathrm{III}) / \mathrm{Co}(\mathrm{IV})$ sugieren que la oxidación del agua electrocatalítica está controlada por el Co(IV). Un parámetro operativo importante para la evaluación del rendimiento de la OER es el sobrepotencial a una corriente fija. Tomando como referencia el valor termodinámico de potencial para OER de $1.23 \mathrm{~V}$ (vs RHE), el electrodo PG/Co2-MOF@Nafion muestra valores de sobrepotencial de 460 y $537 \mathrm{mV}$ a 2 y $5 \mathrm{~mA} \mathrm{~cm}^{-2}$, respectivamente. Estos valores de sobrepotencial son inferiores a los determinados para el MOF mononuclear PG/Co-MOF@Nafion (565 y 687 mV a 2 y $5 \mathrm{~mA} \mathrm{~cm}^{-2}$, respectivamente).

La cinética electrocatalítica para OER se estimó a partir de la correspondiente gráfica de Tafel, obtenida a partir de los datos de densidad de corriente de estado estacionario registrados en el rango de potencial de 1.59-1.85 V (vs RHE) por cronoamperometría potenciostática, con saltos de potencial de $0.02 \mathrm{~V}$ (Figura $7.38 \mathrm{~b}$ ). Este experimento se llevó a cabo 3 veces, con 3 réplicas distintas del electrodo de grafito modificado con Co2-MOF@Nafion para la determinación de la pendiente de Tafel, con una concentración de cobalto electroactivo en superficie $(\Gamma)$ en el rango de $15<\Gamma<30 \mathrm{nmol}$ $\mathrm{cm}^{-2}$. Así, se calculó que la pendiente de Tafel para el Co2-MOF es de $105 \pm 5 \mathrm{mV} \mathrm{\text {dec}^{- }}$ ${ }^{1}$ en una disolución $0.1 \mathrm{M}$ de SPB (pH 7). En las mismas condiciones experimentales, la pendiente de Tafel para el Co-MOF mononuclear es de $125 \pm 5 \mathrm{mV} \mathrm{dec}^{-1}$.

Por otro lado, se determinó el TOF usando la expresión:

$$
\mathrm{TOF}=\mathrm{jA} /(4 F m)
$$

Ecuación 7.1

donde $j$ es la densidad de corriente a un sobrepotencial fijado, $A$ es el área superficial del electrodo de grafito, $F$ es la constante de Faraday y $m$ es el número de moles de cobalto electroactivo que participa en el proceso catalítico. La cantidad de cobalto electroactivo se determinó a partir de la expresión:

$$
\mathrm{m}=\mathrm{Q} /(\mathrm{nF}),
$$

Ecuación 7.2

donde $\mathrm{Q}$ es la carga faradaica bajo el pico voltamétrico que precede a la onda electrocatalítica y $\mathrm{n}$ es el número de electrones transferidos por el centro de cobalto. Aplicando estas expresiones se obtuvo un valor de TOF de $0.026 \pm 0.005 \mathrm{~s}^{-1}$ para el Co2MOF con un sobrepotencial de $400 \mathrm{mV}$, siendo $\mathrm{m}=1.70 \cdot 10^{-9} \mathrm{~mol} \mathrm{y} \mathrm{n}=1$ (Figura 7.38 
c). Este valor es superior al determinado para el Co-MOF mononuclear $(0.014 \pm 0.005$ $\mathrm{s}^{-1}$ con $\mathrm{m}=1.75 \cdot 10^{-9} \mathrm{~mol} \mathrm{y} \mathrm{n}=1$ ).

Además, se evaluó la influencia de la concentración superficial de la especie redox electroactiva del Co2-MOF en la oxidación electrocatalítica del agua. En la Figura 7.39 se puede observar como la densidad de corriente aumenta y el correspondiente sobrepotencial para una densidad de corriente fijada disminuye al aumentar la concentración superficial de la especie redox electroactiva. Además, como se muestra en la Figura 7.39 b el TOF estimado para el Co2-MOF para un sobrepotencial de $400 \mathrm{mV}$ disminuye al aumentar la carga de catalizador hasta que se estabiliza en un valor de $\sim 0.045 \mathrm{~s}^{-1}$ para una concentración superficial de la especie activa de cobalto de $1.7 \times 10^{-}$ $8 \mathrm{~mol} \mathrm{~cm}^{-2}$. Este efecto de estabilización del valor del TOF puede deberse a la aglomeración del catalizador al aumentar la concentración superficial, lo que puede limitar el área superficial catalítica expuesta al disolvente y cambiar el sistema de transporte de masa en la superficie de una simetría cilíndrica a una simetría plana.

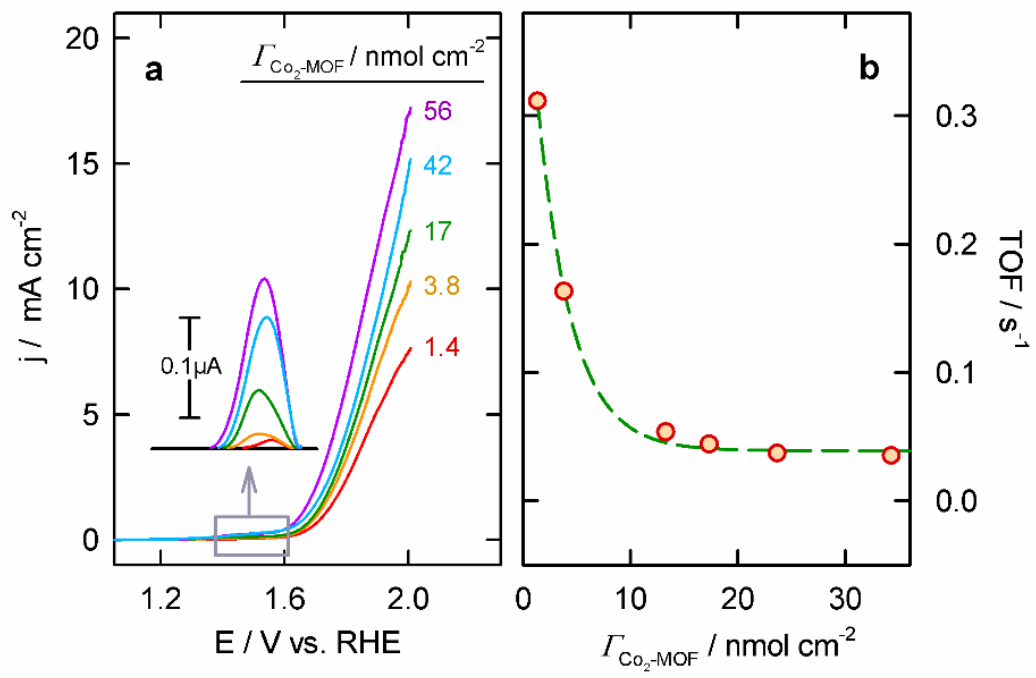

Figura 7.39. a) Voltamogramas de electrodo rotatorio del electrodo de grafito pirolítico modificado con diferentes cantidades electroactivas de Co2-MOF @ Nafion en el rango 0.1$3.9 \cdot 10^{-9} \mathrm{~mol}$, medido a $5 \mathrm{mV} \mathrm{s}^{-1}$ y $4000 \mathrm{rpm}$ en una disolución acuosa que contiene $0.1 \mathrm{M}$ $\mathrm{SPB}, \mathrm{pH} 7, \mathrm{a} 25^{\circ} \mathrm{C}$. Gráfico insertado: Onda voltamétrica I con la línea base corregida. b) TOF estimado para un sobrepotencial de $400 \mathrm{mV}$ en función de la concentración superficial de cobalto electroactivo. La línea verde discontinua solo es una guía visual. Reproducida con permiso de la ref 135. Copyright 2021 American Chemical Society. 
Para evaluar la estabilidad del electrocatalizador durante la OER se han comparado las curvas de polarización medidas antes y después de realizar 500 voltamogramas cíclicos consecutivos en la ventana de potencial de 0.9-1.9 V (vs RHE), a una velocidad de barrido de $0.2 \mathrm{~V} \mathrm{~s}^{-1}$. Como se muestra en la Figura 7.40, la curva de polarización apenas varía después de los 500 ciclos. Además, la robustez y la durabilidad a largo plazo del catalizador han sido evaluadas en condiciones de reacción mediante el registro de la corriente cronoamperométrica a $1.80 \mathrm{~V}$ durante $4 \mathrm{~h}$, que se muestra en el recuadro de la Figura 7.40 b. Este cronoamperograma se caracteriza por una disminución inicial de la corriente hasta que se aproxima a un valor de estado estacionario de un 55\% de la corriente inicial. La invariabilidad de los voltamperogramas registrados antes y después del experimento cronoamperométrico (Figura 7.40 b) demuestra que la disminución de la corriente cronoamperométrica no se debe a una pérdida de actividad del $\mathbf{C o}_{2}$-MOF, sino a una limitación del transporte de masa dentro de la película multicapa.
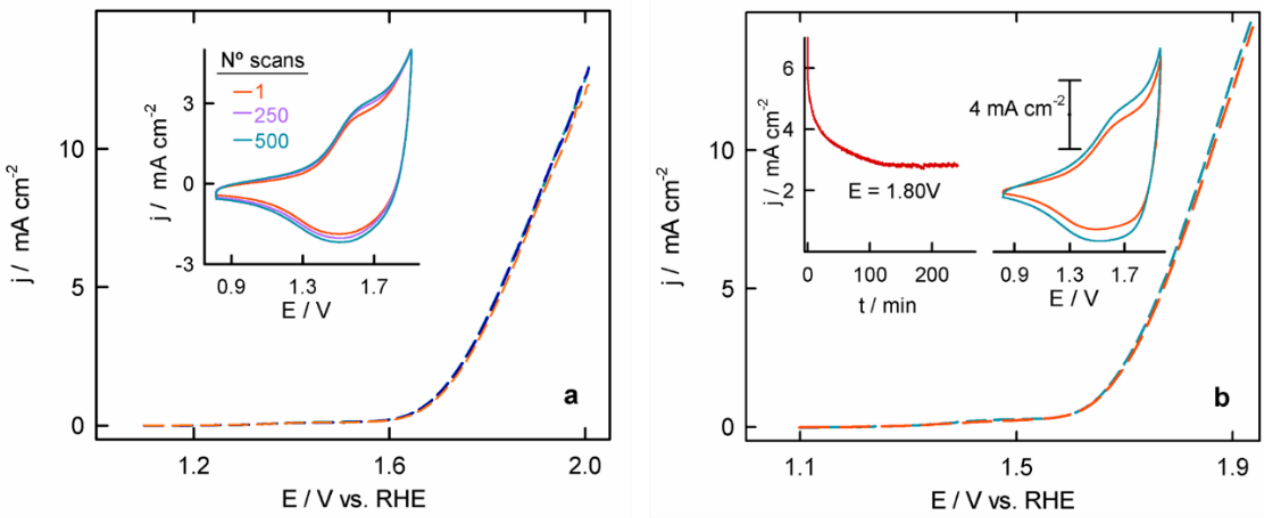

Figura 7.40. a) Voltamograma de electrodo rotatorio para electrodo de grafito modificado con el Co2-MOF @ Nafion medido a $5 \mathrm{mV} \mathrm{s}^{-1}$ después de registrar: 1 scan (línea discontinua naranja), 20 scans consecutivos (línea discontinua azul oscuro), 500 scans consecutivos (línea discontinua azul claro) a $0.2 \mathrm{~V} \mathrm{~s}^{-1}$ en una disolución acuosa $0.1 \mathrm{M}$ de $\mathrm{SPB}, \mathrm{pH} 7$, a $25^{\circ} \mathrm{C}$. Gráfico insertado: voltamogramas medidos al número indicado de scans a $0.2 \mathrm{~V} \mathrm{~s}^{-1} . \mathrm{b}$ ) Voltamogramas de electrodo rotatorio para el electrodo de grafito modificado con Co2MOF@Nafion medido a $5 \mathrm{mV} \mathrm{s}^{-1}$ antes (línea discontinua naranja) y después (línea discontinua azul) de medir la corriente cronoamperométrica a $1.80 \mathrm{~V}$ vs RHE durante 4 horas. La corriente cronoamperométrica a $1.80 \mathrm{~V}$ (vs RHE) durante $4 \mathrm{~h}$ y los voltamogramas cíclicos a $0.2 \mathrm{~V} \mathrm{~s}^{-1}$ antes (línea naranja) y después (línea azul) se representan en los gráficos insertados. Reproducida con permiso de la ref 135. Copyright 2021 American Chemical Society. 
Además, la formación de microburbujas de oxígeno en la superficie del electrodo puede afectar al transporte del agua dentro de la película. Sin embargo, la conservación de las características voltamperométricas después de un experimento electrocatalítico tan largo demuestra la gran estabilidad del catalizador. Para estimar la eficiencia de Faraday del Co2-MOF en la OER, se ha medido la producción de oxígeno durante la electrólisis del agua $\left(\Delta \mathrm{mO}_{2}\right)$ con un sensor de oxígeno polarográfico (Figura 7.41).
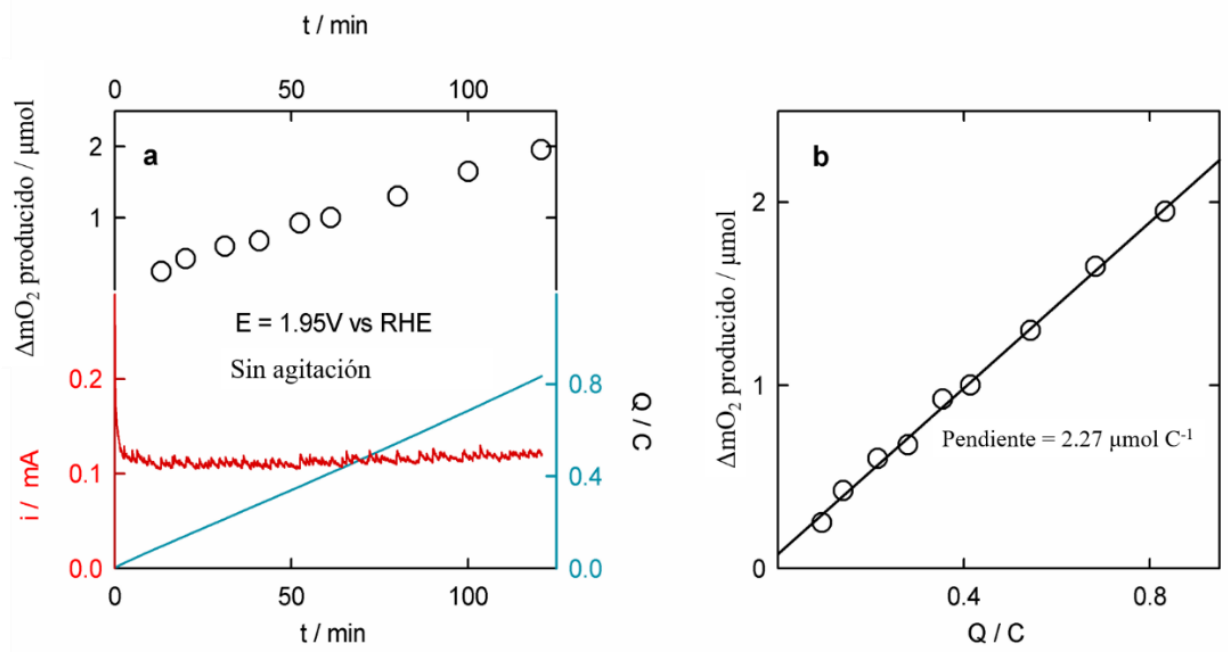

Figura 7.41. a) Corriente cronoamperométrica, carga consumida y producción de oxígeno medido a $1.95 \mathrm{~V}$ (vs NHE) con el electrodo de grafito pirolítico modificado con el Co2MOF@Nafion durante la electrólisis del agua en una disolución acuosa 0.1 M de tampón fosfato de sodio, $\mathrm{pH} 7$, a $25^{\circ} \mathrm{C}$. b) Producción de oxígeno frente a la carga consumida durante la electrólisis del agua. Los símbolos son valores experimentales y la línea sólida es el mejor ajuste lineal de mínimos cuadrados para los datos obtenidos. Reproducida con permiso de la ref 135. Copyright 2021 American Chemical Society.

A partir de este experimento se determinó una eficiencia de Faraday del $87 \%$ a partir de la pendiente del gráfico de $\Delta \mathrm{mO}_{2}$ frente a la carga consumida durante la electrólisis, Q (Figura 7.41). Esto indica que la intensidad de corriente se origina principalmente por la oxidación del agua, como se demuestra con la formación de burbujas de oxígeno en la superficie del electrodo (Figura 7.42). 


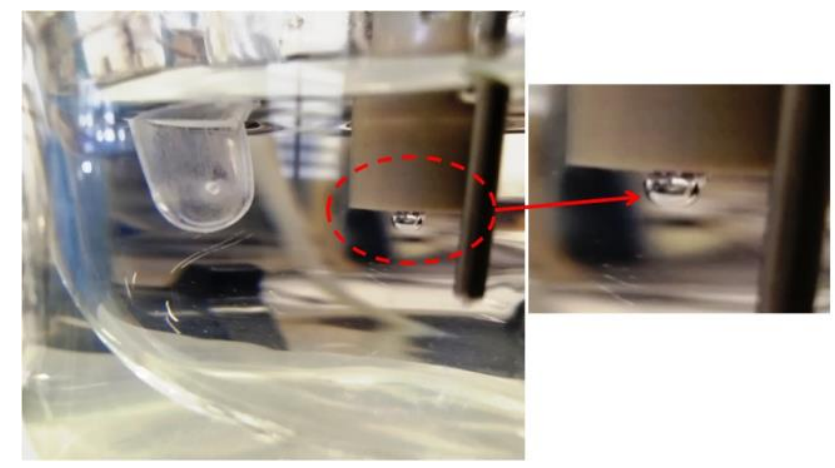

Figura 7.42. Foto del electrodo de grafito pirolítico modificado con Co2-MOF@Nafion durante la electrólisis del agua en una disolución acuosa $0.1 \mathrm{M} \mathrm{SPB}, \mathrm{pH} 7$, a $25^{\circ} \mathrm{C}$ que muestra la formación de burbujas de oxígeno en la superficie del electrodo. Reproducida con permiso de la ref 135. Copyright 2021 American Chemical Society.

Finalmente, cabe destacar que el MOF de cobalto dinuclear estudiado mantiene su actividad electrocatalítica y es estable durante el OER en condiciones aeróbicas (Figura 7.43), lo cual es muy importante para aplicaciones prácticas.
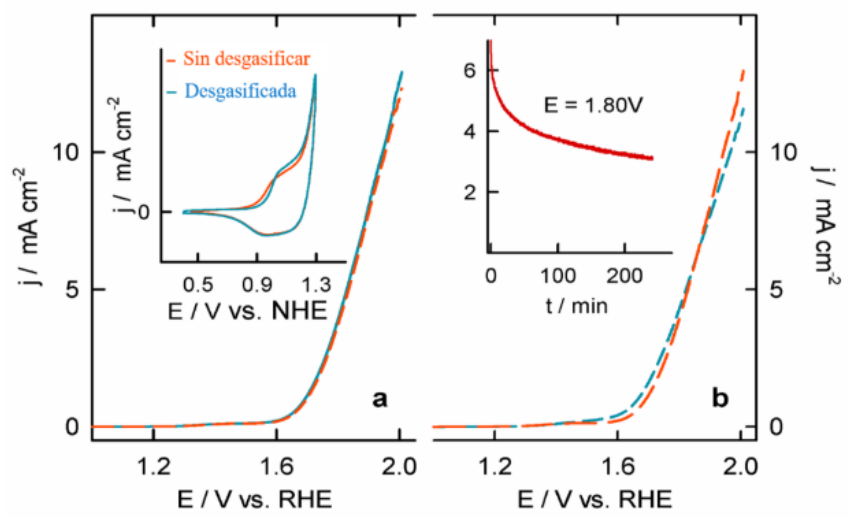

Figura 7.43. a) Voltamograma de electrodo rotatorio del electrodo de grafito pirolítico modificado con Co2-MOF@Nafion medido a $5 \mathrm{mV} \mathrm{s}^{-1}$ y $4000 \mathrm{rpm}$ en una disolución desgasificada (línea naranja) y sin desgasificar (línea azul) que contiene $0.1 \mathrm{M}$ de SPB, pH 7, a $25^{\circ} \mathrm{C}$. Diagrama insertado: Sus correspondientes voltamogramas cíclicos medidos a 10 $\mathrm{mV} \mathrm{s}^{-1}$. b) Voltamograma de electrodo rotatorio para el Co2-MOF@Nafion depositado en el electrodo de grafito medido a $5 \mathrm{mV} \mathrm{s}^{-1}$ antes (línea naranja) y después (línea azul) de medir la corriente cronoamperométrica a $1.80 \mathrm{~V}$ durante $4 \mathrm{~h}$ (representada en el diagrama insertado). Reproducida con permiso de la ref 135. Copyright 2021 American Chemical Society. 
Por otro lado, la estabilidad del Co2-MOF@Nafion después de la electrólisis del agua se ha demostrado empleando análisis EDX y XPS, espectroscopía Raman y PXRD (Figuras 7.44 y 7.45, 7.46a y 7.46b, respectivamente). El análisis de EDX muestra que el cobalto sigue bien distribuido en el material tras los experimentos de electrocatálisis, no observándose agregados del metal.

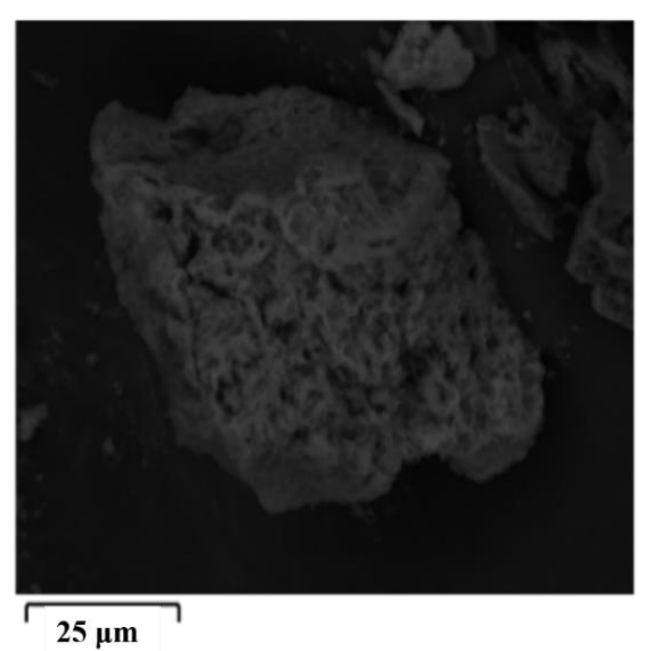

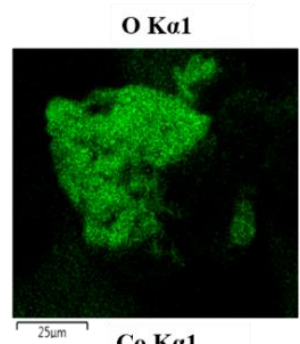

Co Ka1

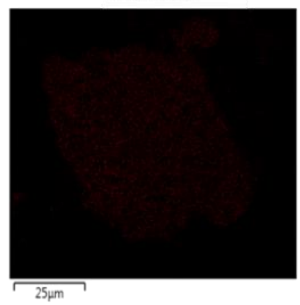

F Ka1_2
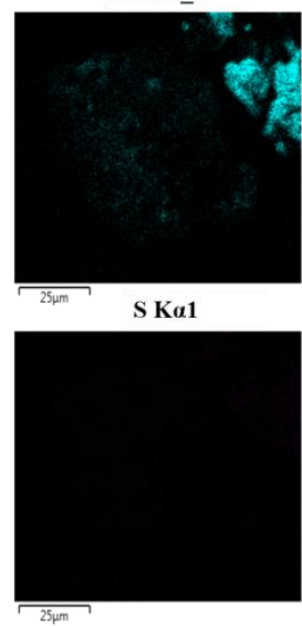

Figura 7.44. Imagen del Co2-MOF@ Nafion tomada por microscopía de barrido electrónico de emisión de campo y análisis EDX. Reproducida con permiso de la ref 135. Copyright 2021 American Chemical Society.

Los datos de XPS del compuesto Co2-MOF@Nafion después de la electrólisis se han analizado siguiendo el mismo criterio que para el $\mathbf{C o}_{2}$-MOF. En este caso, los valores de $\mathrm{E}_{\mathrm{b}}$ para el Co $2 \mathrm{p}_{3 / 2}$, Eb para el Co $2 \mathrm{p}_{1 / 2}$ y $\Delta \mathrm{E}_{1}$ son 782.5 , 798,2 y $15.7 \mathrm{eV}$, respectivamente (Tabla 7.4). Además, se han observado también picos satélite intensos $\left(\Sigma \mathrm{sat} / \mathrm{ICo}_{2 \mathrm{p}}>1.6\right)$. Por lo que, al igual que en el caso anterior, los datos de XPS confirman que el cobalto se mantiene en el mismo estado de oxidación, ya que presenta valores característicos del $\mathrm{Co}$ (II) de alto espín. La mayor diferencia entre este compuesto y el Co2-MOF es el pequeño desplazamiento apreciado en la energía de enlace (1.4 eV mayor para este compuesto). Esto se puede explicar por la presencia de flúor en el compuesto (procedente del Nafion), el cual tiende a inducir grandes cambios químicos en otros elementos. 


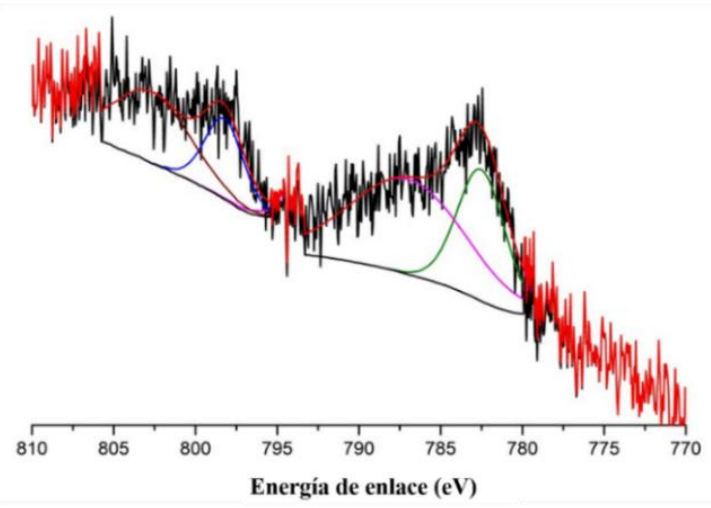

Figura 7.45. Espectro XPS del Co2-MOF @ Nafion después de la electrólisis del agua. Reproducida con permiso de la ref 135. Copyright 2021 American Chemical Society.

Tabla 7.4. Características XPS del Co2-MOF: Energías de enlace de los diferentes picos, máxima anchura a mitad de pico (FWHM, en paréntesis), intensidades relativas (I $\Sigma=$ $\Sigma$ sat/ $\left.\mathrm{I}_{\text {principal }}\right)$, interacción espín-orbital $\left(\Delta \mathrm{E}_{1}\right)$; todas las energías y FWHMs están en eV.

\begin{tabular}{|c|c|}
\hline & $\begin{array}{c}\text { Con-MOF@Nafion- } \\
\text { pr }\end{array}$ \\
\hline $\mathrm{Co}_{2} \mathrm{p}_{3 / 2}$ & $782.5(3.5)$ \\
\hline sat1 & $787(8.3)$ \\
\hline $\mathbf{I}_{\mathbf{\Sigma}}$ & 1.74 \\
\hline $\operatorname{Co2} p_{1 / 2}$ & $798.2(2.8)$ \\
\hline sat1' & $802.7(5.6)$ \\
\hline$I^{\prime}{ }_{\Sigma}$ & 1.74 \\
\hline$\Delta \mathrm{E} 1$ & 15.7 \\
\hline
\end{tabular}

Finalmente, en los espectros Raman y PXRD para el Co2-MOF@Nafion (Figura 7.46) no se observan cambios después del proceso de electrólisis, lo que revela que los centros de cobalto mantienen su esfera de coordinación y el MOF conserva su estructura después del proceso electroquímico. 


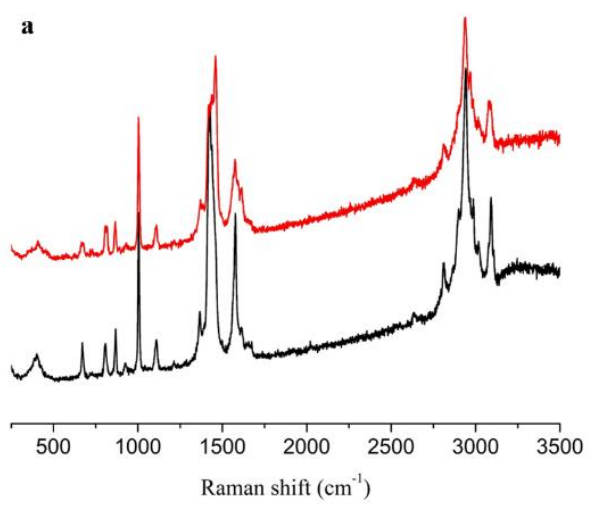

b

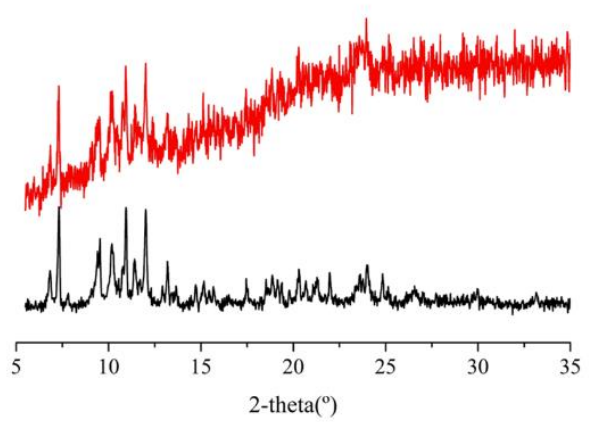

Figura 7.46. a) Espectros Raman del Co2-MOF@Nafion antes (negro) y después (rojo) de la electrólisis del agua. b) Patrones de difracción de rayos X de polvo del Co2-MOF@ Nafion antes (negro) y después (rojo) de la electrólisis del agua. Reproducida con permiso de la ref 135. Copyright 2021 American Chemical Society.

7.3.3.2. Actividad electrocatalítica del $\mathbf{2 D}$-Co-MOF en la reacción de evolución de oxígeno $(O E R)$.

La misma metodología empleada para el Co2-MOF se usó para estudiar la actividad electrocatalítica del 2D-Co-MOF en la reacción de evolución de oxígeno en medio neutro. Todas las medidas se llevaron a cabo con una velocidad de barrido de $5 \mathrm{mV} \mathrm{s}^{-1}$ y una velocidad de rotación de $4000 \mathrm{rpm}$ para preservar un perfil de concentración uniforme alrededor del electrodo de trabajo y para evitar la acumulación de burbujas de $\mathrm{O}_{2}$. En la Figura 7.47 se muestra una curva de polarización típica que muestra un fuerte aumento de la corriente anódica a $1.73 \mathrm{~V}$ (vs RHE) y que se asocia con el inicio de la OER electrocatalítica. 

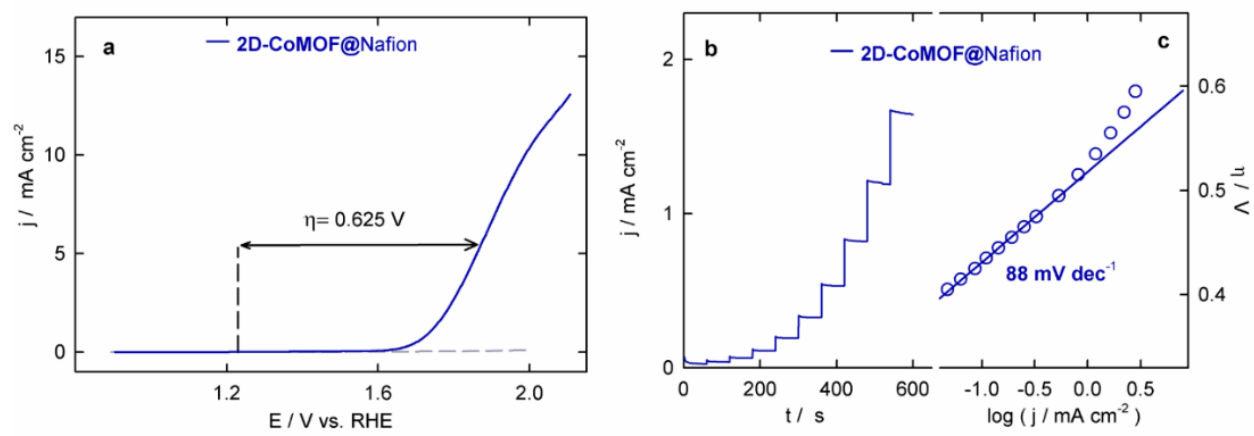

Figura 7.47. a) Voltamogramas de electrodo rotatorio del electrodo de grafito pirolítico modificado con 2D-Co-MOF@Nafion medido a $5 \mathrm{mV} \mathrm{s}^{-1}$ y $4000 \mathrm{rpm}$ en una disolución acuosa $0.1 \mathrm{M}$ de SPB ( $\mathrm{pH} 7)$ a $25^{\circ} \mathrm{C}$. La línea gris discontinua corresponde al voltamograma cíclico del electrodo de grafito pirolítico modificado con Nafion. b) Cronoamperogramas potenciostáticos del electrodo de grafito modificado con 2D-Co-MOF@ Nafion medido a $4000 \mathrm{rpm}$ para saltos de potencial crecientes de $0.01 \mathrm{~V}$ en una disolución acuosa $0.1 \mathrm{M}$ de SPB (pH 7) a $25^{\circ} \mathrm{C}$. c) Diagrama de Tafel para los datos de densidad de corriente de estado estacionario del diagrama $b$.

Como se ha mencionado anteriormente, un parámetro operativo importante para la evaluación del rendimiento de la OER es el sobrepotencial a una corriente fija. Tomando como referencia el valor termodinámico de potencial para OER de $1.23 \mathrm{~V}$ (vs RHE), el electrodo PG/2D-Co-MOF@Nafion muestra valores de sobrepotencial de 548 y 625 mV a 2 y $5 \mathrm{~mA} \mathrm{~cm}^{-2}$, respectivamente.

La cinética para OER electrocatalizada por el 2D-Co-MOF se evaluó a partir de la correspondiente gráfica de Tafel (Figura 7.47 c) obtenida a partir de los datos cronoamperométricos de densidad de corriente de estado estacionario medidos para una secuencia de saltos de potencial de 0.01V (Figura 7.47 b). El MOF de cobalto estudiado presenta un valor de pendiente de Tafel (TS) de $88 \pm 4 \mathrm{mV} \mathrm{dec}^{-1}$. Además, se determinó el valor del TOF a partir de la expresión TOF = i/4Q (donde i es la intensidad de corriente a un sobrepotencial dado y $\mathrm{Q}$ es la carga faradaica bajo el pico voltamperométrico con la base corregida que precede al aumento de corriente electrocatalítica), dando un valor para el 2D-Co-MOF de $0.034 \mathrm{~s}^{-1}$ a un sobrepotencial de $400 \mathrm{mV}\left(\mathrm{Q}=2.5 \cdot 10^{-5} \mathrm{C}\right.$, que corresponde a $2.6 \cdot 10^{-10}$ moles de cobalto electroactivo). En base a esto, se ha evaluado el efecto de la cantidad de 2D-Co-MOF electroactivo en la OER (Figura 7.48). 

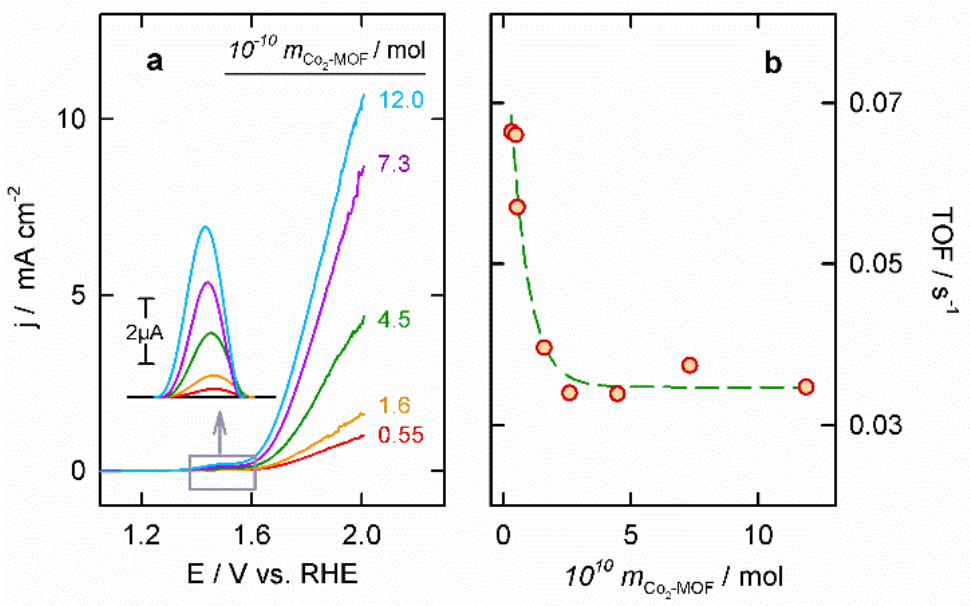

Figura 7.48. a) Voltamograma de electrodo rotatorio de un electrodo de grafito pirolítico modificado con diferentes cantidades de 2D-Co-MOF@Nafion electroactivo en un rango entre $0.55-12 \cdot 10^{-10}$ moles, medido a $5 \mathrm{mV} \mathrm{s}^{-1}$ y $1500 \mathrm{rpm}$ en una disolución acuosa $0.1 \mathrm{M}$ $\mathrm{SPB}$ de $\mathrm{pH} 7$ a $25^{\circ} \mathrm{C}$. Diagrama insertado: Onda voltamétrica I con la línea base corregida. b) Valor del TOF para un sobrepotencial de $395 \mathrm{mV}$ estimado por cronoamperometría como función de la cantidad de cobalto electroactivo superficial. La línea verde discontinua es solo una guía visual. Reproducida con permiso de la ref 153. Copyright 2021 American Chemical Society.

El aumento de concentración de cobalto electroactivo, obtenido mediante el aumento del tiempo de activación electroquímica, da lugar a un aumento de la densidad de corriente electrocatalítica a un potencial determinado, y a una disminución del correspondiente sobrepotencial a una densidad de corriente determinada. Sin embargo, el TOF determinado para un sobrepotencial de $400 \mathrm{mV}$ disminuye al aumentar la concentración de cobalto electroactivo hasta que se estabiliza en un valor de $\sim 0.035 \mathrm{~s}^{-1}$ para una concentración de cobalto electroactivo de $2.0 \cdot 10^{-10}$ mol. Esta dependencia revela que no todos los centros de cobalto son igual de activos en la reacción de oxidación del agua.

La actividad mejorada para la OER del composite 2D-Co-MOF@Nafion puede atribuirse tanto a un transporte de carga más eficiente a través de la capa de catalizador como a un ataque nucleofílico del agua a los centros activos más efectivo, probablemente por la presencia del nitrógeno presente en los ligandos ecuatoriales aromáticos. 
A continuación, se estudió la estabilidad en condiciones de reacción y la durabilidad a largo plazo del electrocatalizador durante la reacción de evolución de oxígeno. En primer lugar, se midió la corriente cronoamperométrica para el electrodo de grafito modificado con el 2D-Co-MOF@Nafion a 1.8V (vs RHE) durante tres ciclos consecutivos de electrólisis del agua que duraron 9 horas (Figura 7.49 a).
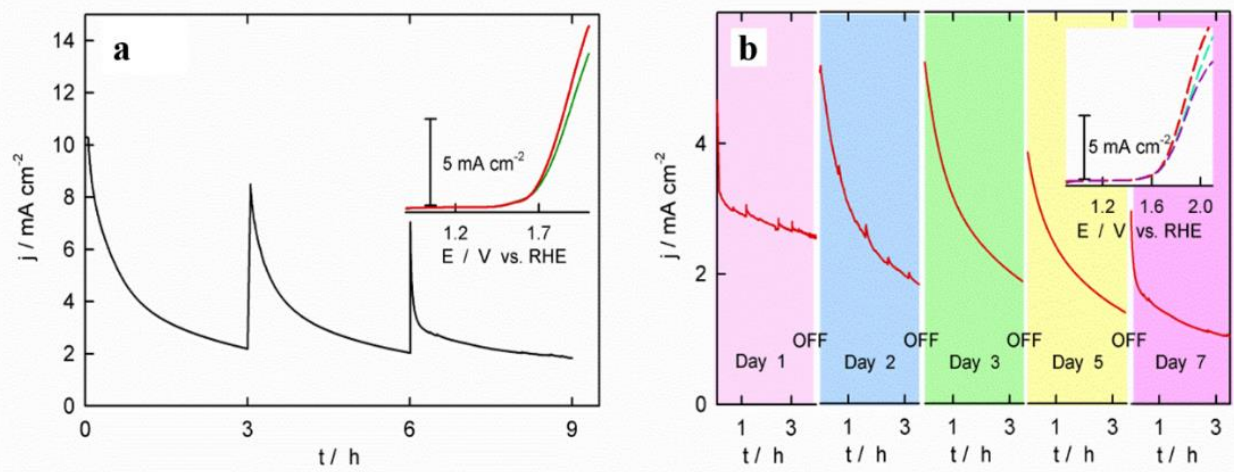

Figura 7.49. a) Cronoamperogramas consecutivos a $1.8 \mathrm{~V}$ (vs RHE) para el electrodo de grafito pirolítico modificado con 2D-Co-MOF@ Nafion en una disolución acuosa 0.1M SPB de $\mathrm{pH} 7$ a $25^{\circ} \mathrm{C}$. Diagrama insertado: voltamograma de electrodo rotatorio medido a $5 \mathrm{mV} \mathrm{s}$ 1 antes (línea roja) y después (línea verde) del experimento cronoamperométrico. b) Cronoamperogramas a $1.8 \mathrm{~V}$ (vs RHE) para diferentes ciclos de reacción consecutivos. Diagrama insertado: voltamogramas de electrodo rotatorio después del ciclo catalítico el día 1 (línea roja), el día 3 (línea verde) y el día 7 (línea violeta). Reproducida con permiso de la ref 153. Copyright 2021 American Chemical Society.

Los cronoamperogramas medidos se caracterizan por una disminución inicial de la corriente que puede atribuirse a la formación de burbujas de oxígeno en la superficie del electrodo, afectando así al transporte del agua a través de la película multicapa (Figura 7.50). A continuación, la corriente se estabiliza en un valor de $\sim 2 \mathrm{~mA} \mathrm{~cm}^{-2}$ en cada cronoamperograma, con una disminución insignificante de la densidad de corriente pasadas las $9 \mathrm{~h}$ de reacción. La similitud de las curvas de polarización del 2D-CoMOF@Nafion completamente activado medidas antes y después de la electrólisis del agua, representadas en el diagrama del recuadro de la Figura 7.49 a, refleja la alta estabilidad de este material. Además, se estimó un valor para la eficiencia faradaica en la OER del 77\% para el 2D-Co-MOF después de un experimento extenso de electrólisis del agua, lo que refleja que la densidad de corriente se origina, principalmente, debido a la oxidación del agua. 


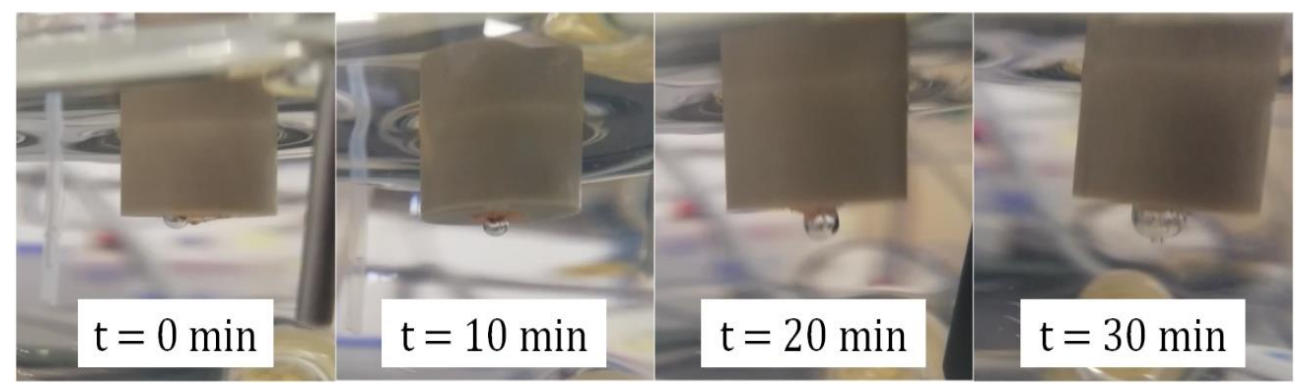

Figura 7.50. Fotografía que muestra el crecimiento de las burbujas de oxígeno sobre el electrodo de grafito pirolítico modificado con el 2D-Co-MOF @ Nafion durante la electrólisis del agua en una disolución acuosa $0.1 \mathrm{M} \mathrm{SPB} \mathrm{pH} 7$ a $25^{\circ} \mathrm{C}$. Reproducida con permiso de la ref 153. Copyright 2021 American Chemical Society.

Además, se estudió la reciclabilidad del catalizador a lo largo de varios reusos catalíticos sucesivos con ciclos de encendido y apagado que duraron 7 días, comprobando que este material no pierde actividad. Como se puede observar en la Figura 7.49 b, la densidad de corriente disminuye en un $50 \%$ después de cinco reusos a lo largo de 7 días. Sin embargo, los voltamogramas registrados después de cada ciclo catalítico revelan que el composite 2D-Co-MOF @ Nafion conserva un notable rendimiento electrocatalítico, sin que se aprecie una pérdida de actividad significativa (gráfico insertado en la Figura 7.49 b).

Por otro lado, para saber si la activación electroquímica y el proceso de electrólisis del agua conduce a cambios estructurales y/o de coordinación en el MOF de cobalto, se llevó a cabo la caracterización del composite antes y después de su activación electroquímica a 1.2V (frente a NHE) para diferentes tiempos de exposición. En primer lugar, se llevó a cabo el estudio mediante espectroscopía Raman y difracción de rayos X de polvo (Figuras 7.51 y 7.52). En los espectros Raman y PXRD para el 2D-Co-MOF@Nafion no se observan cambios a los distintos tiempos de electrólisis, lo que revela que los centros de cobalto mantienen su esfera de coordinación y las nanoláminas individuales conservan su estructura de doble capa durante la activación electroquímica. 

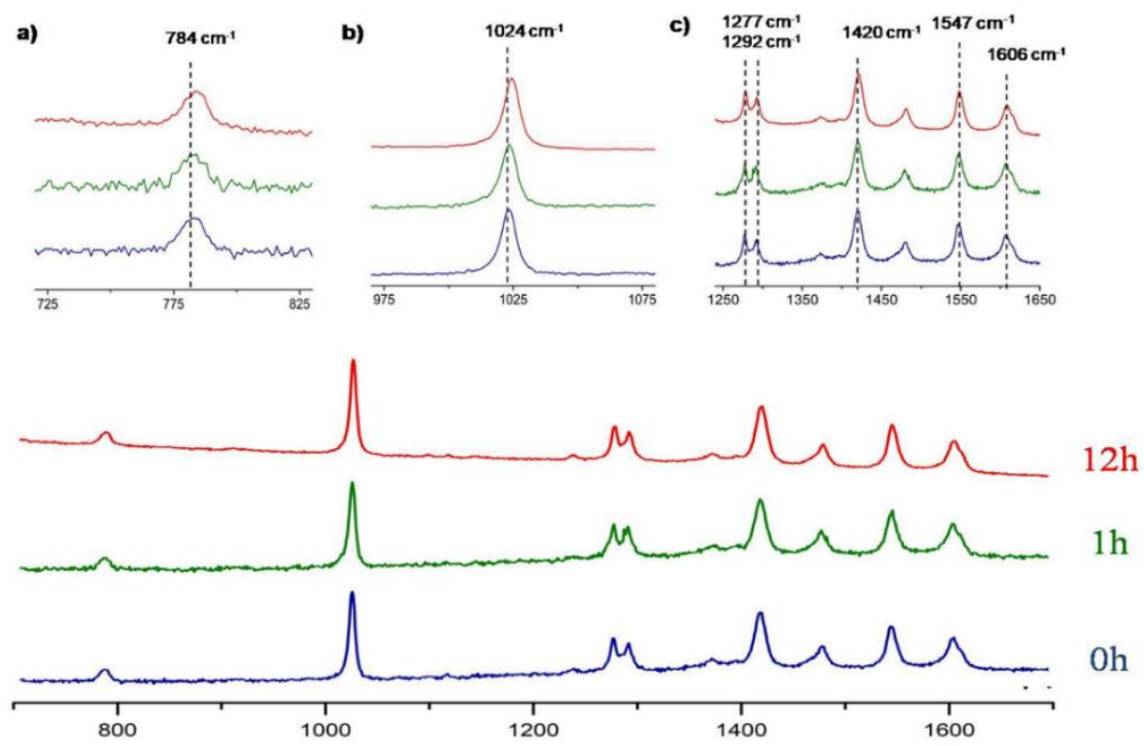

Desplazamiento Raman $\left(\mathrm{cm}^{-1}\right)$

Figura 7.51. Espectros Raman del 2D-Co-MOF @Nafion delaminado a los tiempos de electrólisis del agua indicados. Reproducida con permiso de la ref 153. Copyright 2021 American Chemical Society.

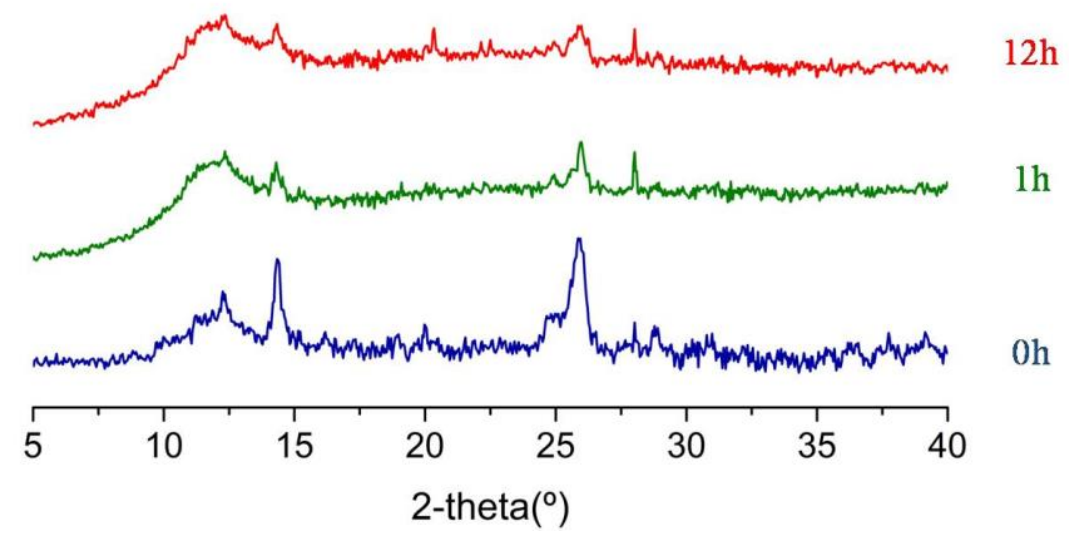

Figura 7.52. Patrones de difracción de rayos X de polvo del 2D-Co-MOF@Nafion delaminado a los tiempos de electrólisis del agua indicados. El pico a $28^{\circ}$ es una contribución del portamuestras. Reproducida con permiso de la ref 153. Copyright 2021 American Chemical Society. 
Además, los espectros de XPS (Figura 7.53 y Tabla 7.5) corroboran esta hipótesis. El análisis XPS revela que la activación electroquímica no afecta al estado de oxidación de los centros de cobalto y que no se detecta la presencia de $\mathrm{CoO}_{\mathrm{x}}$. Para el 2D-CoMOF@Nafion después de la electrólisis del agua durante 12 horas, los valores de $\mathrm{E}_{\mathrm{b}}$ (Co $\left.2 \mathrm{p}_{3 / 2}\right), \mathrm{E}_{\mathrm{b}}\left(\mathrm{Co} 2 \mathrm{p}_{1 / 2}\right)$ and $\Delta \mathrm{E}_{1}$ están en el mismo rango que para el 2D-Co-MOF@ Nafion delaminado, por lo que, también en este caso, los valores de $\Sigma$ sat $/ \mathrm{ICo}_{2 \mathrm{p}}$ and $\Delta \mathrm{E}_{1}$ son característicos de compuestos de cobalto(II) de alto espín, lo que significa que el cobalto permanece en el mismo estado de oxidación en presencia de Nafion y después del proceso electrocatalítico. Además, tampoco se aprecian cambios en los espectros para el O 1s y el $\mathrm{N}$ 1s después de la electrólisis del agua, lo cual corrobora que la coordinación en el MOF no ha cambiado después de $12 \mathrm{~h}$ de electrólisis.
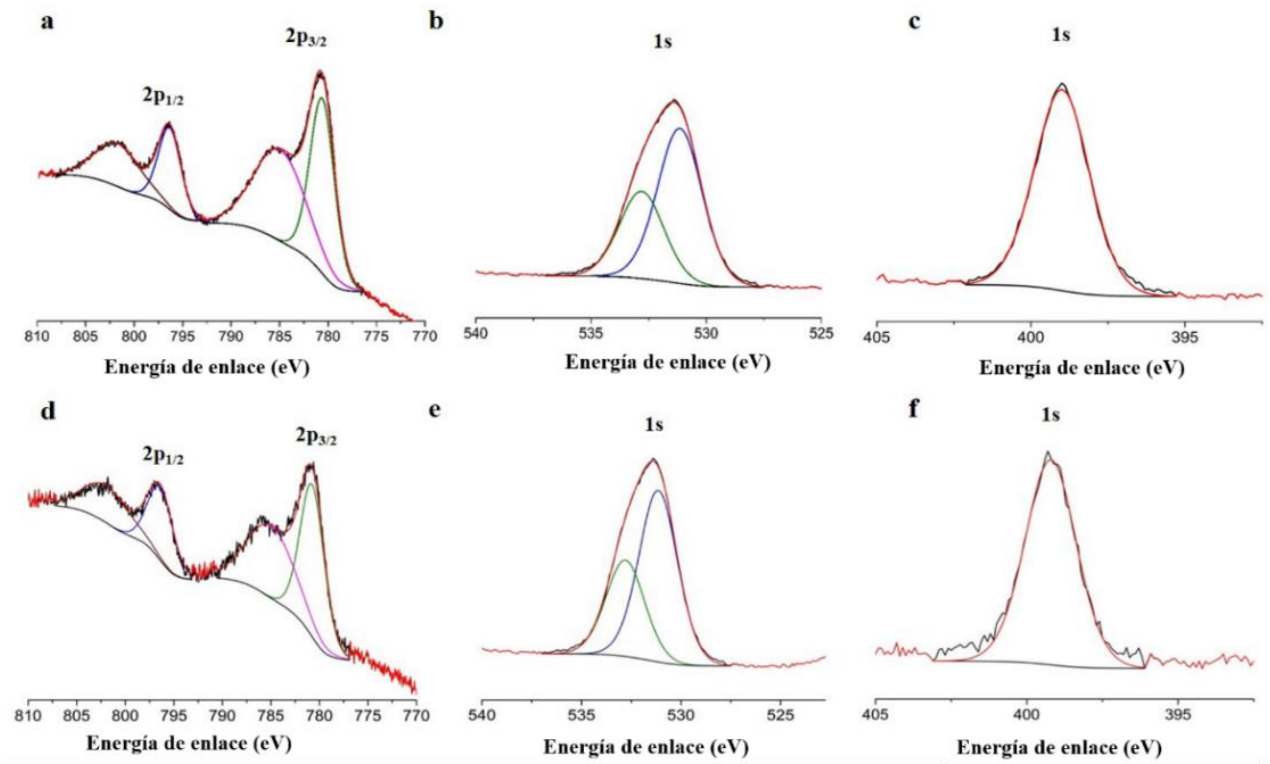

Figura 7.53. Espectros XPS de las líneas de (a, d) Co 2p, (b, e) O 1s y (c, f) N 1s para el 2DCo-MOF@Nafion delaminado antes $(\mathrm{a}, \mathrm{b}, \mathrm{c})$ y después $(\mathrm{d}, \mathrm{e}, \mathrm{f})$ de la electrólisis del agua durante 12 horas. Reproducida con permiso de la ref 153. Copyright 2021 American Chemical Society. 
Tabla 7.5. Características XPS del 2D-Co-MOF delaminado y 2D-Co-MOF@Nafion después de la electrólisis del agua: Energías de enlace de los diferentes picos, máxima anchura a mitad de pico (FWHM, en paréntesis), intensidades relativas (I $\Sigma=\Sigma$ sat $/ \mathrm{I}_{\text {principal }}$ ), interacción espín-orbital $\left(\Delta \mathrm{E}_{1}\right)$; todas las energías y FWHMs están en eV.

\begin{tabular}{|c|c|c|}
\hline & $\begin{array}{l}\text { 2D-Co-MOF } \\
\text { deslaminado }\end{array}$ & $\begin{array}{c}\text { 2D-Co-MOF@ Nafion } \\
\text { Después de la electrólisis }\end{array}$ \\
\hline $\mathrm{Co}_{2} \mathrm{p}_{3 / 2}$ & $780.6(3.0)$ & 780.7 (2.9) \\
\hline sat1 & $785.0(6.4)$ & $785.0(5.8)$ \\
\hline $\mathbf{I}_{\boldsymbol{\Sigma}}$ & 1.68 & 1.69 \\
\hline $\operatorname{Co} 2 p_{1 / 2}$ & $796.3(2.7)$ & $796.4(3.0)$ \\
\hline sat1' & 801.7 (5.4) & $802.0(5.6)$ \\
\hline$I_{\Sigma}$ & 1.68 & 1.69 \\
\hline$\Delta \mathrm{E} 1$ & 15.7 & 15.7 \\
\hline
\end{tabular}

Del mismo modo, tanto las imágenes de FESEM y FIB como el análisis EDX (Figuras 7.64, 7.65 de la sección experimental) muestran claramente que los centros de cobalto están distribuidos homogéneamente en el composite, descartando así la agregación del metal. Teniendo en cuenta estos resultados se puede concluir que las nanoláminas dobles delaminadas conservan su cristalinidad y morfología tras el proceso de electrólisis.

Finalmente, se analizó la disolución electrolítica después de un experimento extenso de electrólisis del agua a través de la técnica UPLC-HRMS (Q-ToF), la cual revela la presencia de una pequeña cantidad de piridina (Figura 7.54), lo que corrobora el mencionado intercambio de ligandos de piridina con agua. Cabe destacar que el $\mathrm{pH}$ de la disolución permanece constante durante el proceso de electrólisis del agua. 
Capítulo 7. MOFs de Cobalto como Catalizadores para la Oxidación Electrocatalítica del Agua en Medio Neutro.
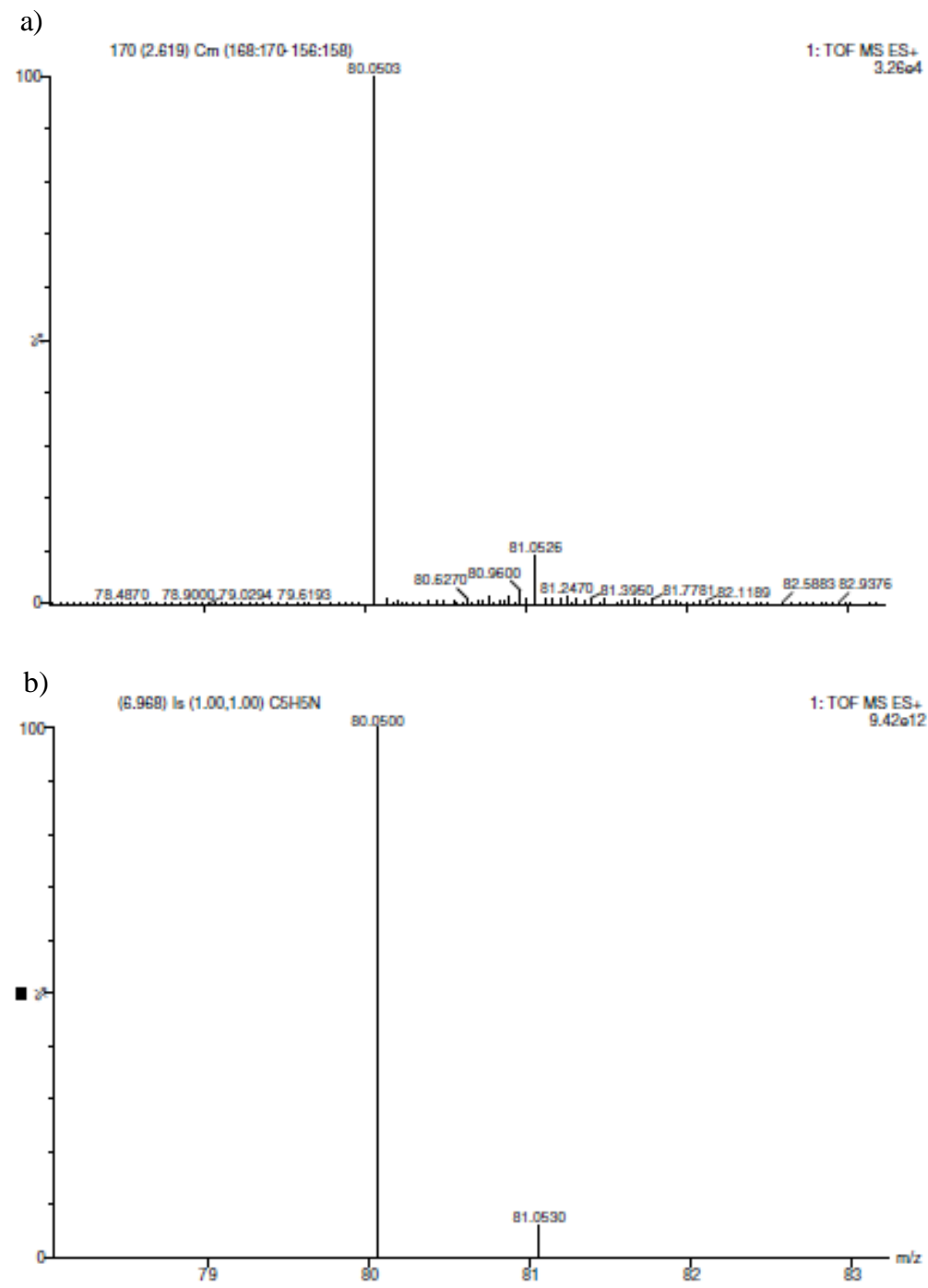

Figura 7.54. a) Espectro ESI-MS de la disolución electrolítica después de un proceso extenso de electrólisis del agua y b) Espectro ESI-MS teórico para la piridina. Reproducida con permiso de la ref 153. Copyright 2021 American Chemical Society. 
En conjunto, estos hallazgos sugieren que el aumento de la actividad electrocatalítica durante la activación electroquímica del compuesto podría tener su origen en un aumento de la permeabilidad iónica de la película en el electrodo, tal y como demuestra la disminución de su resistencia eléctrica determinada por espectroscopía de impedancia electroquímica, más que por cambios estructurales inducidos. En esta línea, podría ser que la generación de microburbujas de oxígeno durante la oxidación electroquímica del agua contribuya a la formación de microcanales en el film, que facilitarían la accesibilidad del electrolito a los centros metálicos. Por lo tanto, en general, la estabilidad a largo plazo del 2D-Co-MOF delaminado en el composite es consistente con la ausencia de cambios estructurales significativos del compuesto durante un proceso extenso de OER.

\section{Estudio mecanístico.}

Con respecto al mecanismo de la reacción de evolución de oxígeno catalizada por catalizadores de cobalto, estudios previos han demostrado que las especies electrocatalíticas activas son las especies Co(IV)-oxo o el radical Co(III)-oxilo generadas a partir del estado de reposo de los centros de cobalto por transferencia de electrones acoplada a protones. En este sentido, se han propuesto diferentes mecanismos para la formación de enlaces O-O catalizada por cobalto:

- Acoplamiento directo entre dos ligandos oxo u oxilo situados en distintos centros de cobalto a través de un enlace peroxo interlaminar. ${ }^{130,131}$

- Acoplamiento geminal de un ligando oxo u oxilo con otro ligando derivado del agua coordinado al mismo centro de cobalto. ${ }^{168,169}$

- Ataque nucleofílico del agua a los ligandos radicales oxo u oxilo, que genera el correspondiente hidroperóxido intermedio. ${ }^{170-172}$

Sin embargo, a pesar de los estudios anteriores, el mecanismo exacto sigue sin conocerse.

En el estudio del mecanismo del OER con el 2D-Co-MOF@Nafion se espera que el intercambio de los ligandos piridina por moléculas de agua facilite la compensación de cargas en la oxidación electroquímica de los centros de cobalto por ionización de los correspondientes ligandos derivados del agua. Para comprobar esta teoría y proporcionar un estudio más completo del comportamiento redox del 2D-Co-MOF inmovilizado, hemos estudiado el efecto del $\mathrm{pH}$ de la disolución en su respuesta voltamperométrica mediante el uso de una disolución de tampón fosfato sódico (Figura 7.55 a). Cabe señalar que el electrodo modificado con el composite 2D-Co-MOF@ Nafion se equilibró en la disolución amortiguadora acuosa de modo que la especie de cobalto de partida fuese 
$\mathrm{Co}^{2+}\left(\mathrm{OH}_{2}\right)$. Comenzando con el 2D-Co-MOF@Nafion activado electroquímicamente en una disolución SPB $0.1 \mathrm{M}$ de $\mathrm{pH}=10$, una disminución del pH de la disolución resultó en el desplazamiento de la onda voltamperométrica del cobalto hacia potenciales más positivos, con una pendiente aproximada de $60 \mathrm{mV} / \mathrm{pH}$ hasta $\mathrm{pH}=6.5$ (Figura $7.55 \mathrm{~b}$ ).
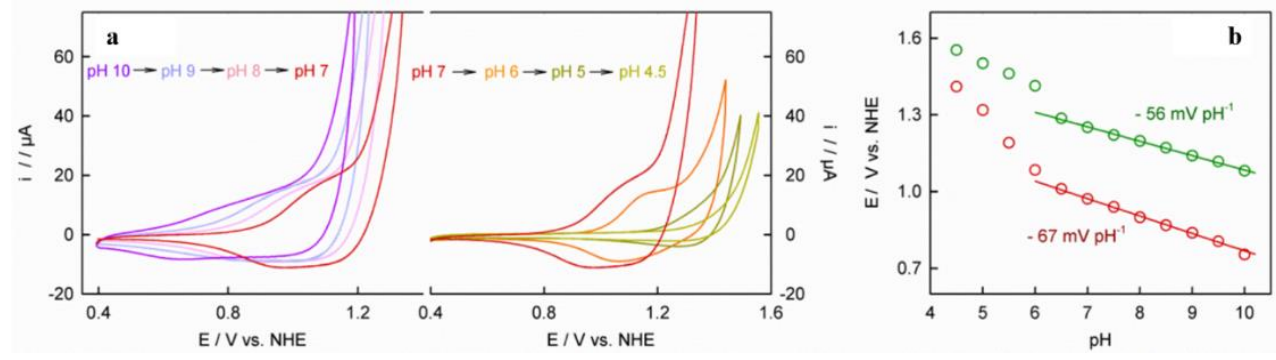

Figura 7.55. a) Voltamogramas cíclicos de un electrodo de grafito pirolítico modificado con 2D-Co-MOF@Nafion medido a $0.05 \mathrm{~V} \mathrm{~s}^{-1}$ a $25^{\circ} \mathrm{C}$ en una disolución acuosa $0.1 \mathrm{M} \mathrm{SPB}$ a los $\mathrm{pH}$ indicados. b) Representación de los correspondientes potenciales (E) frente al $\mathrm{pH}$ estimados a $8 \mu \mathrm{A}$ (símbolos rojos) y $40 \mu \mathrm{A}$ (símbolos verdes). Reproducida con permiso de la ref 153. Copyright 2021 American Chemical Society.

Esta dependencia lineal con el $\mathrm{pH}$ es típica de una conversión redox que implica una transferencia de electrones acoplada a protones. Teniendo en cuenta que el valor de $\mathrm{pKa}$ de la molécula de agua coordinada a Co(III) en los complejos moleculares está en el rango entre 5 y $7,144,173,174$ y en el agua coordinada a Co(II) en los polioxometalatos es mayor que $10,{ }^{172,175}$ la dependencia del $\mathrm{pH}$ anterior es consistente con una desprotonación de la molécula de agua coordinada al oxidarse los centros de $\mathrm{Co}$ (II) de acuerdo con:

$$
\mathrm{Co}(\mathrm{II})-\mathrm{OH}_{2} \rightleftarrows \mathrm{Co}(\mathrm{III})-\mathrm{OH}+e^{-}+\mathrm{H}^{+}
$$

Por debajo de $\mathrm{pH}$ 6, se produce una pérdida progresiva e irreversible de la onda voltamperométrica de cobalto hasta que desaparece a $\mathrm{pH}<5$. La disminución concomitante de la corriente de OER corrobora el papel catalizador de los centros de cobalto. Teniendo en cuenta que los valores de $\mathrm{pK}_{\mathrm{a}}$ de los dos sustituyentes del ácido carboxílico del ligando bda son 1.5 y $3.0,{ }^{176}$ y los valores de $\mathrm{pK}_{\mathrm{a}}$ de los dos nitrógenos piridínicos de la 2,2'-bipiridina son 1.8 y $4.5,{ }^{177,178}$ la pérdida irreversible de la actividad electroquímica puede atribuirse a la descomposición del MOF inducida por la protonación de los grupos ácido/base del ligando bda. 
Por otro lado, la sección voltamperométrica asociada a la oxidación electrocatalítica del agua cambia con el $\mathrm{pH}$ de la disolución de manera similar a las características voltamperométricas del cobalto (símbolos verdes en la Figura 7.55 b), lo que indica que la electrocatálisis de la oxidación del agua mediada por cobalto procede a través de una serie de transferencias de electrones acopladas a protones.

Partiendo de los resultados electroquímicos y espectroscópicos obtenidos en este estudio, se propone el siguiente mecanismo para la conversión redox y la oxidación electrocatalítica del agua con el composite 2D-Co-MOF@ Nafion en disolución acuosa (Figura 7.56). En primer lugar, tiene lugar la oxidación electroquímica de los centros de cobalto $\left(\mathrm{Co}^{2+}-\mathrm{OH}_{2}, \mathbf{1}\right)$ a (vs NHE), que va acompañada de la ionización del ligando aquo para dar la especie $\mathrm{Co}^{3+}-\mathrm{OH}(2)$ a través de una transferencia de electrones acoplados a protones (PCET). A Continuación, se espera un segundo PCET con un potencial algo más positivo para producir la especie oxo intermedia $\mathrm{Co}^{4+}=\mathrm{O}(3)$, que tiene un carácter radicalario importante de $\mathrm{Co}^{3+}$-oxilo $\left(\mathrm{Co}^{3+}-\mathrm{O}^{\bullet}, 4\right)$, el cual ha sido reconocido como la especie catalíticamente activa para la OER.

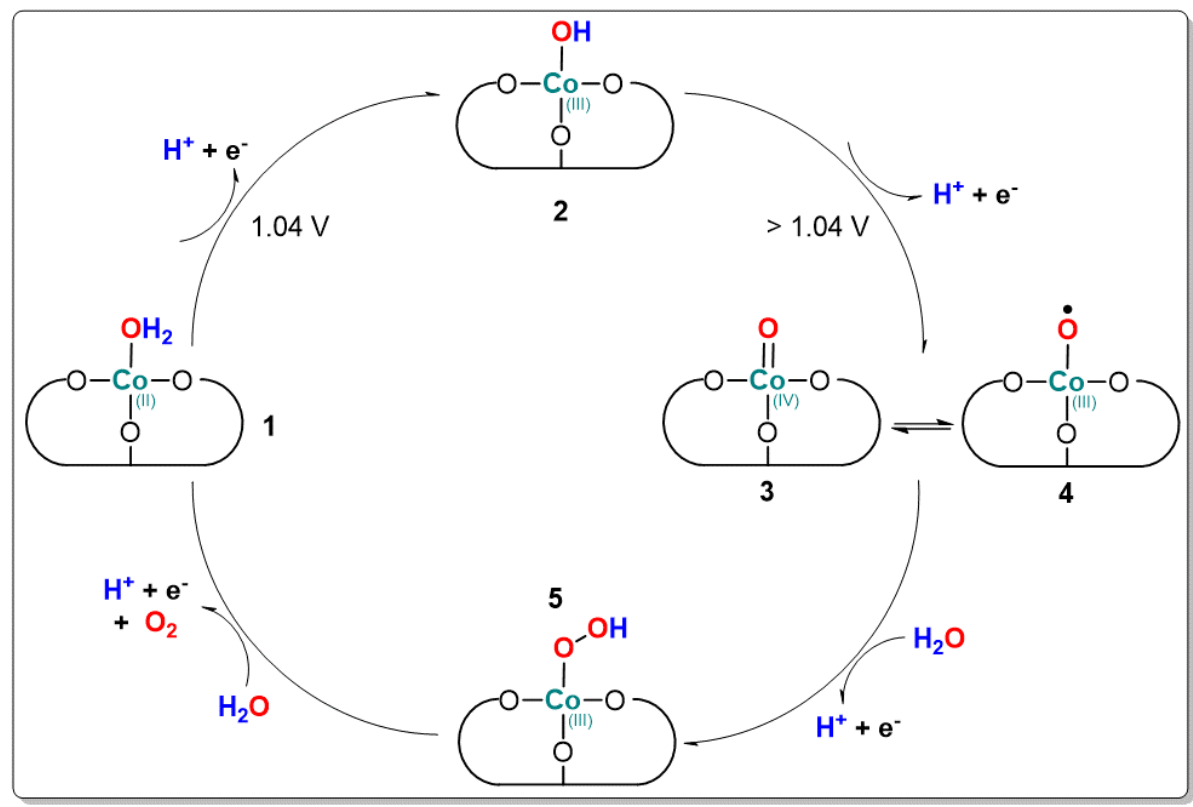

Figura 7.56. Mecanismo propuesto para la reacción de evolución electrocatalítica de oxígeno catalizada por el 2D-Co-MOF a pH neutro. Reproducida con permiso de la ref 153. Copyright 2021 American Chemical Society. 
De los diferentes mecanismos propuestos para la formación del enlace O-O catalizado por cobalto, ${ }^{130,131,168-172}$ el acoplamiento directo entre los dos intermedios de $\mathrm{Co}^{4+}=\mathrm{O}(\mathrm{o}$ $\left.\mathrm{Co}^{3+}-\mathrm{O}^{\bullet}\right)$ de la misma nanolámina se descarta debido a la gran distancia Co-Co (4.69 $\AA$ ). La falta de un segundo ligando derivado del agua en los centros de cobalto descarta también el acoplamiento geminal. Por otro lado, el aumento de la permeabilidad iónica de la película durante la activación electroquímica del composite indica que la electrocatálisis del OER requiere de una buena accesibilidad del electrolito a los centros de cobalto, lo cual se cumple cuando las nanoláminas delaminadas están suficientemente separadas unas de otras. Sin embargo, este escenario no favorece el mecanismo de acoplamiento radical entre láminas, ya que requiere de distancias bastante pequeñas entre las distintas láminas para la formación del correspondiente intermedio dinuclear. Esta situación contrasta con los datos reportados para el óxido de cobalto, donde el mecanismo de acoplamiento radical se propone como un caso realista, ya que involucra dos centros de cobalto con buena accesibilidad para el electrolito. Dado que para el sistema actual los dos requisitos anteriores (proximidad y accesibilidad del electrolito) no pueden cumplirse simultáneamente, el escenario más factible para el mecanismo de la OER es el ataque mononuclear nucleofílico del agua al $\mathrm{Co}^{4+}=\mathrm{O}$ ó $\mathrm{Co}^{3+}-\mathrm{O} \bullet$ para formar el correspondiente hidroperóxido intermedio $\mathrm{Co}^{3+}-\mathrm{O}-\mathrm{OH}(\mathbf{5})$ a través de un PCET, que puede ser facilitado por los ligandos bipiridina ecuatoriales como en el caso de las porfirinas de cobalto altamente eficientes. ${ }^{179}$ Por último, el intermedio 5 reacciona con el agua para formar una molécula de oxígeno y regenerar el estado inicial del $\mathrm{Co}^{2+}-\mathrm{OH}_{2}$ a través de otro PCET.

\subsubsection{Análisis comparativo del rendimiento electrocatalítico del Co $2-M O F @ N a f i o n y$ el2D-Co-MOF@Nafion para la reacción de oxidación del agua.}

Con el fin de evaluar la actividad electrocatalítica de los composites objeto de estudio en

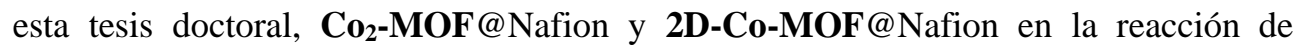
oxidación del agua en medio neutro, se compararon las curvas de polarización de estado estacionario mediante voltamperometría de electrodo rotatorio para los composites y para los electrocatalizadores más conocidos para esta reacción. La Figura 7.57 a muestra las curvas de polarización registradas en medio neutro para el Co2-MOF, el 2D-CoMOF, el $\mathbf{R u O}_{2}$, el $\mathbf{I r O}_{2}$ y el $\mathrm{Co}_{3} \mathbf{O}_{4}$, todos ellos depositados con Nafion en un electrodo de grafito. Los potenciales de inicio de la reacción electrocatalítica fueron de 1.69, 1.73, 1.65, 1.77 y 1.84 (vs NHE) para el $\mathbf{C o}_{2}-\mathbf{M O F}, \mathbf{2 D}-\mathrm{Co}-\mathbf{M O F}, \mathbf{R u O}_{2}, \mathbf{I r O}_{2}$ y $\mathbf{C o}_{3} \mathbf{O}_{4}$, respectivamente y los valores de sobrepotencial correspondientes a $2 \mathrm{~mA} \mathrm{~cm}^{-2}$ fueron 
460, 548, 404, 680 y 595 mV para Co2-MOF, 2D-Co-MOF, $\mathbf{R u O}_{2}$, $\mathbf{I r O}_{2}$ y $\mathbf{C o}_{3} \mathbf{O}_{4}$, respectivamente.
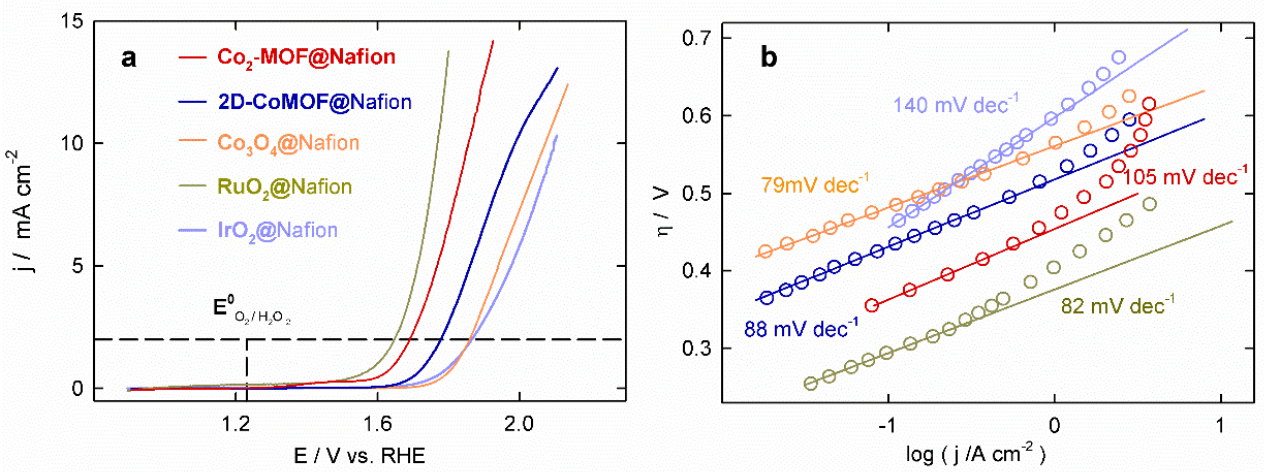

Figura 7.57. a) Voltamogramas de electrodo giratorio medidos a $5 \mathrm{mV} \mathrm{s}^{-1}$ y $4000 \mathrm{rpm}$ y b) Representaciones de Tafel de estado estacionario para un electrodo de grafito pirolítico modificado con los electrocatalizadores indicados en una disolución $0.1 \mathrm{M} \mathrm{SPB} \mathrm{pH} 7$ a $25^{\circ} \mathrm{C}$.

Además, como se puede observar en la Tabla 7.6, el valor del sobrepotencial para el 2DCo-MOF es similar a los valores obtenidos para los electrocatalizadores más activos basados en MOFs de cobalto a pH 7 y el valor para el $\mathbf{C o}_{2}$-MOF es el más bajo, y por lo tanto el mejor valor, reportado en bibliografía comparado con los mencionados anteriormente, con la excepción del MOF híbrido MCF-49. ${ }^{31}$ 
Tabla 7.6. Comparación del rendimiento en OER para MOFs de Co en medio neutro.

\begin{tabular}{ccccccc}
\hline Catalizador & $\begin{array}{c}\boldsymbol{\eta} @ \mathbf{2 m A} \\
\mathbf{c m}^{-2} \\
(\mathbf{m V})\end{array}$ & $\begin{array}{c}\text { Pendiente } \\
\text { Tafel } \\
(\mathbf{m V} \\
\left.\mathbf{d e c}^{-1}\right)\end{array}$ & $\begin{array}{c}\mathbf{T O F}_{\mathbf{\eta}=\mathbf{4 0 0 m V}} \\
\left(\mathbf{s}^{-\mathbf{1}}\right)\end{array}$ & Electrolito & Sustrato & Ref. \\
\hline $\begin{array}{c}\text { 2D-Co- } \\
\text { MOF }\end{array}$ & 548 & 88 & $3.4 \cdot 10^{-2}$ & SPB 0.1M & PGE & $\begin{array}{c}\text { Esta } \\
\text { tesis }\end{array}$ \\
Co2-MOF & 460 & 105 & $2.6 \cdot 10^{-2}$ & SPB 0.1M & PGE & $\begin{array}{c}\text { Esta } \\
\text { tesis }\end{array}$ \\
$\begin{array}{c}\text { Co-MOF } \\
\text { ZIF-67 }\end{array}$ & 565 & 125 & $1.4 \cdot 10^{-2}$ & SPB 0.1M & PGE & $\begin{array}{c}\text { Esta } \\
\text { tesis }\end{array}$ \\
$\begin{array}{c}\text { MAF-X27- } \\
\text { OH }\end{array}$ & 489 & 127 & $1.1 \cdot 10^{-3}$ & PPB 1.0M & GCE & 111 \\
MCF-49 & 431 & 134 & - & SPB 0.1M & GCE & 112 \\
$\begin{array}{c}\text { MOF-74- } \\
\text { Co }\end{array}$ & 492 & 129 & $1.0 \cdot 10^{-3}$ & SPB 0.1M & GCE & 112 \\
$\begin{array}{c}\text { ZIF-67 } \\
\text { Co-ZIF-9 }\end{array}$ & 525 & 125 & $7.0 \cdot 10^{-4}$ & SPB 0.1M & GCE & 112 \\
\hline
\end{tabular}

La cinética para la OER electrocatalítica catalizada por los diferentes electrocatalizadores se evaluó a partir de la correspondiente gráfica de Tafel (Figura 7.57 b) obtenida a partir de los datos cronoamperométricos de densidad de corriente de estado estacionario medidos para una secuencia de saltos de potencial de 0.01V. Los MOFs de cobalto estudiados, Co - MOF, Co-MOF y 2D-Co-MOF, presentan valores de pendiente de Tafel (TS) de $105 \pm 5,125 \pm 5$ y $88 \pm 4 \mathrm{mV} \mathrm{dec}^{-1}$, respectivamente, valores similares a los obtenidos para el $\mathbf{R u O}_{2}$ y el $\mathbf{C o}_{3} \mathbf{O}_{4}\left(82\right.$ y $79 \mathrm{dec}^{-1}$, respectivamente), pero inferiores al valor obtenido en el caso del $\operatorname{IrO}_{2}\left(140 \mathrm{dec}^{-1}\right)$. Hasta donde sabemos, estos son los mejores valores reportados para catalizadores basados en MOF de cobalto que operan en medio neutro (Tabla 7.6) Además, los valores de TOF determinados para los MOFs sintetizados en esta tesis doctoral, 0.026 y $0.034 \mathrm{~s}^{-1}$ (para Co-MOF y 2D-CoMOF, respectivamente) son superiores a los reportados para electrocatalizadores similares basados en cobalto (Tabla 7.6). 


\subsection{Conclusiones}

- Se han desarrollado dos nuevos MOFs de Cobalto, el primero de ellos basado en dos SBUs de cobalto dinucleares (Co2-MOF) y el segundo basado en una estructura de láminas dobles que están fuertemente conectadas por enlaces intermoleculares (2D-Co-MOF). El empleo de un precursor de cobalto tetranuclear es clave para conseguir dichos MOFs de cobalto empleando ligandos orgánicos ampliamente estudiados en la síntesis de MOFs.

- $\quad$ El Co $\mathbf{C o}_{2}$-MOF presenta una topología inusual en la que uno de los cobaltos tiene tres posiciones de coordinación libres, lo cual no tiene precedentes en MOF basados en este metal. Además, este MOF de cobalto presenta canales de gran tamaño (en el rango de 10-12 $\AA$ ), lo que promueve que sea un material prometedor para la separación de $\mathrm{CO}_{2}$ frente a $\mathrm{CH}_{4}$, con valores similares a los de los tamices moleculares zeolíticos.

- En el caso del 2D-Co-MOF, las láminas dobles se mantienen unidas debido a interacciones $\pi$ - $\pi$ entre los ligandos piridina axiales. Se ha demostrado que este material se deslamina en presencia de agua y que la estructura tridimensional original puede ser regenerada a través de un tratamiento solvotermal con piridina, por lo que se podría decir que las láminas llevan asociadas un "efecto memoria".

- La dispersión de estos MOFs de cobalto en una disolución alcohólica de Nafion da como resultado los correspondientes composites (Co2-MOF@Nafion, CoMOF@Nafion y 2D-Co-MOF@Nafion) que presentan buena adherencia a electrodos de grafito y una gran estabilidad química a largo plazo. Estos composites han mostrado un elevado rendimiento electrocatalítico para la reacción de oxidación del agua en medio neutro, con valores de TOF $\left(0.026,0.014\right.$ y $0.034 \mathrm{~s}^{-1}$ para el Co-MOF, Co-MOF y el 2D-Co-MOF, respectivamente) superiores a los reportados para electrocatalizadores de cobalto.

- $\quad$ Además, para el 2D-Co-MOF@ Nafion, la activación electroquímica del electrodo modificado con este composite mejora tanto la migración iónica como la transferencia electrónica a lo largo de la película, lo que promueve la formación de especies de cobalto electrocatalíticamente activas. 
- En base a la topología particular del 2D-Co-MOF, con centros de cobalto distantes dentro de la estructura, y a su caracterización espectroscópica y electroquímica, se puede concluir que la presencia de ligandos ecuatoriales aromáticos que contienen nitrógeno (del fragmento bipy del ligando bda) podrían facilitar el ataque nucleofílico del agua sobre los centros mononucleares.

\subsection{Sección experimental}

\subsubsection{Síntesis y caracterización de los MOFs de Cobalto.}

\subsubsection{Sintesis y caracterización del $\mathrm{Co}_{2}-\mathrm{MOF}$.}

Para la síntesis del Con-MOF se emplearon condiciones solvotermales, usando $\left[\left(\mathrm{Co}_{4} \mathrm{O}_{4}\right)(\mathrm{OAc})_{4}(\mathrm{Py})_{4}\right]$ como precursor del material final. Este material fue sintetizado usando 2.7 equivalentes del ligando $\mathrm{H}_{3} \mathrm{BTC}(2.38 \mathrm{mmol})$ por cada equivalente de $\left[\left(\mathrm{Co}_{4} \mathrm{O}_{4}\right)(\mathrm{OAc})_{4}(\mathrm{Py})_{4}\right](0.89 \mathrm{mmol})$. Ambos compuestos se disolvieron en dos porciones diferentes de DMF de $25 \mathrm{~mL}$ cada una. A continuación, se mezclaron dichas disoluciones y se añadieron 8 equivalentes de ácido trifluoroacético (TFA) a la mezcla de reacción. La disolución resultante se introduce en un autoclave y se calienta a $135^{\circ} \mathrm{C}$ durante 72 horas bajo presión autógena y sin agitación. Pasado este tiempo, se deja enfriar hasta temperatura ambiente, se filtra y se lava con DMF y acetona. Finalmente, el material aislado se seca a vacío a temperatura ambiente. Anal. Calcd for $\mathrm{C}_{35} \mathrm{H}_{39} \mathrm{Co}_{3} \mathrm{~N}_{5} \mathrm{O}_{16}$ : C, 43.676; H, 4.084; N, 7.276; Co, 18.369. Experimental: C, 43.947; H, 4.005; N, 7.593; Co, 18.570 .

Tabla 7.7. Datos cristalográficos y detalles del refinamiento de la estructura para el $\mathbf{C o}_{2-}$ MOF. Las coordenadas atómicas, los parámetros equivalentes de desplazamiento isotrópico, las distancias y ángulos de enlace y los parámetros de desplazamiento anisotrópico se pueden encontrar en el CIF (CCDC 1898281).

\begin{tabular}{|c|c|}
\hline $\mathbf{C o}_{2}$-MOF & \\
\hline Fórmula empírica & $\mathrm{C}_{32} \mathrm{H}_{32} \mathrm{Co}_{3} \mathrm{~N}_{4} \mathrm{O}_{15} \cdot \mathrm{C}_{3} \mathrm{H}_{7} \mathrm{NO}$ \\
\hline Peso molecular & 962.50 \\
\hline Temperatura $(\mathbf{K})$ & $120(2)$ \\
\hline Longitud de onda $(\stackrel{\AA}{)})$ & 0.71073 \\
\hline Sistema cristalográfico & Monoclinico \\
\hline
\end{tabular}




\begin{tabular}{|c|c|}
\hline Grupo especial & $\mathrm{P} 2{ }_{1} / \mathrm{n}$ \\
\hline \multicolumn{2}{|l|}{ Dimensiones celda unidad } \\
\hline $\mathbf{a}(\AA)$ & $13.41540(10)$ \\
\hline b $(\AA)$ & $13.6371(2)$ \\
\hline c $(\AA)$ & $26.1779(3)$ \\
\hline$\alpha\left({ }^{\circ}\right)$ & 90 \\
\hline$\beta\left({ }^{\circ}\right)$ & $98.1900(10)$ \\
\hline$\gamma\left(\left(^{\circ}\right)\right.$ & 90 \\
\hline Volumen (̊̊) & $4740.33(10)$ \\
\hline $\mathbf{Z}$ & 4 \\
\hline Densidad (calculada) & 1.349 \\
\hline Coeficiente de absorción & 1.103 \\
\hline $\mathbf{F}(\mathbf{0 0 0})$ & 1972.0 \\
\hline Tamaño de cristal & $0.16 \times 0.1 \times 0.05$ \\
\hline Radiación & $\operatorname{MoK} \alpha(\lambda=0.71073)$ \\
\hline $\begin{array}{c}\text { Rango theta para la recopilación } \\
\text { de datos }\end{array}$ & $6.484-50.108^{\circ}$ \\
\hline Rango Index & $\begin{array}{c}-15 \leq \mathrm{h} \leq 15,-16 \leq \mathrm{k} \leq 16 \\
-31 \leq 1 \leq 31\end{array}$ \\
\hline Reflexiones recogidas & 163820 \\
\hline Reflexiones independientes & $8358\left[\mathrm{R}_{\mathrm{int}}=0.0894, \mathrm{R}_{\text {sigma }}=0.0361\right]$ \\
\hline Datos/restricciones/parametros & $8358 / 0 / 478$ \\
\hline Goodness-of-fit on F2 & 1.069 \\
\hline Índices R Finales $[I>2 \sigma(I)]$ & $\mathrm{R}_{1}=0.0624, \mathrm{wR}_{2}=0.1642$ \\
\hline Indices $\mathbf{R}$ & $\mathrm{R}_{1}=0.0755, \mathrm{wR}_{2}=0.1731$ \\
\hline
\end{tabular}




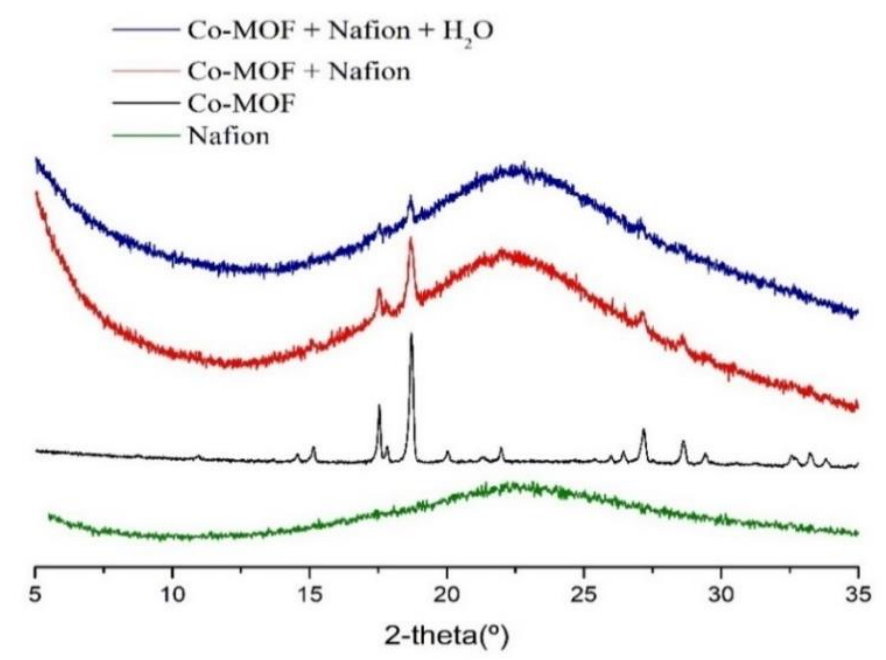

Figura 7.58. Patrones de difracción de rayos X de polvo del Co-MOF@ Nafion (rojo), CoMOF@Nafion después del tratamiento con agua (azul), Co-MOF (negro) y Nafion (verde). Reproducida con permiso de la ref 135. Copyright 2021 American Chemical Society.

\subsubsection{Síntesis y caracterización del 2D-Co-MOF.}

Para llevar a cabo la síntesis del 2D-Co-MOF se utilizan condiciones solvotermales y el compuesto de coordinación $\left[\left(\mathrm{Co}_{4} \mathrm{O}_{4}\right)(\mathrm{OAc})_{4}(\text { py })_{4}\right]$ como precursor del material final. Este MOF de cobalto se sintetizó a partir de 4 equivalentes del ácido 2,2'-bipiridil-4,4'dicarboxílico (bda) $(1.84 \mathrm{mmol})$ por cada equivalente de $\left[\left(\mathrm{Co}_{4} \mathrm{O}_{4}\right)(\mathrm{OAc})_{4}(\mathrm{Py})_{4}\right](0.46$ $\mathrm{mmol}$ ), los cuales se disolvieron en dos porciones diferentes de $30 \mathrm{~mL}$ de piridina. Las dos disoluciones resultantes se mezclaron y se añadieron 8 equivalentes de ácido trifluoroacético (TFA). La disolución resultante se trasvasó a un autoclave, que se introdujo en una estufa a $150^{\circ} \mathrm{C}$ durante 9 días en condiciones estáticas. Pasado este tiempo se dejó enfriar a temperatura ambiente y se filtró la disolución, dando como resultado cristales rojos del 2D-Co-MOF. El sólido se lavó con acetona para eliminar las moléculas de piridina residuales y se secó a vacío a temperatura ambiente. Anal. Calcd for $\mathrm{C}_{18} \mathrm{H}_{11} \mathrm{CoN}_{3} \mathrm{O}_{4}$ : C, 55.119; H, 2.827; N, 10.713; Co, 15.025. Experimental: C, 55.071; H, 3.052; N, 10.773; Co, 15.051 .

Este material laminar se intentó sintetizar a partir de precursores comerciales como el $\mathrm{Co}(\mathrm{OAc})_{2} \cdot 4 \mathrm{H}_{2} \mathrm{O}$ o el $\mathrm{Co}\left(\mathrm{NO}_{3}\right)_{2} \cdot 6 \mathrm{H}_{2} \mathrm{O}$ usando diferentes condiciones de síntesis $(\mathrm{T}=$ 100,135 y $150^{\circ} \mathrm{C}$ durante $1,4,9,14$ y 25 días), pero en ninguno de los casos se obtuvo el material de interés (Tabla 7.8, Figura 7.59). 
Tabla 7.8. Intentos de síntesis del 2D-Co-MOF a partir de precursores de cobalto comerciales.

\begin{tabular}{|c|c|c|c|}
\hline Precursor & $\mathrm{T}\left({ }^{\circ} \mathrm{C}\right)$ & t (días) & Producto (PXRD) \\
\hline \multirow{4}{*}{$\mathrm{Co}(\mathrm{OAc})_{2} \cdot 4 \mathrm{H}_{2} \mathrm{O}$} & 100 & 1 & \multirow{4}{*}{ Sólido amorfo (A) } \\
\hline & 100 & 5 & \\
\hline & 100 & 9 & \\
\hline & 100 & 14 & \\
\hline \multirow{4}{*}{$\mathrm{Co}(\mathrm{OAc})_{2} \cdot 4 \mathrm{H}_{2} \mathrm{O}$} & 135 & 1 & \multirow{4}{*}{ Agujas blancas (B) } \\
\hline & 135 & 5 & \\
\hline & 135 & 9 & \\
\hline & 135 & 14 & \\
\hline \multirow{5}{*}{$\mathrm{Co}(\mathrm{OAc})_{2} \cdot 4 \mathrm{H}_{2} \mathrm{O}$} & 150 & 1 & \multirow{5}{*}{ Agujas blancas (B) } \\
\hline & 150 & 5 & \\
\hline & 150 & 9 & \\
\hline & 150 & 14 & \\
\hline & 150 & 25 & \\
\hline \multirow{4}{*}{$\mathrm{Co}\left(\mathrm{NO}_{3}\right)_{2} \cdot 6 \mathrm{H}_{2} \mathrm{O}$} & 100 & 1 & \multirow{4}{*}{ Sólido amorfo (C) } \\
\hline & 100 & 5 & \\
\hline & 100 & 9 & \\
\hline & 100 & 14 & \\
\hline \multirow{4}{*}{$\mathrm{Co}\left(\mathrm{NO}_{3}\right)_{2} \cdot 6 \mathrm{H}_{2} \mathrm{O}$} & 135 & 1 & \multirow{4}{*}{ Agujas blancas (D) } \\
\hline & 135 & 5 & \\
\hline & 135 & 9 & \\
\hline & 135 & 14 & \\
\hline \multirow{5}{*}{$\mathrm{Co}\left(\mathrm{NO}_{3}\right)_{2} \cdot 6 \mathrm{H}_{2} \mathrm{O}$} & 150 & 1 & \multirow{5}{*}{ Agujas blancas (D) } \\
\hline & 150 & 5 & \\
\hline & 150 & 9 & \\
\hline & 150 & 14 & \\
\hline & 150 & 25 & \\
\hline
\end{tabular}




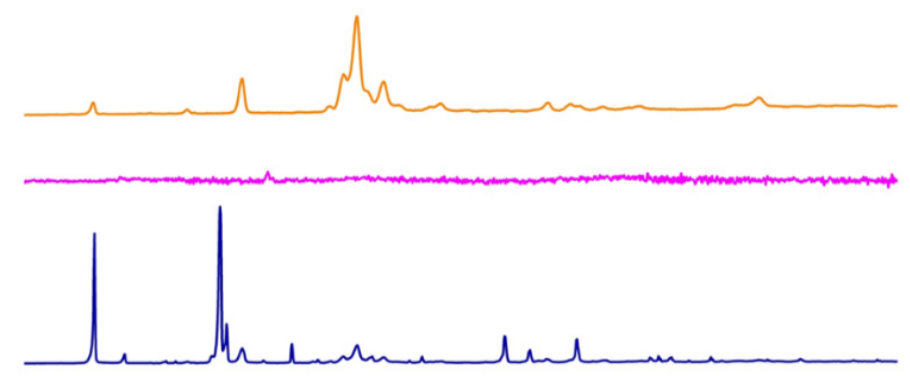

Agujas blancas (D)

Sólido amorfo (C)

Agujas blancas (B)

Sólido amorfo (A)

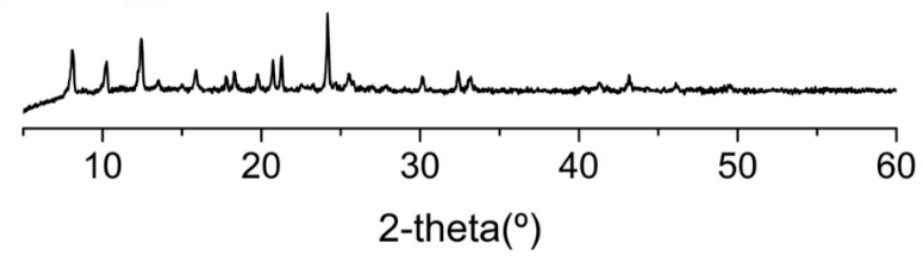

2D-Co-MOF

Figura 7.59. PXRD del 2D-Co-MOF (negro) y los correspondientes materiales sintetizados a partir de los precursores $\mathrm{Co}(\mathrm{OAc})_{2} \cdot 4 \mathrm{H}_{2} \mathrm{O}$ o el $\mathrm{Co}\left(\mathrm{NO}_{3}\right)_{2} \cdot 6 \mathrm{H}_{2} \mathrm{O}$ usando las condiciones de síntesis recogidas en la Tabla 7.8. Reproducida con permiso de la ref 153. Copyright 2021 American Chemical Society.

Tabla 7.9. Datos cristalográficos y detalles del refinamiento de la estructura para el 2D-CoMOF. Las coordenadas atómicas, los parámetros equivalentes de desplazamiento isotrópico, las distancias y ángulos de enlace y los parámetros de desplazamiento anisotrópico se pueden encontrar en el CIF (CCDC 1994492).

\begin{tabular}{|c|c|}
\hline 2D-Co-MOF & \\
\hline Fórmula empírica & $\mathrm{C}_{17} \mathrm{H}_{11} \mathrm{CoN}_{3} \mathrm{O}_{4} \mathrm{C}_{1.25} \mathrm{~N}_{0.25}$ \\
\hline Peso molecular & 398.73 \\
\hline Temperatura $(\mathbf{K})$ & $120(2)$ \\
\hline Longitud de onda $(\AA)$ & 0.71073 \\
\hline Sistema cristalográfico & Monoclínico \\
\hline Grupo especial & $P 2_{1} / c$ \\
\hline
\end{tabular}




\begin{tabular}{|c|c|}
\hline Dimensiones celda unidad & \\
\hline $\mathbf{a}(\AA)$ & $11.0019(4)$ \\
\hline b $(\AA)$ & $11.2711(4)$ \\
\hline c $(\AA)$ & $14.0615(5)$ \\
\hline$\alpha\left({ }^{\circ}\right)$ & 90 \\
\hline$\beta\left({ }^{\circ}\right)$ & $97.279(3)$ \\
\hline$\gamma\left(\left(^{\circ}\right)\right.$ & 90 \\
\hline Volumen $(\AA ̊)$ & $1729.62(11)$ \\
\hline $\mathbf{Z}$ & 4 \\
\hline Densidad (calculada) & 1.531 \\
\hline Coeficiente de absorción & 1.022 \\
\hline $\mathbf{F}(000)$ & 809 \\
\hline Tamaño de cristal & $0.12 \times 0.1 \times 0.08$ \\
\hline Radiación & $\operatorname{MoK} \alpha(\lambda=0.71073)$ \\
\hline $\begin{array}{c}\text { Rango theta para la recopilación } \\
\text { de datos }\end{array}$ & $3.435-28.083^{\circ}$ \\
\hline Rango Index & $\begin{array}{c}-14 \leq \mathrm{h} \leq 14,-14 \leq \mathrm{k} \leq 14 \\
-18 \leq 1 \leq 17\end{array}$ \\
\hline Reflexiones recogidas & 3823 \\
\hline Reflexiones independientes & 2495 \\
\hline Datos/restricciones/parámetros & $3823 / 0 / 237$ \\
\hline Goodness-of-fit on F2 & 1.074 \\
\hline Índices R Finales [I>2 $\sigma(I)]$ & $\mathrm{R}_{1}=0.0706, \mathrm{wR}_{2}=0.1930$ \\
\hline Índices $\mathbf{R}$ & $\mathrm{R}_{1}=0.1181, \mathrm{wR}_{2}=0.2229$ \\
\hline
\end{tabular}




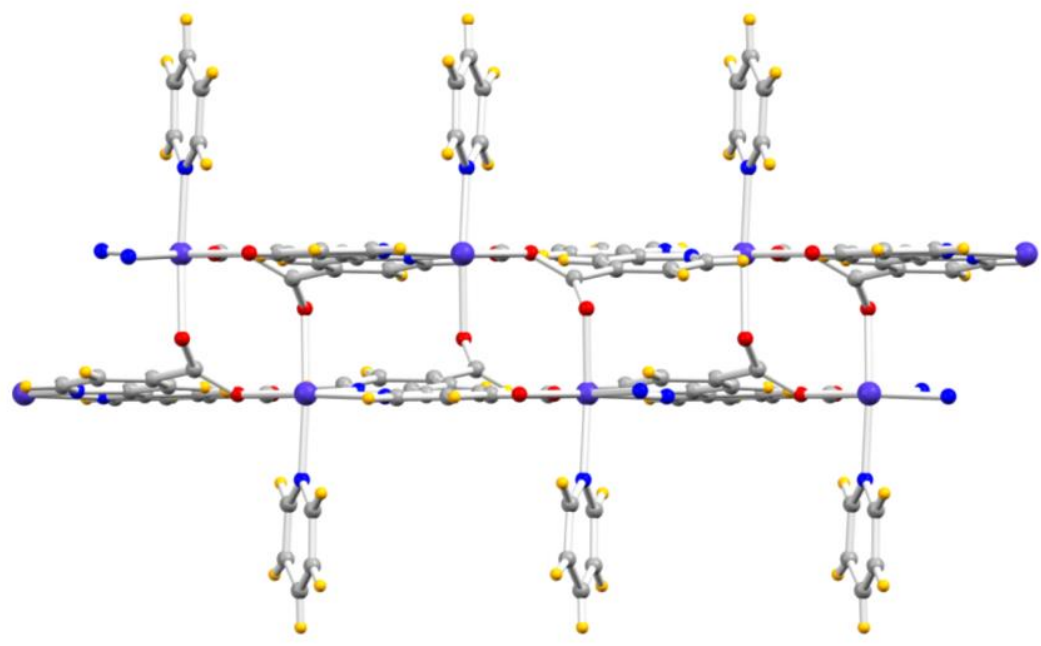

Figura 7.60. Representación de una lámina doble del 2D-Co-MOF a lo largo del eje b. Reproducida con permiso de la ref 153. Copyright 2021 American Chemical Society.

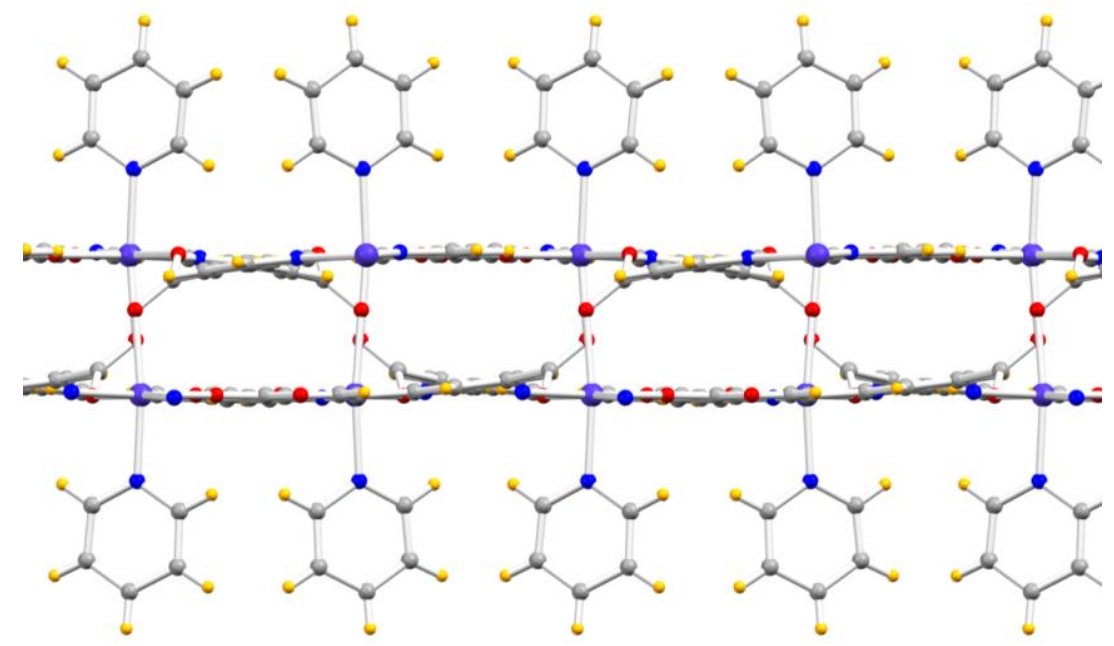

Figura 7.61. Representación de una lámina doble del 2D-Co-MOF a lo largo del eje c. Reproducida con permiso de la ref 153. Copyright 2021 American Chemical Society. 


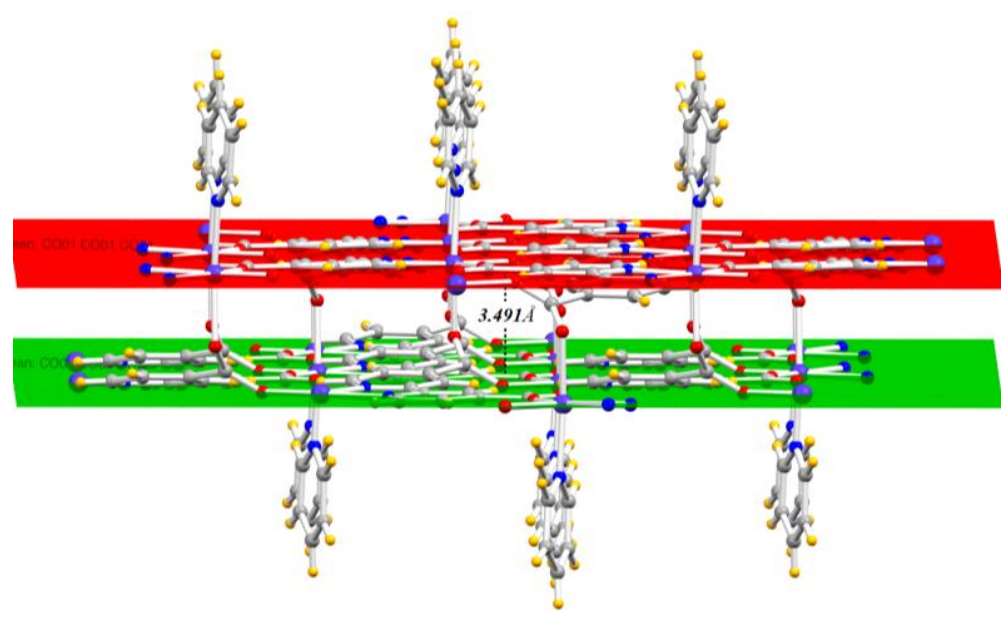

Figura 7.62. Representación de los planos calculados para cada lámina doble del 2D-CoMOF y distancia medida entre los planos. Reproducida con permiso de la ref 153.

Copyright 2021 American Chemical Society.

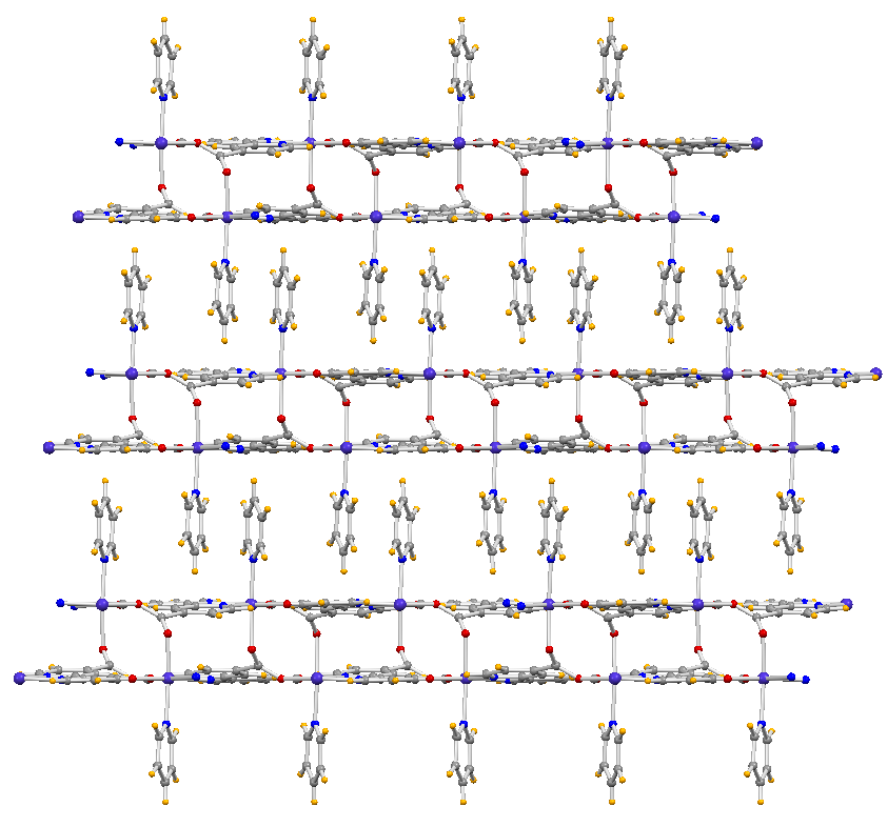

Figura 7.63. Representación de la estructura supramolecular del 2D-Co-MOF a lo largo del eje b. Reproducida con permiso de la ref 153. Copyright 2021 American Chemical Society. 
Capítulo 7. MOFs de Cobalto como Catalizadores para la Oxidación Electrocatalítica del Agua en Medio Neutro.

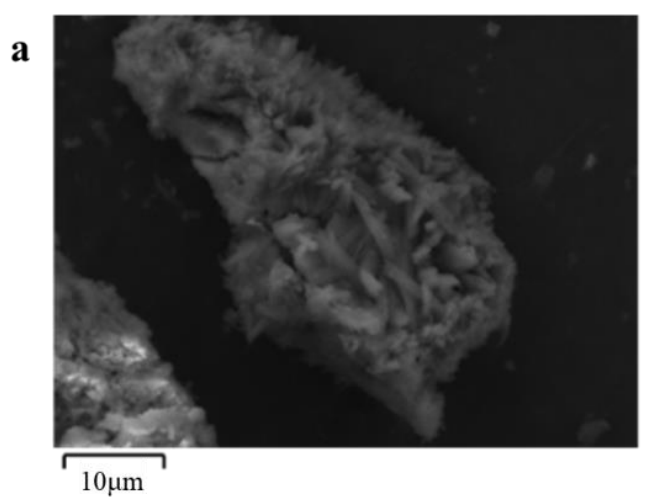

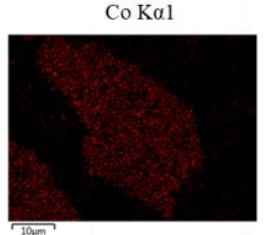

N Kal_ 2

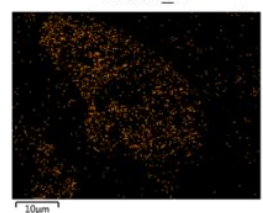

$10 \mathrm{man}$

$\mathrm{CoK} \alpha 1$

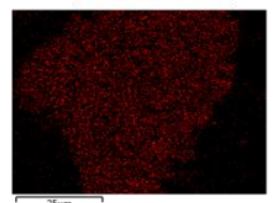

N K $\alpha 12$

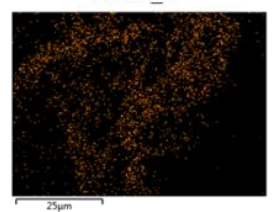

$\mathrm{F} \mathrm{K \alpha 1 \_ 2}$

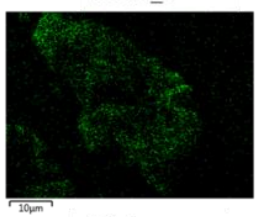

$\mathrm{S} \mathrm{K} \alpha 1$

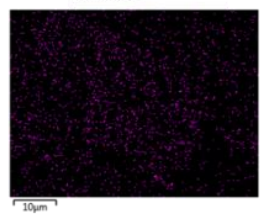

$\mathrm{F} \mathrm{K} \alpha 1 \_2$

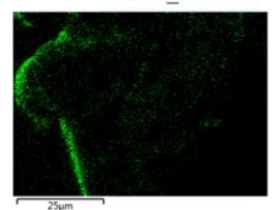

$\mathrm{S} \mathrm{K} \alpha 1$

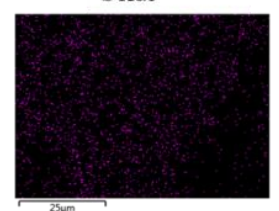

$10 \mu \mathrm{m}$

Figura 7.64. Imágenes tomadas por microscopía electrónica de barrido (FESEM) y análisis EDX del 2D-Co-MOF@Nafion delaminado a) antes y b) después de la electrólisis del agua durante 12 horas. Reproducida con permiso de la ref 153. Copyright 2021 American Chemical Society. 

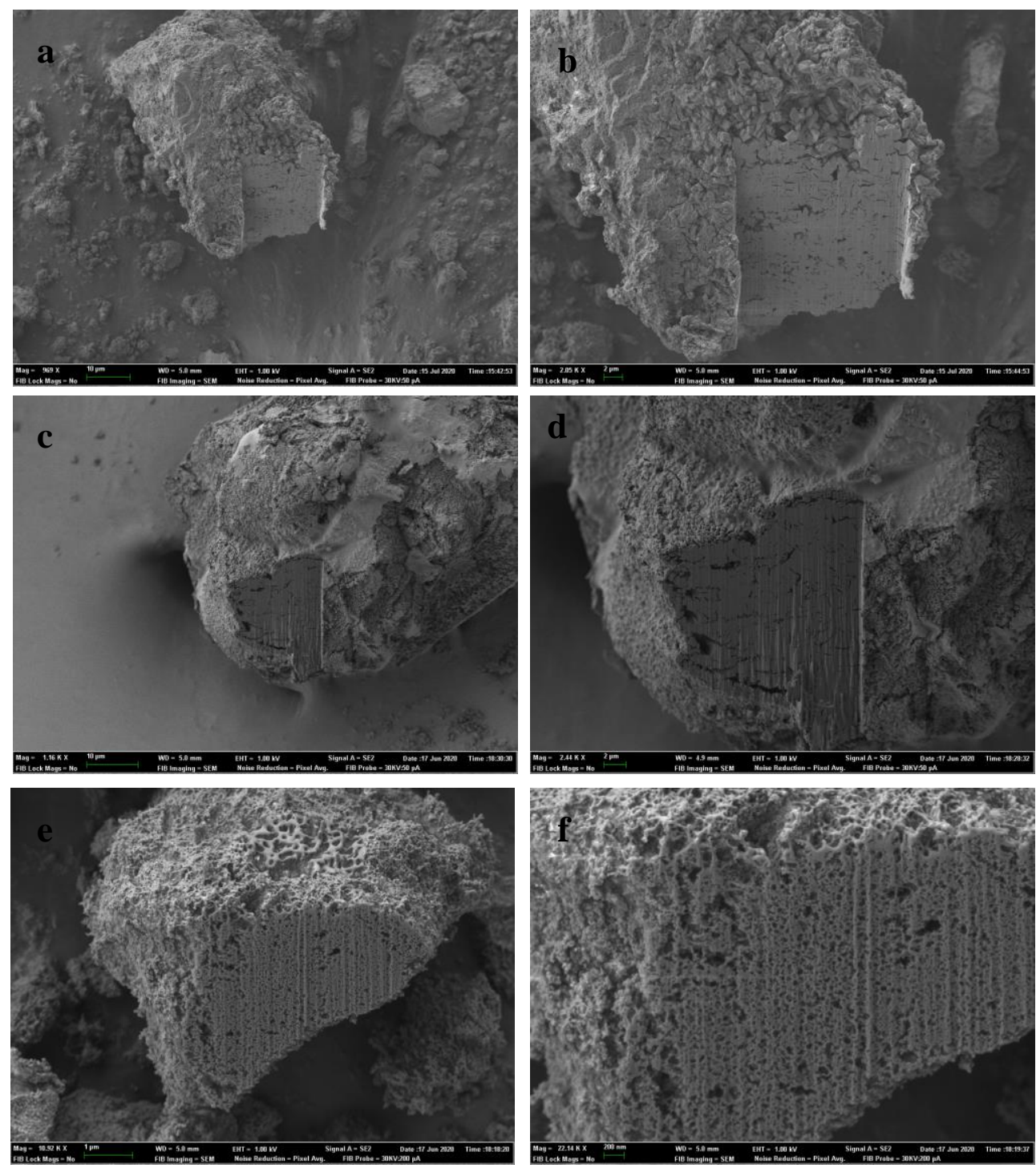

Figura 7.65. Imágenes tomadas con un microscopio electrónico de barrido equipado con un haz de iones focalizados (FIB) de la sección transversal del composite 2D-Co-MOF@ Nafion delaminado antes $(\mathrm{a}, \mathrm{b})$ y después (c, d) de la electrólisis del agua durante 12 horas y del polímero de Nafion (e, f). Reproducida con permiso de la ref 153. Copyright 2021 American Chemical Society. 


\subsubsection{Procedimiento experimental para las medidas de adsorción.}

Las propiedades de adsorción del Co2-MOF se estudiaron tras la activación del material a $100^{\circ} \mathrm{C}$ a vacío. El Co $\mathbf{C o}_{2}-\mathrm{MOF}$ resultante absorbe muy poco $\mathrm{N}_{2}$ a $-176^{\circ} \mathrm{C}$, lo que sugiere que se producen graves limitaciones de difusión durante la adsorción de $\mathrm{N}_{2}$ a temperaturas criogénicas. Siguiendo las recomendaciones de la IUPAC, se midió la isoterma de adsorción de $\mathrm{CO}_{2}$ a $0^{\circ} \mathrm{C} .{ }^{180} \mathrm{Con}$ los datos obtenidos se representa el gráfico de Dubinin-Astakhov para la adsorción de $\mathrm{CO}_{2}$ a $273 \mathrm{~K}$. Los datos experimentales se linealizan con un valor para el exponente Astakhov (n) de 2.14. Según la bibliografía, se ha reportado un valor superior a 2 para los materiales de tamiz molecular con microporos muy homogéneos. Por lo tanto, la modelización de Dubinin-Astakhov indica una gran homogeneidad en la porosidad del adsorbente sólido.

Las isotermas experimentales a diferentes temperaturas se ajustaron haciendo uso de la ecuación de virial: ${ }^{181,182}$

$$
P=\frac{Q}{K_{H}} \exp \left(A_{1} Q+A_{2} Q^{2}+A_{3} Q^{3}+A_{4} Q^{4}\right) \quad \text { Ecuación } 7.3
$$

donde $\mathrm{A}_{\mathrm{i}}$ son los coeficientes de virial y $\mathrm{K}_{\mathrm{H}}$ es la constante de Henry

Las isotermas de $\mathrm{CO}_{2}$ a baja presión (hasta 1 bar) obtenidas en el equipo volumétrico se muestran en la Figura 7.10. Los puntos corresponden a los valores experimentales mientras que las líneas son las ecuaciones de Virial ajustadas. Las isotermas experimentales siguen la tendencia esperada con la temperatura, por lo que puede asumirse que no hay limitaciones difusionales durante la adsorción de $\mathrm{CO}_{2}$. Con el conjunto de isotermas experimentales ajustadas, se calculó el calor isostérico de adsorción de $\mathrm{CO}_{2}$, que se muestra en la Figura $7.10 \mathrm{c}$. Este dato es casi constante dentro del rango estudiado, con un valor de $28 \mathrm{~kJ} / \mathrm{mol}$. El calor isostérico de adsorción de $\mathrm{CO}_{2}$ a cobertura cero $\left(\mathrm{q}_{\mathrm{st}, 0}\right)$ calculado a partir de las constantes de Henry es de $30 \mathrm{~kJ} / \mathrm{mol}$.

A continuación, el calor isostérico de adsorción ( $\mathrm{q}_{\mathrm{st}}$ ) se calculó a partir del conjunto de isotermas ajustadas de acuerdo con la ecuación de Clausius-Clapeyron: ${ }^{183}$

$$
\mathrm{q}_{\mathrm{st}}=-\mathrm{R} \cdot\left[\frac{\partial(\ln \mathrm{P})}{\partial(1 / \mathrm{T})}\right]_{\mathrm{Q}=\text { cte }}
$$

Ecuación 7.4

El calor isostérico de adsorción a cobertura cero $\left(\mathrm{q}_{\mathrm{st}, 0}\right)$ se determinó a partir de las correspondientes constantes de Henry según la expresión: 


$$
\mathrm{q}_{\mathrm{st}, 0}=-\mathrm{R} \cdot\left[\frac{\partial\left(\ln K_{H}\right)}{\partial(1 / \mathrm{T})}\right]
$$

Ecuación 7.5

El área superficial aparente del sólido se estimó mediante la adsorción de $\mathrm{CO}_{2}$ a $273 \mathrm{~K}$. La capacidad de la monocapa $\left(\mathrm{V}_{0}\right)$ se determinó aplicando la ecuación linealizada de Dubinin-Astakhov. ${ }^{184}$

$$
\log (\mathrm{V})=\log \left(\mathrm{V}_{0}\right)-\left[\frac{\mathrm{R} \cdot \mathrm{T}}{\beta \cdot \mathrm{E}_{0}}\right]^{\mathrm{n}}\left[\log \left(\frac{\mathrm{p}_{0}}{\mathrm{p}}\right)\right]^{\mathrm{n}}
$$

Ecuación 7.6

Con los siguientes términos: $\mathrm{V}_{0}$, la capacidad monocapa; $\mathrm{R}$, la constante de gas; $\mathrm{T}$, la temperatura de análisis; $\beta$, el coeficiente de afinidad del $\mathrm{CO}_{2} ; \mathrm{E}_{0}$, la energía característica; n, el exponente de Astajov; $\mathrm{p}_{0}$, la presión de vapor de saturación del $\mathrm{CO}_{2}$ a la temperatura de análisis; y p, la presión de equilibrio. El área transversal ( $\sigma)$ para la molécula de $\mathrm{CO}_{2}$ a $273 \mathrm{~K}$ tiene un valor de $0-187 \mathrm{~nm}^{2} .{ }^{185}$ Por lo tanto, se utilizó la siguiente expresión para calcular el área superficial aparente:

$$
\mathrm{S}\left(\mathrm{m}^{2} / \mathrm{g}\right)=\frac{6.022 \cdot 10^{23}(\mathrm{molécula} / \mathrm{mol}) \cdot \sigma\left(\mathrm{nm}^{2} / \mathrm{molé}^{2} u l a\right) \cdot \mathrm{V}_{0}\left(\mathrm{~cm}^{3} / \mathrm{g}\right)}{22414\left(\mathrm{~cm}^{3} / \mathrm{mol}\right) \cdot 10^{18}\left(\mathrm{~nm}^{2} / \mathrm{m}^{2}\right)}
$$

Ecuación 7.7

Las isotermas de alta presión de $\mathrm{CO}_{2}$ y $\mathrm{CH}_{4}$ (hasta 10 bar) obtenidas a diferentes temperaturas se muestran en la Figura $7.10 \mathrm{~d}$. $\mathrm{El} \mathrm{CH}_{4}$ presenta grandes limitaciones difusionales, a pesar de las condiciones restrictivas de equilibrio. Se puede ver claramente en el hecho de que las isotermas a mayor temperatura se superponen o incluso se cruzan con las de menor temperatura.

Las isotermas experimentales se ajustaron correctamente con la ecuación de Virial, de modo que la selectividad aparente de $\mathrm{CO}_{2} / \mathrm{CH}_{4}$ se calculó a partir de los ajustes como la relación molar de ambos gases según la expresión:

$$
\text { selectividad aparente }=\frac{\mathrm{mol}_{\mathrm{CO}_{2}}}{\mathrm{~mol}_{\mathrm{CH}_{4}}}
$$

Ecuación 7.8 


\subsubsection{Procedimiento experimental para las medidas electroquímicas y la reacción de evolución de oxígeno.}

Para llevar a cabo la voltamperometría de barrido lineal, la cronoamperometría y la espectroscopía de impedancia electroquímica de los distintos catalizadores, se recubre el electrodo de trabajo de grafito pirolítico con el material de interés. Para modificar el electrodo, se prepara una suspensión de $5 \mathrm{mg} / \mathrm{mL}$ de los distintos electrocatalizadores ( $\mathrm{Co}_{2}-\mathrm{MOF}$, $\mathrm{Co}-\mathrm{MOF}, 2 \mathrm{D}-\mathrm{Co}-\mathrm{MOF}, \mathrm{Co}_{3} \mathrm{O}_{4}, \mathrm{IrO}_{2}$ o $\mathrm{RuO}_{2}$ ) por ultrasonidos durante 10 minutos en una disolución de Nafion al $1 \%$ v/v ( 5 wt. \% en alcoholes alifáticos y 15$20 \%$ de agua, de Sigma Aldrich, diluida con etanol absoluto). A continuación, se pone una gota de $\sim 10 \mu \mathrm{L}$ de esta suspensión en el electrodo de grafito y se seca a temperatura ambiente durante toda la noche.

Para la activación electroquímica del electrodo modificado con el 2D-Co-MOF en tampón fosfato de sodio, se aplicó un pulso de potencial de 1.2 V (vs NHE) durante un tiempo determinado. La caída óhmica se compensa utilizando la compensación de retroalimentación positiva implementada en el instrumento. La densidad de corriente se referencia al área geométrica del electrodo.

La respuesta electroquímica de los MOFs de cobalto se estudió por voltamperometría cíclica, tanto en una disolución de acetonitrilo $0.1 \mathrm{M}$ en hexafluorofosfato de tetraetilamonio como en una disolución acuosa de tampón fosfato de sodio $0.1 \mathrm{M}$ de $\mathrm{pH}$ 7, ambas en atmósfera de Argon. Los valores de potencial experimental medidos con el electrodo de referencia $\mathrm{Ag} / \mathrm{AgCl}\left(\mathrm{E}_{\mathrm{Ag} / \mathrm{AgCl}}\right)$ se convirtieron a la escala de potencial del electrodo normal de hidrógeno ( $\left.\mathrm{E}_{\mathrm{NHE}}\right)$ usando la siguiente ecuación:

$$
E_{N H E}=E_{A g / A g C l}+E_{A g / A g C l}^{0}
$$

Ecuación 7.9

donde $E_{A g / A g C l}^{0}$ es el potencial estándar del electrodo saturado $\mathrm{Ag} / \mathrm{AgCl} / \mathrm{NaCl}(0.192 \mathrm{~V}$ at $25^{\circ} \mathrm{C}$ ).

El estudio de la actividad electrocatalítica de los MOFs de cobalto para la oxidación del agua se llevó a cabo por voltamperometría de electrodo rotatorio en una disolución que contenía $0.1 \mathrm{M}$ de tampón fosfato de sodio a $\mathrm{pH} 7$ en condiciones desgasificadas (mediante purga con argón durante 45 minutos) y sin desgasificar. El electrodo rotatorio se utilizó a 1500 o 4000 rpm con un rotador analítico de AMSFRX de Pine. Con el fin de poder comparar, los potenciales medidos frente al electrodo de referencia de $\mathrm{Ag} / \mathrm{AgCl}$ $\left(\mathrm{E}_{\mathrm{Ag} / \mathrm{AgCl}}\right)$ se convirtieron en la escala del electrodo de hidrógeno reversible independiente del pH (RHE, $\mathrm{E}_{\mathrm{RHE}}$ ) haciendo uso de la siguiente ecuación: 


$$
E_{R H E}=E_{A g / A g C l}+E_{A g / A g C l}^{0}+0.059 p H \quad \text { Ecuación } 7.10
$$

Las medidas de espectroscopía de impedancia electroquímica se llevaron a cabo a $1.1 \mathrm{~V}$ (vs NHE) con una perturbación AC de $5 \mathrm{mV}$ en el rango de frecuencia entre $100 \mathrm{kHz}$ y $0.1 \mathrm{~Hz}$.

El valor del TOF se obtuvo a partir de la siguiente expresión: ${ }^{186,187}$

$$
T O F=\frac{j A}{4 F m}
$$

Ecuación 7.11

donde $j$ es la densidad de corriente de estado estacionario a un sobrepotencial dado (obtenido del cronoamperograma), $A$ es el área superficial geométrica del electrodo de grafito, $F$ es la constante de Faraday y $m$ es el número de moles de cobalto electroactivo que participa en el proceso catalítico. El valor de $m$ (que depende del grosor de la película) se determina a partir de la siguiente expresión:

$$
m=\frac{Q}{n F}
$$

Ecuación 7.12

donde $Q$ es la carga faradaica bajo el pico voltamétrico con la línea base corregida que precede la onda electrocatalítica y $n$ es el número de electrones transferidos por centro de cobalto. Combinando las expresiones 9 y 10 , y sabiendo que $\mathrm{j}=\mathrm{i} / \mathrm{A}$, el valor del TOF se puede determinar a partir de la expresión 11 . El valor del TOF se calcula asumiendo una eficiencia faradaica del $100 \%$.

$$
T O F=\frac{i}{4 Q}
$$

Ecuación 7.13

La producción de oxígeno durante la electrólisis, $\Delta m_{\mathrm{O}_{2}}$ se ha medido con un sensor de oxígeno polarográfico y la eficiencia faradaica $\varepsilon_{f}$ se ha determinado a partir del ratio de $\Delta m_{\mathrm{O}_{2}}$ y la carga consumida durante la electrólisis, Q (determinada a partir de la integración de la densidad de corriente):

$$
\mathcal{E}_{f}=\frac{n F \Delta m_{O_{2}}}{Q}
$$

Ecuación 7.14

donde $\mathrm{n}=4$ es el número de electrones transferidos por cada molécula de oxígeno en la reacción de evolución de oxígeno y $F$ es la constante de Faraday.

Por otro lado, la cuantificación del espectro de impedancia electroquímica se llevó a cabo con el circuito equivalente representado en la Figura 7.66. 


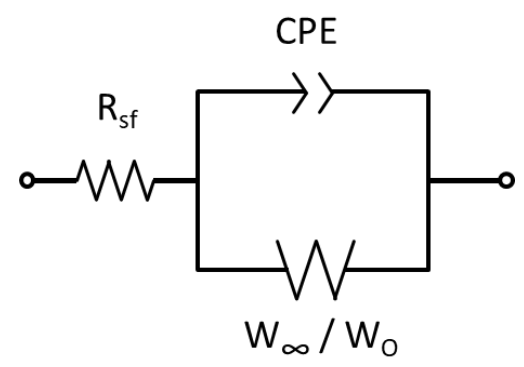

Figura 7.66. Circuito equivalente para la cuantificación del espectro EIS.

En esta Figura, $\mathrm{R}_{\text {sf }}$ representa la resistencia del film y la disolución, CPE es un elemento de fase constante cuya impedancia viene dada por:

$$
Z_{C P E}=\frac{1}{Q(j \omega)^{\alpha}}
$$

Ecuación 7.15

$\mathrm{W}_{\infty}$ es el elemento de difusión semi-infinita de Warburg: ${ }^{188-190}$

$$
Z_{W_{\infty}}=\frac{W_{\infty}}{\omega^{1 / 2}}-\frac{W_{\infty}}{\omega^{1 / 2}} j
$$

Ecuación 7.16

$\mathrm{Y} \mathrm{W}_{0}$ es el elemento de difusión finita con límite reflectivo: ${ }^{163-166}$

$$
Z_{W_{o}}=\frac{W_{o r}}{(j \omega)^{1 / 2}} \operatorname{coth}\left\{W_{o c}(j \omega)^{1 / 2}\right\}
$$

Donde $\omega$ es la frecuencia angular $(\omega=2 \pi f)$ y j es la unidad imaginaria. 


\subsection{Bibliografía}

(1) Yan, Y.; Xia, B. Y.; Zhao, B.; Wang, X., A review on noble-metal-free bifunctional heterogeneous catalysts for overall electrochemical water splitting, $J$. Mater. Chem. A 2016, 4, 17587-17603.

(2) Asefa, T., Metal-Free and Noble Metal-Free Heteroatom-Doped Nanostructured Carbons as Prospective Sustainable Electrocatalysts, Acc. Chem. Res. 2016, 49, 18731883.

(3) Chen, Z.; Duan, X.; Wei, W.; Wang, S.; Ni, B.J., Recent advances in transition metal-based electrocatalysts for alkaline hydrogen evolution, J. Mater. Chem. A 2019, 7, 14971-

15005 .

(4) Li, Y.; Dai, H., Recent advances in zinc-air batteries, Chem. Soc. Rev. 2014, 43, $5257-5275$.

(5) Yan, D.; Li, Y.; Huo, J.; Chen, R.; Dai, L.; Wang, S., Defect chemistry of nonprecious-metal electrocatalysts for oxygen reactions, Adv. Mater. 2017, 29, 1606459.

(6) Wang, J.; Zhang, H.; Wang, X., Recent Methods for the Synthesis of NobleMetal-Free Hydrogen-Evolution Electrocatalysts: From Nanoscale to Sub-nanoscale, Small Methods 2017, 1, 1700118.

(7) Shrivastav, V.; Sundriyal, S.; Goel, P.; Kaur, H.; Tuteja, S.K.; Vikrant, K.; Kim, K. H.;

Tiwari, U. K.; Deep, A.; Metal-organic frameworks (MOFs) and their composites as electrodes for lithium battery applications: Novel means for alternative energy storage, Coord. Chem. Rev. 2019, 393, 48-78.

(8) Li, J.; Güttinger, R.; Moré, R.; Song, F.; Wan W.; Patzke, G. R., Frontiers of water oxidation: the quest for true catalysts, Chem. Soc. Rev. 2017, 46, 6124-6147.

(9) Blakemore, J. D.; Crabtree R. H.; Brudvig, G. W., Molecular catalysts for water oxidation, Chem. Rev. 2015, 115, 12974-13005.

(10) Ren, Q.; Wang, H.; Lu, X. F.; Tong Y. X.; Li, G. R., Recent Progress on MOFDerived Heteroatom-Doped Carbon-Based Electrocatalysts for Oxygen Reduction Reaction, Adv. Sci. 2018, 5, 1700515. 
(11) Downes C. A.; Marinescu, S. C., Electrocatalytic metal-organic frameworks for energy applications, ChemSusChem 2017, 10, 4374-4392.

(12) Shamsipur M.; Pashabadi, A.; Latest advances in PSII features and mechanism of water oxidation, Coord. Chem. Rev. 2018, 374, 153-172.

(13) Zhu, H.; Liu, D.; Zou D.; Zhang, J., The photo-, electro- and photoelectrocatalytic properties and application prospects of porous coordinate polymers, J. Mater. Chem. A 2018, 6, 6130-6154.

(14) Li, W.; Watzele, S.; El-Sayed, H. A.; Liang, Y.; Kieslich, G.; Bandarenka, A. S.; Rodewald, K.; Rieger B.; Fischer, R. A., Unprecedented high oxygen evolution activity of electrocatalysts derived from surface-mounted metal-organic frameworks, $J$. Am. Chem. Soc. 2019, 141, 5926-5933.

(15) Zhao, S.; Wang, Y.; Dong, J.; He, C. T.; Yin, H.; An, P.; Zhao, K.; Zhang, X.; Gao, C.; Zhang, L.; Lv, J.; Wang, J.; Zhang, J.; Khattak, A. M.; Khan, N. A.; Wei, Z.; Zhang, J.; Liu, S.; Zhao H.; Tang, Z., Ultrathin metal-organic framework nanosheets for electrocatalytic oxygen evolution, Nat. Energy 2016, 1, 1-10.

(16) Solomon, M. B.; Church T. L.; D’Alessandro, D. M., Perspectives on metalorganic frameworks with intrinsic electrocatalytic activity, CrystEng-Comm. 2017, 19, 4049-4065.

(17) McCarthy, B. D.; Beiler, A. M.; Johnson, B. A.; Liseev, T.; Castner, A. T.; Ott, S., Analysis of electrocatalytic metal-organic frameworks, Coord. Chem. Rev. 2020, 406, 213137.

(18) Chen, Y. Z.; Zhang, R.; Jiao L.; Jiang, H. L., Metal-organic framework-derived porous materials for catalysis, Coord. Chem. Rev. 2018, 362, 1-23.

(19) Chughtai, A. H.; Ahmad, N.; Younus, H. A.; Laypkov A.; Verpoort, F., Metalorganic frameworks: versatile heterogeneous catalysts for efficient catalytic organic transformations, Chem. Soc. Rev. 2015, 44, 6804-6849.

(20) Lv, H.; Geletii, Y. V.; Zhao, C.; Vickers, J. W.; Zhu, G.; Luo, Z.; Song, J.; Lian, T.; Musaev D. G.; Hill, C. L., Polyoxometalate water oxidation catalysts and the production of green fuel, Chem. Soc. Rev. 2012, 41, 7572-7589. 
(21) Cheng, W.; Zhao, X.; Su, H.; Tang, F.; Che, W.; Zhang H.; Liu, Q., Latticestrained metal-organic-framework arrays for bifunctional oxygen electrocatalysis, Nat. Energy 2019, 4, 115-122.

(22) Singh, C.; Liberman, I.; Shimoni, R.; Ifraemov R.; Hod, I., Pristine versus Pyrolyzed Metal-Organic Framework-based Oxygen Evolution Electrocatalysts: Evaluation of Intrinsic Activity Using Electrochemical Impedance Spectroscopy, $J$. Phys. Chem. Lett. 2019, 10, 3630-3636.

(23) Gao, D.; Trentin, I.; Schwiedrzik, L.; González L.; Streb, C., The Reactivity and Stability of Polyoxometalate Water Oxidation Electrocatalysts, Molecules 2020, 25, 120.

(24) Zhou, X.; Zhang, T.; Abney, C. W.; Li Z.; Lin, W., Graphene-Immobilized Monomeric Bipyridine-M $\mathrm{M}^{\mathrm{x}+}\left(\mathrm{M}^{\mathrm{x}+}=\mathrm{Fe}^{3+}, \mathrm{Co}^{2+}, \mathrm{Ni}^{2+}\right.$, or $\left.\mathrm{Cu}^{2+}\right)$ Complexes for Electrocatalytic Water Oxidation, ACS Appl. Mater. Interfaces 2014, 6, 18475-18479.

(25) Chen K.; Wu, C., Designed fabrication of biomimetic metal-organic frameworks for catalytic applications, Coord. Chem. Rev. 2019, 378, 445-465.

(26) Li, Q. Y.; Zhang, L.; Xu, Y. X.; Li, Q.; Xue H.; Pang, H., Bi SPR-Promoted ZScheme $\mathrm{Bi}_{2} \mathrm{MoO}_{6} / \mathrm{CdS}$-Diethylenetriamine Composite with Effectively Enhanced Visible Light Photocatalytic Hydrogen Evolution Activity and Stability, ACS Sustainable Chem. Eng. 2019, 7, 5027-5033.

(27) Johnson, B. A.; Bhunia A.; Ott, S., Electrocatalytic water oxidation by a molecular catalyst incorporated into a metal-organic framework thin film, Dalton Trans. 2017, 46, 1382-1388.

(28) Lin, S.; Usov P. M.; Morris, A. J., The role of redox hopping in metal-organic framework electrocatalysis, Chem. Commun. 2018, 54, 6965-6974.

(29) Wang, S.; Hou, Y.; Lin S.; Wang, X., Water oxidation electrocatalysis by a zeolitic imidazolate framework, Nanoscale 2014, 6, 9930-9934.

(30) Meyer, T. J.; Sheridan M. V.; Sherman, B. D.; Mechanisms of molecular water oxidation in solution and on oxide surfaces, Chem. Soc. Rev. 2017, 46, 6148-6169.

(31) Liao, P. Q.; Shen J. Q.; Zhang, J. P.; Metal-organic frameworks for electrocatalysis, Coord. Chem. Rev. 2018, 373, 22-48. 
(32) Xia, W.; Mahmood, A.; Zou R.; Xu, Q., Metal-organic frameworks and their derived nanostructures for electrochemical energy storage and conversion, Energy Environ. Sci. 2015, 8, 1837-1866.

(33) Juan-Alcañiz, J.; Gascon J.; Kapteijn, F.; Metal-organic frameworks as scaffolds for the encapsulation of active species: state of the art and future perspectives, J. Mater. Chem. 2012, 22, 10102-10119.

(34) Mahmood, A.; Guo, W.; Tabassum H.; Zou, R., Metal-Organic FrameworkBased Nanomaterials for Electrocatalysis, Adv. Energy Mater. 2016, 6, 1600423.

(35) Dhakshinamoorthy A.; Garcia, H., Catalysis by metal nanoparticles embedded on metal-organic frameworks, Chem. Soc. Rev. 2012, 41, 5262-5284.

(36) Liu J.; Wöll, C., Surface-supported metal-organic framework thin films: fabrication methods, applications, and challenges, Chem. Soc. Rev. 2017, 46, 57305770 .

(37) Liu, J.; Hou, S.; Li, W.; Bandarenka A. S.; Fischer, R. A., Recent Approaches to Design Electrocatalysts Based on Metal-Organic Frameworks and Their Derivatives, Chem. - Asian J. 2019, 14, 3474-3501.

(38) Lee, J.; Jeong, B.; Ocon, J. P., Oxygen electrocatalysis in chemical energy conversion and storage technologies, Curr. Appl. Phys. 2013, 13, 309-321.

(39) Iwakura, C.; Hirao, K.; Tamura, H., Anodic evolution of oxygen on ruthenium in acidic solutions, Electrochim Acta 1977, 22, 329-334.

(40) Galizzioli, D.; Tantardini, F.; Trasatti, S., Ruthenium dioxide: a new electrode material. I. Behaviour in acid solutions of inert electrolytes, J. Appl. Electrochem. 1974, 4, 57-67.

(41) Hu, J. M.; Zhang, J. Q.; Cao, C. N., Oxygen evolution reaction on $\mathrm{IrO}_{2}$-based DSA ${ }^{\circledR}$ type electrodes: kinetics analysis of Tafel lines and EIS, Int. J. Hydrogen Energy 2004, 29, 791-797.

(42) Park, B. O.; Lokhande, C.D.; Park, H. S.; Jung, K. D.; Joo, O. S., Cathodic electrodeposition of $\mathrm{RuO}_{2}$ thin films from $\mathrm{RuCl}_{3}$ solution, Mat. Chem. Phys. 2004, 87, 59-66. 
(43) Doubova, L. M.; De Battisti, A.; Daolio, S.; Pagura, C.; Barison, S.; Gerbasi, R.; Battiston, G.; Guerriero P.; Trasatti S., Effect of Surface Structure on Behavior of $\mathrm{RuO}_{2}$ Electrodes in Sulfuric Acid Aqueous Solution, Russ. J. Electrochem. 2004, 40, 1115-1122.

(44) Cruz, J. C.; Baglio, V.; Siracusano, S.; Ornelas, R.; Ortiz-Frade, L.; Arriaga, L. G.; Antonucci, V.; Aricò, A. S., Nanosized $\mathrm{IrO}_{2}$ electrocatalysts for oxygen evolution reaction in an SPE electrolyzer, J. Nanopart. Res. 2011, 13, 1639-1646.

(45) Wu，Z.P.; Lu，X.F.; Zang, S. Q.; Lou, X.W., Non-Noble-Metal-Based Electrocatalysts toward the Oxygen Evolution Reaction, Adv. Funct. Mater. 2020, 30, 1910274.

(46) Song, J.; Wei, C.; Huang, Z.F.; Liu, C.; Zeng, L.; Wang, X.; Xu, Z. J., A review on fundamentals for designing oxygen evolution electrocatalysts, Chem. Soc. Rev. 2020, $49,2196-2214$.

(47) Zheng, S.; Li, X.; Yan, B.; Hu, Q.; Xu, Y.; Xiao, X.; Xue, H.; Pang, H., Transition-metal (Fe, Co, Ni) based metal-organic frameworks for electrochemical energy storage, Adv. Energy Mater. 2017, 7, 1602733.

(48) Lu, F.; Zhou, M.; Zhou, Y.; Zeng, X., First-row transition metal-based catalysts for the oxygen evolution reaction under alkaline conditions: basic principles and recent advances, Small 2017, 13, 1701931.

(49) Yin, Q.; Tan, J. M.; Besson, C.; Geletii, Y. V.; Musaev, D. G.; Kuznetsov, A. E.; Luo, Z.; Hardcastle, K. I.; Hill, C. L., A fast soluble carbon-free molecular water oxidation catalyst based on abundant metals, Science 2010, 328, 342-345.

(50) Davenport, T. C.; Ahn, H. S.; Ziegler, M. S.; Tilley, T. D., A fast soluble carbonfree molecular water oxidation catalyst based on abundant metals, Chem. Commun. 2014, 50, 6326-6329.

(51) Passard, G.; Ullman, A. M.; Brodsky, C. N.; Nocera, D. G., Oxygen reduction catalysis at a dicobalt center: The relationship of faradaic efficiency to overpotential, $J$. Am. Chem. Soc. 2016, 138, 2925-2928.

(52) Dempsey, J. L.; Brunschwig, B. S.; Winkler, J. R.; Gray, H. B., Hydrogen evolution catalyzed by cobaloximes, Acc. Chem. Res. 2009, 42, 1995. 
(53) Losse, S.; Vos, J. G.; Rau, S., Catalytic hydrogen production at cobalt centres, Coord. Chem. Rev. 2010, 254, 2492.

(54) Artero, V.; Chavarot-Kerlidou, M.; Fontecave, M., Splitting water with cobalt, Angew. Chem. Int. Ed. 2011, 50, 7238.

(55) Artero, V.; Fontecave, M., Solar fuels generation and molecular systems: is it homogeneous or heterogeneous catalysis?, Chem. Soc. Rev. 2013, 42, 2338.

(56) Karkas, M. D.; Verho, O.; Johnston, E. V.; Akermark, B., Artificial photosynthesis: molecular systems for catalytic water oxidation, Chem. Rev. 2014, 114, 11863.

(57) Kaeffer, N.; Chavarot-kerlidou, M.; Artero, V., Hydrogen evolution catalyzed by cobalt diimine-dioxime complexes, Acc. Chem. Res. 2015, 48, 1286.

(58) Wang, J.; Cui, W.; Liu, Q.; Xing, Z.; Asiri, A. M.; Sun, X., Recent Progress in Cobalt-Based Heterogeneous Catalysts for Electrochemical Water Splitting, Adv. Mater. 2016, 28, 215-230.

(59) Liu. S.; Lei, Y.-J.; Xin, Z.-J.; Xiang, R.-J.; Styring, S.; Thapper, A.; Wang, H.Y., Ligand modification to stabilize the cobalt complexes for water oxidation, International Journal of Hydrogen Energy 2017, 42, 29716-29724.

(60) Kong, D.; Wang, H.; Lu, Z.; Cui, Y., $\mathrm{CoSe}_{2}$ Nanoparticles Grown on Carbon Fiber Paper: An Efficient and Stable Electrocatalyst for Hydrogen Evolution Reaction, J. Am. Chem. Soc. 2014, 136, 4897.

(61) Liu, Y.; Cheng, H.; Lyu, M.; Fan, S.; Liu, Q.; Zhang, W.; Zhi, Y.; Wang, C.; Xiao, C.; Wei, S.; Ye, B.; Xie, Y., Low Overpotential in Vacancy-Rich Ultrathin $\mathrm{CoSe}_{2}$ Nanosheets for Water Oxidation, J. Am. Chem. Soc. 2014, 136, 15670.

(62) Cobo, S.; Heidkamp, J.; Jacques, P.-A.; Fize, J.; Fourmond, V.; Guetaz, L.; Jousselme, B.; Ivanova, V.; Dau, H.; Palacin, S.; Fontecave, M.; Artero, V., A Janus cobalt-based catalytic material for electro-splitting of water, Nat. Mater. 2012, 11, 802.

(63) Sun, Y.; Chong, L.; Grauer, D. C.; Yano, J.; Long, J. R.; Yang, P.; Chang, C. J., Electrodeposited cobalt-sulfide catalyst for electrochemical and photoelectrochemical hydrogen generation from water, J. Am. Chem. Soc. 2013, 135, 17699. 
(64) Hu X.; Dong, S., Metal nanomaterials and carbon nanotubes-synthesis, functionalization and potential applications towards electrochemistry, J. Mater. Chem. 2008, 18, 1279-1295.

(65) Bose, S.; Debgupta, J.; Ramsundar R. M.; Das, S. K., Electrochemical Water Oxidation Catalyzed by an In Situ Generated $\alpha-\mathrm{Co}(\mathrm{OH})_{2}$ Film on Zeolite-Y Surface, Chem. - Eur. J. 2017, 23, 8051-8057.

(66) Wight A. P.; Davis, M. E., Design and preparation of organic- inorganic hybrid catalysts, Chem. Rev. 2002, 102, 3589-3614.

(67) Wang, C.; Xie, Z.; Dekrafft K. E.; Lin, W., Doping metal-organic frameworks for water oxidation, carbon dioxide reduction, and organic photocatalysis, J. Am. Chem. Soc. 2011, 133, 13445-13454.

(68) Shekhah, O.; Liu, J.; Fischer R. A.; Wöll, C., MOF thin films: existing and future applications, Chem. Soc. Rev. 2011, 40, 1081-1106.

(69) Dhakshinamoorthy, A.; Alvaro, M.; Garcia, H., Commercial metal-organic frameworks as heterogeneous catalysts, Chem. Commun. 2012, 48, 11275-11288.

(70) Zhao, M.; Ou S.; De Wu, C., Porous metal-organic frameworks for heterogeneous biomimetic catalysis, Acc. Chem. Res. 2014, 47, 1199-1207.

(71) Evans, J. D.; Sumby C. J.; Doonan, C. J., Post-synthetic metalation of metalorganic frameworks, Chem. Soc. Rev. 2014, 43, 5933-5951.

(72) Zhu Q. L.; Xu, Q., Metal-organic framework composites, Chem. Soc. Rev. 2014, $43,5468-5512$.

(73) Meyer, K.; Ranocchiari M.; Van Bokhoven, J. A., Metal organic frameworks for photo-catalytic water splitting, Energy Environ. Sci. 2015, 8, 1923-1937.

(74) Xue, Y.; Zheng, S.; Xue H.; Pang, H., Metal-organic framework composites and their electrochemical applications, J. Mater. Chem. A 2019, 7, 7301-7327.

(75) Cheng, N.; Ren, L.; Xu, X.; Du Y.; Dou, S. X., Recent development of zeolitic imidazolate frameworks (ZIFs) derived porous carbon-based materials as electrocatalysts, Adv. Energy Mater. 2018, 8, 1-21. 
(76) Yan, Y.; He, T.; Zhao, B.; Qi, K.; Liu H.; Xia, B. Y., Metal/covalent-organic frameworks-based electrocatalysts for water splitting, J. Mater. Chem. A 2018, 6, 15905-15926.

(77) Guan, C.; Liu, X.; Ren, W.; Li, X.; Cheng C.; Wang, J., Rational Design of Metal-Organic Framework Derived Hollow $\mathrm{NiCO}_{2} \mathrm{O}_{4}$ Arrays for Flexible Supercapacitor and Electrocatalysis Adv. Energy Mater. 2017, 7, 1-8.

(78) Li, X.; Zheng, S.; Jin, L.; Li, Y.; Geng, P.; Xue, H.; Pang H.; Xu, Q., MetalOrganic Framework-Derived Carbons for Battery Applications, Adv. Energy Mater. 2018, 8, 1-25.

(79) Moon, H. R.; Lim D. W.; Suh, M. P., Fabrication of metal nanoparticles in metal-organic frameworks, Chem. Soc. Rev. 2013, 42, 1807-1824.

(80) Yang, Q.; Xu Q.; Jiang, H. L., Metal-organic frameworks meet metal nanoparticles: synergistic effect for enhanced catalysis, Chem. Soc. Rev. 2017, 46, 47744808 .

(81) Bhardwaj, S. K.; Bhardwaj, N.; Kaur, R.; Mehta, J.; Sharma, A. L.; Kim K. H.; Deep, A., An overview of different strategies to introduce conductivity in metal-organic frameworks and miscellaneous applications thereof, J. Mater. Chem. A 2018, 6, 14992 15009 .

(82) Mukhopadhyay, S.; Basu, O.; Nasani, R.; Das, S. K., Evolution of metal organic frameworks as electrocatalysts for water oxidation, Chem. Commun. 2020, 56, 11735.

(83) Liang, Q.; Chen, J.; Wang, F.; Li, Y., Transition metal-based metal-organic frameworks for oxygen evolution reaction, Coord. Chem. Rev. 2020, 424, 213488.

(84) Liu, J.; Chen, L.; Cui, H.; Zhang, J.; Zhang, L.; Su, C.Y., Applications of metalorganic frameworks in heterogeneous supramolecular catalysis, Chem. Soc. Rev. 2014, 43, 6011-6061.

(85) Shen, K.; Zhang, L.; Chen, X.; Liu, L.; Zhang, D.; Han, Y.; Chen, J.; Long, J.; Luque, R.; Li, Y.; Chen, B., Ordered macro-microporous metal-organic framework single crystals, Science 2018, 359, 206-210.

(86) Wang, Q.; Astruc, D., State of the art and prospects in metal-organic framework (MOF)-based and MOF-derived nanocatalysis, Chem. Rev. 2020, 120, 1438-1511. 
(87) Llabres i Xamena, F.; Casanova, O.; Galiassotailleur, R.; Garcia, H.; Corma, A., Metal organic frameworks (MOFs) as catalysts: A combination of $\mathrm{Cu}^{2+}$ and $\mathrm{Co}^{2+} \mathrm{MOFs}$ as an efficient catalyst for tetralin oxidation, J. Catal. 2008, 255, 220-227.

(88) Zhou, W.; Wu, H.; Yildirim, T., Enhanced $\mathrm{H}_{2}$ Adsorption in Isostructural Metal-Organic Frameworks with Open Metal Sites: Strong Dependence of the Binding Strength on Metal Ions, J. Am. Chem. Soc. 2008, 130, 15268-15269.

(89) Brown, J. W.; Henderson, B. L.; Kiesz, M. D.; Whalley, A. C.; Morris, W.; Grunder, S.; Deng, H.; Furukawa, H.; Zink, J. I.; Stoddart, J. F.; Yaghi, O. M., Photophysical pore control in an azobenzene-containing metal-organic framework, Chem. Sci. 2013, 4, 2858-2864.

(90) Mason, J. A.; Veenstra, M.; Long, J. R., Evaluating metal-organic frameworks for natural gas storage, Chem. Sci. 2014, 5, 32-51.

(91) Stavila, V.; Talin, A. A.; Allendorf, M. D., MOF-based electronic and optoelectronic devices, Chem. Soc. Rev. 2014, 43, 5994-6010.

(92) Jin, S.; Son, H.-J.; Farha, O. K.; Wiederrecht, G. P.; Hupp, J. T., Energy transfer from quantum dots to metal-organic frameworks for enhanced light harvesting, J. Am. Chem. Soc. 2013, 135, 955-958.

(93) Hendon, C. H.; Tiana, D.; Walsh, A., Conductive metal-organic frameworks and networks: fact or fantasy?, Phys. Chem. Chem. Phys. 2012, 14, 13120-13132.

(94) Hendon, C. H.; Tiana, D.; Vaid, T. P.; Walsh, A., Thermodynamic and electronic properties of tunable II-VI and IV-VI semiconductor-based metal-organic frameworks from computational chemistry, J. Mater. Chem. C 2013, 1, 95-100.

(95) Tiana, D.; Hendon, C. H.; Walsh, A.; Vaid, T. P., Computational screening of structural and compositional factors for electrically conductive coordination polymers, Phys. Chem. Chem. Phys. 2014, 16, 14463-14472.

(96) Liang, Z.; Qu, C.; Guo, W.; Zou, R.; Xu, Q., Pristine metal-organic frameworks and their composites for energy storage and conversion, Adv. Mater. 2018, 30, 1702891.

(97) Yang, L.; Zeng, X.; Wang, W.; Cao, D., Recent progress in MOF-derived, heteroatom-doped porous carbons as highly efficient electrocatalysts for oxygen reduction reaction in fuel cells, Adv. Funct. Mater. 2018, 28, 1704537. 
(98) Li, D.; Xu, H.-Q.; Jiao, L.; Jiang, H.-L., Metal-organic frameworks for catalysis: State of the art, challenges, and opportunities, Energy Chem. 2019, 1, 100005.

(99) Zhang, H.; Nai, J.; Yu, L.; Lou, X.W., Metal-organic-framework-based materials as platforms for renewable energy and environmental applications, Joule 2017, $1,77-107$.

(100) Guo, W.; Sun, W.; Lv, L.P.; Kong, S.; Wang, Y., Microwave-Assisted Morphology Evolution of Fe-Based Metal-Organic Frameworks and Their Derived $\mathrm{Fe}_{2} \mathrm{O}_{3}$ Nanostructures for Li-Ion Storage, ACS Nano 2017, 11, 4198-4205.

(101) Rodenas, T.; Beeg, S.; Spanos, I.; Neugebauer, S.; Girgsdies, F.; Algara-Siller, G.; Schleker, P.P. M.; Jakes, P.; Pfänder, N.; Willinger, M.; Greiner, M.; Prieto, G.; Schlögl, R.; Heumann, S., 2D Metal Organic Framework-Graphitic Carbon Nanocomposites as Precursors for High-Performance $\mathrm{O}_{2}$-Evolution Electrocatalysts, Adv. Energy Mater. 2018, 8, 1802404.

(102) Wu, H.B.; Lou, X.W., Metal-organic frameworks and their derived materials for electrochemical energy storage and conversion: Promises and challenges, Sci. Adv. 2017, 3,12 , eaap9252.

(103) Zhang, H.; Liu, X.; Wu, Y.; Guan, C.; Cheetham, A.K.; Wang, J., MOF-derived nanohybrids for electrocatalysis and energy storage: current status and perspectives, Chem. Commun. 2018, 54, 5268-5288.

(104) Xiao, X.; Zou, L.; Pang, H.; Xu, Q., Synthesis of micro/nanoscaled metalorganic frameworks and their direct electrochemical applications, Chem. Soc. Rev. 2020, 49, 301-331.

(105) Shi, Q.; Fu, S.; Zhu, C.; Song, J.; Du, D.; Lin, Y., Metal-organic frameworksbased catalysts for electrochemical oxygen evolution, Mater. Horiz. 2019, 6, 684-702.

(106) Zhou, H.; Zheng, M.; Tang, H.; Xu, B.; Tang, Y.; Pang, H., Amorphous Intermediate Derivative from ZIF-67 and Its Outstanding Electrocatalytic Activity, Small 2020, 16, 1904252.

(107) Gong, Y.; Hao, Z.; Meng, J.; Shi, H.; Jiang, P.; Zhang, M.; Lin, J., Two Co ${ }^{\text {II }}$ Metal-Organic Frameworks Based on a Multicarboxylate Ligand as Electrocatalysts for Water Splitting ChemPlusChem 2014, 79, 266-277. 
(108) Gong, Y.; Shi, H. F.; Jiang, P. G.; Hua, W.; Lin, J. H., Metal (II)-induced coordination polymer based on 4-(5-(Pyridin-4-yl)-4H-1,2,4-triazol-3-yl) benzoate as an electrocatalyst for water splitting, Cryst. Growth Des. 2014, 14, 649-657.

(109) Wang, H.; Yin, F.; Li, G.; Chen, B.; Wang, Z., Preparation, characterization and bifunctional catalytic properties of MOF ( $\mathrm{Fe} / \mathrm{Co}$ ) catalyst for oxygen reduction/evolution reactions in alkaline electrolyte, Int. J. Hydrogen Energy 2014, 39, 16179-16186.

(110) Xu, Q.; Li, H.; Yue, F.; Chi, L.; Wang, J., Nanoscale cobalt metal-organic framework as a catalyst for visible light-driven and electrocatalytic water oxidation, New J. Chem. 2016, 40, 3032-3035.

(111) Lu, X. F.; Liao, P. Q.; Wang, J. W.; Wu, J. X.; Chen, X. W.; He, C. T.; Zhang, J. P.; Li, G. R.; Chen, X. M., An alkaline-stable, metal hydroxide mimicking metalorganic framework for efficient electrocatalytic oxygen evolution, J. Am. Chem. Soc. 2016, 138, 8336-8339.

(112) Shen, J. Q.; Liao, P. Q.; Zhou, D. D.; He, C. T.; Wu, J. X.; Zhang, W. X.; Zhang, J. P.; Chen, X. M., Modular and stepwise synthesis of a hybrid metal-organic framework for efficient electrocatalytic oxygen evolution, J. Am. Chem. Soc. 2017, 139, 1778-1781.

(113) Song, J.; Zhu, G.; Xu, B. Z.; Fu, S.; Engelhard, M. H.; Ye, R.; Du, D.; Beckman, S. P.; Li, Y., Bimetallic Cobalt-Based Phosphide Zeolitic Imidazolate Framework: $\mathrm{CoP}_{\mathrm{x}}$ Phase-Dependent Electrical Conductivity and Hydrogen Atom Adsorption Energy for Efficient Overall Water Splitting, Adv. Energy Mater. 2017, 7, 1601555.

(114) Jiang, Z.; Ge, L.; Zhuang, L.; Li, M.; Wang, Z.; Zhu, Z., Fine-Tuning the Coordinatively Unsaturated Metal Sites of Metal-Organic Frameworks by Plasma Engraving for Enhanced Electrocatalytic Activity, ACS Appl. Mater. Interfaces 2019, $11,44300-44307$.

(115) Xue, Z.; Liu, K.; Liu, Q.; Li, Y.; Li, M.; Su, C.-Y.; Ogiwara, N.; Kobayashi, H.; Kitagawa, H.; Liu, M.; Li, G., Missing-linker metal-organic frameworks for oxygen evolution reaction, Nat. Commun. 2019, 10, 5048.

(116) Zou, Z.; Wang, T.; Zhao, X.; Jiang, W. J.; Pan, H.; Gao, D.; Xu, C., Expediting in-Situ Electrochemical Activation of Two-Dimensional Metal-Organic Frameworks for Enhanced OER Intrinsic Activity by Iron Incorporation, ACS Catal. 2019, 9, 7356-7364. 
(117) Gao, Z.; Yu, Z. W.; Liu, F. Q.; Yang, C.; Yuan, Y. H.; Yu, Y.; Luo, F., Stable Iron Hydroxide Nanosheets@ Cobalt-Metal-Organic-Framework Heterostructure for Efficient Electrocatalytic Oxygen Evolution, ChemSusChem 2019, 12, 4623-4628.

(118) Takaishi, S.; Hosoda, M.; Kajiwara, T.; Miyasaka, H.; Yamashita, M.; Nakanishi, Y.; Kitagawa, Y.; Yamaguchi, K.; Kobayashi, A.; Kitagawa, H., Electroconductive Porous Coordination Polymer $\mathrm{Cu}\left[\mathrm{Cu}(\mathrm{pdt})_{2}\right]$ Composed of Donor and Acceptor Building Units, Inorg. Chem. 2009, 48, 9048-9050.

(119) Miyasaka, H., Control of charge transfer in donor/acceptor metal-organic frameworks, Acc. Chem. Res. 2013, 46, 248-257.

(120) Huo, P.; Chen, T.; Hou, J. Le; Yu, L.; Zhu, Q. Y.; Dai, J., Ligand-to-Ligand Charge Transfer within Metal-Organic Frameworks Based on Manganese Coordination Polymers with Tetrathiafulvalene-Bicarboxylate and Bipyridine Ligands, Inorg. Chem. 2016, 55, 6496-6503.

(121) Leong, C. F.; Chan, B.; Faust, T. B.; D'Alessandro, D. M., Controlling charge separation in a novel donor-acceptor metal-organic framework via redox modulation, Chem. Sci. 2014, 5, 4724- 4728.

(122) Darago, L. E.; Aubrey, M. L.; Yu, C. J.; Gonzalez, M. I.; Long, J. R., Electronic conductivity, ferrimagnetic ordering, and reductive insertion mediated by organic mixed-valence in a ferric semiquinoid metal-organic framework, J. Am. Chem. Soc. 2015, 137, 15703-15711.

(123) Murase, R.; Leong, C. F.; D’Alessandro, D. M., Mixed valency as a strategy for achieving charge delocalization in semiconducting and conducting framework materials, Inorg. Chem. 2017, 56, 14373-14382.

(124) Dissegna, S.; Epp, K.; Heinz, W. R.; Kieslich, G.; Fischer, R. A., Defective Metal-Organic Frameworks, Adv. Mater. 2018, 30, 1704501.

(125) Shearer, G. C.; Chavan, S.; Bordiga, S.; Svelle, S.; Olsbye, U.; Lillerud, K. P., Defect engineering: tuning the porosity and composition of the metal-organic framework UiO-66 via modulated synthesis, Chem. Mater. 2016, 28, 3749-3761.

(126) Tao, L.; Lin, C.-Y.; Dou, S.; Feng, S.; Chen, D.; Liu, D.; Huo, J.; Xia, Z.; Wang, S., Creating coordinatively unsaturated metal sites in metal-organic-frameworks as 
efficient electrocatalysts for the oxygen evolution reaction: Insights into the active centers, Nano Energy 2017, 41, 417-425.

(127) Slater, B.; Wang, Z. R.; Jiang, S. X.; Hill, M. R.; Ladewig, B. P., Missing Linker Defects in a Homochiral Metal-Organic Framework: Tuning the Chiral Separation Capacity, J. Am. Chem. Soc. 2017, 139, 18322-18327.

(128) Yuan, S.; Qin, J. S.; Zou, L.; Chen, Y. P.; Wang, X.; Zhang, Q.; Zhou, H. C., Thermodynamically guided synthesis of mixed-linker Zr-MOFs with enhanced tunability, J. Am. Chem. Soc. 2016, 138, 6636-6642.

(129) Fang, Z.; Dürholt, J. P.; Kauer, M.; Zhang, W.; Lochenie, C.; Jee, B.; Albada, B.; Metzler-Nolte, N.; Pöppl, A.; Weber, B.; Muhler, M.; Wang, Y.; Schmid, R.; Fischer, R. A., Structural complexity in metal-organic frameworks: Simultaneous modification of open metal sites and hierarchical porosity by systematic doping with defective linkers, J. Am. Chem. Soc. 2014, 136, 9627-9636.

(130) Wang, L.-P.; Van Voorhis, T., Direct-Coupling $\mathrm{O}_{2}$ Bond Forming a Pathway in Cobalt Oxide Water Oxidation Catalysts. J. Phys. Chem. Lett. 2011, 2, 2200-2204.

(131) Ullman A. M., Brodsky C. N., Li N., Zheng S. L., Nocera D. G., Probing Edge Site Reactivity of Oxidic Cobalt Water Oxidation Catalysts. J. Am. Chem. Soc. 2016, $138,4229-4236$.

(132) Tan, K.; Nijemm, N.; Canepa, P.; Gong, Q.; Li, J.; Thonhauser, T.; Chabal, Y. J., Stability and Hydrolyzation of Metal Organic Frameworks with Paddle.Wheel SBUs upon Hydration, Chem. Mater. 2012, 24, 2153-3167.

(133) Zhang, Z.-J.; Zhang, L.-P.; Wojtas, L.; Eddaoudi, M.; Zaworotko, M. J.; Template-Directed Synthesis of Nets Based upon Octahemioctahedral Cages That Encapsulate Catalytically Active Metalloporphyrins, J. Am. Chem. Soc. 2012, 134, 928 -

(134) Nguyen, A. I.; Ziegler, M. S.; Oña-Burgos, P.; Sturzbecher-Hohne, M.; Kim, W.; Bellone, D. E.; Tilley, T. D., Mechanistic Investigations of Water Oxidation by a Molecular Cobalt Oxide Analogue: Evidence for a Highly Oxidized Intermediate and Exclusive Terminal Oxo Participation, J. Am. Chem. Soc. 2015, 137, 40, 12865-12872.

(135) Gutiérrez-Tarriño, S.; Olloqui-Sariego, J. L.; Calvente, J. J.; Palomino, M.; Mínguez-Espallargas, G.; Jordá, J. L.; Rey, F.; Oña-Burgos, P., Cobalt Metal-Organic 
Framework Based on Two Dinuclear Secondary Building Units for Electrocatalytic Oxygen Evolution, ACS Appl. Mater. Interfaces 2019, 11, 46658-46665.

(136) Davies, J. E.; Rivera, A. V.; Sheldrick, G. M., Tetra-[ $[\mu]$-benzoato-bis(4methylquinoline)dicobalt(II). Acta Crystallogr. Sect. B 1977, 33, 156-158.

(137) Catterick, J.; Hursthouse, M. B.; Thornton, P.; Welch, A. J., Crystal and Molecular Structure of Tetra-p-benzoato-bisquinolinedicobalt(II), a Binuclear Cobalt(II) Carboxylate. J. Chem. Soc., Dalton Trans. 1977, 223-226.

(138) Cui, Y.; Zheng, F.; Huang, J., Tetrakis([ $\mu]$-phenylacetato-O:O')bis[(quinolineN)cobalt(II)]. Acta Crystallogr., Sect. C 1999, 55, 1067-1069.

(139) Cui, Y.; Long, D.; Huang, X.; Zheng, F.; Chen, W.; Huang, J., Synthesis and Crystal Structure of a Binuclear Cobalt(II)Carboxylate Complex $\mathrm{Co}_{2}\left(\mathrm{O}_{2} \mathrm{CCMe}_{3}\right)_{4}\left(\mathrm{C}_{9} \mathrm{H}_{7} \mathrm{~N}\right)_{2}$. Chinese J. Struct. Chem. 1999, 18, 9-13.

(140) Golubichnaya, M. A.; Sidorov, A.A.; Fomina, I. G.; Eremenko, L. T.; Nefedov, S. E.; Eremenko, I. L.; Moiseev, I. I., Cobalt(II) Binuclear Trimethylacetate Complexes: Synthesis and Structure of $\mathrm{Co}_{2} \mathrm{Py}_{4}\left(\mu-\mathrm{OH}_{2}\right)\left(\mu-\mathrm{OOCCMe}_{3}\right)_{2}\left(\mathrm{OOCCMe}_{3}\right)_{2}$ and $\mathrm{Co}_{2} \mathrm{Py}_{2}(\mu-$ $\left.\mathrm{OOCCMe}_{3}\right)_{4}$. Russ. J. Inorg. Chem. 1999, 44, 1401-1410.

(141) Benbellat, N.; Gavrilenko, K. S.; Gal, Y. L.; Cador, O.; Golhen, S.; Gouasmia, A.; Fabre, J-H.; Ouahabi, L., Co(II)-Co(II) Paddlewheel Complex with a Redox-Active Ligand Derived from TTF. Inorg. Chem. 2006, 45, 10440-10442.

(142) Palomino, M.; Corma, A.; Rey, F.; Valencia, S., New Insights on $\mathrm{CO}_{2}-$ Methane Separation Using LTA Zeolites with Different Si/Al Ratios and a First Comparison with MOFs. Langmuir 2010, 26, 1910-1917.

(143) Palomino, M.; Corma, A.; Jordá, J. L.; Rey, F.; Valencia, S., Zeolite Rho: a Highly Selective Adsorbent for $\mathrm{CO}_{2} / \mathrm{CH}_{4}$ Separation Induced by a Structural Phase Modification. Chem. Commun. 2012, 48, 215-217.

(144) Biesinger, M. C.; Payne, B. P.; Grosvenor, A. P.; Lau, L. W. M.; Gerson, A. R.; Smart, R. S. C., Resolving surface chemical states in XPS analysis of first row transition metals, oxides and hydroxides: Cr, Mn, Fe, Co and Ni. Appl. Surf. Sci. 2011, 257, 27172730 . 
(145) Ivanova, T.; Naumkin, A.; Sidorov, A.; Eremenko, I.; Kiskin, M.; X-Ray Photoelectron Spectra and Electron Structure of Polynuclear Cobalt Complexes. J. Electron Spectrosc. Relat. Phenom. 2007, 156-158, 200-203.

(146) Fadley, C.S.; Shirley, D.A., J. Chem. Phys. 1972, 57, 973.

(147) Frost, C.; McDowell, C. F.; Woolsey, I. S.; X-Ray Photoelectron Spectra of Cobalt Compounds. Mol. Phys. 1974, 27, 1473-1489.

(148) Briggs, D.; Gibson, V. A., Direct Observation of Multiplet Splitting in 2P Photoelectron Peaks of Cobalt Complexes, Chem. Phys. Lett. 1974, 25, 493-496.

(149) Yasuaki, O.; Hajime, N.; Toshinobu, I.; Shiichiro, T., X-Ray Photoelectron Spectroscopic Studies of Catalysts -Supported Cobalt Catalysts. Bull. Chem. Soc. Jpn, 1975, 48, 1163-1168.

(150) Yaghi, O. M.; Li, H.; Groy, T. L., Construction of Porous Solids from Hydrogen-Bonded Metal Complexes of 1,3,5-benzenetricarboxylic Acid. J. Am. Chem. Soc. 1996, 118, 9096-9101.

(151) Kim H. J.; Talukdar K.; Choi S-J., Tuning of Nafion ${ }^{\circledR}$ by HKUST-1 as Coordination Network to Enhance Proton Conductivity for Fuel Cell Applications. J. Nanopart. Res. 2016, 18, 47-53.

(152) Kabir M.D. L.; Kim H. J.; Choi S-J., Highly Proton Conductive Zn(II)-Based Metal-Organic Framework/Nafion ${ }^{\circledR}$ Composite Membrane for Fuel Cell Application. Sci. Adv. Mater. 2018, 10, 1630-1635(6).

(153) Gutiérrez-Tarriño, S.; Olloqui-Sariego, J. L.; Calvente, J. J.; MínguezEspallargas, G.; Rey, F.; Corma, A.; Oña-Burgos, P., Cobalt Metal-Organic Framework Based on Layered Double Nanosheets for Enhanced Electrocatalytic Water Oxidation in Neutral Media J. Am. Chem. Soc. 2020, 142, 19198-19208.

(154) Fang, H.; Huang, T.; Liang, D.; Qiu, M.; Sun, Y.; Yao, S.; Yu, J.; Dinesh, M. M.; Guo, Z.; Xia, Y.; Mao S., Prussian blue analog-derived 2D ultrathin $\mathrm{CoFe}_{2} \mathrm{O}_{4}$ nanosheets as high-activity electrocatalysts for the oxygen evolution reaction in alkaline and neutral media. J. Mater. Chem. A 2019, 7, 7328-7332.

(155) Palomares, A. E.; Patro, J. G.; Rey, F.; Corma, Using the "Memory Effect" of Hydrotalcites for Improving the Catalytic Reduction of Nitrates in Water, J. of Catal. 2004, 221, 62-66. 
(156) Li, G.; Yang, D.; Chuang, P. A., Defining Nafion Ionomer Roles for Enhancing Alkaline Oxygen Evolution Electrocatalysis, ACS Catal. 2018, 8, 11688-11698.

(157) Surendranath Y., Kanan M. W., Nocera D. G., Mechanistic Studies of the Oxygen Evolution Reaction by a Cobalt-Phosphate Catalyst at Neutral pH. J. Am. Chem. Soc. 2010, 132, 16501-16509.

(158) Laviron E.; Roullier L.; Degrand C., A Multilayer Model for the Study of Space Distrbuted Redox Modified Electrodes: Part II. Theory and Application of Linear Potential Sweep Voltammetry for a Simple Reaction. J. Electroanal. Chem. 1980, 112, 1123.

(159) Tagliazucchi M.; Calvo E. J., Charge Transport in Redox Polyelectrolyte Multilayer Films: The Dramatic Effects of Outmost Layer and Solution Ionic Strength. ChemPhysChem 2010, 11, 2957-2968.

(160) Jayaramulu, K.; Masa, J.; Morales, D. M.; Tomanec, O.; Ranc, V.; Petr, M.; Wilde, P.; Chen, Y. T.; Zboril, R.; Schuhmann, W.; Fischer, R. A., Ultrathin 2D Cobalt Zeolite-Imidazole Framework Nanosheets for Electrocatalytic Oxygen Evolution, $A d v$. Sci. 2018, 5, 1801029.

(161) Costentin, C.; Savéant, J.-M. Cyclic Voltammetry Analysis of Electrocatalytic Films. J. Phys. Chem. C 2015, 119, 12174-12182.

(162) Costentin, C.; Savéant, J.-M. Cyclic Voltammetry of Fast Conducting Electrocatalytic Films. Phys. Chem. Chem. Phys. 2015, 17, 19350-19359.

(163) Inzelt, G.; Lang, G. Model Dependence and Reliability of the Electrochemical Quantities Derived from the Measured Impedance Spectra of Polymer Modified Electrodes. J. Electroanal. Chem. 1994, 378, 39-49.

(164) Bisquert, J.; Garcia-Belmonte, G.; Bueno, P.; Longo, E.; Bulhoes, L. O. S., Impedance of Constant Phase Element (CPE)-Blocked Diffusion in Film Electrodes. $J$. Electroanal. Chem. 1998, 452, 229-234.

(165) Bisquert, J.; Garcia-Belmonte, G.; Fabregat-Santiago, F.; Bueno, P. R., Theoretical Models for a.c. Impedance of Finite Diffusion Layers Exhibiting Low Frequency Dispersion. J. Electroanal. Chem. 1999, 475, 152-163.

(166) Huang, J. Diffusion Impedance of Electroactive Materials, Electrolytic Solutions and Porous Electrodes: Warburg Impedance and Beyond. Electrochim. Acta 
2018, $281,170-188$.

(167) Lasia, A. Electrochemical Impedance Spectroscopy and Its Applications, Modern Aspects of Electrochemistry, B. E. Conway, J. Bockris, and R.E. White, Edts., Kluwer Academic/Plenum Publishers, New York 1999, 32, 143.

(168) Mattioli, G.; Giannozzi, P.; Amore Bonapasta, A.; Guidoni, L., Reaction Pathways for Oxygen Evolution Promoted by Cobalt Catalyst. J. Am. Chem. Soc. 2013, $135,15353-15363$.

(169) Smith, P. F.; Hunt, L.; Laursen, A. B.; Sagar, V.; Kaushik, S.; Calvinho, K. U. D.; Marotta, G.; Mosconi, E.; De Angelis, F.; Dismukes, G. C., Water Oxidation by the $\left[\mathrm{Co}_{4} \mathrm{O}_{4}(\mathrm{OAc})_{4}(\mathrm{Py})_{4}\right]$ Cubium Is Initiated by $\mathrm{OH}-$ Addition. J. Am. Chem. Soc. 2015, 137, 15460-15468.

(170) Li, X.; Siegbahn, P. E. M., Water Oxidation Mechanism for Synthetic CoOxides with Small Nuclearity. J. Am. Chem. Soc. 2013, 135, 13804-13813.

(171) Pham, H. H.; Cheng, M.-J.; Frei, H.; Wang, L.-W., Surface Proton Hopping and Fast-Kinetics Pathway of Water Oxidation on $\mathrm{Co}_{3} \mathrm{O}_{4}$ (001) Surface. ACS Catal. 2016, 6, 5610-5617.

(172) Soriano-Lopez, J.; Musaev, D. G.; Hill, C. L.; Galan-Mascaros, J. R.; Carbo, J. J.; Poblet, J. M., Tetracobalt-Polyoxometalate Catalysts for Water Oxidation: Key Mechanistic Details. J. Catal. 2017, 350, 56-63.

(173) Kenley, R. A.; Fleming, R. H.; Laine, R. M.; Tse, D. S.; Winterle, J. S., Cobalt(III) Complex Catalyzed Hydrolysis of Phosphorus Esters. Inorg. Chem. 1984, 23, 1870-1876.

(174) Lei, H.; Han, A.; Li, F.; Zhang, M.; Han, Y.; Du, P.; Lai, W.; Cao, R. Electrochemical, Spectroscopic and Theoretical Studies of a Simple Bifunctional Cobalt Corrole Catalyst for Oxygen Evolution and Hydrogen Production. Phys. Chem. Chem. Phys. 2014, 16, 1883-1893.

(175) Lieb, D.; Zahl, A.; Wilson, E. F.; Streb, C.; Nye, L. C.; Meyer, K.; IvanovicBurmazovic, I., Water Exchange Reactivity and Stability of Cobalt Polyoxometalates under Catalytically Relevant $\mathrm{pH}$ Conditions: Insight into Water Oxidation Catalysis. Inorg. Chem. 2011, 50, 9053-9058.

(176) Nazeeruddin, M. K.; Zakeeruddin, S. M.; Humphry-Baker, R.; Jirousek, M.; 
Liska, P.; Vlachopoulos, N.; Shklover,V.; Fischer, C. H.; Graltzel M., Acid-Base Equilibria of (2,2'-Bipyridyl-4,4'-dicarboxylic acid)ruthenium(II) Complexes and the Effect of Protonation on Charge-Transfer Sensitization of Nanocrystalline Titania. Inorg. Chem. 1999, 38, 6298-6305

(177) Lõkov, M.; Tshepelevitsh, S.; Heering A.; Plieger, P. G.; Vianello, R.; Leito I., On the Basicity of Conjugated Nitrogen Heterocycles in Different Media. Eur. J. Org. Chem. 2017, 4475-4489.

(178) Nazeeruddin, M. K.; Kalyanasundaram, K., Acid-Base Behavior in the Ground and Excited States of Ruthenium(II) Complexes Containing Tetraimines or Dicarboxybipyridines as Protonatable Ligands. Inorg. Chem. 1989, 28, 4251-4259.

(179) Wang, D.; Groves, J. T., Efficient Water Oxidation Catalyzed by Homogeneous Cationic Cobalt Porphyrins with Critical Roles for the Buffer Base. Proc. Natl. Acad. Sci. U. S. A. 2013, 110, 15579-15584.

(180) Thommes, M.; Kaneko, K.; Neimark, A. V.; Olivier, J. P.; Rodriguez-Reinoso, F.; Rouquerol, J.; Sing, K. S. W., Physisorption of Gases, with Special Reference to the Evaluation of Surface Area and Pore Size Distribution (IUPAC Technical Report), Pure and Applied Chemistry 2015, 87, 1051-1069.

(181) McMillan, W. G.; Mayer, J. E.; The Statistical Thermodynamics of Multicomponent Systems. J. Chem. Phys. 1945, 13, 276-305.

(182) Pierotti, R. A., On the Virial Expansion Treatment of Physical Adsorption. Chem. Phys. Lett. 1968, 2, 385-388.

(183) Hill, T. L., Statistical Mechanics of Adsorption. V. Thermodynamics and Heat of Adsorption. J. Chem. Phys. 1949, 17, 520-535.

(184) Dubinin, M. M., Physical Adsorption of Gases and Vapors in Micropores, vol. 9. Academic Press, Inc. 1975.

(185) Iley, M.; Marsh, H.; Reinoso, F. R., The Adsorptive Properties of Carbonised Olive Stones. Carbon 1973, 11, 633-638.

(186) Song, F.; Hu, X. Ultrathin cobalt-manganese layered double hydroxide is an efficient oxygen evolution catalyst, J. Am. Chem Soc. 2014, 136, 47, 16481-16484. 
(187) Trotochaud, L.; Ranney, J. K.; Williams, K. N.; Boettcher, S. W., Solution-Cast Metal Oxide Thin Film Electrocatalysts for Oxygen Evolution, J. Am. Chem. Soc. 2012, $134,41,17253-17261$.

(188) Orazem, M. E.; Tribollet, B., Electrochemical Impedance Spectroscopy; John Wiley \& Sons, Inc.: Hoboken, New Jersey 2008.

(189) Lasia, A. Electrochemical Impedance Spectroscopy and Its Applications; Springer: New York 2014.

(190) Barsoukov, E.; Macdonald, J. R., Impedance Spectroscopy: Theory, Experiment, and Applications, 3rd ed.; Eds.; John Wiley \& Sons Inc: Hoboken, New Jersey 2018. 



\section{Capítulo 8}

\section{Conclusiones generales}



De acuerdo con los resultados obtenidos en esta Tesis Doctoral se presentan las siguientes conclusiones generales:

1. Se han desarrollado distintos catalizadores de cobalto para llevar a cabo reacciones de interés industrial o relacionadas con las tecnologías energéticas sostenibles emergentes, como son la hidrosililación de alquenos, la reducción de nitroarenos y síntesis de aminas secundarias e isoindolinonas a través de reacciones en cascada, la oxidación de alcanos no activados, como el ciclohexano, y la reacción de oxidación del agua (OER), a través de la activación de moléculas pequeñas, siguiendo las directrices de la Química Verde.

2. Con respecto a la hidrosililación de alquenos, se ha desarrollado una nueva familia de compuestos de coordinación de Co(II), estables al aire y a la humedad, activos y selectivos en la hidrosililación de alquenos con distintos silanos (hidrosilanos primarios y secundarios, alcoxisilanos e hidrosiloxanos) y en la síntesis de polímeros de entrecruzamiento tipo silicona. Esta reacción se ha llevado a cabo en condiciones suaves de reacción y en ausencia de co-catalizadores o activadores externos. Además, este es el primer caso en el que estas reacciones se llevan a cabo en condiciones aeróbicas con complejos metálicos de la primera serie de transición. Finalmente, se ha llevado a cabo un estudio mecanístico con el fin de correlacionar la estructura con la actividad del catalizador más activo. Esta investigación abre una nueva puerta al estudio de catalizadores que puedan tener aplicación industrial para este proceso, sustituyendo a los catalizadores basados en platino.

3. El catalizador homoléptico $\mathrm{Co}(\mathrm{tpy})_{2}$ desarrollado en el estudio de las hidrosililaciones se ha heterogeneizado siguiendo la metodología de impregnación húmeda en un soporte de alta área superficial, como es el carbón activo. La estructura de este compuesto de coordinación de cobalto, rodeado por seis átomos de nitrógeno, es clave para conseguir nanoclústeres de cobalto estabilizados por la especie Co- $\mathrm{N}_{\mathrm{x}} \mathrm{y}$ recubiertos por capas de carbón dopado con nitrógeno, que protegen al cobalto metálico de la sobreoxidación en condiciones aeróbicas. El catalizador obtenido tras pirolizar este material a $800^{\circ} \mathrm{C}(\mathbf{C o} @ \mathbf{N C - 8 0 0})$ muestra una elevada dispersión de los nanoclústeres en el soporte carbonoso, confirmado mediante distintas técnicas de caracterización, y la presencia de una mayor cantidad de nitrógeno en el soporte de carbón facilita una ruptura heterolítica del hidrógeno en condiciones suaves de reacción. De hecho, este catalizador ha demostrado ser altamente activo y selectivo en la hidrogenación de un amplio rango de nitroarenos en condiciones suaves de reacción y usando 
agua como disolvente, además de ser reutilizable en varios ciclos. Además, este catalizador es activo en la síntesis de aminas secundarias e isoindolinonas a través de reacciones en cascada que implican la reducción de un grupo nitro en medio acuoso.

4. Se ha desarrollado una familia de clústeres de cobalto en la que se pueden modular las propiedades electrónicas del cubano $\left[\mathrm{Co}_{4} \mathrm{O}_{4}\right]$ a través del uso del ligando adecuado. Estos clústeres tetranucleares de cobalto han mostrado una elevada actividad y selectividad en la reacción de oxidación de ciclohexano, en condiciones suaves de reacción, usando aire empobrecido como oxidante y sin necesidad de usar disolvente ni aditivos. Además, se ha estudiado el mecanismo de reacción mediante la técnica de atrapamiento de espín por EPR, Raman in-situ y estudios experimentales, lo cual ha permitido correlacionar la actividad de cada catalizador con su potencial de oxidación y, por tanto, con su estructura. Este estudio mecanístico, además, ha permitido dilucidar la contribución de estos catalizadores de cobalto en cada etapa del proceso global y relacionarla con su densidad electrónica.

5. Por último, el clúster de cobalto $\left[\mathrm{Co}_{4} \mathrm{O}_{4}(\mathrm{OAc})_{4}(\mathrm{py})_{4}\right]$ se ha utilizado como precursor en la síntesis de dos MOFs de cobalto, con ligandos monofuncionales y bifuncionales, respectivamente. El MOF obtenido a partir del ligando monofuncional $\left(\mathbf{C o}_{2}-\right.$ MOF) está basado en dos SBUs de cobalto dinucleares y el segundo, obtenido a partir del ligando bifuncional (2D-Co-MOF) está basado en una estructura de láminas dobles que están fuertemente conectadas por enlaces intermoleculares. En este sentido, el empleo del precursor tetranuclear es clave para conseguir dichos MOFs de cobalto empleando ligandos orgánicos ampliamente estudiados en la síntesis de este tipo de materiales. La dispersión de estos MOFs de cobalto en una solución alcohólica de Nafion da como resultado los correspondientes composites, que presentan una buena adherencia a los electrodos de grafito, una alta estabilidad a largo plazo y, además, un elevado rendimiento electrocatalítico para la reacción de oxidación del agua (OER) en medio neutro. Finalmente, basándonos en la topología particular del 2DCo-MOF, con centros de cobalto distantes dentro de la estructura, y en la caracterización espectroscópica y electroquímica, se ha propuesto un mecanismo de reacción para esta reacción, lo cual ha permitido correlacionar la actividad de este MOF con su estructura, es decir, con la presencia de ligandos ecuatoriales aromáticos que contienen nitrógeno, que podrían facilitar el ataque nucleofílico del agua. 
6. Por tanto, el desarrollo de esta tesis doctoral ha permitido llevar a cabo la síntesis de distintos catalizadores de cobalto según las necesidades de cada tipo de reacción, mejorando en la mayoría de los casos los resultados para los catalizadores de cobalto reportados en bibliografía hasta el momento. 



\section{Publicaciones}



- Gutiérrez-Tarriño, S.; Concepción, P.; Oña-Burgos, P., Cobalt Catalysts for Alkene Hydrosilylation under Aerobic Conditions without Dry Solvents or Additives, Eur. J. Inorg. Chem. 2018, 45, 4867-4874.

- Gutiérrez-Tarriño, S.; Olloqui-Sariego, J. L.; Calvente, J. J.; Palomino, M.; Mínguez-Espallargas, G.; Jordá, J. L.; Rey, F.; Oña-Burgos, P., Cobalt Metal-Organic Framework Based on Two Dinuclear Secondary Building Units for Electrocatalytic Oxygen Evolution, ACS Appl. Mater. Interfaces 2019, 11, 46658-46665.

- Gutiérrez-Tarriño, S.; Olloqui-Sariego, J. L.; Calvente, J. J.; Mínguez-Espallargas, G.; Rey, F.; Corma, A.; Oña-Burgos, P., Cobalt Metal-Organic Framework Based on Layered Double Nanosheets for Enhanced Electrocatalytic Water Oxidation in Neutral Media J. Am. Chem. Soc. 2020, 142, 19198-19208.

- Gutiérrez-Tarriño, S.; Rojas-Buzo, S.; Lopes, C. W.; Agostini, G.; Calvino, J. J.; Corma, A.; Oña-Burgos, P., Cobalt Nanoclusters Cover by N-Doped Carbon Layers as Core-Shell for Tandem Reactions in Aquo Media Mediated by Chemoselective Nitroarene Hydrogenation, Green Chem. 2021. doi.org/10.1039/D1GC00706H 



\section{Resúmenes}



La presente tesis doctoral se enmarca en el ámbito de la Química Sostenible, en el cual se identifica la catálisis como una de las herramientas más importantes para su aplicación. En este sentido, en esta tesis doctoral, se han desarrollado catalizadores de cobalto para llevar a cabo reacciones de interés industrial o relacionadas con las tecnologías energéticas emergentes a través de la activación de moléculas pequeñas. Estas reacciones se llevan a cabo a nivel industrial con catalizadores basados en metales nobles o en condiciones de reacción severas. El objetivo es reemplazar estos catalizadores por otros basados en metales más abundantes en la corteza terrestre, en este caso el cobalto, o llevar a cabo las reacciones en condiciones de reacción más suaves, respectivamente, estudiando en todo caso la relación entre la estructura y la actividad del catalizador. Los resultados de esta tesis doctoral se presentan en cuatro capítulos.

En el capítulo cuatro, se presentan los resultados del desarrollo de catalizadores de cobalto estables al aire y a la humedad basados en compuestos de coordinación para llevar a cabo la hidrosililación de alquenos sin aditivos y evitando el uso de atmósfera inerte durante la reacción. Además, se ha estudiado la actividad de estos catalizadores usando un amplio rango tanto de alquenos como de silanos para comprobar la generalidad de la reacción. Finalmente, se ha estudiado el mecanismo de reacción usando Raman in-situ, lo cual ha permitido identificar la especie de cobalto activa como intermedio de reacción.

En el capítulo cinco, uno de los compuestos de coordinación estudiados para el proceso de hidrosililación de alquenos, se ha heterogeneizado usando como soporte un carbón activo de alta área superficial. La presencia de 6 nitrógenos coordinados al cobalto en el precursor inicial ha sido clave en la formación del material final, que es altamente activo y selectivo en la reacción de hidrogenación de nitroarenos y en la síntesis de aminas secundarias y de isoindolinonas en reacciones tándem en condiciones de reacción más suaves que las reportadas en bibliografía y usando agua como medio de reacción. Además, este catalizador puede ser reusado en varios ciclos de reacción sin una pérdida apreciable de actividad, demostrando que es un material heterogéneo y robusto. La estructura del catalizador se ha estudiado por varias técnicas de caracterización avanzadas, con el fin de correlacionar su estructura con la actividad en estas reacciones catalíticas.

En el sexto capítulo se resumen los resultados obtenidos para el desarrollo de una familia de compuestos tetranucleares de cobalto, cuya densidad electrónica puede ser modulada haciendo uso de diferentes ligandos. Esta densidad electrónica está correlacionada con su actividad catalítica en reacciones de oxidación, como la oxidación de ciclohexano a 
ciclohexanol y ciclohexanona. En este sentido, se ha llevado a cabo un amplio estudio de la actividad catalítica de esta familia de catalizadores, que han demostrado ser activos y selectivos en esta reacción, en condiciones netas y usando aire empobrecido como oxidante, y del mecanismo de reacción a través de EPR y Raman, que ha permitido correlacionar la estructura de cada catalizador con su papel en cada proceso individual del mecanismo global de esta reacción.

Finalmente, en el capítulo siete, uno de los compuestos tetranucleares de cobalto se ha utilizado como precursor en la síntesis de MOFs con ligandos ampliamente utilizados en la síntesis de estos materiales, como son el $\mathrm{H}_{3} \mathrm{BTC}$ y el $\mathrm{H}_{2}$ bda, obteniéndose dos MOFs nuevos, el primero de ellos ( $\mathbf{C o}_{2}$-MOF) basado en dos SBUs de cobalto dinucleares en la que una de ellas presenta tres posiciones de coordinación libres, con las ventajas que esto conlleva y, el segundo de ellos (2D-Co-MOF), basado en nanoláminas dobles apiladas por interacciones $\pi-\pi$ stacking entre los ligandos piridina axiales. La dispersión de estos MOFs en Nafion da como resultado los correspondientes composites, que presentan una buena adherencia a los electrodos de grafito, una alta estabilidad a largo plazo y, además, un elevado rendimiento electrocatalítico para la reacción de oxidación del agua en medio neutro, mejorando los resultados reportados en bibliografía para materiales similares. Además, se ha estudiado el mecanismo de reacción, que sigue sin conocerse a ciencia cierta hoy en día, para el 2D-Co-MOF, basándonos en su topología particular y en estudios espectroscópicos y electroquímicos. 
This thesis is focused on the field of Green Chemistry, in which catalysis is identified as one of the most important tools for its application. In this sense, in this thesis, cobalt catalysts were developed to carry out reactions of industrial interest or related to emerging energy technologies, through the activation of small molecules. These reactions are usually performed at industrial scale with catalysts based on noble metals or under severe reaction conditions. The main objective of this thesis is to replace these catalysts by others based on more abundant metals in the earth's crust, in this case cobalt, or to carry out the reactions in milder reaction conditions, respectively, studying in each case the relationship between the structure and the activity of the catalyst. The results of this thesis are presented in four chapters.

In the first chapter, the results for the catalytic hydrosilylation of alkenes under aerobic conditions and without dry solvents or additives are presented, where the development of air-stable cobalt-aquo complexes is pivotal. In fact, this is the first case where these reactions are performed under aerobic conditions with first-row transition metal complexes. In addition, the activity of these catalysts has been studied using a wide range of both alkenes and silanes to check the scope of the reaction. Finally, the reaction mechanism has been studied using in-situ Raman, which has allowed the identification of the active cobalt species as a reaction intermediate.

In the second chapter, one of the coordination compounds studied for the alkene hydrosilylation process has been heterogenized using an activated carbon with high area as support. The employment of a suitable molecular complex consisting of six bounds N$\mathrm{Co}$ as initial precursor has been key in the formation of the final material. This catalyst has demonstrated to be highly active and selective in the hydrogenation of nitroarenes and in the synthesis of secondary amines and isoindolinones in tandem reactions under milder reaction conditions than those reported in the literature and using water as reaction medium. Moreover, this catalyst can be reused in several reaction cycles without an appreciable loss of activity. The structure of the catalyst has been studied by several advanced characterization techniques in order to correlate its structure with the activity in these catalytic reactions.

In the third chapter, the results obtained for the development of a family of tetranuclear cobalt compounds, whose electron density is modulated by using different ligands, are summarized. This electron density is correlated with their catalytic activity in the oxidation of cyclohexane to cyclohexanol and cyclohexanone. In this sense, an extensive study of the catalytic activity of this family of catalysts, which have been shown to be active 
and selective in this reaction, has been carried out under neat conditions and using depleted air as oxidant. Moreover, the reaction mechanism has been studied through EPR and Raman, which has allowed to correlate the structure of each catalyst with its role in each individual step of the global mechanism of this reaction.

Finally, in the fourth chapter, one of the tetranuclear cobalt compounds has been used as precursor in the synthesis of MOFs with ligands widely used in the synthesis of these materials, such as $\mathrm{H}_{3} \mathrm{BTC}$ and $\mathrm{H}_{2}$ bda, obtaining two new MOFs. The first one ( $\mathbf{C o}_{2}$ MOF) based on two dinuclear cobalt SBUs in which one of them presents three free coordination positions, with the advantages that this entails and, the second one (2D-CoMOF), based on double nanolayers stacked by $\pi-\pi$ stacking interactions between the axial pyridine ligands. The dispersion of these MOFs in Nafion results in the corresponding composites, which exhibit good adherence to graphite electrodes, high long-term stability and, in addition, high electrocatalytic performance for the water oxidation reaction (OER) in neutral media, improving the results reported in literature for similar materials. Furthermore, the reaction mechanism, which is still unresolved, has been studied for 2D-Co-MOF, based on its particular topology and on spectroscopic and electrochemical studies. 
La present tesi doctoral s'emmarca en l'àmbit de la Química Sostenible, en el qual s'identifica la catàlisi com una de les eines més importants per a la seua aplicació. En aquest sentit, en aquesta tesi doctoral, s'han desenvolupat catalitzadors de cobalt per a dur a terme reaccions d'interés industrial o relacionades amb les tecnologies energètiques emergents a través de l'activació de molècules xicotetes. Aquestes reaccions es duen a terme a nivell industrial amb catalitzadors basats en metalls nobles o en condicions de reacció severes. L'objectiu és reemplaçar aquests catalitzadors per altres basats en metalls més abundants en l'escorça terrestre, en aquest cas el cobalt, o dur a terme les reaccions en condicions de reacció més suaus, respectivament, estudiant en tot cas la relació entre l'estructura i l'activitat del catalitzador. Els resultats d'aquesta tesi doctoral es presenten en quatre capítols.

En el quart capítol, es presenten els resultats del desenvolupament de catalitzadors de cobalt estables a l'aire i a la humitat basats en compostos de coordinació per a dur a terme la hidrosililació d'alquens sense additius i evitant l'ús d'atmosfera inerta durant la reacció. A més, s'ha estudiat l'activitat d'aquests catalitzadors usant un ampli rang tant d'alquens com de silanes per a comprovar la generalitat de la reacció. Finalment, s'ha estudiat el mecanisme de reacció usant Raman in-situ, la qual cosa ha permés identificar l'espècie de cobalt activa com a intermedi de reacció.

En el quint capítol, un dels compostos de coordinació estudiats per al procés de hidrosililació d'alquens, s'ha heterogeneït usant com a suport un carbó actiu d'alta àrea. La presència de 6 nitrògens coordinats al cobalt en el precursor inicial ha sigut clau en la formació del material final, que és altament actiu i selectiu en la reacció d'hidrogenació de nitroarenos i en la síntesi d'amines secundàries i de isoindolinons en reaccions tàndem en condicions de reacció més suaus que les reportades en bibliografia i usant aigua com a mitjà de reacció. A més, aquest catalitzador pot ser reusat en diversos cicles de reacció sense una pèrdua apreciable d'activitat, demostrant que és un material heterogeni i robust. L'estructura del catalitzador s'ha estudiat per diverses tècniques de caracterització avançades, amb la finalitat de correlacionar la seua estructura amb l'activitat en aquestes reaccions catalítiques.

En el capítol sis es resumeixen els resultats obtinguts per al desenvolupament d'una família de compostos tetranuclears de cobalt, la densitat electrònica del qual pot ser modulada fent ús de diferents lligands. Aquesta densitat electrònica està correlacionada amb la seua activitat catalítica en reaccions d'oxidació, com l'oxidació de ciclohexà a ciclohexanol i ciclohexanona. En aquest sentit, s'ha dut a terme un ampli estudi de l'activitat catalítica d'aquesta família de catalitzadors, que han demostrat ser actius i 
selectius en aquesta reacció, en condicions netes i usant aire empobrit com a oxidant, i del mecanisme de reacció a través de EPR i Raman, que ha permés correlacionar l'estructura de cada catalitzador amb el seu paper en cada procés individual del mecanisme global d'aquesta reacció.

Finalment, en el sèptim capítol, un dels compostos tetranuclears de cobalt s'ha utilitzat com a precursor en la síntesi de MOFs amb lligands àmpliament utilitzats en la síntesi d'aquests materials, com són l' $\mathrm{H}_{3} \mathrm{BTC}$ i el $\mathrm{H}_{2}$ bda, obtenint-se dos MOFs nous. El primer d'ells ( $\mathbf{C o}_{2}$-MOF) basat en dos SBUs de cobalt dinuclears en la qual una d'elles presenta tres posicions de coordinació lliures, amb els avantatges que això comporta. El segon (2D-Co-MOF), basat en nanolámines dobles apilades per interaccions $\pi$ - $\pi$ stacking entre els lligands piridina axials. La dispersió d'aquests MOFs en Nafion dona com a resultat els corresponents composites, que presenten una bona adherència als elèctrodes de grafit, una alta estabilitat a llarg termini i, a més, un elevat rendiment electrocatalític per a la reacció d'oxidació de l'aigua al mig neutre, millorant els resultats reportats en bibliografia per a materials similars. A més, s'ha estudiat el mecanisme de reacció, que segueix sense conéixer-se amb certesa hui dia, per al 2D-Co-MOF, basant-nos en la seua topologia particular i en estudis espectroscòpics i electroquímics. 
Índice de Figuras 



\section{Capítulo 1. Introducción.}

1.1 Progreso de la reacción química catalizada (rojo) y sin catalizar (negro) .....10

1.2 Métodos de inmovilización de catalizadores en soportes sólidos....................21

\section{Capítulo 4. Complejos de Cobalto para la hidrosililación de alquenos en condiciones aeróbicas.}

4.1 Catalizador de Karstedt. .58

4.2 Ejemplos de catalizadores de cobalto para hidrosililación de alquenos. ........62

4.3 Estructuras moleculares de los complejos a) $\left[\mathrm{Co}(\mathrm{OAc})\left(\mathrm{H}_{2} \mathrm{O}\right)_{2}(\right.$ tpy $\left.)\right] \mathrm{OAc}, \mathbf{1 b}$ y b) $\left[\mathrm{Co}(\text { tpy })_{2}\right] \mathrm{Cl}_{2} \cdot 6 \mathrm{H}_{2} \mathrm{O}$, 2c. Los elipsoides se muestran a un $30 \%$ de probabilidad. Los átomos de hidrógeno y las moléculas de disolvente y los aniones cloruro del complejo $2 \mathbf{c}$ se omiten por claridad. Gris $=\mathrm{C}$, azul $=\mathrm{N}$, rojo $=\mathrm{O}$, marrón $=$ Co. . .66

4.4 ${ }^{1} \mathrm{H}-\mathrm{RMN}$ de la mezcla de reacción del ligando tpy y el precursor de cobalto $\mathbf{1 a}$ (abajo), donde (*) son las señales del complejo homoléptico, y del ligando tpy con el precursor de cobalto $\mathbf{2 a}$ (arriba), respectivamente.

4.5 Comparación de los espectros de absorción UV-Vis para los precatalizadores de Co(II) $\mathbf{1 b}(0.0535 \mathrm{mg} / \mathrm{mL})$, $\mathbf{1 b}$ aislado $(0.0690 \mathrm{mg} / \mathrm{mL}), \mathbf{2 b}(0.0273 \mathrm{mg} / \mathrm{mL}), \mathbf{2 c}$ aislado $(0.0219 \mathrm{mg} / \mathrm{mL}), \mathbf{3 b}(0.0915 \mathrm{mg} / \mathrm{mL})$ and $\mathbf{4 b}(0.1025 \mathrm{mg} / \mathrm{mL})$ en metanol ........68

4.6 Espectros EPR de los precursores de cobalto (II) $\mathbf{1 b}$ (rojo) y $2 \mathrm{c}$ (negro) .....69

4.7 Extensión de ${ }^{1} \mathrm{H}$ RMN de $\mathbf{1 b}$ en MeOD en relación con el MeOD................70

4.8 Extensión de ${ }^{1} \mathrm{H}$ RMN de 2c en MeOD en relación con el MeOD.................70

4.9 Estudio cinético de la reacción de hidrosililación del 4-vinilciclohexeno con $\mathrm{PhSiH}_{3}$ para la evaluación de los precatalizadores de cobalto. Los números en la figura se corresponden con las entradas en la Tabla 4.2 .....................................................73

4.10 Dependencia de la velocidad inicial de la reacción con a) concentración de alqueno, b) concentración de silano y c) concentración de Catalizador.

4.11 Experimento de espectroscopía Raman in-situ. Código de colores: Azul: catalizador 3b, Negro: $(\mathbf{E t O})_{3} \mathbf{S i H}$, Rojo: mezcla de reacción entre el catalizador $\mathbf{3 b}$ y el (EtO) $)_{3} \mathbf{S i H}$, y Verde: mezcla de reacción tras la adición del alqueno..............................80

4.12 Espectro ESI de 1b, que corresponde a la fórmula $\mathrm{C}_{17} \mathrm{H}_{13} \mathrm{~N}_{3} \mathrm{O}_{2} \mathrm{Co}$................88 
4.13 Espectro ESI de $\mathbf{2 b}$ que corresponde a la fórmula $\mathrm{C}_{20} \mathrm{H}_{18} \mathrm{~N}_{3} \mathrm{O}_{3} \mathrm{Co}$ 89

4.14 Espectro ESI de 1 b aislado que corresponde a la fórmula $\mathrm{C}_{17} \mathrm{H}_{13} \mathrm{~N}_{3} \mathrm{O}_{2} \mathrm{Co} . .90$

4.15 Espectro ESI de $2 c$ aislado que corresponde a la fórmula $\mathrm{C}_{30} \mathrm{H}_{20} \mathrm{~N}_{6} \mathrm{Co}$ 91

4.16 Espectro de absorción UV/Vis del $\mathrm{Co}(\mathrm{OAc})_{2} \cdot 4 \mathrm{H}_{2} \mathrm{O}(0.825 \mathrm{mg} / \mathrm{mL})$, terpiripina $(0.026 \mathrm{mg} / \mathrm{mL})$ y el complejo $\mathbf{1 b}(0.054 \mathrm{mg} / \mathrm{mL})$ en metanol.

4.17 Espectro de absorción UV/Vis del Co(acac) $)_{2} \cdot \mathrm{H}_{2} \mathrm{O}(0.029 \mathrm{mg} / \mathrm{mL})$, terpiridina $(0.026 \mathrm{mg} / \mathrm{mL})$ y el complejo $2 \mathbf{b}(0.027 \mathrm{mg} / \mathrm{mL})$ en metanol. .92

4.18 Espectro de absorción UV/Vis del Co(napht $)_{2}(1.310 \mathrm{mg} / \mathrm{mL})$, terpiridina $(0.026 \mathrm{mg} / \mathrm{mL})$ y el complejo $\mathbf{3 b}(0.092 \mathrm{mg} / \mathrm{mL})$ en metanol. .93

4.19 Espectro de absorción UV/Vis del Co(oct $)_{2}(0.612 \mathrm{mg} / \mathrm{mL})$, terpiridina $(0.026$ $\mathrm{mg} / \mathrm{mL})$ y el complejo $\mathbf{4 b}(0.103 \mathrm{mg} / \mathrm{mL})$ en metanol.

4.20 ${ }^{1} \mathrm{H}-\mathrm{RMN}$ del crudo de reacción de 4-vinilciclohexeno y $\mathrm{PhSiH}_{3}$ catalizada por el precatalizador $\mathbf{3 b}$ cada 30 minutos, a) $30 \mathrm{~min}$; b) $60 \mathrm{~min}$; c) $90 \mathrm{~min}$; d) $120 \mathrm{~min} . . . .96$

4.21 Estudio cinético de la reacción de hidrosililación de 4-vinilciclohexeno con $\mathrm{PhSiH}_{3}$ para la evaluación de los precatalizadores de cobalto por ${ }^{1} \mathrm{H}-\mathrm{RMN}$ in-situ. Los números de la figura se corresponden con las entradas de la Tabla 4.11.... . .97

\section{Capítulo 5. Nanoclústeres de Cobalto como catalizadores para la hidrogenación quimioselectiva de nitroarenos y reacciones tándem.}

5.1 Perfil cinético para la hidrogenación de nitrobenceno a anilina catalizada por Co@NC-800 en las condiciones optimizadas de reacción. 120

5.2 Análisis por reducción a temperatura programada de los catalizadores Co@NC-T. .125

$5.3 \quad a)$ imagen del Co@NC-800 tomada con HAADF-STEM. Los puntos brillantes de alta intensidad corresponden a nanoclústeres de Co, b) mapa STEM-EDX de alta resolución de Co@NC-800. El mapa de cobalto se ha superpuesto en la imagen de STEM-HAADF. c) Distribución del tamaño de partícula del catalizador Co@NC-800 (se han contado 200 partículas). El diagrama insertado muestra el porcentaje de partículas entre 30 y $50 \mathrm{~nm}$ 126 
5.4 Patrones de difracción de rayos X de a) soporte de carbón (negro) y Co@NC800 (rojo), b) soporte de carbón (negro), Co@NC-400 (azul claro), Co@NC-500 (verde), Co@NC-600 (azul oscuro), Co@NC-700 (naranja) y Co@NC-800 (rojo)..127

5.5 Espectros XPS del Co@NC-800 de las líneas a) N 1s y b) Co 2p. 128

5.6 Espectros XANES normalizados $(\mathrm{a}, \mathrm{b})$ en el borde $\mathrm{K}$ del Co para el precursor de Co, Co@NC-800 y los respectivos estándares c) Modulo de la transformada de Fourier y ajustes de la curva para el precursor de Co y Co@NC-800.

5.7 Espectro ATR-IR del catalizador Co@NC-800 sin pretratamiento (línea negra) y con las especies pre-adsorbidas, nitrobenceno (línea roja) y 3-nitroestireno (línea azul). 135

5.8 a) Experimentos de reusos del catalizador Co@NC-800, se hace un tratamiento de pirólisis (línea discontinua) después del cuarto uso y b) test de filtración en caliente para la hidrogenación catalítica de nitrobenceno a anilina en las condiciones optimizadas. 136

5.9 Imágenes STEM de a) Co@NC-400, b) Co@NC-500, c) Co@NC-600, d) Co@NC-700, e) Co@NC-800 y f) Co@C-800. 143

5.10 Espectro Raman para Co@NC-800..........................................................144

5.11 $|\mathrm{FT}|$ ponderada en $\mathrm{k}^{2}$ (puntos rojos) y ajuste de la curva alternativo (línea negra) usando como referencia el archivo CIF de la estructura de monocristal para el precursor de Co. La línea verde representa la suma de todas las trayectorias generadas por FEFF al utilizar el CIF del complejo como modelo. Las partes imaginarias se han representado también con fines comparativos........................................................144

5.12 Espectro FTIR del nitrobenceno en $\mathrm{KBr}$................................................146

5.13 Espectro FTIR del 3-nitroestireno en $\mathrm{KBr}$..................................................147

\section{Capítulo 6. Complejos tetranucleares de cobalto para la oxidación selectiva de ciclohexano.}

6.1 Estructura de rayos X de monocristal de 2, 5 y 6, respectivamente. Los átomos de hidrógeno se han omitido por claridad de la imagen. 176

6.2 Voltamperogramas cíclicos para los clústeres de cobalto medidos a $100 \mathrm{mV} / \mathrm{s}$ en una disolución $1 \mathrm{mM}$ en acetonitrilo con $0.01 \mathrm{M}$ del electrolito TBAP. Los potenciales 
de oxidación calculados para cada complejo son: $\mathbf{1}(\mathrm{E}=0.704 \mathrm{~V}), \mathbf{2}(\mathrm{E}=0.857 \mathrm{~V}), \mathbf{3}(\mathrm{E}$ $=0.670 \mathrm{~V}), 4(\mathrm{E}=0.783 \mathrm{~V}), 5(\mathrm{E}=0.956 \mathrm{~V})$ and $6(\mathrm{E}=0.743 \mathrm{~V})$.

6.3 Datos de los potenciales de oxidación de los clústeres 1-6. Estos datos se correlacionan con los valores de $\sigma^{+}$de la ecuación de Hammet.

6.4 Resumen de la actividad catalítica para la oxidación de ciclohexano con los catalizadores a) 1, b) 2, c) 3, d) 4, e) 5, f) 6, g) $\mathrm{Co}(\mathrm{OAc})_{2}$ y h) blanco. Condiciones de reacción: Línea negra: conversión total (eje derecho), línea roja: ciclohexanol, línea azul: ciclohexanona, línea verde: CHHP y línea naranja: ácido adípico (eje izquierdo)......181

6.5 a) Estudio cinético para la oxidación del ciclohexano con los clústeres tetranucleares de cobalto 1-6 y $\mathrm{Co}(\mathrm{OAc})_{2}$. b) Correlación entre la conversión y el potencial de oxidación para cada clúster.

182

6.6 Comparación de los catalizadores de cobalto 1-6 (puntos rojos) con otros catalizadores reportados (puntos azules) para la oxidación aeróbica de ciclohexano en condiciones similares.

183

6.7 Espectro EPR experimental y deconvolución de los aductos de spin obtenidos durante la descomposición del CHHP en ciclohexano en presencia de los clústeres de cobalto $\mathbf{2}$ (a) y $\mathbf{5}$ (b). Espectro experimental (negro), espectro simulado (rojo), aducto de spin DMPO-O- $\mathrm{C}_{6} \mathrm{H}_{11}$ (azul), aducto centrado en el carbono, DMPO-C $(\mathrm{OH}) \mathrm{R}_{2}$ (verde) y aducto DMPO-OO- $\mathrm{C}_{6} \mathrm{H}_{11}$ (morado).

.187

6.8 Espectro Raman de los complejos 1 (a), 3 (b) y 6 (c) entre 850 y $350 \mathrm{~cm}^{-1}$ en argón (negro) y pasando un flujo de $\mathrm{O}_{2}$ (rojo).

6.9 Espectros Raman de los complejos 2 (a) y 4 (b) entre 1700 y $900 \mathrm{~cm}^{-1}$ en argón (negro) y pasando un flujo de $\mathrm{O}_{2}$ (rojo).

6.10 Espectro Raman del complejo 5 en argón (negro) y pasando un flujo de $\mathrm{O}_{2}$ (rojo). 194

6.11 Voltamogramas cíclicos a $100 \mathrm{mV} / \mathrm{s}$ de una disolución $1 \mathrm{mM}$ de los complejos: $\mathbf{1}$ (negro), $\mathbf{2}$ (rojo) y $\mathbf{3}$ (verde) en $\mathrm{AcN}$ con $0.01 \mathrm{M}$ del electrolito TBAP. .201

6.12 Voltamogramas cíclicos a $100 \mathrm{mV} / \mathrm{s}$ de una disolución $1 \mathrm{mM}$ de los complejos: 4 (negro), 5 (verde) y 6 (rojo) en AcN con $0.01 \mathrm{M}$ del electrolito TBAP. .201

6.13 Espectro ESI del complejo 1, que corresponde con la fórmula $\mathrm{C}_{28} \mathrm{H}_{32} \mathrm{Co}_{4} \mathrm{~N}_{4} \mathrm{O}_{12}$ .202 
6.14 Espectro ESI del complejo 2, que corresponde con la fórmula $\mathrm{C}_{40} \mathrm{H}_{48} \mathrm{Co}_{4} \mathrm{~N}_{4} \mathrm{O}_{20}$ 202

6.15 Espectro ESI del complejo 3, que corresponde con la fórmula $\mathrm{C}_{32} \mathrm{H}_{40} \mathrm{Co}_{4} \mathrm{~N}_{4} \mathrm{O}_{16}$

6.16 Espectro ESI del complejo 4, que corresponde con la fórmula $\mathrm{C}_{48} \mathrm{H}_{40} \mathrm{Co}_{4} \mathrm{~N}_{4} \mathrm{O}_{12}$ 203

6.17 Espectro ESI del complejo 5, que corresponde con la fórmula $\mathrm{C}_{60} \mathrm{H}_{56} \mathrm{Co}_{4} \mathrm{~N}_{4} \mathrm{O}_{20}$. .204

6.18 Espectro ESI del complejo 6, que corresponde con la fórmula $\mathrm{C}_{52} \mathrm{H}_{48} \mathrm{Co}_{4} \mathrm{~N}_{4} \mathrm{O}_{16}$ 204

6.19 ${ }^{1} \mathrm{H}$ RMN del complejo 1. * señales del $\mathrm{CH}_{2} \mathrm{Cl}_{2}$, agua y DMSO-d $\mathrm{d}_{6}$, respectivamente. 205

6.20 ${ }^{13} \mathrm{C}$ RMN del complejo 1. *Señal del DMSO-d 6 . 205

6.21 ${ }^{1} \mathrm{H}$ RMN del complejo 2. *Señales del $\mathrm{CH}_{2} \mathrm{Cl}_{2}$, agua y DMSO-d 6 , respectivamente. 206

6.22 ${ }^{13} \mathrm{C}$ RMN del complejo 2. *Señal del DMSO-d 6 . 206

6.23 ${ }^{1} \mathrm{H}$ RMN del complejo 3. *Señales del $\mathrm{CH}_{2} \mathrm{Cl}_{2}$, agua y DMSO-d 6 , respectivamente. 207

6.24 ${ }^{13} \mathrm{C}$ RMN del complejo 3. *Señal del DMSO-d 6 . 207

6.25 ${ }^{1} \mathrm{H}$ RMN del complejo 4. *Señales del $\mathrm{CH}_{2} \mathrm{Cl}_{2}$, agua y DMSO-d $\mathrm{d}_{6}$, respectivamente. .208

6.26 ${ }^{13} \mathrm{C}$ RMN del complejo 4. *Señal del DMSO-d 6 . 208

6.27 ${ }^{1} \mathrm{H}$ RMN del complejo 5. *Señales del $\mathrm{CH}_{2} \mathrm{Cl}_{2}$, agua y DMSO-d 6 , respectivamente. 209

6.28 ${ }^{13} \mathrm{C}$ RMN del complejo 5. *Señal del DMSO-d $\mathrm{d}_{6}$ 209

6.29 ${ }^{1} \mathrm{H}$ RMN del complejo 6. *Señales del $\mathrm{CH}_{2} \mathrm{Cl}_{2}$, agua y DMSO-d $\mathrm{d}_{6}$, respectivamente. 210

6.30 $\quad{ }^{1} \mathrm{H},{ }^{13} \mathrm{C}$ gHMQC RMN del complejo 6. 210

6.31 Espectro EPR del experimento de atrapamiento de spin con $\mathbf{1}$. 215 
6.32 Espectro EPR del experimento de atrapamiento de spin con 2. ..................215

6.33 Espectro EPR del experimento de atrapamiento de spin con 3. ..................216

6.34 Espectro EPR del experimento de atrapamiento de spin con 4. ..................216

6.35 Espectro EPR del experimento de atrapamiento de spin con 5. ..................217

6.36 Espectro EPR del experimento de atrapamiento de spin con 6. ....................217

6.37 Espectro Raman del complejo 1 en argón (negro) y pasando un flujo de $\mathrm{O}_{2}$ (rojo). .218

6.38 Espectro Raman del complejo 2 en argón (negro) y pasando un flujo de $\mathrm{O}_{2}$ (rojo).

6.39 Espectro Raman del complejo 3 en argón (negro) y pasando un flujo de $\mathrm{O}_{2}$ (rojo).

6.40 Espectro Raman del complejo 4 en argón (negro) y pasando un flujo de $\mathrm{O}_{2}$ (rojo). 220

6.41 Espectro Raman del complejo 6 en argón (negro) y pasando un flujo de $\mathrm{O}_{2}$ (rojo).

\section{Capítulo 7. MOFs de Cobalto como Catalizadores para la Oxidación Electrocatalítica del Agua en Medio Neutro.}

7.1 Ruptura electroquímica del agua para generar $\mathrm{O}_{2}$ e $\mathrm{H}_{2}$ mediante oxidación del agua (en el ánodo) y reducción de protones (en el cátodo), respectivamente.

7.2 El papel del OER para un futuro sostenible y energéticamente seguro.......234

7.3 Síntesis de materiales metal-orgánicos (MOFs) ...................................237

7.4 (a) Estructura cristalográfica del Co2-MOF, (b) representación de las dos unidades diméricas que forman el compuesto (SBU1 y SBU2) Los átomos de hidrógeno se han omitido para clarificar la estructura.

7.5 Representación de las dos SBUs diméricas encontradas en el Co2-MOF. a) Distancias de enlace en la SBU1: $\mathrm{a}=2.086 \AA, \mathrm{b}=2.027 \AA, \mathrm{c}=2.026 \AA, \mathrm{d}=2.015 \AA$, e $=1.988 \AA, \mathrm{f}=2.833 \AA$. b) Distancias de enlace en la SBU2: $\mathrm{a}=2.098 \AA, \mathrm{b}=2.241 \AA$, c $=2.402 \AA, \mathrm{d}=2.063 \AA, \mathrm{e}=2.011 \AA, \mathrm{f}=2.011 \AA, \mathrm{g}=2.132 \AA, \mathrm{h}=2.120 \AA, \mathrm{i}=2.075$ 
$\AA ⿻$ $\mathrm{j}=2.110 \AA \mathrm{n}, \mathrm{k}=2.055 \AA, \mathrm{l}=2.095 \AA$. Los átomos de hidrógeno se omiten para clarificar la estructura.

7.6 Difractograma de rayos X de polvo del Co2-MOF medido (negro) y calculado a partir de los datos de difracción de rayos $\mathrm{X}$ de monocristal (rojo).

7.7 Difractograma de rayos $\mathrm{X}$ de polvo del $\mathbf{C o}_{2}$-MOF (negro), del MOF sintetizado usando $\mathrm{Co}(\mathrm{OAc})_{2} \cdot 4 \mathrm{H}_{2} \mathrm{O}$ como precursor (rojo) y del MOF sintetizado usando $\mathrm{Co}\left(\mathrm{NO}_{3}\right)_{2} \cdot 6 \mathrm{H}_{2} \mathrm{O}$ como precursor (azul) a $135^{\circ} \mathrm{C}$ durante 72 horas.

7.8 Representación del Co2-MOF: (a) a lo largo del eje a, (b) a lo largo del eje b, (c) a lo largo del eje c. El disolvente y los átomos de hidrógeno se omiten para clarificar la estructura..

7.9 Análisis termogravimétrico del $\mathbf{C o}_{2}$-MOF 244

7.10 a) Aplicación de la ecuación de Dubinin-Astakhov para la adsorción de $\mathrm{CO}_{2}$ a 273K para el $\mathbf{C o}_{2}$-MOF. b) Isotermas de adsorción de $\mathrm{CO}_{2}$ para el $\mathbf{C o}_{2}$-MOF a diferentes temperaturas. Los puntos son valores experimentales y las líneas son ajustes de Virial. c) Calor isostérico de adsorción de $\mathrm{CO}_{2}$ en el $\mathbf{C o}_{2}$-MOF. d) Isotermas de adsorción de $\mathrm{CO}_{2}$ (símbolos cerrados) y $\mathrm{CH}_{4}$ (símbolos abiertos) para el $\mathrm{Co}_{2}$-MOF. Los puntos son valores experimentales y las líneas son ajustes de Virial. Negro: $283 \mathrm{~K}$, Rojo: $298 \mathrm{~K}$, Verde: 313 K, Azul: 333 K. e) Selectividad aparente $\mathrm{CO}_{2} / \mathrm{CH}_{4}$. Negro: 283 K, Rojo: 298 K, Verde: 313 K, Azul: 333 K. 245

7.11 Imagen del Co2-MOF tomada con microscopía electrónica de barrido de emisión de campo (FESEM) y análisis EDX.

7.12 Espectro XPS de la línea del Co 2p del Con-MOF. 247

7.13 Patrones de difracción de rayos X de polvo del Co2-MOF antes (negro) y después de tratarlo con diferentes disolventes o mezclas de disolventes: A: agua (rojo), B: $15 \%$ etanol en agua (verde), C: $50 \%$ etanol en agua (azul), D: $15 \%$ de agua en etanol (naranja), E: etanol (azul claro).

7.14 Patrones de difracción de rayos X de polvo del Co2-MOF@Nafion (rojo), Co2-MOF@Nafion tras el tratamiento con agua (azul), Co2-MOF (negro) y Nafion (verde).

7.15 Esfera de coordinación en el 2D-Co-MOF. Distancias y ángulos de enlace: $\mathrm{Co}-\mathrm{O}(1)=2.126 \AA$, Co- $\mathrm{O}(2)=2.055 \AA$, $\mathrm{Co}-\mathrm{O}(3)=2.088 \AA, \mathrm{Co}-\mathrm{N}(1)=2.160 \AA, \mathrm{Co}-\mathrm{N}(2)$ $=2.180 \AA$, Co-N $(3)=2.146 \AA$; N $(1)-\mathrm{Co}-\mathrm{N}(2)=75.83^{\circ}, \mathrm{N}(1)-\mathrm{Co}-\mathrm{O}(2)=91.69^{\circ}, \mathrm{O}(2)-\mathrm{Co}-$ $\mathrm{O}(3)=91.10^{\circ}, \mathrm{O}(3)-\mathrm{Co}-\mathrm{N}(2)=101.46^{\circ}, \mathrm{O}(1)-\mathrm{Co}-\mathrm{N}(3)=172.64^{\circ}$. .250 
7.16 Estructura de Rayos X del 2D-Co-MOF. a) unidad de construcción secundaria (SBU), b) una nanolámina que incluye dos láminas individuales, c) Estructura apilada por interacciones $\pi-\pi$ de las láminas dobles del 2D-Co-MOF. La flecha azul indica la distancia entre dos láminas individuales dentro de la nanolámina (3.491 ̊̊) y la flecha roja indica la distancia interláminas en la estructura apilada por interacciones $\pi-\pi(7.422$ $\AA$ ).

7.17 Patrones de difracción de rayos X de polvo del 2D-Co-MOF medido (negro) y calculado a partir de los datos de difracción de rayos $\mathrm{X}$ de monocristal (rojo).

.251

7.18 Análisis termogravimétrico de a) 2D-Co-MOF y b) 2D-Co-MOF después de tratarlo a $150^{\circ} \mathrm{C}$ durante 24 horas.

253

7.19 Aplicación de la ecuación de Dubinin-Astakhov de la adsorción de $\mathrm{CO}_{2}$ a 273 $\mathrm{K}$ al 2D-Co-MOF, b) isoterma de adsorción para el 2D-Co-MOF a $273 \mathrm{~K}$.

7.20 Imagen de FESEM y análisis EDX del 2D-Co-MOF. 254

7.21 Espectro XPS de a) línea Co 2p, b) línea O 1s, c) N 1s del 2D-Co-MOF. .255

7.22 Patrones de difracción de rayos X de polvo del 2D-Co-MOF (negro) y después de ser tratado con distintos disolventes como etanol (rojo), acetonitrilo (azul) y trietilamina $(\mathrm{pH}=12.7)$ (verde) 256

7.23 Patrón de difracción de rayos $\mathrm{X}$ de polvo (izquierda) y espectro Raman (derecha) del 2D-Co-MOF apilado por interacciones $\pi-\pi$ antes (negro) y después de tratamiento sucesivo con agua durante $5 \mathrm{~min}$ (rojo) y con piridina durante 2 días a $150^{\circ} \mathrm{C}$ (verde).

7.24 Espectro XPS de las líneas de Co 2p y O 1s del 2D-Co-MOF antes (abajo) y después (arriba) de su tratamiento con agua. 258

7.25 Espectro XPS para las líneas (a, d) Co 2p, (b, e) O 1s y (c, f) N 1s del 2D-CoMOF (a, b, c) y el 2D-Co-MOF después de ser tratado sucesivamente con agua y con piridina a $150^{\circ} \mathrm{C}$ durante 2 días $(\mathrm{d}, \mathrm{e}, \mathrm{f})$.

259

7.26 Patrones de difracción de rayos X de polvo del Nafion (azul), 2D-Co-MOF apilado por interacciones $\pi-\pi$ (negro), 2D-Co-MOF@ Nafion (rojo), 2D-CoMOF@Nafion tras su tratamiento durante $5 \mathrm{~min}$ con agua (verde) y 2D-CoMOF@Nafion tras su tratamiento durante 1 hora con agua (rosa). 
7.27 a) Voltamogramas cíclicos del electrodo de grafito pirolítico modificado con Co2-MOF@ Nafion (línea roja) o con Co-MOF@Nafion (línea azul) medido a 0.05 V $\mathrm{s}^{-1}$ en una disolución que contiene $0.1 \mathrm{M}$ de $\left[\mathrm{Et}_{4} \mathrm{~N}_{\mathrm{B}} \mathrm{BF}_{4}\right.$ en acetonitrilo a $25^{\circ} \mathrm{C}$. Conversiones redox implicadas en la respuesta voltamétrica del b) Co-MOF y c) $\mathbf{C o}_{2}-$ MOF.

7.28 a) Voltamogramas cíclicos del electrodo de grafito pirolítico modificado con Co2-MOF@Nafion medido a diferentes velocidades de barrido de potencial en una disolución que contiene $0.1 \mathrm{M}$ de $\left[\mathrm{Et}_{4} \mathrm{~N}_{3}\right] \mathrm{BF}_{4}$ en acetonitrilo a $25^{\circ} \mathrm{C}$. b) Cargas anódicas voltamétricas de Faraday y c) picos de potencial anódicos como una función de la velocidad de barrido de potencial.

7.29 a) Voltamogramas cíclicos del electrodo de grafito pirolítico modificado con Co-MOF@Nafion medido a diferentes velocidades de barrido de potencial en una disolución que contiene $0.1 \mathrm{M}$ de $\left[\mathrm{Et}_{4} \mathrm{~N}_{3}\right] \mathrm{BF}_{4}$ en acetonitrilo a $25^{\circ} \mathrm{C}$. b) Cargas anódicas voltamétricas de Faraday y c) picos de potencial anódicos como una función de la velocidad de barrido de potencial.

7.30 a) Voltamogramas cíclicos del electrodo de grafito pirolítico modificado con Co2-MOF@Nafion medido en una disolución que contiene $0.1 \mathrm{M}$ de $\left[\mathrm{Et}_{4} \mathrm{~N}\right] \mathrm{BF}_{4}$ en acetonitrilo a $25{ }^{\circ} \mathrm{C}$. Diagrama integrado: respuesta voltamétrica en la ventana de potencial negativo para un electrodo de grafito pirolítico modificado con Nafion (línea azul) y con Co2-MOF @Nafion (línea roja).

7.31 a) Voltamogramas cíclicos para el electrodo de grafito pirolítico modificado con el Co2-MOF@ Nafion medido a $10 \mathrm{mV} \mathrm{s}^{-1}$ para los ratios acetonitrilo/disolución acuosa SPB (pH 7) indicados. b) Voltamogramas cíclicos para el electrodo de grafito pirolítico modificado con Nafion (línea gris discontinua) o Co2-MOF@Nafion (línea roja) medidos a $10 \mathrm{mV} \mathrm{s}^{-1}$ en una disolución acuosa $0.1 \mathrm{M} \mathrm{SPB}(\mathrm{pH} 7)$ a $25^{\circ} \mathrm{C}$.

265

7.32 a) Voltamogramas cíclicos del electrodo de grafito pirolítico modificado con Co2-MOF@Nafion medido a diferentes velocidades de barrido de potencial en una disolución acuosa de $0.1 \mathrm{M} \mathrm{SPB}$ de $\mathrm{pH} 7$ a $25^{\circ} \mathrm{C}$. b) Cargas voltamétricas de Faraday y c) potenciales de pico y potenciales de punto medio en función de la velocidad de barrido de potencial.

7.33 a) Voltamograma cíclico de un electrodo de grafito pirolítico modificado con Nafion (línea gris discontinua) o con 2D-Co-MOF@Nafion (línea negra) medidos a 0.05 $\mathrm{V} \mathrm{s}^{-1}$ en acetonitrilo. b) Voltamograma cíclico medido a $0.05 \mathrm{~V} \mathrm{~s}^{-1}$ en una disolución acuosa de tampón fosfato de $\mathrm{pH} 7$ a $25^{\circ} \mathrm{C}$ antes (línea azul) y después (línea roja) de la 
activación química del 2D-Co-MOF@Nafion depositado en un electrodo de grafito pirolítico.

7.34 Voltamogramas cíclicos medidos a $0.05 \mathrm{~V} \mathrm{~s}^{-1}$ en una disolución acuosa $0.1 \mathrm{M}$ de tampón fosfato de $\mathrm{pH} 7$ a $25^{\circ} \mathrm{C}$ de un electrodo de grafito pirolítico modificado con 2DCo-MOF@Nafion con el contenido de Nafion indicado en el composite después de la activación electroquímica durante 2 horas. El voltamograma cíclico representado en verde corresponde al MOF no activado. 268

7.35 Voltamogramas cíclicos de un electrodo de grafito pirolítico modificado con 2D-Co-MOF@Nafion medidos a $0.05 \mathrm{~V} \mathrm{~s}^{-1}$ a $25^{\circ} \mathrm{C}$ en una disolución que contiene acetonitrilo y las concentraciones de agua indicadas.

7.36 a) Voltamograma cíclico de un electrodo de grafito pirolítico modificado con 2D-Co-MOF@Nafion medido a varias velocidades de barrido de potencial en una disolución acuosa $0.1 \mathrm{M}$ de tampón fosfato de sodio $(\mathrm{pH} 7)$ a $25^{\circ} \mathrm{C}$. b) Corriente del pico anódico con la línea base corregida como una función de la velocidad de barrido de potencial (gráfica de la izquierda) o raíz cuadrada de la velocidad de barrido de potencial (gráfica de la derecha). c) Carga anódica voltamétrica faradaica en función de la velocidad de barrido de potencial.

270

$\mathbf{7 . 3 7}$ a) Representaciones de Nquist, b) y c) Representaciones de Bode para el 2DCo-MOF@Nafion depositado sobre un electrodo de grafito pirolítico, antes (símbolos azules) y después (símbolos rojos) de la activación electroquímica. Las líneas son los mejores ajustes usando el circuito equivalente insertado en a) y los valores para los parámetros que aparecen en la Tabla 7.3.

270

7.38 a) Voltamogramas de electrodo rotatorio del electrodo de grafito pirolítico modificado con Co2-MOF@Nafion (línea roja) o con el MOF hidrolizado CoMOF@Nafion (línea azul) medido a $5 \mathrm{mV} \mathrm{s}^{-1}$ y $4000 \mathrm{rpm}$ en una disolución acuosa 0.1 $\mathrm{M}$ de SPB (pH 7) a $25^{\circ} \mathrm{C}$. La línea gris discontinua corresponde al voltamograma cíclico del electrodo de grafito pirolítico modificado con Nafion. b) Cronoamperogramas potenciostáticos del electrodo de grafito modificado con Co2-MOF@ Nafion (línea roja) y Co-MOF@Nafion (línea azul) medidos a $4000 \mathrm{rpm}$ para saltos de potencial crecientes de $0.02 \mathrm{~V}$, desde $1.59 \mathrm{~V}$ a $1.85 \mathrm{~V}$, en una disolución acuosa $0.1 \mathrm{M}$ de $\mathrm{SPB}(\mathrm{pH} 7)$ a $25^{\circ} \mathrm{C}$. c) Diagrama de Tafel para los datos de densidad de corriente de estado estacionario del diagrama $b$.

7.39 a) Voltamogramas de electrodo rotatorio del electrodo de grafito pirolítico modificado con diferentes cantidades electroactivas de $\mathbf{C o}_{2}$-MOF@Nafion en el rango 
0.1-3.9 $10^{-9} \mathrm{~mol}$, medido a $5 \mathrm{mV} \mathrm{s}{ }^{-1}$ y $4000 \mathrm{rpm}$ en una disolución acuosa que contiene $0.1 \mathrm{M} \mathrm{SPB}, \mathrm{pH} 7$, a $25^{\circ} \mathrm{C}$. Gráfico insertado: Onda voltamétrica I con la línea base corregida. b) TOF estimado para un sobrepotencial de $400 \mathrm{mV}$ en función de la concentración superficial de cobalto electroactivo. La línea verde discontinua solo es una guía visual.

7.40 a) Voltamograma de electrodo rotatorio para electrodo de grafito modificado con el Co2-MOF@Nafion medido a $5 \mathrm{mV} \mathrm{s}^{-1}$ después de registrar: 1 scan (línea discontinua naranja), 20 scans consecutivos (línea discontinua azul oscuro), 500 scans consecutivos (línea discontinua azul claro) a $0.2 \mathrm{~V} \mathrm{~s}^{-1}$ en una disolución acuosa $0.1 \mathrm{M}$ de $\mathrm{SPB}, \mathrm{pH} 7$, a $25^{\circ} \mathrm{C}$. Gráfico insertado: voltamogramas medidos al número indicado de scans a $0.2 \mathrm{~V} \mathrm{~s}^{-1}$. b) Voltamogramas para el electrodo de grafito modificado con Co2MOF@Nafion medido a $5 \mathrm{mV} \mathrm{s}^{-1}$ antes (línea discontinua naranja) y después (línea discontinua azul) de medir la corriente cronoamperométrica a $1.80 \mathrm{~V}$ vs RHE durante 4 horas. La corriente cronoamperométrica a $1.80 \mathrm{~V}$ (vs RHE) durante $4 \mathrm{~h}$ y los voltamogramas cíclicos a $0.2 \mathrm{~V} \mathrm{~s}^{-1}$ antes (línea naranja) y después (línea azul) se representa en el gráfico insertado.

275

7.41 a) Corriente cronoamperométrica, carga consumida y producción de oxígeno medido a $1.95 \mathrm{~V}$ (vs NHE) con el electrodo de grafito pirolítico modificado con el Co2MOF@Nafion durante la electrólisis del agua en una disolución acuosa 0.1 M de tampón fosfato de sodio, $\mathrm{pH} 7$, a $25^{\circ} \mathrm{C}$. b) Producción de oxígeno frente a la carga consumida durante la electrólisis del agua. Los símbolos son valores experimentales y la línea sólida es el mejor ajuste lineal de mínimos cuadrados para los datos obtenidos.

276

7.42 Foto del electrodo de grafito pirolítico modificado con Co2-MOF@Nafion durante la electrólisis del agua en una disolución acuosa $0.1 \mathrm{M} \mathrm{SPB}, \mathrm{pH} 7$, a $25^{\circ} \mathrm{C}$ que muestra la formación de burbujas de oxígeno en la superficie del electrodo.

277

$\mathbf{7 . 4 3}$ a) Voltamograma de electrodo rotatorio del electrodo de grafito pirolítico modificado con $\mathbf{C o}_{2}$-MOF@ Nafion medido a $5 \mathrm{mV} \mathrm{s}^{-1}$ y $4000 \mathrm{rpm}$ en una disolución desgasificada (línea naranja) y sin desgasificar (línea azul) que contiene 0.1 M de SPB, $\mathrm{pH} 7$, a $25^{\circ} \mathrm{C}$. Diagrama insertado: Sus correspondientes voltamogramas cíclicos medidos a $10 \mathrm{mV} \mathrm{s}^{-1}$. b) Voltamograma de electrodo rotatorio para el Co2-MOF@ Nafion depositado en el electrodo de grafito medido a $5 \mathrm{mV} \mathrm{s}^{-1}$ antes (línea naranja) y después (línea azul) de medir la corriente cronoamperométrica a $1.80 \mathrm{~V}$ durante $4 \mathrm{~h}$ (representada en el diagrama insertado).

277

7.44 Imagen del Co2-MOF@Nafion tomada por microscopía de barrido electrónico de emisión de campo y análisis EDX.................................................278 
7.45 Espectro XPS del Co2-MOF@Nafion después de la electrólisis del agua..279

7.46 a) Espectros Raman del Co2-MOF@Nafion antes (negro) y después (rojo) de la electrólisis del agua. b) Patrones de difracción de rayos $\mathrm{X}$ de polvo del Co2MOF@Nafion antes (negro) y después (rojo) de la electrólisis del agua.

280

7.47 a) Voltamogramas de electrodo rotatorio del electrodo de grafito pirolítico modificado con 2D-Co-MOF@ Nafion medido a $5 \mathrm{mV} \mathrm{s}^{-1}$ y 4000 rpm en una disolución acuosa $0.1 \mathrm{M}$ de SPB $(\mathrm{pH} 7)$ a $25^{\circ} \mathrm{C}$. La línea gris discontinua corresponde al voltamograma cíclico del electrodo de grafito pirolítico modificado con Nafion. b) Cronoamperogramas potenciostáticos del electrodo de grafito modificado con 2D-CoMOF@Nafion medido a $4000 \mathrm{rpm}$ para saltos de potencial crecientes de $0.01 \mathrm{~V}$ en una disolución acuosa $0.1 \mathrm{M}$ de SPB (pH 7) a $25^{\circ} \mathrm{C}$. c) Diagrama de Tafel para los datos de densidad de corriente de estado estacionario del diagrama $b$.

281

7.48 a) Voltamograma de electrodo rotatorio de un electrodo de grafito pirolítico modificado con diferentes cantidades de 2D-Co-MOF@ Nafion electroactivo en un rango entre $0.55-12 \cdot 10^{-10}$ moles, medido a $5 \mathrm{mV} \mathrm{s}^{-1}$ y $1500 \mathrm{rpm}$ en una disolución acuosa $0.1 \mathrm{M}$ SPB de $\mathrm{pH} 7$ a $25^{\circ} \mathrm{C}$. Diagrama insertado: Onda voltamétrica I con la línea base corregida. b) Valor del TOF para un sobrepotencial de $395 \mathrm{mV}$ estimado por cronoamperometría como función de la cantidad de cobalto electroactivo superficial. La línea verde discontinua es solo una guía visual.

282

7.49 a) Cronoamperogramas consecutivos a $1.8 \mathrm{~V}$ (vs RHE) para el electrodo de grafito pirolítico modificado con 2D-Co-MOF@ Nafion en una disolución acuosa 0.1M $\mathrm{SPB}$ de $\mathrm{pH} 7$ a $25^{\circ} \mathrm{C}$. Diagrama insertado: voltamograma de electrodo rotatorio medido a $5 \mathrm{mV} \mathrm{s}^{-1}$ antes (línea roja) y después (línea verde) del experimento cronoamperométrico. b) Cronoamperogramas a $1.8 \mathrm{~V}$ (vs RHE) para diferentes ciclos de reacción consecutivos. Diagrama insertado: voltamogramas de electrodo rotatorio después del ciclo catalítico el día 1 (línea roja), el día 3 (línea verde) y el día 7 (línea violeta).

283

7.50 Fotografía que muestra el crecimiento de las burbujas de oxígeno sobre el electrodo de grafito pirolítico modificado con el 2D-Co-MOF@Nafion durante la electrólisis del agua en una disolución acuosa $0.1 \mathrm{M} \mathrm{SPB} \mathrm{pH} 7$ a $25^{\circ} \mathrm{C}$.

284

7.51 Espectros Raman del 2D-Co-MOF@Nafion delaminado a los tiempos de electrólisis del agua indicados.

285 
7.52 Patrones de difracción de rayos X de polvo del 2D-Co-MOF@Nafion delaminado a los tiempos de electrólisis del agua indicados. El pico a $28^{\circ}$ es una contribución del portamuestras.

285

7.53 Espectros XPS de las líneas de (a, d) Co 2p, (b, e) O 1s y (c, f) N 1s para el 2D-Co-MOF@Nafion delaminado antes (a, b, c) y después (d, e, f) de la electrólisis del agua durante 12 horas

.286

$\mathbf{7 . 5 4}$ a) Espectro ESI-MS de la disolución electrolítica después de un proceso extenso de electrólisis del agua y b) Espectro ESI-MS teórico para la piridina.

.288

7.55 a) Voltamogramas cíclicos de un electrodo de grafito pirolítico modificado con 2D-Co-MOF@ Nafion medido a $0.05 \mathrm{~V} \mathrm{~s}^{-1}$ a $25^{\circ} \mathrm{C}$ en una disolución acuosa $0.1 \mathrm{M}$ $\mathrm{SPB}$ a los $\mathrm{pH}$ indicados. b) Representación de los correspondientes potenciales (E) frente al $\mathrm{pH}$ estimados a $8 \mu \mathrm{A}$ (símbolos rojos) y $40 \mu \mathrm{A}$ (símbolos verdes).

290

7.56 Mecanismo propuesto para la reacción de evolución electrocatalítica de oxígeno catalizada por el 2D-Co-MOF a pH neutro.

7.57 a) Voltamogramas de electrodo giratorio medidos a $5 \mathrm{mV} \mathrm{s}^{-1}$ y $4000 \mathrm{rpm}$ y b) Representaciones de Tafel de estado estacionario para un electrodo de grafito pirolítico modificado con los electrocatalizadores indicados en una disolución $0.1 \mathrm{M} \mathrm{SPB} \mathrm{pH} 7$ a $25^{\circ} \mathrm{C}$.

293

7.58 Patrones de difracción de rayos X de polvo del Co-MOF@ Nafion (rojo), CoMOF@Nafion después del tratamiento con agua (azul), Co-MOF (negro) y Nafion (verde).

7.59 PXRD del 2D-Co-MOF (negro) y los correspondientes materiales sintetizados a partir de los precursores $\mathrm{Co}(\mathrm{OAc})_{2} \cdot 4 \mathrm{H}_{2} \mathrm{O}$ o el $\mathrm{Co}\left(\mathrm{NO}_{3}\right)_{2} \cdot 6 \mathrm{H}_{2} \mathrm{O}$ (espectros coloreados) usando las condiciones de síntesis recogidas en la Tabla 7.8.

7.60 Representación de una lámina doble del 2D-Co-MOF a lo largo del eje b 302 7.61 Representación de una lámina doble del 2D-Co-MOF a lo largo del eje c.302

7.62 Representación de los planos calculados para cada lámina doble del 2D-CoMOF y distancia medida entre los planos. 303

7.63 Representación de la estructura supramolecular del 2D-Co-MOF a lo largo del eje $b$. 303 
7.64 Imágenes tomadas por microscopía electrónica de barrido (FESEM) y análisis EDX del 2D-Co-MOF@ Nafion delaminado a) antes y b) después de la electrólisis del agua durante 12 horas.

304

7.65 Imágenes tomadas con un microscopio electrónico de barrido equipado con un haz de iones focalizados (FIB) de la sección transversal del composite 2D-CoMOF@Nafion delaminado antes (a, b) y después (c, d) de la electrólisis del agua durante 12 horas y del polímero de Nafion (e, f) 305

7.66 Circuito equivalente para la cuantificación del espectro EIS. 310 
Índice de Esquemas 



\section{Capítulo 1. Introducción}

1.1 Ejemplos de procesos catalíticos industriales importantes con catalizadores de cobalto.

\section{Capítulo 4. Complejos de Cobalto para la hidrosililación de alquenos en condiciones aeróbicas.}

4.1 Hidrosililación de enlaces múltiples.........................................................57

4.2 Hidrosililación de 1-octeno con triclorosilano. .............................................57

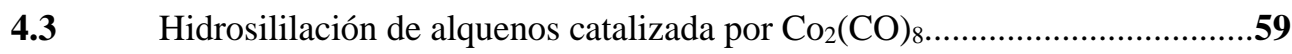

4.4 Mecanismo de Chalk-Harrod para la hidrosililación de alquenos con

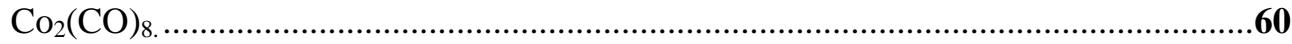

4.5 Mecanismo de Chalk-Harrod modificado para la hidrosililación de alquenos

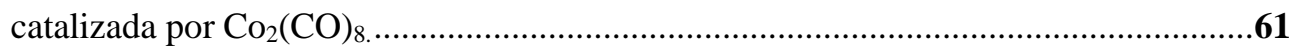

4.6 Ilustración general de la síntesis de los complejos de cobalto(II) $\mathbf{1 b}$-4b.......65

4.7 Fluidos de entrecruzamiento de siliconas....................................................78

4.8 Propuesta mecanística para la hidrosililación de alquenos catalizada por cobalto.

Capítulo 5. Nanoclústeres de Cobalto como catalizadores para la hidrogenación quimioselectiva de nitroarenos y reacciones tándem.

5.1 Hidrogenación de nitroarenos catalizada por Co. .116

5.2 Síntesis de los catalizadores Co@NC-800 por pirólisis del complejo $\left[\mathrm{Co}(\text { tpy })_{2}\right]\left(\mathrm{NO}_{3}\right)_{2}$ soportado en carbón.

118

5.3 Camino de reacción para la reacción de aminación reductiva. .137

5.4 Aminación reductiva de nitroarenos con catalizadores heterogéneos de cobalto. 139 


\section{Capítulo 6. Complejos tetranucleares de cobalto para la oxidación selectiva de ciclohexano.}

6.1 Intermedios en la producción del nylon-6 y el nylon-6,6 a partir del ciclohexano.

6.2 a) Mecanismo de formación del enlace $\mathrm{O}-\mathrm{O}$ usando $\left[\mathrm{Co}_{4} \mathrm{O}_{4}(\mathrm{OAc})_{4} \mathrm{py}_{4}\right]$. b) Mecanismo de activación del $\mathrm{O}_{2}$ para la oxidación de enlaces $\mathrm{CH}$ usando hemocatalizadores.

6.3 a) Esquema sintético general de los clústeres de cobalto tetranucleares 1-6. b) Síntesis de los clústeres 4-6 usando los clústeres 1-3 como precursores......................175

6.4 Posibles caminos de reacción en la oxidación de ciclohexano......................185

6.5 Ilustración esquemática del principio de atracción de spin y estructura de los aductos de spin que pueden detectarse en la reacción entre el DMPO y los intermedios de reacción.

186

6.6 Mecanismo propuesto para la oxidación de ciclohexano con los clústeres de cobalto 1-6. Activación de $\mathrm{O}_{2}$ (arriba) y descomposición de CHHP (abajo). 195

6.7 Descomposición del CHHP y cálculo de la eficiencia de la reacción. .218 
Índice de Tablas 



\section{Capítulo 1. Introducción}

1.1 Datos de producción y generación de residuos en diversos campos ................7

1.2 Comparativa catalizadores homogéneos y heterogéneos................................13

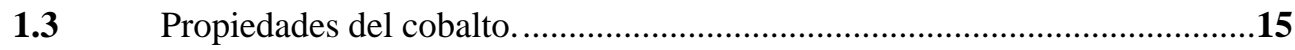

1.4 Ejemplos de procesos catalíticos industriales importantes basados en

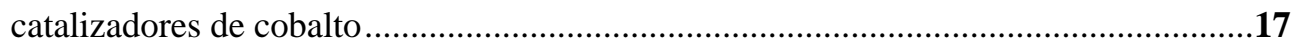

\section{Capítulo 4. Complejos de Cobalto para la hidrosililación de alquenos en condiciones aeróbicas.}

4.1 Evaluación de la influencia del ligando y el estado de oxidación del metal en la actividad de los complejos de cobalto para la hidrosililación del 1-octeno con $\mathrm{PhSiH}_{3}{ }^{[\mathrm{a}]}$ . .65

4.2 Evaluación de los precatalizadores de cobalto para la hidrosililación del 4vinilciclohexeno con $\mathrm{PhSiH}_{3} .{ }^{[\mathrm{a}]}$

4.3 Productos de hidrosililación funcionalizados con $\mathrm{PhSiH}_{3}$ usando los precursores de cobalto $\mathbf{2 a}, \mathbf{3 a}$ and $\mathbf{4 a}$ con tpy. ${ }^{[\mathrm{a}, \mathrm{b}]}$.....................................................74

4.4 Productos de hidrosililación funcionalizados con $\mathrm{Ph}_{2} \mathrm{SiH}_{2}$ usando los

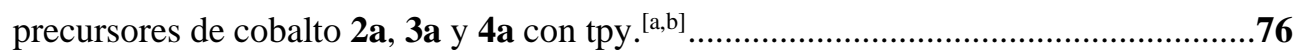

4.5 Productos de hidrosililación funcionalizados con $(\mathrm{EtO})_{3} \mathrm{SiH}$ usando los

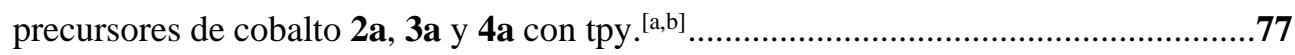

4.6 Productos de hidrosililación funcionalizados con $\left(\mathrm{CH}_{3}\right)_{3} \mathrm{SiOSiH}\left(\mathrm{CH}_{3}\right)_{2}$ usando los precursores de cobalto 2a, 3a y $4 \mathbf{a}$ con tpy. ${ }^{[a, b]}$

4.7 Datos cristalográficos y detalles del refinamiento de las estructuras para los complejos $\mathbf{1 b}$ y 2c. Las coordenadas atómicas, los parámetros equivalentes de desplazamientos isotrópicos, las distancias y ángulos de enlace se pueden consultar en la base de datos (CCDC 1817714 and CCDC 1817709, respectivamente). . .84

4.8 Distancias y ángulos de enlace más importantes para el complejo $\mathbf{1 b}$...........86

4.9 Distancias y ángulos de enlace más importantes para el complejo 2c...........87

4.10 Optimización de las condiciones de reacción con el precatalizador de Co 3a y el ligando tpy en la reacción de hidrosililación del 4-vinilciclohexeno con $\mathrm{PhSiH}_{3}$.....94 
4.11 Evaluación de los precatalizadores de cobalto en la reacción de hidrosililación del 4-vinilciclohexeno con $\mathrm{PhSiH}_{3}$ por ${ }^{1} \mathrm{H}-\mathrm{RMN}$ in-situ.

\section{Capítulo 5. Nanoclústeres de Cobalto como catalizadores para la hidrogenación quimioselectiva de nitroarenos y reacciones tándem.}

5.1 Optimización de las condiciones de reacción ${ }^{[a]}$. 121

5.2 Comparación de la actividad catalítica de Co@NC-800 en la reducción de nitrobenceno con otros catalizadores de Co reportados en bibliografía.

5.3 Resumen de los parámetros optimizados mediante el ajuste de los datos EXAFS en el borde $\mathrm{K}$ del Co. ${ }^{[\mathrm{a}]}$

5.4 Hidrogenación de nitroarenos sustituidos catalizada por Co@NC-800. ${ }^{[a, b]} \mathbf{1 3 4}$

5.5 Reacción tándem para aminación reductiva de nitroarenos sustituidos con benzaldehído catalizada por $\mathbf{C o} @ \mathbf{N C - 8 0 0} .^{[a, b]}$

138

5.6 Reacción tándem para la síntesis de isoindolinonas a partir de nitroarenos sustituidos y 2-carboxibenzaldehído catalizada por Co@NC-800. . $^{[a, b]}$ 140

\section{Capítulo 6. Complejos tetranucleares de cobalto para la oxidación selectiva de ciclohexano.}

6.1 Distancias interatómicas promedio ( $\mathrm{A})$ y ángulos de enlace (deg) para los complejos 2,5 y 6 comparados con 1 y 4 ......

6.2 Resultados de análisis elemental, ICP y ESI-MS para los clústeres de cobalto 1-6. 177

6.3 Resumen de la actividad catalítica (conversión y distribución de productos) de los catalizadores de cobalto en la oxidación de ciclohexano. 180

6.4 Comparación entre el clúster de cobalto más activo (5) con catalizadores reportados para la oxidación de ciclohexano en condiciones de reacción similares usando $\mathrm{O}_{2}$ o aire como oxidante. 183

6.5 Abundancia relativa (\%) de los aductos de spin con DMPO obtenidos en la reacción de descomposición del CHHP en ciclohexano. 189 
6.6 Resumen de la actividad catalítica (conversión y distribución de productos) de los catalizadores 1-6 en la oxidación de ciclohexano empleando CHHP como oxidante primario.

6.7 Datos cristalográficos y detalles del refinamiento de las estructuras de los complejos 2, 5 y 6. Las coordenadas atómicas, los parámetros equivalentes de desplazamiento isotrópico, las distancias y ángulos de enlace y los parámetros de desplazamiento anisotrópico se pueden encontrar en los CIFs (CCDC 1874019, CCDC 1874000 y CCDC 1873998, respectivamente).

199

6.8 Resumen de la actividad catalítica (conversión y distribución de productos) de los catalizadores de cobalto para la oxidación de ciclohexano. Condiciones de reacción: $3 \mathrm{~g}$ de ciclohexano $(36 \mathrm{mmol}), 0.14 \mathrm{ppm}$ de $\mathrm{Co}, 130{ }^{\circ} \mathrm{C}, 6$ bar $\left(\mathrm{N}_{2}: \mathrm{O}_{2}=95: 5\right), \mathrm{Q}=10$ $\mathrm{ml} / \mathrm{min}$. [a] $\mathrm{A}=$ alcohol, ciclohexanol; [b] $\mathrm{K}=$ cetona, ciclohexanona; $[\mathrm{c}] \mathrm{CHHP}=$ ciclohexil hidroperóxido; [d] AA = ácido adípico; [e] Selectividad total observada. .212

\section{Capítulo 7. MOFs de Cobalto como Catalizadores para la Oxidación Electrocatalítica del Agua en Medio Neutro.}

7.1 Características XPS del Co2-MOF: Energías de enlace de los diferentes picos, máxima anchura a mitad de pico (FWHM), intensidades relativas (I $\Sigma=\Sigma$ sat $\left./ \mathrm{I}_{\text {principal }}\right)$, interacción espín-orbital $\left(\Delta \mathrm{E}_{1}\right)$; todas las energías y FWHMs están en eV.

247

7.2 Resultados de Análisis Elemental e ICP para el 2D-Co-MOF y el 2D-CoMOF después de ser tratado sucesivamente con agua y con piridina a $150^{\circ} \mathrm{C}$ durante 2 días.

7.3 Parámetros EIS para el circuito equivalente de la Figura 7.37 (AE = Activación electroquímica).

7.4 Características XPS del Co2-MOF: Energías de enlace de los diferentes picos, máxima anchura a mitad de pico (FWHM), intensidades relativas ( $\mathrm{I} \Sigma=\Sigma$ sat $/ \mathrm{I}_{\text {principal }}$ ), interacción espín-orbital $\left(\Delta \mathrm{E}_{1}\right)$; todas las energías y FWHMs están en eV.

7.5 Características XPS del 2D-Co-MOF delaminado y 2D-Co-MOF @ Nafion después de la electrólisis del agua: Energías de enlace de los diferentes picos, máxima anchura a mitad de pico (FWHM), intensidades relativas (I $\Sigma=\Sigma$ sat $\left./ I_{\text {principal }}\right)$, interacción espín-orbital $\left(\Delta \mathrm{E}_{1}\right)$; todas las energías y FWHMs están en eV.

.287

7.6 Comparación del rendimiento en OER para MOFs de cobalto en medio neutro. 
7.7 Datos cristalográficos y detalles del refinamiento de la estructura para el Co - -MOF. Las coordenadas atómicas, los parámetros equivalentes de desplazamiento isotrópico, las distancias y ángulos de enlace y los parámetros de desplazamiento anisotrópico se pueden encontrar en el CIF (CCDC 1898281)...296

7.8 Intentos de síntesis del 2D-Co-MOF a partir de precursores de cobalto comerciales. .299

7.9 Datos cristalográficos y detalles del refinamiento de la estructura para el 2DCo-MOF. Las coordenadas atómicas, los parámetros equivalentes de desplazamiento isotrópico, las distancias y ángulos de enlace y los parámetros de desplazamiento anisotrópico se pueden encontrar en el CIF (CCDC 1994492). .300 
Abreviaturas 

acac Acetilacetonato.

AcN Acetonitrilo.

ATR-FTIR Attenuated total reflectance in Fourier transform infrared.

BE Binding energy.

bpy 2,2'-Bipyridine.

bs Broad signal.

CCDC Cambridge Crystallographic Data Centre.

CHHP Ciclohexil hidroperóxido.

CHP Ciclohexil peróxido.

CPE Constant phase element.

CV Cyclic voltammetry.

CW Continuous wave.

d Doblete.

DMF $\quad N, N$-Dimetilformamida.

DMPO 5,5-Dimethyl-1-pyrroline $N$-oxide.

DMSO Dimetil sulfóxido.

E Potencial.

EA Elemental análisis.

EDG Electron drawing group.

EDX Scanning transmission electron microscopy.

Eg Diferencia energética HOMO-LUMO.

EIS Electrochemical Research-Impedance.

EPA Environmental protection agency.

EPR Electronic paramagnetic resonance.

ESI Electrospray ionization. 
EWG Electron withdrawing group.

FE Faraday efficiency.

FEFF Free Energy Force Field.

FESEM Field Emission Scanning Electron Microscope.

FIB Focused Ion Beam

FWHM Full Width at Half Maximum.

GC Gas chromatography.

GC-MS Gas chromatography-mass spectrometry.

gHMQC Gradient Heteronuclear Multiple Quantum Coherence.

HAADF High-angle annular dark-field.

HER Hydrogen evolution reaction.

HOAc Ácido acético.

HRMS High resolution mass spectrometry.

HRTEM High-resolution Transmission Electron Microscope.

$\mathbf{H}_{2}$ bda $\quad$ 2,2'-bipyridine-4,4'-dicarboxylic acid.

H3 $_{3}$ BTC Ácido benceno tricarboxílico.

ICP-AES Inductively coupled plasma atomic emission spectroscopy.

JCPDS Joint Committee on Powder Diffraction Standards

m Multiplete.

MDI Diisocianato de metileno.

MeOH Metanol

MID Multiple ion detection.

MOFs Metal-organic frameworks.

NHE Normal hydrogen electrode.

NPs Nanopartículas

OAc Acetato. 
OER Oxygen evolution reaction.

PCET Proton-coupled electron transfer.

PET Tereftalato de polietileno.

pKa constante de acidez.

pKb constante de basicidad.

Ppm Partes por millón.

py piridina.

PXRD Powder X-ray diffraction.

Q flujo

RHE Reversible hydrogen electrode.

RMN Resonancia magnética nuclear.

$\mathbf{R}_{\mathrm{sf}} \quad$ Resistencia de la disolución y de la película.

rt room temperature.

s singlete.

SBU Secondary building unit.

SPB Sodium phosphate buffer.

STEM Scanning transmission electron microscopy.

t triplete.

TBAP perclorato de tetrabutilamonio.

TCD Thermal conductivity detector.

TFA Ácido trifluoroacético.

TFF Trifenilfosfina.

TGA Thermogravimetric analysis.

THF Tetrahidrofurano.

TLC Thin layer chromatography. 
TOF Turn over frequency.

ToF Time-of-Flight.TON Turn over number.

TPR Temperature programed reduction.

tpy $2,2^{\prime} ; 6^{\prime}, 2^{\prime \prime}$-terpyridine.

TS Tafel Slope.

UV-Vis Ultravioleta-visible.

WO Water oxidation.

WS Water splitting

$\mathbf{W}_{\infty} \quad$ Elemento Warburg de difusión semi infinita.

XANES X-ray absorption near edge structure.

XAS X-ray absorption spectroscopy.

XPS X-ray photoelectron spectroscopy.

Z Número atómico.

$\Delta \mathbf{m O}_{2} \quad$ Producción de oxígeno. 